FEB 17.1989

\title{
Impact of Radiation Embrittlement on Integrity of Pressure Vessel Supports for Two PWR Plants
}

Prepared by R.D. Cheverton, W.E. Pennell, G.C. Robinson, R.K. Nanstad

Oak Ridge National Laboratory

Prepared for

U.S. Nuclear Regulatory

Commission

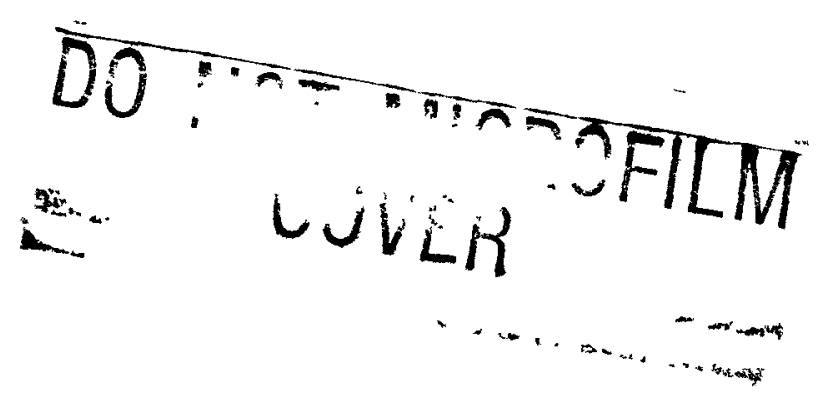




\section{DISCLAIMER}

This report was prepared as an account of work sponsored by an agency of the United States Government. Neither the United States Government nor any agency Thereof, nor any of their employees, makes any warranty, express or implied, or assumes any legal liability or responsibility for the accuracy, completeness, or usefulness of any information, apparatus, product, or process disclosed, or represents that its use would not infringe privately owned rights. Reference herein to any specific commercial product, process, or service by trade name, trademark, manufacturer, or otherwise does not necessarily constitute or imply its endorsement, recommendation, or favoring by the United States Government or any agency thereof. The views and opinions of authors expressed herein do not necessarily state or reflect those of the United States Government or any agency thereof. 


\section{DISCLAIMER}

Portions of this document may be illegible in electronic image products. Images are produced from the best available original document. 


\section{NOTICE}

This report was prepared as an account of work sponsored by an agency of the United States Government. Neither the United States Government nor any agency thereof, or any of their employees, makes any warranty, expressed or implied, or assumes any legal liability of re. sponsibility for any third party's use, or the results of such use, of any information, apparatus, product or process disclosed in this report, or represents that its use by such third party would not infringe privately owned rights.

\section{NOTICE}

Availability of Reference Materials Cited in NRC Publications

Most documents clted in NRC publications will be available from one of the following sources:

1. The NRC Public Document Room, 1717 H Street, N.W. Washington, DC 20555

2. The Superintendent of Documents, U.S. Government Printing Office, Post Office Box 37082 , Washington, DC 20013-7082

3. The National Technical Information Service, Springfield, VA 22161

Although the listing that follows represents the majority of docum: its cited in NRC publications, it is not intended to be exhaustive.

Referenced documents available for inspection and copying for a fee from the NRC Public Document Room include NRC correspondence and internal NRC memoranda; NRC Office of Inspection and Enforcement bulletins, circulars, information notices, inspection and investigation notices; Licensee Event Reports; vendor reports and correspondence; Commission papers; and applicant and licensee documents and correspondence.

The following documents in the NUREG series are available for purchase from the GPO Sales Program: formal NRC staff and contractor reports, NRC-sponsored conference proceedings, and NRC booklets and brochures. Also available are Regulatory Guides, NRC regutations in the Code of Federal Regulations, and Nuclear Regulatory Commission Issuances.

Documents available from the National Technical Information Service include NUREG series reports and technical reports prepared by other federal agencies and reports prepared by the Atomic Energy Commission, forerunner agency to the Nuclear Regulatory Commission.

Documents available from public and special technical libraries include all open literature items, such as books, journal and periodical articles, and transactions. Federal Register notices, federal and state legislation, and congressional reports can usually be obtained from these libraries.

Documents such as theses, dissertations, foreign reports and translations, and non-NRC conference proceedings are available for purchase from the organization sponsoring the publication cited.

Single copies of NRC draft reports are available free, to the extent of supply, upon written request to the Division of Information Support Services, Distribution Section, U.S. Nuclear Regulatory Commission, Washington, DC 20555.

Copies of industry codes and standards used in a substantive manner in the NRC regulatory process are maintained at the NRC Library, 7920 Norfolk Avenue, Bethesda, Maryland, and are available there for reference use by the public. Codes and standards are usually copyrighted and may be purchased from the originating organization or, if they are American National Standards, from the American National Standards Institute, 1430 Broadway, New York, NY 10018. 


\title{
Impact of Radiation Embrittlement on Integrity of Pressure Vessel Supports for Two PWR Plants
}

NUREG/CR- -5320

TI89 007009

Manuscript Completed: January 1989

Date Published: January 1989

Prepared by

R.D. Cheverton, W.E. Pennell, G.C. Robinson, R.K. Nanstad

Oak Ridge National Laboratory

Oak Ridge, TN 37831

\author{
Prepared for \\ Division of Engineering \\ Office of Nuclear Regulatory Research \\ U.S. Nuclear Regulatory Commission \\ Washington, DC 20555 \\ NRC FIN B0119
}

\section{DISCLAIMER}

\begin{abstract}
This report was prepared as an account of work sponsored by an agency of the United States Government. Neither the United States Government nor any agency thereof, nor any of their exployees, makes any warranty, express implied, or assumes any legal liability or responsibility for the accuracy, completeness, or usefulness of any information, apparatus, product, or process disclosed, or represents that its use would not infringe privately owned rights. Referprocess disclosed, or service by trade name, trademark, ence herein to any specifnc commerial product, process, manufacturer, or otherwise does not necessarily constitute or imply its endorsen. The views mendation, or favoring by the United States Government or any agency thereof. The the and opinions of authors expressed herein do not

United States Government or any agency thereof.
\end{abstract}


$\because$ 
Recent data from the HFIR vessel surveillance program indicate a substantial radiation embrittlement rate effect at low irradiation temperatures $\left(\sim 120^{\circ} \mathrm{F}\right)$ for A212-B, A350-LF3, A105-II, and corresponding welds. PWR vessel supports are fabricated of similar materials and are subjected to the same low temperatures and fast neutron fluxes $\left(10^{8}\right.$ to $10^{9}$ neutrons $/ \mathrm{cm}^{2} \cdot \mathrm{s}, E>1.0 \mathrm{MeV}$ ) as those in the HFIR vessel. Thus, the embrittlement rate of these structures may be greater than previously anticipated.

A study sponsored by the NRC is under way at ORNL to determine the impact of the rate effect on PWR vessel-support life expectancy. The scope includes the interpretation and application of the HFIR data, a survey of all light-water-reactor vessel support designs, and a structural and fracture-mechanics analysis of the supports for two specific PWR plants of particular interest with regard to a potential for support failure as a result of propagation of flaws. Calculations performed thus far indicate best-estimate critical flaw sizes, corresponding to 32 EFPY, of $\sim 0.2$ in. for one plant and $\sim 0.4$ in. for the other. These flaw sizes are small enough to be of concern. However, it appears that low-cycle fatigue is not a viable mechanism for creation of flaws of this size, and thus, presumably, such flaws would have to exist at the time of fabrication. 


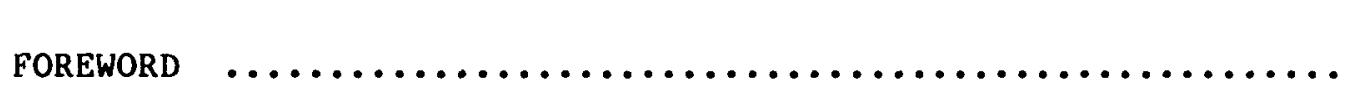

LIST OF ACRONYMS

$\underline{\text { Page }}$

LIST OF FIGURES

ix

LIST OF TABLES

xix

$\mathbf{x x i}$

$\operatorname{xxix}$

ACKNOWLEDGMENTS

$x \times x i$ i

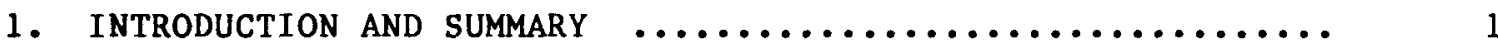

References $\quad \ldots \ldots \ldots \ldots \ldots \ldots \ldots \ldots \ldots \ldots \ldots \ldots \ldots \ldots \ldots \ldots \ldots \ldots \ldots \ldots \ldots . \ldots \ldots$

2. HFIR VESSEL SURVEILLANCE DATA ...................... . . 7

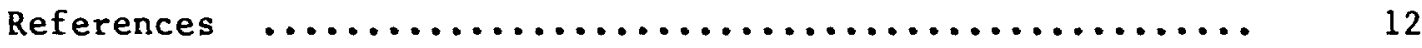

3. APPLICATION OF HFIR DATA TO VESSEL SUPPORT EVALUATION $\ldots \ldots . \quad 14$

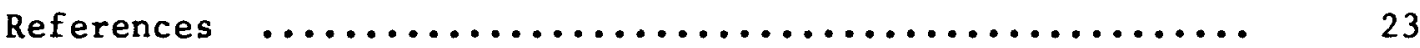

4. SURVEY OF SUPPORT DESIGN FEATURES ...................... 24

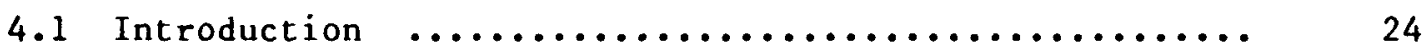

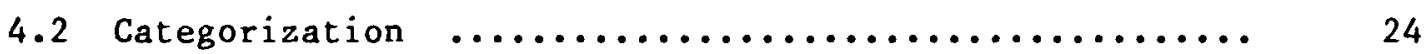

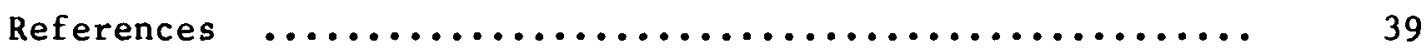

5. SELECTION OF LWR PLANTS FOR SPECIFIC-PLANT ANALYSIS ...... 40

6. BRITTLE FRACTURE EVALUATION OF TROJAN NUCLEAR PLANT

REACTOR PRESSURE VESSEL SUPPORTS ........................ 42

6.1 Introduction and summary ..................... 42

6.2 Scope and Objective .......................... 44

6.3 Loading and Operating Environment ............... 46

6.3 .1 Normal plus upset loading ................ 46

6.3 .2 Faulted conditions ..................... 46

6.3 .3 Cyclic loading $\ldots \ldots \ldots \ldots \ldots \ldots \ldots \ldots \ldots \ldots \ldots \ldots \ldots \ldots$

6.3 .4 Operating environment $\ldots \ldots \ldots \ldots \ldots \ldots \ldots \ldots \ldots$

6.3 .5 Load combinations $\ldots \ldots \ldots \ldots \ldots \ldots \ldots \ldots \ldots \ldots \ldots \ldots$

6.4 Support Beam Analysis ......................... 47

6.4 .1 Analytical model $\ldots \ldots \ldots \ldots \ldots \ldots \ldots \ldots \ldots \ldots \ldots \ldots \ldots$

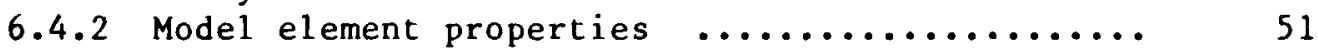

6.4 .2 .1 Beam (solid section) .............. 51

6.4.2.2 Beam (section with 4-in.-diam

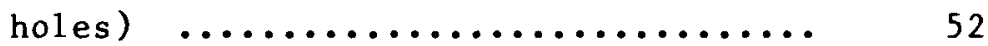

6.4 .2 .3 Concrete foundation .............. 52

6.4.2.4 Flange of the front support

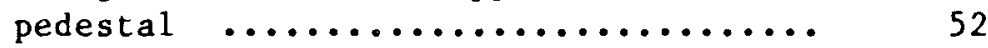

6.4 .2 .5 Front support pedestal web ......... 53

6.4.2.6 Flange section of the rear support ... 53 
$\underline{\text { Page }}$

6.4.2.7 Web section of the rear support $\ldots \ldots . .53$

6.4.2.8 Foundation modeling sensitivity as ses sment

53

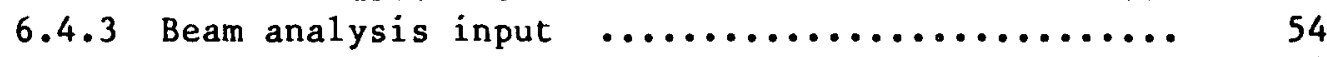

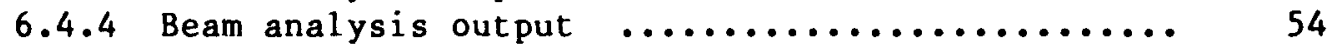

6.4.4.1 Effectiveness of the inner concrete support $\ldots \ldots \ldots \ldots \ldots \ldots \ldots \ldots . \ldots \ldots \ldots$

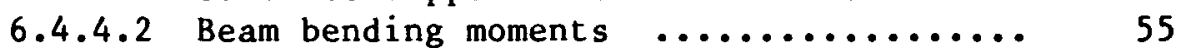

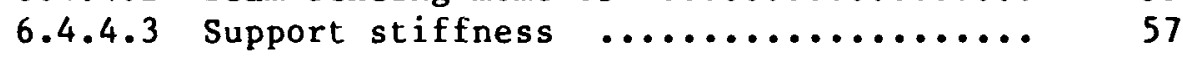

6.5 Material Fracture Toughness ................... 58

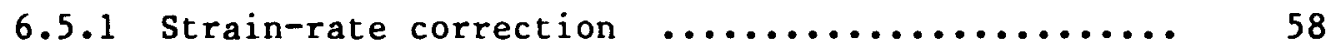

6.5.2 Data correlation and extrapolation .............. 62

6.5.3 Plane-strain to plane-stress transition ........ 66

6.5 .4 Fracture-toughness design curves ............... 68

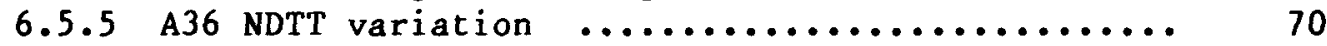

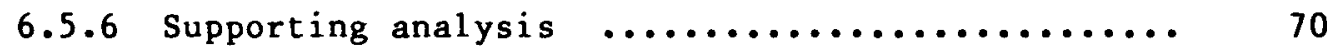

6.5.7 Reactor support/bridge structure comparison .... 70

6.5.8 Fracture-toughness data evolution ........... 75

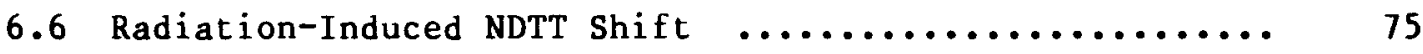

6.7 Critical-Flaw-Depth Analysis $\ldots \ldots \ldots \ldots \ldots \ldots \ldots \ldots \ldots \ldots . \ldots$

6.7 .1 Cavity linear interface $\ldots \ldots \ldots \ldots \ldots \ldots \ldots \ldots . \ldots . \ldots . \ldots$

6.7.2 Maximum bending moment location (Node 4) ..... 82

6.7 .3 Beam-flange grout-hole location ............ 87

6.7.3.1 Flaw-tip stress-intensity-factor

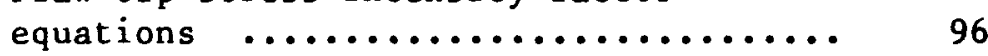

6.7.3.2 Flaw-tip stress-intensity factors ..... 98

6.7.3.3 Lifetime critical-flaw-depth analyses $\ldots \ldots \ldots \ldots \ldots \ldots \ldots \ldots \ldots \ldots \ldots . \ldots \ldots$

6.7.3.4 The impact of NDTT variations ........ 105

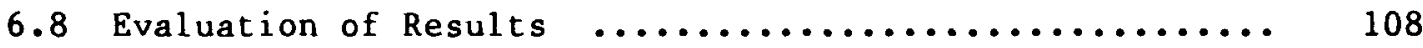

6.8 .1 Flaw growth as a result of cyclic loading ...... 108

6.8.2 Interface with the reactor cavity liner ........ 109

6.8.3 Maximum bending moment location (Node 4) ...... 109

6.8 .4 Beam top-flange grout-hole location ........... 109

6.8.5 Compatibility check on the stress-intensity-

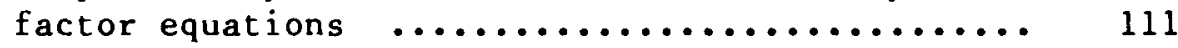

6.8 .6 Load sensitivity comparison $\ldots \ldots \ldots \ldots \ldots \ldots \ldots \ldots . \ldots 113$

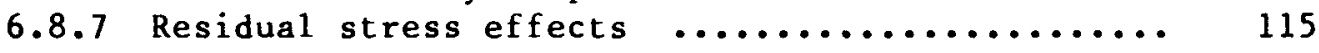

6.8 .7 .1 Analysis approach $\ldots \ldots \ldots \ldots \ldots \ldots \ldots \ldots . \ldots \ldots$

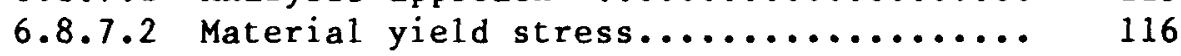

6.8.7.3 Upper bound residual stress estimate .. 117

6.8.7.4 Residual stress distribution ......... 119

6.8.7.5 Residual stress-stress-intensity-

factors equations $\ldots \ldots \ldots \ldots \ldots \ldots \ldots . \ldots 121$ 
6.8.7.6 Ligament combined stress-intensity

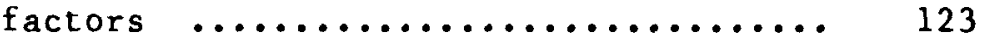

6.8.7.7 Assessment of results $\ldots \ldots \ldots \ldots \ldots \ldots \ldots 124$

6.9 Conclusions and Recommendations ............... 130

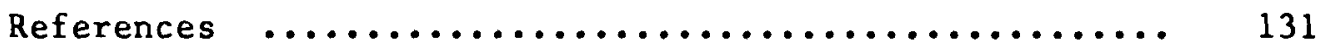

7. BRITTLE FRACTURE EVALUATION OF TURKEY POINT UNIT 3

REACTOR PRESSURE VESSEL SUPPORTS $\ldots \ldots \ldots \ldots \ldots \ldots \ldots \ldots \ldots \ldots .133$

7.1 Introduction and Summary $\ldots \ldots \ldots \ldots \ldots \ldots \ldots \ldots \ldots . \ldots \ldots$

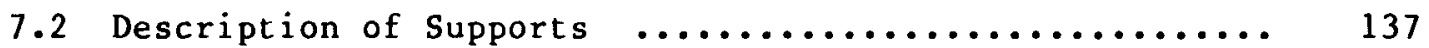

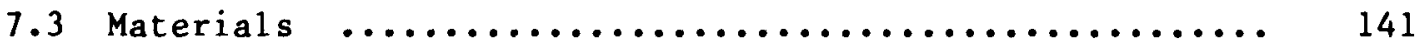

7.4 Material Fracture-Toughness Properties ............. 141

7.5 Thermal and Radiation Environment ................ 145

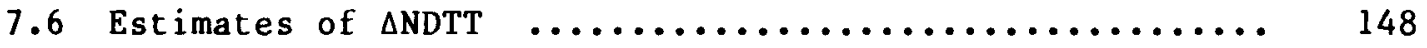

7.7 Support Loadings and Stress Analysis .............. 148

7.8 Stress-Intensity-Factor $\left(\mathrm{K}_{\mathrm{I}}\right)$ Evaluation $\ldots \ldots \ldots \ldots \ldots .150$

7.9 Discussion of Results and Conclusions ............. 166

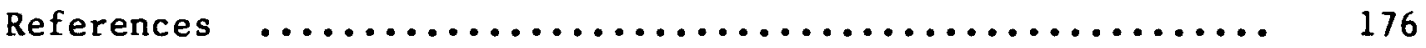

8. CONCLUSIONS AND RECOMMENDATIONS $\ldots \ldots \ldots \ldots \ldots \ldots \ldots \ldots \ldots \ldots \ldots$

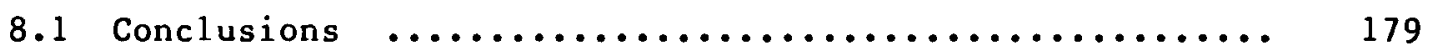

8.2 Recommendations $\ldots \ldots \ldots \ldots \ldots \ldots \ldots \ldots \ldots \ldots \ldots \ldots . \ldots \ldots$

APPENDIX 1. TROJAN SUPPORT BEAM ANALYSIS INPUT AND OUTPUT

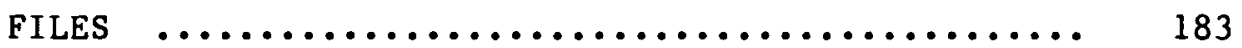

APPENDIX 2. TROJAN CRITICAL-FLAW-SIZE ANALYSIS FOR THE BEAMTOP FLANGE AT THE INTERSECTION WITH THE REACTOR CAVITY LINER $\ldots \ldots \ldots \ldots \ldots \ldots \ldots \ldots \ldots \ldots \ldots \ldots \ldots \ldots$

APPENDIX 3. TROJAN CRITICAL-FLAW-SIZE ANALYSIS FOR THE BEAMTOP FLANGE AT THE PEAK BENDING MOMENT LOCATION (NODE 4)

APPENDIX 4. TROJAN CRITICAL-FLAW-SIZE ANALYSIS FOR THE BEAMTOP FLANGE AT THE LOCATION OF THE 4-in.-diam GROUT HOLES

APPENDIX 5. AN EVALUATION OF THE IMPACT OF ASSUMPTIONS MADE IN MODELING THE VESSEL-SUPPORT BEAM ELASTIC FOUNDATION

APPENDIX 6. CALCULATION OF $\mathrm{K}_{\mathrm{I}}$ VALUES FOR CRACKS EMANATING FROM A HOLE IN A PLATE (TROJAN) ........ 245 



\section{FOREWORD}

The work reported here was performed at Oak Ridge National Laboratory under the Heavy-Section Steel Technology (HSST) Program, W. R. Corwin, Program Manager. The program is sponsored by the office of Nuclear Regulatory Research of the U.S. Nuclear Regulatory Commission (NRC). The technical monitor for the NRC is M. E. Mayfield.

This report is designated HSST Report 99. Prior reports in this series are listed below.

1. S. Yukawa, Evaluation of Periodic Proof Testing and Warm Prestressing Procedures for Nuclear Reactor Vessels, HSSTP-TR-1, General Electric Company, Schenectady, N.Y. (July 1, 1969).

2. L. W. Loechel, The Effect of Testing Variables on the Transition Temperature in Steel, MCR-69-189, Martin Marietta Corporation, Denver, Colo. (November 20, 1969).

3. P. N. Randall, Gross Strain Measure of Fracture Toughness of Steels, HSSTP-TR-3, TRW Systems Group, Redondo Beach, Calif. (November 1, 1969).

4. C. Visser, S. E. Gabrielse, and W. VanBuren, A Two-Dimensional Elastic-Plastic Analysis of Fracture Test Specimens, WCAP-7368, Westinghouse Electric Corporation, PWR Systems Division, Pittsburgh, Pa. (October 1969).

5. T. R. Mager and F. 0. Thomas, Evaluation by Linear Elastic Fracture Mechanics of Radiation Damage to Pressure Vessel Steels, WCAP-7328 (Rev.), Westinghouse Electric Corporation, PWR Systems Division, Pittsburgh, Pa. (October 1969).

6. W. O. Shabbits, W. H. Pryle, and E. T. Wessel, Heavy-Section Fracture Toughness Properties of $A 533$ Grade $B$ Class 1 Steel Plate and Submerged Arc Weldment, WCAP-7414, Westinghouse Electric Corporation, PWR Systems Divison, Pittsburgh, Pa. (December 1969).

7. F. J. Loss, Dynamic Tear Test Investigations of the Fracture Toughness of Thick-Section Steel, NRL-7056, Naval Research Laboratory, Washington, D.C. (May 14, 1970).

8. P. B. Crosley and E. J. Ripling, Crack Arrest Fracture Toughness of A533 Grade B Class 1 Pressure Vessel Steel, HSSTP-TR-8, Materials Research Laboratory, Inc., Glenwood, I11. (March 1970).

9. T. R. Mager, Post-Irradiation Testing of $2 T$ Compact Tension Specimens, WCAP-7561, Westinghouse Electric Corporation, PWR Systems Division, Pittsburgh, Pa. (August 1970).

10. T. R. Mager, Fracture Toughness Characterization Study of A533, Grade $B$, Class 1 Steel, WCAP-7578, Westinghouse Electric Corporation, PWR Systems Division, Pittsburgh, Pa. (October 1970).

11. T. R. Mager, Notch Preparation in Compact Tension Specimens, WCAP7579, Westinghouse Electric Corporation, PWR Systems Division, Pittsburgh, Pa. (November 1970). 
12. N. Levy and P. V. Marcal, Three-Dimensional Elastic-Plastic Stress and Strain Analysis for Fracture Mechanics, Phase I: Simple Flawed Specimens, HSSTP-TR-12, Brown University, Providence, R.I. (December 1970).

13. W. 0. Shabbits, Dynamic Fracture Toughness Properties of Heavy Section A533 Grade B Class 1 Steel Plate, WCAP-7623, Westinghouse Electric Corporation, PWR Systems Division, Pittsburgh, Pa. (December 1970).

14. P. N. Randal1, Gross Strain Crack Tolerance of A 533-B Steel, HSSTP-TR-14, TRW Systems Group, Redondo Beach, Calif. (May 1, 1971).

15. H. T. Corten and R. H. Sailors, Relationship Between Material Fracture Toughness Using Fracture Mechanics and Transition Temperature Tests, T\&AM Report 346, University of I11inois, Urbana, I11. (August 1, 1971).

16. T. R. Mager and V. J. McLaughlin, The Effect of an Environment of High Temperature Primary Grade Nuclear Reactor Water on the Fatigue Crack Growth Characteristics of A533 Grade B Class 1 plate and Weldment Material, WCAP-7776, Westinghouse Electric Corporation, PWR Systems Division, Pittsburgh, Pa. (October 1971).

17. N. Levy and P. V. Marcal, Three-Dimensional Elastic-Plastic Stress and Strain Analysis for Fracture Mechanics, Phase II: Improved Modelling, HSSTP-TR-17, Brown University, Providence, R.I. (November 1971).

18. S. C. Grigory, Tests of 6-in.-Thick Flawed Tensile Specimens, First Technical Summary Report, Longitudinal Specimens Numbers I through 7, HSSTP-TR-18, Southwest Research Institute, San Antonio, Tex. (June 1972).

19. P. N. Randall, Effects of Strain Gradients on the Gross Strain Crack Tolerance of A533-B Steel, HSSTP-TR-19, TRW Systems Group, Redondo Beach, Calif. (June 15, 1972).

20. S. C. Grigory, Tests of 6-Inch-Thick Flawed Tensile Specimens, Second Technical Summary Report, Transverse Specimens Numbers 8 through 10, Welded specimens Numbers 11 through 13, HSSTP-TR-20, Southwest Research Institute, San Antonio, Tex. (June 1972).

21. L. A. James and J. A. Williams, Heavy Section Steel Technology Program Technical Report No. 21, The Effect of Temperature and Neutron Irradiation Upon the Fatigue-Crack Propagation Behavior of ASTM A533 Grade B, Class 1 Steel, HEDL-TME 72-132, Hanford Engineering Development Laboratory, Richland, Wash. (September 1972).

22. S. C. Grigory, Tests of 6-Inch-Thick Flawed Tensile specimens, Third Technical Summary Report, Longitudinal Specimens Numbers 14 through 16, Unflawed Specimen Number 17, HSSTP-TR-22, Southwest Research Institute, San Antonio, Tex. (October 1972).

23. S. C. Grigory, Tests of 6-Inch-Thick Tensile Specimens, Fourth Technical Summary Report, Tests of 1-Inch-Thick Flawed Tensile 
Specimens for Size Effect Evaluation, HSSTP-TR-23, Southwest Research Institute, San Antonio, Tex. (June 1973).

24. S. P. Ying and S. C. Grigory, Tests of 6-Inch-Thick Tensile Specimens, Fifth Technical Summary Report, Acoustic Emission Monitoring of One-Inch and Six-Inch-Thick Tensile Specimens, HSSTP-TR-24, Southwest Research Institute, San Antonio, Tex. (November 1972).

25. R. W. Derby, J. G. Merkle, G. C. Robinson, G. D. Whitman, and F. J. Witt, Test of 6-Inch-Thick Pressure Vessels. Series 1: Intermediate Test Vessels $V-1$ and $V-2$, ORNL-4895, Oak Ridge Natl. Lab., Oak Ridge, Tenn. (February 1974).

26. W. J. Stelzman and R. G. Berggren, Radiation Strengthening and Embrittlement in Heavy Section Steel Plates and Welds, ORNL-4871, Oak Ridge Nat1. Lab., Oak Ridge, Tenn. (June 1973).

27. P. B. Crosley and E. J. Ripling, Crack Arrest in an Increasing $K-F i e l d$, HSSTP-TR-27, Materials Research Laboratory, Inc., Glenwood, Ill. (January 1973).

28. P. V. Marcal, P. M. Stuart, and R. S. Bettes, Elastic-Plastic Behavior of a Longitudinal Semi-Elliptic Crack in a Thick Pressure Vesse1, HSSTP-TR-28, Brown University, Providence, R.I. (June 1973).

29. W. J. Stelzman, R. G. Berggren, and T. N. Jones, ORNL Characterization of Heavy-Section Steel Technology Program Plates 01, 02 and 03, NUREG/CR-4092 (ORNL/TM-9491), Oak Ridge Nat1. Lab., Oak Ridge, Tenn. (April 1985).

30. Canceled.

31. J. A. Williams, The Irradiation and Temperature Dependence of Tensile and Fracture Properties of ASTM A533, Grade B, Class 1 Steel Plate and Weldment, HEDL-TME 73-75, Hanford Engineering Development Laboratory, Richland, Wash. (August 1973).

32. J. M. Steichen and J. A. Williams, High Strain Rate Tensile Properties of Irradiated ASTM A533 Grade B Class I Pressure Vessel Steel, Hanford Engineering Development Laboratory, Richland, Wash. (July 1973).

33. P. C. Riccardella and J. L. Swedlow, A Combined Analytical-Experimental Fracture Study of the Two Leading Theories of ElasticPlastic Fracture (J-Integral and Equivalent Energy), WCAP-8224, Westinghouse Electric Corporation, Pittsburgh, Pa. (October 1973).

34. R. J. Podlasek and R. J. Eiber, Final Report on Investigation of Mode III Crack Extension in Reactor Piping, Battelle Columbus Laboratories, Columbus, Ohio (December 14, 1973).

35. T. R. Mager, J. D. Landes, D. M. Moon, and V. J. McLaughlin, Interim Report on the Effect of Low Frequencies on the Fatigue Crack Growth Characteristics of A533 Grade B Class 1 Plate in an Environment of High-Temperature Primary Grade Nuclear Reactor Water, WCAP8256, Westinghouse Electric Corporation, Pittsburgh, Pa. (December $1973)$. 
36. J. A. Williams, The Irradiated Fracture Toughness of ASTM A533, Grade $B$, Class 1 Steel Measured with a Four-Inch-Thick Compact Tension Specimen, HEDL-TME 75-10, Hanford Engineering Development Laboratory, Richland, Wash. (January 1975).

37. R. H. Bryan, J. G. Merkle, M. N. Raftenberg, G. C. Robinson, and J. E. Smith, Test of 6-Inch-Thick Pressure Vesse1s. Series 2: Intermediate Test Vessels $V-3, V-4$, and $V-6$, ORNL-5059, Oak Ridge Nat l. Lab., Oak Ridge, Tenn. (November 1975).

38. T. R. Mager, S. E. Yanichko, and L. R. Singer, Fracture Toughness Characterization of HSST Intermediate Pressure Vessel Material, WCAP-8456, Westinghouse Electric Corporation, Pittsburgh, Pa. (December 1974).

39. J. G. Merkle, G. D. Whitman, and R. H. Bryan, An Evaluation of the HSST Program Intermediate Pressure Vessel Tests in Terms of LightWater-Reactor Pressure Vessel Safety, ORNL/TM-5090, Oak Ridge Natl. Lab., Oak Ridge, Tenn. (November 1975).

40. J. G. Merkle, G. C. Robinson, P. P. Holz, J. E. Smith, and R. H. Bryan, Test of 6-In.-Thick Pressure Vessels. Series 3: Intermediate Test Vessel $V-7$, ORNL/NUREG-1, Oak Ridge Nat1. Lab., Oak Ridge, Tenn. (August 1976).

41. J. A. Davidson, L. J. Ceschini, R. P. Shogan, and G. V. Rao, The Irradiated Dynamic Fracture Toughness of ASTM A533, Grade B, Class 1 Steel Plate and Submerged ArC Weldment, WCAP-8775, Westinghouse Electric Corporation, Pittsburgh, Pa. (October 1976).

42. R. D. Cheverton, Pressure Vessel Fracture Studies Pertaining to a PWR LOCA-ECC Thermal Shock: Experiments TSE-1 and TSE-2, ORNL/ NUREG/TM-31, Oak Ridge Nat1. Lab., Oak Ridge, Tenn. (September 1976).

43. J. G. Merkle, G. C. Robinson, P. P. Holz, and J. E. Smith, Test of 6-In. Thick Pressure Vessels. Series 4: Intermediate Test Vessels $V-5$ and $V-9$ with Inside Nozzle Corner Cracks, ORNL/NUREG-7, Oak Ridge Nat1. Lab., Oak Ridge, Tenn. (August 1977).

44. J. A. Williams, The Ductile Fracture Toughness of Heavy Section Steel Plate, NUREG/CR-0859, Hanford Engineering Development Laboratory, Richland, Wash. (September 1979).

45. R. H. Bryan, T. M. Cate, P. P. Holz, T. A. King, J. G. Merkle, G. C. Robinson, G. C. Smith, J. E. Smith, and G. D. Whitman, Test of 6-in.-Thick Pressure Vessels. Series 3: Intermediate Test Vessel $V-7 A$ Under Sustained Loading, ORNL/NUREG-9, Oak Ridge Nat1. Lab., Oak Ridge, Tenn. (February 1978).

46. R. D. Cheverton and S. E. Bolt, Pressure Vessel Fracture Studies Pertaining to a PWR LOCA-ECC Thermal Shock: Experiments TSE-3 and TSE-4 and Update of TSE-1 and TSE-2 Analysis, ORNL/NUREG-22, Oak Ridge Nat1. Lab., Oak Ridge, Tenn. (December 1977).

47. D. A. Canonico, Significance of Reheat Cracks to the Integrity of Pressure Vessels for Light-Water Reactors, ORNL/NUREG-15, Oak Ridge Nat1. Lab., Oak Ridge, Tenn. (July 1977). 
48. G. C. Smith and P. P. Holz, Repair Weld Induced Residual Stresses in Thick-Walled Steel Pressure Vessels, NUREG/CR-0093 (ORNL/NUREG/ TM-153), Oak Ridge Nat1. Lab., Oak Ridge, Tenn. (June 1978).

49. P. P. Holz and S. W. Wismer, Half-Bead (Temper) Repair Welding for HSST Vesse1s, NUREG/CR-0113 (ORNL/NUREG/TM-177), Oak Ridge Nat1. Lab., Oak Ridge, Tenn. (June 1978).

50. G. C. Smith, P. P. Holz, and W. J. Stelzman, Crack Extension and Arrest Tests of Axially Flawed Steel Model Pressure Vessels, NUREG/ CR-0126 (ORNL/NUREG/TM-196), Oak Ridge Nat1. Lab., Oak Ridge, Tenn. (October 1978).

51. R. H. Bryan, P. P. Holz, J. G. Merkle, G. C. Smith, J. E. Smith, and W. J. Stelzman, Test of 6-in.-Thick Pressure Vessels. Series 3: Intermediate Test Vessel $V-7 B$, NUREG/CR-0309 (ORNL/NUREG-38), Oak Ridge Nat1. Lab., Oak Ridge, Tenn. (October 1978).

52. R. D. Cheverton, S. K. Iskander, and S. E. Bolt, Applicability of LEFM to the Analysis of PWR Vessels Under LOCA-ECC Thermal Shock Conditions, NUREG/CR-0107 (ORNL/NUREG-40), Oak Ridge Nat1. Lab., Oak Ridge, Tenn. (October 1978).

53. R. H. Bryan, D. A. Canonico, P. P. Holz, S. K. Iskander, J. G. Merkle, J. E. Smith, and W. J. Stelzman, Test of 6-in.-Thick Pressure Vessels, Series 3: Intermediate Test Vessel V-8, NUREG/CR0675 (ORNL/NUREG-58), Oak Ridge Nat1. Lab., Oak Ridge, Tenn. (December 1979).

54. R. D. Cheverton and S. K. Iskander, Application of Static and Dynamic Crack Arrest Theory to TSE-4, NUREG/CR-0767 (ORNL/NUREG57), Oak Ridge Nat1. Lab., Oak Ridge, Tenn. (June 1979).

55. J. A. Williams, Tensile Properties of Irradiated and Unirradiated Welds of A533 Steel Plate and A508 Forgings, NUREG/CR-1158 (ORNL/ Sub-79/50917/2), Hanford Engineering Development Laboratory, Richland, Wash. (July 1979).

56. K. W. Carlson and J. A. Williams, The Effect of Crack Length and Side Grooves on the Ductile Fracture roughness Properties of ASTM A533 Steel, NUREG/CR-1171 (ORNL/Sub-79/50917/3), Hanford Engineering Development Laboratory, Richland, Wash. (October 1979).

57. P. P. Holz, Flaw Preparations for HSST Program Vessel Fracture Mechanics Testing; Mechanical-Cyclic Pumping and Electron-Beam Weld-Hydrogen Charge Cracking Schemes, NUREG/CR-1274 (ORNL/NUREG/ TM-369), Oak Ridge Nat1. Lab., Oak Ridge, Tenn. (May 1980).

58. S. K. Iskander, Two Finite Element Techniques for Computing Mode I Stress Intensity Factors in Two- or Three-Dimensional Problems, NUREG/CR-1499 (ORNL/NUREG/CSD/TM-14), Computer Sciences Div., Union Carbide Corp. Nuclear Div., Oak Ridge, Tenn. (February 1981).

59. P. B. Crosley and E. J. Ripling, Development of a Standard Test for Measuring $K_{I a}$ with a Modified Compact Specimen, NUREG/CR-2294 (ORNL/Sub-81/7755/1), Materials Research Laboratory, Glenwood, I11. (August 1981). 
60. S. N. Atluri, B. R. Bass, J. W. Bryson, and K. Kathiresan, NOZFLAW: A Finite Element Program for Direct Evaluation of Stress Intensity Factors for Pressure Vessel Nozzle-Corner Flaws, NUREG/ CR-1843 (ORNL/NUREG/CSD/TM-18), Computer Sciences Div., Oak Ridge Gaseous Diffusion Plant, Oak Ridge, Tenn. (March 1981).

61. A. Shukla, W. L. Fourney, and G. R. Irwin, Study of Energy Loss and Its Mechanisms in Homalite 100 During Crack Propagation and Arrest, NUREG/CR-2150 (ORNL/Sub-7778/1), University of Maryland, College Park, Md. (August 1981).

62. S. K. Iskander, R. D. Cheverton, and D. G. Ba11, OCA-I, A Code for Calculating the Behavior of Flaws on the Inner Surface of a Pressure Vessel Subjected to Temperature and Pressure Transients, NUREG/CR-2113 (ORNL/NUREG-84), Oak Ridge Nat1. Lab., Oak Ridge, Tenn. (August 1981).

63. R. J. Sanford, R. Chona, W. L. Fourney, and G. R. Irwin, A Photoelastic Study of the Influence of Non-Singular Stresses in Fracture Test Specimens, NUREG/CR-2179 (ORNL/Sub-7778/2), University of Maryland, College Park, Md. (August 1981).

64. B. R. Bass, S. N. Atluri, J. W. Bryson, and K. Kathiresan, OR-FLAW: A Finite Element Program for Direct Evaluation of K-Factors for User-Defined Flaws in Plate, Cylinders, and Pressure-Vessel Nozzle Corners, NUREG/CR-2494 (ORNL/CSD/TM-165), Oak Ridge Nat1. Lab., Oak Ridge, Tenn. (April 1982).

65. B. R. Bass and J. W. Bryson, ORMGEN-3D: A Finite Element Mesh Generator for 3-Dimensional Crack Geometries, NUREG/CR-2997, Vo1 . 1 (ORNL/TM-8527/V1), Oak Ridge Natl. Lab., Oak Ridge, Tenn. (December 1982).

66. B. R. Bass and J. W. Bryson, ORVIRT: A Finite Element Program for Energy Release Rate Calculations for 2-Dimensional and 3-Dimensional Crack Mode1s, NUREG/CR-2997, Vol. 2 (ORNL/TM-8527/V2), Oak Ridge Nat1. Lab., Oak Ridge, Tenn. (February 1983).

67. R. D. Cheverton, S. K. Iskander, and D. G. Ball, PWR Pressure Vessel Integrity During Overcooling Accidents: A Parametric Analysis, NUREG/CR-2895 (ORNL/TM-7931), Oak Ridge Nat1. Lab., Oak Ridge, Tenn. (February 1983).

68. D. G. Ball, R. D. Cheverton, J. B. Drake, and S. K. Iskander, OCAII, A Code for Calculating Behavior of 2-D and 3-D Surface Flaws in a Pressure Vessel Subjected to Temperature and Pressure Transients, NUREG/CR-3491 (ORNL-5934), Oak Ridge Nat1. Lab., Oak Ridge, Tenn. (February 1984).

69. A. Sauter, R. D. Cheverton, and S. K. Iskander, Modification of OCA-I for Application to a Reactor Pressure Vessel with Cladding on the Inner Surface, NUREG/CR-3155 (ORNL/TM-8649), Oak Ridge Natl. Lab., Oak Ridge, Tenn. (May 1983).

70. R. D. Cheverton and D. G. Ball, OCA-P, A Deterministic and Probabilistic Fracture-Mechanics Code for Application to Pressure Vessels, NUREG/CR-3618 (ORNL-5991), Oak Ridge Natl. Lab., Oak Ridge, Tenn. (May 1984). 
71. J. G. Merkle, An Examination of the Size Effects and Data Scatter observed in Small specimen Cleavage Fracture Toughness Testing, NUREG/CR-3672 (ORNL/TM-9088), Oak Ridge Nat1. Lab., Oak Ridge, Tenn. (April 1984).

72. C. E. Pugh et al., Heavy-Section Steel Technology Program-FiveYear Plan FY 1983-1987, NUREG/CR-3595 (ORNL/TM-9008), Oak Ridge Nat1. Lab., Oak Ridge, Tenn. (April 1984).

73. D. G. Ball, B. R. Bass, J. W. Bryson, R. D. Cheverton, and J. B. Drake, Stress Intensity Factor Influence Coefficients for Surface Elaws in Pressure Vessels, NUREG/CR-3723 (ORNL/CSD/TM-216), Oak Ridge Nat1. Lab., Oak Ridge, Tenn. (February 1985).

74. W. R. Corwin, R. G. Berggren, and R. K. Nanstad, Charpy Toughness and Tensile Properties of Neutron Irradiated Stainless Steel Submerged-ArC Weld Cladding Overlay, NUREG/CR-3927 (ORNL/TM-9309), Oak Ridge Natl. Lab., Oak Ridge, Tenn. (September 1984).

75. C. W. Schwartz, R. Chona, W. L. Fourney, and G. R. Irwin, SAMCR: A Two-Dimensional Dynamic Finite Element Code for the Stress Analysis of Moving CRacks, NUREG/CR-3891 (ORNL/Sub/79-7778/3), University of Maryland, College Park, Md. (November 1984).

76. W. R. Corwin, G. C. Robinson, R. K. Nanstad, J. G. Merkle, R. G. Berggren, G. M. Goodwin, R. L. Swain, and T. D. Owings, Effects of Stainless Steel Weld overlay Cladding on the Structural Integrity of Flawed Steel plates in Bending, Series 1, NUREG/CR-4015 (ORNL/TM-9390), Oak Ridge Nat1. Lab., Oak Ridge, Tenn. (April 1985).

77. R. H. Bryan, B. R. Bass, S. E. Bolt, J. W. Bryson, D. P. Edmonds, R. W. McCulloch, J. G. Merkle, R. K. Nanstad, G. C. Robinson, K. R. Thoms, and G. D. Whitman, Pressurized-Thermal-Shock Test of 6-in.Thick Pressure Vessels. PTSE-1: Investigation of Warm Prestressing and Upper-Shelf Arrest, NUREG/CR-4106 (ORNL-6135), Oak Ridge Nat l. Lab., Oak Ridge, Tenn. (April 1985).

78. R. D. Cheverton, D. G. Ball, S. E. Bolt, S. K. Iskander, and R. K. Nanstad, Pressure Vessel Fracture studies Pertaining to the PWR Thermal-Shock Issue: Experiments TSE-5, TSE-5A, and TSE-6, NUREG/ CR-4249 (ORNL-6163), Martin Marietta Energy Systems, Inc., Oak Ridge Nat1. Lab., Oak Ridge, Tenn. (June 1985).

79. R. D. Cheverton, D. G. Ball, S. E. Bolt, S. K. Iskander, and R. K. Nanstad, Pressure Vessel Fracture Studies Pertaining to the PWR Thermal-Shock Issue: Experiment TSE-7, NUREG/CR-4304 (ORNL-6177), Martin Marietta Energy Systems, Inc., Oak Ridge Natl. Lab., Oak Ridge, Tenn. (August 1985).

80. R. H. Bryan, B. R. Bass, S. E. Bolt, J. W. Bryson, J. G. Merkle, R. K. Nanstad, and G. C. Robinson, Test of 6-in.-Thick Pressure Vessels. Series 3: Intermediate Test Vessel V-8A-Tearing Behavior of Low Upper-Shelf Material, NUREG/CR-4760 (ORNL-6187), Martin Marietta Energy Systems, Inc., Oak Ridge Nat1. Lab., Oak Ridge, Tenn. (May 1987). 
81. R. D. Cheverton and D. G. Bal1, A Parametric Study of PWR Pressure Vessel Integrity During Overcooling Accidents, Considering Both 2-D and 3-D Flaws, NUREG/CR-4325 (ORNL/TM-9682), Martin Marietta Energy Systems, Inc., Oak Ridge Natl. Lab., Oak Ridge, Tenn. (August 1985).

82. E. C. Rodabaugh, Comments on the Leak-Before-Break Concept for Nuclear Power Plant Piping Systems, NUREG/CR-4305 (ORNL/Sub/8222252/3), E. C. Rodabaugh Associates, Inc., Hilliard, Ohio (August 1985).

83. J. W. Bryson, ORVIRT.PC: A 2-D Finite Element Fracture Analysis Program for a Microcomputer, NUREG/CR-4367 (ORNL-6208), Mart in Marietta Energy Systems, Inc., Oak Ridge Natl. Lab., Oak Ridge, Tenn. (October 1985).

84. D. G. Ball and R. D. Cheverton, Adaptation of OCA-P, A Probabilistic Fracture-Mechanics Code, to a Personal Computer, NUREG/CR4468 (ORNL/CSD/TM-233), Martin Marietta Energy Systems, Inc., Oak Ridge Nat1. Lab., Oak Ridge, Tenn. (January 1986).

85. J. W. Bryson and B. R. Bass, ORMGEN.PC: A Microcomputer Program for Automatic Mesh Generation of 2-D Crack Geometries, NUREG/CR4475 (ORNL-6250), Martin Marietta Energy Systems, Inc., Oak Ridge Nat1. Lab., Oak Ridge, Tenn. (March 1986).

86. G. D. Whitman, Historical Summary of the Heavy-Section Steel Technology Program and Some Related Activities in Light-Water Reactor Pressure Vessel Safety Research, NUREG/CR-4489 (ORNL-6259), Martin Marietta Energy Systems, Inc., Oak Ridge Natl. Lab., Oak Ridge, Tenn. (March 1986).

87. C. Inversini and J. W. Bryson, ORPLOT.PC: A Graphic Utility for ORMGEN.PC and ORVIRT.PC, NUREG/CR-4633 (ORNL-6291), Martin Marietta Energy Systems, Inc., Oak Ridge Nat1. Lab., Oak Ridge, Tenn. (June 1986).

88. J. J. McGowan, R. K. Nanstad, and K. R. Thoms, Characterization of Irradiated Current-Practice Welds and $A 533$ Grade $B$ Class 1 plate for Nuclear Pressure Vessel Service, NUREG/CR-4880 (ORNL/TM-10387), Martin Marietta Energy Systems, Inc., Oak Ridge Natl. Lab., Oak Ridge Tenn. (to be published).

89. K. V. Cook and R. W. McClung, Flaw Density Examinations of a Clad Boiling Water Reactor Pressure Vessel Segment, NUREG/CR-4860 (ORNL/TM-10364), Martin Marietta Energy Systems, Inc., Oak Ridge Nat1. Lab., Oak Ridge, Tenn. (April 1987).

90. D. J. Naus et al., Crack-Arrest Behavior in SEN Wide Plates of Quenched and Tempered A 533 Grade B Steel Tested Under Nonisothermal Conditions, NUREG/CR-4930 (ORNL-6388), Martin Marietta Energy Systems, Inc., Oak Ridge Nat1. Lab., Oak Ridge, Tenn. (August 1987).

91. D. B. Barker et al., A Report on the Round Robin Program Conducted to Evaluate the Proposed ASTM Standard Test Method for Determining 
the Plane Strain Crack Arrest Fracture Toughness $K_{1 a^{\prime}}$ of Ferritic Materials, NUREG/CR-4966 (ORNL/Sub/79-7778/4), University of Maryland, College Park, Md. (January 1988).

92. W. H. Bamford, A Summary of Environmentally Assisted Crack-Growth Studies Performed at Westinghouse Electric Corporation Under Funding from the Heavy-Section Steel Technology Program, NUREG/CR-5020 (ORNL/Sub/82/21598/1), Westinghouse Electric Corp., Pittsburgh, Pa. (May 1988).

93. R. H. Bryan et al., Pressurized-Thermal-Shock Test of 6-in.-Thick Pressure Vessels. PTSE-2: Investigation of Low Tearing Resistance and Warm Prestressing, NUREG/CR-4888 (ORNL-6377), Martin Marietta Energy Systems, Inc., Oak Ridge Nat1. Lab., Oak Ridge, Tenn. (December 1987).

94. J. H. Giovanola and R. W. Klopp, Viscoplastic Stress-Strain Characterization of $A 533 B$ Class 1 Steel, NUREG/CR-5066 (ORNL/Sub/87SA193/1), SRI International, Menlo Park, Calif. (to be published).

95. L. F. Miller et al., Neutron Exposure Parameters for the Metallurgical Test specimens in the Fifth Heavy-Section Steel Technology Irradiation Series Capsules, NUREG/CR-5019 (ORNL/TM-10582), Martin Marietta Energy Systems, Inc., Oak Ridge Natl. Lab., Oak Ridge, Tenn. (to be published).

96. B. R. Bass et al., Viscoplastic Dynamic Fracture Analyses of the WP-1 Series of Wide-Plate Crack-Arrest Tests, NUREG/CR-XXXX (ORNLXXXX), Martin Marietta Energy Systems, Inc., Oak Ridge Nat1. Lab., Oak Ridge, Tenn. (to be published).

97. D. J. Naus, J. Keeney-Walker, and B. R. Bass, High-Temperature Crack-Arrest Behavior in 152-mm-Thick SEN Wide Plates of Quenched and Tempered A 533 Grade $B$ Steel, NUREG/CR-XXXX (ORNL/TM-XXXXX), Martin Marietta Energy Systems, Inc., Oak Ridge Natl. Lab., Oak Ridge, Tenn. (to be published).

98. K. V. Cook, R. A. Cunningham, Jr., and R. W. McClung, Detection and Characterization of Indications in Segments of Reactor Pressure Vessels, NUREG/CR-5322 (ORNL/TM-11072), Martin Marietta Energy Systems, Inc., Oak Ridge Nat1. Lab., Oak Ridge, Tenn. (to be publ ished).

99. R. D. Cheverton, W. E. Penne11, G. C. Robinson, and R. K. Nanstad, Impact of Radiation Embrittlement on Integrity of Pressure Vessel Supports for Two PWR Plants, NUREG/CR-5320 (ORNL/TM-10966), Martin Marietta Energy Systems, Inc., Oak Ridge Natl. Lab., Oak Ridge, Tenn. (to be published). 



$\begin{array}{ll}\text { AE } & \text { architect engineer } \\ \text { ASME } & \text { American Society of Mechanical Engineers } \\ \text { ASTM } & \text { American Society for Testing and Materials } \\ \text { B\&W } & \text { Babcock \& Wilcox Company } \\ \text { BWR } & \text { boiling-water reactor } \\ \text { CE } & \text { Combustion Engineering } \\ \text { CVN } & \text { Charpy V-notch } \\ \text { DL } & \text { dead load } \\ \text { dPa } & \text { displacements per atom } \\ \text { DW } & \text { dead weight } \\ \text { E } & \text { operating base earthquake } \\ \text { E } & \text { no-loss-of-function earthquake } \\ \text { EFPY } & \text { effective full-power years } \\ \text { EPRI } & \text { Electric Power Research Institute } \\ \text { EGCR } & \text { Experimental Gas-Cooled Reactor } \\ \text { FSAR } & \text { Final Safety Analysis Report } \\ \text { GE } & \text { General Electric } \\ \text { HAZ } & \text { heat-affected zone } \\ \text { HFIR } & \text { High Flux Isotope Reactor } \\ \text { LBLOCA } & \text { large-break loss-of-coolant accident } \\ \text { LEFM } & \text { linear elastic fracture mechanics } \\ \text { LOCA } & \text { loss-of-coolant accident } \\ \text { LWR } & \text { light-water reactor } \\ \text { MTR } & \text { Materials Testing Reactor } \\ \text { NDTT } & \text { nil ductility transition temperature } \\ \text { NDTT } & \text { increase in nil ductility transition temperature } \\ \text { NOAC } & \text { Nuclear Operations Analysis Center } \\ \text { NSSS } & \text { nuclear steam supply system } \\ \text { NRC } & \text { Nuclear Regulatory Commission } \\ \text { OBE } & \text { operating basis earthquake } \\ \text { ORNL } & \text { Oak Ridge National Laboratory } \\ \text { ORR } & \text { Oak Ridge Research Reactor } \\ \text { PGE } & \text { Portland General Electric } \\ \text { PSAR } & \text { Preliminary Safety Analysis Report } \\ \text { PWR } & \text { pressurized-water reactor } \\ \text { SBLOCA } & \text { small-break loss-of-coolant accident } \\ \text { SEN } & \text { single-edge notch } \\ \text { SSE } & \text { safe shutdown earthquake } \\ \text { W } & \text { Westinghouse Electric Corporation } \\ \end{array}$



1.1 PWR vessel support located in cavity between vessel and biological shield $\ldots . \ldots \ldots \ldots \ldots \ldots \ldots \ldots \ldots \ldots \ldots \ldots \ldots$.

2.1 Cross section of HFIR vessel and core at midheight of core, indicating locations of vessel surveillance specimens (Keys $1-7$ ) $\ldots \ldots \ldots \ldots \ldots \ldots \ldots \ldots \ldots \ldots \ldots \ldots \ldots \ldots$

2.2 Increase in NDTT with fluence ( $>1.0 \mathrm{MeV}$ ) for A212-B irradiated in HFIR (vessel surveillance positions) and ORR and for several similar materials

2.3 Increase in NDTT with fluence ( $>1 \mathrm{MeV}$ ) for irradiations in HFIR (vessel surveillance positions) and MTR .... 10

2.4 Increase in NDTT with dpa for irradiations in HFIR (vessel surveillance positions), ORR, and MTR .......... 11

2.5 Effects of neutron radiation on Charpy-V transition temperature behavior of Army RPV steels ............... 12

3.1 Method for extrapolating HFIR vessel surveillance $\triangle N D T T$ vs dpa $(E>0.1 \mathrm{MeV})$ data, assuming $\triangle \mathrm{NDTT}=$ $145 \mathrm{ln} \mathrm{dpa} / \mathrm{d}^{\circ} \mathrm{F}$ for $\triangle N D T T>50^{\circ} \mathrm{F} \ldots \ldots \ldots \ldots \ldots \ldots \ldots \ldots \ldots \ldots \ldots \ldots \ldots \ldots \ldots$

3.2 Method for extrapolating HFIR vessel surveillance $\triangle$ NDTT vs dpa ( $\mathrm{E}>0.1 \mathrm{MeV})$ data, assuming $\Delta$ NDTT $=d(d p a) 0.688$ for $10 \leq \Delta N D T T \leq 300^{\circ} \mathrm{F}$

$3.3 \mathrm{dpa}(\mathrm{E}>0.1 \mathrm{MeV})$ vs dpa rate for specific values of $\triangle$ NDTT, based on data in Fig. $3.1 \ldots \ldots \ldots \ldots \ldots \ldots \ldots \ldots$

$3.4 \mathrm{dpa}(\mathrm{E}>0.1 \mathrm{MeV})$ vs dpa rate for specific values of $\triangle$ NDTT, based on data in Fig. $3.2 \ldots \ldots \ldots \ldots \ldots \ldots \ldots \ldots . \ldots . \ldots 22$

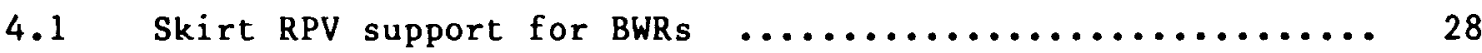

4.2 BWR (Big Rock Point) vessel with suspension supports .... 29

4.3 PWR vessel with skirt support $\ldots \ldots \ldots \ldots \ldots \ldots \ldots \ldots \ldots \ldots . \ldots \ldots$

4.4 PWR vessel with long-column supports $\ldots \ldots \ldots \ldots \ldots \ldots \ldots \ldots . \ldots . \ldots$

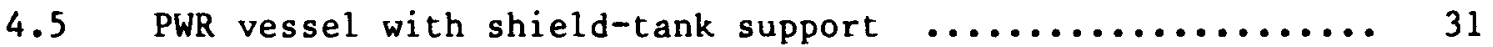

4.6 PWR vessel with category 4A support $\ldots \ldots \ldots \ldots \ldots \ldots \ldots \ldots . \ldots . \ldots . \ldots$

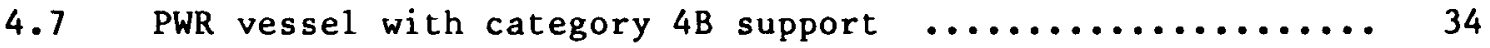

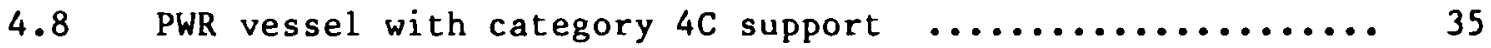

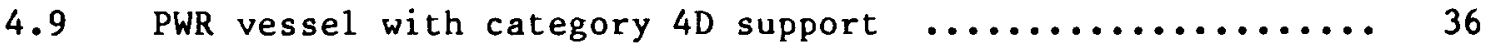

4.10 PWR vessel with category 4 E support $\ldots \ldots \ldots \ldots \ldots \ldots \ldots \ldots . \ldots \ldots$

4.11 PWR vessel with cateogry $4 \mathrm{~F}$ support $\ldots \ldots \ldots \ldots \ldots \ldots \ldots \ldots . \ldots \ldots$ 
4.12 PWR vessel with category $4 \mathrm{G}$ support $\ldots \ldots \ldots \ldots \ldots \ldots \ldots \ldots . \ldots \ldots$

5.1 Relative axial variation of fast neutron ( $E>1.0$ $\mathrm{MeV}) \mathrm{flux}$ and fluence within pressure vessel wall

6.1 Radial section through Trojan reactor vessel supports showing principal structural and kinematic elements

6.2 Geometry and dimensions of Trojan reactor vessel support beams .......................... 48

6.3 Cross-section geometry and dimensions for Trojan reactor vessel support beam pedestals ................

6.4 Trojan reactor vessel support beam beam-on-elasticfoundation analytical model, showing locations of nodes on model and in structure $\ldots \ldots \ldots \ldots \ldots \ldots \ldots \ldots \ldots$

6.5 Details of the Trojan reactor vessel-support-beam analytical model at the beam-flange grout-hole location

6.6 Elastic-foundation reaction loads produced by 200-kip "unit load" applied to lugs of Trojan reactor vessel support beams $\ldots \ldots \ldots \ldots \ldots \ldots \ldots \ldots \ldots \ldots$

6.7 Bending-moment distributions in Trojan reactor vessel support beams produced by 200-kip "unit load" applied at support beam lugs .................

6.8 Deflection distributions for Trojan reactor vessel support beams produced by 200-kip "unit load" applied at support beam lugs $\ldots \ldots \ldots \ldots \ldots \ldots \ldots \ldots \ldots \ldots \ldots$

6.9 Fracture-toughness data for A36 steel showing temperature dependence and strain-rate sensitivity ......

6.10 Fracture-toughness data for A36 before transposition to prototypic reactor vessel support beam straining

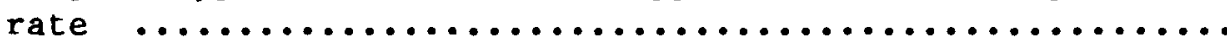

6.11 Fracture-toughness data for A36 after transposition to prototypic reactor vessel support beam straining

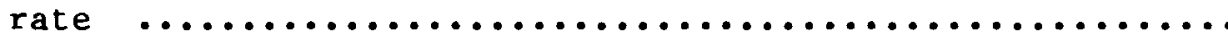

6.12 Best-fit mean curve superposed on transposed A36

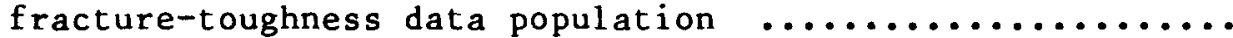

6.13 Definition of temperature limits for cleavage fracture of $A 36$ at prototypic reactor vessel

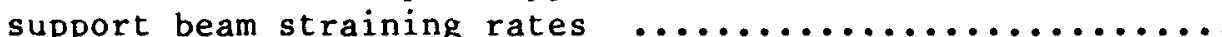

6.14 Extrapolation of best-fit, mean fracture-toughness curve for A36, showing compatibility of fitted curve with cleavage-fracture temperature 1 imit

6.15 Plane-stress, fracture-toughness curve for A36 derived from best-fit, plain-strain $k_{I d}$ curve $\ldots \ldots \ldots \ldots$ 
xxiii

6.16 Blending of the mean plane-stress and plane-strain fracture-toughness curves for $A 36 \quad \ldots \ldots \ldots \ldots \ldots \ldots \ldots \ldots$

6.17 Lower bound, plane-strain/plane-stress, fracturetoughness curves for A36 showing compatibility with ASME Code temperature 1 imit for exemption from fracture-toughness testing $\ldots \ldots \ldots \ldots \ldots \ldots \ldots \ldots \ldots \ldots$

6.18 Fracture-toughness design curve for A36 at prototypic reactor vessel straining rates $\ldots \ldots \ldots \ldots \ldots \ldots \ldots \ldots \ldots \ldots$

6.19 Radiation-induced NDTT shifts at critical locations on Trojan reactor vessel support beams .............. 76

6.20 dpa rate within Trojan reactor cavity wall at reactor vessel support beam elevation $\ldots \ldots \ldots \ldots \ldots \ldots \ldots$

6.21 Predicted lifetime variation in fracture toughness of $A 36$ at reactor vessel support beam grout-hole

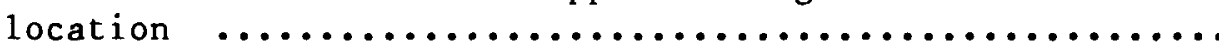

6.22 Stress-intensity factors at cavity liner interface as function of $f l a w$ depth and flaw aspect ratio:

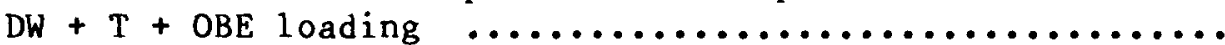

6.23 Stress-intensity factors at cavity liner interface as function of flaw depth and $f l a w$ aspect ratio:

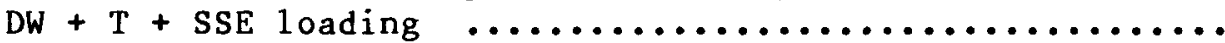

6.24 Stress-intensity factors at cavity liner interface as function of flaw depth and flaw aspect ratio: $\mathrm{DW}+\mathrm{T}+$ SBLOCA loading

6.25 Stress-intensity factors at cavity liner interface as function of flaw depth and flaw aspect ratio:

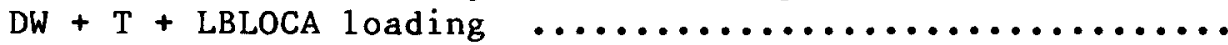

6.26 Critical flaw depths at cavity liner interface after

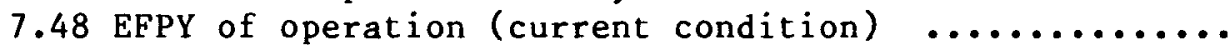

6.27 Critical flaw depths at cavity liner interface after

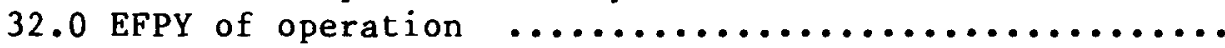

6.28 Stress-intensity factors at maximum bending-moment location as function of $f l a w$ depth and flaw aspect ratio: $\mathrm{DW}+\mathrm{T}+\mathrm{OBE}$ loading: no inner concrete support $\ldots \ldots \ldots \ldots$

6.29 Stress-intensity factors at maximum bending-moment location as function of flaw depth and flaw aspect ratio: $\mathrm{DW}+\mathrm{T}+\mathrm{SSE}$ loading: no inner concrete support .........

6.30 Stress-intensity factors at maximum bending-moment 1ocation as function of flaw depth and flaw aspect ratio: $\mathrm{DW}+\mathrm{T}+$ SBLOCA loading: no inner concrete support ......

6.31 Stress-intensity factors at maximum bending-moment 1ocation as function of flaw depth and flaw aspect ratio: $\mathrm{DW}+\mathrm{T}+$ LBLOCA loading: no inner concrete support ...... 
xxiv

6.32 Stress-intensity factors at maximum bending-moment 1ocation as function of $f$ law depth and flaw aspect ratio: $\mathrm{DW}+\mathrm{T}+\mathrm{OBE}$ loading: with inner concrete support ......

6.33 Stress-intensity factors at maximum bending-moment location as function of flaw depth and flaw aspect ratio: $\mathrm{DW}+\mathrm{T}+\mathrm{SSE}$ loading: with inner concrete support .......

6.34 Stress-intensity factors at maximum bending-moment location as function of flaw depth and flaw aspect ratio: $\mathrm{DW}+\mathrm{T}+$ SBLOCA loading: with inner concrete support ....

6.35 Stress-intensity factors at maximum bending-moment location as function of flaw depth and flaw aspect ratio: $D W+T+$ LBLOCA loading: with inner concrete support ...

6.36 Critical flaw depths at maximum bending-moment

location after 7.4 EFPY of operation (current condition): no inner concrete support

6.37 Critical flaw depths at maximum bending-moment

location after 32 EFPY of operation: no inner

concrete support

6.38 Critical flaw depths at maximum bending-moment

location after 7.48 EFPY of operation: with inner

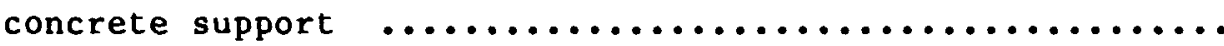

6.39 Critical flaw depths at maximum bending-moment

location after 32 EFPY of operation: with inner

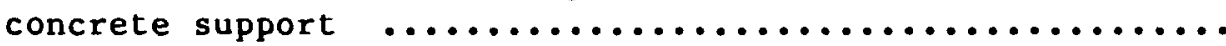

6.40 Stress-intensity-factor equation used at beam

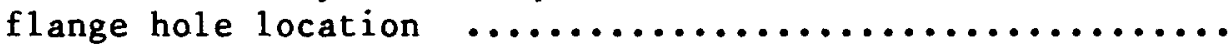

6.41 Comparison of beam-flange boundary conditions with boundary conditions used in the Newman analysis .........

6.42 Stress-intensity factors at beam-flange grout-hole location as function of flaw depth and vessel support

loading: no inner concrete support ................. 101

6.43 Stress-intensity factors at beam-flange grout-hole location as function of flaw depth and vessel support

loading: no inner concrete support

6.44 Stress-intensity factors at beam-flange grout-hole location as function of flaw depth and vessel support loading: with inner concrete support $\ldots \ldots \ldots \ldots \ldots \ldots \ldots \ldots$

6.45 Stress-intensity factors at beam-flange grout-hole location as function of flaw depth and vessel support loading: with inner concrete support ............... 102

6.46 Lifetime variation of critical flaw depths at beamflange grout-hole location for DW + T + SBLOCA loading ... 104

6.47 Lifetime variation of critical flaw depths at beamflange grout-hole location for range of vessel support beam loading conditions: no inner concrete support ..... 104 
6.48 Lifetime variation of critical flaw depths at beamflange grout-hole location for range of vessel support beam loading conditions: with inner concrete support

6.49 Carpet plot used to assess the impact on critical flaw depth of variations in NDTT, support operating temperature, and support load .................... 106

6.50 Fatigue crack-growth rates for $A 36 \ldots \ldots \ldots \ldots \ldots \ldots \ldots \ldots$

6.51 Compatibility check on the stress-intensity-factor equations used in flaw tolerance analysis

6.52 Comparison of the critical-flaw-depth sensitivity to support load variations at cavity liner interface and beam-flange grout-hole location

6.53 Stress distributions in the beam-flange ligament showing stress concentrations adjacent to the grout hol

6.54 Envelope of residual stresses used in residual stress impact assessment

6.55 Normalized distribution of strain-controlled residual stresses in beam-flange grout-hole ligament based on analysis of photomicrograph data taken from sections of flame-cut, 12-in.-thick ASTM A533-Bl plate .......... 122

6.56 Combination of primary stresses and residual stresses used for flaw tolerance analysis of point $E$ on residual stress envelope .........................

6.57 Superposition of residual stresses and stresses produced by $\mathrm{DW}+\mathrm{T}+\mathrm{SBLOCA}$ loading condition

6.58 Stress-intensity factors produced by combination of primary stresses and residual stresses at point $E$ on beam-flange grout-hole residual stress envelope

6.59 Stress-intensity factors produced by combination of primary stresses and residual stresses at point $F$ on beam-flange grout-hole residual stress envelope .........

7.1 Reactor vessel supports plan view $\ldots \ldots \ldots \ldots \ldots \ldots \ldots \ldots \ldots 133$

7.2 Elevation view of reactor vessel support system $\ldots \ldots \ldots \ldots 134$

7.3 Symmetric support-array plan view $\ldots \ldots \ldots \ldots \ldots \ldots \ldots \ldots \ldots \ldots$

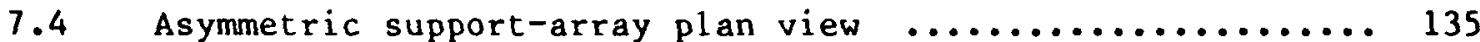

7.5 Section elevation of symmetric array $\ldots \ldots \ldots \ldots \ldots \ldots \ldots \ldots 136$

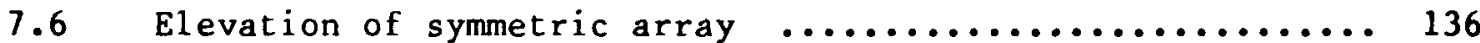

7.7 Critical size of corner flaw in cantilever beam vs service 1 ife and fracture-toughness curve (mean value of $T$ - NDTT, $L=17-i n$. position, $D L+$ LOCA loading, Method B $\triangle$ NDTT) 
7.8 Critical size of corner flaw in cantilever beam vs service 1 ife and $T$ - NDTT Gaussian position ( $L=17$ in. position, DL + LOCA loading, Method B $\triangle$ NDTT, ASME K $\mathrm{IR}_{\mathrm{R}}$ ) .. 138

7.9 Critical size of corner flaw in cantilever beam vs service life and $T$ - NDTT Gaussian position ( $L=17-i n$. position, DL + LOCA loading, Method B $\triangle$ NDTT, ASME $\mathrm{K}_{\mathrm{Ic}}$ ) $\ldots$

7.10 Critical size of corner flaw in cantilever beam vs service 1 ife and fracture-toughness curve ( $L=17-i n$. position, DL + SSE loading, Method B $\triangle$ NDTT)

7.11 Critical size of corner flaw in cantilever beam vs service 1 ife and $T$ - NDTT Gaussian position ( $L=17-$ in. position, DL + SSE loading, Method B $\triangle$ NDTT, ASME $\left.K_{I R}\right) \ldots . .140$

7.12 Critical size of corner flaw in cantilever beam vs service life and $T$ - NDTT Gaussian position ( $L=17$-in. position, DL + SSE loading, Method B $\triangle$ NDTT, ASME $\mathrm{K}_{\mathrm{Ic}}$ curve)

7.13 Estimated $K_{I d}$ values for $A 588$ steel from $B_{K_{c}}$-corrected $K_{c}$ data compared with ASME $K_{I c}$ and $K_{I R}$ curves $\ldots \ldots \ldots \ldots . .142$

7.14 Method A extrapolation of HFIR $\triangle$ NDTT vs dpa, dpa/s data .. 144

7.15 Method B extrapolation of HFIR $\triangle$ NDTT vs dpa, dpa/s data .. 144

7.16 Location for which neutron fluxes calculated .......... 146

7.17 Fast-flux distribution in biological shield ........... 148

7.18 Stress-intensity factor vs crack depth for cantilever beam with semielliptical surface flaw (case 3A) ........ 153

7.19 Stress-intensity factor vs flaw depths for cantilever beam with semielliptical surface flaw (case 3B) ........ 153

7.20 Stress-intensity factor vs crack depth for cantilever beam with semielliptical surface flaw (case 6A) ........ 154

7.21 Stress-intensity factor vs crack depth for cantilever beam with semielliptical surface flaw (case 6B) ........ 154

7.22 Stress-intensity factor vs crack depth for cantilever beam with SEN flaw on top surface (case 3A) ........... 155

7.23 Stress-intensity factor vs crack depth for cantilever beam with SEN flaw on top surface (case 3B) ............ 155

7.24 Stress-intensity factor vs crack depth for cantilever beam with SEN flaw on top surface (case 6A) ........... 156

7.25 Stress-intensity factor vs crack depth for cantilever beam with SEN flaw on top surface (case 6B) ............ 156

7.26 Stress-intensity factor vs crack depth for cantilever

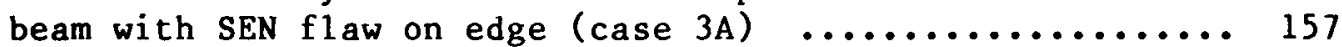

7.27 Stress-intensity factor vs crack depth for cantilever beam with SEN flaw on edge (case 3B) 
7.28 Stress-intensity factor vs crack depth for cantilever

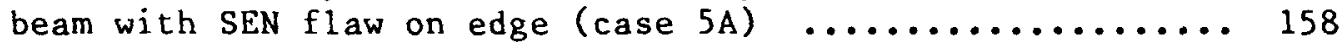

7.29 Stress-intensity factor vs crack depth for cantilever

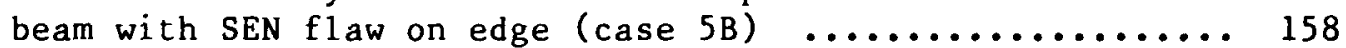

7.30 Stress-intensity factor vs crack depth for cantilever beam with corner crack (case 3A, Liu model) ........... 159

7.31 Stress-intensity factor vs crack depth for cantilever beam with corner crack (case 3B, Liu model) ............ 159

7.32 Stress-intensity factor vs crack depth for cantilever beam with corner crack (case 5A, Liu model) ........... 160

7.33 Stress-intensity factor vs crack depth for cantilever beam with corner crack (case 5B, Liu model) ........... 160

7.34 Stress-intensity factor vs crack depth for cantilever beam with corner crack (case 6A, Liu model) ........... 161

7.35 Stress-intensity factor vs crack depth for cantilever beam with corner crack (case 6B, Liu model) ............ 161

7.36 Stress-intensity factor vs crack depth for cantilever beam with corner crack (case 3A, Newman-Raju model) ..... 162

7.37 Stress-intensity factor vs crack depth for cantilever beam with corner crack (case 3B, Newman-Raju model) ..... 162

7.38 Stress-intensity factor vs crack depth for cantilever beam with corner crack (case 5A, Newman-Raju model) ..... 163

7.39 Stress-intensity factor vs crack depth for cantilever beam with corner crack (case 5B, Newman-Raju model) ..... 163

7.40 Stress-intensity factor vs crack depth for cantilever beam with corner crack (case 6A, Newman-Raju model) ..... 164

7.41 Stress-intensity factor vs crack depth for cantilever beam with corner crack (case 6B, Newman-Raju model) ..... 164

7.42 Stress-intensity factor vs crack depth for girder-tocantilever-beam bolt circumferential flaw (case 3A) $\ldots . . .165$

7.43 Stress-intensity factor vs crack depth for girder-tocantilever-beam bolt circumferential flaw (case 5A) ......

7.44 Stress-intensity factor vs crack depth for girder-tocantilever-beam bolt with circumferential flaw for assumed tightening load

7.45 Stress-intensity factor vs crack depth for lateral restraint with semielliptical surface flaw (case 3A) .... 167

7.46 Stress-intensity factor vs crack depth for lateral restraint with semielliptical surface flaw (case 5A) .... 167

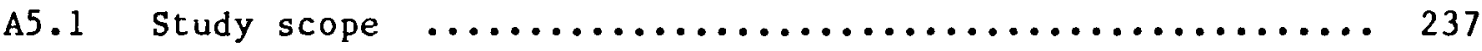

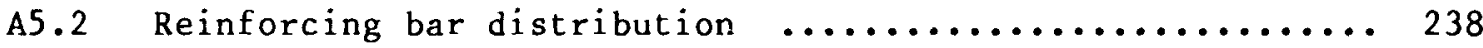


A5.3 Reinforcing bar representation $\ldots \ldots \ldots \ldots \ldots \ldots \ldots \ldots \ldots \ldots$

A5.4 Analytical model: (a) complete model and (b) detail

of vertical beam modeling ....................... 240

A5.5 Concrete elastic modulus adjustment ................ 240

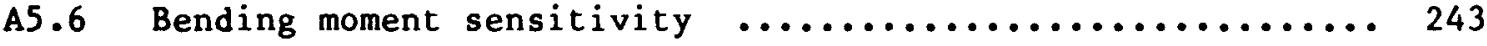

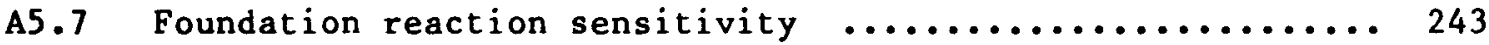

A6.1 Newman solution for cracks emanating from circular

hole in finite rectangular plate subjected to

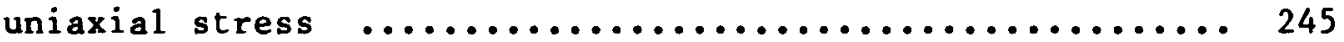

A6.2 Finite-element model for beam flange with uniform

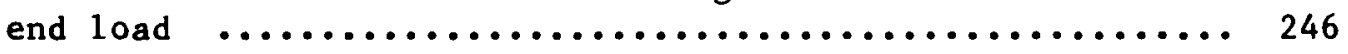

A6.3 Finite-element model for beam flange with line load ..... 247 
1.1 Vessel support $\triangle$ NDTT values corresponding to 32 EFPY and midheight of core ("typical" LWR plants) ............ 3

1.2 Summary of best-estimate minimum critical flaw sizes and values of $T$ - NDTT for Trojan and Turkey Point

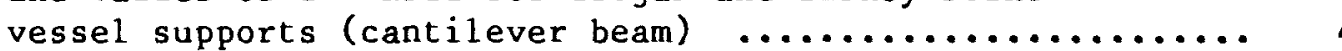

2.1 Summary of irradiation effect for selected HFIR pressure vessel materials ........................ 9

3.1 Calculated (DOT, 3-D) neutron energy spectra for

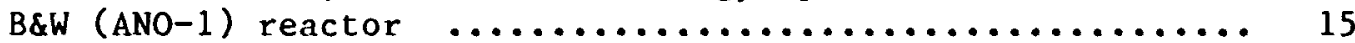

3.2 4-Group fluxes and total dpa rate for B\&W (ANO-1)

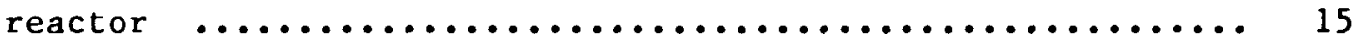

3.3 Calculated (DOT, 3-D) neutron energy spectra for

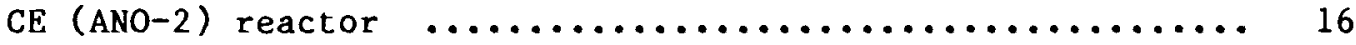

3.4 4-Group fluxes and total dpa rate for CE (ANO-2) reactor .. 16

3.5 Calculated (DOT, 3-D) neutron energy spectra for W reactor McQuire Unit 1 , Cycle $1 \ldots \ldots \ldots \ldots \ldots \ldots \ldots . \ldots . \ldots 17$

3.64 -Group fluxes and total dpa rate for $\underline{w}$ reactor $\ldots \ldots \ldots \ldots 17$

3.7 Calculated (DOT, 3-D) neutron energy spectra for GE reactor ................................... 18

3.84 -Group fluxes and total dpa rate for GE reactor.......... 19

3.9 Summary of fast-neutron fluxes ( $E>0.1 \mathrm{MeV}$ ) for LWR cavities and HFIR surveillance specimens ............ 19

3.10 Summary of calculated fluxes for "typical" BWR and PWR vessels and cavities ........................ 19

4.1 Basic type of support for LWR vessels $\ldots \ldots \ldots \ldots \ldots \ldots \ldots . \ldots 25$

6.1 Temperature adjustment vs strain rate for A36 .......... 61

6.2 Construction of the A36 plane-strain fracturetoughness curves for reactor support loading rates ....... 71

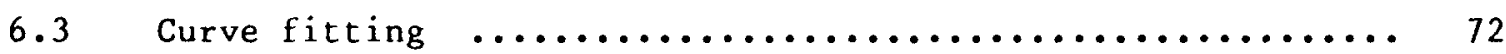

6.4 Plane strain-plane stress transition $\ldots \ldots \ldots \ldots \ldots \ldots \ldots \ldots . \ldots 73$

6.5 Composite plane strain-plane stress fracture-

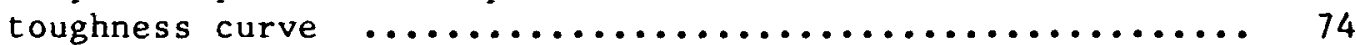

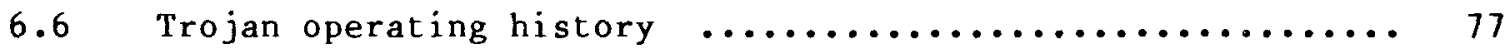

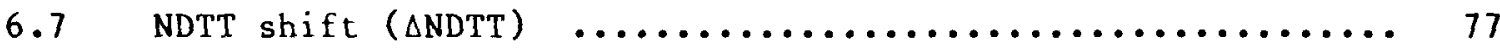

6.8 Design dynamic stress-intensity factors $\ldots \ldots \ldots \ldots \ldots \ldots \ldots .78$ 
6.9 Lifetime variation in T - NDTT and material

fracture-toughness, beam-flange-hole location .......... 79

6.10 Trojan: support beam critical flaw size analysis, summary for interface with cavity liner $\ldots \ldots \ldots \ldots . \ldots . \ldots 1$

6.11 Trojan: support beam critical flaw size analysis, $K_{I}$ at interface with cavity 1 iner $\ldots \ldots \ldots \ldots \ldots \ldots \ldots \ldots . \ldots 3$

6.12 Trojan: support beam critical flaw size analysis, summary for Node 4 , inner concrete not effective ........ 88

6.13 Trojan: support beam critical flaw size analysis,

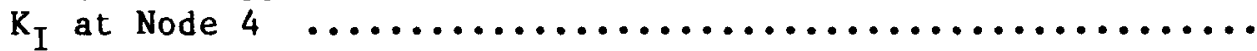

6.14 Trojan: support beam critical flaw size analysis, summary for grout hole, inner concrete effective .........

6.15 Trojan: support beam critical flaw size analysis,

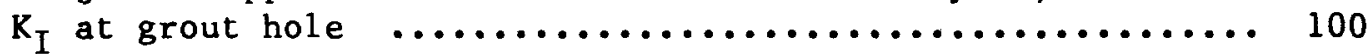

6.16 Summary of critical crack lengths $\ldots \ldots \ldots \ldots \ldots \ldots \ldots \ldots \ldots$

6.17 Lifetime variation of critical flaw sizes at the

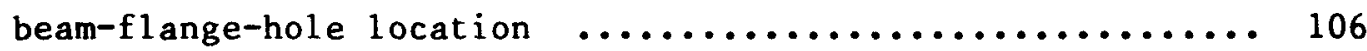

6.18 Critical flaw depths as a function of support load

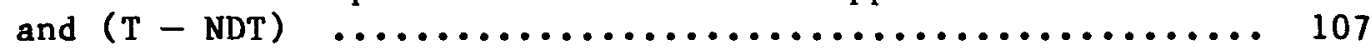

6.19 Order-of-magnitude fatigue crack growth analysis ........ 110

6.20 Stress-intensity-factor equation compatibility check ..... 112

6.21 Beam-flange grout-hole 1 igament stresses $\ldots \ldots \ldots \ldots \ldots \ldots \ldots 118$

6.22 Beam-flange grout-hole limiting residual stresses ........ 120

6.23 Combined beam-flange 1 igament stresses $\ldots \ldots \ldots \ldots \ldots \ldots \ldots .125$

6.24 Impact of residual stress on critical flaw sizes in the beam-flange grout-hole ligament: Case "E" .......... 127

6.25 Impact of residual stress on critical flaw sizes in the beam-flange grout-hole ligament: Case "F" .......... 128

7.1 Calculated dpa rates around the Turkey Point reactor vessel supports ........................ 147

7.2 Time-weighted dpa rates $(E>0.1 \mathrm{MeV})$ and dpa as a function of fuel cycle ...................... 147

7.3 Summary of estimated radiation-damage shift $\triangle$ NDTT as a function of extrapolation method and service 1 ife for each component $\ldots \ldots \ldots \ldots \ldots \ldots \ldots \ldots$

7.4 Summary of Turkey Point vessel and vessel support loads

7.5 Summary of stress values for components of Turkey Point reactor vessel supports as a function of loading condition 
$\operatorname{xxxi}$

7.6 Summary of ( $T$ - NDTT) as a function of Gaussian point and service 1 ife for each component

7.7 Summary of estimated fracture toughness from ASME $K_{I c}$ and $K_{I R}$ curves as a function of Gausian point and service life for each component

7.8 Summary of estimated critical flaw sizes for cantilever beam as a function of type of flaw, $\triangle N D T T$ method, Gaussian point, ASME $K_{I c}$ or $K_{I R}$ evaluation, location, loading case, and service life ..... 171

7.9 Summary of critical flaw sizes for girder-to-cantilever beam bolts as a function of $\triangle N D T T$ method, Gaussian point, loading condition, and service life

7.10 Summary of girder-to-cantilever-beam bolt critical

flaw sizes with pretightening to $70 \%$ yield load

(160 kips) as a function of NDTT, operating temperature, and assumed fracture toughness (ASME $K_{I C}$ or $K_{I R}$ ) 


\section{ACKNOWLEDGMENTS}

The authors wish to acknowledge contributions made by J. W. Bryson (fracture analysis), W. R. Corwin (HSST program manager), K. Farrell (radiation embrittlement), S. K. Iskander (review), F. B. Kam (neutron fluxes), J. G. Merkle (fracture mechanics and review), and C. E. Pugh (PVT section head), all at Oak Ridge National Laboratory, and $T$. $J$. Griesbach (Electric Power Research Institute), J. R. Hawthorne (Materials Engineering Associates), and G. R. Odette (University of California, Santa Barbara). 


\section{IMPACT OF RADIATION EMBRITTLEMENT ON INTEGRITY OF PRESSURE-VESSEL SUPPORTS FOR TWD PWR PLANTS}
R. D. Cheverton
G. C. Robinson
W. E. Pennell
R. K. Nanstad

\section{INTRODUCTION AND SUMMARY}

Structural supports for most pressurized-water-reactor (PWR) pressure vessels are located in the cavity between the vessel and the biological shield (Fig. 1.1). Within the cavity the fast neutron flux $(\phi)$ for energies $E>1.0 \mathrm{MeV}$ is $\leq 2 \times 10^{9}$ neutrons $/ \mathrm{cm}^{2} \cdot \mathrm{s}$, and temperatures are $<150^{\circ} \mathrm{F}$. The corresponding calculated increase in the nil ductility

ORNL DWG 88-4837 ETD

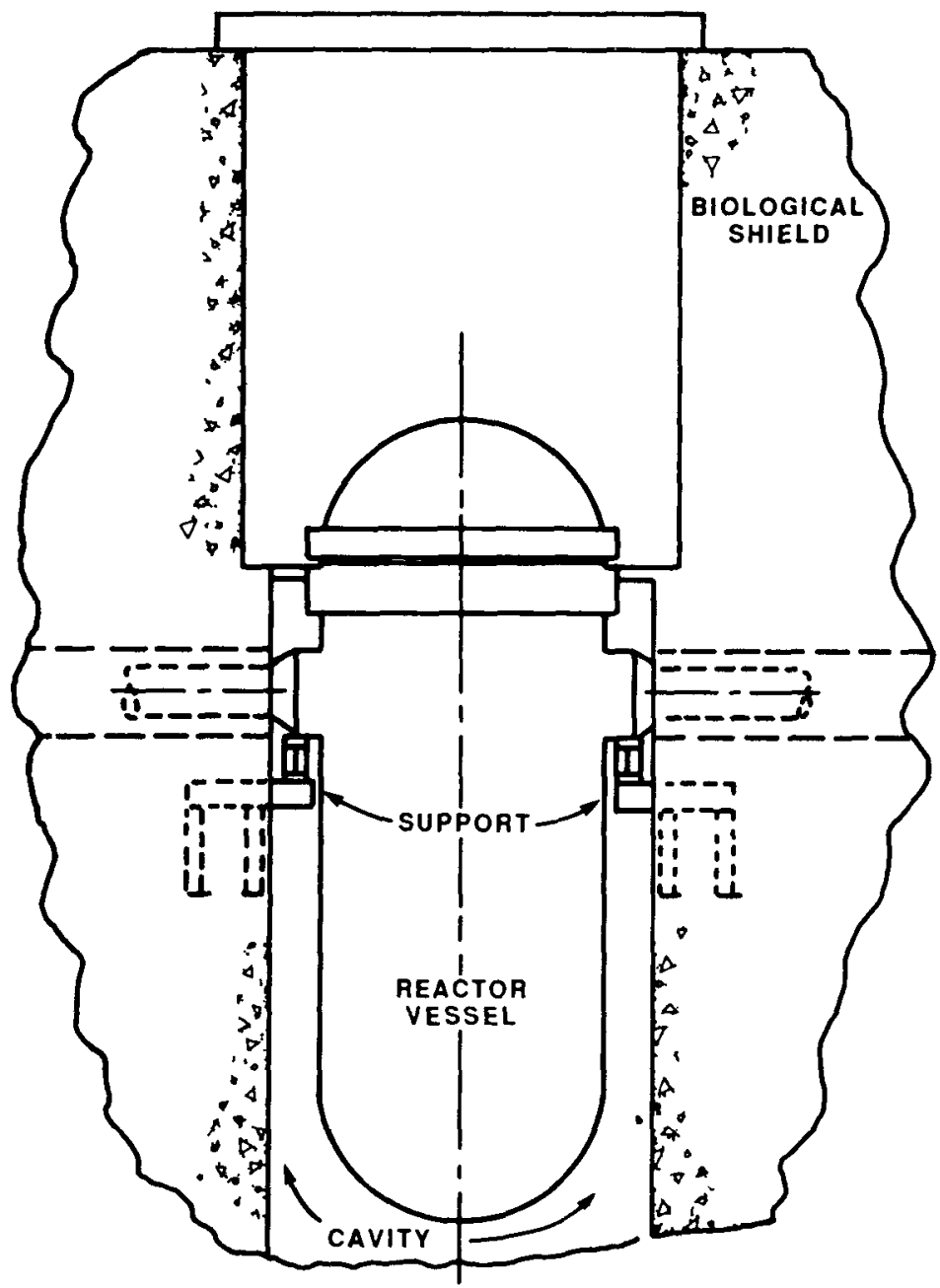

Fig. 1.1. PWR vessel support located in cavity between vessel and biological shield. 
transition temperature (NDTT) by 32 effective full-power years (EFPY), based on the radiation embrittlement data available from materials testing reactors (MTRs) before $1987,1,2$ is quite small, if the difference in the MTR and the PWR cavity fast neutron energy spectra is neglected.

Early in 1978 it became apparent that the fast neutron spectrum above $0.1 \mathrm{MeV}$ was much softer in the PWR cavity than in the MTRs (the result of inelastic scattering in the PWR vessel wall), and thus correlating the MTR embrittlement data with fast neutron fluence ( $\Phi$ ) for $E>1.0 \mathrm{MeV}$ resulted in an underestimation of the increase in the nil ductility transition temperature ( $\triangle$ NDTT) for supports in the cavity. As a part of the more recent study discussed herein, the MTR data were correlated with displacements per atom (dpa) for $E>0.1 \mathrm{MeV}$, and $\triangle \mathrm{NDTT}$ values of $\leq 70^{\circ} \mathrm{F}$ were calculated for 32 EFPY for supports located in the cavity at midheight of the core.

Several studies pertaining to radiation damage of PWR vessel supports were conducted between 1978 and $1987,3-6$ and during this period, presumably there was no reason to believe that low-temperature $\left(<200^{\circ} \mathrm{F}\right)$ MTR embrittlement data, correlated with dpa (E $>0.1 \mathrm{MeV}$ ), were not appropriate for evaluating embrittlement of PWR vessel supports. However, late in 1986, data from the High Flux Isotope Reactor (HFIR)? vessel surveillance program, 9 indicated that the embrittlement rates of the several vessel materials (A212-B, A350-LF3, and A105-II) were substantially greater than anticipated on the basis of MTR data.9 Further evaluation of the HFIR data suggested that a fluence-rate effect was responsible for the apparent discrepancy because the fast neutron flux in the MTR that provided the design datal was $\sim 10^{5}$ times that in the HFIR vessel, while the small differences in the fast neutron energy spectra were accounted for by correlating the data with dpa ( $E>0.1$ $\mathrm{MeV})$, and the irradiation temperatures were nearly the same $(120$ to $200^{\circ} \mathrm{F}$ ). As a result of this new information, the Nuclear Regulatory Commission (NRC) requested that the Oak Ridge National Laboratory (ORNL) evaluate the impact of the apparent embrittlement rate effect on the integrity of light-water-reactor (LWR) vessel supports.

The purpose of this first report is to provide a preliminary indication of whether the integrity of reactor vessel supports is likely to be challenged by radiation-induced embrittlement before 32 EFPY. Because of the diversity in support designs, specific-plant evaluations were undertaken, and because of the urgency associated with the preliminary report, only readily available data for these plants were used. This and other factors have resulted in some inconsistencies in the evaluations of the plants considered. Even so, the report satisfies its intended purpose.

The scope of the ORNL evaluation included

1. correlation of the HFIR data for application to the evaluation of LWR vessel supports,

2. a survey and cursory evaluation of all U.S. LWR vessel support designs,

3. selection of two plants in accordance with established criteria for specific-plant evaluation, and

4. a specific-plant evaluation of both plants to determine critical flaw sizes for their vessel supports. 
The two plants selected for specific-plant evaluation were Trojan (Portland General Electric) and Turkey Point Unit 3 (Florida Power and Light), both of which are PWR plants with a vessel support similar to that shown in Fig. 1.1. Westinghouse was the nuclear-steam-supplysystem (NSSS) designer, and Bechtel was the architect-engineer for both plants. The utilities and their contractors have been very cooperative in providing, where possible, design data required for the ORNL study.

Over the course of several months, two sets of radiation-damage trend curves ( $\triangle$ NDTT vs dpa), based on the HFIR vessel surveillance data, were developed, and 32-EFPY $\triangle$ NDTT values were calculated for "typical" General Electric (GE), Babcock and Wilcox ( $B \& W)$, Westinghouse (W), and Combustion Engineering (CE) plants, assuming that a critical portion of a support existed in the cavity at midheight of the core. The results, presented in Table 1.1, indicate much larger shifts in NDTT based on the HFIR data than on the MTR data.

Table 1.1. Vessel support $\triangle$ NDTT values corresponding to 32 EFPY and midheight of core

("typical" LWR plants)

\begin{tabular}{|c|c|c|c|c|c|c|}
\hline \multirow{3}{*}{$\begin{array}{l}\text { NSSS } \\
\text { designer } \\
\text { (type } \\
\text { reactor) }\end{array}$} & \multirow{3}{*}{$\begin{array}{c}(E>1 \mathrm{MeV}) \\
\left.\text { (neutrons } / \mathrm{cm}^{2} \cdot \mathrm{s}\right)\end{array}$} & \multirow{3}{*}{$\begin{array}{c}\text { dpa rate } \\
\left(E^{>} 0.1 \mathrm{MeV}\right) \\
\left(\mathrm{s}^{-1}\right)\end{array}$} & \multirow{3}{*}{ dpa } & \multicolumn{3}{|c|}{$\triangle \operatorname{NDTT}\left({ }^{\circ} \mathrm{F}\right)$} \\
\hline & & & & \multirow{2}{*}{$\begin{array}{l}\text { MTR } \\
\text { data }\end{array}$} & \multicolumn{2}{|c|}{ HFIR data } \\
\hline & & & & & $A^{a}$ & $\mathrm{~B}^{a}$ \\
\hline GE (BWR) & $2.9 \times 10^{7}$ & $5.8 \times 10^{-14}$ & $5.8 \times 10^{-5}$ & 0 & $b$ & $b$ \\
\hline B\&W（PWR） & $2.0 \times 10^{8}$ & $6.1 \times 10^{-13}$ & $6.1 \times 10^{-4}$ & 20 & 180 & 130 \\
\hline$\underline{W}(P W R)$ & $5.9 \times 10^{8}$ & $3.9 \times 10^{-12}$ & $3.9 \times 10^{-3}$ & 50 & 240 & 220 \\
\hline CE (PWR) & $1.8 \times 10^{9}$ & $4.5 \times 10^{-12}$ & $4.5 \times 10^{-3}$ & 70 & 250 & 220 \\
\hline
\end{tabular}

${ }^{2} \triangle N D T T$ vs dpa (E $>0.1 \mathrm{MeV}$ ) correlations $A$ and $B$.

$b_{\triangle N D T T}$ not estimated for dpa $<10^{-4}$.

Many of the vessel supports are not located at midheight of the core and thus experience smaller shifts in NDTT than those indicated in Table 1.1. For instance, all but one of the GE boiling-water-reactor (BWR) vessels and all but one of the B\&W PWR vessels are supported by a skirt at the bottom of the vessel where the fluxes are much less. However, $\sim 25 \%$ of the PWR vessel supports are exposed to the peak flux, and many others are exposed to fluxes within a factor of one-half of the peak.

The concern over radiation embrittlement is that it increases the potential for propagation of flaws that might exist in the support structures. In this study the potential for propagation of flaws was evaluated using linear-elastic fracture mechanics, which requires knowledge of the stresses in the structure and the fracture toughness of the 
material. The output of the fracture-mechanics analysis for this study is the critical flaw size, that is, the size of the smallest flaw that will propagate under a given set of assumed conditions and will result in failure of the support. If the critical flaw size is small enough that the critical flaw is likely to exist, then the frequency of failure is equal to the frequency of application of the assumed load. A determination of the probability of the existence of flaws was not, however, included in the scope of this study.

loading conditions were provided by the utilities and included large- and small-break loss-of-coolant accidents (LBLOCA and SBLOCA), seismic loading, thermal loading, and dead-weight loading. Dynamic loading conditions were available for Trojan but were not available for Turkey Point.

Several uncertainties exist in the analysis, and those judged to be the most significant are related to the radiation-damage trend curve deduced from the HFIR surveillance data, the fracture toughness of the material, including the initial NDTT, and the normal operating temperature of the structure at the critical location $(T)$. These uncertainties result in a wide variation in calculated critical flaw size. The critical flaw size is, of course, also dependent on load and the location and type of flaw. Critical flaw sizes (depth/surface length) were calculated for a reasonable range of conditions, and 32-EFPY "best-estimate" values for the most sensitive location and type of flaw and for the most severe credible loading conditions are $0.4 / 2.5 \mathrm{in}$. for Trojan and $0.3 / 0.6$ in. for Turkey Point (Table 1.2). Corresponding values for late 1988 are $0.9 / 16$ and $0.3 / 0.6$ in., respectively.

Table 1.2. Summary of best-estimate minimum critical

flaw sizes and values of $T$ - NDTT for

Trojan and Turkey Point vessel

supports (cantilever beam)

\begin{tabular}{|c|c|c|c|c|c|c|}
\hline \multirow{2}{*}{ Plant } & \multirow{2}{*}{ EFPY } & \multicolumn{2}{|c|}{$\begin{array}{c}T-\text { NDTT } \\
\left({ }^{\circ} \mathrm{F}\right)\end{array}$} & \multicolumn{3}{|c|}{$\begin{array}{c}\text { Critical flaw size } \\
\text { (depth } \times \text { surface length) } \\
(\text { in. })\end{array}$} \\
\hline & & $a$ & $b$ & LBLOCA & SBLOCA & $\begin{array}{l}\text { Seismic } \\
(\mathrm{SSE})^{c}\end{array}$ \\
\hline \multirow[t]{2}{*}{ Trojan } & $7.5^{d}$ & -12 & -12 & & $0.9 \times 16.0$ & $1.1 \times 16.0$ \\
\hline & 32 & -13 & -118 & & $0.4 \times 2.5$ & $1.2 \times 2.5$ \\
\hline \multirow[t]{2}{*}{ Turkey Point } & $11.8^{d}$ & 28 & 10 & $0.3 \times 0.6$ & & $1.0 \times 2.0$ \\
\hline & 32 & -25 & -25 & $0.3 \times 0.6$ & & $0.9 \times 1.8$ \\
\hline
\end{tabular}

${ }^{a}$ At location of minimum-depth critical flaw.

${ }^{b}$ At inner surface of biological shield (cavity interface).

$c_{\text {Safe shutdown earthquake. }}$

${ }^{d}$ Late 1988. 
For both plants the flaw location resulting in the smallest critical flaw depth was on the upper flange of the horizontal cantilever beam at a point within the concrete biological shield (Fig. 1.1). The bestestimate values of $\mathrm{T}-$ NDTT at these locations are -13 and $-25^{\circ} \mathrm{F}$ for 32 EFPY and -12 and $28^{\circ} \mathrm{F}$ for late 1988 for Trojan and Turkey Point, respectively.

The propagation of flaws by low-cycle fatigue was calculated to be negligible. Thus, if corrosion is not a viable means of growing flaws to critical size or larger, flaws of critical size or larger would have to be present at the time of fabrication. As already mentioned, this report does not address the question regarding the probability of existence of flaws.

Details regarding the HFIR vessel surveillance data, development of the corresponding embrittlement trend curves, a survey and cursory evaluation of the LWR support designs, selection of two LWR plants for specific-plant evaluation of the supports, and the specific-plant analyses are included in the following sections of this report.

\section{References}

1. J. R. Hawthorne, Studies of Radiation Effects and Recovery of Notch Ductility of Pressure Vessel Steels, British Nuclear Energy Conference, Iron and Steel Institute, London, England, November 30, 1960.

2. L. E. Steele et al., Irradiated Materials Evaluation and Reactor Pressure Vessel Surveillance for the Army Nuclear Power Program, NRL Memorandum Report 1644, September 1, 1965.

3. G. A. Knorovski, R. D. Krieg, and G. C. Allen, Jr., Sandia National Laboratory, Fracture Toughness of PWR Components Supports, NUREG/CR3009 (SAND78-2347), February 1983.*

4. Electric Power Research Institute, Requirements and Guidelines for Evaluating Component Support Materials Under Unresolved Safety Issue $A-12$, EPRI NP-3528, June 1984.

5. W. C. Hopkins and W. L. Grove, A Study of the Embrittlement of Reactor Vessel Steel Supports, Reactor Dosimetry, Volume 2, J. P. Genthon and H. Rottger (eds.), Dordrecht, Netherlands: D. Reidel Publishing Company, 1985, pp. 621-28.

6. W. G. Hopkins, Idaho National Engineering Laboratory, Reactor Pressure Vessel Supports for Pressurized Water Reactors and Boiling Water Reactors, Residual Life Assessment of Major Light Water Reactor Components - Overview, Volume 1, NUREG/CR-4731 (EGG-2469), Vol. 1, June 1987.*

7. R. D. Cheverton and T. M. Sims, Union Carbide Corp. Nuclear Div., Oak Ridge Nat1. Lab., HFIR Core Nuclear Design, ORNL-4621, July 1971. 
8. J. R. McWherter, R. E. Schappel, and J. R. McGuffey, Union Carbide Corp. Nucl. Division, Oak Ridge Nat1. Lab., HFIR Pressure Vessel and Structural Components Material Surveillance Program, ORNL/TM-1372, January 1966.

9. R. D. Cheverton, J. G. Merkle and R. K. Nanstad, eds., Martin Marietta Energy Systems, Inc., Oak Ridge Natl. Lab., Evaluation of HFIR Pressure-Vessel Integrity Considering Radiation Embrittlement, ORNL/TM-10444, April 1988.

*Available for purchase from National Technical Information Service, Springfield, Virginia 22161. 
2. HFIR VESSEL SURVEILLANCE DATA

The High Flux Isotope Reactor ${ }^{1}$ is a high-performance, light-watercooled, low-temperature $\left(120\right.$ to $\left.160^{\circ} \mathrm{F}\right)$ research reactor that began operation in 1965 at ORNL. Its stainless-steel-clad, carbon-steel pressure vessel (Fig. 2.1) was designed for 20 EFPY, and a surveillance program was maintained to monitor the actual radiation-induced embrittlement. 2 Late in 1986 , a reevaluation of the integrity of the vessel was commenced in an effort to extend the permissible life. ${ }^{3}$ The surveillance data, which had not been carefully examined since 1974, indicated that the embrittlement rate was significantly greater than had

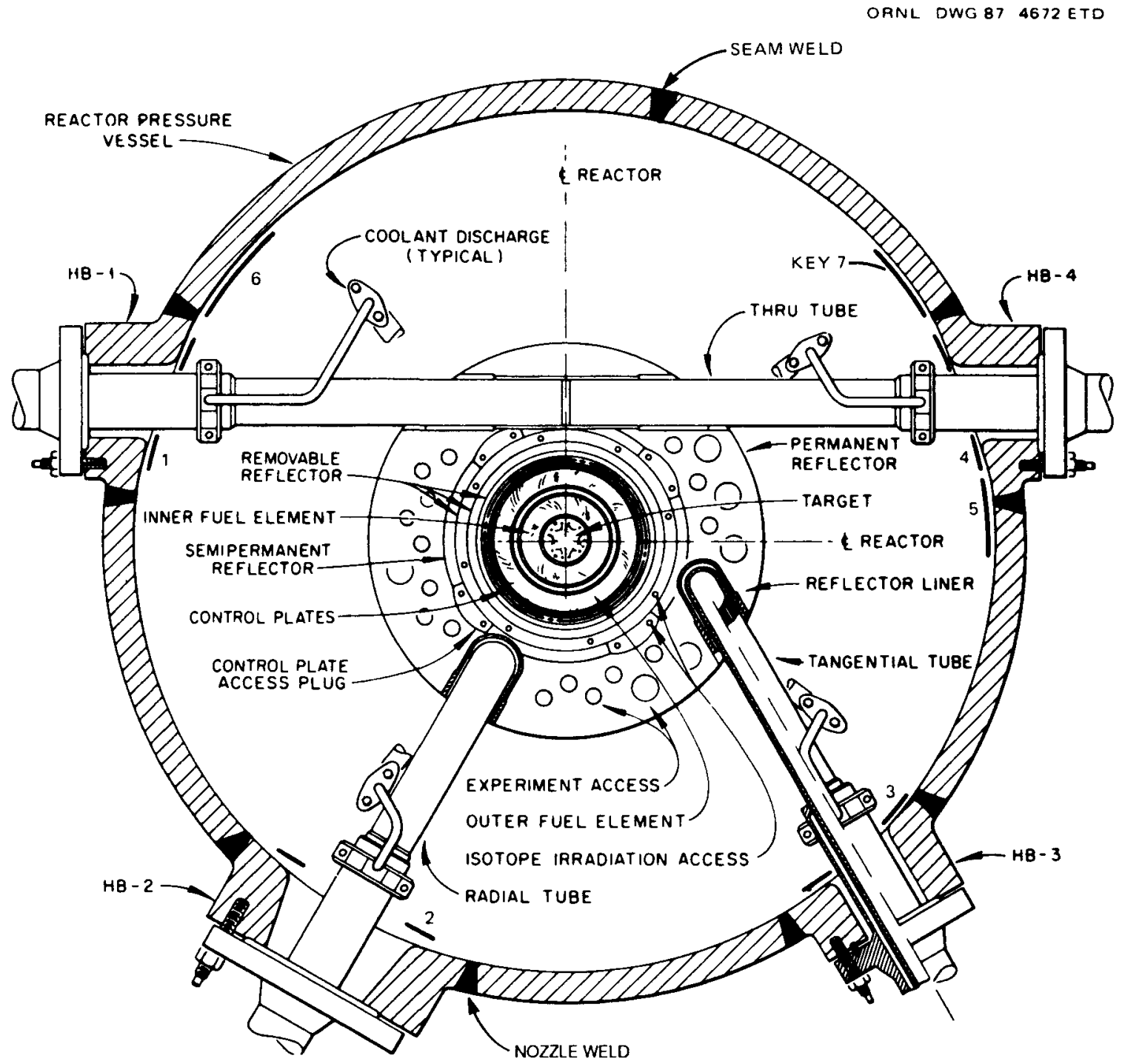

Fig. 2.1. Cross section of HFIR vessel and core at midheight of core, indicating locations of vessel surveillance specimens (Keys 1-7). 
been anticipated on the basis of data obtained in the early $1960 \mathrm{~s}$ from MTRs. ${ }^{4}$ The neutron energy spectra and the irradiation temperatures for the HFIR surveillance specimens and for specimens in the MTRs were believed to be essentially the same, and the materials were very similar; however, the fast neutron flux in the MTRs was about $10^{5}$ times that in the HFIR specimens. Thus, it appeared that the lower flux in HFIR was responsible for the relatively large amount of embrittlement per neutron; that is, there appeared to be a negative fluence-rate effect.

The portions of the HFIR vessel that are subjected to the highest fast-neutron fluxes are close to the beam tubes (Fig. 2.1) because the beam tubes displace beryllium (reflector) and water that otherwise constitute shielding for the vessel wall. Thus, both shell material (A212-B) and beam-tube nozzle materials (A105-II and A350-LF3) were included in the HFIR vessel materials surveillance program, and the surveillance capsules, each containing three Charpy V-notch (CVN) specimens and a flux monitor, were located close to the beam tubes (keys 1-7, Fig. 2.1).

Surveillance specimens of $A 212-B$ were removed for testing after 15.0 and 17.5 EFPY, and A105-II and A350-LF3 specimens were removed after $2.3,6.5,15.0$, and 17.5 EFPY. The corresponding $\triangle$ NDTT data are presented in Table 2.1;4 in Figs. 2.2 and 2.3, plots of $\triangle$ NDTT vs fast neutron fluence $(\Phi)$ ( $E>1.0 \mathrm{MeV}$ ) are compared with the MTR datas available when the vessel was designed. If it is assumed that spectrum and chemistry effects are not responsible for the incongruity of the several sets of data, the comparison indicates a fluence-rate effect.

To evaluate the effects of possible differences in chemistry and fast spectrum, HFIR archive $A 212-B$ material was recently irradiated in the Oak Ridge Research Reactor (ORR), a typical MTR, and the HFIR and ORR A212-B data were plotted as a function of dpa for $E>0.1 \mathrm{MeV}$ (Fig. 2.4) $*$ as well as a function of $\Phi$ for $E>1.0 \mathrm{MeV}$ (Figs. 2.2 and 2.3). (The ORR data and values of dpa corresponding to both the HFIR and ORR data are included in Table 2.1.) Figure 2.2 shows the A212-B archive material (irradiated in the ORR) to be consistent with the MTR data, implying that the chemistry of the HFIR A212-B material is not significantly different than that corresponding to the MTR data (assuming that a difference in spectrum does not compensate for a difference in chemistry). Furthermore, surveillance data from Army reactors 6 (Fig. 2.5) indicate no significant difference in sensitivity between A212-B and A350-LF3, at least for the specific exposure conditions. These latter data also indicate that for the relatively high fluxes in the Army reactors, the increase in NDTT for A212-B at a fluence of 1 to $2 \times 10^{17}$ neutrons $/ \mathrm{cm}^{2}$ is much less than that obtained from HFIR, indicating that the HFIR data are not simply a part of the tail of the MTR data.

Figure 2.4 shows that when the HFIR and MTR data are plotted as a function of dpa $(E>0.1 \mathrm{MeV})$, there is still evidence of a significant rate effect. Thus, the small differences in the HFIR and MTR fast spectra are not responsible for the incongruity in Figs. 2.2 and 2.3.

*To obtain the MTR curve, it was assumed that the calculated spectrum for the ORR was appropriate for the "MTR" data. 
Table 2.1. Summary of irradiation effect for selected HFIR pressure vessel materials

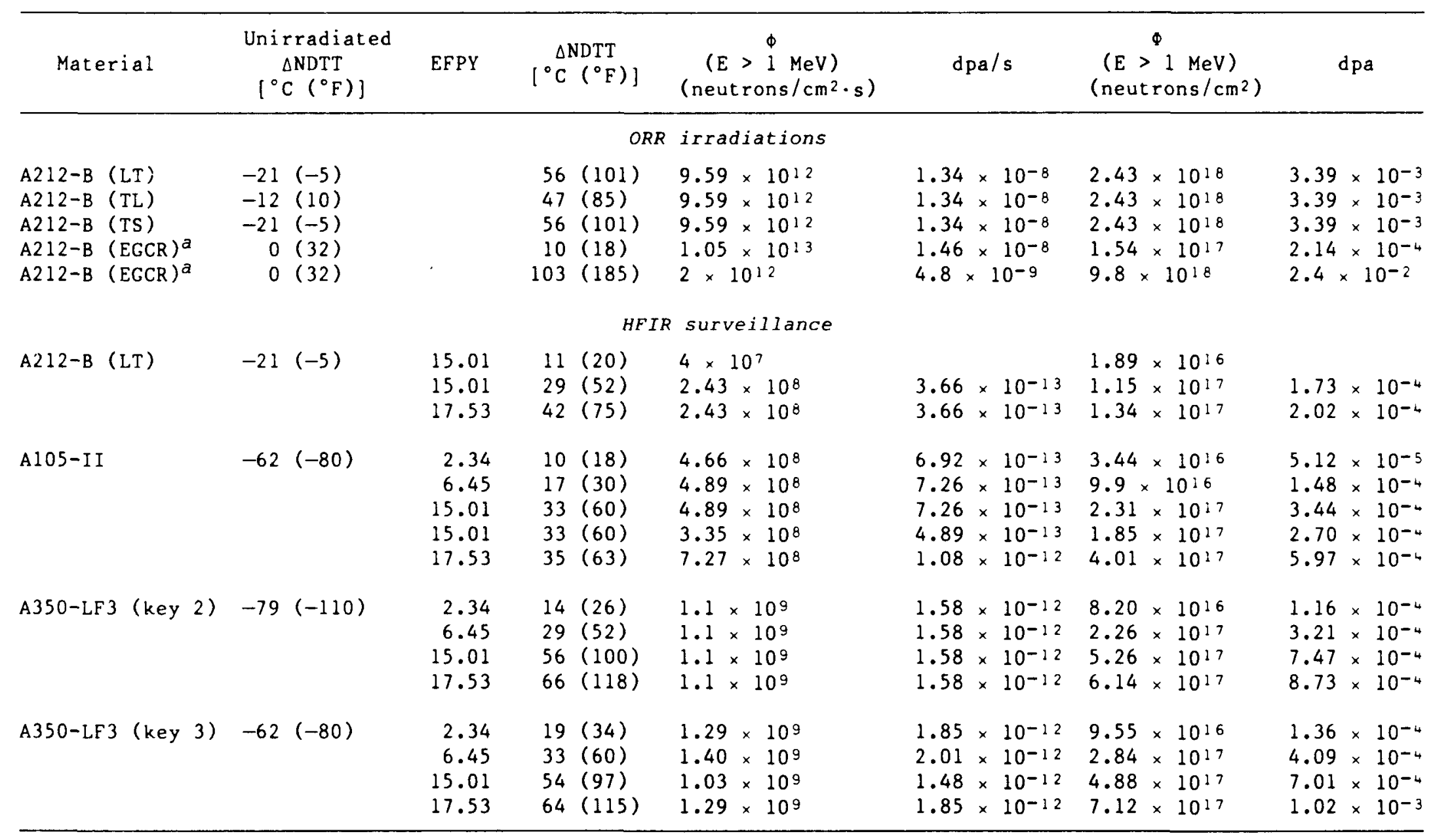

a Material from previous ORNL study on Experimental Gas-Cooled Reactor. 


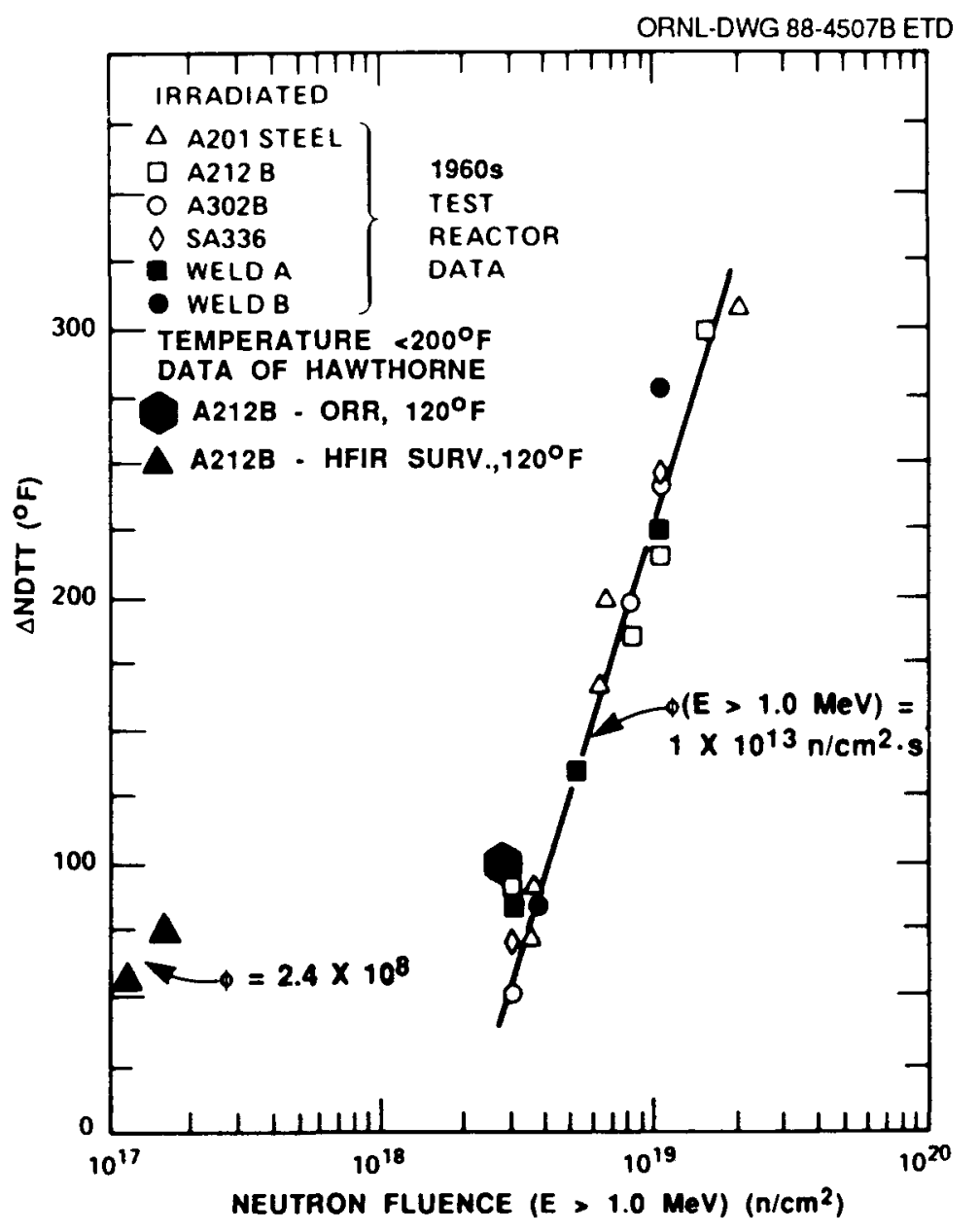

Fig. 2.2. Increase in NDTT with fluence (E $>1.0 \mathrm{MeV}$ ) for A212-B irradiated in HFIR (vessel surveillance positions) and $O R R$ and for several similar materials irradiated in MTR . 5

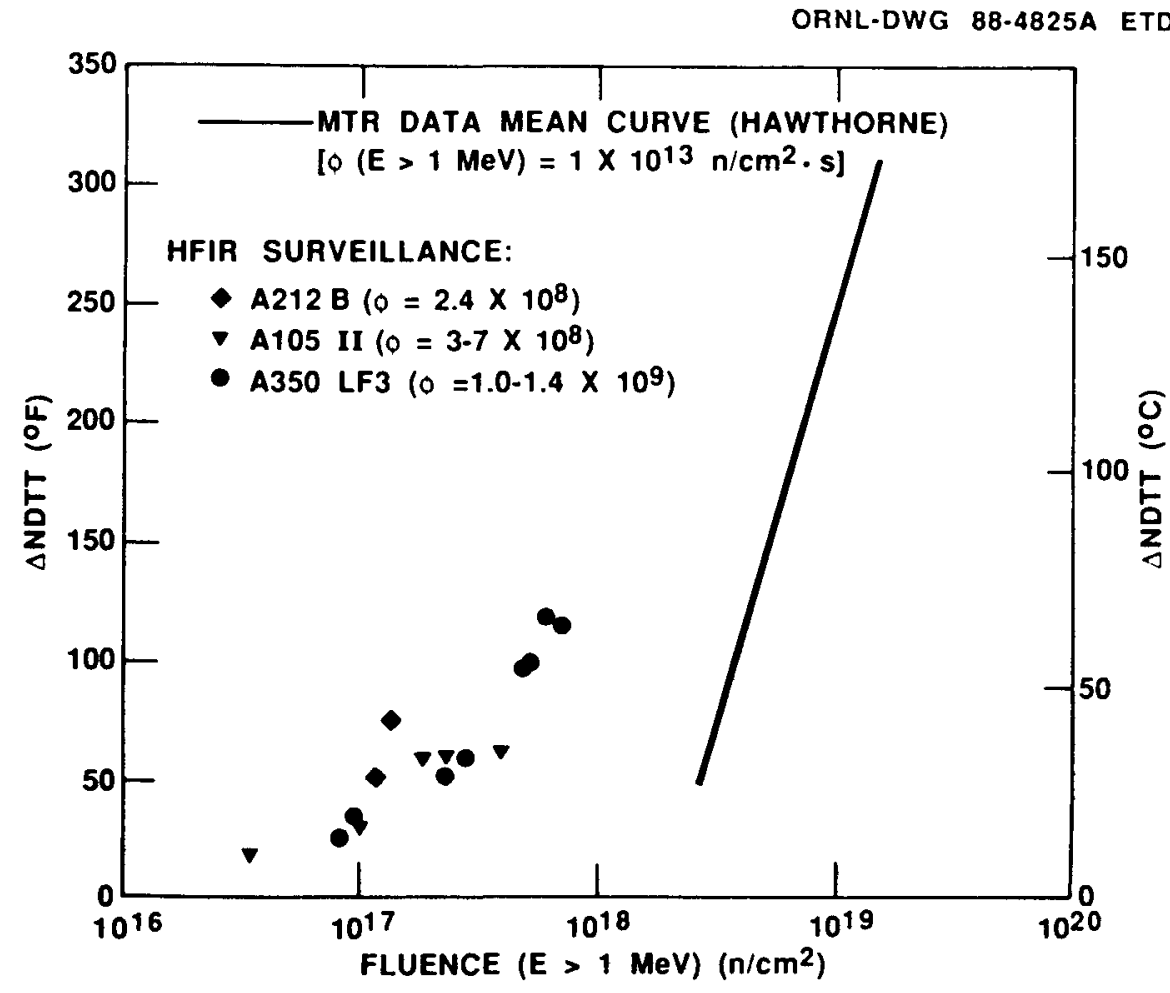

Fig. 2.3. Increase in NDTT with fluence $(E>1$ $\mathrm{MeV}$ ) for irradiations in HFIR (vessel surveillance positions) and MTR. 5 


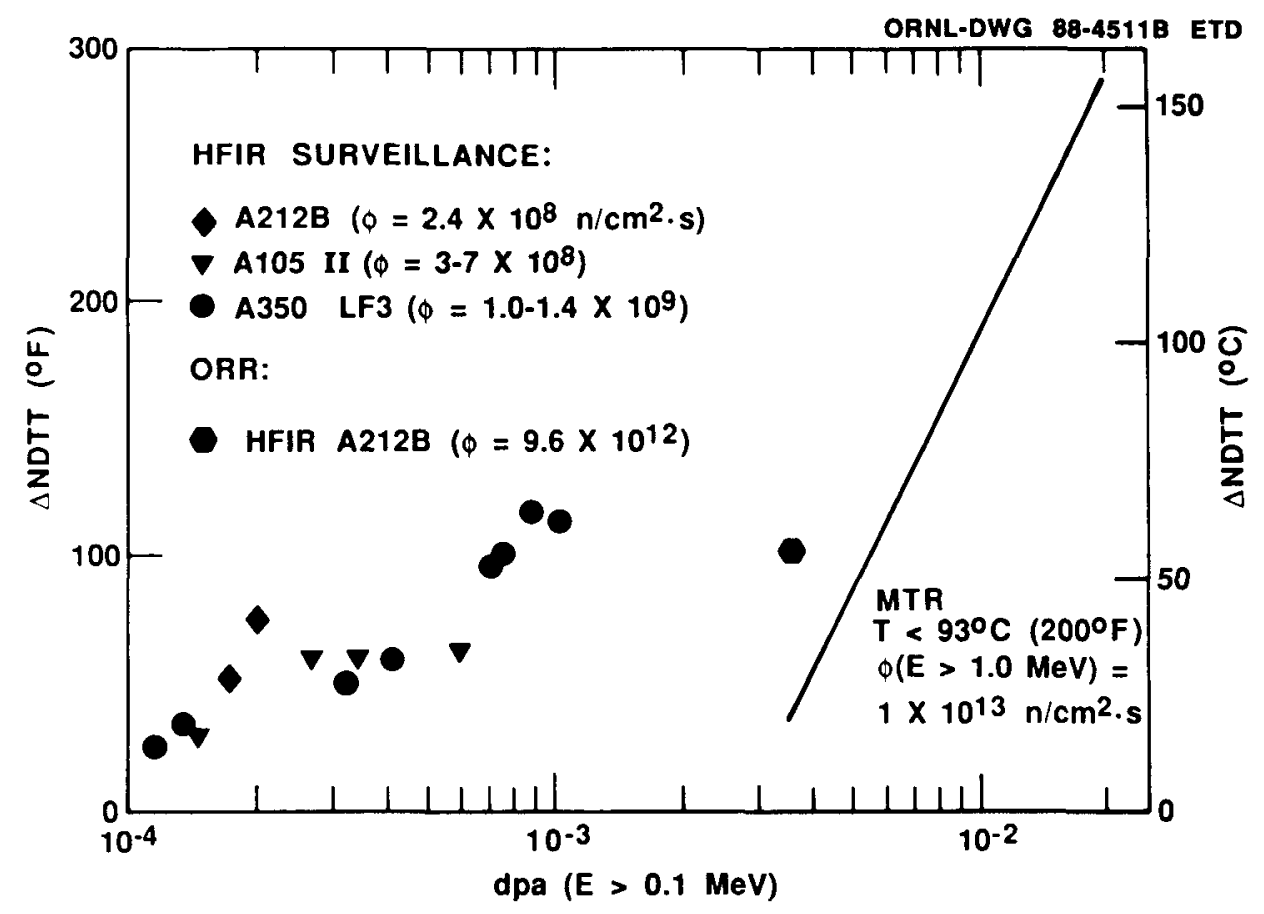

Fig. 2.4. Increase in NDTT with dpa for irradiations in HFIR (vessel surveillance positions), ORR, and MTR.5

If an embrittlement rate effect exists, the total reaction rate associated with embrittlement should probably be accounted for when applying the HFIR data to a situation involving a different fast spectrum. This can be accomplished by correlating NDTT with dpa rate rather than $\phi$, integrating the dpa rate over all energies that contribute significantly to embrittlement.

In the previous discussions, the only spectral variations considered were those above $0.1 \mathrm{MeV}$. However, Nanstad et a1. ${ }^{7}$ have suggested that lower energy neutrons may be making a significant contribution and that there might be significant differences in the low-energy spectra of HFIR and the MTRs. Multigroup transport calculations performed at ORNL 8 indicate that the HFIR spectrum above $1.0 \mathrm{MeV}$ is somewhat harder than that in the ORR; the epithermal flux is a smaller fraction of the total nonthermal $\mathrm{flux}$; and $\phi_{\mathrm{th}} / \phi_{\mathrm{f}}$, the ratio of the thermal to fast $(\mathrm{E}>1.0$ $\mathrm{MeV})$, is greater in HFIR $(\sim 50)$ than in ORR $(\sim 8)$. Thus, the trend in Figs. 2.2 and 2.3 is not the result of differences in the epithermal fluxes, but the comparison of $\phi_{t h} / \phi_{f}$ suggests a possible thermal-flux effect. In addition, Alborman et a1.9 irradiated $A 537$ at $140^{\circ} \mathrm{F}$ in a spectrum with $\phi_{t h} / \phi_{f} \sim 1000$ and found that $>70 \%$ of the embrittlement was caused by thermal neutrons. Thus, perhaps thermal-neutron embrittlement is at least in part responsible for what was otherwise believed to be a rate effect.10 At this time, however, there are not enough data to support this contention. 
ORNL-DWG 88-4458 ETD

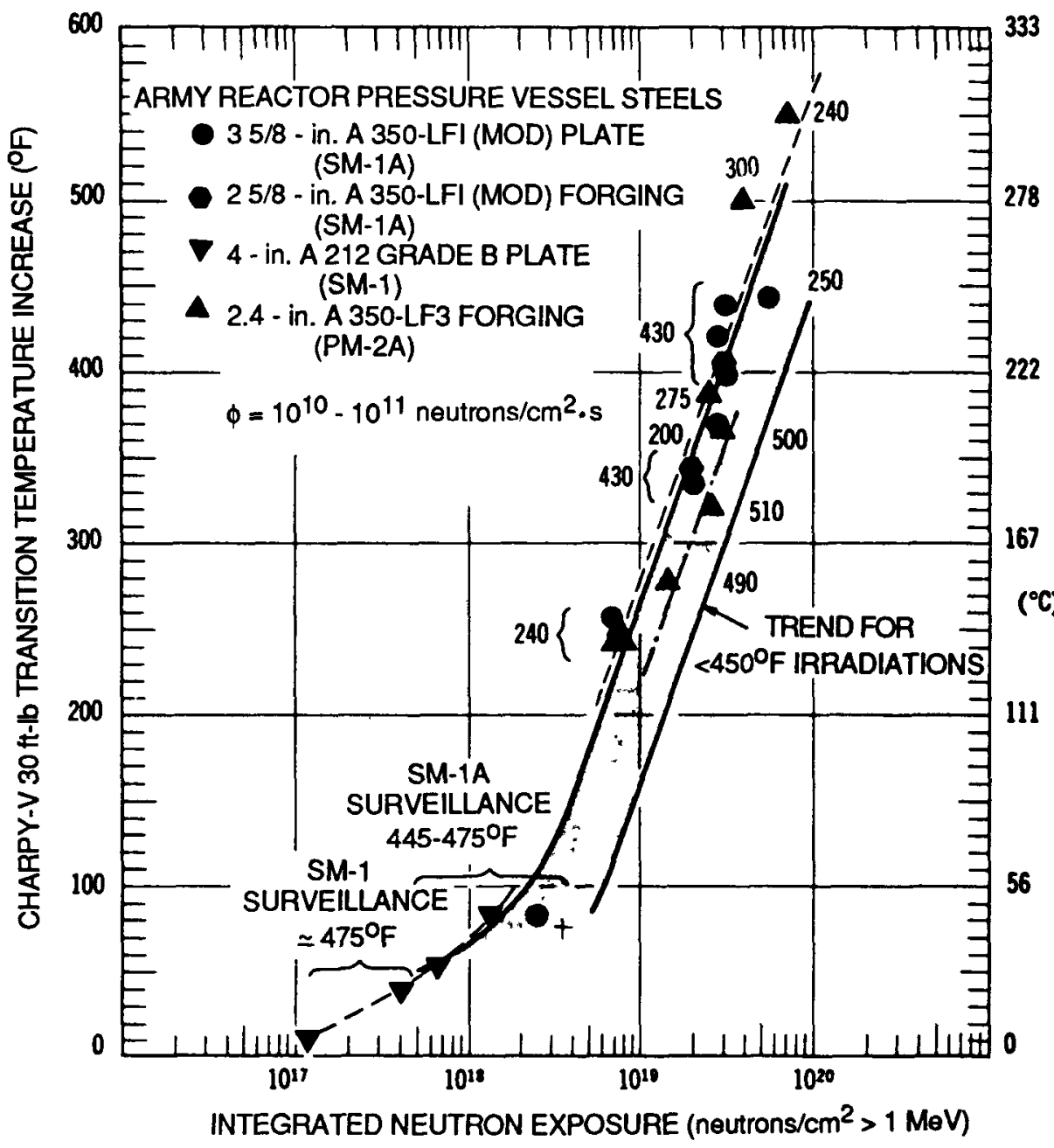

Fig. 2.5. Effects of neutron radiation on Charpy-V transition temperature behavior of Army RPV steels. (Numbers adjacent to data points indicate exposure temperatures.) Source: Ref. 6.

\section{$\underline{\text { References }}$}

1. R. D. Cheverton and T. M. Sims, Union Carbide Corp. Nuclear Div., Oak Ridge Nat1. Lab., HFIR Core Nuclear Design, ORNL-4621, July 1971.

2. J. R. McWherter, R. E. Schappel, and J. R. McGuffey, Union Carbide Corp. Nuclear Div., Oak Ridge Natl. Lab., HFIR Pressure Vessel and Structural Components Material Surveillance Program, ORNL/TM-1372, January 1966. 
3. R. D. Cheverton, J. G. Merkle, and R. K. Nanstad, eds., Martin Marietta Energy Systems, Inc., Oak Ridge Natl. Lab., Evaluation of HFIR Pressure-Vessel Integrity Considering Radiation Embrittlement, ORNL/TM-10444, April 1988.

4. R. K. Nanstad et al., Effects of $50^{\circ} \mathrm{C}$ Surveillance and Test Reactor Irradiation on Ferritic Pressure Vessel Steel Embrittlement, presented at 14th International Symposium on the Effects of Radiation on Materials, Andover, Mass., June 27, 1988, to be published in ASTM STP.

5. J. R. Hawthorne, Studies of Radiation Effects and Recovery of Notch Ductility of Pressure Vessel Steels, British Nuclear Energy Conference, Iron and Steel Institute, London, England, November 30, 1960.

6. L. E. Steele et al., Irradiated Materials Evaluation and Reactor Pressure Vessel Surveillance for the Army Nuclear Power Program, NRL Memorandum Report 1644, September 1, 1965.

7. R. K. Nanstad et al., "Accelerated Neutron Embrittlement of Ferritic Steels at Low Fluence: Flux and Spectrum Effects," $J$. of Nuc. Matls. 158, 1-6 (1988).*

8. R. L. Childs, Oak Ridge National Laboratory, personal communication to R. K. Nanstad, Oak Ridge National Laboratory, August 10, 1988.

9. A. Alborman et al., "Influence of Thermal Neutrons on the Brittleness of High-Temperature Gas-Cooled Reactor Liner Steel," Nuclear Technology 66, 639-46 (September 1984).*

10. L. K. Mansur and N. K. Farre11, Oak Ridge National Laboratory, private communication to R. D. Cheverton and R. K. Nanstad, Oak Ridge National Laboratory, September 1988.

*Available in public technical libraries. 


\section{APPLICATION OF HFIR DATA TO VESSEL SUPPORT EVALUATION}

Soon after the HFIR surveillance data were evaluated in late 1986, it became apparent that the indicated embrittlement rate effect might apply to the supports of some LWR vessels because fast neutron fluxes, irradiation temperatures, and materials were thought to be similar. Temperatures of the supports range from $\sim 500^{\circ} \mathrm{F}$, at the point where they contact the vessel, to $<150^{\circ} \mathrm{F}$ at a point where they contact the biological shield $\left(150^{\circ} \mathrm{F}\right.$ is the normal maximum permissible operating temperature of the concrete biological shield). The temperature of the HFIR vessel and surveillance specimens is $\sim 120^{\circ} \mathrm{F}$. Thus, presumably a portion of the support operates at a temperature close to that of the HFIR vessel.

Multigroup neutron transport calculations were performed recently for the vessel wall and the cavity of one BWR and three PWRs, and the results are provided in Tables $3.1-3.8 .1,2$ Table 3.9 summarizes the fast fluxes ( $\mathrm{E}>1.0 \mathrm{MeV}$ ) [as well as dpa rate $(\mathrm{E}>0.1 \mathrm{MeV})$ ] for the LWR cavities and the HFIR surveillance specimens (also, see Table 2.1). It is apparent that $\phi(E>1.0 \mathrm{MeV})$ for the PWR cavities is similar to that for the HFIR surveillance specimens ( $10^{8}$ to $10^{9}$ neutrons $\left./ \mathrm{cm}^{2} \cdot \mathrm{s}\right)$, while that for the BWR is much less.

Table 3.10 summarizes LWR fast-flux data for $E>1.0 \mathrm{MeV}$ (group A) and $0.1 \leq E \leq 1.0 \mathrm{MeV}$ (group $B$ ). These data indicate that the ratio of group A to group B fluxes is much less in the cavity than it is at the inner surface of the vessel wall (the result of inelastic scattering in the vessel wall). Thus, the fast flux $(E>0.1 \mathrm{MeV})$ in the LWR cavity is much softer than that at the location of the HFIR surveillance specimens. As suggested in Chap. 2, to account for this difference in energy spectrum when applying the HFIR data to the evaluation of the supports in the cavity, the $\triangle$ NDTT data can be correlated with dpa rate and dpa for $E>0.1 \mathrm{MeV}$ instead of $\phi$ and $\phi$ for $E>1.0 \mathrm{MeV}$, the assumption being made that most of the neutrons contributing to embrittlement have energies $>0.1 \mathrm{MeV}$. A comparison of dpa rate ( $E>0.1 \mathrm{MeV}$ ) for HFIR and the LWR cavities (Table 3.9) indicates that the maximum cavity dpa rate $\left(5.0 \times 10^{-12} \mathrm{~s}^{-1}\right)$ is about twice the maximum HFIR dpa rate $\left(2.0 \times 10^{-12}\right)$, while the maximum fast flux values $(E>1.0 \mathrm{MeV})$ are about the same. This indicates that some extrapolation of the HFIR data is necessary.

Application of the HFIR data to the LWR vessel supports requires extrapolation with regard to both dpa rate and dpa. Thus, correlations between $\triangle N D T T$, dpa rate, and dpa are required. Two different correlations between $\triangle$ NDTT and dpa are proposed and are shown in Figs. 3.1 and 3.2. Figure 3.1 was created by drawing separate straight-1ine curves through the maximum $\triangle$ NDTT data points, for the A212-B and A350-LF3 HFIR surveillance materials, parallel to the materials testing reactor (MTR) curve, which Hawthorne constructed as a straight 1 ine on semilog paper. 3

The other correlation (Fig. 3.2) was obtained by first plotting the HFIR A350-LF3 data on log-log paper and constructing a best-fit straight-1ine curve. Next, the ORR A212-B data obtained in connection with the recent HFIR vessel study ${ }^{4}$ and a much earlier study of the vessel for the Experimental Gas-Cooled Reactor (EGCR)5 (Table 2.1) were 
Table 3.1. Calculated (DOT, 3-D) neutron energy spectra for B\&W (ANO-1) reactor

\begin{tabular}{|c|c|c|c|c|}
\hline \multirow{2}{*}{ Group } & \multirow{2}{*}{$\begin{array}{c}E \text { (upper) } \\
(\mathrm{MeV})\end{array}$} & \multicolumn{3}{|c|}{ Flux (neutrons $/ \mathrm{cm}^{2} \cdot \mathrm{s}$ ) } \\
\hline & & $0 \mathrm{~T}^{a}$ & $T / 4$ & Cavity \\
\hline $\begin{array}{r}1 \\
2 \\
3 \\
4 \\
5 \\
6 \\
7 \\
8 \\
9 \\
10 \\
11 \\
12 \\
13 \\
14 \\
15 \\
16 \\
17 \\
18 \\
19 \\
20 \\
21 \\
22 \\
23 \\
24 \\
25 \\
26\end{array}$ & $\begin{array}{l}1.733+01 \\
1.221+01 \\
1.000+01 \\
7.408+00 \\
4.966+00 \\
3.012+00 \\
2.466+00 \\
2.307+00 \\
1.653+00 \\
1.003+00 \\
7.427-01 \\
4.979-01 \\
2.972-01 \\
1.832-01 \\
1.111-01 \\
6.738-02 \\
3.183-02 \\
2.606-02 \\
2.418-02 \\
1.503-02 \\
7.102-03 \\
4.540-04 \\
1.013-04 \\
1.855-06 \\
4.140-07 \\
1.000-11 \\
61\end{array}$ & $\begin{array}{l}2.699+07 \\
6.543+07 \\
2.743+08 \\
7.879+08 \\
1.133+09 \\
7.621+08 \\
3.448+08 \\
1.376+09 \\
2.000+09 \\
1.108+09 \\
1.863+09 \\
2.052+09 \\
1.171+09 \\
1.235+09 \\
8.378+08 \\
3.851+08 \\
1.820+08 \\
3.043+08 \\
6.040+08 \\
6.938+08 \\
2.697+09 \\
1.489+09 \\
3.968+09 \\
1.272+09 \\
9.277+09\end{array}$ & $\begin{array}{l}1.258+07 \\
2.940+07 \\
1.205+08 \\
3.242+08 \\
4.882+08 \\
3.822+08 \\
1.794+08 \\
9.010+08 \\
1.688+09 \\
9.956+08 \\
2.314+09 \\
3.036+09 \\
1.214+09 \\
1.643+09 \\
1.303+09 \\
6.444+08 \\
7.730+07 \\
4.703+08 \\
6.469+08 \\
3.110+08 \\
1.528+09 \\
8.032+08 \\
1.807+09 \\
3.777+08 \\
2.232+08\end{array}$ & $\begin{array}{l}5.175+05 \\
1.061+06 \\
3.694+06 \\
7.908+06 \\
1.348+07 \\
1.244+07 \\
5.967+06 \\
3.893+07 \\
1.176+08 \\
1.036+08 \\
3.413+08 \\
5.289+08 \\
2.908+08 \\
3.327+08 \\
2.556+08 \\
1.953+08 \\
2.832+07 \\
1.094+08 \\
2.004+08 \\
1.652+08 \\
4.918+08 \\
2.364+08 \\
4.823+08 \\
1.309+08 \\
5.184+08\end{array}$ \\
\hline
\end{tabular}

anner surface of vessel.

Table 3.2. 4-Group fluxes and total dpa rate for B\&W (ANO-1) reactor

\begin{tabular}{lllll}
\hline & \multicolumn{2}{c}{$\begin{array}{c}\text { Energy } \\
\text { range }\end{array}$} & \multicolumn{3}{c}{ Flux $^{a}$} \\
\cline { 3 - 5 } & & & \multicolumn{3}{c}{$\mathrm{TT}^{\mathrm{b}}$} & $1 / 4 \mathrm{~T}$ & Cavity \\
\hline 1 & $1.0 \mathrm{MeV}-17 \mathrm{MeV}$ & 0.186 & 0.192 & 0.044 \\
2 & $0.111 \mathrm{MeV}-1.0 \mathrm{MeV}$ & 0.204 & 0.428 & 0.346 \\
3 & $0.4 \mathrm{eV}-0.111 \mathrm{MeV}$ & 0.355 & 0.370 & 0.498 \\
4 & $10^{-5}-0.4 \mathrm{eV}$ & 0.255 & 0.010 & 0.112 \\
\hline & $\mathrm{dpa} / \mathrm{s}\left(\mathrm{E}>10^{-5} \mathrm{eV}\right)$ & $1.041 \mathrm{E}-11$ & $7.232 \mathrm{E}-12$ & $6.829 \mathrm{E}-13$ \\
\hline
\end{tabular}

a Normalized to unity.

$b_{\text {Inner surface of vessel. }}$ 
Table 3.3. Calculated (DOT, 3-D) neutron energy spectra for CE (ANO-2) reactor

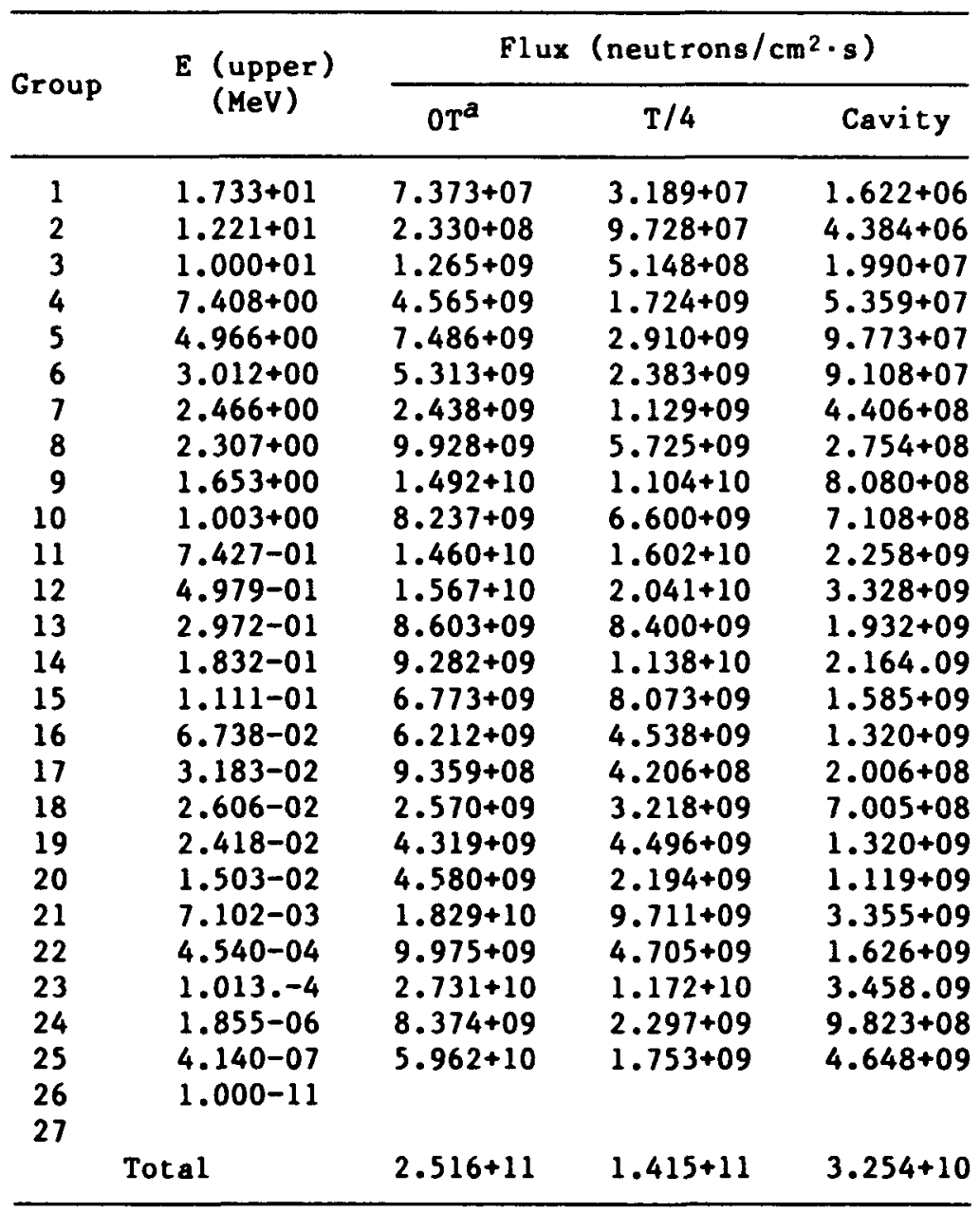

${ }^{a}$ Inner surface of vessel.

Table 3.4. 4-Group fluxes and total dpa rate for CE (ANO-2) reactor

\begin{tabular}{|c|c|c|c|c|}
\hline \multirow{2}{*}{ Group } & \multirow{2}{*}{$\begin{array}{l}\text { Energy } \\
\text { range }\end{array}$} & \multicolumn{3}{|c|}{ Flux $x^{a}$} \\
\hline & & $\mathrm{OT}^{b}$ & $1 / 4 \mathrm{~T}$ & Cavity \\
\hline $\begin{array}{l}1 \\
2 \\
3 \\
4\end{array}$ & $\begin{array}{l}1.0 \mathrm{MeV}-17 \mathrm{MeV} \\
0.111 \mathrm{MeV}-1.0 \mathrm{MeV} \\
0.4 \mathrm{eV}-0.111 \mathrm{MeV} \\
10^{-5} \mathrm{eV}-0.4 \mathrm{eV}\end{array}$ & $\begin{array}{l}0.184 \\
0.224 \\
0.355 \\
0.237\end{array}$ & $\begin{array}{l}0.181 \\
0.444 \\
0.363 \\
0.012\end{array}$ & $\begin{array}{l}0.055 \\
0.319 \\
0.483 \\
0.143\end{array}$ \\
\hline & $\mathrm{dpa} / \mathrm{s}\left(\mathrm{E}>10^{-5} \mathrm{eV}\right)$ & $7.041 \mathrm{E}-11$ & $4.549 E-11$ & $4.975 E-12$ \\
\hline
\end{tabular}

a Normalized to unity.

${ }^{b}$ Inner surface of vessel. 
Table 3.5. Calculated (DOT, 3-D) neutron energy specra for $W$ reactor McQuire Unit 1 , Cycle 1

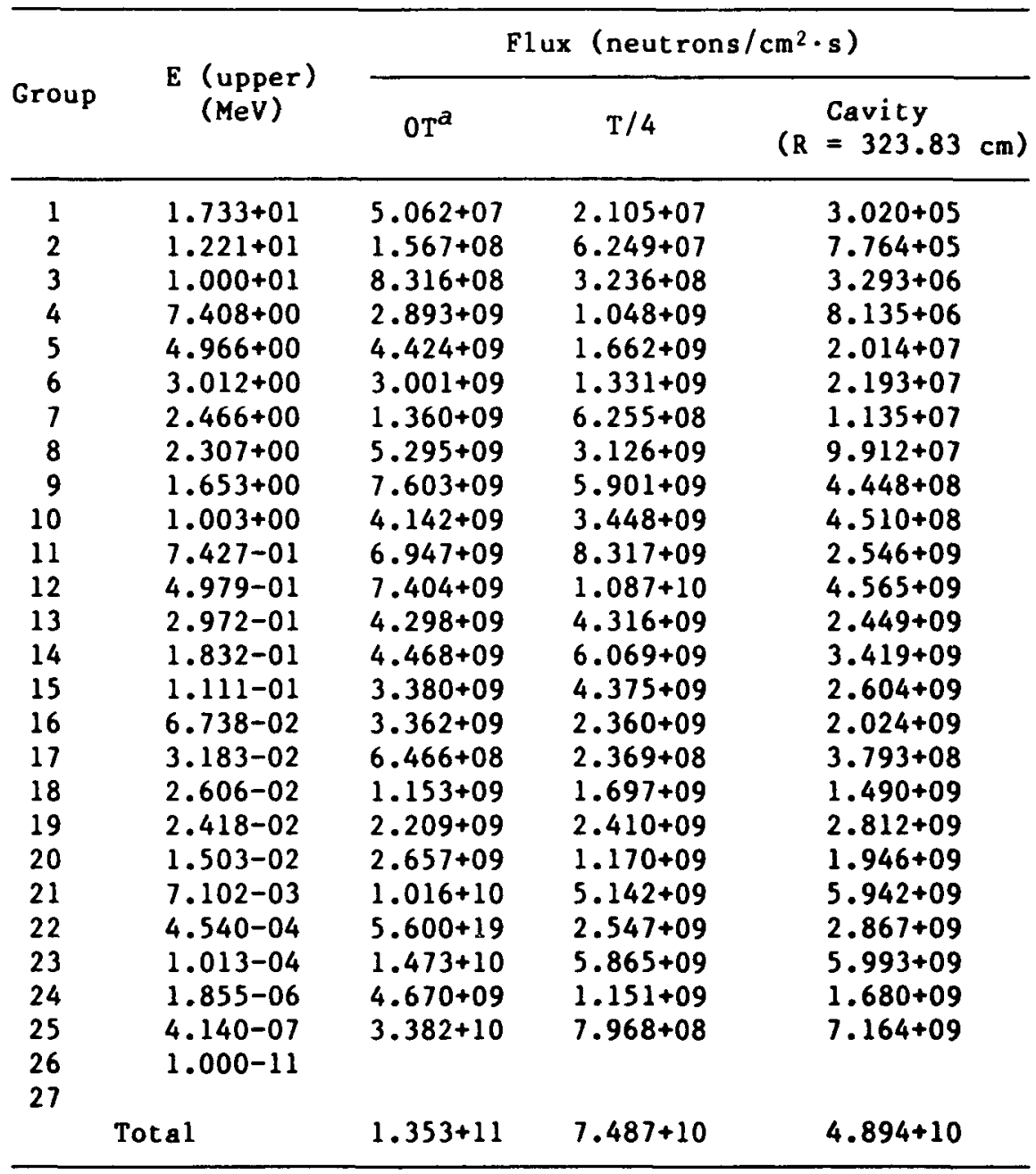

${ }^{a}$ Inner surface of vessel.

Table 3.6. 4-Group fluxes and total dpa rate for $\underline{W}$ reactor

\begin{tabular}{lllll}
\hline \multirow{2}{*}{ Group } & \multicolumn{2}{c}{$\begin{array}{c}\text { Energy } \\
\text { range }\end{array}$} & & \multicolumn{3}{c}{ Flux } \\
\cline { 3 - 5 } & & $0 \mathrm{~T}^{b}$ & $1 / 4 \mathrm{~T}$ & Cavity \\
\hline 1 & $1.0 \mathrm{MeV}-17 \mathrm{MeV}$ & 0.184 & 0.188 & 0.012 \\
2 & $0.111 \mathrm{MeV}-1.0 \mathrm{MeV}$ & 0.202 & 0.441 & 0.274 \\
3 & $0.4 \mathrm{eV}-0.911 \mathrm{MeV}$ & 0.359 & 0.360 & 0.567 \\
4 & $10^{-5} \mathrm{eV}-0 ! 4 \mathrm{eV}$ & 0.250 & 0.011 & 0.146 \\
\hline & $\mathrm{dpa} / \mathrm{s}\left(\mathrm{E}>10^{-5} \mathrm{eV}\right)$ & $3.874 \mathrm{E}-11$ & $2.484 \mathrm{E}-11$ & $4.712 \mathrm{E}-12$
\end{tabular}

${ }^{a}$ Normalized to unity.

${ }^{b}$ Inner surface of vessel. 
Table 3.7. Calculated (DOT, 3-D) neutron energy spectra for GE reactor

\begin{tabular}{|c|c|c|c|c|}
\hline \multirow{2}{*}{ Group } & \multirow{2}{*}{$\begin{array}{c}\text { E (upper) } \\
(\mathrm{MeV})\end{array}$} & \multicolumn{3}{|c|}{ Flux (neutrons $/ \mathrm{cm}^{2} \cdot \mathrm{s}$ ) } \\
\hline & & $0 T^{a}$ & $\mathrm{~T} / 4$ & Cavity \\
\hline 1 & $1.733 E+01$ & $2.78532 E+05$ & $1.19476 \mathrm{E}+05$ & $1.26309 E+04$ \\
\hline 2 & $1.419 \mathrm{E}+01$ & $1.17743 E+06$ & $5.10065 \mathrm{E}+05$ & $5.31195 E+04$ \\
\hline 3 & $1.221 \mathrm{E}+01$ & $4.20585 E+06$ & $1.73173 E+06$ & $1.64842 \mathrm{E}+05$ \\
\hline 4 & $1.000 \mathrm{E}+01$ & $7.86872 E+06$ & $3.22077 \mathrm{E}+06$ & $2.92429 E+05$ \\
\hline 5 & $8.607 \mathrm{E}+00$ & $1.27925 \mathrm{E}+07$ & $5.10243 E+06$ & $4.31247 \mathrm{E}+05$ \\
\hline 6 & $7.408 \mathrm{E}+00$ & $2.97338 \mathrm{E}+07$ & $1.15308 \mathrm{E}+07$ & $8.93362 E+05$ \\
\hline 7 & $6.065 E+00$ & $3.82946 \mathrm{E}+07$ & $1.42439 \mathrm{E}+07$ & $1.06782 E+06$ \\
\hline 8 & $4.966 \mathrm{E}+00$ & $5.75978 \mathrm{E}+07$ & $2.15559 \mathrm{E}+07$ & $1.67350 \mathrm{E}+06$ \\
\hline 9 & $3.679 \mathrm{E}+00$ & $3.59718 \mathrm{E}+07$ & $1.51213 \mathrm{E}+07$ & $1.29333 E+06$ \\
\hline 10 & $3.012 \mathrm{E}+00$ & $2.41009 E+07$ & $1.12497 \mathrm{E}+07$ & $9.89848 \mathrm{E}+05$ \\
\hline 11 & $2.725 E+00$ & $2.59448 E+07$ & $1.28555 \mathrm{E}+07$ & $1.19784 \mathrm{E}+06$ \\
\hline 12 & $2.466 \mathrm{E}+00$ & $1.25811 \mathrm{E}+07$ & $6.32145 E+06$ & $6.21796 \mathrm{E}+05$ \\
\hline 13 & $2.365 E+00$ & $3.22105 E+06$ & $1.78435 E+06$ & $1.76455 E+05$ \\
\hline 14 & $2.346 \mathrm{E}+00$ & $1.50974 \mathrm{E}+07$ & $8.68747 E+06$ & $8.79155 E+05$ \\
\hline 15 & $2.231 E+00$ & $3.58901 E+07$ & $2.23694 \mathrm{E}+07$ & $2.14032 E+06$ \\
\hline 16 & $1.920 \mathrm{E}+00$ & $3.56560 \mathrm{E}+07$ & $2.62479 \mathrm{E}+07$ & $2.89304 \mathrm{E}+06$ \\
\hline 17 & $1.653 \mathrm{E}+00$ & $4.59384 \mathrm{E}+07$ & $3.65276 \mathrm{E}+07$ & $4.35308 E+06$ \\
\hline 18 & $1.353 E+00$ & $6.38427 E+07$ & $6.42605 E+07$ & $9.28453 \mathrm{E}+06$ \\
\hline 19 & $1.003 E+00$ & $4.05210 \mathrm{E}+07$ & $4.46711 E+07$ & $7.60235 E+06$ \\
\hline 20 & $8.208 E+01$ & $2.11290 \mathrm{E}+07$ & $1.92272 \mathrm{E}+07$ & $4.04310 \mathrm{E}+06$ \\
\hline 21 & $7.427 \mathrm{E}+01$ & $4.78865 \mathrm{E}+07$ & $6.94558 \mathrm{E}+07$ & $1.34120 \mathrm{E}+07$ \\
\hline 22 & $6.081 E+01$ & $4.06699 \mathrm{E}+07$ & $5.56024 \mathrm{E}+07$ & $1.30706 \mathrm{E}+07$ \\
\hline 23 & $4.979 E+01$ & $4.48645 E+07$ & $6.27020 E+07$ & $1.33038 E+07$ \\
\hline 24 & $3.688 \mathrm{E}+01$ & $4.04880 \mathrm{E}+07$ & $6.98931 E+07$ & $1.48399 E+07$ \\
\hline 25 & $2.972 E+01$ & $6.22632 E+07$ & $7.57791 \mathrm{E}+07$ & $2.24843 \mathrm{E}+07$ \\
\hline 26 & $1.832 E+01$ & $5.40647 E+07$ & $7.47653 \mathrm{E}+07$ & $2.27497 \mathrm{E}+07$ \\
\hline 27 & $1.111 \mathrm{E}-01$ & $4.23644 \mathrm{E}+07$ & $4.61578 E+07$ & $1.65013 \mathrm{E}+07$ \\
\hline 28 & $6.738 \mathrm{E}-02$ & $3.61008 \mathrm{E}+07$ & $3.55079 E+07$ & $1.25341 E+07$ \\
\hline 29 & $4.087 \mathrm{E}-02$ & $1.56710 \mathrm{E}+07$ & $9.46462 \mathrm{E}+06$ & $4.06071 E+06$ \\
\hline 30 & $3.183 \mathrm{E}-02$ & $1.18315 \mathrm{E}+07$ & $2.92956 \mathrm{E}+06$ & $4.08343 E+06$ \\
\hline 31 & $2.606 \mathrm{E}-02$ & $7.64521 \mathrm{E}+06$ & $1.84057 \mathrm{E}+07$ & $5.40984 E+06$ \\
\hline 32 & $2.418 \mathrm{E}-02$ & $7.29383 E+06$ & $1.11433 \mathrm{E}+07$ & $3.93861 \mathrm{E}+06$ \\
\hline 33 & $2.188 \mathrm{E}-02$ & $2.23029 E+07$ & $1.78285 \mathrm{E}+07$ & $8.46670 E+06$ \\
\hline 34 & $1.503 \mathrm{E}-02$ & $4.12070 \mathrm{E}+07$ & $2.00703 E+07$ & $1.19762 \mathrm{E}+07$ \\
\hline 35 & $7.102 \mathrm{E}-03$ & $4.04597 \mathrm{E}+07$ & $2.52165 E+07$ & $1.15085 E+07$ \\
\hline 36 & $3.355 E-03$ & $3.90943 \mathrm{E}+07$ & $1.99575 \mathrm{E}+07$ & $1.03076 \mathrm{E}+07$ \\
\hline 37 & $1.585 \mathrm{E}-03$ & $6.33659 \mathrm{E}+07$ & $3.07840 \mathrm{E}+07$ & $1.57353 E+07$ \\
\hline 38 & $4.540 \mathrm{E}-04$ & $3.75323 \mathrm{E}+07$ & $1.35174 \mathrm{E}+07$ & $8.53409 E+06$ \\
\hline 39 & $2.144 E-04$ & $3.76390 \mathrm{E}+07$ & $1.74130 \mathrm{E}+07$ & $8.29094 E+06$ \\
\hline 40 & $1.013 E-04$ & $5.01136 \mathrm{E}+07$ & $2.50163 \mathrm{E}+07$ & $1.05576 \mathrm{E}+07$ \\
\hline 41 & $3.727 \mathrm{E}-05$ & $6.23387 \mathrm{E}+\mathrm{C7}$ & $3.06902 \mathrm{E}+07$ & $1.23638 \mathrm{E}+07$ \\
\hline 42 & $1.068 \mathrm{E}-05$ & $3.71304 \mathrm{E}+07$ & $1.64081 \mathrm{E}+07$ & $6.92802 E+06$ \\
\hline 43 & $5.043 E-06$ & $4.87669 \mathrm{E}+07$ & $1.80571 \mathrm{E}+07$ & $8.48279 E+06$ \\
\hline 44 & $1.855 \mathrm{E}-06$ & $3.58256 \mathrm{E}+07$ & $9.95936 \mathrm{E}+06$ & $5.74201 \mathrm{E}+06$ \\
\hline 45 & $8.764 E-07$ & $3.49526 \mathrm{E}+07$ & $6.91034 \mathrm{E}+06$ & $5.16106 \mathrm{E}+06$ \\
\hline 46 & $4.140 \mathrm{E}-07$ & $1.19921 \mathrm{E}+08$ & $6.44878 \mathrm{E}+06$ & $1.10811 \mathrm{E}+07$ \\
\hline 47 & $1.000 \mathrm{E}-07$ & $1.25993 \mathrm{E}+09$ & $9.40594 \mathrm{E}+06$ & $3.51009 E+07$ \\
\hline 48 & $1.000 \mathrm{E}-11$ & & & \\
\hline Total & $2.8536 E+09$ & $1.1268 \mathrm{E}+09$ & $3.5669 \mathrm{E}+08$ & \\
\hline
\end{tabular}

anner surface of vessel. 
Table 3.8. 4-Group fluxes and total dpa rate for GE reactor

\begin{tabular}{|c|c|c|c|c|c|c|}
\hline \multirow[b]{2}{*}{ Group } & \multirow{2}{*}{$\begin{array}{l}\text { Energy } \\
\text { range }\end{array}$} & \multicolumn{5}{|c|}{ Flux $x^{a}$} \\
\hline & & $\begin{array}{c}\text { Core } \\
\text { boundary }\end{array}$ & $\begin{array}{c}\text { Mid- } \\
\text { downcomer }\end{array}$ & $o T^{b}$ & $1 / 4 \mathrm{~T}$ & Cavity \\
\hline $\begin{array}{l}1 \\
2 \\
3 \\
4\end{array}$ & $\begin{array}{l}1.0 \mathrm{MeV}-17 \mathrm{MeV} \\
0.111 \mathrm{MeV}-1.0 \mathrm{MeV} \\
0.4 \mathrm{eV}-0.111 \mathrm{MeV} \\
10^{-5} \mathrm{eV}-0.4 \mathrm{eV}\end{array}$ & $\begin{array}{l}0.096 \\
0.314 \\
0.460 \\
0.130\end{array}$ & $\begin{array}{l}0.149 \\
0.099 \\
0.237 \\
0.515\end{array}$ & $\begin{array}{l}0.158 \\
0.123 \\
0.235 \\
0.484\end{array}$ & $\begin{array}{l}0.234 \\
0.419 \\
0.333 \\
0.014\end{array}$ & $\begin{array}{l}0.080 \\
0.313 \\
0.478 \\
0.129\end{array}$ \\
\hline & $\mathrm{dpa} / \mathrm{s}\left(E>10^{-5} \mathrm{eV}\right)$ & & & $6.909 \mathrm{E}-13$ & $4.303 E-13$ & $6.335 E-14$ \\
\hline
\end{tabular}

${ }^{a}$ Normalized to unity.

$b_{\text {Inner surface of vessel. }}$

Table 3.9. Summary of fast-neutron fluxes ( $\mathrm{P}>0.1 \mathrm{MeV}$ ) for LWR cavities and HFIR surveillance specimens

\begin{tabular}{lcc}
\hline Reactor & $\begin{array}{c}(E>1.0 \mathrm{MeV}) \\
\left(\text { neut rons } / \mathrm{cm}^{2} \cdot \mathrm{s}\right)\end{array}$ & $\begin{array}{c}\mathrm{dpa} / \mathrm{s} \\
(\mathrm{E}>0.1 \mathrm{MeV})\end{array}$ \\
\hline HFIR & $2.4 \times 10^{8-1.4 \times 10^{-9}}$ & $3.7 \times 10^{-13-2.0 \times 10^{-12}}$ \\
GE (BWR) & $2.8 \times 10^{7}$ & $6.3 \times 10^{-14}$ \\
B\&W (PWR) & $2.1 \times 10^{8}$ & $6.8 \times 10^{-13}$ \\
W (PWR) & $6.1 \times 10^{8}$ & $4.7 \times 10^{-12}$ \\
CE (PWR) & $1.8 \times 10^{-12}$ & $5.0 \times 10^{-12}$ \\
\hline
\end{tabular}

Table 3.10. Summary of calculated fluxes for "typical" BWR and PWR vessels and cavities

\begin{tabular}{|c|c|c|c|c|c|c|c|c|}
\hline \multirow{3}{*}{ Reactor } & \multicolumn{8}{|c|}{$\begin{array}{c}\text { Neutron flux } \\
\text { (neutrons } / \mathrm{cm}^{2} \cdot \mathrm{s} \text { ) }\end{array}$} \\
\hline & \multicolumn{5}{|c|}{ Vessel inner surface } & \multicolumn{3}{|c|}{ Cavity } \\
\hline & & $A^{a}$ & & $\mathrm{~B}^{\mathbf{a}}$ & $A / B$ & $\mathbf{A}$ & B & $\mathrm{A} / \mathrm{B}$ \\
\hline GE (BWR) & 6.3 & $\times 10^{8}$ & 3.5 & $\times 10^{8}$ & 1.8 & $2.8 \times 10^{7}$ & $1.1 \times 10^{8}$ & 0.3 \\
\hline B\&W (PWR) & 5.8 & $\times 10^{9}$ & 7.4 & $\times 10^{9}$ & 0.8 & $2.1 \times 10^{8}$ & $1.6 \times 10^{9}$ & 0.1 \\
\hline$\underline{W}$ (PWR) & 2.6 & $\times 10^{10}$ & 2.7 & $\times 10^{10}$ & 1.0 & $6.1 \times 10^{8}$ & $1.3 \times 10^{10}$ & 0.5 \\
\hline CE (PWR) & 4.6 & $\times 1010$ & 5.6 & $\times 1010$ & 0.8 & $1.8 \times 10^{9}$ & $1.0 \times 1010$ & 0.2 \\
\hline
\end{tabular}

${ }^{a_{A}}: \quad \mathrm{E}>1.0 \mathrm{MeV} ; \mathrm{B}: 0.1 \leq \mathrm{E} \leq 1.0 \mathrm{MeV}$. 


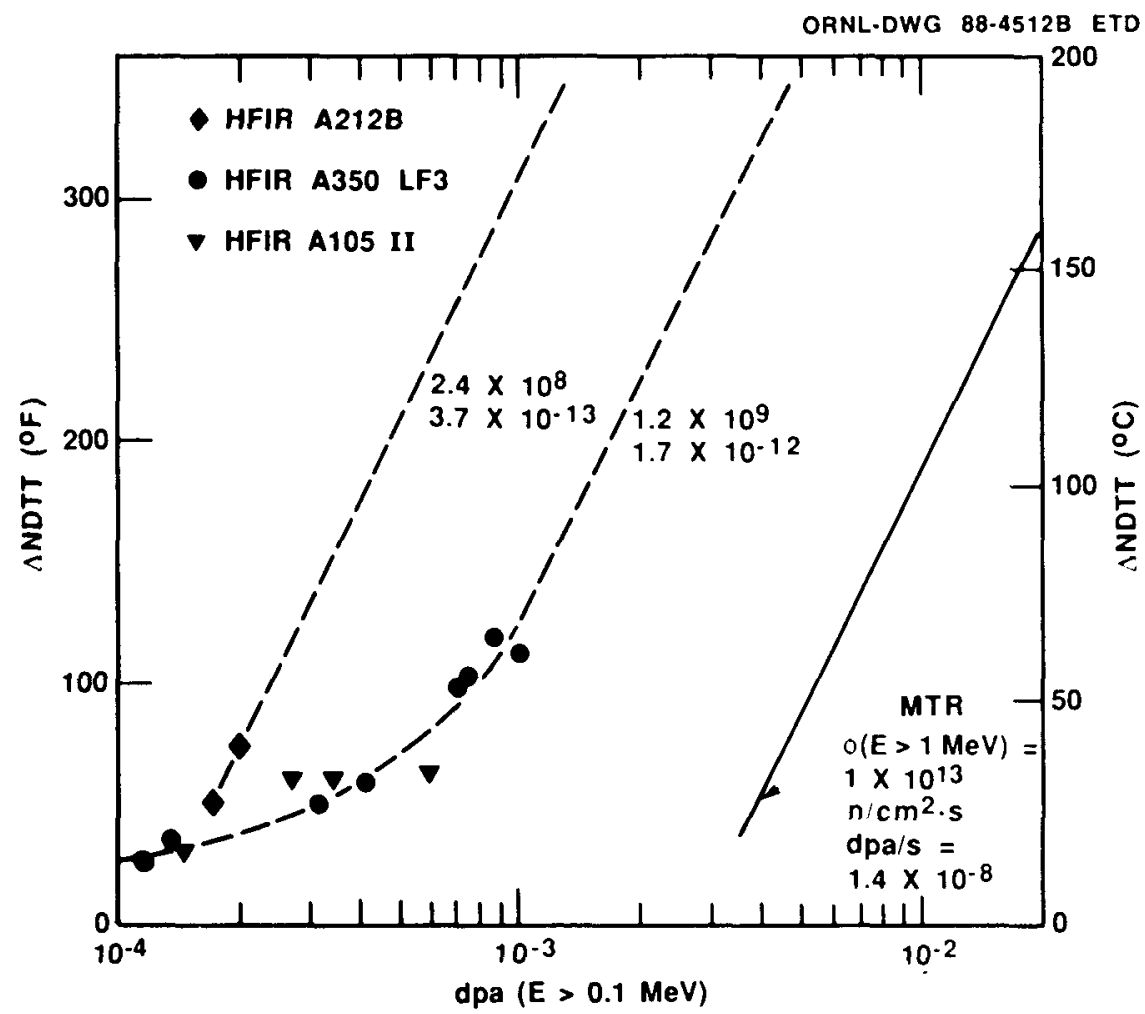

Fig. 3.1. Method for extrapolating HFIR vessel surveillance $\triangle$ NDTT vs $\mathrm{dpa}(\mathrm{E}>0.1 \mathrm{MeV})$ data, assuming $\triangle \mathrm{NDTT}=145 \mathrm{ln} \mathrm{dpa} / \mathrm{d}^{\circ} \mathrm{F}$ for $\Delta$ NDTT $>$ $50^{\circ} \mathrm{F}$.

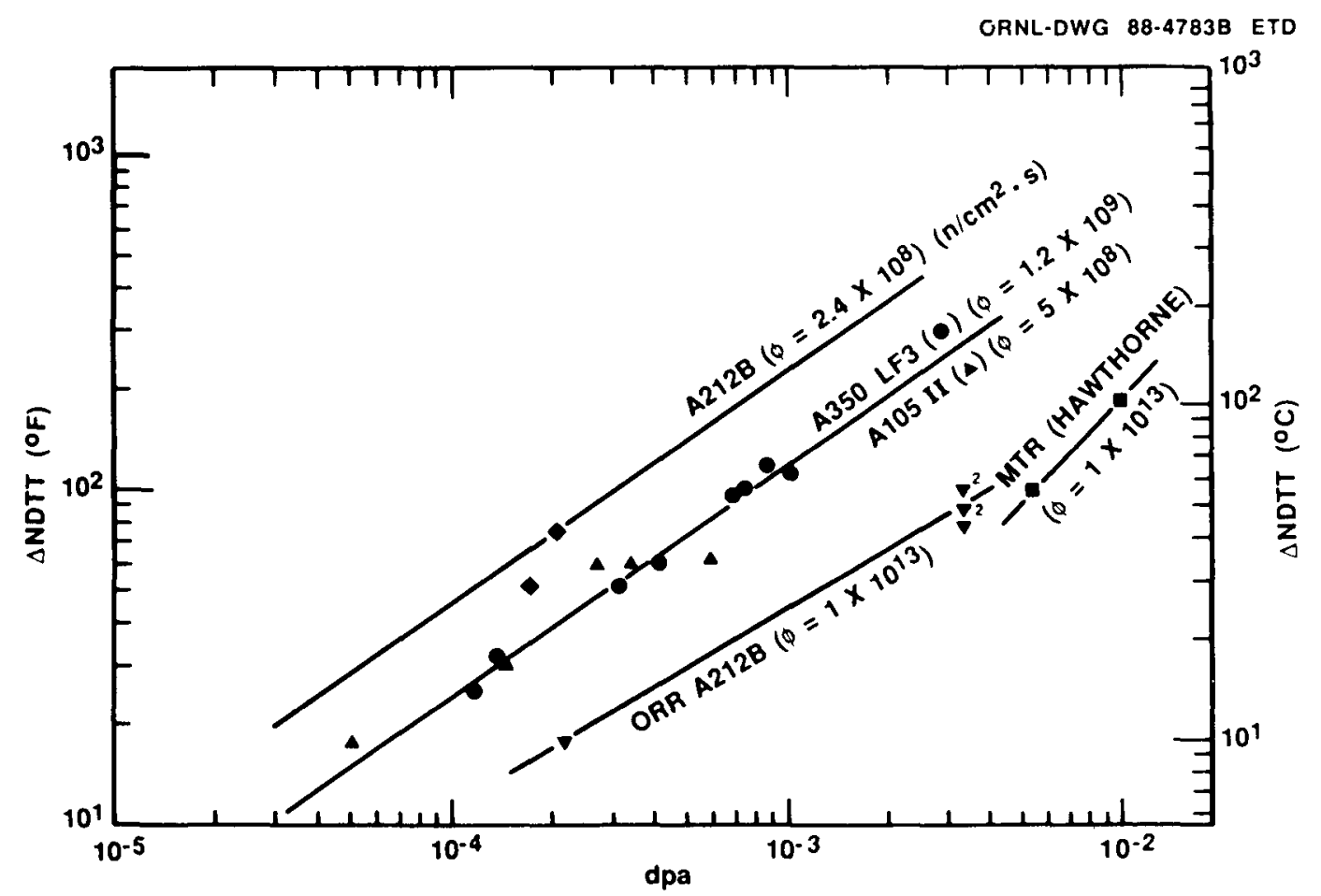

Fig. 3.2. Method for extrapolating HFIR vessel surveillance $\triangle$ NDTT vs $\mathrm{dpa}(\mathrm{E}>0.1 \mathrm{MeV})$ data, assuming $\triangle \mathrm{NDTT}=\mathrm{d}(\mathrm{dpa}) 0.688$ for $10 \leq \triangle N D T T$ $\leq 300^{\circ} \mathrm{F}$. 
plotted and a straight line was constructed. And, finally the MTR data ${ }^{3}$ above $\triangle$ NDTT $=100^{\circ} \mathrm{F}$ were plotted and a straight line was constructed. The indication is that the relatively high fast-flux data (ORR and MTR) are essentially parallel to the HFIR A350-LF3 data. This was used as justification for constructing a curve through the HFIR A212-B data points parallel to the A350-LF3 curve. The upper A212-B point was used as a conservative measure.

A comparison of the correlations represented by Figs. 3.1 and 3.2 (upper two curves) shows that Fig. 3.2 predicts 1 ess of a rate effect between $\phi(E>1.0 \mathrm{MeV})=2.4 \times 10^{8}$ and $1.2 \times 10^{9}$ neutrons $/ \mathrm{cm}^{2} \cdot \mathrm{s}$. In this study, the authors have considered the correlation implied by Fig. 3.2 to provide the more accurate estimate of $\triangle$ NDTT for the LWR vessel supports.

One might argue that the small difference in fast fluxes corresponding to the HFIR A212-B and A350-LF3 irradiations $\left(2.4 \times 10^{8}\right.$ and $1.2 \times 10^{9}$ neutrons $\left./ \mathrm{cm}^{2} \cdot \mathrm{s}\right)$ relative to the factor of $\sim 10^{5}$ between HFIR and the MTRs $\left(\sim 10^{8}\right.$ and $10^{13}$ neutrons $\left./ \mathrm{cm}^{2} \cdot \mathrm{s}\right)$ would not permit distinguishing between the two HFIR fluxes with regard to establishing a rate effect. However, Hamilton 6 recently presented data that indicate essentially no rate effect in the fast flux ( $E>1.0 \mathrm{MeV}$ ) range of $1 \times 10^{10}$ to $3 \times 10^{13}$ neutrons $/ \mathrm{cm}^{2} \cdot \mathrm{s}$ at $\sim 200^{\circ} \mathrm{F}$. This indicates that the $\triangle N D T T$ differences observed between HFIR and the MTRs are associated with a rate effect below a fluence rate of $\sim 1 \times 10^{10}$ neutrons $/ \mathrm{cm}^{2} \cdot \mathrm{s}$. Thus, for this study, the observed difference in $\triangle$ NDTT for fluxes of $2.4 \times 10^{8}$ and $1.2 \times 10^{9}$ neutrons $/ \mathrm{cm}^{2} \cdot \mathrm{s}$ were considered to be real. There is, however, an inconsistency with regard to the Al05-II data: although these data correspond to an intermediate flux level ( 3 to $7 \times 10^{8}$ neutrons $\left./ \mathrm{cm}^{2} \cdot \mathrm{s}\right)$, they tend to coincide with the A350-LF3 data, which correspond to a higher flux $\left(1.2 \times 10^{9}\right.$ neutrons $\left./ \mathrm{cm}^{2} \cdot \mathrm{s}\right)$. Perhaps this implies that a rate effect is not discernible within the flux range of $2.4 \times 10^{8}$ to $1.2 \times 10^{9}$ neutrons $/ \mathrm{cm}^{2} \cdot \mathrm{s}$. However, for this study the Al05-II data were discounted insofar as establishing a rate effect.

Extrapolation and interpolation of the HFIR data for application to the support study were accomplished by assuming that dpa $\alpha$ (dpa rate) for a given value of $\triangle$ NDTT. Corresponding values of dpa, dpa rate, and $\triangle$ NDTT were taken from Figs. 3.1 and 3.2 to obtain the log-log plots in Figs. 3.3 and 3.4 , respectively. As mentioned above, Fig. 3.2 and thus Fig. 3.4 are believed to be the more accurate representation of the trends. However, it must also be emphasized that in either case the values of $\triangle N D T T>100^{\circ} \mathrm{F}$ and values of dpa rate outside the range of $3.7 \times 10^{-13}$ to $1.7 \times 10^{-12} \mathrm{~s}^{-1}$ represent extrapolations of the HFIR data. 


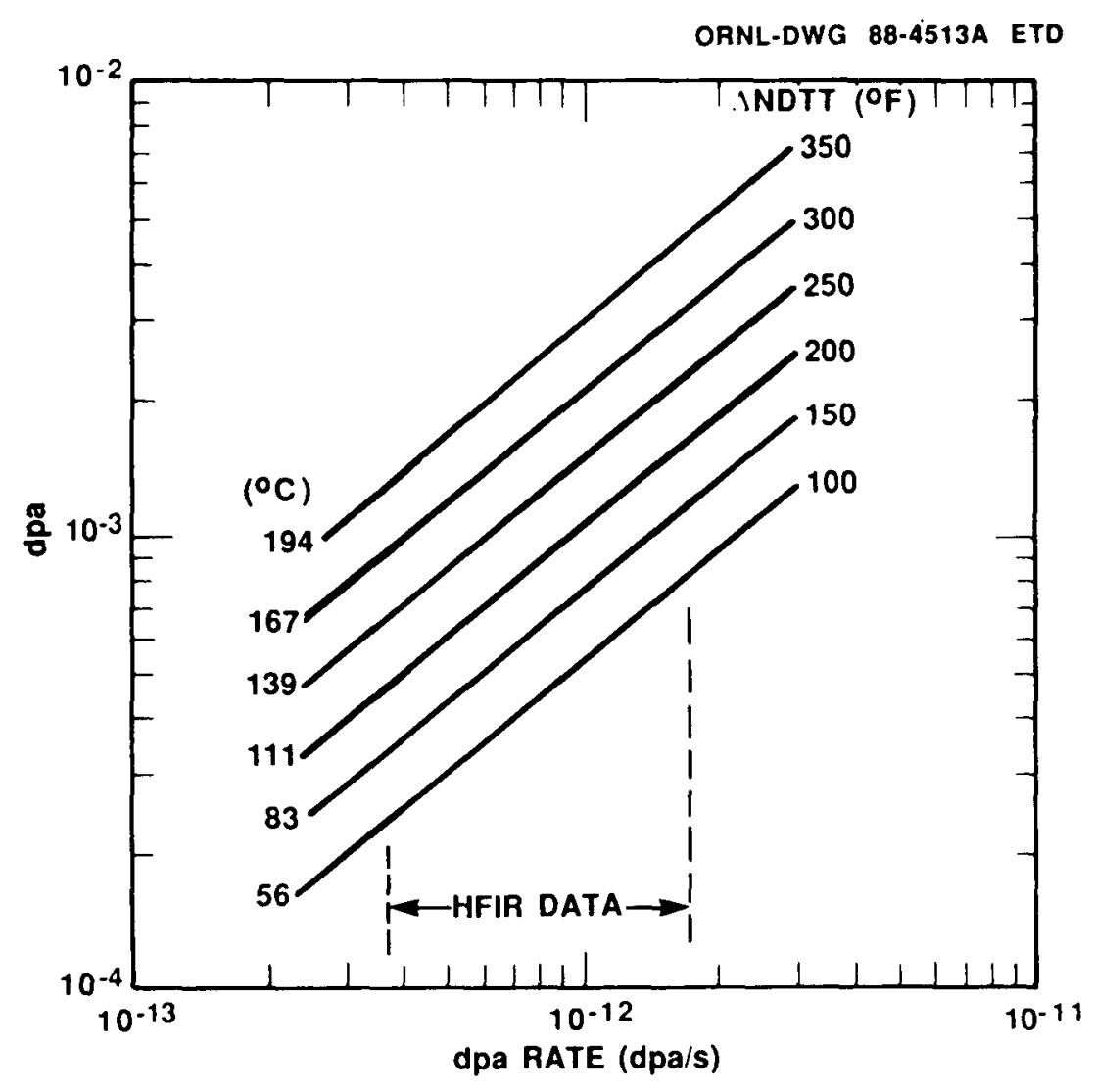

Fig. 3.3. dpa ( $E>0.1 \mathrm{MeV}$ ) vs dpa rate for specific values of $\triangle N D T T$, based on data in Fig. 3.1.

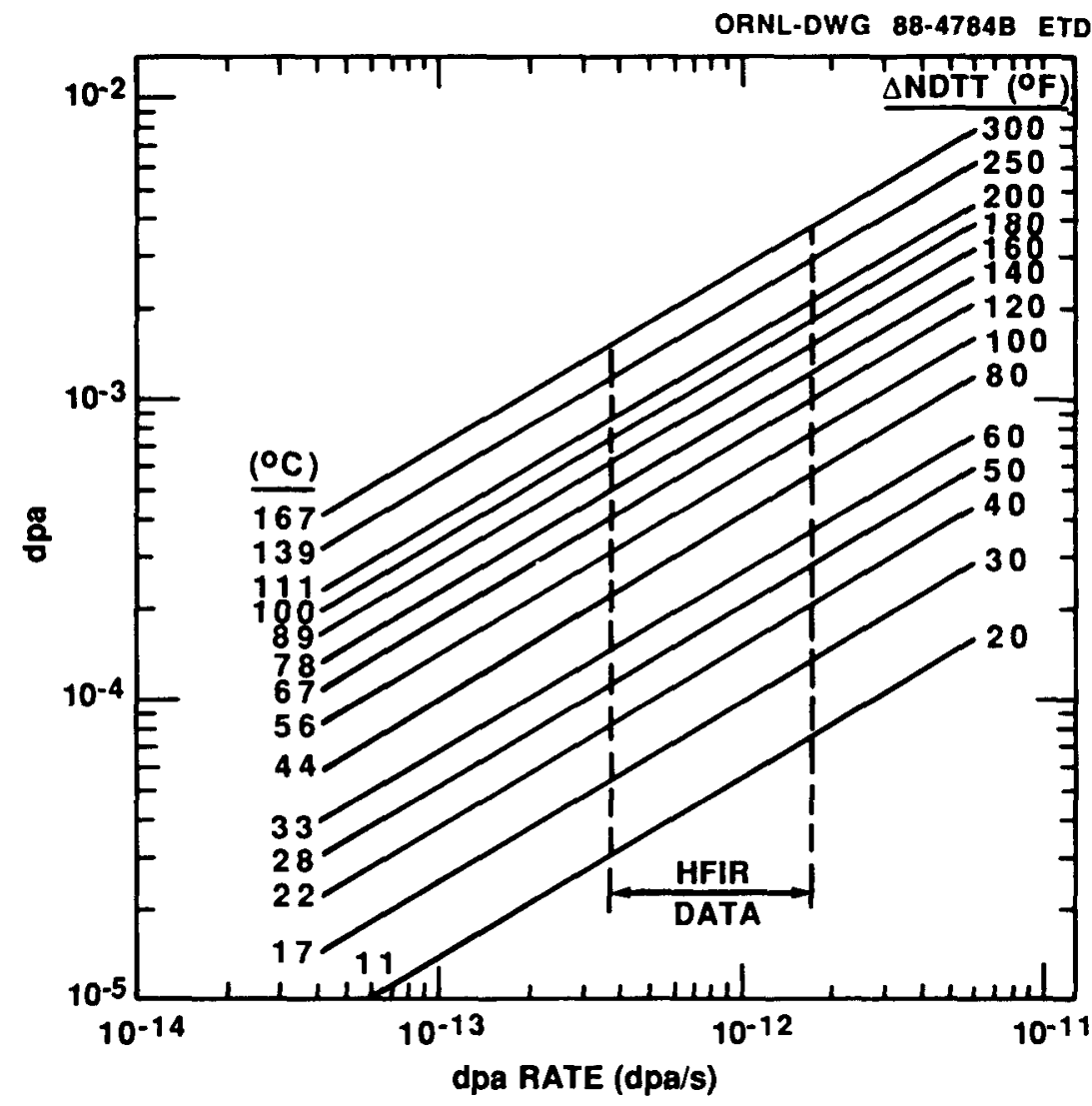

Fig. 3.4. dpa ( $\mathrm{E}>0.1 \mathrm{MeV}$ ) vs dpa rate for specific values of $\triangle N D T T$, based on data in Fig. 3.2. 


\section{$\underline{\text { References }}$}

1. Nicolas Tsoulfanidis et al., "Neutron Energy Spectrum Calculations in Three PWR's," p. 693-701 in Proceedings of the Fifth ASTMEURATOMS Symposium on Reactor Dosimetry, 1985.*

2. M. L. Williams, Oak Ridge National Laboratory, personal communication.

3. J. R. Hawthorne, Studies of Radiation Effects and Recovery of Notch Ductility of Pressure Vessel Steels, British Nuclear Energy Conference, Iron and Steel Institute, London, England, November 30, 1960.

4. R. D. Cheverton, J. G. Merkle, and R. K. Nanstad, eds., Martin Marietta Energy Systems, Inc., Oak Ridge Natl. Lab., Evaluation of HFIR Pressure-Vessel Integrity Considering Radiation Embrittlement, ORNL/TM-10444, April 1988.

5. M. S. Wechsler, R. G. Berggren, N. E. Hinkle, and W. J. Stelzman, Radiation Hardening and Embrittlement in a Low-Carbon Pressure Vessel Steel, Irradiation Effects in Structural Alloys for Thermal and Fast Reactors, STP 457, American Society for Testing and Material, Philadelphia, 1969, pp. 242-60.

6. M. L. Hamilton and H. L. Heinesch, Pacific Northwest Laboratories, "Tensile Properties of Neutron Irradiated A212-B Pressure Vessel Material," ASTM 14th International Symposium on Effects of Radiation on Materials, Andover, Mass., June 27-29, 1988.

*Available for purchase from the National Technical Information Service, Springfield, Virginia 22161. 


\section{SURVEY OF SUPPORT DESIGN FEATURES}

\subsection{Introduction}

A survey was made of LWR vessel supports using the file of final safety analysis reports (FSARs) located at the Nuclear Operations Analysis Center (NOAC) at ORNL. Because of limited time and resources, virtually no contacts were made with industry, that is, with nuclear steam system suppliers (NSSSs), architect-engineers (AE) organizations, or with utilities. The objective of this survey was twofold: (1) to determine if supports or any part thereof are susceptible to significant radiation damage and (2) to determine if the loading conditions and/or fabrication techniques would result in significant primary or secondary tensile stresses.

Two prior studies ${ }^{1,2}$ were very useful in elucidating, corroborating, and supplementing the FSAR data. For several nuclear plants the available data from all sources were too sketchy to be definitive. Consequently, the reader should understand that although most of the FSAR data are clear, there may be specific plants for which the inferences are based on meager data and may be incorrect. Nevertheless, for most plants the survey provides data that permit an understanding of the design rationale followed by NSSS and $A E$ designers.

of the 125 LWR plants surveyed, 96 plants were operating, with the remainder having received construction permits. Since the survey was completed, one of the plants, LaCrosse, has been decommissioned.

\subsection{Categorization}

The reactor vessel support designs for the 125 plants were divided into five broad categories. These categories, which are assigned to each plant in Table 4.1, include (1) skirt, (2) long column, (3) shield tank, (4) short column, and (5) suspension. All of the GE BWR plants (41), except two (Big Rock Point and LaCrosse), have skirt supports typically as shown in Fig. 4.1. (As noted previously, the LaCrosse plant has been decommissioned.)

Because the skirt supports are located remotely from the core with a large volume of intervening metal and water, radiation damage is not anticipated. In addition, the very large section modulus of the skirt's design is anticipated to result in very low stresses resulting from bending loads of all types. The Big Rock Plant reactor vessel, the only Category 5 plant in Table 4.1, has suspension supports as shown in Fig. 4.2. The suspension supports are designed to have significant primary tensile stresses and are also anticipated to reside within a zone of potential radiation damage.

Seven of the PWR plants have skirt supports for the reactor vesse1

(Fig. 4.3). The comments on the BWR skirt supports are believed to apply also to the PWR reactor vessel supports (i.e., insignificant radiation damage and low tensile-stress state for all loading conditions). Babcock and Wilcox (B\&W) served as the NSSS on all seven of these plants. 
Table 4.1 Basic type of support for LwR vessels

\begin{tabular}{|c|c|c|c|c|c|c|c|}
\hline \multirow{3}{*}{ No. } & \multirow{3}{*}{$\begin{array}{l}\text { Power } \\
\text { station } \\
\text { name }\end{array}$} & \multirow{3}{*}{$\begin{array}{l}\text { Type } \\
\text { of } \\
\text { plant }\end{array}$} & \multicolumn{5}{|c|}{ Type of support } \\
\hline & & & Skirt & $\begin{array}{l}\text { Long } \\
\text { col umn }\end{array}$ & $\begin{array}{l}\text { Shield } \\
\text { tank }\end{array}$ & $\begin{array}{l}\text { Short } \\
\text { column }\end{array}$ & Suspension \\
\hline & & & 1 & 2 & 3 & 4 & 5 \\
\hline 1 & Arkansas Nuclear Unit 1 & PWR & 1 & & & & \\
\hline 2 & Arkansas Nuclear Unit 2 & PWR & & 2 & & & \\
\hline 3 & Beaver Valley Unit 1 & PWR & & & 3 & & \\
\hline 4 & Big Rock Point Unit 1 & BWR & & & & & 5 \\
\hline 5 & Browns Ferry Unit 1 & BWR & 1 & & & & \\
\hline 6 & Browns Ferry Unit 2 & BWR & 1 & & & & \\
\hline 7 & Browns Ferry Unit 3 & BWR & 1 & & & & \\
\hline 8 & Brunswick Unit 1 & BWR & 1 & & & & \\
\hline 9 & Brunswick Unit 2 & BWR & 1 & & & & \\
\hline 10 & Byron Unit 1 & PWR & & & & $4 \mathrm{E}$ & \\
\hline 11 & Callaway Unit 1 & PWR & & & & $4 \mathrm{C}$ & \\
\hline 12 & Calvert Cliffs Unit 1 & PWR & & & & $4 \mathrm{C}$ & \\
\hline 13 & Calvert $C l$ iffs Unit 2 & PWR & & & & $4 \mathrm{C}$ & \\
\hline 14 & Catawba Unit 1 & PWR & & & & $4 G$ & \\
\hline 15 & Cook Unit 1 & PWR & & & & $4 \mathrm{C}$ & \\
\hline 16 & Cook Unit 2 & PWR & & & & $4 C$ & \\
\hline 17 & Cooper Station & BWR & 1 & & & & \\
\hline 18 & Crystal River Unit 3 & PWR & 1 & & & & \\
\hline 19 & Davis-Besse Unit 1 & PWR & & & & $4 A$ & \\
\hline 20 & Diablo Canyon Unit 1 & PWR & & & & $4 F$ & \\
\hline 21 & Diablo Canyon Unit 2 & PWR & & & & $4 F$ & \\
\hline 22 & Dresden Unit 2 & BWR & 1 & & & & \\
\hline 23 & Dresden Unit 3 & BWR & 1 & & & & \\
\hline 24 & Duane Arnold & BWR & 1 & & & & \\
\hline 25 & Farley Unit 1 & PWR & & & & $4 C$ & \\
\hline 26 & Farley Unit 2 & PWR & & & & $4 C$ & \\
\hline 27 & Fitzpatrick & BWR & 1 & & & & \\
\hline 28 & Fort Calhoun Unit 1 & PWR & & & & $4 C$ & \\
\hline 29 & Fort St. Vrain & GCR & & Not & applicable & & \\
\hline 30 & Ginna & PWR & & & & $4 C$ & \\
\hline 31 & Grand Gulf Unit 1 & BWR & 1 & & & & \\
\hline 32 & Haddam Neck & PWR & & & & $4 \mathrm{C}$ & \\
\hline 33 & Hatch Unit 1 & BWR & 1 & & & & \\
\hline 34 & Hatch Unit 2 & BWR & 1 & & & & \\
\hline 35 & Indian Point Unit 2 & PWR & & & & $4 F$ & \\
\hline 36 & Indian Point Unit 3 & PWR & & & & $4 \mathrm{~F}$ & \\
\hline 37 & Kewaunee & PWR & & & & $4 \mathrm{C}$ & \\
\hline 38 & La Crosse & BWR & 1 & & & & \\
\hline 39 & La Salle Unit 1 & BWR & $i$ & & & & \\
\hline 40 & La Salle Unit 2 & BWR & 1 & & & & \\
\hline 41 & Limerick Unit 1 & BWR & 1 & & & & \\
\hline 42 & Maine Yankee & PWR & & & 3 & & \\
\hline
\end{tabular}


Table 4.1 (continued)

\begin{tabular}{|c|c|c|c|c|c|c|c|}
\hline \multirow{3}{*}{ No. } & \multirow{3}{*}{$\begin{array}{l}\text { Power } \\
\text { station } \\
\text { name }\end{array}$} & \multirow{3}{*}{$\begin{array}{l}\text { Type } \\
\text { of } \\
\text { plant }\end{array}$} & \multicolumn{5}{|c|}{ Type of support } \\
\hline & & & Skirt & $\begin{array}{l}\text { Long } \\
\text { col umn }\end{array}$ & $\begin{array}{c}\text { Shield } \\
\text { tank }\end{array}$ & $\begin{array}{l}\text { Short } \\
\text { column }\end{array}$ & Suspension \\
\hline & & & 1 & 2 & 3 & 4 & 5 \\
\hline 43 & McGuire Unit 1 & PWR & & & & 4G & \\
\hline 44 & McGuire Unit 2 & PWR & & & & 4G & \\
\hline 45 & Millstone Unit 1 & BWR & 1 & & & & \\
\hline 46 & Millstone Unit 2 & PWR & & & & 4G & \\
\hline 47 & Monticello & BWR & 1 & & & & \\
\hline 48 & Catawba Unit 2 & PWR & & & & $4 \mathbf{G}$ & \\
\hline 49 & Hope Creek Unit 1 & BWR & 1 & & & & \\
\hline 50 & Millstone Unit 3 & PWR & & & 3 & & \\
\hline 51 & Nine Mile Point Unit 1 & BWR & 1 & & & & \\
\hline 52 & North Anna Unit 1 & PWR & & & 3 & & \\
\hline 53 & North Anna Unit 2 & PWR & & & 3 & & \\
\hline 54 & Oconee Unit 1 & PWR & 1 & & & & \\
\hline 55 & Oconee Unit 2 & PWR & 1 & & & & \\
\hline 56 & Oconee Unit 3 & PWR & 1 & & & & \\
\hline 57 & Oyster Creek Unit 1 & BWR & 1 & & & & \\
\hline 58 & Palisades & PWR & & & & 4D & \\
\hline 59 & Palo Verde Unit 1 & PWR & & 2 & & & \\
\hline 60 & Palo Verde Unit 2 & PWR & & 2 & & & \\
\hline 61 & Peach Bottom Unit 2 & BWR & 1 & & & & \\
\hline 62 & Peach Bottom Unit 3 & BWR & 1 & & & & \\
\hline 63 & Pilgrim Unit 1 & BWR & $i$ & & & & \\
\hline 64 & Point Beach Unit 1 & PWR & & & & $4 F$ & \\
\hline 65 & Point Beach Unit 2 & PWR & & & & $4 \mathbf{F}$ & \\
\hline 66 & Prairie Island Unit 1 & PWR & & 2 & & & \\
\hline 67 & Prairie Island Unit 2 & PWR & & 2 & & & \\
\hline 68 & Quad Cities Unit 1 & BWR & 1 & & & & \\
\hline 69 & Quad Cities Unit 2 & BWR & 1 & & & & \\
\hline 70 & Rancho Seco Unit 1 & PWR & 1 & & & & \\
\hline 71 & River Bend Unit 1 & BWR & 1 & & & & \\
\hline 72 & Robinson Unit 2 & PWR & & & & $4 \mathrm{C}$ & \\
\hline 73 & Salem Unit 1 & PWR & & & & $4 \mathbf{F}$ & \\
\hline 74 & Salem Unit 2 & PWR & & & & $4 \mathrm{~F}$ & \\
\hline 75 & San Onofre Unit 1 & PWR & & & & $4 ?$ & \\
\hline 76 & San Onofre Unit 2 & PWR & & 2 & & & \\
\hline 77 & San Onofre Unit 3 & PWR & & 2 & & & \\
\hline 78 & Sequoyah Unit 1 & PWR & & & & 4C & \\
\hline 79 & Sequoyah Unit 2 & PWR & & & & 4C & \\
\hline 80 & St. Lucie Unit 1 & PWR & & 2 & & & \\
\hline 81 & St. Lucie Unit 2 & PWR & & 2 & & & \\
\hline 82 & Summer Unit 1 & PWR & & & & 4C & \\
\hline 83 & Surry Unit 1 & PWR & & & 3 & & \\
\hline 84 & Surry Unit 2 & PWR & & & 3 & & \\
\hline
\end{tabular}


Table 4.1 (cont inued)

\begin{tabular}{|c|c|c|c|c|c|c|c|}
\hline \multirow{3}{*}{ No. } & \multicolumn{2}{|l|}{ " } & \multicolumn{5}{|c|}{ Type of support } \\
\hline & $\begin{array}{l}\text { station } \\
\text { name }\end{array}$ & $\begin{array}{l}\text { of } \\
\text { plant }\end{array}$ & Skirt & $\begin{array}{l}\text { Long } \\
\text { column }\end{array}$ & $\begin{array}{l}\text { Shield } \\
\text { tank }\end{array}$ & $\begin{array}{l}\text { Short } \\
\text { column }\end{array}$ & Suspension \\
\hline & & & 1 & 2 & 3 & 4 & 5 \\
\hline 85 & Susquehanna Unit 1 & BWR & 1 & & & & \\
\hline 86 & Susquehanna Unit 1 & BWR & 1 & & & & \\
\hline 87 & Three Mile Island Unit 1 & PWR & 1 & & & & \\
\hline 88 & Trojan & PWR & & & & $4 \mathrm{~A}$ & \\
\hline 89 & Turkey Point Unit 3 & PWR & & & & $4 \mathrm{~A}$ & \\
\hline 90 & Turkey Point Unit 4 & PWR & & & & 4A & \\
\hline 91 & Vermont Yankee Unit 1 & BWR & 1 & & & & \\
\hline 92 & Washington Nuclear Unit 2 & BWR & 1 & & & & \\
\hline 93 & Waterford Unit 3 & PWR & & & & 4D & \\
\hline 94 & Wolfe Creek Unit 1 & PWR & & & & $4 \mathrm{C}$ & \\
\hline 95 & Yankee-Rowe Unit 1 & PWR & & & & $4 \mathrm{~B}$ & \\
\hline 96 & Zion Unit 1 & PWR & & & & $4 \mathrm{E}$ & \\
\hline 97 & Zion Unit 2 & PWR & & & & $4 E$ & \\
\hline 98 & Vogtle Unit 1 & PWR & & & & $4 \mathrm{C}$ & \\
\hline 99 & Vogtle Unit 2 & PWR & & & & $4 \mathrm{C}$ & \\
\hline 100 & Beaver Valley Unit 2 & PWR & & & 3 & & \\
\hline 101 & Bellefonte Unit 1 & PWR & & & & 4D & \\
\hline 102 & Bellefonte Unit 2 & PWR & & & & 4D & \\
\hline 103 & Braidwood Unit 1 & PWR & & & & $4 E$ & \\
\hline 104 & Braidwood Unit 2 & PWR & & & & $4 E$ & \\
\hline 105 & Byron Unit 2 & PWR & & & & $4 E$ & \\
\hline 106 & Clinton Unit 1 & BWR & 1 & & & & \\
\hline 107 & Comanche Peak Unit 1 & PWR & & & & $4 \mathrm{C}$ & \\
\hline 108 & Comanche Peak Unit 2 & PWR & & & & $4 \mathrm{C}$ & \\
\hline 109 & Fermi Unit 2 & BWR & 1 & & & & \\
\hline 110 & Grand Gulf Unit 2 & BWR & 1 & & & & \\
\hline 111 & Limerick Unit 2 & BWR & 1 & & & & \\
\hline 112 & Nine Mile Point Unit 2 & BWR & 1 & & & & \\
\hline 113 & Palo Verde Unit 3 & PWR & & 2 & & & \\
\hline 114 & Perry Unit 1 & PWR & 1 & & & & \\
\hline 115 & Perry Unit 2 & PWR & 1 & & & & \\
\hline 116 & Seabrook Unit 1 & PWR & & & & $4 \mathrm{~F}$ & \\
\hline 117 & Seabrook Unit 2 & PWR & & & & $4 F$ & \\
\hline 118 & Shearon Harris Unit 1 & PWR & & & & $4 \mathrm{~F}$ & \\
\hline 119 & Shearon Harris Unit 2 & PWR & & & & $4 F$ & \\
\hline 120 & Shoreham & BWR & 1 & & & & \\
\hline 121 & South Texas Unit 1 & PWR & & & & $4 C$ & \\
\hline 122 & South Texas Unit 2 & PWR & & & & $4 \mathrm{C}$ & \\
\hline 123 & Watts Bar Unit 1 & PWR & & & & $4 \mathrm{C}$ & \\
\hline 124 & Watts Bar Unit 2 & PWR & & & & $4 \mathrm{C}$ & \\
\hline 125 & Washington Nuclear Unit 1 & PWR & & & & 4C & \\
\hline 126 & Washington Nuclear Unit 3 & PWR & & 2 & & & \\
\hline
\end{tabular}




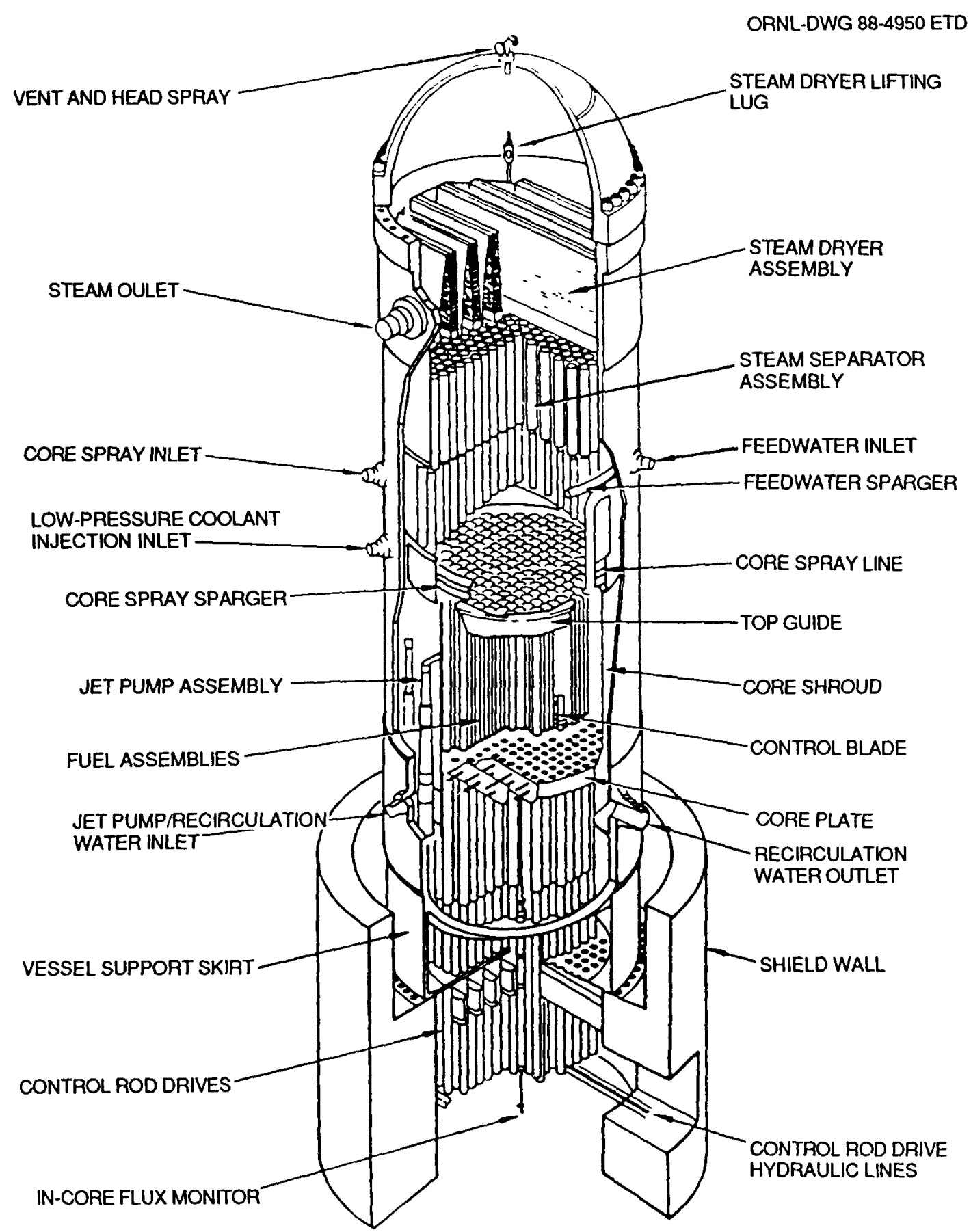

Fig. 4.1. Skirt RPV support for BWRs. 


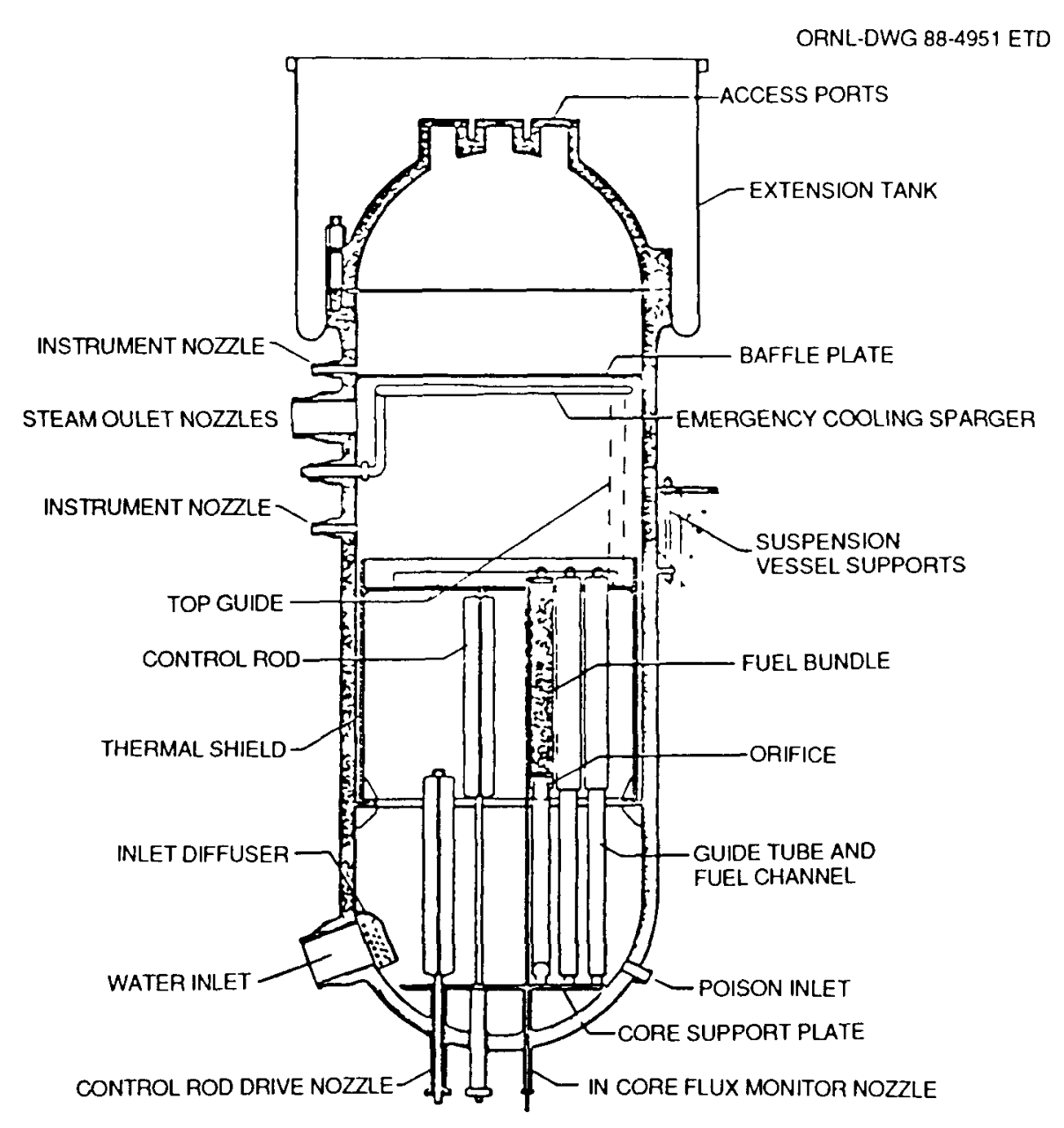

Fig. 4.2. BWR (Big Rock Point) vessel with suspension supports.

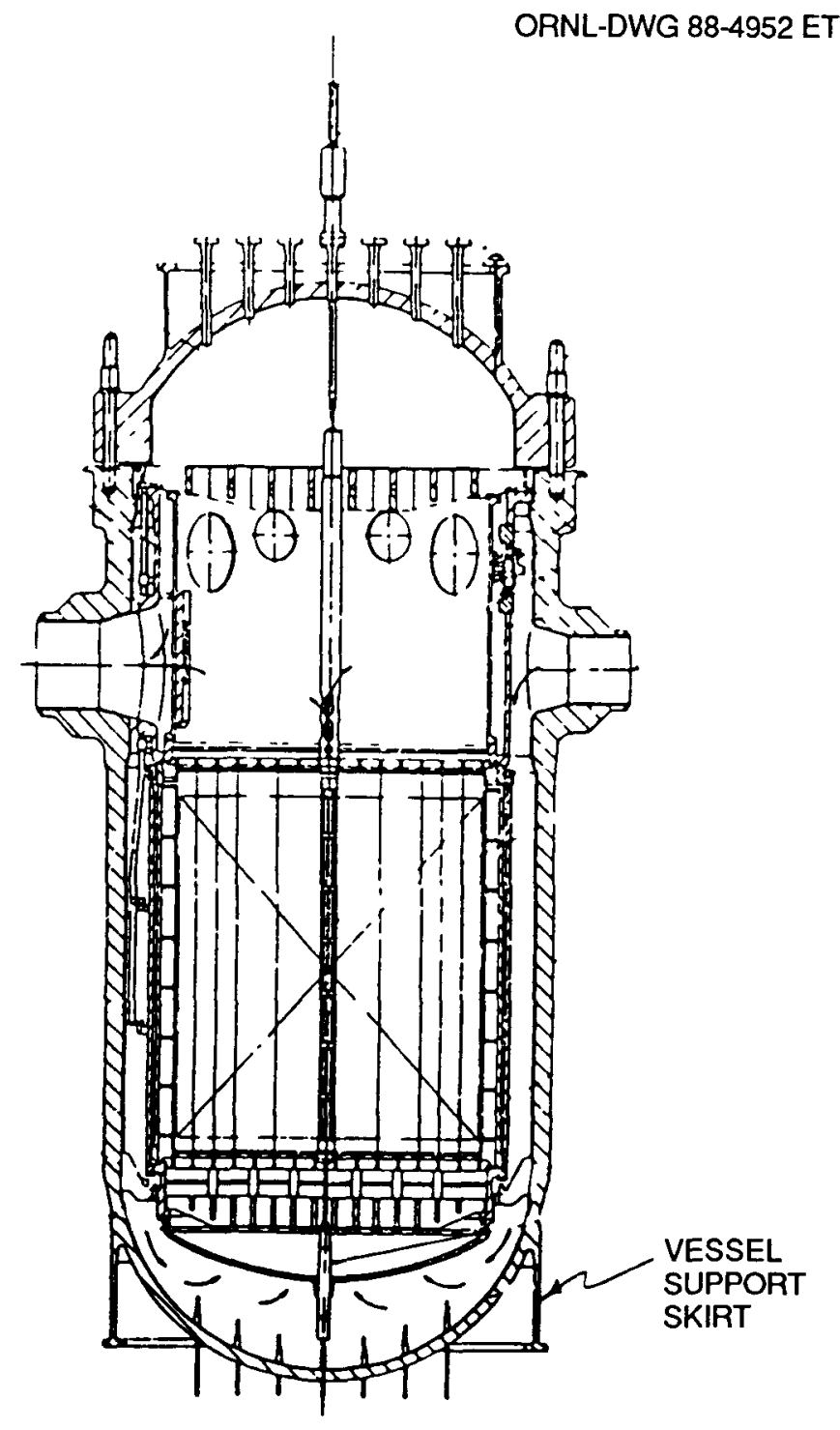

Fig. 4.3. PWR vessel with skirt support. 
Supports for 11 plants have been placed in the long-column category (Fig. 4.4). Small keyway gap size leads to the inference that tensile stresses in the column from all loadings should be low. On the other hand, the columns are located in a zone of potentially high radiation damage. For nine of the plants in this category, Combustion Engineering, Inc. (CE) acted as the NSSS, and for two of the plants, Westinghouse Electric Company (W) acted as the NSSS.

Eight plants have had the supports categorized as shield-tank type. For all of these plants, Stone \& Webster has acted as the AE. W was the NSSS for seven plants, and CE for one of the plants. It is not completely clear from FSAR data if the supports for this latter plant should be classified as shield tank. Figure 4.5 shows design features typical of shield-tank-supported reactor vessels. It is evident that much of the structure would be highly susceptible to the radiation damage hypothesized herein. On the other hand, it would be anticipated that the structure would be quite stiff and consequently have very low primary stresses from all loading cases. It is uncertain as to whether

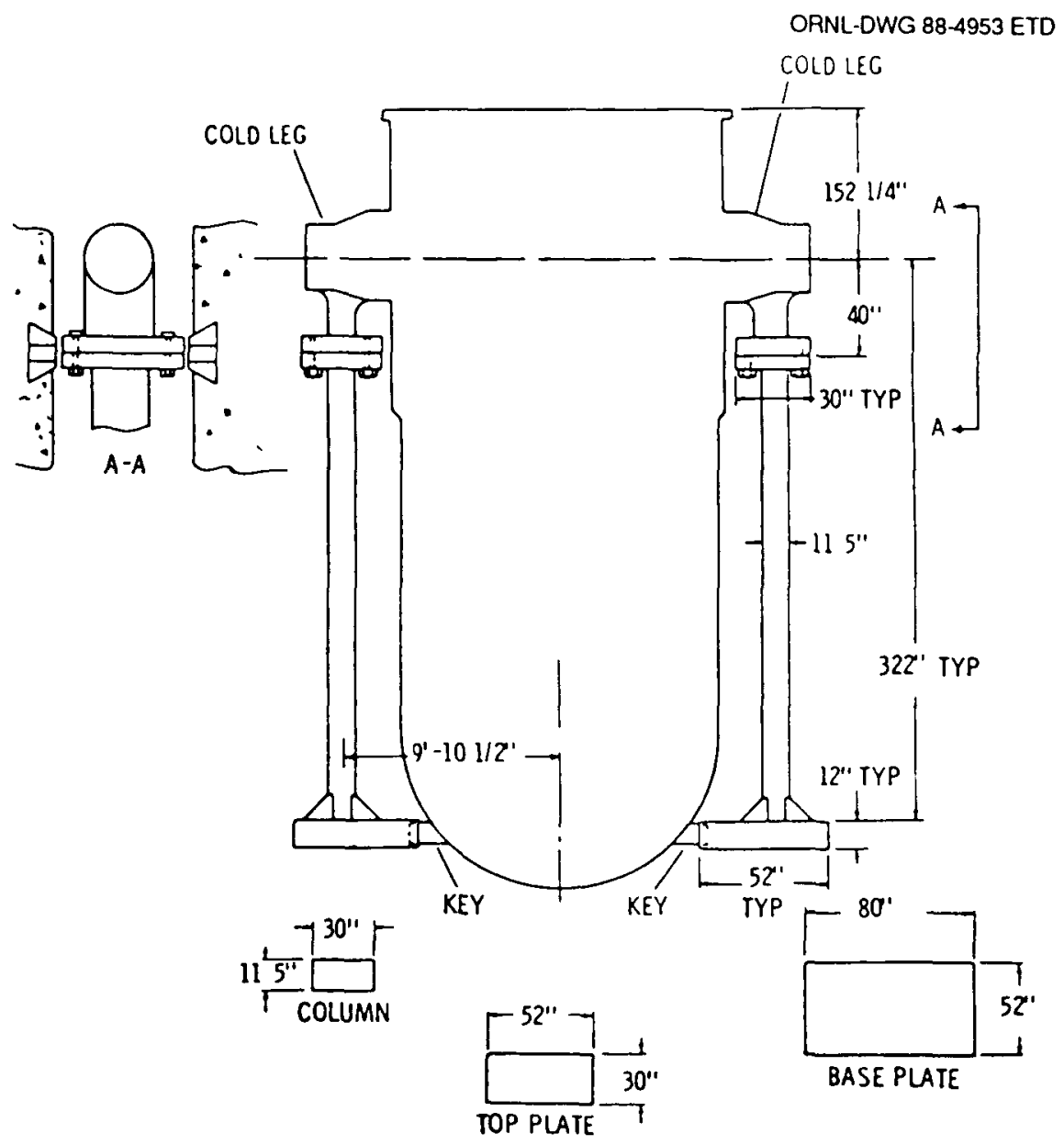

Fig. 4.4. PWR vessel with long-column supports. 


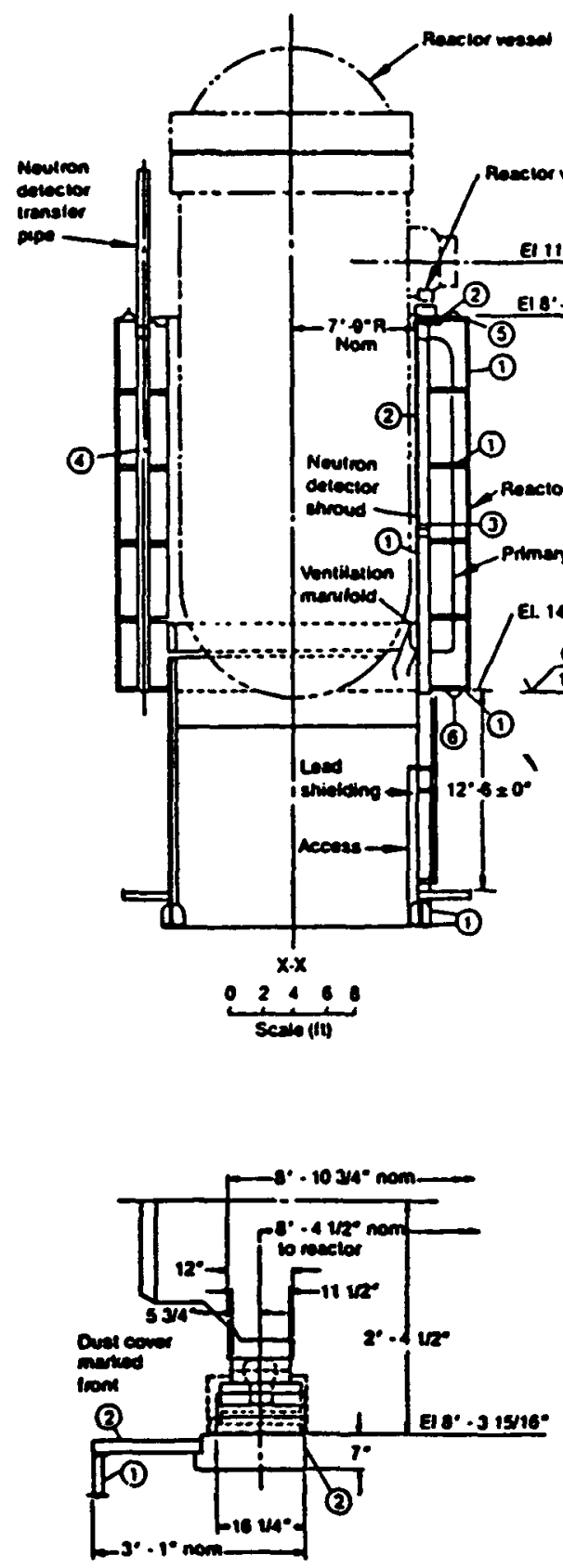

00

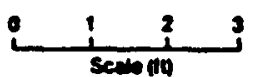

ORNL-DWG 88-4954 ETD
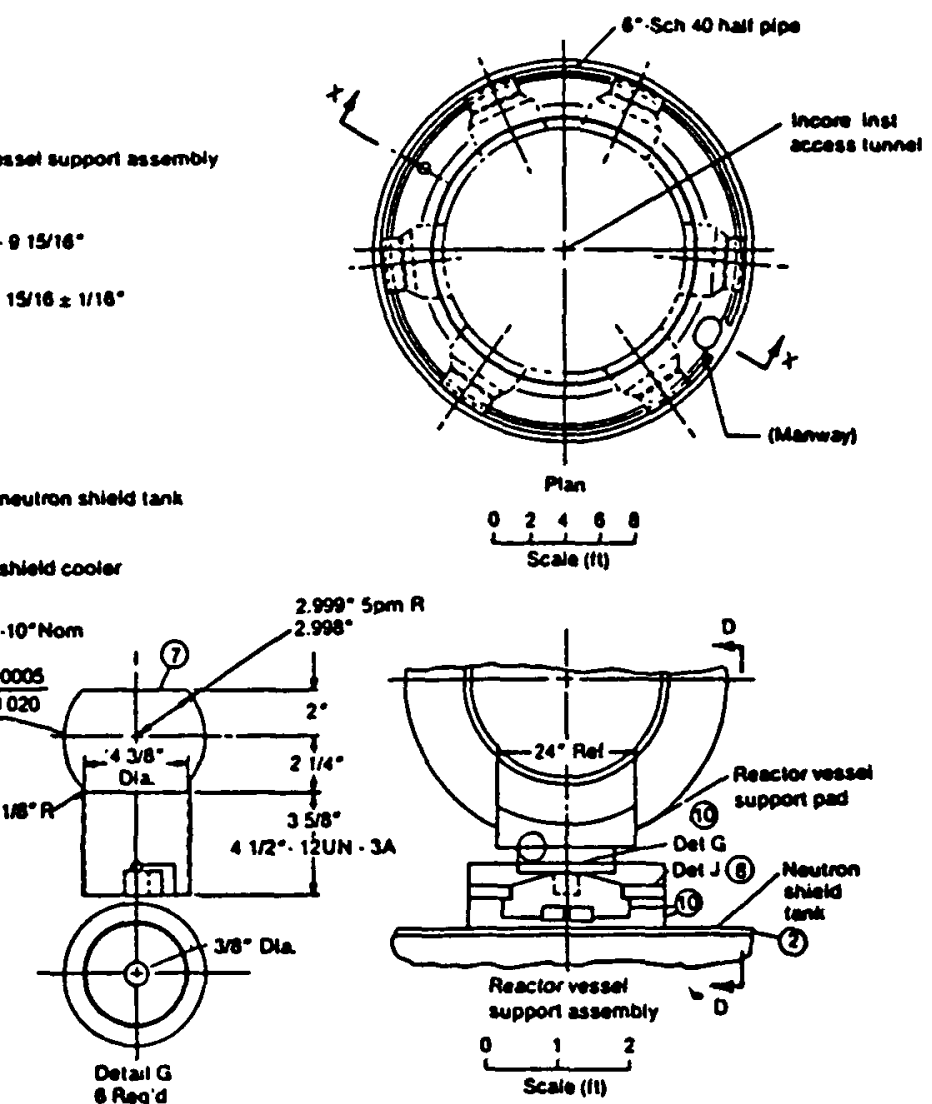

Q2 23456

Bth of Malerials

Pacecior nevtion shiadd lank

No. Name Meterla

(1) PlateA ASTM-ASTS GA Co FBX (nomnelien)

(2) Prate 8 ASTM-AS16 GA 60 FBX (eustomianas

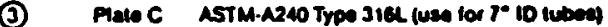

(4) Ppe A ASTM.A312 iypo 31 LLSST

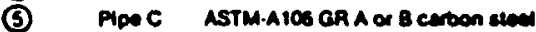

Rasctor vased aupport assembly

Item

No. Neme Mnerte

(7) Bell Maraced ateen 320.000 PSI min Y.P.

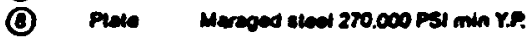

6 Forging Mecoed sted 270.000 pest min re

Fig. 4.5. PWR vessel with shield-tank support. 
secondary stresses (e.g., thermal or residual) could have a significant role in a fracture analysis of a support of this type.

Category 4 (short column), which includes the largest number of PWR plants (58), is an assemblage of designs with two principal commonalities: (1) loads, vertical and horizontal, are transmitted from the vessel nozzles (and vessel brackets in a few instances) through a radially keyed structure to the biological-shield wall and (2) none of the structural components within the reactor vessel biological-shield annulus extends below the core midplane.

In general, the biological-shield wall of most plants is designed for a maximum temperature of $150^{\circ} \mathrm{F}$ for protection of the concrete. As a consequence, many of the Category 4 supports, because of the short heatflow path from reactor vessel nozzle to biological-shield wall, have special designs for heat dissipation. In particular, many of the shortcolumn designs are weldments with openings to promote natural-convection cooling or to assist forced-convection cooling. Others use cooling coils with water as the cooling medium. Because of the large variation in designs of these structures few generalizations can be made. They appear to have a large variability in susceptibility to radiation damage because of the large variability in vertical location relative to the reactor core. On the other hand, designs with relatively broad cavities between the reactor vessel and biological shield are subject to neutron streaming that elevates the fluence experienced for a significant distance above the top of the core.

Because of inferred design characteristics that would promote significant differences in radiation-damage susceptibility or in bending or primary tensile-stress fields, Category 4 was subdivided into subgroups 4A through 4G. Figure 4.6 provides several views and details of a PWR vessel with a Category 4A support having some features that are similar to the Trojan and Turkey Point plants, which were selected for detailed evaluations (Chaps. 5, 6, and 7). In this support category, vertical loads are transmitted from vessel nozzle weld pads through a short-keyed pedestal or girder to steel beams cantilevered radially inward from the biological-shield wall, and horizontal loads are transmitted through the same load path or to separate structures. The radial beams of this category are susceptible to potential radiation damage and are designed to resist vertical loading with primary bending stresses.

-Figure 4.7 is a sectional elevation view of a PWR vessel with a Category 4B support. In this design, loads are transferred from vessel brackets to a ring girder weldment that is supported from the biological shield. Because the loadings are resisted by the girder by means of a torsional moment, primary bending stresses are induced. The girder is located below the top of the core but tends to be shielded by the adjacent suspended neutron shield tank. Thus, the potential for radiation damage is unclear.

Figure 4.8 provides perspective and elevation views of a PWR vessel equipped with a Category 4C support. Vertical loads pass from the vessel nozzle weld pads through radially keyed shoes to short weldment pedestals anchored on the bottom surfaces to recesses in the biological shield. Horizontal loadings are resisted by bending and shear stresses in the shoes and pedestal weldments. Insufficient information is available for assessment of potential secondary tensile stresses, that is, 


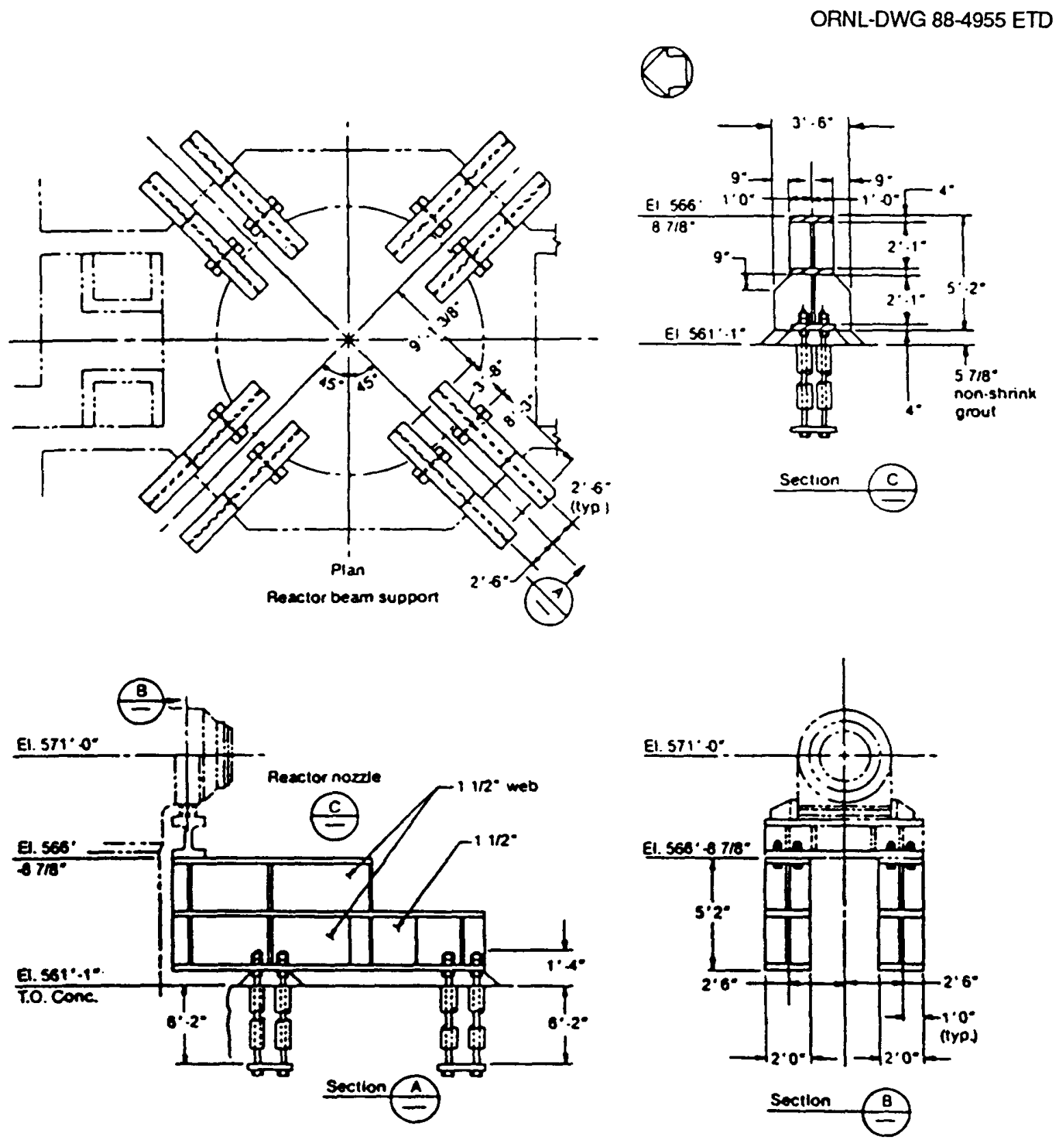

Fig. 4.6. PWR vessel with category $4 \mathrm{~A}$ support. 


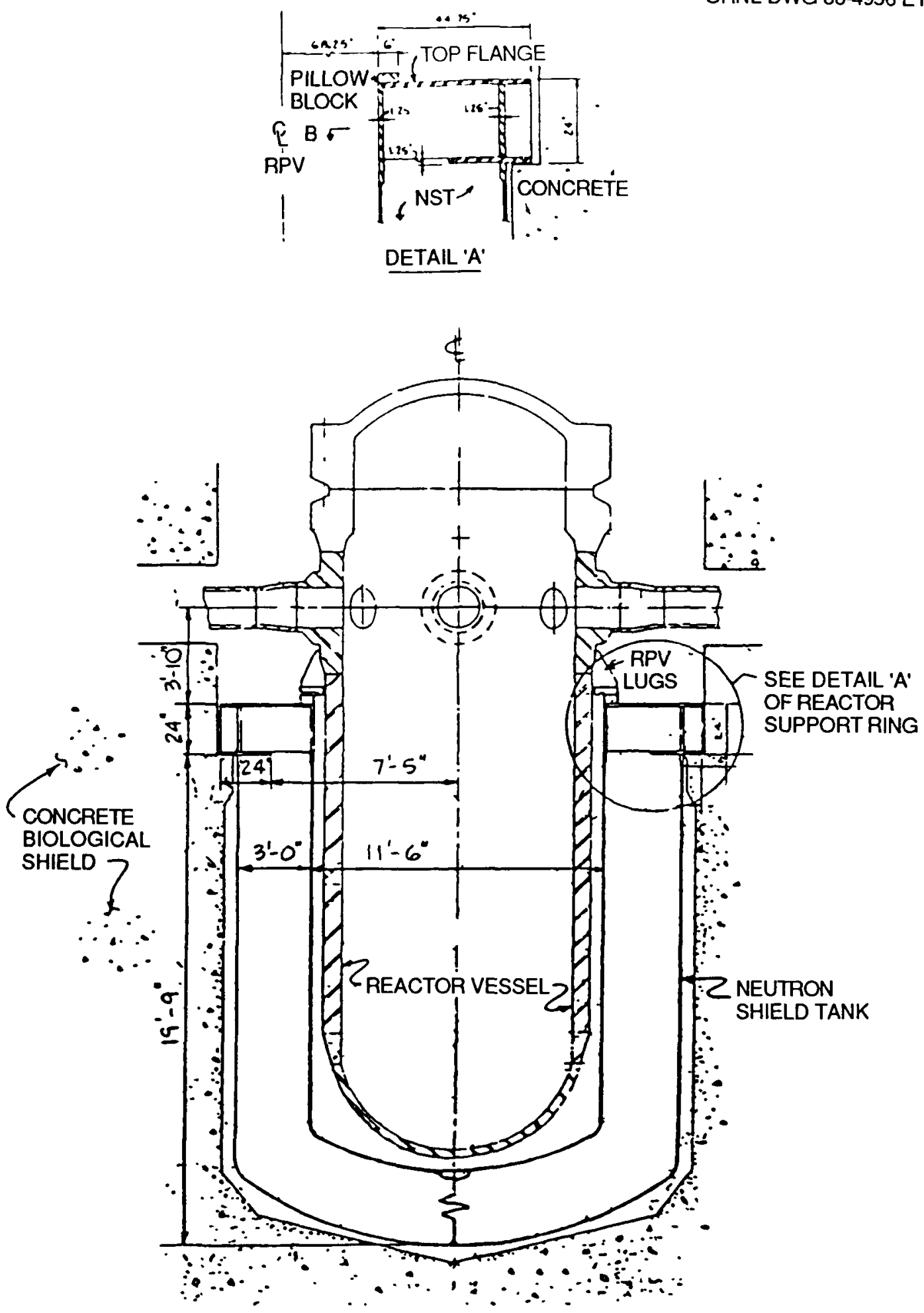

ORNL-DWG 88-4956 ETD

Fig. 4.7. PWR vessel with category 4B support. 


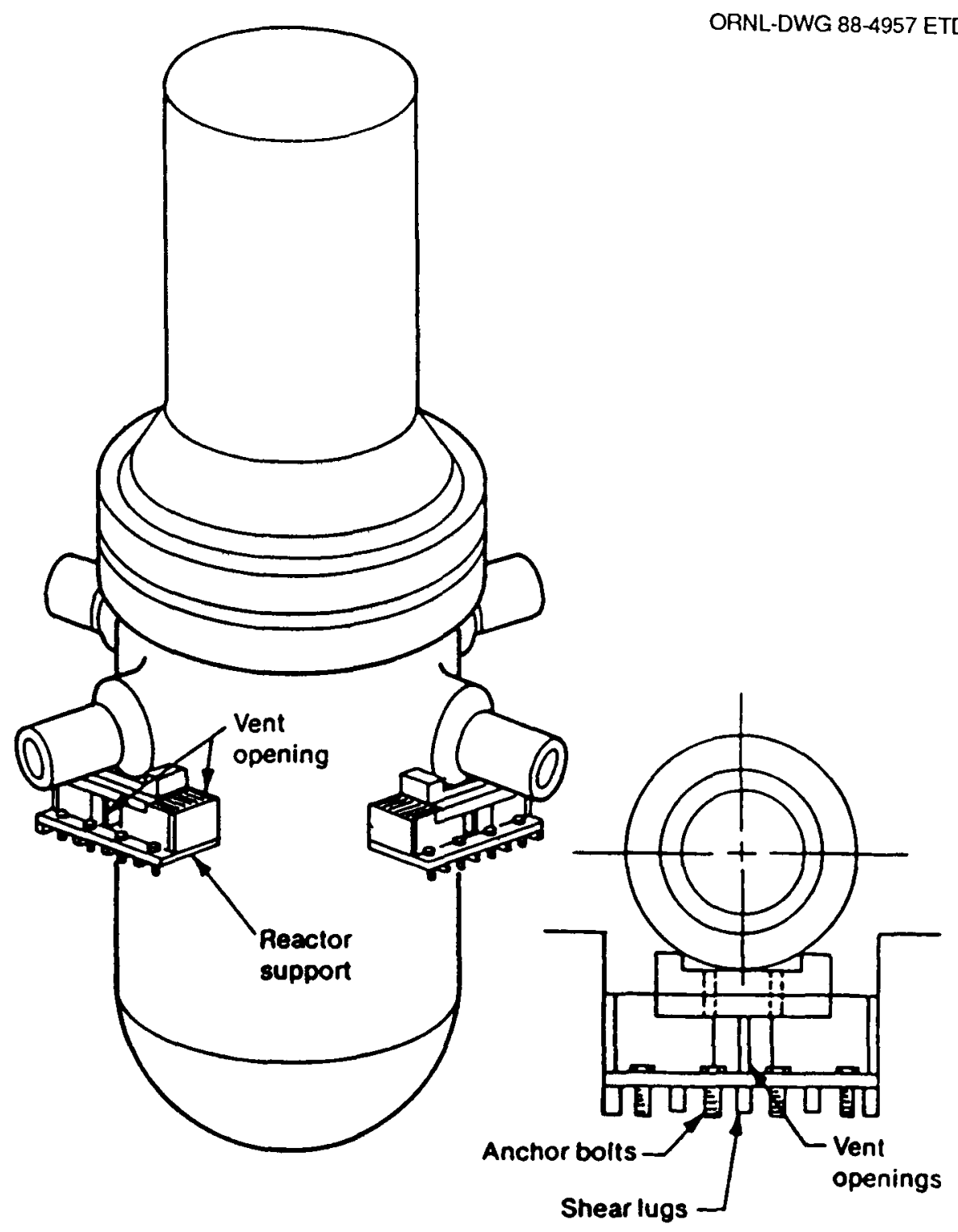

Fig. 4.8. PWR vessel with category $4 \mathrm{C}$ support.

from thermal or residual stress sources. Because of the short height, heat transfer provisions (vent openings and water cooling) are incorporated in the design to promote rapid cooling. Radiation-damage susceptibility is among the lowest of Category 4 because of the short height generally employed. This design concept has the highest frequency of use within Category 4 with its employment in 25 plants.

Figure 4.9 provides a section elevation view of a PWR vessel equipped with Category 4D supports. Features are similar to Category 4E with the employment of short pedestal weldments to transfer vessel loadings to either reinforced concrete corbels or structural-steel brackets cantilevered radially inward from the biological shield. Except for the uncertainty as to whether structural-steel brackets are actually used, 


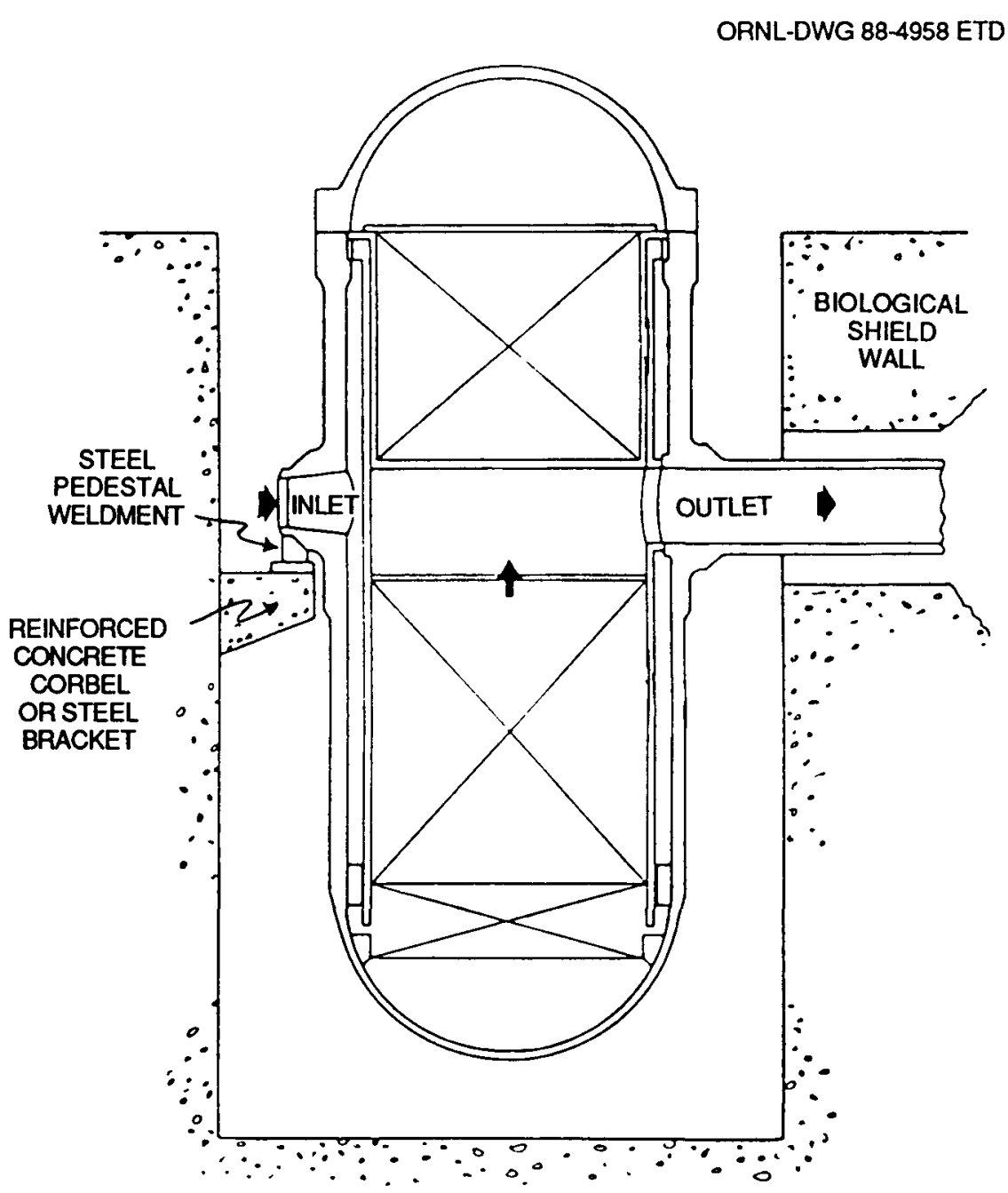

Fig. 4.9. PWR vessel with category 4D support.

the susceptibility to radiation damage and the level of primary and secondary stresses would appear to be similar to Category $4 \mathrm{C}$.

Figure 4.10 provides plan and elevation views of a PWR vessel equipped with a Category $4 \mathrm{E}$ support. Provisions are similar to a Category 4C support except for the incorporation of brackets at the level of the radially keyed shoe to resist horizontal loadings. The susceptibility to radiation damage would appear to be similar to Category $4 \mathrm{C}$.

Figure 4.11 provides perspective and section elevation views of a PWR vessel equipped with a Category $4 \mathrm{~F}$ support. With this support scheme, vertical and horizontal loads are transmitted through nozzle weld pads to radial keys mounted on a structural-steel ring girder that is in turn mounted on short weldment pedestals. In some cases the relative position of the ring girder and short weldment pedestals are inverted. The distinguishing feature of this category, relative to Category 4C, is the employment of a structural-steel ring girder for 
ORNL-DWG 88-4959 ETD
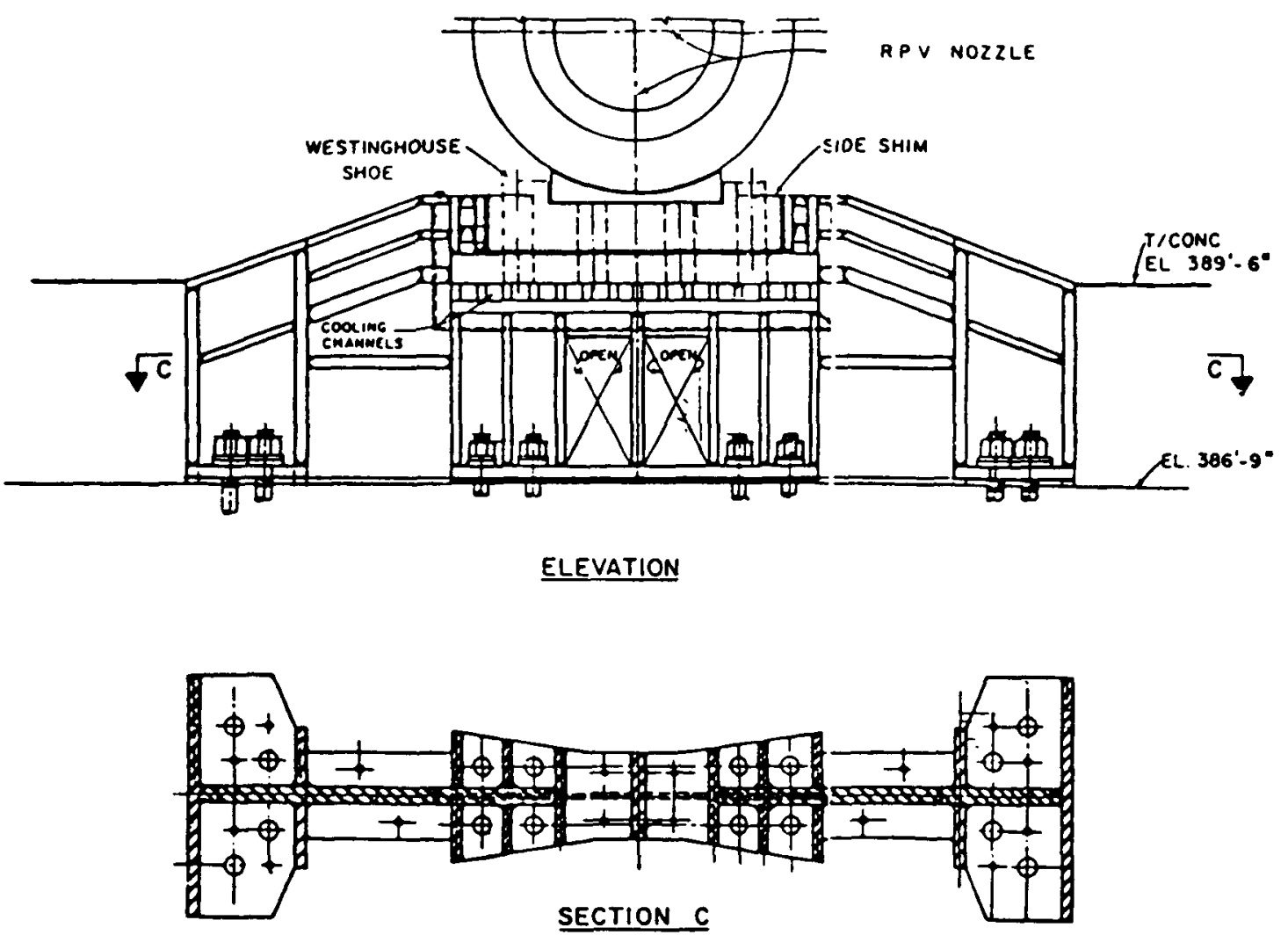

Fig. 4.10. PWR vessel with category 4E support.

transference of horizontal loadings. Otherwise, the conclusions with regard to radiation-damage susceptibility and stress state would appear to be the same.

Figure 4.12 provides a section elevation view of a PWR vessel equipped with a Category 4G support. Features of this support are similar to Category $4 \mathrm{C}$ except that horizontal loading is transferred directly to the reinforced concrete structure of the biological shield. The sides, as well as the bottom of the recess in the biological shield wall, provide for load transference; consequently, no significant primary tensile- or bending-stress fields should be generated within the support structure.

A fundamental objective of the design of all PWR support systems is the incorporation of guides to establish a fixed reactor vessel centerline for all operating, upset, and faulted conditions. In general, the vertical loadings on the supports are applied to components designed to accommodate radial thermal expansion by sliding. Two exceptions to this method of accommodating radial thermal expansion are the provisions of pivoting columns in the Trojan supports and nested rollers in the Turkey Point supports. As noted by Hopkins, ${ }^{1}$ the NSSS and AE designers have assumed that the imposed forces on the supports resulting from differential friction effects are negligible. The FSAR data on supports verify 


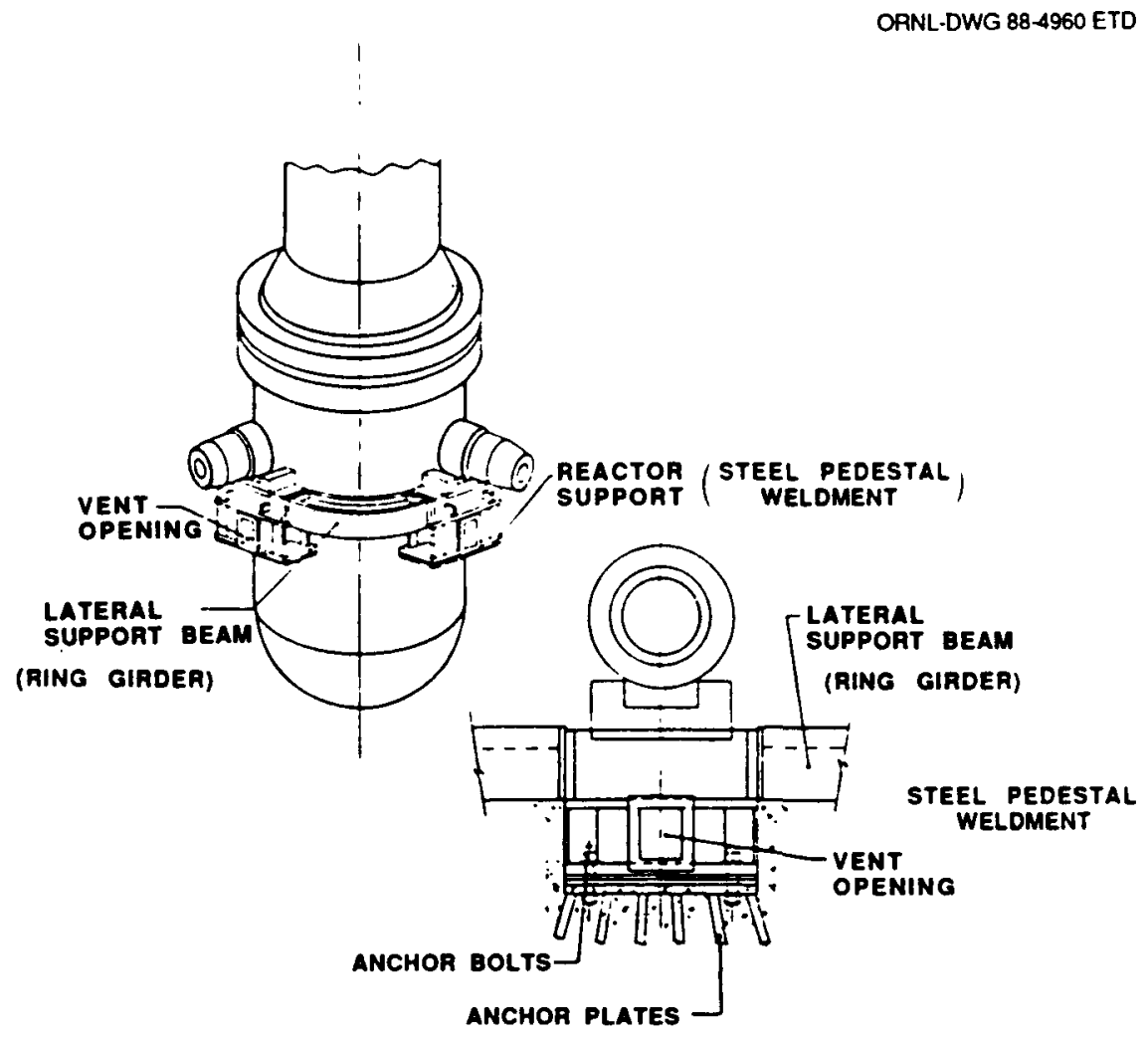

Fig. 4.11. PWR vessel with cateogry 4F support.

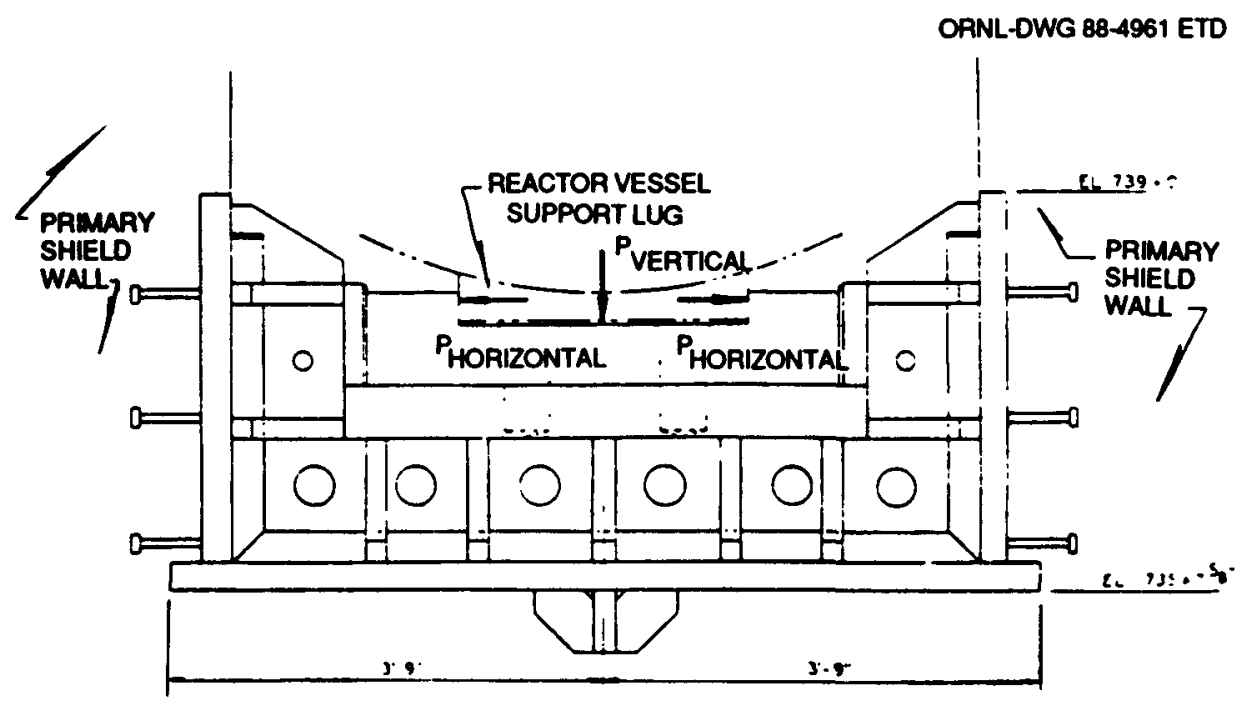

Fig. 4.12. PWR vessel with category 4G support. 
this observation. ORNL is not aware of any attempt to examine loadings that would result from differential friction effects.

\section{References}

1. W. G. Hopkins, Idaho National Engineering Laboratory, Reactor Pressure Vessel Supports for Pressurized Water Reactors and Boiling Water Reactors, Residual Life Assessment of Major Light Water Reactor Components - Overview Volume 1, NUREG/CR-4731 (EGG-2469, Vol. 1), June 1987.*

2. G. A. Knorovski, R. D. Krieg, and G. C. Allen, Jr., Sandia National Laboratories, Fracture Toughness of PWR Component Support, NUREG/CR3009 (SAND78-2347), February 1983.*

*Available for purchase from National Technical Information Service, Springfield, Virginia 22161. 


\section{SELECTION OF LWR PLANTS FOR SPECIFIC-PLANT ANALYSIS}

The criteria established for selection of two plants for specificplant analysis are as follows:

The plants should be among those having a relatively high potential for vesse1-support failure as a result of radiation-enhanced propagation of flaws. Compliance with this condition was judged on the basis of the following considerations:

1. A potentially critical portion of the support should be exposed to the relatively high-neutron-flux regions of the cavity (from midheight to the end of the core).

2. The support material should have a relatively high potential for radiation embrittlement.

3. The portion of the support within the high-flux region should be subjected to relatively high tensile stresses, primary-load tensile stresses being of particular concern. Secondary tensile stresses (thermal and residual) are also of concern.

4. The potentially critical portion of the support should have a relatively high potential for flaws of critical size.

Information in Table 3.5 indicates that the cavity fluxes for the BWRs are much less than those for PWRs; as indicated in Chap. 4, BWR vessels are supported on skirts that are far removed from the bottom end of the core.* Thus, BWRs were excluded from consideration. All but one of the B\&W PWRs are supported on skirts, and they also were excluded from consideration.

About $10 \%$ of the PWR vessels are supported on long columns and another $10 \%$ on shield tanks that extend the length of the core and thus are exposed to the maximum flux. At the outset of this study each of the PWR NSSS vendors and the Electric Power Research Institute (EPRI) were contacted informally and given the opportunity to contribute to the study. Combustion Engineering (CE) and EPRI responded informally with updated analyses of the long columns (CE) and shield tanks (EPRI and Stone and Webster), considering the HFIR surveillance data. The preliminary indication was that critical flaw sizes corresponding to 32 EFPY were "acceptably" large. Thus, these supports also were excluded from consideration in this study. (ORNL has not reviewed the industry evaluations in detail and thus is not in a position to comment on the industry conclusion.)

The remaining PWR vessel supports fall in the short-column category (Chap. 4). As one extreme, this category includes very short, stubby supports (columns) that rest directly on the concrete biological shield at an elevation above the upper end of the core where the flux is relatively low (Fig. 5.1), and the other extreme is columns extending to about midheight of the core and resting on steel cantilever beams. As indicated in Chap. 4, only Trojan and perhaps Davis Besse are of this

*Big Rock Point is an exception but was not considered because of its small size. 


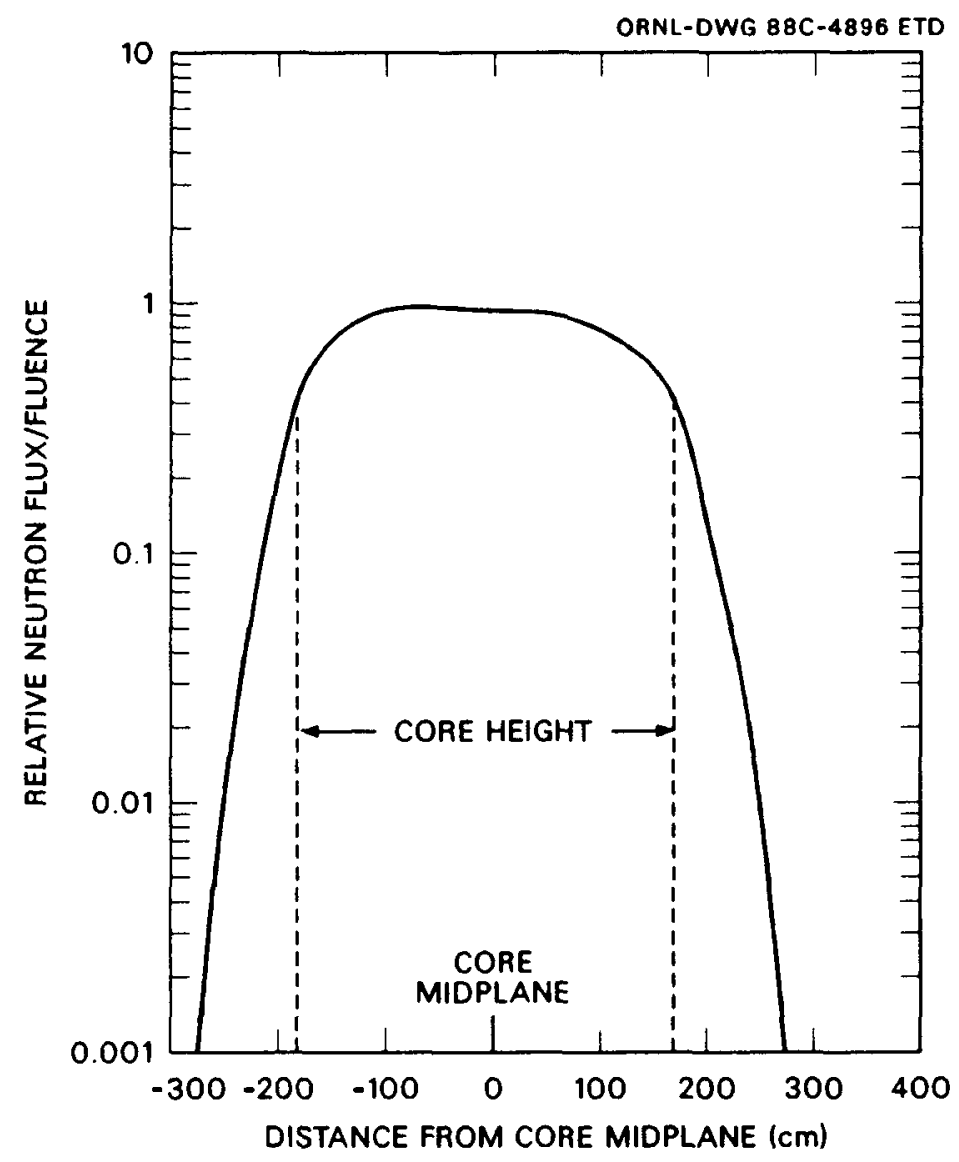

Fig. 5.1. Relative axial variation of fast neutron ( $\mathrm{C}>1.0 \mathrm{MeV}$ ) flux and fluence within pressure vessel wall.

latter type, while Turkey Point Units 3 and 4 (identical supports) are similar to Trojan but with the steel cantilever beam located closer to the top of the core, where the flux is somewhat less. Of all plants in the short-column category, Trojan and Turkey Point appeared to have the greatest potential for fracture-related failure of the vessel supports. Both designs include cantilever beams in high-flux regions of the cavity, and both cantilevers are stressed in tension by primary loads. As mentioned in Chap. 4, Trojan and Turkey Point Unit 3 were selected for the specific-plant analyses in this study. 


\section{BRITTLE FRACTURE EVALUATION OF TROJAN NUCLEAR PLANT REACTOR PRESSURE VESSEL SUPPORTS}

\subsection{Introduction and Summary}

The Trojan vessel-support structure is comprised of upper components that resist horizontal loads, lower components (cantilever beams) that resist vertical loads, and pinned columns that transfer vertical loads from the vessel to the lower components. Only the cantilever beam is considered in this study because this component of the structure is subjected to a relatively high fast-neutron fluence, and the applied loads result in primary tensile stresses. Several potentially limiting locations on the lower support beam are within the portion of the assembly embedded in the concrete biological shield. A beam-on-elasticfoundation-analysis model provided a detailed definition of stresses at these locations.

Stress analyses of the support beam, and postulated flaws within it, were planned in the form of a parametric study. This approach permitted a broad evaluation of the potential impact of premature embrittlement on the support beam structural integrity. Parameters included in the study were locations in the beam ( 3 ), loading conditions (4), beam support configurations (2), flaw aspect ratios (5), flaw depths (6), and plant operating times ( 3 ).

The support beam weldments are fabricated from A36 material. Fracture-toughness properties of this material have been shown to be strainrate sensitive. Materials data were taken from the open literature and converted to a strain rate appropriate to the dynamic response of the reactor vessel on its supports. Equations were fitted to the data, and a lower bound design curve was defined.

Irradiation-induced shifts in nil ductility transition temperature (NDTT) were calculated using correlations developed from the High Flux Isotope Reactor (HFIR) data (Chap. 3). Analysis of the plant operating profile gave radiation-induced NDTT shifts at the critical location within the beam ranging from $30^{\circ} \mathrm{F}$ at the present time to $75^{\circ} \mathrm{F}$ at a plant operating time of 32 effective full-power years (EFPY). Strain rates produced by the vessel system response to accident loading produce a further $60^{\circ} \mathrm{F}$ NDTT shift (relative to strain rates associated with slow bend tests). Design fracture-toughness values at the beam locations selected for analysis ranged from a high of $49 \mathrm{ksi} \cdot \sqrt{\mathrm{in}}$. to a low of

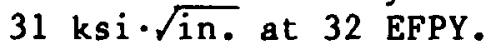

Dynamic fracture-toughness limits were superposed on results from the stress-intensity-factor analyses to generate curves of critical flaw depth as a function of loading applied to the vessel support. Critical flaw depths obtained for the maximum loading condition [sma11-break loss-of-coolant accident (SBLOCA)] are summarized in the following table. 


\begin{tabular}{|c|c|c|c|c|}
\hline \multirow{2}{*}{ Beam location } & \multirow{2}{*}{ Loading } & \multicolumn{2}{|c|}{$\begin{array}{c}\text { Critical flaw depth } \\
\text { (in.) }\end{array}$} & \multirow{2}{*}{$\begin{array}{c}\text { Flaw length at } \\
\text { beam surface } \\
\text { (in.) }\end{array}$} \\
\hline & & $\begin{array}{l}7.48^{a} \\
\text { EFPY }\end{array}$ & $\begin{array}{c}32 \\
\text { EFPY }\end{array}$ & \\
\hline $\begin{array}{l}\text { Interface with the } \\
\text { reactor cavity }\end{array}$ & SBLOCA & 0.89 & 0.68 & $\begin{array}{l}\text { Ful1 flange } \\
\text { width ( } 16 \text { in.) }\end{array}$ \\
\hline $\begin{array}{l}\text { Maximum bending } \\
\text { moment location }\end{array}$ & SBLOCA & 0.88 & 0.61 & $\begin{array}{l}\text { Full flange } \\
\text { width }(16 \text { in.) }\end{array}$ \\
\hline $\begin{array}{l}\text { Flange grout } \\
\text { hole }\end{array}$ & SBLOCA & $>2.0$ & 0.42 & $\begin{array}{l}\text { Full flange } \\
\text { depth }(2.5 \text { in. })\end{array}$ \\
\hline
\end{tabular}

${ }^{a}$ Current condition (late 1988).

The grout hole, which is $4.0 \mathrm{in}$. in diameter and located in the upper flange of the embedded portion of the beam $11 \mathrm{in}$. from the inner surface of the biological shield, results in the smallest critical flaw size for times approaching 32 EFPY.

Factors with the potential for influencing the calculated critical flaw depths in the beam flange are (1) refinement of the stress-intensity-factor correlation to include shear-lag effects, (2) variations in the material NDTT, (3) residual stress effects, and (4) inclusion of support for the beams from concrete inboard of the inner support pedestal. Pilot evaluations of these effects, included in this report, indicate that their combined effect will be to produce critical flaw sizes that are not greater than those given in the summary table.

Fatigue-induced flaw growth makes a negligible contribution to the above critical flaw dimensions. The flaws would thus have to have been present at final inspection of the support structure to constitute a brittle fracture hazard.

The question regarding the existence of flaws of critical size has not been addressed in this study. Note, however, that at the two locations other than the grout hole, the surface length of the critical flaw is the full width of the flange ( 16 in.). It seems that a flaw of this size would be readily detectable at the time of fabrication.

Detection of the critical flaw in the, edge of the grout hole appears less likely because the flaw is smaller $(0.4 \times 2.5 \mathrm{in.})$, and the hole was flame-cut and dressed, a process normally resulting in a rather rough surface.

In-service inspection for flaws in the lower support beam may be impractical, particularly for the portion of the beam embedded in the concrete biological shield. Inspection records, however, may shed light on the likelihood of significant flaws existing [utility records were not available to Oak Ridge National Laboratory (ORNL) at the time of this study].

Principal uncertainties in the flaw tolerance analysis of the support beams are related to (1) the fracture-toughness data for A36 at 
strain rates and temperature appropriate to the support beam loading conditions, (2) the correlation used for applying the HFIR embrittlement data to the evaluation of PWR vessel support, (3) the initial NDTT for the material, (4) the operating temperatures of the support, and (5) the magnitude of residual stresses. There is also a considerable uncertainty regarding the existence of flaws in the beams.

\subsection{Scope and Objective}

The Trojan vessel-support structurel is comprised of upper and lower beam structures joined by pinned columns (Fig. 6.1). This analysis considers only the lower beam because (1) it is loaded to give some of the highest bending-induced tensile stresses in the support and (2) it is the component located closest to the core midplane, where the fast-neutron fluence is nearly a maximum.

At the time of this analysis, no data were available on the geometric characteristics of potential flaws in the support beams. The analysis was therefore performed as a parametric study with a range of flaw depths and aspect ratios considered. The analysis objective was to define the critical flaw size envelope for the high-stress and/or highfluence locations within the support beam. It is intended that this

ORNL-DWG 88-4858 ETD

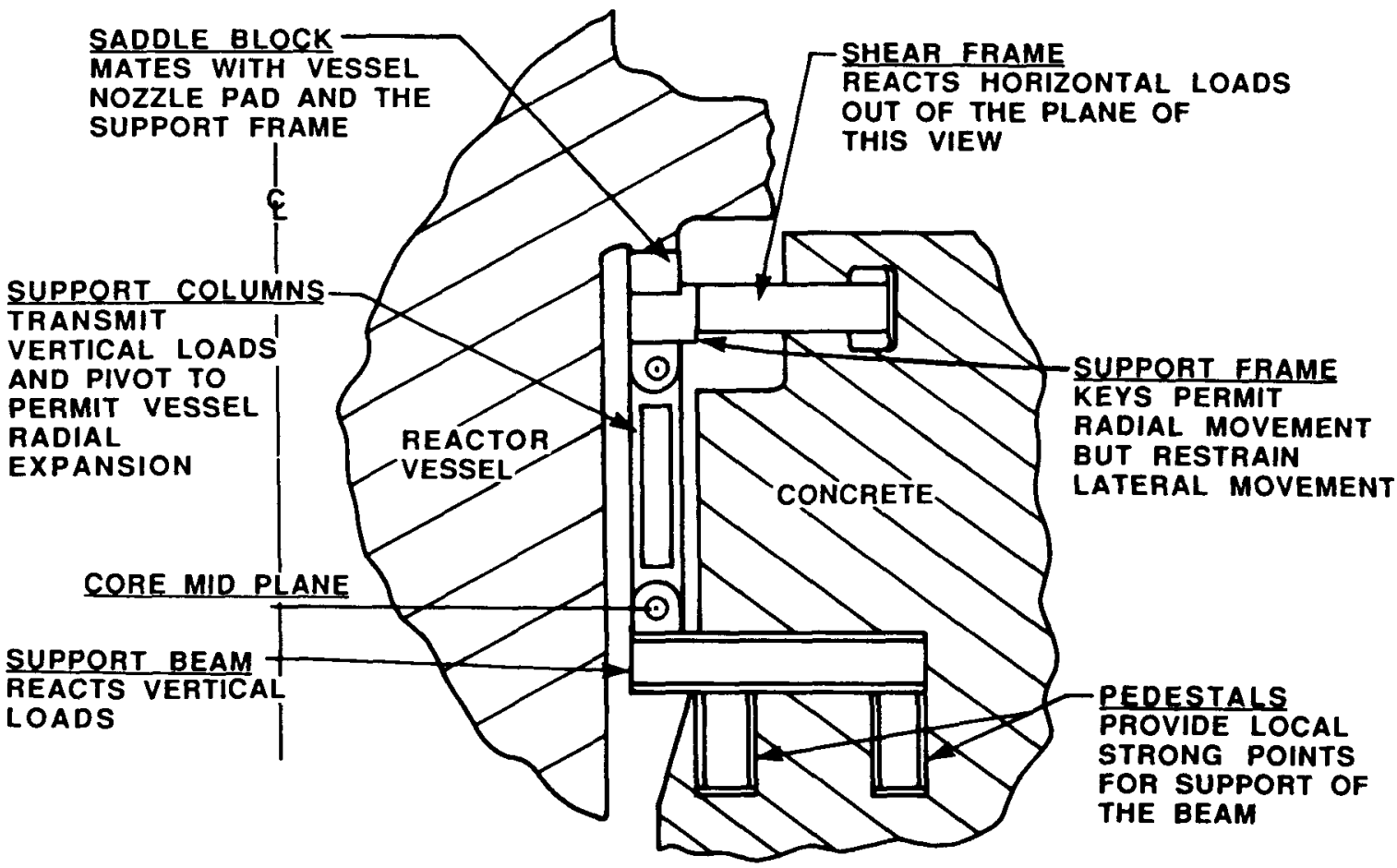

Fig. 6.1. Radial section through Trojan reactor vessel supports showing principal structural and kinematic elements. 
envelope be used as a basis for evaluating the postulated beam flaws, when a definition of the flaw population becomes available.

A critical-flaw-size analysis was performed for three locations on the beam. These locations and the bases for their selection were as follows:

1. Interface with the reactor cavity liner: a transverse fillet weld between the beam flange and the cavity liner exists at this location. A potential exists therefore for weld-induced cracking over the full width of the flange. This location also experiences the maximum radiation-induced displacements per atom (dpa) and dpa rate of all three locations considered.

2. Location of the beam maximum bending moment: the beam is supported on pedestals and is cast in concrete from the cavity liner interface back into the cavity wall. This type of support can be characterized as a beam-on-elastic-foundation support in which the support stiffness varies along the length of the beam. With this type of support, the peak bending moment (and the associated beam flange primary bending stress) is located a short distance back from the start of the elastic foundation support. This location is clearly one of the critical locations on the beam.

3. Four-inch-diameter beam flange grout holes: these holes are located in both the upper and lower beam flanges, directly over the centerline of the inner support pedestal. While not necessarily located at the point of maximum bending moment, they are close to it. This fact, coupled with the loss of $25 \%$ of the flange area and the introduction of a geometric stress concentration $\left(K_{T}=2.43\right)$, makes the flange hole a potentially limiting location. The fact that the flange holes were flame-cut adds to the potential for the introduction of undetected flaws during the fabrication process.

A further parameter considered in the analysis was the effectiveness of that portion of the concrete inboard of the inner support pedestal inner flange. This portion of the concrete foundation would be expected to experience some of the highest elastic foundation compression stresses and could potentially be loaded beyond its crushing strength. In addition, some uncertainty exists relative to the degree of fit achieved between the concrete and the support beam flanges at this critical location. To accommodate these potential effects, all analyses were run both with and without the inner concrete included in the foundation model.

Four loading cases were considered in the analysis. Load sources contributing to the support loads were dead weight (DW), pipe thermal thrusts ( $T$ ), the operating basis earthquake (OBE), the safe shutdown earthquake (SSE), and both small- and large-break loss-of-coolant accidents (SBLOCA and LBLOCA). Specific load combinations considered in the analysis were as follows:

$$
\begin{aligned}
& \text { Normal }+ \text { upset }=\mathrm{DW}+\mathrm{T} \pm \mathrm{OBE} \\
& \text { Faulted }(1)=\mathrm{DW}+\mathrm{T} \pm \mathrm{SSE} \\
& \text { Faulted }(2)=\mathrm{DW}+\mathrm{T} \pm \mathrm{SBLOCA} \\
& \text { Faulted }(3)=\mathrm{DW}+\mathrm{T} \pm \text { LBLOCA }
\end{aligned}
$$


Subsequent to the initiation of the analysis, Oak Ridge National Laboratory (ORNL) was informed that Nuclear Regulatory Commission (NRC) had approved the Trojan leak-before-break analysis, thereby eliminating the double-ended pipe-break (LBLOCA) from the plant faulted condition transient loading list. Analysis was completed for the LBLOCA condition, however, because the addition of this fourth loading-condition result improves the definition of load-dependent variables and thus improves the accuracy of interpolation between the load cases considered. In this connection, note that the critical flaw size is a nonlinear function of the applied stress.

The SBLOCA loading condition provided by the utility constitutes a generic, bounding case that involves failure of auxiliary coolant lines and thus represents a more severe loading condition than often referred to as SBLOCA.

Three specific times in the life of the plant were considered in the analysis: (1) start of life, (2) current condition (late 1988, $7.48 \mathrm{EFPY}$ ), and (3) $32 \mathrm{EFPY}$, which is the approximate present 1 icense period. Interest in the start-of-life condition stems from the strainrate sensitivity of the fracture-toughness data for A36. follows:

In summary, the scope of the support beam parametric study was as

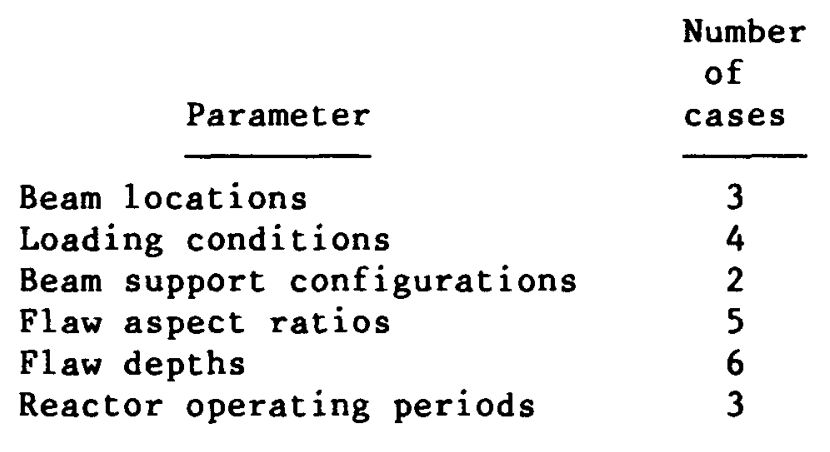

\subsection{Loading and Operating Environment}

Al1 loading cases have been taken from (1) the minutes of the June 29-30, 1988, Pittsburgh meeting ${ }^{2}$ of Portland General Electric (PGE), Westinghouse, NRC, and ORNL and (2) the PGE letter of August 2, 1988.3

\section{3 .1 Normal plus upset loading}

$$
\begin{aligned}
& \text { Maximum load/support for } \mathrm{T}+\mathrm{DW}+\mathrm{OBE} \\
& \mathrm{P}_{1}=288+530+281=1099 \mathrm{kips} .
\end{aligned}
$$

\subsubsection{Faulted conditions}

1. SSE

$$
\begin{gathered}
\text { Maximum load/support for } T+D W+S S E=P_{1} \\
P_{1}=288+530+394=1212 \text { kips. }
\end{gathered}
$$


2. SBLOCA

$$
\begin{gathered}
\text { Maximum load/support for } \mathrm{T}+\mathrm{DW}+\mathrm{SBLOCA}=\mathrm{P}_{2} \\
\mathrm{P}_{2}=288+530+740=1558 \mathrm{kips} .
\end{gathered}
$$

3. LBLOCA

$$
\begin{gathered}
\text { Maximum } 1 \mathrm{oad} / \text { support for } \mathrm{T}+\mathrm{DW}+\mathrm{LBLOCA}=\mathrm{P}_{3} \\
\mathrm{P}_{3}=288+530+1625=2443 \mathrm{kips} .
\end{gathered}
$$

\begin{tabular}{|c|c|c|c|}
\hline Event & $\begin{array}{c}P_{\max } \\
(k i p s)\end{array}$ & $\begin{array}{c}P_{\min } \\
(\text { kips })\end{array}$ & $\begin{array}{c}\text { Number } \\
\text { of } \\
\text { cycles }\end{array}$ \\
\hline Refueling & 818 & 395 & 40 \\
\hline OBE & 1099 & 537 & 400 \\
\hline SSE & 1212 & 424 & 20 \\
\hline SBLOCA & 1558 & 78 & 5 \\
\hline
\end{tabular}

6.3.3 Cyclic loading

\subsubsection{Operating environment}

Beam temperature $\simeq 90^{\circ} \mathrm{F}$.

\subsubsection{Load combinations}

Deterministic load combinations are used in Chap. 6 to define the load-time-history required as input to the strain-rate element of the material fracture-toughness evaluation. Probabilistic combinations of the SSE and SBLOCA loads will produce a peak load $6.3 \%$ higher than that given in Sect. 6.3.2. Plots of critical flaw depth as a function of support load are included to permit an approximate evaluation of the impact of this load increment. However, these plots do not reflect the potential increase in straining rate possible with the combined SSE/ SBLOCA loading and the associated influence of straining rate on the support material fracture toughness.

\subsection{Support Beam Analysis}

\subsubsection{Analytical model}

An overview of the support beam geometry is given in Fig. 6.1, with additional details of the structural members given in Figs. 6.2 and 6.3 .

Vertical loading is applied to lugs on the inboard end of the beam via pins and vertical links. Lateral shear loading is reacted by a 

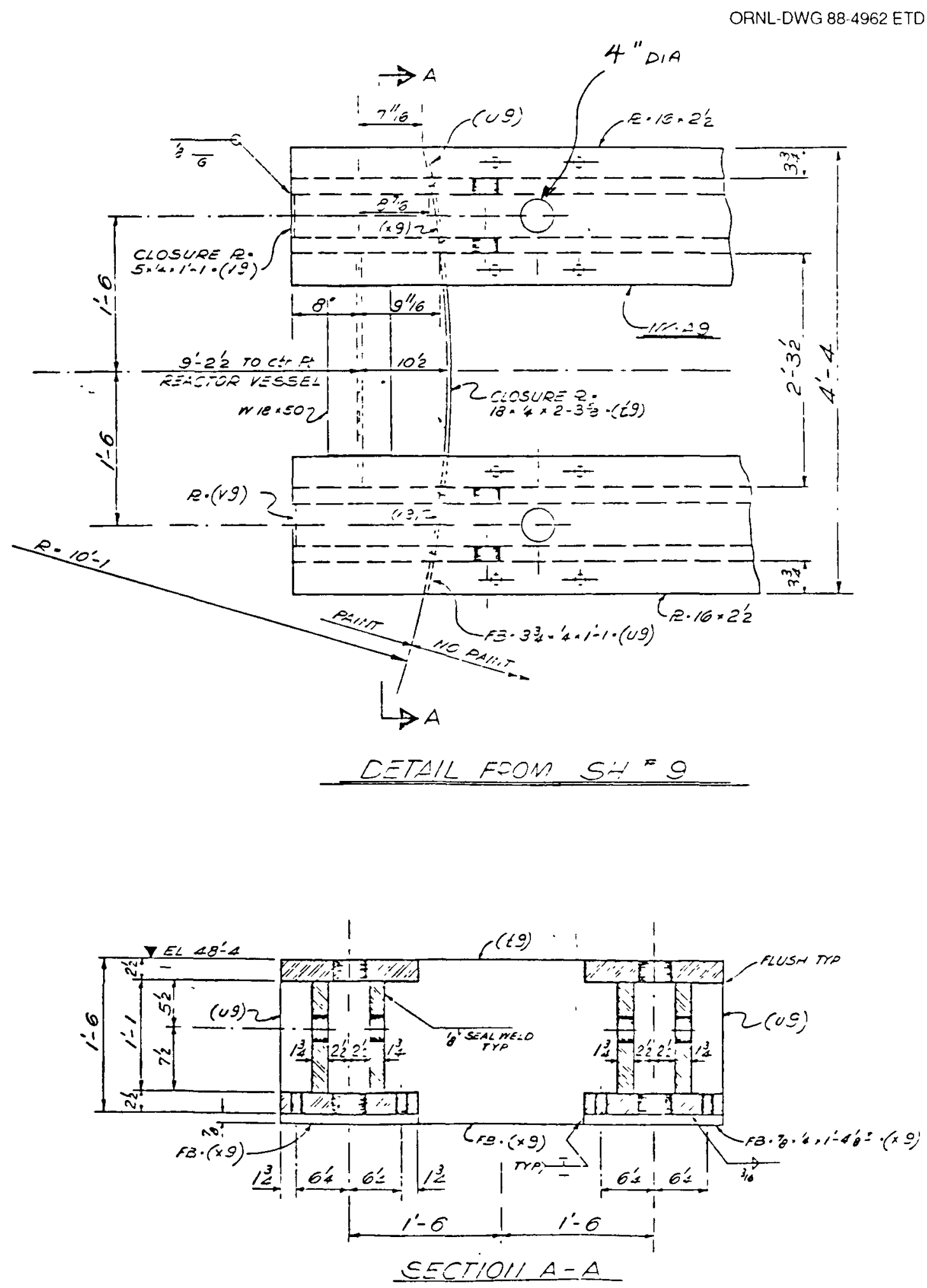
beams .

Fig. 6.2. Geometry and dimensions of Trojan reactor vessel support 


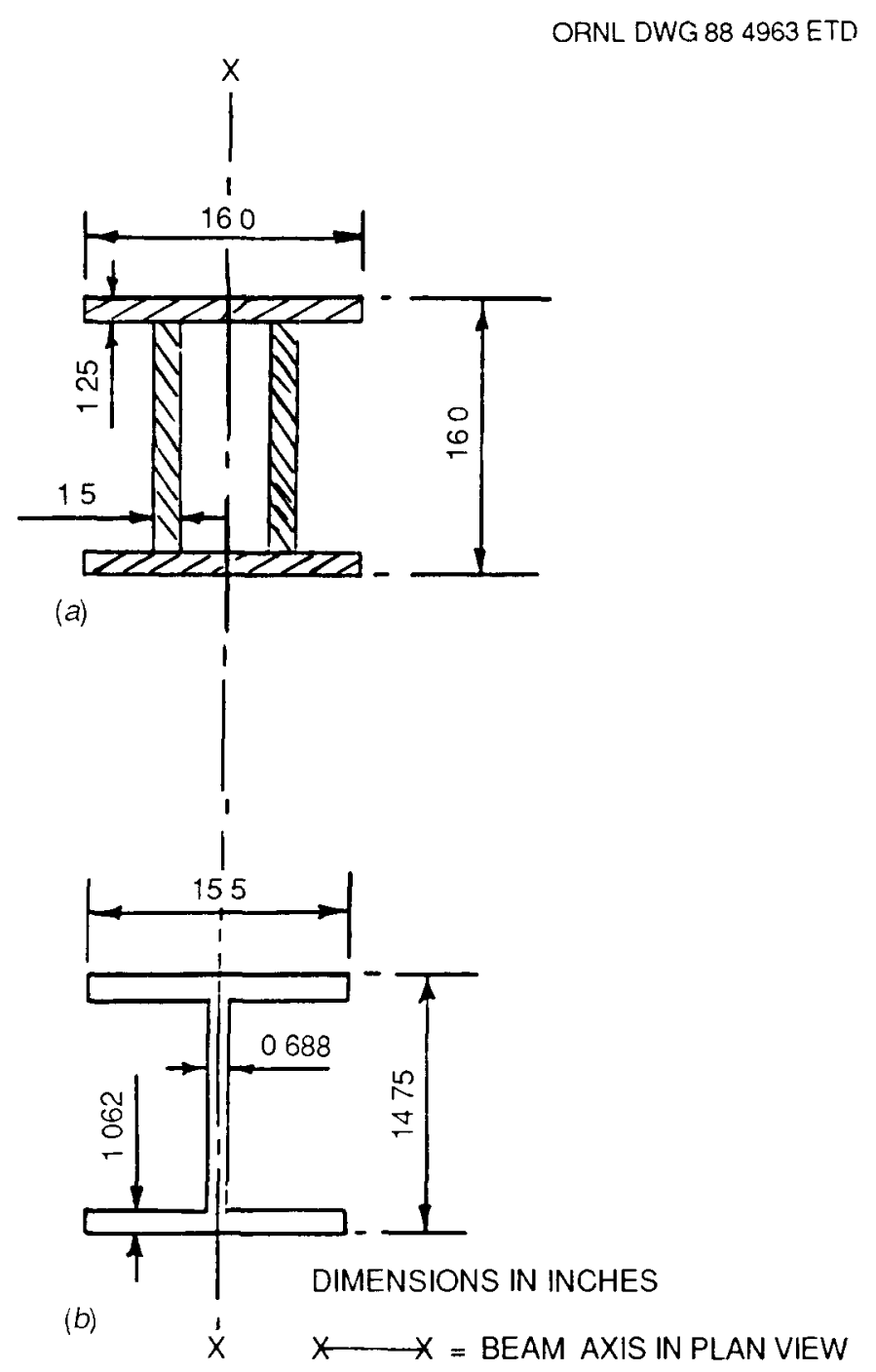

Fig. 6.3. Cross-section geometry and dimensions for Trojan reactor vessel support beam pedestals. (a) Inner pedestal, (b) outer pedestal.

separate structure located just below the elevation of the vessel nozzles. Loads applied to the support beam thus remain vertical for all loading cases.

Reaction to the applied loads is provided by (1) support pedestals built into the cavity wall and (2) interaction directly with the cavity wall concrete. It was considered important to model these interactions as accurately as possible because the modeling assumptions could have a significant influence on the magnitude and distribution of bending moments in that portion of the beam located within the cavity wall. Note that the 4-in.-diam holes in the beam flanges are located in that portion of the beam within the cavity wall.

A beam on the elastic-foundation model was selected on the basis of its ability to provide a detailed definition of the bending moment distribution within the cavity wall. Rather than use the conventional 
approach to beam-on-elastic-foundation analysis, it was decided to model the support as a series of closely spaced struts with prototypic axial stiffness and very low bending stiffness. This approach permitted a detailed representation of the distribution of support stiffness as the beam passed over the various elements of the support pedestals.

The analytical model for both the support beam and the foundation elements is shown in Fig. 6.4, together with a sketch of the beam and its support pedestals. Node points and numbers are indicated on both the model and the sketch to aid in interpretation of the analysis results. The model beam numbering system is illustrated in Fig. 6.5(a) together with details of the model in Fig. $6.5(b)$, showing beam and node numbers near the location of the flange holes. Note that the flexural rigidity of the vertical foundation members is set at a very low value, thereby ensuring that they take only axial loading.

ORNL-DWG 8BC-4964 ETD

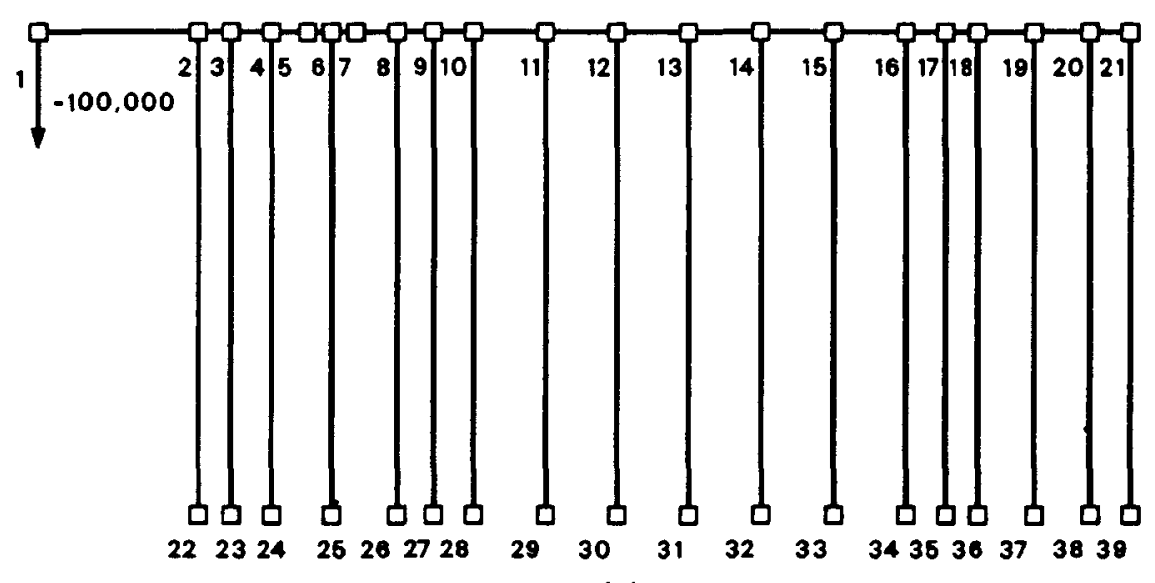

(a)

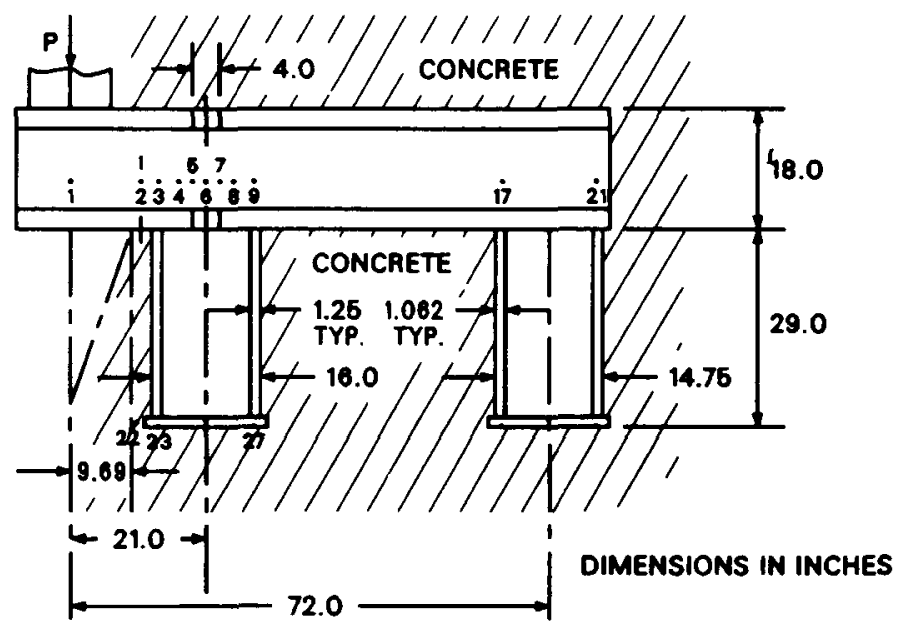

(b)

Fig. 6.4. Trojan reactor vessel support beam beam-on-elastic foundation analytical model, showing locations of nodes on model and in structure. (a) Analytical model node numbers, (b) node locations on support beam and its foundation. 

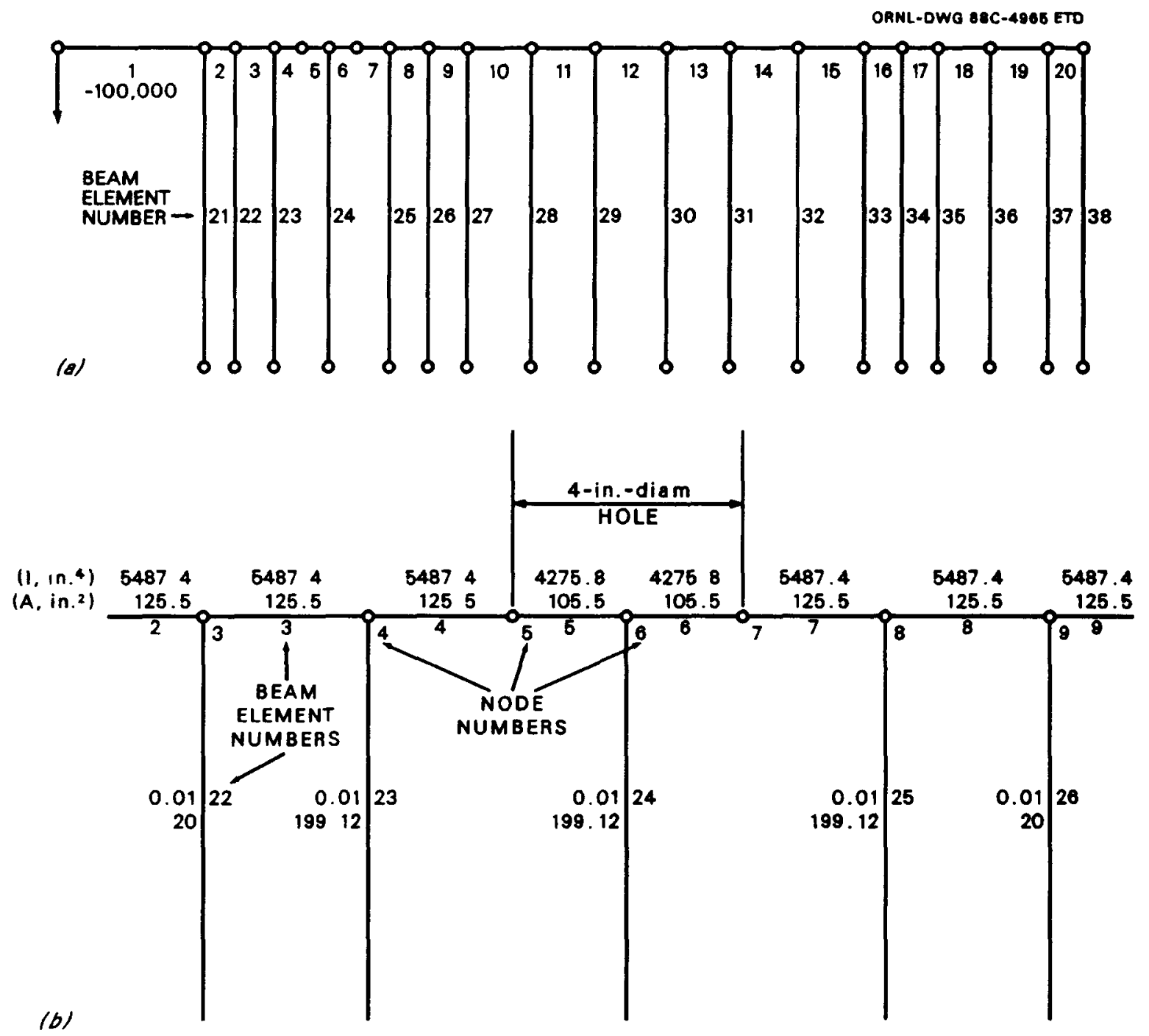

Fig. 6.5. Details of the Trojan reactor vessel-support-beam analytical model at the beam-flange grout-hole location. (a) Model beam numbers (pin joints on vertical foundation beams), (b) model details at the flange hole.

\subsubsection{Model element properties}

6.4.2.1 Beam (solid section). See Fig. 6.2 for the section geometry.

$$
\begin{aligned}
A_{1} & =16 \times 2.5 \times 2+13 \times 1.75 \times 2 \\
& =125.5 \text { in. } 2
\end{aligned}
$$




$$
\begin{aligned}
I_{1} & =\frac{\left(16 \times 18^{3}-12.5 \times 13^{3}\right.}{12} \\
& =5487.4 \mathrm{in.}^{4}
\end{aligned}
$$

\subsubsection{Beam (section with 4-in.-diam holes)}

$$
\begin{aligned}
A_{2} & =125.5-2 \times 4 \times 2.5=105.5 \mathrm{in} .2 \\
I_{2} & =5487.4-2 \times 4 \times 2.5 \times 7.75^{2}-2 \times 4 \times 2.5^{3} / 12 \\
& =4275.8 \mathrm{in} .4
\end{aligned}
$$

6.4.2.3 Concrete foundation. Assume that compressive loads from the beam flange diffuse into the concrete such that the effective boundary of the concrete column projects $\pm 30^{\circ}$ from verticals drawn from the edges of the beam flange. The foundation depth is taken as the dimension from the underside of the beam to the lower surface of the support column base plate.

$$
\begin{aligned}
& \text { Column width at top }=\text { flange width }=16.0 \mathrm{in} . \\
& \begin{aligned}
\text { Column width at bottom } & =16+2 \times 29 \times \tan 30^{\circ} \\
& =49.5 \mathrm{in} .
\end{aligned}
\end{aligned}
$$

The average concrete support column area for a unit length of support beam is thus obtained as

$$
\begin{aligned}
A_{c}= & (16.0+49.5) / 2=32.75 \mathrm{in} .2 / \mathrm{in} . \\
E_{c}= & 6 \times 10^{6} 1 \mathrm{~b} / \mathrm{in} .{ }^{2} \text { based upon aging in excess of } 5 \text { years } \\
& (\operatorname{Ref} .4 \text { and Appendix } 5) .
\end{aligned}
$$

Note that all foundation areas are calculated in terms of square inch per inch of beam length. Each vertical support member represents the support provided by a segment of the foundation extending equal distances on either side of the beam/foundation member interaction node point. The unit length support areas are multiplied by the appropriate foundation lengths to obtain the area for a given foundation support element.

The concrete foundation elements can react loads only in the compression mode. Concrete foundation material exists, however, both above and below the support beams, thereby giving the concrete elements the capability of providing reaction loads in both directions. In the model, this condition is simulated by giving these foundation elements both tension and compression capability.

6.4.2.4 Flange of the front support pedestal. See Fig. 6.3(a) for geometry. 


$$
\begin{aligned}
& A=16.0 \mathrm{in.} 2 / \mathrm{in} . \\
& E=29.0 \times 10^{6} \mathrm{lb} / \mathrm{in.}^{2}
\end{aligned}
$$

6.4.2.5 Front support pedestal web. The web steel and the surrounding concrete both provide support to the beam in this segment of the foundation. The foundation area per unit length will thus be expressed in terms of an equivalent concrete area with a stiffness equal to that of the steel-concrete combination.

$$
\begin{aligned}
& A_{\text {steel }}=A_{S}=2 \times 1.5=3.0 \mathrm{in.} 2 / \mathrm{in} . \\
& A_{\text {concrete }}=A_{C}=32.75-3.0=29.75 \mathrm{in} .2 / \mathrm{in} . \\
& A_{\text {equivalent }}=A_{E}=A_{c}+A_{s} . E s / E c \\
& . . A C=29.75+3.0 \times 29 / 6=44.25 \mathrm{in} .2 / \mathrm{in} .
\end{aligned}
$$

6.4.2.6 Flange section of the rear support. Section dimensions shown in Fig. $6.3(b)$ for the rear support were taken from Ref. 5.

$$
A=15.5 \text { in. } 2 / \text { in. }
$$

6.4.2.7 Web section of the rear support. This is another area where both the web steel and the surrounding concrete provide foundation support. The equivalent concrete formulation of Sect. 6.4.2.5 is used.

$$
A=(32.75-0.688)+0.688 \times 29 / 6=35.39 \text { in. } 2 / \text { in. }
$$

6.4.2.8 Foundation modeling sensitivity assessment. It is evident from the previous sections that a number of assumptions are built into the modeling of the beam-elastic-foundation support. A sensitivity analysis was performed to determine the degree to which these assumptions influence the distribution and magnitude of the calculated bending moments in the support beams. Parameters included in this sensitivity study were (1) representation of the concrete reinforcing steel, (2) the concrete elastic modulus, and (3) representation of the concrete inboard of the inner support pedestal.

Results from this study showed that inclusion of the inner concrete in the foundation model could decrease the peak bending moment in the support beams by up to $13 \%$. This segment of the foundation was therefore included as a variable in the parametric analysis of the support beams. The other foundation modeling variables, however, were found to influence the support beam bending moments by $<1 \%$. These variables were not, therefore, included in the support beam parametric analysis. 
Further details of the beam-elastic-foundation modeling sensitivity analysis can be found in Appendix 5.

\subsubsection{Beam analysis input}

The unit length foundation areas were first converted to foundation member areas by multiplying the unit length areas by the foundation length represented by the foundation support members. This operation is summarized in Table $A$ of Appendix 1. Elastic moduli associated with each of the foundation elements are also 1 isted in Table $A$.

$A$ unit load (200-kip) beam bending analysis was run using the Microsafe -2D finite-element program.6 The input data file for this analysis is given in Table B of Appendix 1. Note that each support incorporates two beams (see Fig. 6.2). The unit load of 200 kips thus corresponds to a load of $100 \mathrm{kips}$ on each beam.

Analyses were run for two foundation support configurations. In the first configuration, the effective area of foundation element No. 21 [extending between nodes 2 and 22 in Fig. $6.4(a)$ ] was input at a value of 108.4 in.2 (see Table A of Appendix 1). This condition represents the concrete inboard of the inner support pedestal remaining fully effective throughout all loading events. In the second configuration the area of foundation element No. 21 was reduced to near zero. This represents the other 1 imiting boundary condition in which the inner concrete segment is assumed to have failed locally in compression and so becomes ineffective as a foundation element. The version of the input file given in Table $B$ of Appendix 1 represents the condition where element 21 is not providing support.

\subsubsection{Beam analysis output}

Output files from the two beam/support configurations analyzed are provided in Tables $C$ and $D$ of Appendix 1. Note that only load and moment data from these tables are used in the subsequent analysis of postulated flaws in the beams. The beam stresses calculated by the program are not used because the beam element in the program has a solid rectangular section, which is not representative, of the Trojan support
beams.

6.4.4.1 Effectiveness of the inner concrete support. Table $E$ of Appendix 1 gives the foundation loading for the unit load case (loads are given for a single beam). The load per inch in the region inboard of the inner support pedestal is $13,317 \mathrm{lb} / \mathrm{in}$. The width of the lower beam flange is $16.0 \mathrm{in}$. The bearing stress produced by the 200-kip unit load case is thus obtained as

$$
\sigma_{e}=13,317 / 16=8321 \mathrm{~b} / \mathrm{in} .^{2} \text {. }
$$

Bearing (compressive) stresses in the upper portions of the inner concrete can be obtained by factoring the unit load bearing stress by $F$, where $F=1$ load case maximum load/unit load. The ultimate compressive stress for the fully aged concrete is taken as $6.0 \mathrm{kips} / \mathrm{in} .2$ (Ref. 4). 
The inner concrete reserve factor is defined as

$$
\mathrm{RF}=\frac{\text { allowable stress }}{\text { applied stress }}
$$

The inner concrete is taken to be effective in providing support for the beam for all cases in which $R F \geq 1.0$. Using the load case maximum loads from Sect. 6.3 in conjunction with the unit load concrete compressive stress results, the effectiveness of the inner concrete in the four loading cases considered is assessed as follows:

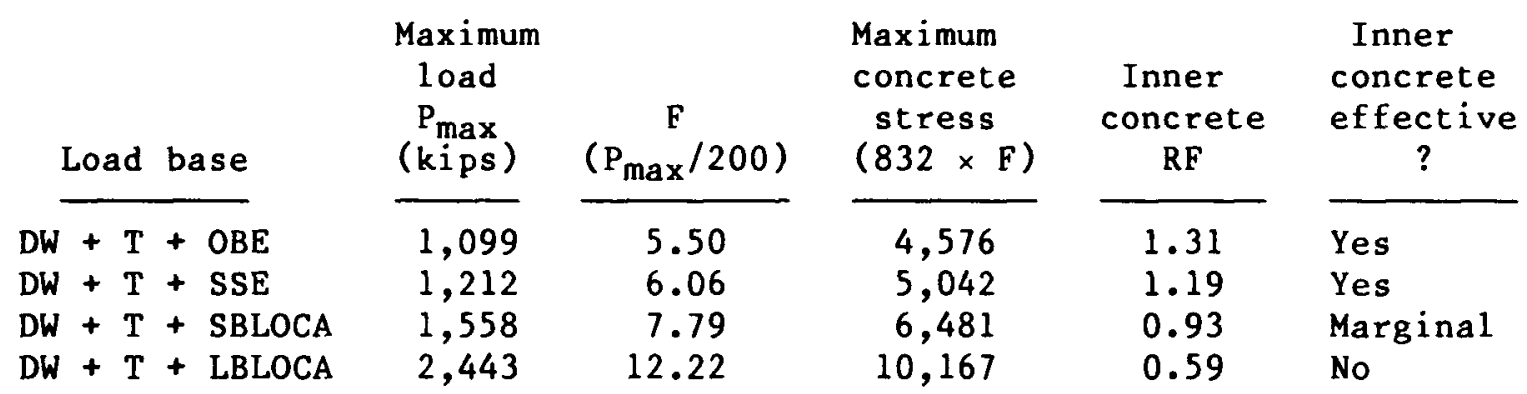

Based upon these results, the inner concrete could be considered effective in supporting the beam for the seismic events but not for the LBLOCA event. The SBLOCA event represents a transition condition in which the inner concrete will provide something less than full support. All subsequent analyses, however, considered both inner concrete support conditions because this provides a basis for assessing issues relating to clearances between the concrete and the beam.

The unit load foundation reaction distribution is shown in Fig. 6.6. Reaction loads peak over the inner flange of the inner support pedestal. Compressive loads in that portion of the concrete located outboard of the inner support pedestal are substantially lower than those for the inboard concrete. Some slightly higher foundation reaction loads occur within the web area of the inner support pedestal for the case of no inner concrete support, but these occur in a region of the foundation reinforced by the pedestal webs and are not considered limiting.

6.4.4.2 Beam bending moments. Beam bending moment diagrams for the 200-kip unit loading condition are plotted in Fig. 6.7 for both inner concrete support conditions. Note that the presence of the inner concrete support has the effect of reducing the peak (Node 4) bending moment by $12.7 \%$.

The bending moment diagrams of Fig. 6.7 are of interest because they provide a measure of the impact of simplifying assumptions that are sometimes incorporated into the analyses of partially embedded beams. The assumption that the maximum bending moment in an embedded cantilever occurs at the interface with the concrete would have produced an error in the estimate of the maximum bending moment of $-27 \%$. Conversely, the assumption of zero distributed support from the concrete (e.g., the beam being simply supported at the centers of its support pedestals) would 
ORNL DWG 884966 ETD

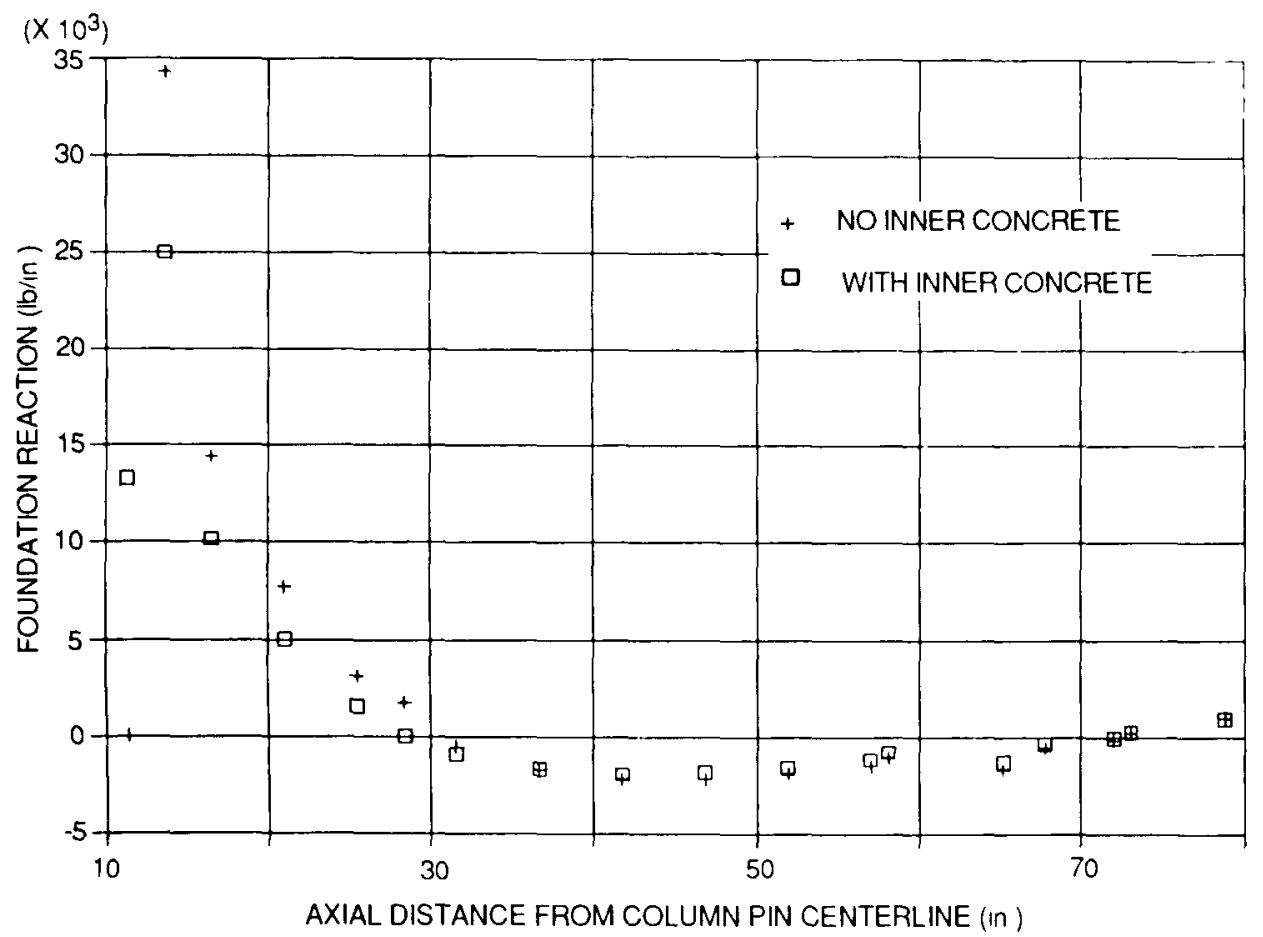

Fig. 6.6. Elastic-foundation reaction loads produced by 200-kip "unit load" applied to lugs of Trojan reactor vessel support beams.

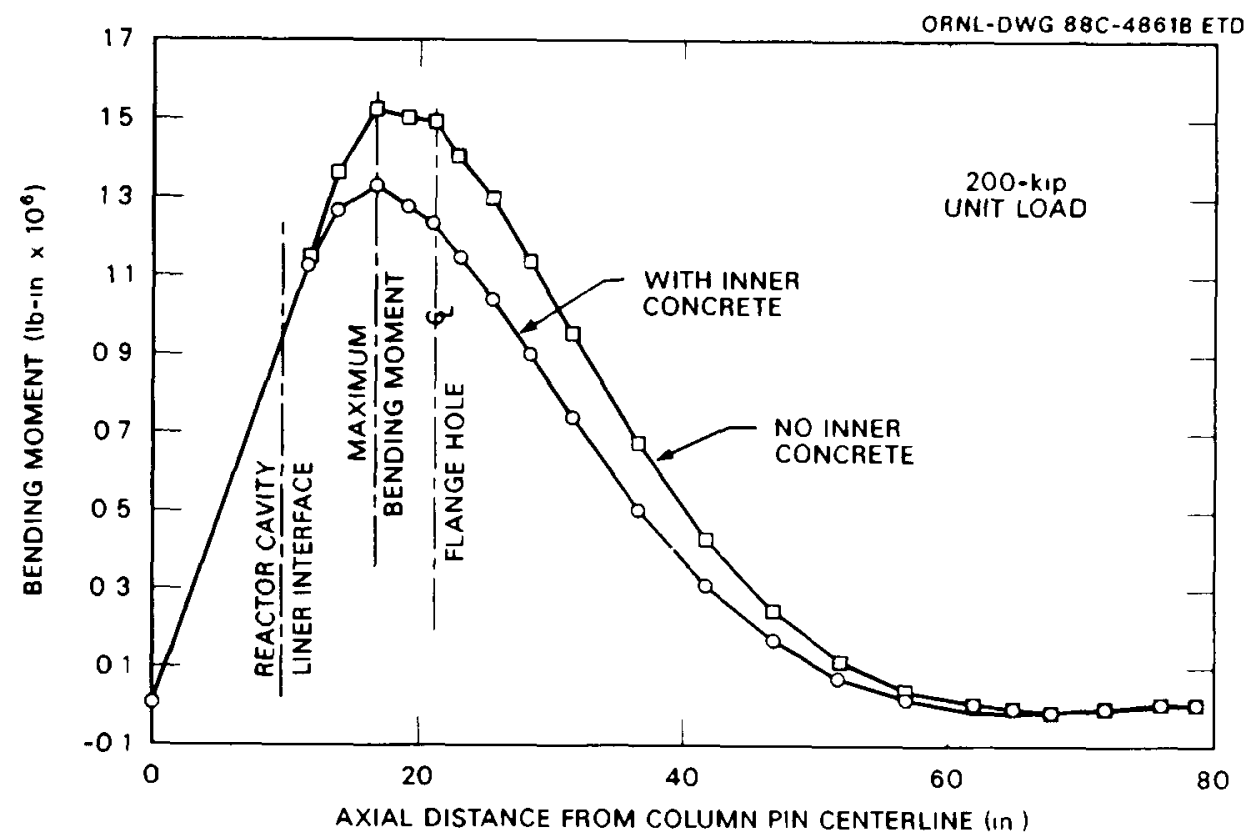

Fig. 6.7. Bending-moment distributions in Trojan reactor vessel support beams produced by 200-kip "unit load" applied at support beam lugs. 
have produced an overestimate of the peak bending moment of $57.5 \%$. It would be fairly standard civil engineering practice, however, to select the inner face of the front support column as the location of maximum moment, in which case the error in maximum bending moment would be $\sim 11 \%$ (low). These results suggest that modeling of the distributed foundation support may in general be necessary for the evaluation of any postulated flaws located within the embedded length of the support beam.

Bending moments are required from the unit load case for input into the flaw tolerance analysis. Figure 6.7 shows the location on the bending moment diagrams of the three locations selected for flaw tolerance analyses. Bending moments at these locations are as follows:

Location on beam

Cavity liner interface

Node 4: maximum bending moment

Node 4: maximum bending moment

Flange hole centerline

Flange hole centerline
Inner concrete
effective

?

NA

Yes

No

Yes

No
Unit load (200-kip)
bending moment

( $1 \mathrm{~b}$ in.)

$0.969 \times 10^{6}$

$1.333 \times 10^{6}$

$1.527 \times 10^{6}$

$1.238 \times 10^{6}$

$1.493 \times 10^{6}$

6.4.4.3 Support stiffness. OBE, SSE, and both SBLOCA and LBLOCA loads are all the product of dynamic analyses in which the vessel-suport stiffness is a critical element. It is appropriate therefore to check the support stiffness given by the beam-on-elastic-foundation model with that used in the dynamic load analysis to verify compatibility of the models. The support stiffness used in the vessel dynamic response analysis was obtained from Ref. 2 as $1.94 \times 10^{4} \mathrm{kip} / \mathrm{in}$.

Deflections of the beam under the 200-kip unit load are plotted in Fig. 6.8. The tip deflection for the case in which the inner concrete is effective is $0.00437 \mathrm{in}$. This translates to a stiffness $\mathrm{K}$ of

$$
\mathrm{K}=200 / 0.00437=4.58 \times 10^{4} \mathrm{kip} / \mathrm{in} .
$$

The stiffness value in Ref. 2 includes elements of the support structure ( 1 inks, pins, shoes, etc.) that would introduce additional flexibility but are not included in this calculation. The calculated beam model stiffness is therefore considered to be compatible with that used in the original generation of the support dynamic loads. 
ORNL-DWG 88-4967 ETD

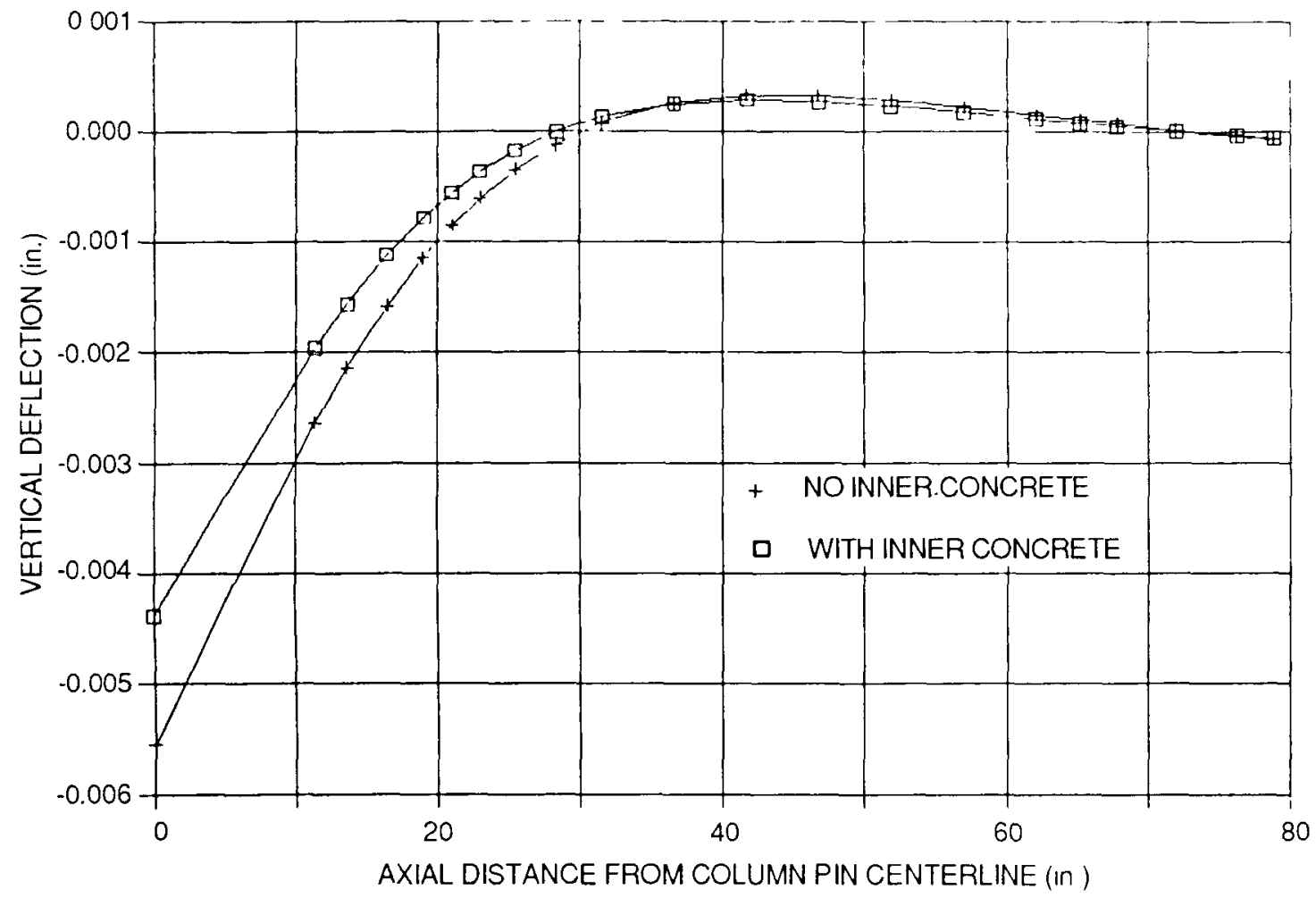

Fig. 6.8. Deflection distributions for Trojan reactor vesse1 support beams produced by 200-kip "unit load" applied at support beam lugs.

\subsection{Material Fracture Toughness}

Fracture-toughness data for A36 in the unirradiated condition were taken from Ref. 7. These data are reproduced in Fig. 6.9.

A number of operations must be performed on the data of Fig. 6.9 to prepare a dynamic fracture-toughness curve suitable for a fracture mechanics evaluation of the vessel-support beam. As a prelude to performing these operations, the data of Fig. 6.9 were first converted into digital form and entered into a Lotus 123 spreadsheet. Figure 6.10 is a plot of the data entered into the spreadsheet. A visual comparison of Figs. 6.9 and 6.10 was used to verify the accuracy of the data transfer. Note that the two data points from Fig. 6.9, for which precise strain rates were not available, were not used in the analysis.

\subsubsection{Strain-rate correction}

The data of Fig. 6.9 show A36 to be a strain-rate sensitive material. The test temperature required to achieve a fracture toughness of $40 \mathrm{ksi} \cdot \sqrt{\mathrm{in}}$. increases by $\sim 150^{\circ} \mathrm{F}$ as the test straining rate increases 


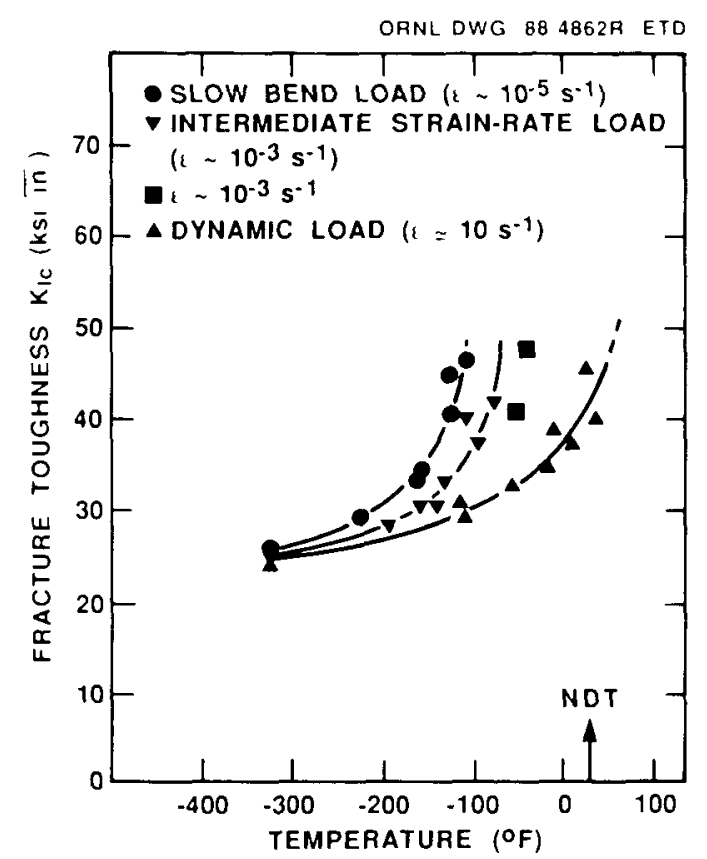

Fig. 6.9. Fracture-toughness data for A36 steel showing temperature dependence and strain-rate sensitivity.

ORNL DWG 884968 ETD

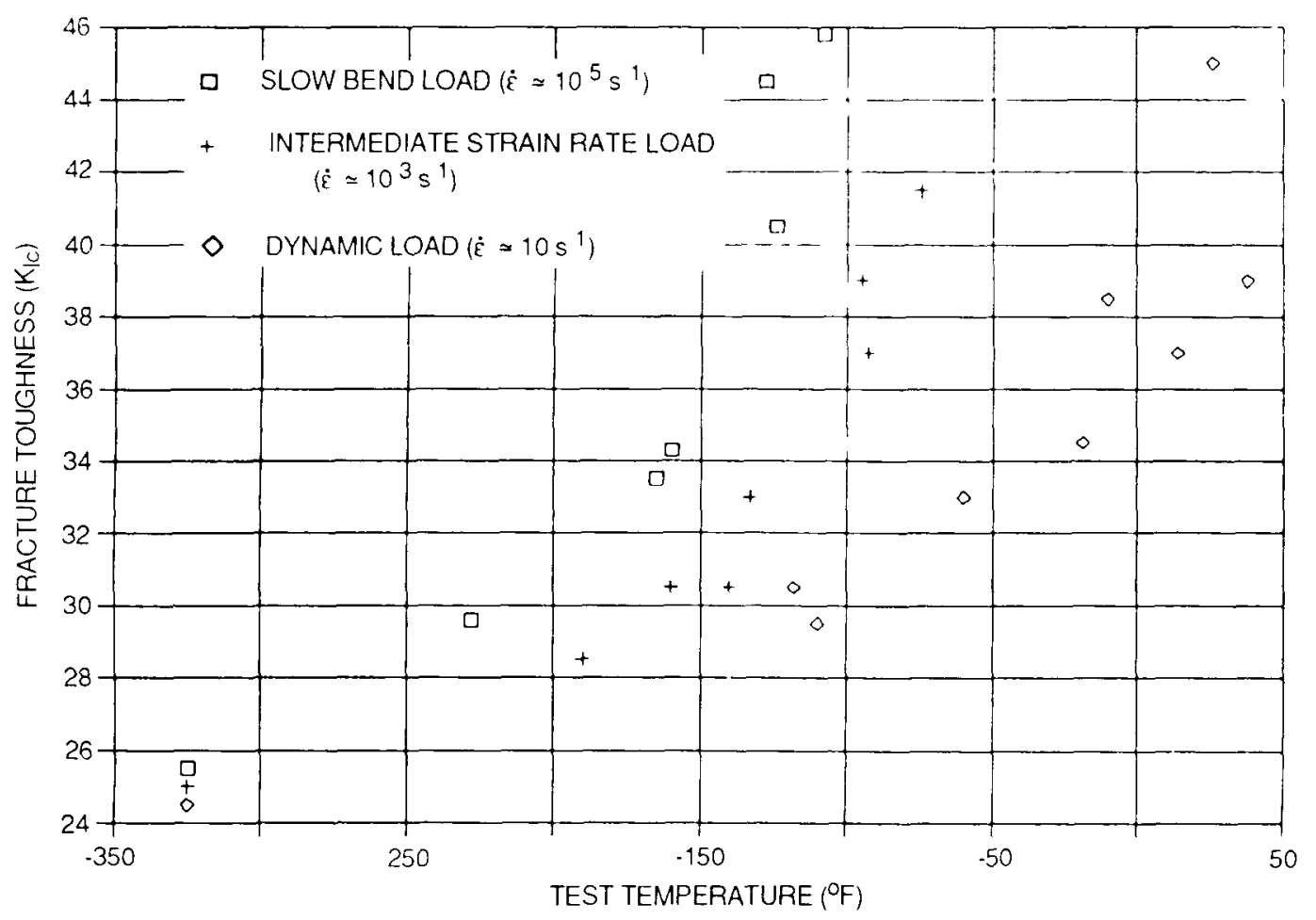

Fig. 6.10. Fracture-toughness data for A36 before transposition to prototypic reactor vessel support beam straining rate. 


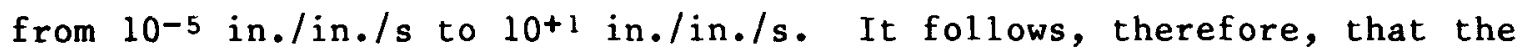
fracture-toughness data used to evaluate the support beam flaw tolerance must be adjusted to be compatible with the vessel-support straining rate. The temperature shift relationship required to accomplish this adjustment is as follows.8

$$
\Delta T=\left(150-\sigma_{y s}\right) \dot{\varepsilon}^{0.17},
$$

where

$$
\begin{aligned}
\Delta T & =\text { temperature shift relative to static data }\left({ }^{\circ} \mathrm{F}\right), \\
\sigma_{y s} & =\text { room temperature yield strength }(\mathrm{ksi}), \\
\dot{\varepsilon} & =\text { strain rate }(\mathrm{in} . / \mathrm{in} . / \mathrm{s}) .
\end{aligned}
$$

The strain rate is calculated for a point on the elastic-plastic boundary for the crack tip according to the following equation:

$$
\dot{\varepsilon}=\frac{2 \sigma y s}{t E},
$$

where $t$ is the loading time and $E$ is the elastic modulus for the material.

The static yield stress for the vessel support beam material was obtained from Ref. 2 as $40.0 \mathrm{ksi}$. This value has been used in all of the support beam calculations. The beam material yield stress is close to the mean yield stress value given for A36 in Ref. 7 (38.1 ksi) and should therefore be representative of the test material yield stress.

All of the vessel-support loading cases considered involve a substantial increment of dynamic load, generated by either a seismic or a loss-of-coolant accident event. Loading rates for this dynamic component of the support load are dictated by the dynamic response of the vesse1, which is dominated by the first rocking mode frequency of the vessel on its supports. The vessel first-mode frequency was obtained from Ref. 9 as 20 cps.*

It is evident from examination of the cyclic loading data of Sect. 6.3.3 that the loading for OBE, SSE, and SBLOCA events cycles between two positive values. The loading time for those events is therefore one-half the vessel first-mode vibration period.

$$
t=1 /(20 \times 2)=0.025 \mathrm{~s} .
$$

\footnotetext{
*Information received from PGE subsequent to completion of this phase of the analysis reduced the loading frequency to $15 \mathrm{cps}$. This change influences the straining rate dependent temperature shift by $3.5^{\circ} \mathrm{F}$. This small change was not incorporated into the analysis.
} 
In the case of the LBLOCA loading, the magnitude of the cyclic load exceeds that of the combined $D W$ and $T$. It is to be anticipated therefore that the vessel will lift off its suppert during the negative segment of the LBLOCA loading cycle, thereby extending the vessel firstmode vibration period. Dynamic response time history data for the DW + $T+$ LBLOCA event are, however, not currently available. The loading time for the LBLOCA event has therefore been taken as identical with that of the other dynamic loading events.

The elastic modulus appropriate to the support beam operating temperature $\left(90^{\circ} \mathrm{F}\right)$ was obtained from Table I.6 of Ref. 10 as $29.0 \times 10^{6}$ $1 \mathrm{~b} /$ in. ${ }^{2}$ Substituting the above values into $\mathrm{Eq}$. (2) gives an effective crack-tip straining rate for the support beam.

$$
\dot{\varepsilon}_{\text {beam }}=\frac{2 \times 40 \times 10^{3}}{0.025 \times 29 \times 10^{6}}=0.1103 \mathrm{in} . / \mathrm{in} . / \mathrm{s},
$$

$$
\simeq 0.11 \mathrm{in.} / \mathrm{in.} / \mathrm{s}
$$

Substituting for $\dot{\varepsilon}$ and $\sigma_{\mathrm{y}}$ in Eq. (1) gives

$$
\Delta \mathrm{T}_{\text {beam }}=(150-40) \times 0.110 .17=75.6^{\circ} \mathrm{F}
$$

Strain rates for the fracture-toughness data of Ref. 7 vary from $10^{-5} \mathrm{in./in./s}$ to $10 \mathrm{in./in./s.} \mathrm{Inserting} \mathrm{these} \mathrm{values} \mathrm{into} \mathrm{Eq.} \mathrm{(1)}$ yields the $\Delta \mathrm{T}$ values in Table 6.1 .

Table 6.1. Temperature adjustment vs strain rate for $\mathrm{A} 36$

\begin{tabular}{crr}
\hline $\begin{array}{c}\text { Strain rate } \\
\text { (in./in./s) }\end{array}$ & $\begin{array}{c}\Delta \mathrm{T} \\
\left({ }^{\circ} \mathrm{F}\right)\end{array}$ & $\begin{array}{c}\text { Temperature } \\
\text { ad justment } \\
\left({ }^{\circ} \mathrm{F}\right)\end{array}$ \\
\hline $10^{-5}$ & 15.5 & +60.1 \\
$10^{-3}$ & 34.0 & +41.6 \\
$10^{+1}$ & 162.7 & -87.1 \\
0.11 & 75.6 & 0.0 \\
\hline
\end{tabular}

The strain-rate temperature adjustment in column three of Table 6.1 is applied to the test temperatures for the data of Fig. 6.10 to convert the data to a straining rate appropriate to the vessel-support beam.

Results obtained from the application of the strain-rate correction temperature shift are plotted in Fig. 6.11. All points plotted in the 
ORNL-DWG $88-4969$ ETD

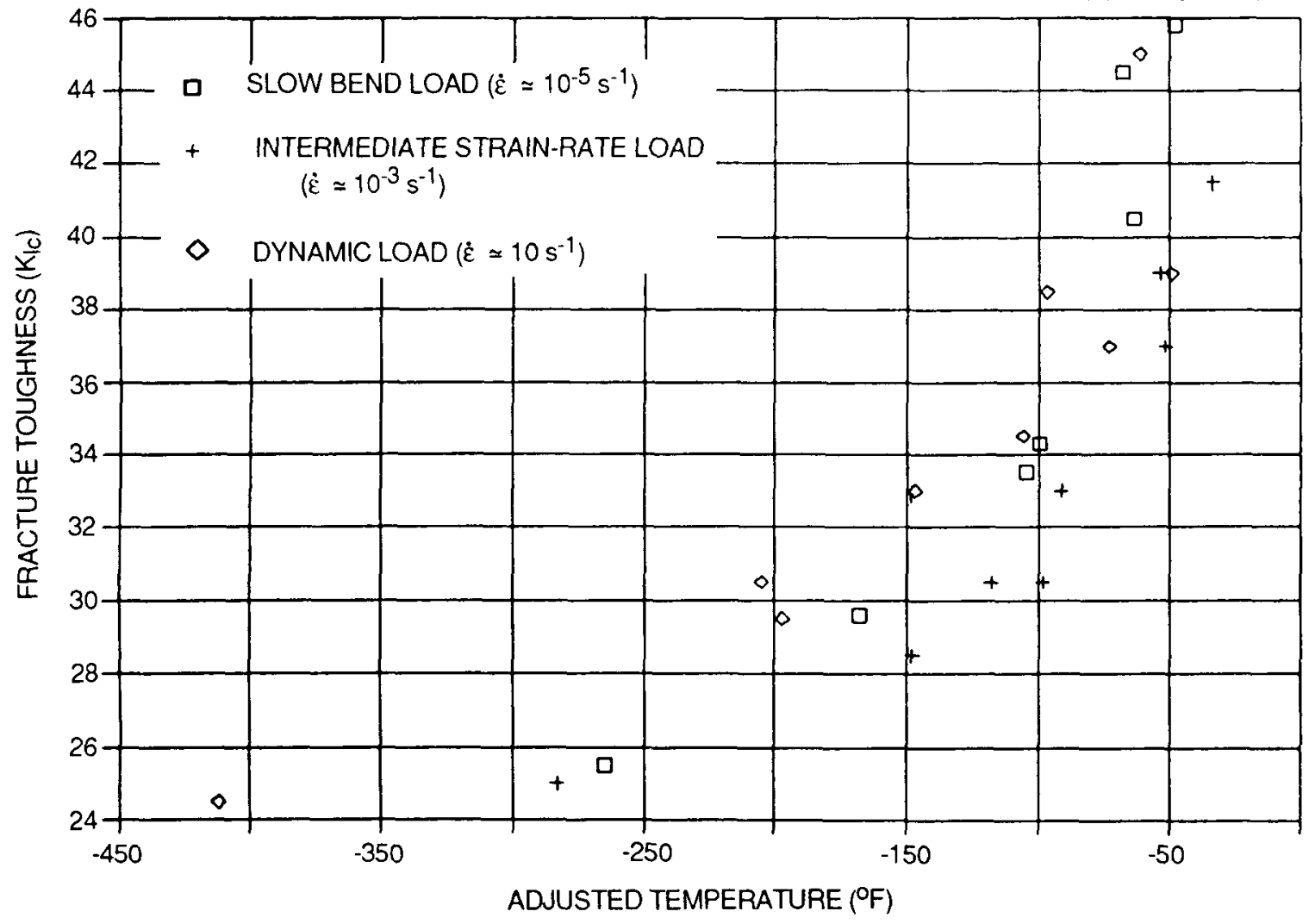

Fig. 6.11. Fracture-toughness data for A36 after transposition to prototypic reactor vessel support beam straining rate.

figure have been adjusted to the support beam straining rate $(0.11$ in./in./s).

\subsubsection{Data correlation and extrapolation}

A best-fit mean curve for the data of Fig. 6.11 was obtained using the Statpad-Curvefit template in conjunction with the Lotus 123 spreadsheet computer program. The program fits 25 different curves to the data and provides a correlation coefficient for each curve. The highest correlation coefficient $(0.866)$ was obtained for a Cauchy curve with the following coefficients:

$$
K_{\text {Id }}=1 /\left[1.5 \times 10^{-7}(T-382.28)^{2}+0.041014\right]
$$

This curve is shown superposed on the data base in Fig. 6.12.

Primary uses of the mean curve fitted to the data are to provide (1) a basis for extrapolating the data trend to higher temperatures; (2) a base upon which to construct a lower bound curve that in effect defines the design plane-strain, fracture-toughness curve for A36 at the 
ORNL-DWG 884970 ETD

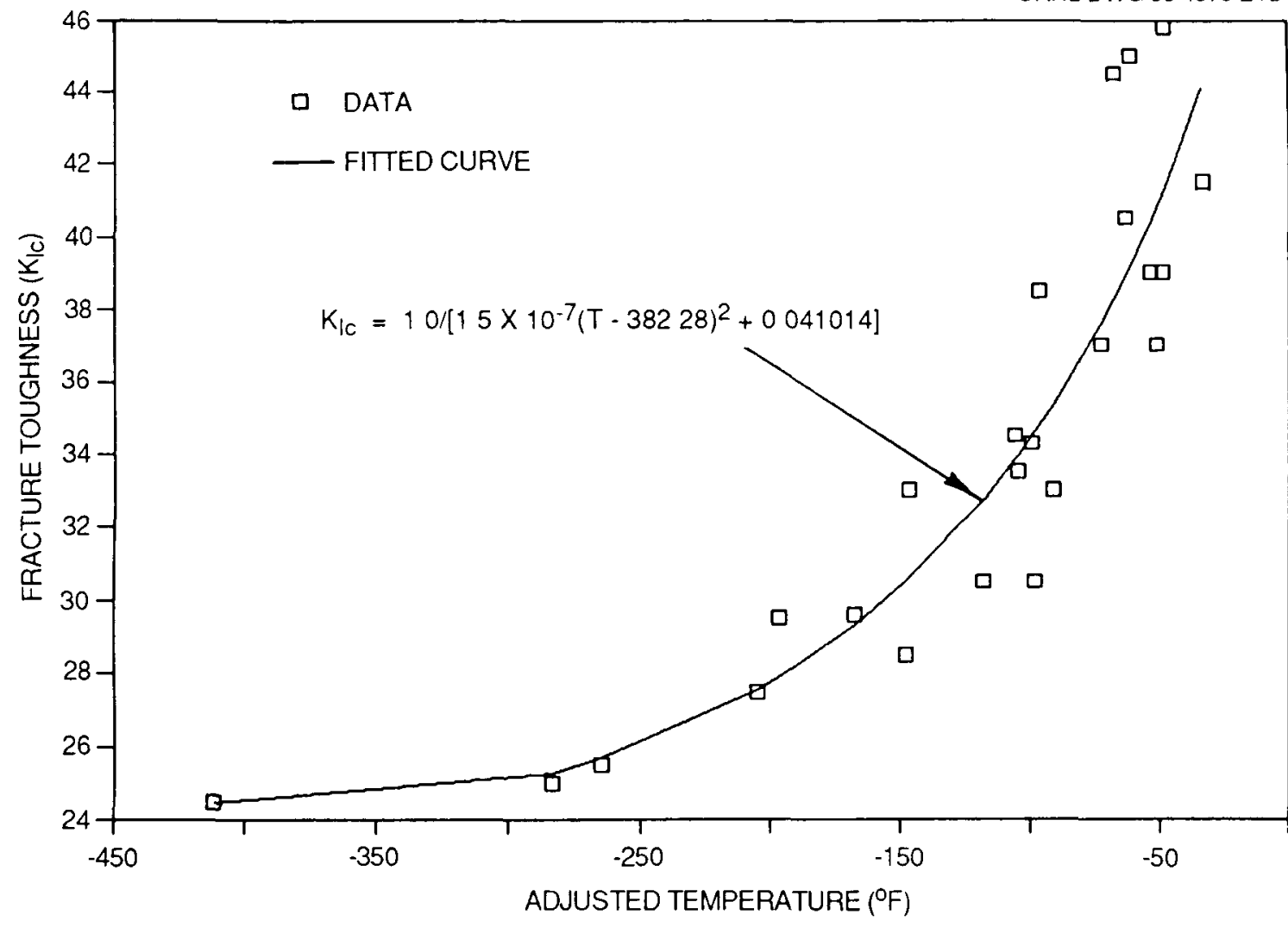

Fig. 6.12. Best-fit mean curve superposed on transposed A36 fracture-toughness data population.

vessel-support straining rate; and (3) a base for construction of a plane-stress, fracture-toughness $K_{c}$ curve for use where the plane-strain constraint requirements are not satisfied. It is important therefore that the validity of the mean curve, when extrapolated to higher temperatures, be verified. In particular, it must be shown that the slope (d $\mathrm{K}_{\mathrm{Id}} / \mathrm{dT}$ ) of the mean curve approaches infinity at a temperature corresponding closely to the limit of applicability of linear elastic fracture mechanics (LEFM).

The highest temperature at which cleavage fracture will occur is defined in Ref. 11 as follows:

$$
T \rightarrow T_{\infty} \text { as } \sigma_{y} / K_{I d}+0
$$

where

$$
\begin{aligned}
\mathrm{T}_{\infty} & =\text { the upper bound temperature limit for LEFM applicability, } \\
\sigma_{\mathrm{y}} & =\text { dynamic yield stress at temperature } \mathrm{T}, \\
\mathrm{K}_{\mathrm{Id}} & =\text { fracture toughness at temperature } \mathrm{T} .
\end{aligned}
$$


An empirical equation for computing the yield stress of a material over the range of temperatures of interest in fracture-toughness evaluations is given in Ref. 12 as follows:

$$
\sigma_{y(T, t)}=\sigma_{y(0,0)}+\frac{174,000}{\log (2 \times 1010 t)(T+459)}-27.4,
$$

where

$$
\begin{aligned}
& \sigma_{\mathrm{y}(\mathrm{T}, \mathrm{t})}= \begin{array}{l}
\text { dynamic yield stress expressed as a function test } \\
\text { temperature and loading time, }
\end{array} \\
& \sigma_{\mathrm{y}(0,0)}=\text { static room temperature yield stress }(40 \mathrm{ksi}), \\
& \mathrm{t}=\text { loading time }(0.025 \mathrm{~s}), \\
& \mathrm{T}=\text { temperature }\left({ }^{\circ} \mathrm{F}\right) .
\end{aligned}
$$

Yield stress values appropriate to the temperatures for the $\mathrm{K}_{\mathrm{Id}}$ data points were calculated using $\mathrm{Eq}$. (5). $\sigma_{\mathrm{y}} / \mathrm{K}_{\mathrm{Id}}$ values were then calculated and plotted as a function of the test temperature (adjusted for strain rate) in Fig. 6.13. A mean curve was fitted to the data.

ORNL-DWG 88-4971 ETD

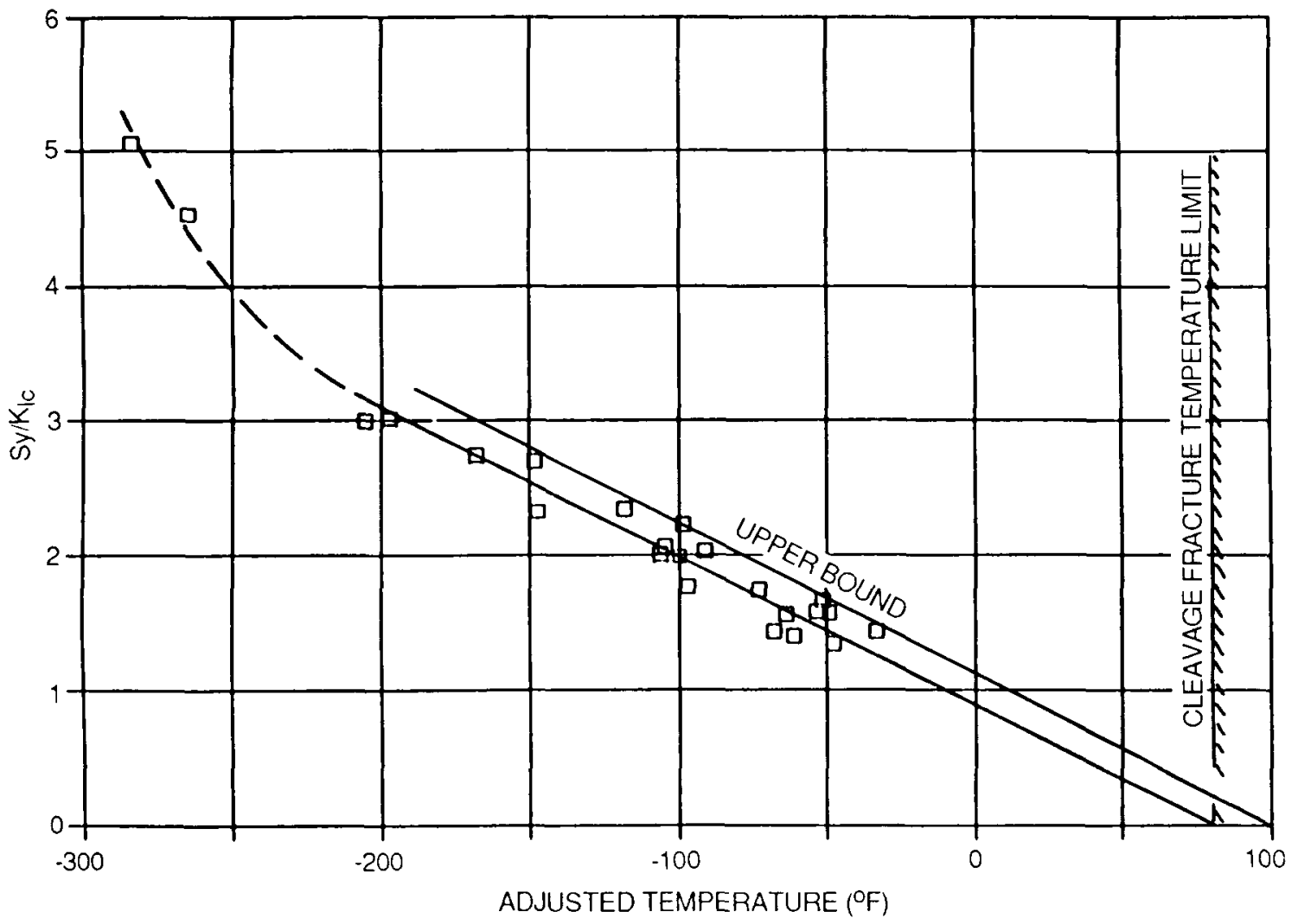

Eig. 6.13. Definition of temperature limits for cleavage fracture of $A 36$ at prototypic reactor vessel support beam straining rates. 
Extrapolation of this curve to the point where $s_{y} / K_{I d}=0$ gave an intersection with the $X$ axis at $T=77^{\circ} \mathrm{F}$. This represents the maximum temperature for cleavage fracture based on the mean of the data base. The upper bound 1 imit is obtained in a similar manner as $100^{\circ} \mathrm{F}$. Note that these temperature 1 imits apply to unirradiated material.

Extrapolation of the best-fit mean data curve to a temperature of $75^{\circ} \mathrm{F}$ is shown in Fig. 6.14. The slope of the curve can be seen to increase rapidly at $\mathrm{T}=75^{\circ} \mathrm{F}$. The calculated slope at $\mathrm{T}=77^{\circ} \mathrm{F}$ is 1.6 $\mathrm{ksi} /{ }^{\circ} \mathrm{F}$. The best-fit mean data curve is seen to be consistent with the limits defined in Ref. 11 and is thus considered validated as a basis for constructing the fracture-toughness design curve for $\mathrm{A} 36$.

It is important to recognize that the extrapolated $\mathrm{K}_{\mathrm{Id}}$ curves, while providing a valid base for constructing the final fracturetoughness design curve, are not suitable for direct use in a fracturetoughness evaluation. This limitation results from the fact that the constraint conditions at the crack tip in the material change from plane strain to plane stress as the ratio of fracture toughness to dynamic yield stress increases. The use of the extrapolated curve in deriving the fracture-toughness design curve is discussed further in the following section.

ORNL-DWG 88-4972 ETD

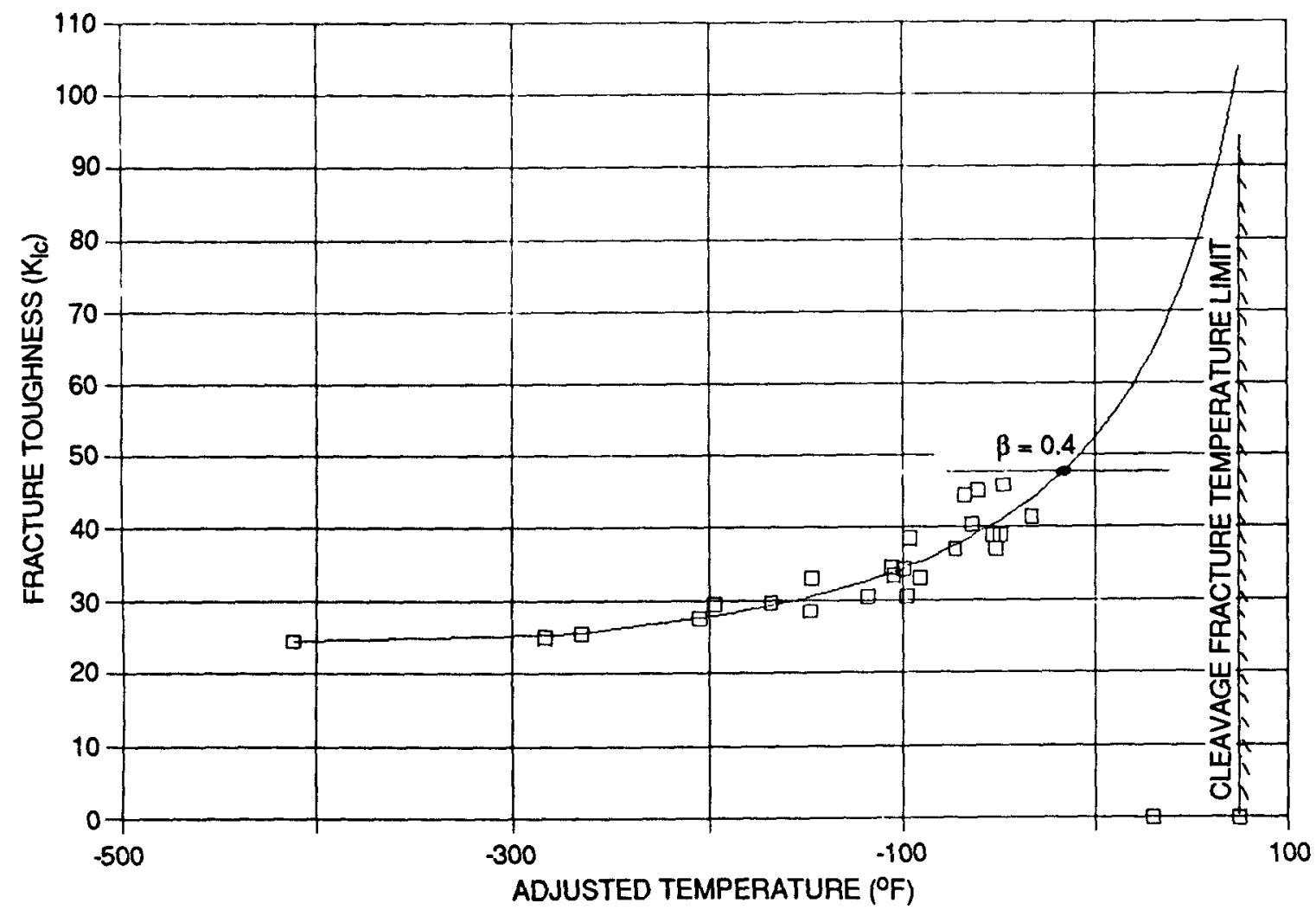

Fig. 6.14. Extrapolation of best-fit, mean fracture-toughness curve for A36, showing compatibility of fitted curve with cleavagefracture temperature limit. 


\subsubsection{Plane-strain to plane-stress transition}

Irwin has defined the upper bound limit for pure plane-strain behavior at a crack.tip in terms of a $B$ parameter as follows: 13

$$
\beta_{I c}=\frac{1}{B}\left[\frac{K_{I c}}{\sigma_{y s}}\right]^{2} \leq 0.4,
$$

where

$$
\begin{aligned}
\mathrm{B} & =\text { material thickness, } \\
\mathrm{K}_{\mathrm{Ic}} & =\text { plane-strain fracture toughness, } \\
\sigma_{\mathrm{ys}} & =\text { dynamic yield stress. }
\end{aligned}
$$

The data of Fig. 6.9 are also given in Fig. 4.12 of Ref. 13, with $B=0.4$ intercepts superposed on the fracture-toughness curves. These intercepts indicate that the limiting $K_{I d}$ value for plane-strain conditions at the crack tip is $48 \mathrm{ksi} \cdot \sqrt{\mathrm{in}}$. Above this value, adjustments must be made for the onset of plane-stress behavior at the crack tip.

The relationship between the plane-strain fracture toughness $\mathrm{K}_{\mathrm{Ic}}$ and the plane-stress fracture toughness $K_{c}$ is given in Ref. 13 as follows:

$$
K_{c}^{2}=K_{I c}^{2}\left(1+1.4 \times B_{I c}^{2}\right)
$$

Equation (7) has been demonstrated to be accurate only for cases in which differences between $K_{I c}$ and $K_{c}$ are small. In the absence of plane-stress, fracture-toughness data, however, Eq. (7) was used to predict plane-stress, fracture-toughness behavior.

The plane-stress, fracture-toughness curve is shown superposed on the data base, together with the plane-strain, fracture-toughness curve in Fig. 6.15. Note that the difference between the best-fit plane strain and the estimated plane-stress curves at the $B=0.41$ imit is small ( $2 \mathrm{ksi} \cdot \sqrt{\mathrm{in} .})$. The two mean curves were blended together, starting at the point $\mathrm{K}_{\mathrm{Ic}}=48 \mathrm{ksi} \cdot \sqrt{\mathrm{in}}$. on the plane-strain, fracture-toughness curve. Note that the $K_{I c}$ value of $48 \mathrm{ksi} \cdot \sqrt{i n}$. corresponds to a strainrate adjusted temperature of $-15^{\circ} \mathrm{F}$. The blending curve is shown in Fig. 6.16 . 


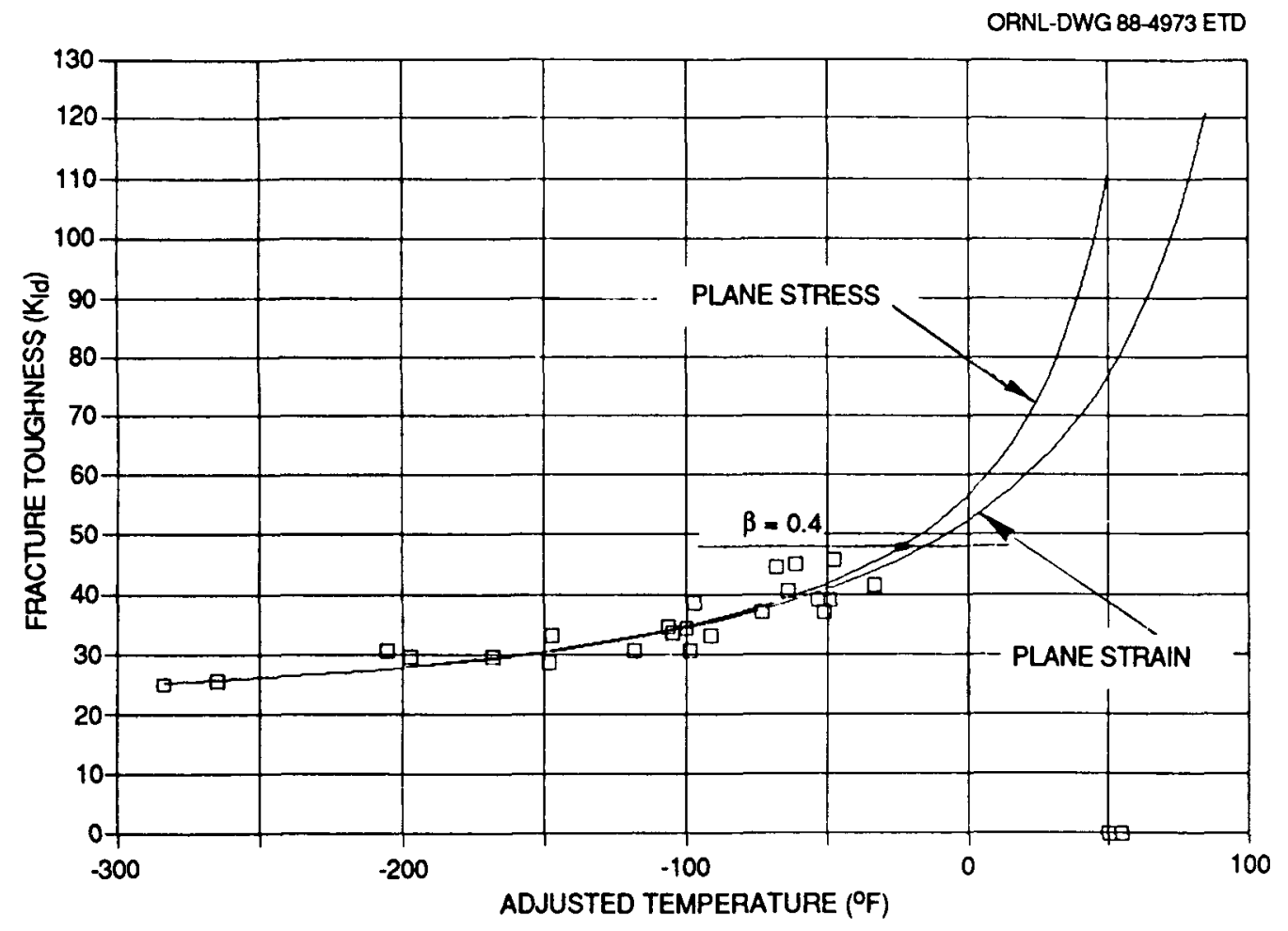

Fig. 6.15. Plane-stress, fracture-toughness curve for A36 derived from best-fit, plain-strain $K_{I d}$ curve.

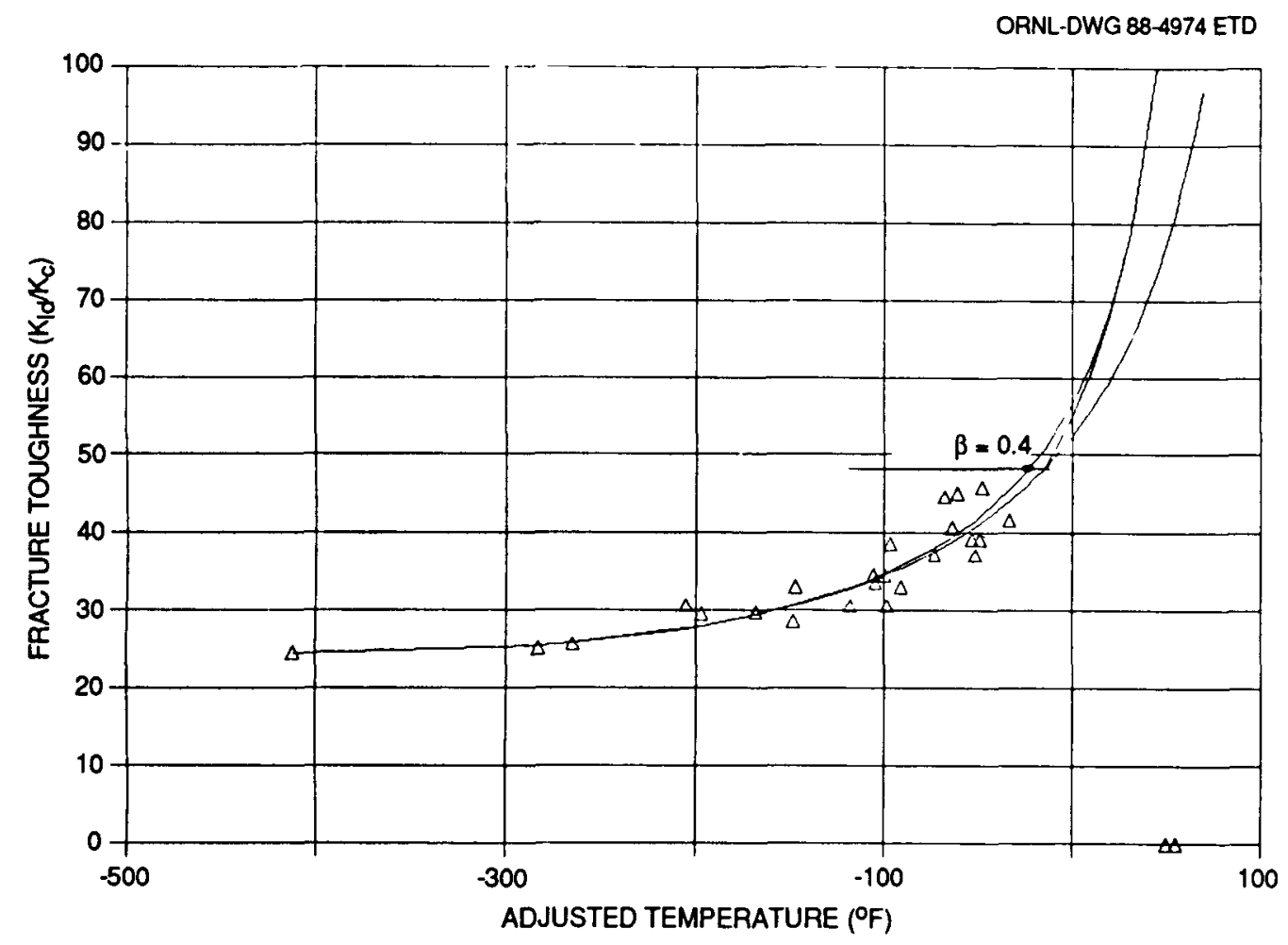

Fig. 6.16. Blending of the mean plane-stress and plane-strain fracture-toughness curves for A36. 


\subsubsection{Fracture-toughness design curves}

A lower bound, plane-strain, fracture-toughness curve was constructed by applying a $50^{\circ} \mathrm{F}$ temperature shift to the plane-strain portion of the mean value curve.* The plane-stress extension of the lower bound curve was then constructed by applying Eq. (7) to the lower bound plane-strain curve for temperatures above $-15^{\circ} \mathrm{F}$. The resulting curve is shown in Fig. 6.17, superposed on the data set. Note that the lower bound curve passes through the lowest data point.

Requirements for impact testing of materials intended for service in nuclear component supports are given in Subsect. NF of Sect. III of the ASME Boiler and Pressure Vessel Code.14 These requirements were used in a further validity check on the lower bound curve of Fig. 6.17.

Impact testing requirements for materials intended for service in component supports are defined in Paragraph NF-2311 of Ref. 14. Impact

${ }^{*}$ The $50^{\circ} \mathrm{F}$ shift is suggested by examining the shift of the ASME lower bound $K_{I c}$ or $K_{I R}$ curve from the mean curves of the corresponding data sets ("Flaw Evaluation Procedures," ASME Sect. XI, EPRI NP-719-SR, August 1978).

ORNL-DWG 88-4975 ETD

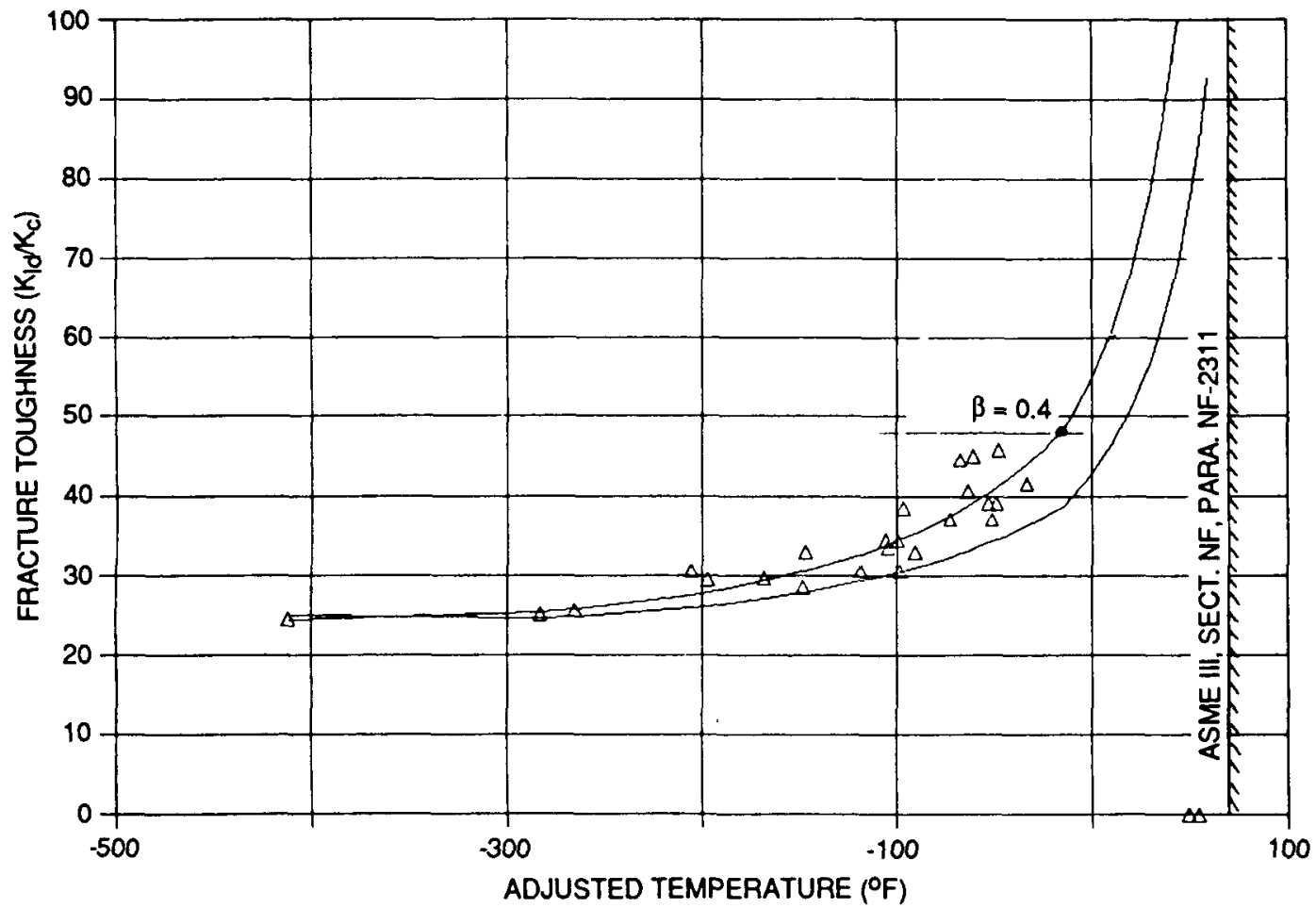

Fig. 6.17. Lower bound, plane-strain/plane-stress, fracture-toughness curves for A36 showing compatibility with ASME Code temperature limit for exemption from fracture-toughness testing. 
testing is not required when the support service temperature exceeds NDTT $+30^{\circ} \mathrm{F}$. NDTT for A36 plate is given in Table NF-2311(b)-1 as $40^{\circ} \mathrm{F}$, giving a lower bound service temperature (for unirradiated material) of $70^{\circ} \mathrm{F}$ for exemption from the impact testing requirement. In the following discussion, this temperature is interpreted as a lower bound temperature for design without consideration for brittle fracture.

The $70^{\circ} \mathrm{F}$ temperature 1 imit from Ref. 14 is shown superposed on the lower bound, fracture-toughness curve in Fig. 6.17. The lower bound curve increases rapidly as it approaches the Ref. 14 limiting value. Intersection of the lower bound curve with the $70^{\circ} \mathrm{F}$ limit occurs at a $\mathrm{K}_{\mathrm{Id}}$ value of $120 \mathrm{ksi} \cdot \sqrt{\mathrm{in}}$. Analysis results in Sect. 6.7 (Table 6.17) show critical flaw depths to be increasing rapidly as the critical stress-intensity factor increases by $10 \mathrm{ksi} \cdot \sqrt{\mathrm{in}}$. from 70 to 80 ksi. $\sqrt{\text { in. }}$ Critical flaw depths at a $K_{\mathrm{Id}}$ value of $120 \mathrm{ksi} \cdot \sqrt{\mathrm{in}}$. would be predicted to be very large and, therefore, compatible with elimination of the requirement for materials impact testing. The lower bound curve of Fig. 6.16 is therefore compatible with the interpretation of the fracture-toughness behavior of unirradiated A36 material incorporated into the materials impact testing requirements of Ref. 14.

The final step in construction of the fracture-toughness design curve was to replot the curve in terms of $T$ - NDTT. The NDTT was obtained from Ref. 7 as $28^{\circ} \mathrm{F}$. The resulting fracture-toughness design curve is given in Fig. 6.18 .

ORNL-DWG 88-4976 ETD

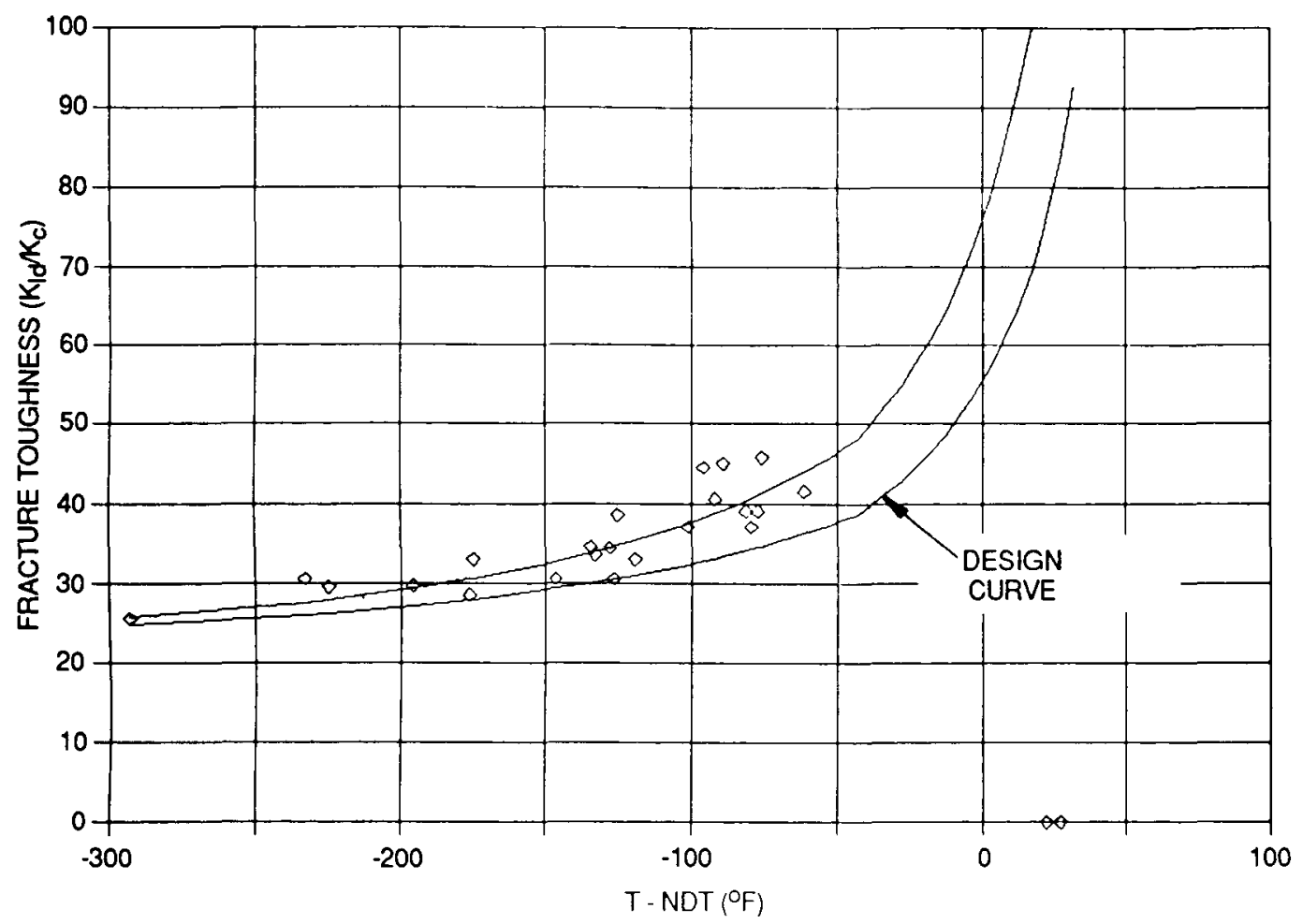

Fig. 6.18. Fracture-toughness design curve for $A 36$ at prototypic reactor vessel straining rates. 


\subsubsection{A36 NDTT variation}

The NDTT for A36 plate used in this analysis was taken from Ref. 7 as $28^{\circ} \mathrm{F}$. Heat-to-heat variations in NDTT for a range of materials used in PWR component supports were evaluated in an extensive survey conducted by Sandia National Laboratory.15 Results quoted in Ref. 15 for carbon-manganese steels, including A36, give the mean NDTT value as $22^{\circ} \mathrm{F}$, and a population standard deviation $\sigma$ as $13^{\circ} \mathrm{F}$. The (mean $+1.3 \sigma$ ) value for NDTT, corresponding to a $90 \%$ confidence 1 imit, is given as $39^{\circ} \mathrm{F}$. An increase of $11^{\circ} \mathrm{F}$ in NDTT must therefore be applied to the results given in this report to obtain critical flaw depths corresponding to a $90 \%$ confidence limit on NDTT.

A carpet plot giving critical flaw depths as a function of (1) $T$ NDTT and (2) support loading is given in Fig. 6.49 (Sect.6.7) for the beam flange grouthole location. This plot can be used to rapidly assess the impact of applying the $90^{\circ} \mathrm{F}$ confidence limit temperature shift $\left(11^{\circ} \mathrm{F}\right)$ on the calculated critical flaw depths.

\subsubsection{Supporting analysis}

A summary of analyses performed to construct the A36 fracturetoughness, lower bound curves is provided in Tables $6.2-6.5$.

\subsubsection{Reactor support/bridge structure comparison}

A36 is widely used in bridge construction where it has performed satisfactorily. It is of interest therefore to compare the service conditions appropriate to bridge application with those encountered in the reactor vessel-support beam application. In particular, the effect of the differing dynamic response characteristics of the two structural systems will be considered here.

Bridges are typically relatively flexible structures with low natural frequencies. Peak straining rates in bridge structures during response to impulsive loading are 1 imited by their low natural frequency to relatively low values. Strain rates induced by the application of live locds are likewise 1 imited to relatively low values by the bridgespan traverse time of heavily loaded vehicles. Rolfe and Barsom ${ }^{3}$ place the upper bound, crack-tip straining rate for bridge structures under dynamic loading conditions at $0.001 \mathrm{in./in./s.} \mathrm{This} \mathrm{straining} \mathrm{rate} \mathrm{is}$ $\sim 2$ orders of magnitude slower than that encountered in the vesselsupport beam application. The temperature-adjustment results of Table 6.1 show that this straining rate difference produces a temperature shift of $\sim 40^{\circ} \mathrm{F}$. Design stress-intensity-factor values at a given temperature for the support beam application are thus lower than the corresponding values for a bridge application. 
Table 6.2. Construction of the A36 plane strain fracture-toughness curves for reactor support loading rates

\begin{tabular}{|c|c|c|c|c|c|c|c|c|c|}
\hline $\begin{array}{l}\text { Test } \\
\text { Tempersture }\end{array}$ & $\begin{array}{l}\text { Teat } \\
\text { Stroin } \\
\text { Rote }\end{array}$ & $\begin{array}{l}\text { Frecture } \\
\text { Toughneses }\end{array}$ & $\begin{array}{l}\text { straining } \\
\text { Rate Tem. } \\
\text { Mdjustiment } \\
\text { Inerement }\end{array}$ & $\begin{array}{l}\text { Temperature } \\
\text { Adjested for } \\
\text { streining } \\
\text { Rate }\end{array}$ & sy/kic & $\begin{array}{l}\text { Col cul ated } \\
\text { Dest Bit } \\
\text { Mean Curve } \\
\text {. } 11 \text { in/ins }\end{array}$ & $\begin{array}{l}\text { calculated } \\
\text { Lower sound } \\
\text { curve } \\
\text {.11linvins }\end{array}$ & T.NOT & $\begin{array}{l}\text { Yield } \\
\text { stress }\end{array}$ \\
\hline \multirow[t]{26}{*}{ Deg. F. } & In/in/see & 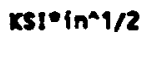 & Ders. F. & $\begin{array}{l}\text { Deg. F. } \\
1.000 E+02\end{array}$ & & & $\begin{array}{c}(\text { Meen-50) } \\
7.702 E+01\end{array}$ & $\begin{array}{l}\text { Deg. F. } \\
7.200 E+01\end{array}$ & \\
\hline & & & & $9.500 E+01$ & & & $7.33 \pi E+01$ & 6. TOOE+01 & \\
\hline & & & & $9.000 E+01$ & & & $7.090 E+01$ & $6.200 E+01$ & \\
\hline & & & & $8.500 E+01$ & & & $6.713 E+01$ & $5.700 E+01$ & \\
\hline & & & & $8.000 E+01$ & & & $6.646 E+01$ & $3.200 E+01$ & \\
\hline & & & & $7.500 E+01$ & & & $6.199 E+01$ & $4.700 E+01$ & \\
\hline & & & & $7.000 E+01$ & & & $5.974 E+01$ & $4.200 E+01$ & \\
\hline & & & & $6.500 E+01$ & & & $5.767 E+01$ & $3.700 E+01$ & \\
\hline & & & & $6.000 E+01$ & & & $5.577 E+01$ & $3.200 E+01$ & \\
\hline & & & & S.500E+01 & & & $5.601 E+01$ & $2.700 E+01$ & \\
\hline & & & & $5.000 E+01$ & & $7.702 E+01$ & $5.237 E+01$ & $2.200 E+01$ & \\
\hline & & & & $4.500 E+09$ & & $7.337 E+01$ & $5.086 E+09$ & $1.700 E+01$ & \\
\hline & & & & $4.000 E+01$ & & $7.010 E+01$ & $4.964 E+01$ & $1.200 E+01$ & \\
\hline & & & & $3.500 E+01$ & & $6.713 E+01$ & $4.812 E+01$ & $7.000 E+00$ & \\
\hline & & & & $3.000 E+01$ & & $6.666 E+01$ & 4.689E+01 & $2.000 E+00$ & \\
\hline & & & & $2.500 E+01$ & & $6.199 E+01$ & $6.573 E+01$ & $-3.000 E+00$ & \\
\hline & & & & $2.000 E+01$ & & $5.974 E+01$ & $4.465 E+01$ & $-8.000 E+00$ & \\
\hline & & & & $1.500 E+01$ & & $5.767 E+01$ & $4.362 E+01$ & $-1.300 E+01$ & \\
\hline & & & & $1.000 E+01$ & & $5.577 E+01$ & $4.266 E+01$ & $-1.800 E+01$ & \\
\hline & & & & $5.000 E+00$ & & $5.601 E+09$ & 6.17SE+01 & $-2.300 E+01$ & \\
\hline & & & & $0.000 E+0 \sigma$ & & $5.237 E+01$ & $4.090 E+01$ & $-2.800 E+01$ & \\
\hline & & & & $-1.000 \varepsilon+01$ & & $6.964 E+01$ & $3.932 E+01$ & $-3.800 E+01$ & \\
\hline & & & & $-1.500 E+01$ & & $4.812 E+01$ & $3.859 E+01$ & $-6.300 E+01$ & \\
\hline & & & & $-2.000 E+01$ & & 4.689E+01 & $3.790 E+01$ & $-4.800 E+01$ & \\
\hline & & & & $-2.500 E+01$ & & $4.573 E+01$ & $3.724 E+01$ & $-5.300 E+01$ & \\
\hline & & & & $-3.000 E+01$ & & $4.465 E+01$ & $3.662 E+01$ & $-5.800 E+01$ & \\
\hline$-7.500 E+01$ & $1.000 \varepsilon \cdot 03$ & $4.150 E+01$ & $4.160 E+01$ & $-3.340 E+01$ & $1.636 E+00$ & 4.394E+01 & $3.621 E+01$ & $-6.160 E+0 ?$ & $5.960 E+01$ \\
\hline -1.080E+02 & $1.000 E \cdot 05$ & $4.580 E+01$ & $6.010 E+01$ & $-4.790 E+01$ & $1.337 E+00$ & $6.125 E+01$ & $3.462 E+01$ & $-7.590 E+01$ & $6.126 E+01$ \\
\hline $3.800 E+01$ & $1.000 E \bullet 01$ & $3.900 E+01$ & $-8.710 E+01$ & $-4.910 E+01$ & $1.574 E+00$ & 6. 105E+01 & $3.450 E+01$ & $\cdot 7.710 E+01$ & $6.160 E+01$ \\
\hline$-9.300 E+01$ & $1.000 E-03$ & $3.700 E+01$ & $4.160 \varepsilon+01$ & $-5.140 E+01$ & $1.66 \pi+00$ & $4.066 E+01$ & $3.42 \pi E+01$ & $-7.960 E+01$ & $6.167 E+01$ \\
\hline$-9.500 E+01$ & $1.000 E-03$ & $3.900 E+01$ & $4.160 E+01$ & $-5.360 E+01$ & $1.588 E+00$ & $4.034 E+01$ & $3.407 E+01$ & $-8.160 E+01$ & $6.192 E+01$ \\
\hline $2.600 E+09$ & $1.000 E+01$ & $6.500 E+01$ & $-8.710 E+01$ & $-6.110 \varepsilon+01$ & $1.397 \mathrm{E}+00$ & $3.915 E+01$ & $3.335 E+01$ & $-8.910 E+01$ & $6.287 E+01$ \\
\hline$-1.240 E+02$ & $1.000 E \cdot 05$ & $4.050 E+01$ & $6.010 E+01$ & $-6.390 E+01$ & $1.561 E+00$ & $3.875 E+01$ & $3.310 E+01$ & $-9.190 E+01$ & $6.323 E+01$ \\
\hline$-1.280 E+02$ & $1.000 E \cdot 05$ & $4.450 E+01$ & $6.010 E+01$ & $-6.790 E+01$ & $1.632 E+00$ & $3.818 E+01$ & $3.276 E+01$ & $• 9.590 E+01$ & 6.374E+01 \\
\hline $1.400 E+01$ & $1.000 E+01$ & $3.700 E+01$ & $-8.710 E+01$ & $-7.310 E+01$ & $1.741 E+\infty 0$ & $3.749 E+01$ & $3.232 \mathrm{E}+01$ & $-1.011 E+02$ & $6.663 E+01$ \\
\hline$-1.330 E+02$ & $1.000 E \cdot 03$ & $3.300 E \bullet 01$ & $4.160 E+01$ & $-9.140 E+01$ & $2.031 E+00$ & $3.531 E+01$ & $3.095 E+01$ & $-1.194 E+02$ & $6.701 E+01$ \\
\hline$-1.000 E+01$ & $1.000 E+01$ & $3.850 E+01$ & $-8.710 E+01$ & $-9.710 E+01$ & $1.763 E+00$ & $3.670 E+01$ & $3.056 E+01$ & $-1.251 E+02$ & $6.787 E+01$ \\
\hline$-1.400 \varepsilon+02$ & $1.000 E-03$ & $3.050 E+01$ & $6.160 E+01$ & $-9.860 E+01$ & $2.232 E+00$ & $3.457 E+01$ & $3.048 E+01$ & $-1.264 E+02$ & $6.807 \varepsilon+09$ \\
\hline$-1.600 \varepsilon+02$ & $1.000 E \cdot 05$ & $3.630 E+01$ & $6.010 E+01$ & $-9.990 E+01$ & $1.991 E+00$ & $3.442 E+01$ & $3.038 E+01$ & $-1.279 E+02$ & $6.830 E+01$ \\
\hline$-1.650 E+02$ & $1.000 E \cdot 05$ & $3.350 E+01$ & $6.010 E+01$ & $-1.069 E+02$ & $2.062 E+00$ & $3.393 E+01$ & $3.007 E+01$ & $-1.329 E+02$ & $6.909 E+01$ \\
\hline$-1.900 E+01$ & $1.000 E+01$ & $3.450 E+01$ & $-8.710 E+01$ & $-1.061 E+02$ & $2.008 E+00$ & $3.381 E+01$ & 2.999E+01 & $-1.361 E+02$ & $6.928 E+01$ \\
\hline$-1.600 E+02$ & $1.000 E \cdot 03$ & $3.050 E+01$ & $4.160 E+01$ & $-1.184 E+02$ & $2.339 E+00$ & $3.271 E+01$ & $2.928 E+01$ & $-1.664 E+02$ & $7.133 E+01$ \\
\hline$-6.000 E+01$ & $1.000 E+01$ & $3.300 E+01$ & $-8.710 E+01$ & $-1.679 E+02$ & $2.325 E+00$ & $3.056 E+01$ & $2.788 E+01$ & $-1.751 E+02$ & $7.673 E+01$ \\
\hline$-1.900 E+02$ & $9.000 E \cdot 03$ & $2.850 E+01$ & $4.160 E+01$ & $-1.484 E+02$ & $2.702 \varepsilon+00$ & $3.048 E+01$ & $2.782 E+01$ & $-1.764 E+02$ & $7.700 E+01$ \\
\hline$-2.280 \varepsilon+02$ & $1.000 E \cdot 05$ & $2.960 E+01$ & $6.010 E+01$ & $-1.679 E+02$ & $2.74 \pi E+00$ & $2.931 E+01$ & $2.706 E+01$ & $-1.959 E+02$ & $8.131 E+01$ \\
\hline$-1.100 E+02$ & $1.000 E+09$ & $2.950 E+01$ & $-8.710 E \bullet 01$ & -1.971E+02 & $3.016 E+00$ & $2.788 E+01$ & $2.613 E+01$ & $-2.251 E+02$ & $8.897 E+01$ \\
\hline$-1.180 E+02$ & $1.000 E+01$ & $3.050 E+01$ & $-8.710 E+01$ & $-2.051 E+02$ & $2.996 E+00$ & $2.734 E+01$ & $2.591 E+01$ & $-2.331 E+02$ & $9.138 E \bullet 01$ \\
\hline
\end{tabular}


Table 6.3

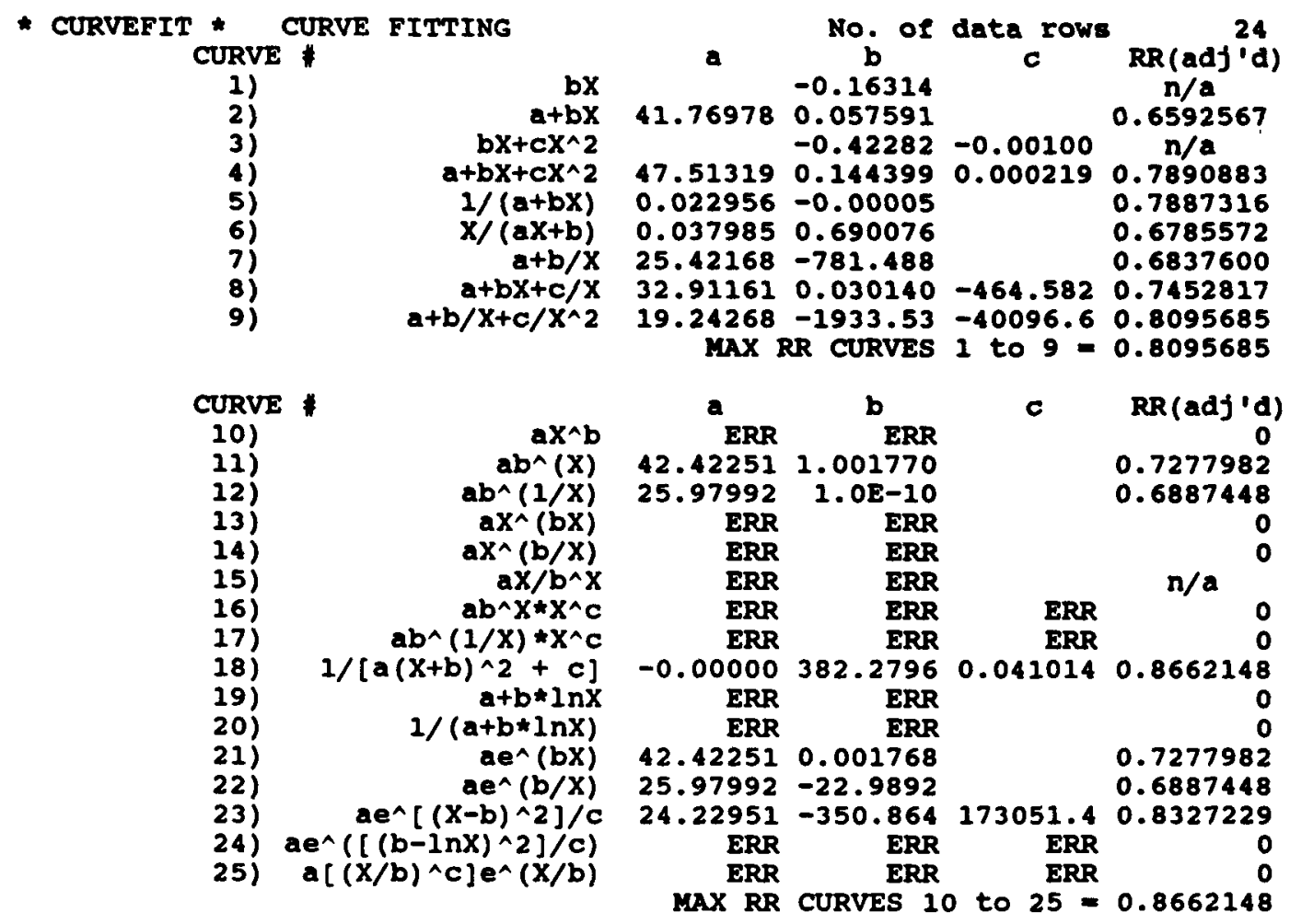

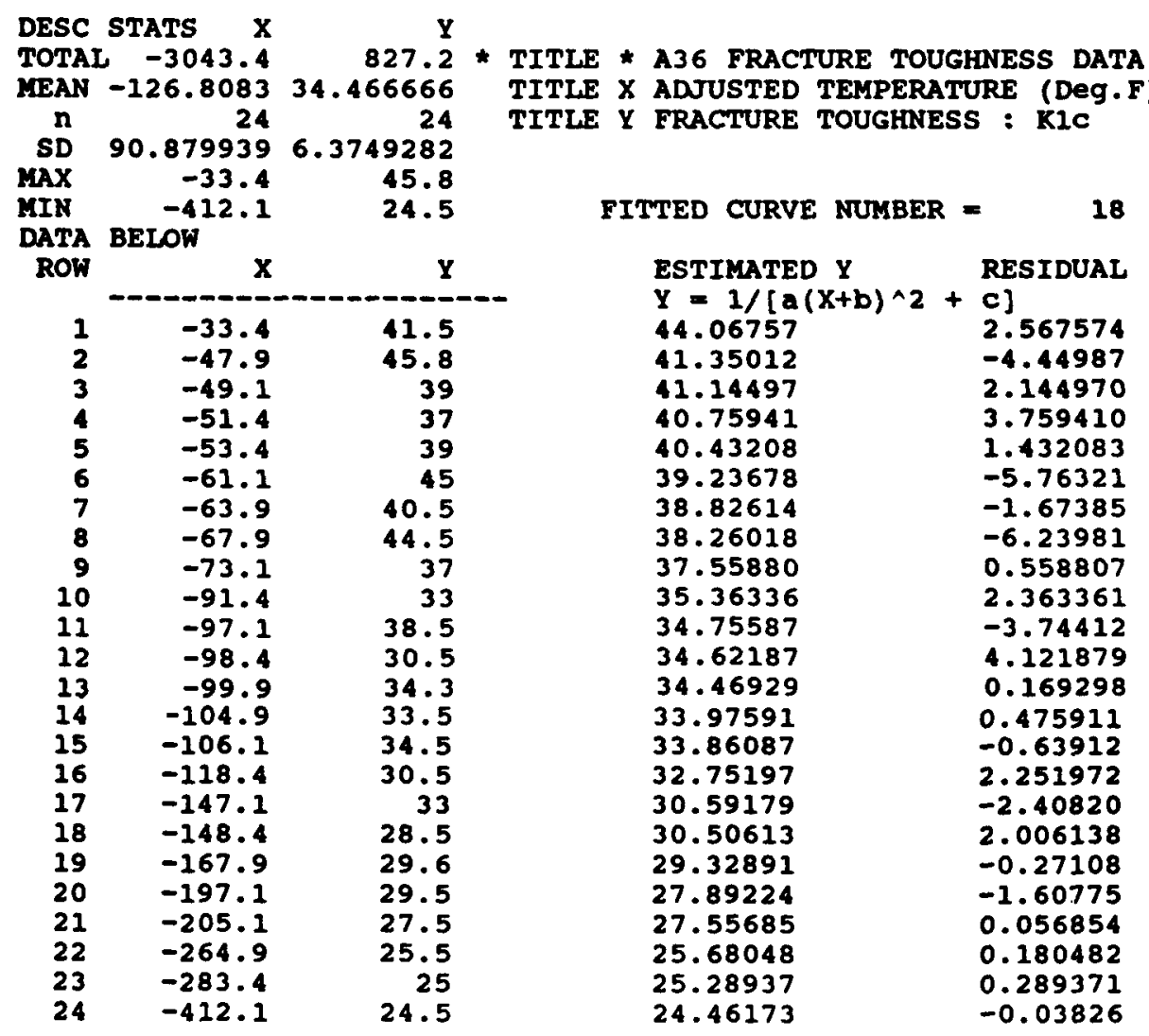


Table 6.4. Plane strain-plane stress transition (Ref. 13, page 114)

\begin{tabular}{|c|c|c|c|c|c|c|}
\hline ite thi & $=$ & & & & & \\
\hline & Calculated & Calculated & & BETAIC & & Calculated \\
\hline & & Plane strain & Yield & & & Plane Stress \\
\hline $\begin{array}{l}\text { Straining } \\
\text { Rate }\end{array}$ & $\begin{array}{l}\text { Mean Curve } \\
.11 \mathrm{in} / \mathrm{in} / \mathrm{s}\end{array}$ & $\begin{array}{l}\text { Lower Bound } \\
.19 \mathrm{in} / \mathrm{in} / \mathrm{s}\end{array}$ & Stress & & $\begin{array}{l}\text { Mean Curve } \\
.11 \text { in/in/s }\end{array}$ & $\begin{array}{l}\text { Lower Bound } \\
.11 \mathrm{in} / \mathrm{in} / \mathrm{s}\end{array}$ \\
\hline Deg. F. & Strain Rate & $\begin{array}{l}\text { Strain Rate } \\
\text { (Mean-50) }\end{array}$ & & & Strain Rate & $\begin{array}{l}\text { Strain Rate } \\
\text { (Mean.50) }\end{array}$ \\
\hline $1.000 E+02$ & $1.633 E+02$ & $7.702 E+01$ & $4.838 E+01$ & $4.555 E+00$ & & \\
\hline $9.500 E+01$ & $1.461 E+02$ & $7.337 E+01$ & $4.871 E+01$ & $3.599 E+00$ & & \\
\hline $9.000 E+01$ & $1.323 E+02$ & $7.010 E+01$ & $4.903 E+01$ & $2.913 E+00$ & & \\
\hline $8.500 E+01$ & $1.210 E+02$ & $6.713 E+01$ & $4.937 E+01$ & $2.405 E+00$ & & \\
\hline $8.000 E+01$ & $1.116 E+02$ & $6.444 E+01$ & $4.971 E+01$ & $2.017 E+00$ & & \\
\hline $7.500 E+01$ & $1.036 E+02$ & $6.199 E+01$ & $5.006 E+01$ & $1.715 E+00$ & & \\
\hline $7.000 E+01$ & $9.680 E+01$ & $5.974 E+01$ & $5.041 E+01$ & $1.475 E+00$ & $1.947 E+02$ & $1.202 E+02$ \\
\hline $6.500 E+01$ & $9.087 E+01$ & $5.767 E+01$ & $5.077 E+01$ & $1.281 E+00$ & $1.650 E+02$ & $1.047 E+02$ \\
\hline $6.000 E+01$ & $8.567 E+01$ & $5.577 E+01$ & $5.114 E+01$ & $1.123 E+00$ & $1.424 E+02$ & $9.272 E+01$ \\
\hline $5.500 E+01$ & $109 E+01$ & $5.401 E+01$ & $5.152 E+01$ & 9.911E-01 & $1.250 E+02$ & $8.323 E+01$ \\
\hline $5.000 E+01$ & $7.702 E+01$ & $5.237 E+01$ & $5.190 E+01$ & $8.809 E-01$ & $1.112 E+02$ & $7.565 E+01$ \\
\hline $4.500 E+01$ & $7.337 E+01$ & $5.086 E+01$ & $5.229 E+01$ & $7.877 E-01$ & $9.003 E+02$ & $6.952 E+01$ \\
\hline $4.000 E+01$ & $7.010 E+01$ & $4.944 E+01$ & $5.268 E+01$ & $7.081 E-01$ & $9.145 E+01$ & $6.450 E+01$ \\
\hline $3.500 E+01$ & $6.713 E+01$ & $4.812 E+09$ & $5.309 E+01$ & $6.396 E-01$ & $8.419 E+01$ & $6.035 E+01$ \\
\hline $3.000 E+01$ & $6.444 E+01$ & $4.689 E+01$ & $5.350 E+01$ & $5.803 E-01$ & $7.817 E+01$ & $5.688 E+01$ \\
\hline $2.500 E+01$ & $199 E+01$ & $4.573 E+01$ & $5.393 E+01$ & $5.285 E \cdot 01$ & $7.311 E+01$ & $5.394 E+01$ \\
\hline $2.000 E+01$ & $5.974 E+01$ & $4.465 E+01$ & $5.436 E+01$ & $4.831 E \cdot 01$ & $6.881 E+01$ & $5.142 E+01$ \\
\hline $1.500 E+01$ & $767 E+01$ & $4.362 E+01$ & $5.480 E+01$ & $4.630 \mathrm{E} \cdot 01$ & $6.512 E+01$ & $4.925 E+01$ \\
\hline $1.000 E+01$ & $5.577 E+01$ & $4.266 E+01$ & $5.525 E+01$ & $4.075 E-01$ & $6.191 E+01$ & $4.736 E+01$ \\
\hline $5.000 E+00$ & $5.401 E+01$ & $4.175 E+01$ & $5.571 E+01$ & $3.759 E-01$ & $5.911 E+01$ & $70 E+01$ \\
\hline $0.000 E+00$ & $5.237 E+01$ & $4.090 E+01$ & $5.698 E+01$ & $3.477 \mathrm{E}-01$ & $5.663 E+01$ & $4.422 E+01$ \\
\hline$\cdot 1.000 E+01$ & $4.944 E+01$ & $3.932 E+01$ & $5.715 E+01$ & $2.994 E-01$ & $5.245 E+01$ & $\mid E+01$ \\
\hline$-1.500 E+01$ & $4.812 E+01$ & $3.859 E+01$ & $5.765 E+01$ & $2.787 E-01$ & $5.067 E+01$ & $4.063 E+01$ \\
\hline$\cdot 2.000 E+01$ & $4.689 E+01$ & $3.790 E+01$ & $5.816 E+01$ & $2.600 E-01$ & $4.906 E+01$ & $3.965 E+01$ \\
\hline$\cdot 2.500 E+01$ & $4.573 E+01$ & $3.724 E+01$ & $5.869 E+01$ & $2.429 \mathrm{E}-01$ & $4.758 E+01$ & $3.875 E+01$ \\
\hline$-3.000 E+01$ & $4.465 E+01$ & $3.662 E+01$ & $5.923 E+01$ & $2.273 E \cdot 01$ & $4.623 E+01$ & $92 E+01$ \\
\hline$-3.340 E+01$ & $4.394 E+01$ & $3.621 E+01$ & $5.960 E+01$ & $2.175 E \cdot 01$ & $4.537 E+01$ & $3.739 E+01$ \\
\hline$-4.790 E+01$ & $4.125 E+01$ & $3.462 E+01$ & $6.126 E+01$ & $1.814 E \cdot 01$ & $4.219 E+01$ & $3.541 E+01$ \\
\hline$-4.910 E+01$ & $4.105 E+01$ & $3.450 \varepsilon+01$ & $6.140 E+01$ & $1.788 \mathrm{E} \cdot 01$ & $4.195 E+01$ & $3.526 E+01$ \\
\hline$-5.140 E+01$ & $4.066 E+01$ & $3.427 E+01$ & $6.167 E+01$ & $1.739 \mathrm{E}-01$ & $4.152 E+01$ & $3.499 E+01$ \\
\hline$-5.340 E+01$ & $4.034 E+01$ & $3.407 E+01$ & $6.192 E+01$ & $1.698 E-01$ & $4^{\prime} \cdot 115 E+01$ & $3.475 E+01$ \\
\hline$-6.110 E+01$ & $3.915 E+01$ & $3.335 E+01$ & $6.287 E+01$ & $1.551 \mathrm{E} \cdot 01$ & $3.981 E+01$ & $3.391 E+01$ \\
\hline$-6.390 E+01$ & $3.875 E+01$ & $3.310 E+01$ & $6.323 E+01$ & $1.502 E \cdot 01$ & $3.935 E+01$ & $3.362 E+01$ \\
\hline$-6.790 E+01$ & $3.818 E+01$ & $3.276 E+01$ & $6.374 E+01$ & $1.435 \mathrm{E} \cdot 01$ & $3.873 E+01$ & $3.322 E+01$ \\
\hline$-7.310 E+09$ & $3.749 E+01$ & $3.232 E+09$ & $6.443 E+01$ & $1.354 \mathrm{E} \cdot 01$ & $3.797 E+01$ & $3.274 E+01$ \\
\hline$-9.140 E+01$ & $.531 E+01$ & $3.095 E+01$ & $6.701 E+01$ & $1.110 E-01$ & $3.561 \varepsilon+01$ & $3.122 E+01$ \\
\hline$-9.710 E+D 1$ & $3.470 E+01$ & $3.056 E+09$ & $6.787 E+01$ & $1.046 \mathrm{E}-01$ & $3.497 E+01$ & $3.080 E+01$ \\
\hline$-9.840 E+01$ & $3.457 E+01$ & $3.048 E+01$ & $6.807 E+01$ & $1.032 E-01$ & $3.483 E+01$ & $3.071 E+01$ \\
\hline$-9.990 E+09$ & $3.442 E+01$ & $3.038 E+01$ & $6.830 E+01$ & $1.016 \mathrm{E} \cdot 01$ & $3.467 E+01$ & $3.060 E+01$ \\
\hline$-1.049 E+02$ & $3.393 E+01$ & $3.007 E+01$ & $6.909 E+01$ & $9.647 \mathrm{E}-02$ & $3.495 E+01$ & $3.026 E+01$ \\
\hline$-1.061 E+02$ & $3.381 E+01$ & $2.899 E+01$ & $6.928 E+01$ & $9.529 \mathrm{E} \cdot 02$ & $3.403 E+01$ & $3.018 E+01$ \\
\hline$-1.184 E+02$ & $3.271 E+01$ & $2.928 E+01$ & $7.133 E+01$ & $8.414 E-02$ & $3.287 E+01$ & $2.963 E+01$ \\
\hline$-1.471 E+02$ & $3.056 E+01$ & $2.728 E+01$ & $7.673 E+01$ & $6.347 \mathrm{E} \cdot 02$ & $3.065 E+01$ & $2.796 E+01$ \\
\hline$-1.484 E+02$ & $3.048 E+01$ & $2.782 E+01$ & $7.700 E+01$ & $6.268 E-02$ & $3.056 E+01$ & $2.790 E+01$ \\
\hline$-1.679 E+02$ & $2.931 E+01$ & $2.706 E+01$ & $8.131 E+01$ & $5.197 \mathrm{E} \cdot 02$ & $2.936 E+01$ & $2.711 E+01$ \\
\hline
\end{tabular}




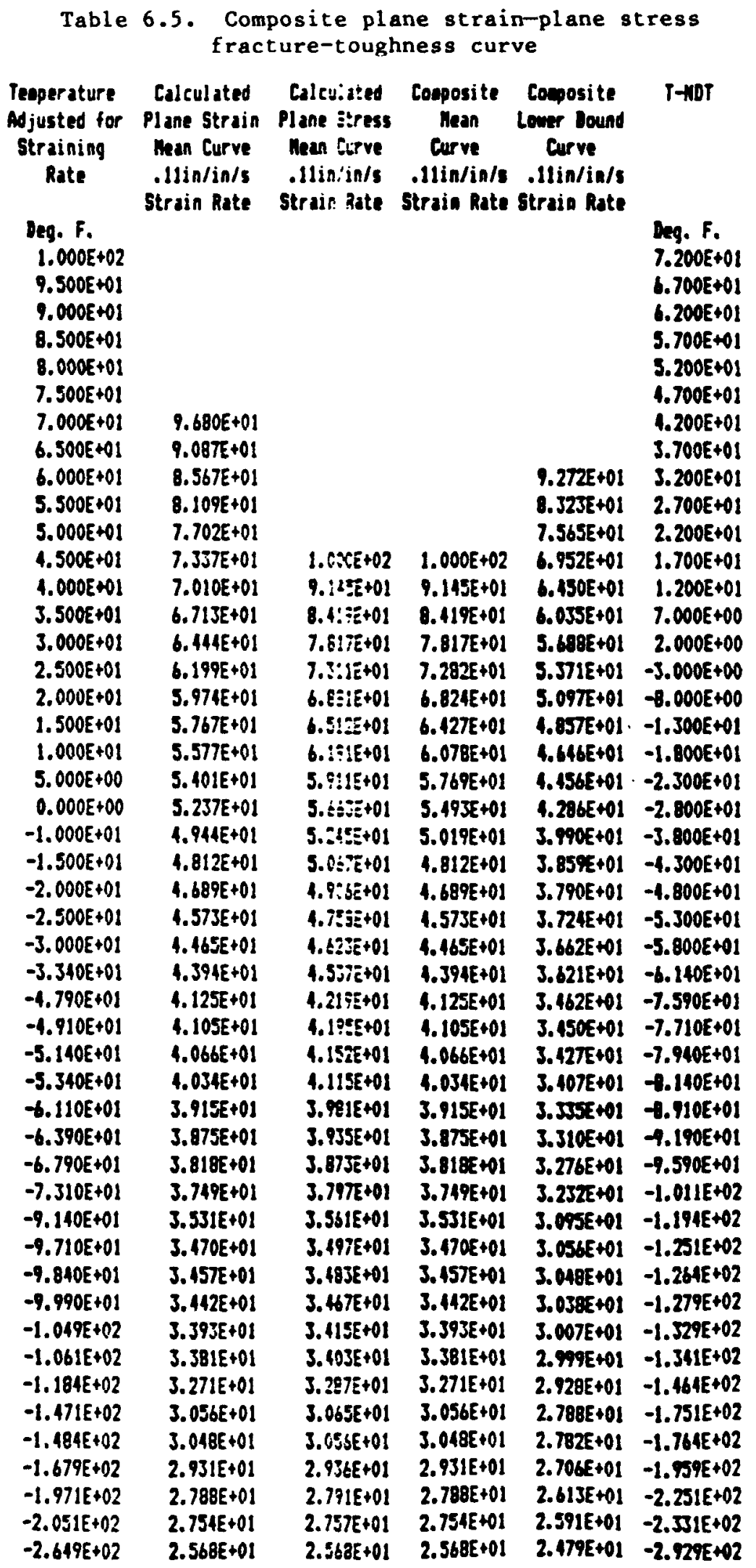




\subsubsection{Fracture-toughness data evolution}

Recently published analyses of shallow- and deep-crack A36 croD fracture-toughness specimens indicate that higher fracture toughness can be generated in specimens with small crack depths.16 This development is noted as a pointer to considerations for possible inclusion in any further evaluation of the support beams. The results of Ref. 16 are not incorporated into the current analysis.

\subsection{Radiation-Induced NDTT Shift}

NDTT shift ( $\triangle$ NDTT) values were calculated for three governing locations on the support beams for both the current condition existing at Trojan and for 32 EFPY. The steps in the analysis were as follows:

1. Determine the core midplane dpa-rate profile into the reactor cavity wall for the Trojan initial core configuration. Select dpa rates for the three governing locations.

2. Catalog the Trojan operating history to date and determine the projected operating condition in terms of the ratio $R$ of the reactor cavity dpa rate to the cavity dpa rate associated with the first core. Calculate the time-averaged, dpa-rate ratios for both prior operations and projected lifetime operations.

3. Using the dpa-rate ratios from step (2) in conjunction with the cycle 1 dpa rates from step (1), calculate effective dpa rates and total dpas for both the current condition and the projected end of life condition.

4. Using the dpa and dpa-rate data from step (3), enter Fig. 3.4 to obtain the $\triangle$ NDTT for each of the three governing locations on the beam (see Fig. 6.19).

Core midplane dpa data were obtained from Westinghouse 17 and are plotted in Fig. 6.20. Note that the data points plotted in Fig. 6.20 are the result of calculations normalized to a measured dpa rate for Diablo Canyon Unit 2. The dpa rates for the points of interest on the support beams were as follows:

\begin{tabular}{lc}
\multicolumn{1}{c}{ Beam location } & $\mathrm{dpa} / \mathrm{s}$ \\
\cline { 2 - 2 } Cavity inner surface interface & $2.79 \times 10^{-12}$ \\
Node 4: Maximum bending moment & $2.65 \times 10^{-13}$ \\
Flange hole centerline & $1.09 \times 10^{-13}$
\end{tabular}

Trojan operating history data and planned future operating conditions were obtained from Ref. 18. These data are reproduced in Table 6.6 and indicate the following dpa ratios:

$$
\begin{aligned}
& \text { Operations to date } R=7.593 / 7.48=1.015 \\
& \text { Future operation }=0.65
\end{aligned}
$$


ORNL-DWG 88C-4977 ETD

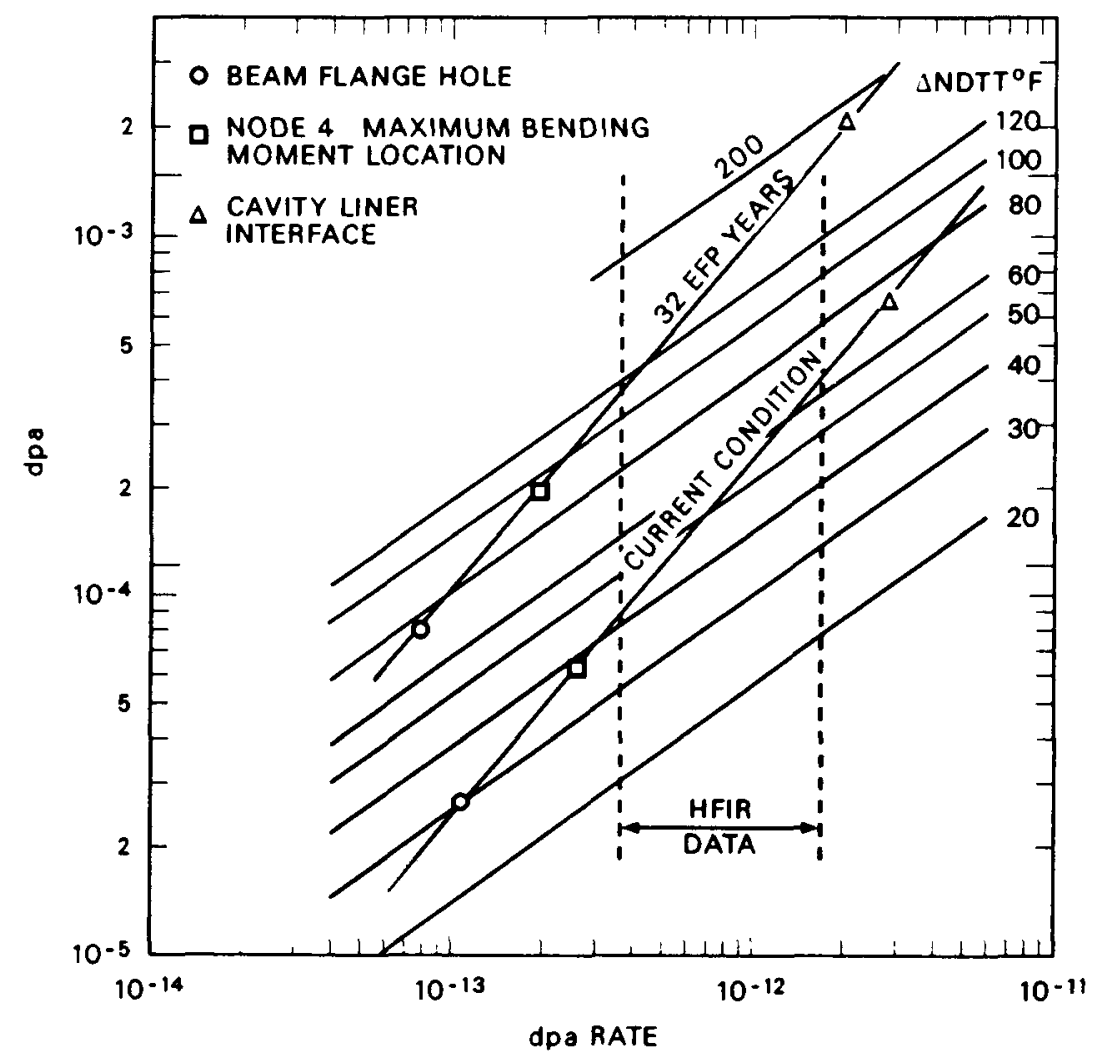

Fig. 6.19. Radiation-induced NDTT shifts at critical locations on Trojan reactor vessel support beams.

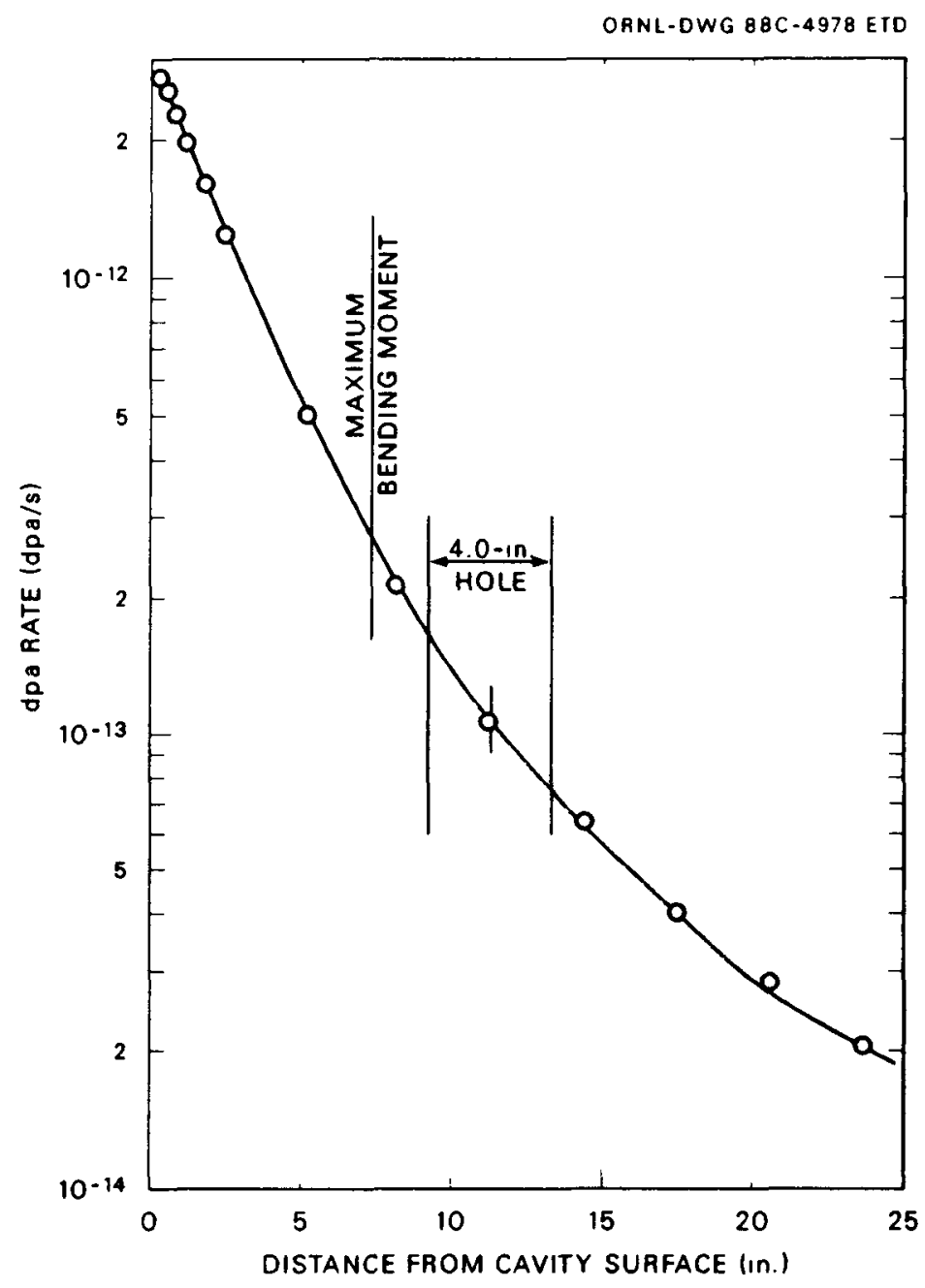

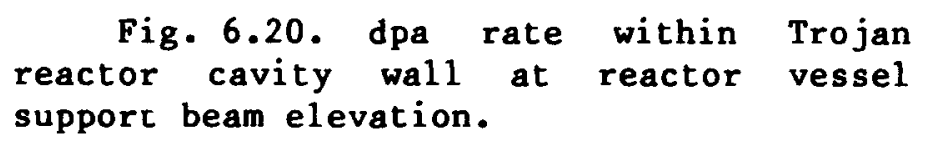
support beam elevation. 
Table 6.6. Trojan operating history

\begin{tabular}{cccc}
\hline $\begin{array}{c}\text { Reactor } \\
\text { cycle }\end{array}$ & EFPY & $\begin{array}{c}\text { Three-assembly } \\
\text { average power } \\
\text { ratio }\end{array}$ & $\begin{array}{c}\text { Weighted } \\
\text { EFPY }\end{array}$ \\
\hline 1 & 1.13 & 1 & 1.13 \\
2 & 0.78 & 1.26 & 0.9828 \\
3 & 0.69 & 1.23 & 0.8487 \\
4 & 0.59 & 1.25 & 0.7375 \\
5 & 0.37 & 1.26 & 0.4662 \\
6 & 0.68 & 1.12 & 0.7616 \\
7 & 0.51 & 0.75 & 0.3825 \\
8 & 0.69 & 0.75 & 0.5175 \\
9 & 0.74 & 0.88 & 0.6512 \\
10 & 0.5 & 0.867 & 0.435 \\
11 & 0.8 & 0.85 & 0.68 \\
12 Onward & & 0.65 & \\
& & & 7.593 \\
Totals & 7.48 & & \\
\hline
\end{tabular}

Results from the analysis of steps (3) and (4) are summarized in Table 6.7. At the present time Trojan has operated for $<25 \%$ of its presently licensed life (32 EFPY). The maximum dpa in that portion of the support beam that projects into the reactor cavity has reached a level where a $\triangle$ NDTT of $75^{\circ} \mathrm{F}$ is predicted. $\triangle$ NDTT at this location is predicted to increase to $180^{\circ} \mathrm{F}$ by 32 EFPY. Corresponding values of

Table 6.7. NDTT shift ( $\triangle$ NDTT)

\begin{tabular}{|c|c|c|c|}
\hline Beam location ${ }^{2}$ & $\begin{array}{l}\text { Cavity inner } \\
\text { surface } \\
\text { interface }\end{array}$ & $\begin{array}{l}\text { Node 4: Maximum } \\
\text { bending moment } \\
\text { location }\end{array}$ & $\begin{array}{l}\text { Beam flange } \\
\text { hole center- } \\
\text { line }\end{array}$ \\
\hline Cycle 1 dpa rate $(\mathrm{dpa} / \mathrm{s})$ & $2.790000 \mathrm{E}-12$ & $2.650000 \mathrm{E}-13$ & $1.090000 \mathrm{E}-13$ \\
\hline Average dpa ratio to date & 1.015 & 1.015 & 1.015 \\
\hline EFPY to date & 7.48 & 7.48 & 7.48 \\
\hline Total dpa to date & 0.0006680878 & 0.0000634564 & 0.0000261009 \\
\hline dpa rate to date & $2.831850 E-12$ & $2.689750 \mathrm{E}-13$ & $1.106350 \mathrm{E}-13$ \\
\hline NDTT shift to date $\left({ }^{\circ} \mathrm{F}\right)$ & 75 & 38 & 30 \\
\hline Remaining 1 ifetime (EFPY) & 24.52 & 24.52 & 24.52 \\
\hline Planned dpa ratio & 0.65 & 0.65 & 0.65 \\
\hline Additional dpa & 0.0014024898 & 0.0001332114 & 0.0000547926 \\
\hline 32-EFPY dpa & 0.0020705776 & 0.0001966678 & 0.0000808935 \\
\hline Average lifetime dpa rate & $2.051539 \mathrm{E}-12$ & $1.948595 \mathrm{E}-13$ & $8.014974 \mathrm{E}-14$ \\
\hline$\triangle$ NDTT at 32 EFPY $\left({ }^{\circ} \mathrm{F}\right)$ & 180 & 96 & 75 \\
\hline
\end{tabular}


$\triangle N D T T$ at the beam flange grout-hole centerline are $30^{\circ} \mathrm{F}$ at the present time and $75^{\circ} \mathrm{F}$ at 32 EFPY.

$T$ - NDTT values were calculated for both the current condition and 32 EFPY for a range of support beam operating temperatures. The support beam operating temperature has been set at $90^{\circ} \mathrm{F}$ (Ref. 2 ), but a range of support beam operating temperatures was included in the analyses to provide some insight into the impact of potential refinements in the definition of this parameter.

The T-NDTT values were superposed on the fracture-toughness design curve of Fig. 6.18 to obtain fracture-toughness design values for each of the critical locations on the support beam for initial, current, and 32-EFPY conditions. The resulting fracture-toughness design values are summarized in Table 6.8 .

Table 6.8. Design dynamic stress-intensity factors

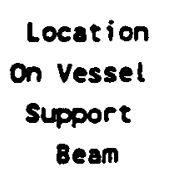

(a) T - NDT

Support beam temperature(DegF)

Cavity liner interface

Cavity liner interface

Cavity liner interface

Mode 4 : Max. Bending Moment

Node 4 : Max. Bending Moment

Node 4 : Max. Bending Moment

Beam $f$ lange hole

Beam flange hole

Beam flange hole

(b) Design fracture toughness

Cavity liner interface

Cavity liner interface

Cavity liner interface

Node 4 : Max. Bending Moment

Node 4 : Max. Bending Moment

Node 4 : Max. Bending Moment

Beam flange hole

seam flange hole

Bean flange hole

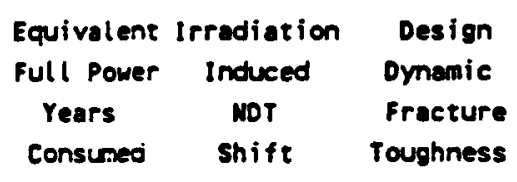

Design
Dynamic
Fracture
Toughness

Design Dymanic

Fracture Toughness 
In the case of the beam flange grout hole, additional analyses were performed to define the design fracture toughness as a function of time between the current time (7.48 EFPY) and 32 EFPY. Results from this additional analysis are summarized in Fig. 6.21. Supporting calcu-

lations for Fig. 6.21 are summarized in Table 6.9. Note that while

ORNL-DWG 88-4979 ETD

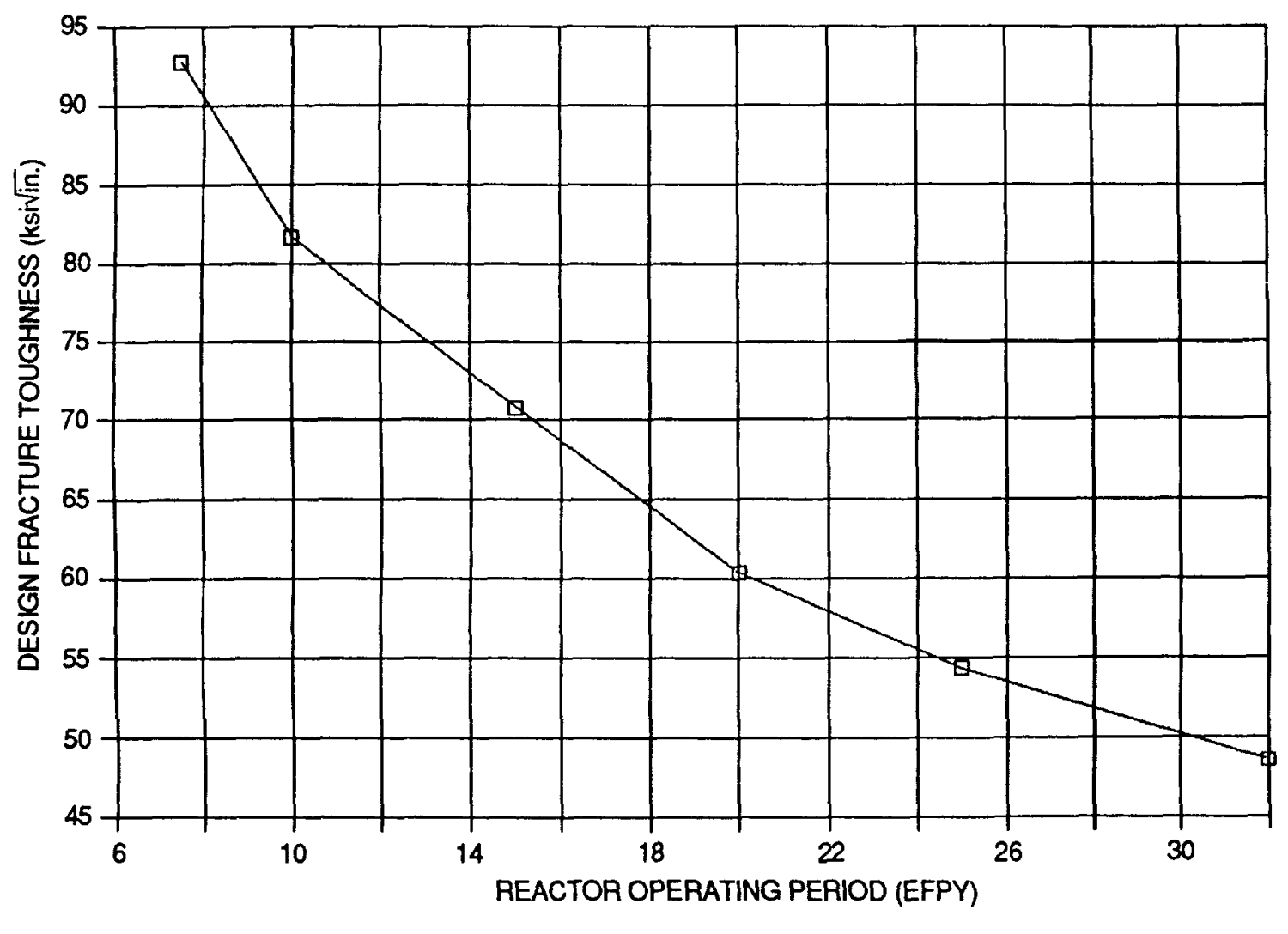

Fig. 6.21. Predicted lifetime variation in fracture toughness of A36 at reactor vessel support beam grout-hole location.

Table 6.9. Lifetime variation in $T$ - NDTT and material fracture-toughness, beam-flange-hole location BEAM FLANGE HOLE RADIAL FLAWS
E.F.P.Y.$$
\text { | 7.48E+00 1.00E+01 1.50E+01 2.00E+01 2.50E+01 3.20E+01 }
$$
Total D.P.A. 1
RT NDT Shift

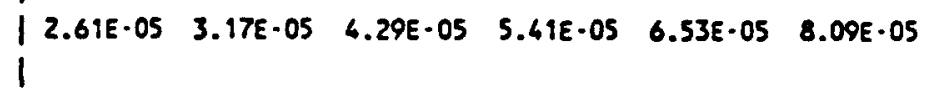
Design fracture toughness| $9.27 E+01$
8.17E+01 7.08E+01
$5.50 E+01$
$6.60 E+01$
$7.50 E+01$ 
the design fracture toughness is a nonlinear function of operating time, $\triangle$ NDTT varies with time in a roughly linear manner between 7.48 and 32.0 EFPY. An increase in the beam operating temperature can thus be used to offset additions to the reactor operating period using the following relationship:

$$
\Delta(\text { EFPY })_{\text {EFFECTIVE }}=\Delta(\text { EFPY })_{\text {ACTUAL }}-0.54(\mathrm{~T}-90),
$$

where $\mathrm{T}$ is the operating temperature at the location of concern on the support beam $\left({ }^{\circ} \mathrm{F}\right)$.

\subsection{Critica1-Flaw-Depth Ana1ysis}

Stress-intensity factors were calculated using the methods and data of Article A-3000 of Ref. 19. Lotus 123 spreadsheet templates were prepared to accept input from (1) the unit loading beam bending analysis, (2) the load case definitions, (3) the flaw shape parameter $Q$, and (4) the flaw membrane and bending stress correction factors $M_{m}$ and $M_{b}$. The spreadsheets then calculated the flaw-tip, stress-intensity factor $K_{I}$ for a range of $f 1$ aw depths (a) and flaw aspect ratios (a/1).

Note that the flaw-tip, stress-intensity factors are a nonlinear function of the applied loading. The analysis results cannot therefore be directly factored for application to other loading conditions. The analyses were, however, performed for four different peak loading conditions. A plot of results for these loading conditions provides a means of estimating the flaw-tip, stress-intensity factor for intermediate loading conditions.

Results from the flaw-tip, stress-intensity analyses were plotted as a function of flaw depth for each of the flay aspect ratios evaluated. Fracture-toughness values determined in Sect. 6.6 (see Table 6.8) were then superposed on the $K_{I}$ plots. Critical flaw depths were obtained from the intersection of the $K_{I}$ and fracture-toughness curves. Finally, the critical flaw depths calculated for each of the four loading conditions evaluated were combined in a single plot, giving critical flaw depth as a function of the maximum vessel-support load.

\subsubsection{Cavity linear interface}

A sample of the spreadsheets used to calculate stress-intensity factors at this location is given in Table 6.10. Engineers bending theory was used to calculate a linear distribution of bending stress in the overall beam section. The membrane and bending elements of stress in the upper flange were then calculated. Using these results, flawtip, stress-intensity factors were calculated for each of the flaw depths using the equation of Ref. 19, which is reproduced below as

$$
K_{I}=\sigma_{m} M_{m} \sqrt{\pi} \sqrt{a / Q}+\sigma_{b} M_{b} \sqrt{\pi} \sqrt{a / Q},
$$


TROJAN : SUPPORT BEAN CRITICAL FLAN SIZE ANALYSIS

Stress location :
Flaw type
Flaw aspect ratio a/l
Plate thickness in.

Stresses in bean flange without flaw :

Faulted (2) $=$ OH + + + S8:LOCA

Faulted (3) = OU + T + LB:LOCA

Flaw shape paraneter $=0$

Flaw depth ia" in.

Flaw depth to flange thickness ratio

Neabrane correction factor $\mathrm{he}$

Bending correction factor ito

Faulted condition (2)
(a) = SathatoSORT(PI) +asent (a/0) ;

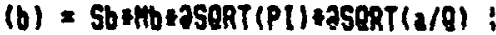
$K J=(a)+(b)$

Faulted condition (3)

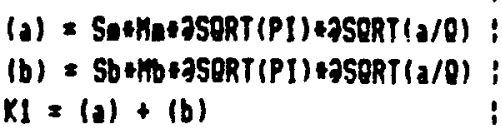

interface with the cavity liner

Eliptical surface flan

$\quad 0.100$

i

Unit lood lload case iload rase (1200 Kipl Bn inaximug load laaxious BH

:

; $969000.000 ; 1559000.000 ; 7548510.000$

$969000.000: 2443000.000: 11836335.000$

inạx. sur

Con

12380.470 :

19413.022

if lange

iflanae bend. istress

10660.960 istress

$2696.253:$

$$
\text { Sy }=
$$

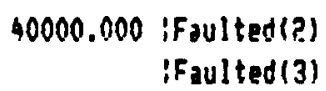

$(50+5 b) / 5 y=$

$(S a+5 b) / S y=$

0.310 i

$0=\quad \mathrm{i} .090$

$\theta=1.060$

0.050

0.020

$1.100:$

$$
0.100:
$$

$0.200:$

0.040 :

$1.100:$

0.680

$1.120:$

$1.040:$

1.020 :

0.980 :

$0.300:$

$0.120:$

$1.140:$

$0.600:$

0.240 :

1.250

$1.250:$

0.500 :

$0.940:$

0.870 i

0.890 :
4451.800 : 678.867 :

5130.667 :

$7079.67 b$

1079.446

8158.122 :
6295.797 :

$941.500:$

7237.39? :

9065.485 1279.403 :

10344.888

11301.172 1502.986: 12804.158 i

17524.420 1957.257:

19491.677 :

\subsection{7 :}

$2904.767:$

39530.944 :
14414.758 : 2034.341 ! 16449.099 ;
17969.658 2389.853 : 20359.511 i

\section{$27865.059: 58239.196:$} 3129.079 ; $\quad 618.784$ 30993.137; 62856.981; 
where

$$
\begin{aligned}
\sigma_{m}, \sigma_{b}= & \text { membrane and bending stresses (psi) in accordance with } \\
& A-3200 ; \\
a= & \text { minor half-diameter (in.) of embedded flaw, flaw depth for } \\
& \text { surface flaw; } \\
Q= & \text { flaw shape parameter as determined from Fig. A-3300-1 } \\
& \text { using }\left(\sigma_{m}+\sigma_{b}\right) / \sigma_{y s} \text { and the flaw geometry; } \\
M_{m}= & \text { correction factor for membrane stress (see Fig. A-3300-2 } \\
& \text { for subsurface flaws and Fig. A-3300-3 for surface flaws); } \\
M_{b}= & \text { correction factor for bending stress (see Fig. A-3300-4 } \\
& \text { for subsurface flaws and Fig. A-3300-5 for surface flaws). }
\end{aligned}
$$

Considerations of the effectiveness of the inner section of the concrete foundation in providing support to the beam do not influence either the distribution of bending stresses or the calculation of flawtip, stress-intensity factors at the cavity liner interface location.

A summary of flaw-tip, stress-intensity factors calculated for the support beam flange at the reactor cavity liner interface is given in Table 6.11. The analysis sheets from which these data were taken are provided in Appendix 2 .

Plots of the flaw-tip, stress-intensity factors for each of the load combinations considered are given in Figs. 6.22-6.25. The 32-EFPY $K_{\text {Id }}$ value derived for this location on the beam is $31 \mathrm{ksi} \cdot \sqrt{\text { in. }}$ Critical flaw depths corresponding to 7.48 and 32 EFPY of operation are shown plotted in Figs. 6.26 and 6.27. The critical depth under SBLOCA loading for a uniform flaw extending across the entire 16-in. width of the beam flange $(a / 1=0)$ ranges from a maximum of 0.89 in. at the current time ( 7.48 EFPY) to a minimum of 0.68 in. at 32 EFPY. The a/1 $=0 \mathrm{f} 1$ aw is common to all locations evaluated and therefore provides a useful measure of the relative severity of the brittle fracture potential at each location.

Note that the flaw tolerance at the cavity liner interface increases rapidly as the flaw aspect ratio increases above zero. Critical flaw depths were not calculated for cases in which a $>t / 2$.

A non-heat-treated fillet weld exists at the interface between the support beam flange and the reactor cavity liner. Residual stresses from the weld have not been incorporated in the flaw tolerance analysis. This approach was taken based upon the assumption that the critical flaw depths would be such as to be beyond the zone of any significant stresses introduced by this relatively small (the cavity 1 iner thickness is $0.25 \mathrm{in.)}$ fillet weld. The critical flaw depths calculated for this location appear to justify this assumption.

\subsubsection{Maximum bending moment location (Node 4)}

Node 4 is located within the concrete embedment at a point 16.5 in. from the point of application of the load. The beam geometry at this location is identical with that at the cavity liner interface, and the 
Table 6.11

TROJAY: SUPPORT REAH CRIIICAL FLAU SIZE AKALYE'j

STRESS IXTENSITY SUMYARY : INTERFACE WITH THE :HIITY LIMER

\begin{tabular}{|c|c|c|c|c|c|c|c|c|c|}
\hline \multirow[t]{2}{*}{ Load case } & \multirow{2}{*}{$\begin{array}{c}\text { Inner } \\
\text { Concrete } \\
\text { Effective? }\end{array}$} & \multirow{2}{*}{$\begin{array}{l}\text { flaw } \\
\text { Aspect } \\
\text { Ratio }\end{array}$} & \multirow[b]{2}{*}{$r .00$} & \multirow[b]{2}{*}{0.05} & \multirow[b]{2}{*}{0.10} & \multirow[b]{2}{*}{0.20} & \multirow[b]{2}{*}{0.30} & \multirow[b]{2}{*}{0.60} & \multirow[b]{2}{*}{1.25} \\
\hline & & & & & & & & & \\
\hline$D N+T+O B E$ & Mo & $n .00$ & 0.13 & 3891.00 & 5683.00 & 7964.00 & $1013 n .0 n$ & 17252.00 & 55956,00 \\
\hline$D N+T+O B E$ & ko & 0.10 & $0.0^{n}$ & 3602.00 & 5081.00 & 7263.00 & 8990.00 & 13686.00 & 27757.01 \\
\hline$D W+T+O B E$ & No & 0.20 & 0.99 & 3322.00 & 4680.00 & 6577.00 & 7993.00 & 11582.00 & 19575.00 \\
\hline $0 U+T+0 B E$ & No & 0.30 & 0.69 & 2939.00 & 4140.00 & 5810.00 & 7061.00 & 9965.00 & 15101.00 \\
\hline$D N+T+O B E$ & No & 0.50 & 0.9 & 2393.00 & 3379.00 & 4741.00 & 5752.09 & 7968.00 & 10933.00 \\
\hline$D W+T+0 B E$ & Yes & 0.00 & 0.60 & M.A. & N.A. & N.A. & X.A. & N.A. & H.A. \\
\hline$D W+T+0 B E$ & Yes & 0.10 & 0.99 & M.A. & Y.A. & H.A. & M.A. & H.A. & H.A. \\
\hline$O W+T+08 E$ & Yes & 0.20 & 0.00 & M.A. & N.A. & N.A. & M.A. & H.A. & A.A. \\
\hline$D W+T+O B E$ & Yes & 0.30 & 0.91 & N.A. & H.A. & N.A. & N.A. & N.A. & H.A. \\
\hline$D W+T+0 B E$ & Yes & 0.50 & 0.60 & N.A. & H.A. & R.A. & R.A. & N.A. & N.A. \\
\hline$D U+T+55 E$ & No & 0.00 & 0.39 & 4292.00 & 6047.00 & 8783.00 & 11227.00 & 19026.00 & 61709.00 \\
\hline OW+T+SSE & No & 0.10 & $0.0 \hat{0}$ & 3973.00 & 5604.00 & 8010.00 & 9915.00 & 15093.00 & $30611.0 n$ \\
\hline$B N+T+S S E$ & Mo & 0.20 & $n . m$ & 3664.00 & 5162.00 & 7253.00 & 8815.00 & 12773.00 & 21598.00 \\
\hline$B W+T+5 S E$ & No & 0.30 & $0 . \hat{\imath} \hat{v}$ & 3231.00 & 4552.00 & 6389.00 & 7764.00 & 10957.00 & $166 n 3.00$ \\
\hline$D H+T+S S E$ & $N_{0}$ & 0.50 & $0.3 n$ & 2667.00 & 3757.00 & 5272.00 & 6407.00 & 8860.00 & 12517.00 \\
\hline$D U+T+S S E$ & Yes & 0.00 & $0 . r 0$ & N.A. & M.A. & N.A. & H.A. & N.A. & N.A. \\
\hline DU+T+SSE & Yes & 0.10 & $0 . \therefore$ & A.A. & H.A. & M.A. & M.A. & N.A. & M.A. \\
\hline$D W+T+5 S E$ & Yes & 0.20 & $0 . \wedge 0$ & N.A. & A.A. & N.A. & H.A. & N.A. & M.A. \\
\hline$D U+T+5 S E$ & Yes & 0.30 & 0.02 & M.A. & H.A. & N.A. & M.A. & N.A. & H.A. \\
\hline$D W+T+5 S E$ & Yes & 0.50 & $0 . \wedge 1$ & N.A. & H.A. & N.A. & H.A. & A.A. & H.A. \\
\hline$D W+T+S B: L O C A$ & No & 0.00 & $1 . m$ & 5545.20 & 7813.04 & 11347.94 & 14505.67 & 24580.89 & 79726.00 \\
\hline OU +T+SB:LCCA & No & 0.10 & $0.5^{\prime \prime}$ & $513 n . k^{7}$ & 7237.60 & 10344.89 & 12904.16 & 19491.68 & 39530.96 \\
\hline$O U+T+5 B: L O C A$ & No & 0.20 & $0.1^{9}$ & 4728.56 & 6661.64 & 9380.75 & 11376.00 & 16484.56 & 27859.37 \\
\hline$D U+T+S B$ : LOCA & No & 0.30 & 0.19 & 4179.59 & 5888.17 & 8263.09 & 10041.71 & 14171.53 & 21676.39 \\
\hline OU+T+5B:LOCA & No & 0.50 & $0 . \hat{*}$ & 3607.38 & 4800.25 & 6735.23 & 3186.04 & 11319.89 & 15531.72 \\
\hline$D W+T+5 B: L O C A$ & Yes & 0.00 & 0.80 & N.A. & M.A. & M.A. & H.A. & W.A. & M.A. \\
\hline$D H+T+5 B: L O C A$ & Yes & 0.10 & 0.00 & H.A. & M.A. & H.A. & M.A. & ค.A. & M.A. \\
\hline BW+T+SB:LOCA & Yes & 0.20 & 0.60 & H.A. & N.A. & N.A. & H.A. & N.A. & ด.A. \\
\hline OW+T+58:LOCA & Yes & 0.30 & n..' & N.A. & M.A. & N.A. & N.A. & M.A. & N.A. \\
\hline BU+T+SB:LOCA & Yes & 0.50 & 0.91 & N.A. & N.A. & N.A. & H.A. & A.A. & N.A. \\
\hline$O W+T+L B: L O C A$ & Mo & 0.00 & 0.10 & 8794.00 & 12378.00 & $1797 h .0 n$ & 22978.00 & 38939.00 & 126295.00 \\
\hline DW+T+LB:LOCA & $x_{0}$ & 0.10 & 0.00 & 815. & 11507,00 & 16449.00 & 20350.10 & 30993.00 & 6295.6 .00 \\
\hline$O W+T+L B: L O C A$ & Ho & 0.20 & 0.10 & $7473.0 n$ & 10528.00 & $\$ 4794.00$ & 17978.00 & 26052.00 & 44029,10 \\
\hline$B y+T+L B: L O C A$ & No & 0.30 & $0 . \wedge \hat{v}$ & 6594.00 & $9290.0 \mathrm{n}$ & 13037.00 & 15943.00 & 22359.10 & $3388 \mathrm{i} .00$ \\
\hline$D U+J+L B: L O C A$ & $N_{0}$ & 0.50 & 0.60 & 5364.00 & $7559.0 n$ & 10606.00 & 12989.01 & 17823.00 & 24654.00 \\
\hline OW+THLA:LOCA & Yes & 0.00 & $0.6 n$ & M.A. & R.A. & N.A. & N.A. & H.A. & M.A, \\
\hline$O W+1+L B: \angle O C A$ & Yes & 0.10 & 0.00 & H.A. & M.A. & N.A. & M.A. & M.A. & M.A. \\
\hline DW+THE:LOCA & Yes & 0.20 & $0.9 n$ & M.A. & W.A. & R.A. & H.A. & B.A. & N.A. \\
\hline$O U+T+\angle B: \angle O C A$ & Yes & 0.39 & $n .9 n$ & N.A. & H.A. & X.A. & M.A. & M.A. & M.A. \\
\hline$O N+T+L B: L O C A$ & Yes & 0.50 & 0.10 & M.A. & H.A. & N.A. & M.A. & N.A. & N.A. \\
\hline
\end{tabular}

$O H+T+O B E=1099 K_{105} . \quad O H+T+5 R: 1 C C 7=1558 K_{105}$

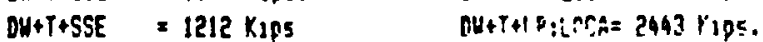


ORNL-DWG $88-4980$ ETD

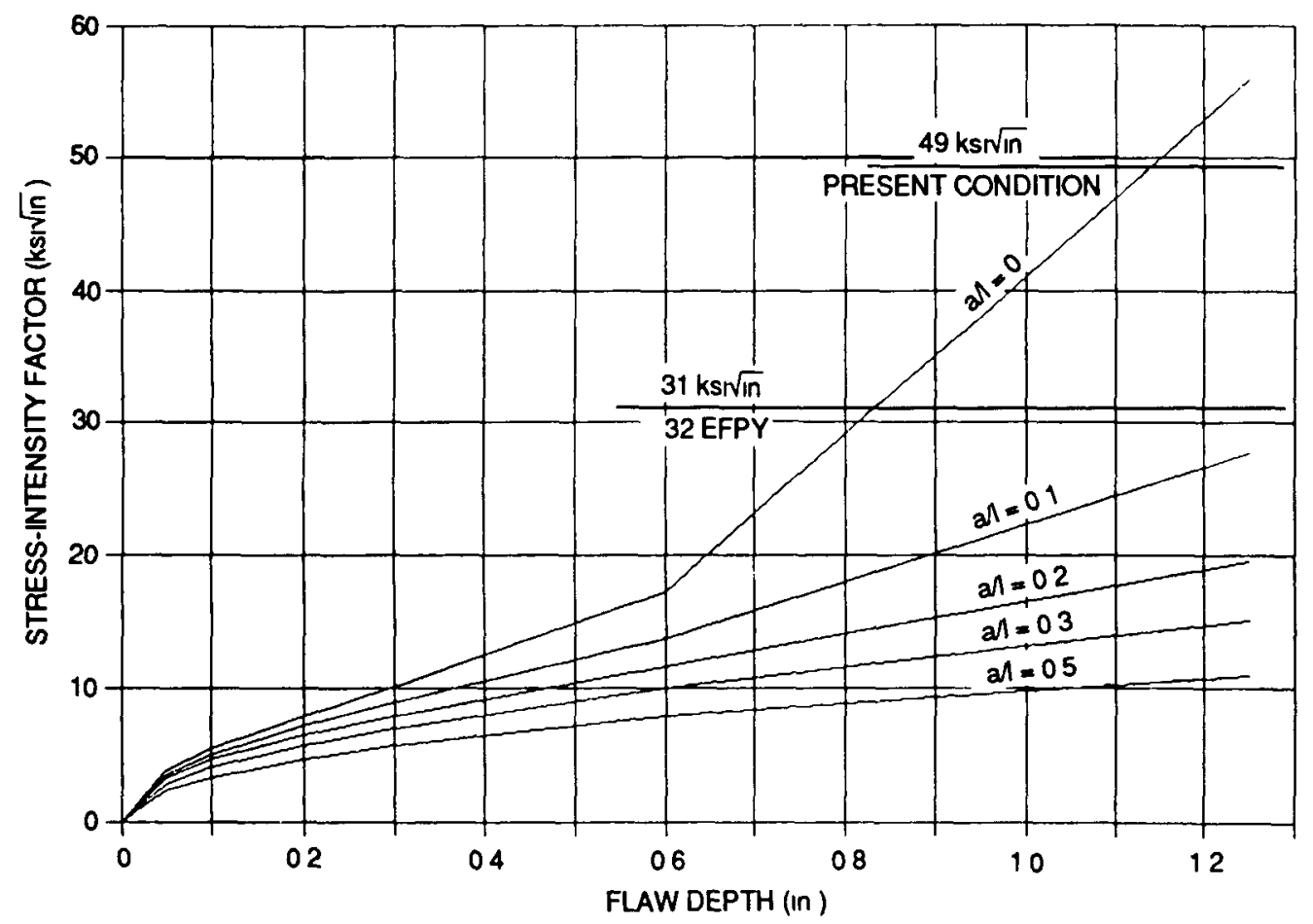

Fig. 6.22. Stress-intensity factors at cavity liner interface as function of flaw depth and flaw aspect ratio: $D W+T+O B E$ loading.

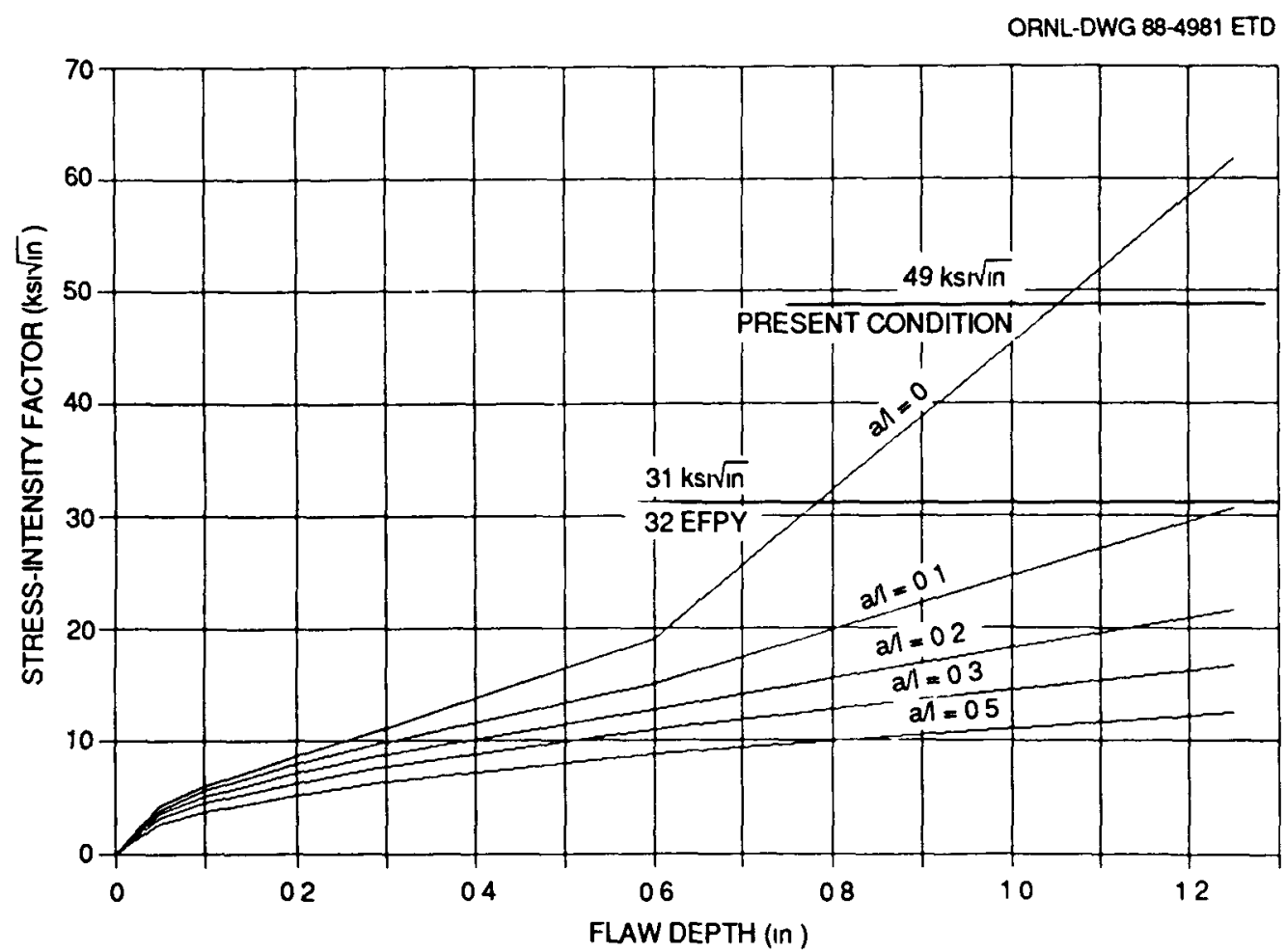

Fig. 6.23. Stress-intensity factors at cavity liner interface as function of flaw depth and flaw aspect ratio: $D W+T+S S E$ loading. 


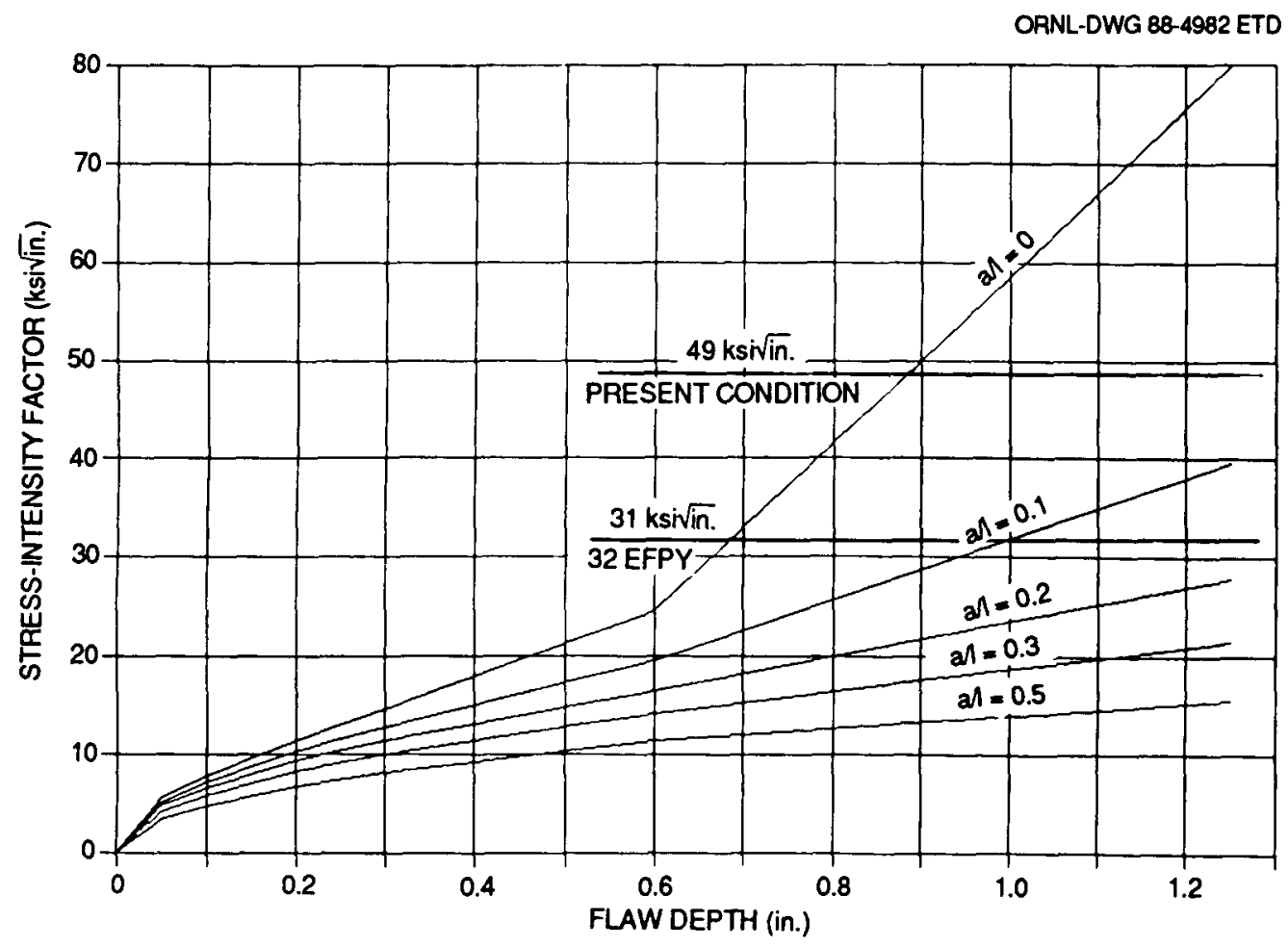

Fig. 6.24. Stress-intensity factors at cavity liner interface as function of flaw depth and flaw aspect ratio: DW + T + SBLocA loading.

ORNL-DWG 88-4983 ETD

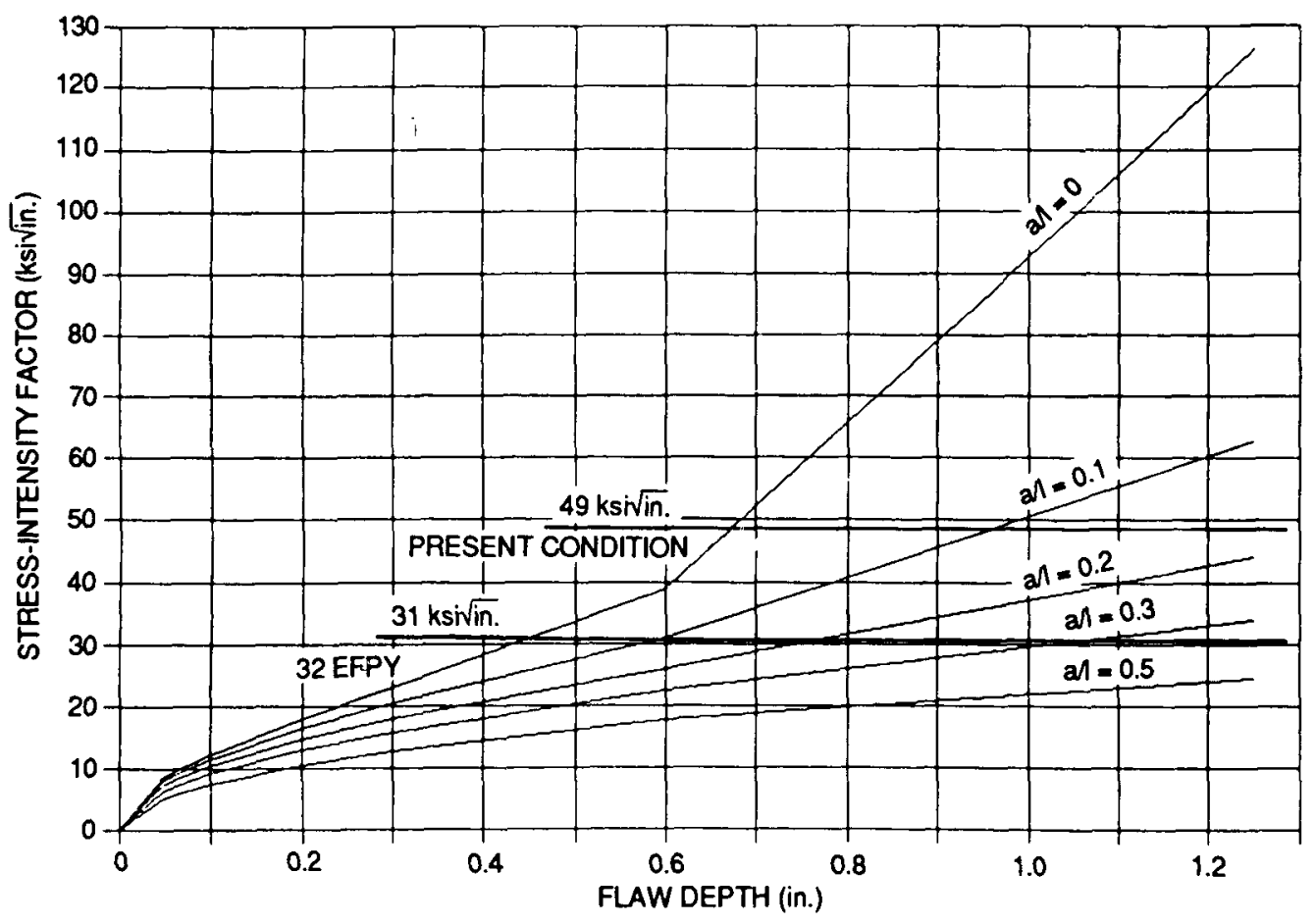

Fig. 6.25. Stress-intensity factors at cavity liner interface as function of flaw depth and flaw aspect ratio: DW + T + LBLOCA loading. 


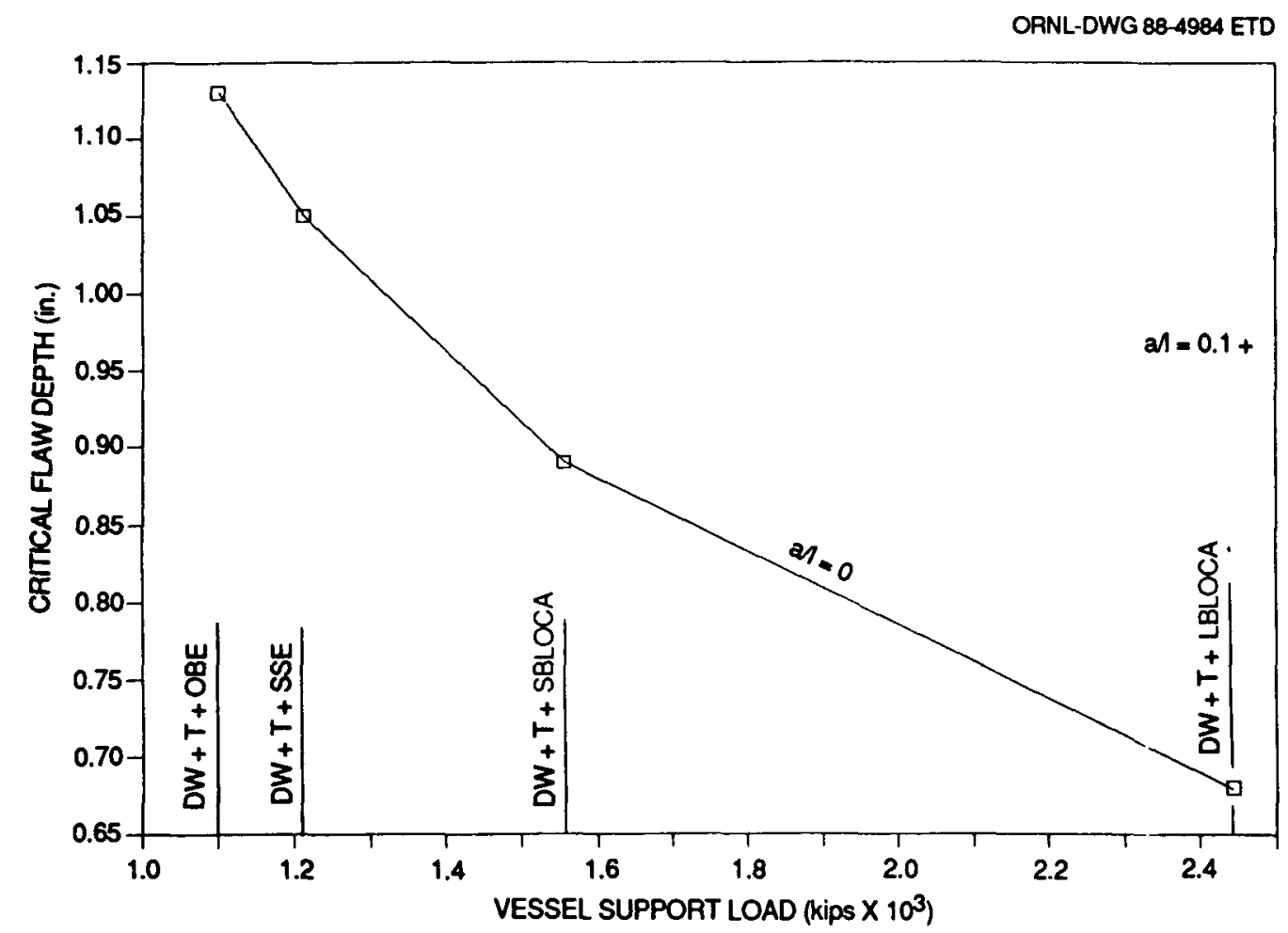

Fig. 6.26. Critical flaw depths at cavity liner interface after 7.48 EFPY of operation (current condition).

ORNL-DWG $88-4985$ ETD

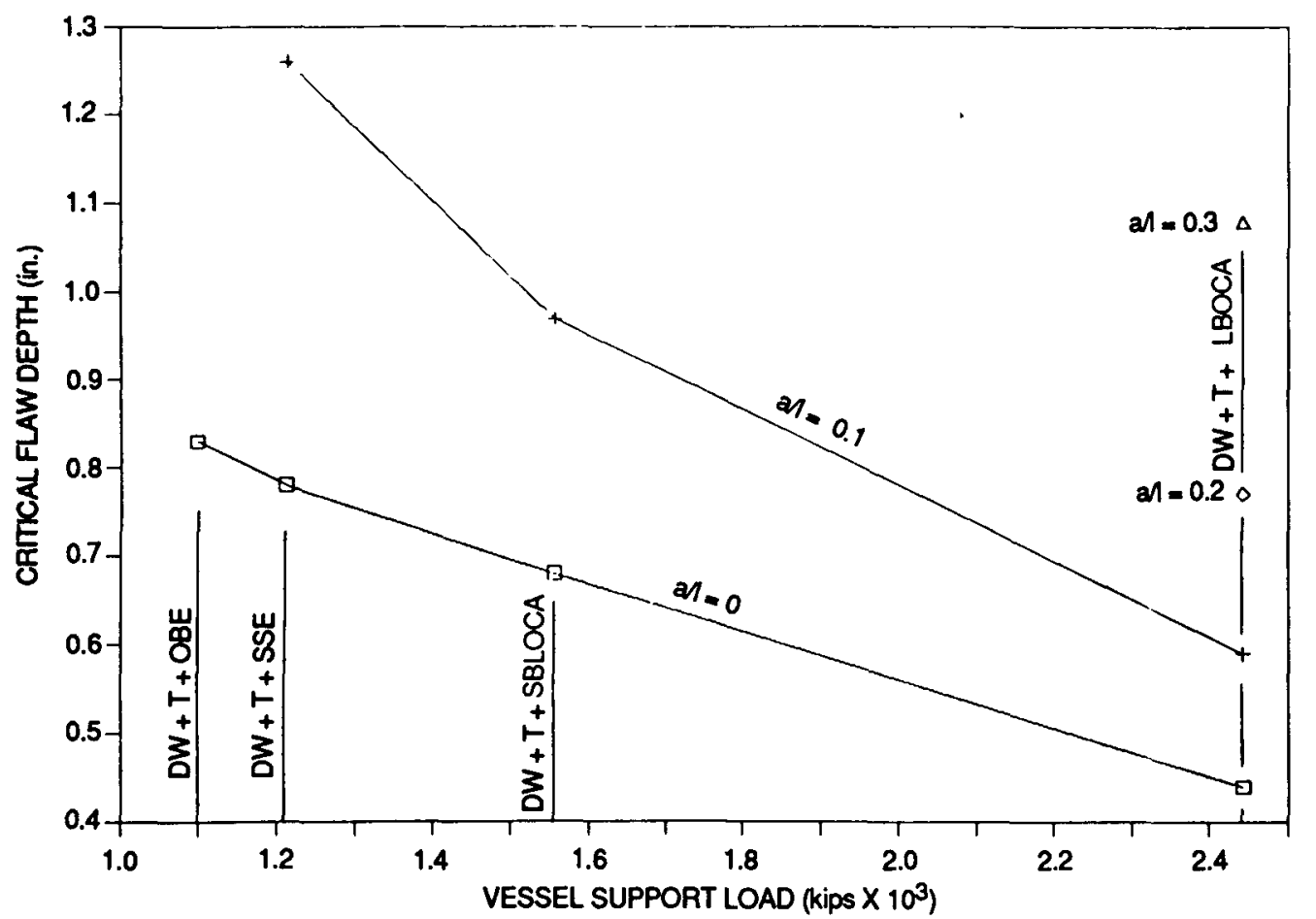

Fig. 6.27. Critical flaw depths at cavity liner interface after 32.0 EFPY of operation. 
method of analysis is thus very similar to that described in Sect. 6.7.1 (only the input parameters are different). Examination of Fig. 6.7 and Table 6.8, however, shows the existence of a substantial difference between the two locations. The bending moment diagram of Fig. 6.7 shows a $57.6 \%$ increase (for the case where the inner concrete does not provide support for the beam) at Node 4 relative to the cavity liner interface, whereas the fracture-toughness data of Table 6.8 show only a $32 \%$ increase between the same two points at 32 EFPY. It is to be anticipated therefore that critical flaw depths at the Node 4 location will be smaller than those at the cavity liner interface. To balance this view, however, it must be recognized that no attachments or processes with known crack-producing potential exist at Node 4, whereas a fillet weld between the cavity liner and the beam flange exists at the cavity liner interface.

A sample spreadsheet used in the analysis of the Node 4 stressintensity factors is given in Table 6.12 , and a summary of the stressintensity-factor results is given in Table 6.13. Appendix 3 contains al1 of the spreadsheets used in the analysis of the Node 4 location.

Note that the results for Node 4 are influenced by the effectiveness of the internal concrete in providing foundation support for the beam. The results of Sect. 6.4.4.1 suggest that the inner concrete can be assumed effective for seismic loading cases but not for the doubleended break (LBLOCA) case. The SBLOCA case represents a transition condition.

Plots of the flaw-tip, stress-intensity factors are given in Figs. 6.28-6.31 for the case in which the inner concrete provides no foundation support and in Figs. 6.32-6.35 for the case where the inner concrete provides support. Cross plots of the critical flaw size as a function of the applied vessel support loading are given in Figs. 6.36 and 6.37 for the cases of no inner concrete support and in Figs. 6.38 and 6.39 for the case of fully effective inner concrete support.

Critical 32-EFPY flaw depths for SBLOCA loading for the a/1 $=0$ case, with no inner concrete support, range from a maximum of 0.88 in. for the current condition ( 7.48 EFPY) to a minimum of 0.61 in. at 32 EFPY. With the inner concrete providing foundation support, these values increase to 0.97 and 0.65 in., respectively. Critical flaw depths at the maximum bending moment location are thus similar to those calculated for the cavity liner interface location. The trend of rapidly increasing critical flaw depths as the flaw aspect ratio increases above zero is also observed in the Node 4 analysis results.

\subsubsection{Beam-flange grout-hole location}

The grout-hole location in the beam flange differs substantially from the other locations considered because (1) the crack front of the flaw of concern is parallel to the axis of the hole rather than parallel to the free surface of the flange (as was the case in the previous two locations considered) and (2) the presence of the flange hole introduces a substantial stress concentration at the surface of the flange hole. Feature (1) requires that the stress at the middle plane of the beam flange be used in the stress-intensity-factor calculation to satisfy the 
TROJAN : SUPPORT BEAM CRITICaL FLAM SIZE AMaLYSIS

Stress locstion:

Flaw type

Flaw aspect ratio a/l

Plate thickness in.

Stresses in beas flange nithout flan

Faulted (2) $=$ OU $+T+$ SB:LOCA

Faulted $(3)=O N+T+$ LB:LDCA

Flaw shape paraseter $=$ ?

Flan depth "a" in.

Flaw depth to flange thickness ratio

Meabrane correction factor the

Bending correction factor

Faslted condition (2)

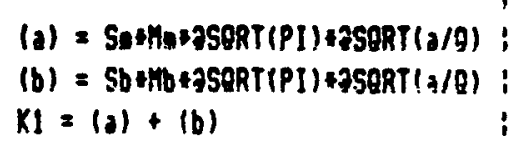

Faulted condition (3)

$$
\begin{aligned}
& \text { (a) = Sa+MareSQRT (PI) +3SERT (a/O) }
\end{aligned}
$$

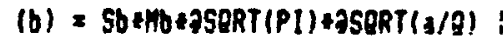

$$
\begin{aligned}
& K l=(a)+(b)
\end{aligned}
$$

Inode Ai Max. Bn: Immer concrete not effective iEliptical zurface flax

$\quad 0.190$

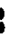

lload case lLozd case i(200 Kipl gu iadiaus load inaxigun on

$i$

1527000.000 : 1558000.009: :11895330.000 $1527000.060 \div 2443000.000: 18652305.060$

istress

\section{istres}

i

19509.781

30592.037

:Flange sean

iflanoe bend. istress

;

16800.089: 2709.67?:

26343.143 i 4248.894 ;

Sy $=$

40000.000 IFaulted(2)

0.050

$0.020:$

1.100 :

$1.140:$

$0.100:$

0.040

$1.100:$

$1.020:$

iFaulted(3)

$(50+5 b) / 5 y=$

$(5 s+5 b) / 5 y=$

$$
\begin{aligned}
& 0.200: \\
& 0.030: \\
& 1.120: \\
& 0.980:
\end{aligned}
$$

$0.300:$

$0.120:$

$1.140:$

$0.940:$

$0.488: \quad 0=1.010$
$0.765 ; \quad 0=0.970$

$0.600: 1.250:$

$0.240: 0.500:$

$1.250: \quad 1.210:$

$0.870: 0.890:$

7297.919 :

1111.25\% :

2399.273 :

10306.673 ;

14840.852 2094.475

$11848.161 ＼mathrm{~ 16935.328 ： ~}$

18500.834 3460.496 2095!.33n:

28688.739 3220.542 : $31709.282:$

$59959.694:$

$4755.313:$

64715.000

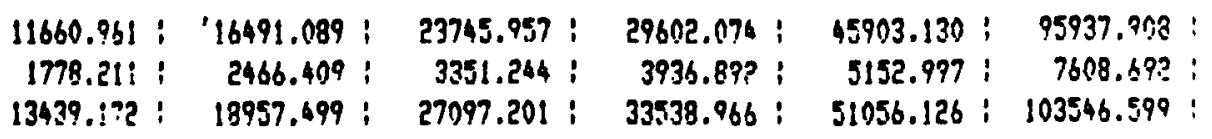


Table 6.13

TROJAN: SUPPORT BEAN CRITICAL FLAH SIZE AHAIYSIS

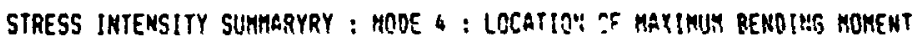

\begin{tabular}{|c|c|c|c|c|c|c|c|c|c|}
\hline \multirow[t]{2}{*}{ Load case } & \multirow{2}{*}{$\begin{array}{c}\text { Inner } \\
\text { Concrete } \\
\text { Effective? }\end{array}$} & \multirow{2}{*}{$\begin{array}{l}\text { Flay } \\
\text { Aspect } \\
\text { Rat10 }\end{array}$} & \multirow[b]{2}{*}{0.10} & \multirow[b]{2}{*}{0.05} & \multirow[b]{2}{*}{0.10} & \multirow[b]{2}{*}{0.20} & \multirow[b]{2}{*}{0.30} & \multirow[b]{2}{*}{0.60} & \multirow[b]{2}{*}{1.25} \\
\hline & & & & & & & & & \\
\hline$O H+7+O B E$ & No & 0.00 & 0.90 & 6133.00 & 3641.00 & 12551.00 & 16043.00 & 27186.00 & 88178.00 \\
\hline$D U+T+O B E$ & No & 0.10 & $n . \therefore 0$ & 5677.00 & 8008.00 & 11446.00 & 14168.00 & c1568.10 & $637 \$ 2.00$ \\
\hline $\mathrm{OH}+\mathrm{T}+\mathrm{OBE}$ & No & 0.20 & $n . \cap ?$ & 5175.00 & 7291.00 & 1024h.nก & 12652.00 & 18044.00 & 30495.100 \\
\hline$D U+T+O B E$ & No & 0.30 & $n . m ?$ & 4617.00 & 6505.00 & 9124.00 & 11094.00 & 15657.00 & 23725. \\
\hline $\mathrm{OH}+\mathrm{T}+\mathrm{OBE}$ & $N_{0}$ & 0.50 & 0.09 & 3819.09 & 5380.00 & 7550.00 & 3175.00 & 12687.00 & 17408.09 \\
\hline$D N+T+D B E$ & Yes & 0.00 & 0.00 & 5327.00 & 7506.00 & 10902.00 & 13935.00 & 23615.00 & 76593.00 \\
\hline $\mathrm{OH}+\mathrm{T}+\mathrm{DBE}$ & Yes & 0.10 & $0.9 ?$ & 4933.00 & 6959.00 & 9947.09 & 12312.00 & 18762.00 & $3801 ? .00$ \\
\hline$D U+T+D R E$ & Yes & 0.20 & $0 . \mathrm{An}^{n}$ & 4501.00 & 6341.00 & 8910.00 & IORP29. & 15692.00 & $265 e n .00$ \\
\hline $\mathrm{DH}+\mathrm{T}+\mathrm{CBE}$ & Yes & 0.30 & 0.00 & 4006.00 & 5644.00 & 7921.00 & Ps23.00 & 13535.00 & $205,35.00$ \\
\hline $\mathrm{DH}+\mathrm{T}+\mathrm{OBE}$ & Yes & 0.50 & 0.93 & 3313.00 & 4667.00 & 6550.00 & 7959.06 & 11007.00 & 15102.00 \\
\hline$D H+T+$ SSE & No & 0.00 & 0.60 & 6832.00 & 9636.00 & 1398?..00 & $1787 ? .00$ & 30285.00 & 98232.00 \\
\hline$D U+T+S S E$ & $\mathrm{Ho}_{0}$ & 0.10 & 0.00 & 6348.00 & 8954.00 & 12799.00 & 15842.00 & 24116.00 & 48911.00 \\
\hline$D W+T+S S E$ & no & 0.20 & $0, A^{1}$ & 5819.00 & 8198.00 & 11520.00 & 140000.00 & 20287.00 & 34286.00 \\
\hline$D U+T+5 S E$ & $N_{0}$ & 0.30 & $0.6 n$ & 5139.00 & 7240.60 & 10160.00 & 12347.00 & 17426.00 & $26406.0 n$ \\
\hline DH+T+SSE & No & 0.50 & 0.09 & $422^{9} .09$ & 5959.00 & 8361.00 & 10150.00 & 14050.00 & 19278.00 \\
\hline$D U+T+5 S E$ & Yes & 0.00 & $0 . \mathrm{Mn}$ & 5934.00 & 8361.00 & 12143.00 & 15523.00 & 26305.00 & 85318.00 \\
\hline $\mathrm{OH}+\mathrm{T}+$ SSE & Yes & 0.10 & 0.91 & 5490.00 & 7745.00 & $11070.9 n$ & 13702.00 & 20958.00 & 42303.00 \\
\hline$D H+T+S S E$ & Yes & 0.20 & $n . n^{n}$ & so21.0n & 7073.00 & 9939.00 & 12079.010 & 17504.00 & 29583.10 \\
\hline OH+T+SSE & Yes & 0.30 & $0 .{ }^{n}$ & 4472.09 & 6301.00 & 8842.00 & 10765.00 & 15165.00 & 22980.00 \\
\hline$D H+T+S S E$ & Yes & 0.50 & $0 . \hat{n}^{n}$ & 3676.00 & 5179.00 & $3268.0 n$ & 8932.00 & 12214.00 & 16759.00 \\
\hline$O H+7+5 B: \angle O C A$ & Ho & 0.00 & 0.60 & 9064.76 & $1277 ? .01$ & 18550.52 & 23712.47 & 40192.44 & 13032R.35 \\
\hline$O H+T+S B: L O C A$ & $H_{0}$ & 0.10 & 0.00 & $8399 . ? 7$ & 11868.14 & 16935.33 & $2096 \mathrm{i.33}$ & 31909.28 & 64715.01 \\
\hline$O H+T+5 B: \angle O C A$ & No & 0.20 & $0 . \because n$ & 7601.46 & 10709.00 & $1504 ? .98$ & 18237.62 & 26479.95 & 44795.66 \\
\hline$D H+T+58: \angle D C A$ & No & 0.30 & $0 . r 0$ & 6732.55 & 9484.78 & 13310.32 & 16175.38 & 22.827 .78 & 36591.35 \\
\hline $\mathrm{DH}+\mathrm{T}+58: \mathrm{LOCA}$ & No & 0.50 & 0.03 & 5483.06 & 7726.43 & 10837.75 & 13172.75 & 18215.64 & 24993,20 \\
\hline$O U+T+58: L O C A$ & Yes & 0.00 & $0 . c^{n}$ & 7787.17 & 10971.91 & 15936.00 & 20370.42 & 34519.10 & 111959.80 \\
\hline $\mathrm{OH}+\mathrm{T}+\mathrm{SB}: \mathrm{LOCA}$ & Yes & 0.10 & 0.09 & 7191.16 & 10143.98 & $16499.4 ?$ & 17946.34 & 27319.59 & 55408.68 \\
\hline DH+T+SB:LOCA & Yes & 0.20 & 0.00 & 6530.38 & 9200.06 & 12927.67 & 15710.83 & $2276 h .00$ & 38675.19 \\
\hline$D H+T+S B: L O C A$ & Yes & 0.30 & $0.0 ?$ & 5821.49 & 8201.29 & 11509,15 & 13996.51 & 19738.70 & 29910.41 \\
\hline$D U+T+S B: L O C A$ & Yes & 0.50 & 0.50 & 4756.07 & 6700.26 & 9402.52 & 11426.18 & 15800.44 & 21679.38 \\
\hline$D H+T+1 B: L D C A$ & No & 0.00 & 0.60 & 14616.00 & 20594.00 & ?\$91?.00 & 38235.00 & 66772.100 & 210149.00 \\
\hline DULT+LB:LCCA & No & 0.10 & $0 . \mathrm{n}$ & 13439.00 & $1895 ? .00$ & 27097.00 & 33539.00 & 510.56 .00 & 103546.00 \\
\hline$D H+T+18: \angle O C A$ & No & $0.2 n$ & $0.9 n$ & 12067.00 & 170000.00 & 23988.00 & $29031.0 n$ & 42069.00 & 71097.00 \\
\hline$D H+T+L 8: L O C A$ & $N_{0}$ & 0.30 & $0 . r c$ & 10694.00 & 15066.00 & 21143.00 & 25695.00 & 36262.00 & 54969.00 \\
\hline$D H+T+L B: L O C A$ & $N_{2}$ & 0.50 & 0.09 & 8653.00 & 12191,00 & 17107.00 & 20789.00 & 28747.00 & 39443.00 \\
\hline$D H+T+L B: L O C A$ & Yes & 0.00 & Q.6n & 12476.00 & $17578.0 n$ & 25531.00 & 32636.00 & 55304.00 & 179373.09 \\
\hline$O H+T+\angle B: L O C A$ & Yes & 0.10 & $n . A n$ & 11394.00 & 18059.00 & 22955.0n & $29412.0 \mathrm{~m}$ & 43252.00 & 87719.00 \\
\hline DU $+1+L B: L O C A$ & Yes & 0.20 & $0.6^{n}$ & 10363.00 & 14599,00 & 20516.00 & 24931.00 & 36127.00 & 61055.00 \\
\hline$D U+T+L B: L O C A$ & Yes & 0.30 & 0.919 & P157. .0. & 12990.00 & 18102.00 & 22000.00 & 31048.00 & 47048.00 \\
\hline$D U+T+L B: L O C A$ & Yes & 0.50 & $n .1 n$ & 7457.00 & 105ns.00 & $1+743.00$ & 17916.00 & 26775.00 & 33994.00 \\
\hline
\end{tabular}




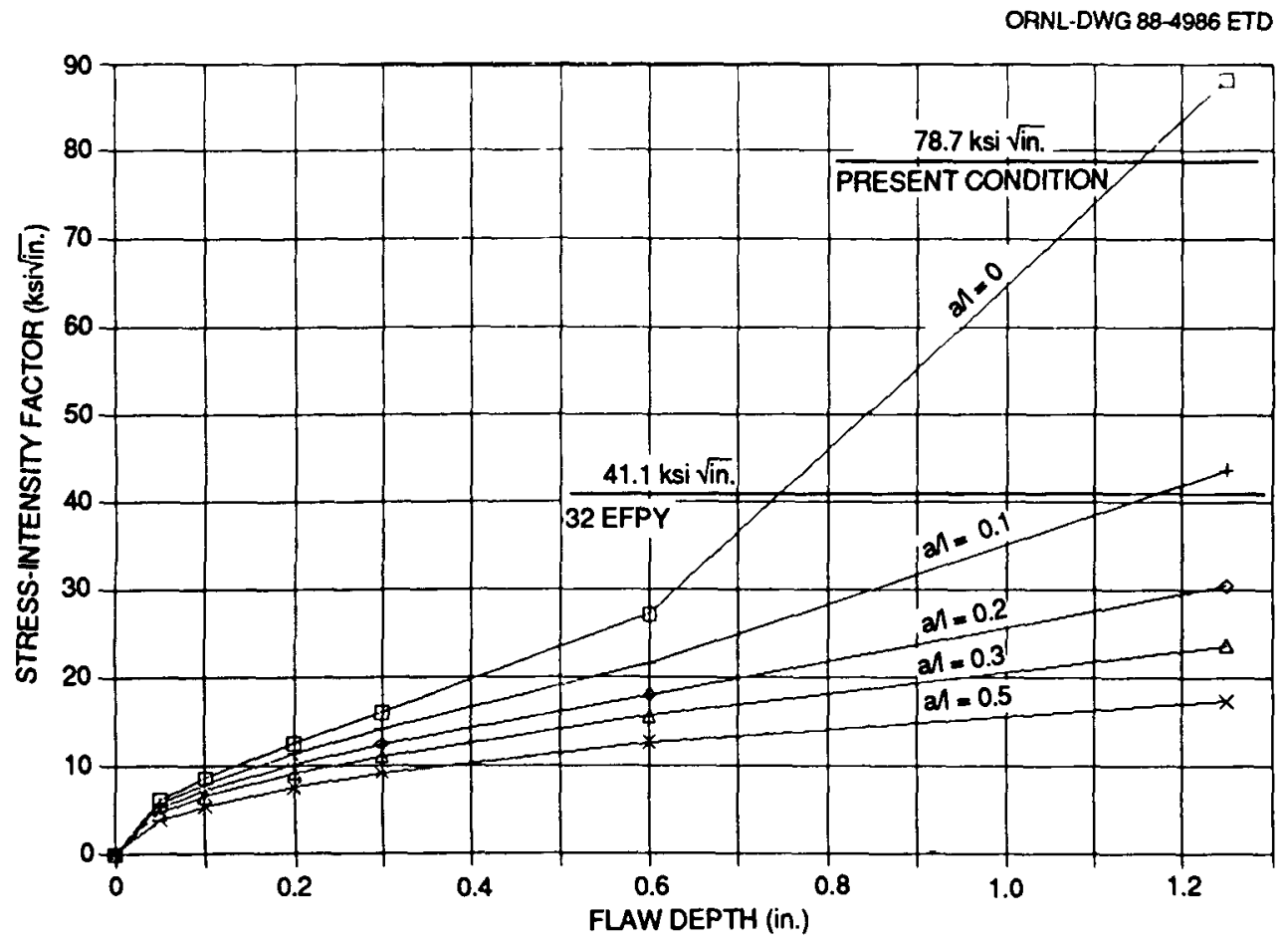

Fig. 6.28. Stress-intensity factors at maximum bending-moment location as function of flaw depth and flaw aspect ratio: $D W+T+O B E$ loading: no inner concrete support.

ORNL-DWG $88-4987$ ETD

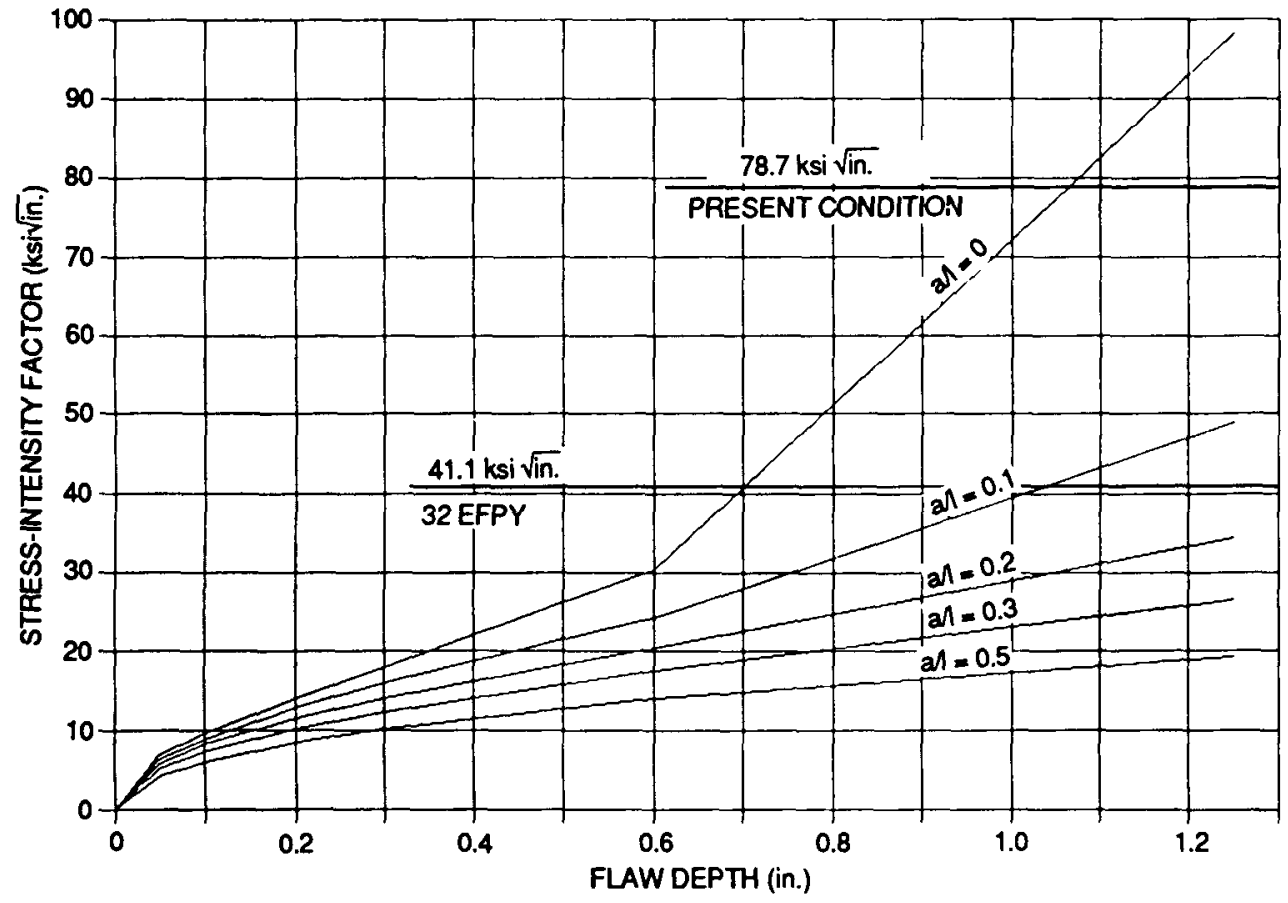

Fig. 6.29. Stress-intensity factors at maximum bending-moment location as function of flaw depth and flaw aspect ratio: DW + T + SSE loading: no inner concrete support. 
ORNL-DWG 88-4988 ETD

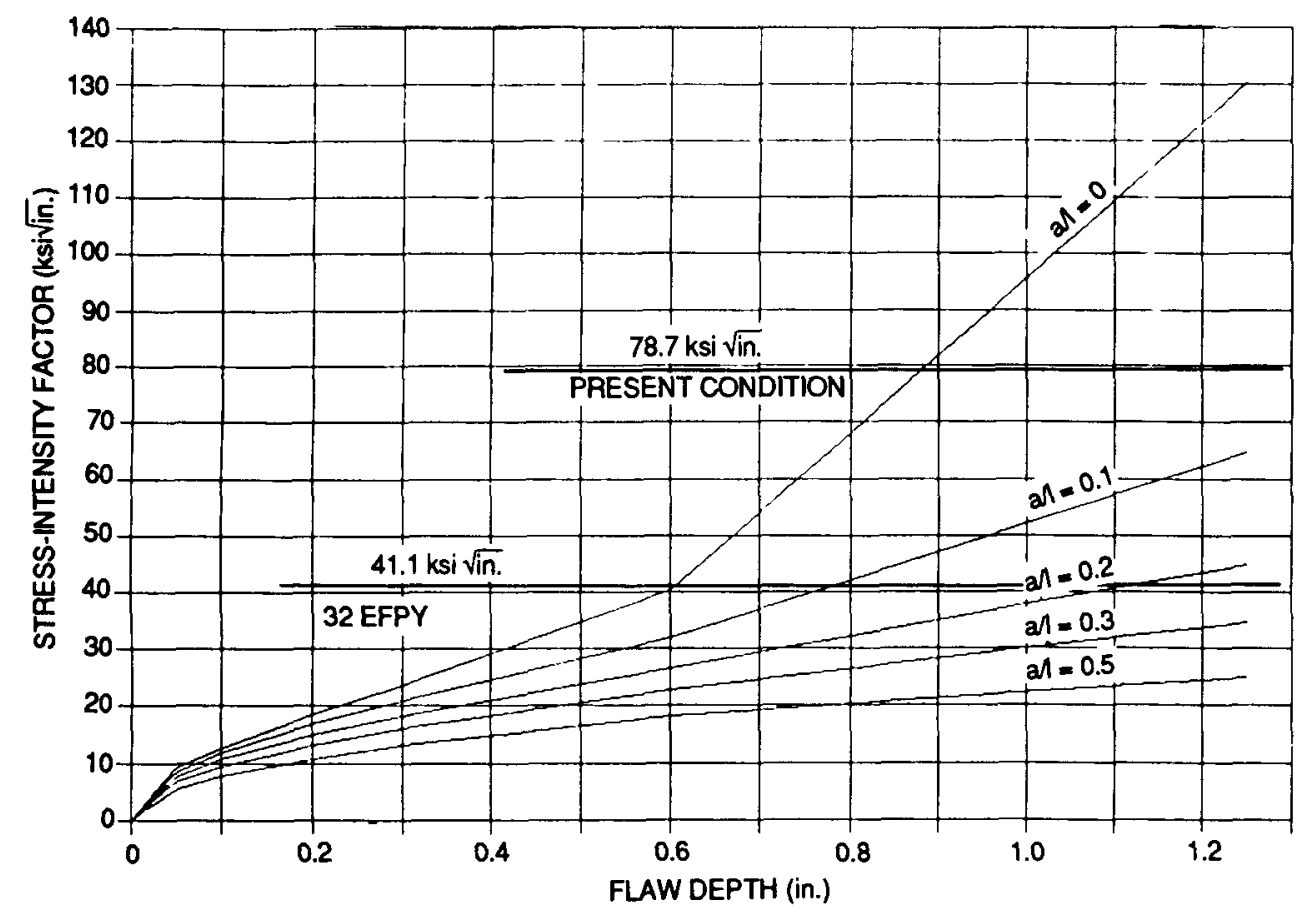

Fig. 6.30. Stress-intensity factors at maximum bending-moment location as function of $f l a w$ depth and $f 1$ aw aspect ratio: $D W+T+$ SBLOCA loading: no inner concrete support.

ORNL-DWG $88-4989$ ETD

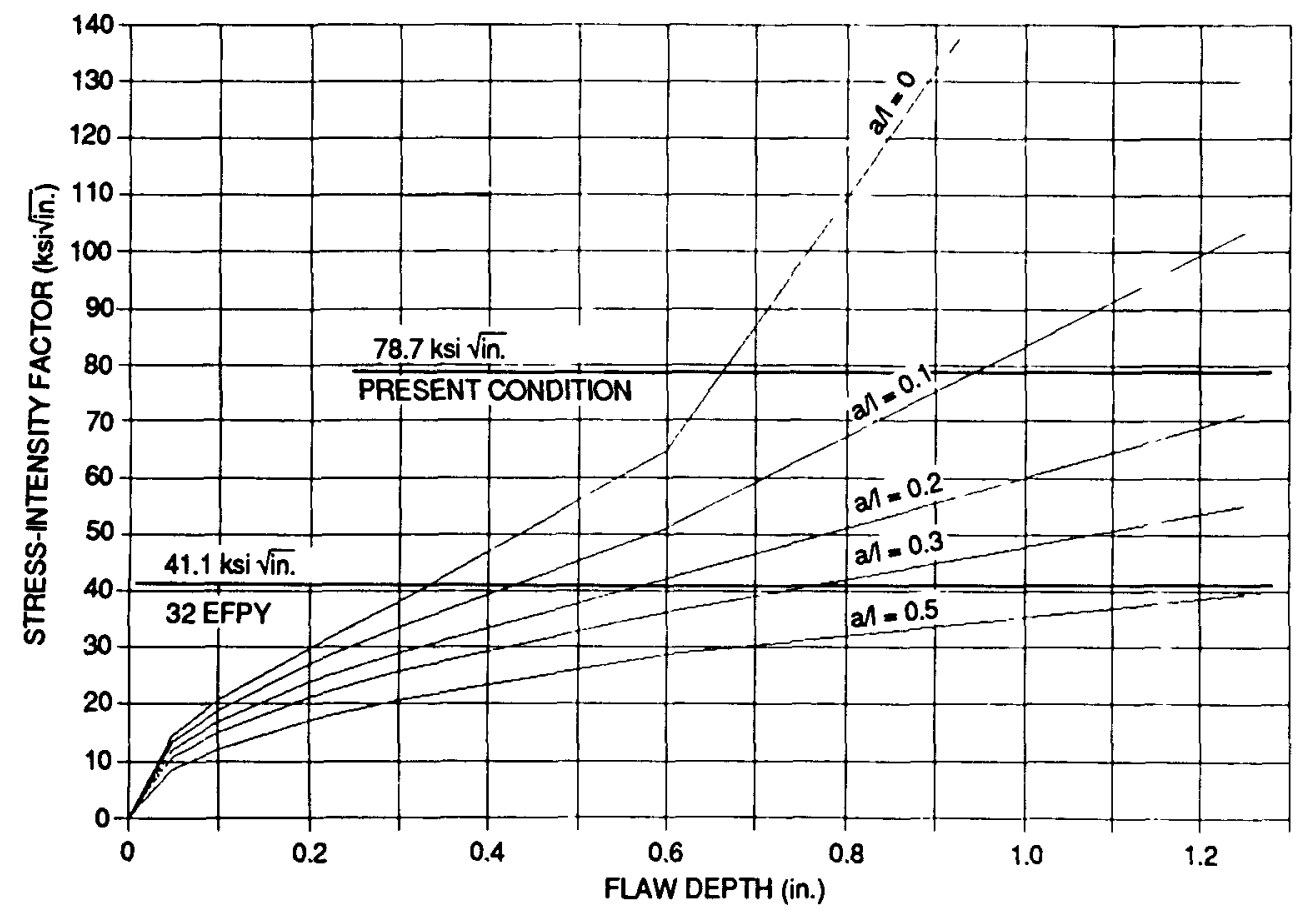

Fig. 6.31. Stress-intensity factors at maximum bending-moment location as function of flaw depth and flaw aspect ratio: $D W+T+$ LBLOCA loading: no inner concrete support. 
OPNL-DWG $88-4990$ ETD

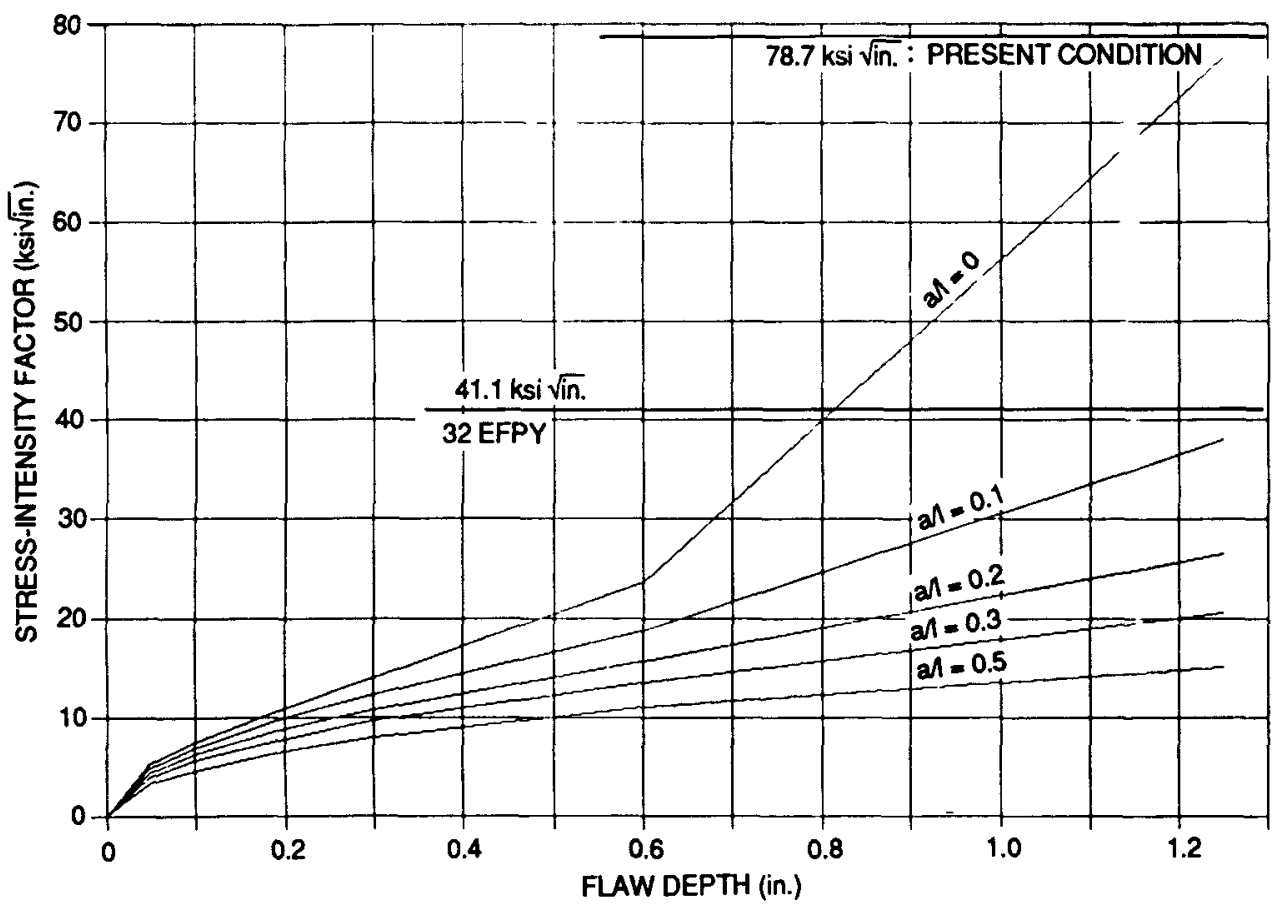

Fig. 6.32. Stress-intensity factors at maximum bending-moment location as function of flaw depth and flaw aspect ratio: $D W+T+O B E$ loading: with inner concrete support.

ORNL-DWG 88-4991 ETO

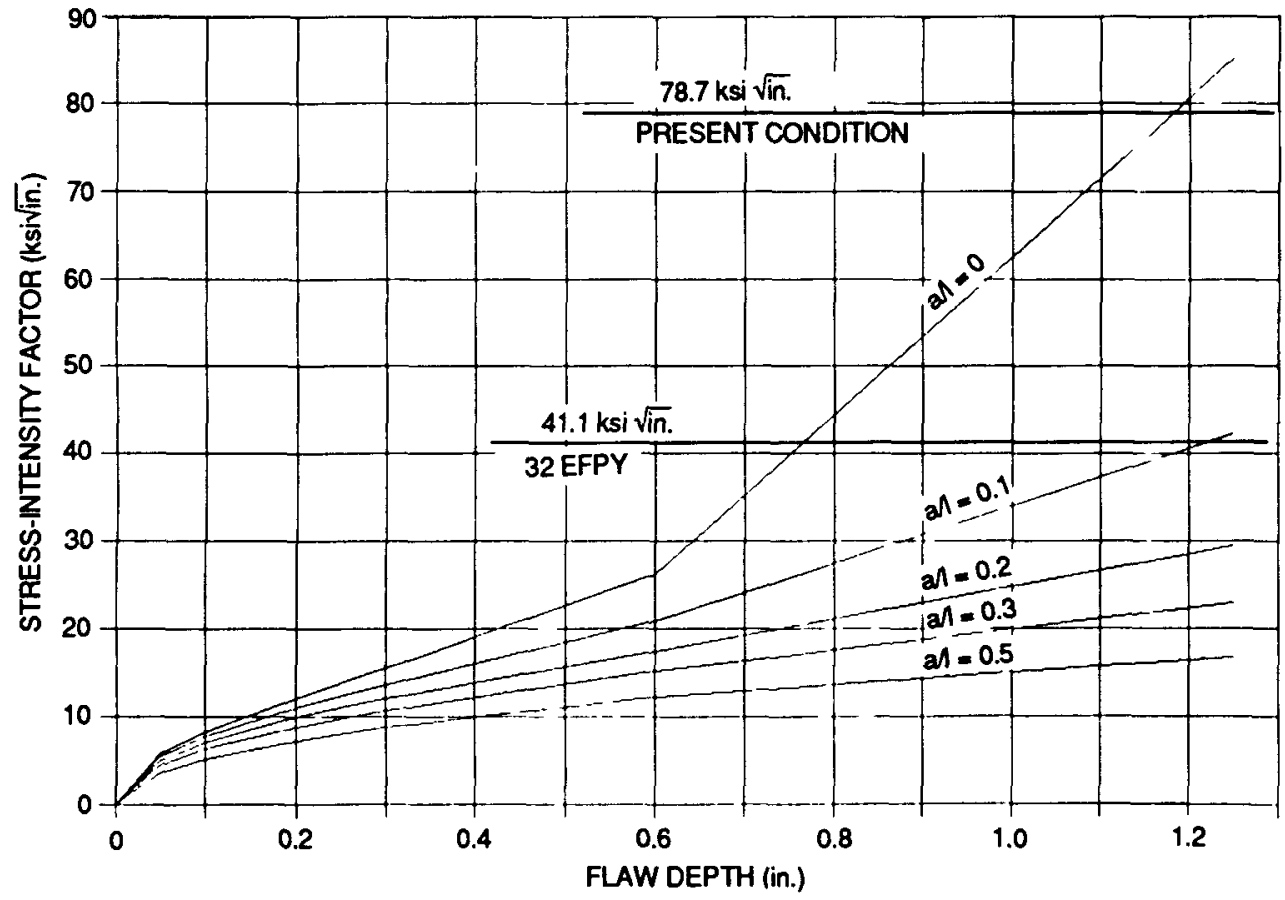

Fig. 6.33. Stress-intensity factors at maximum bending-moment location as function of flaw depth and flaw aspect ratio: DW $+T+$ SSE loading: with inner concrete support. 
ORNL-DWG 88-4992 ETD

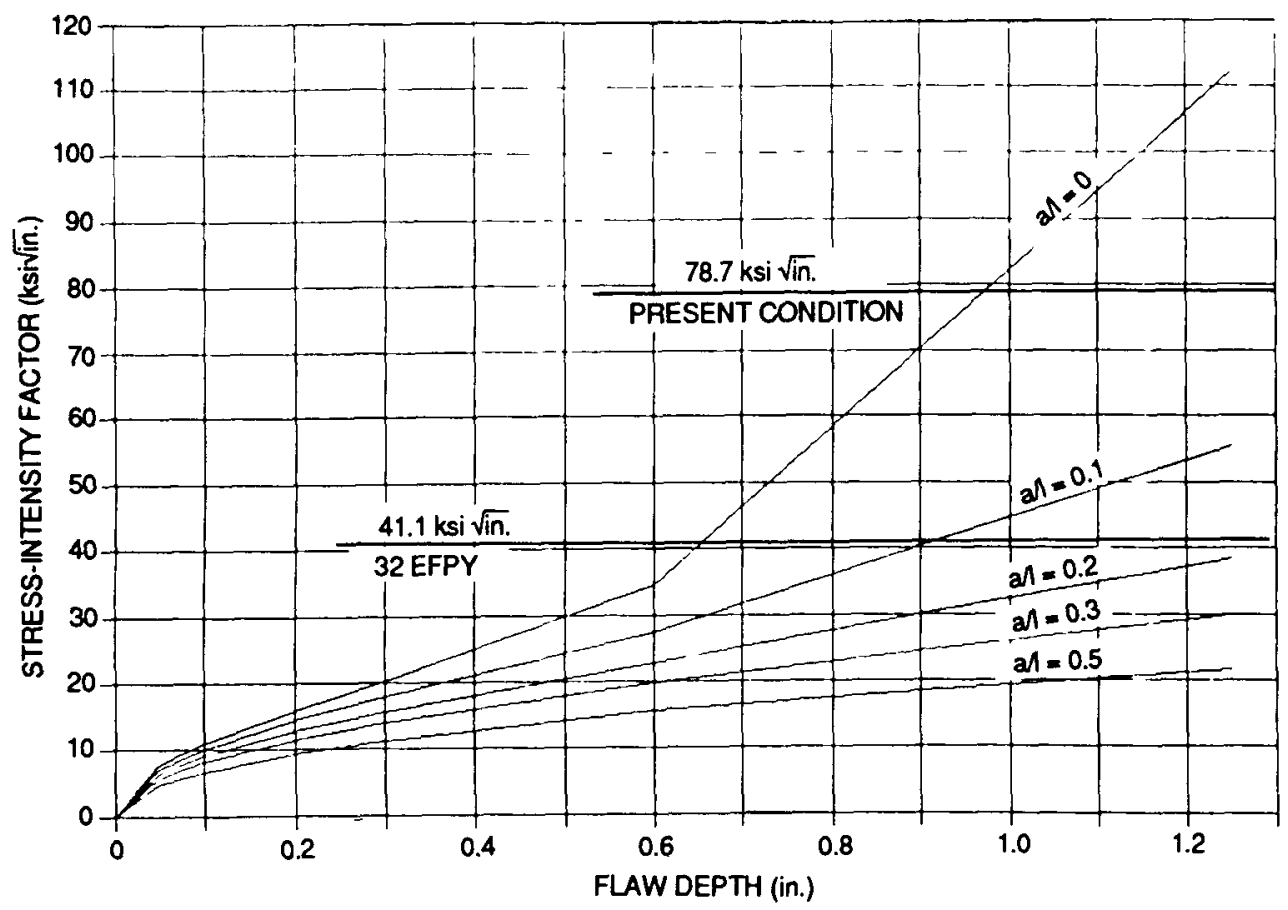

Fig. 6.34. Stress-intensity factors at maximum bending-moment location as function of flaw depth and flaw aspect ratio: $\mathrm{DW}+\mathrm{T}+$ SBLOCA loading: with inner concrete support.

ORNL-DWG 88-4993 ETD

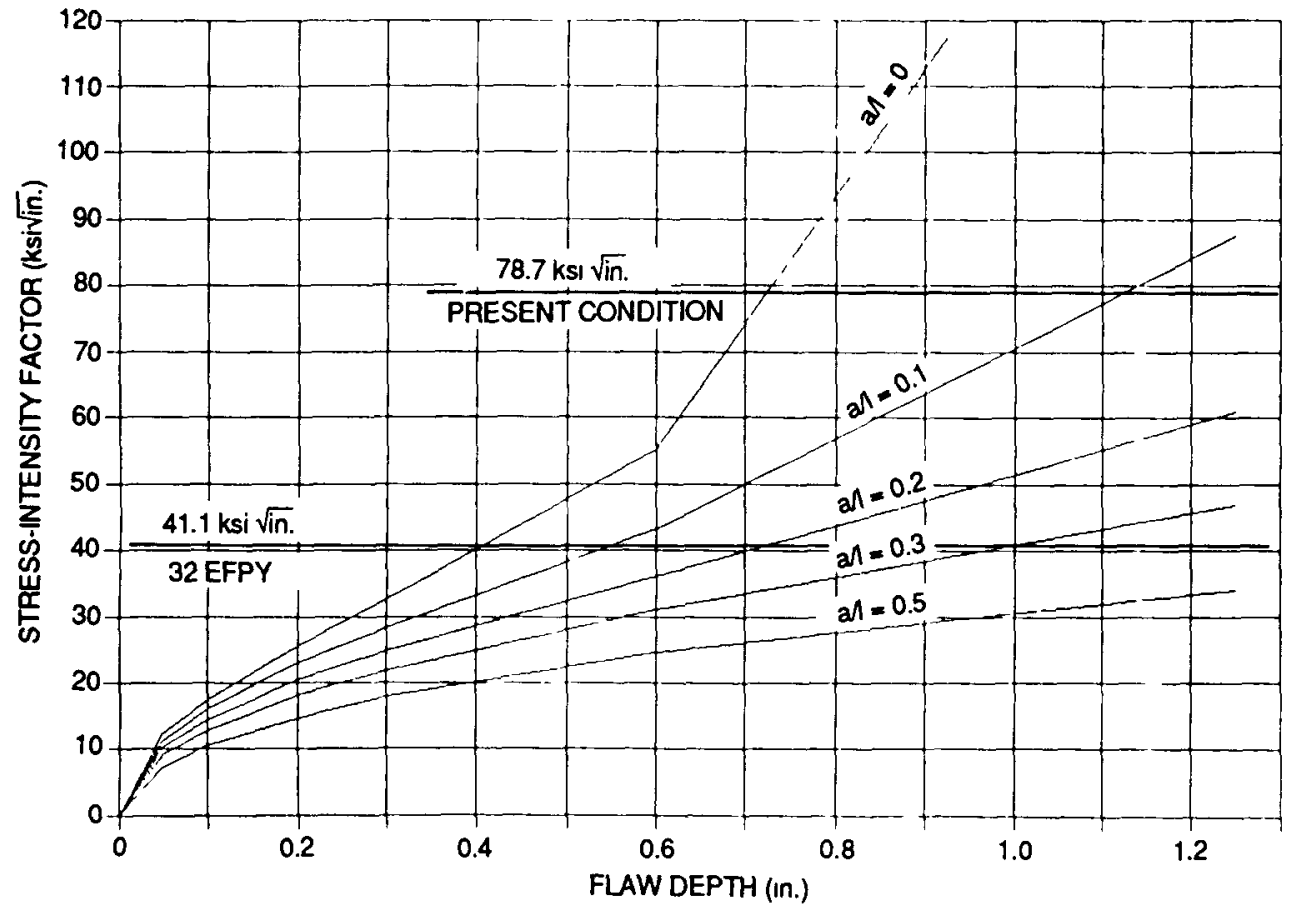

Fig. 6.35. Stress-intensity factors at maximum bending-moment location as function of $\mathrm{flaw}$ depth and flaw aspect ratio: $\mathrm{DW}+\mathrm{T}+$ LBLOCA loading: with inner concrete support. 


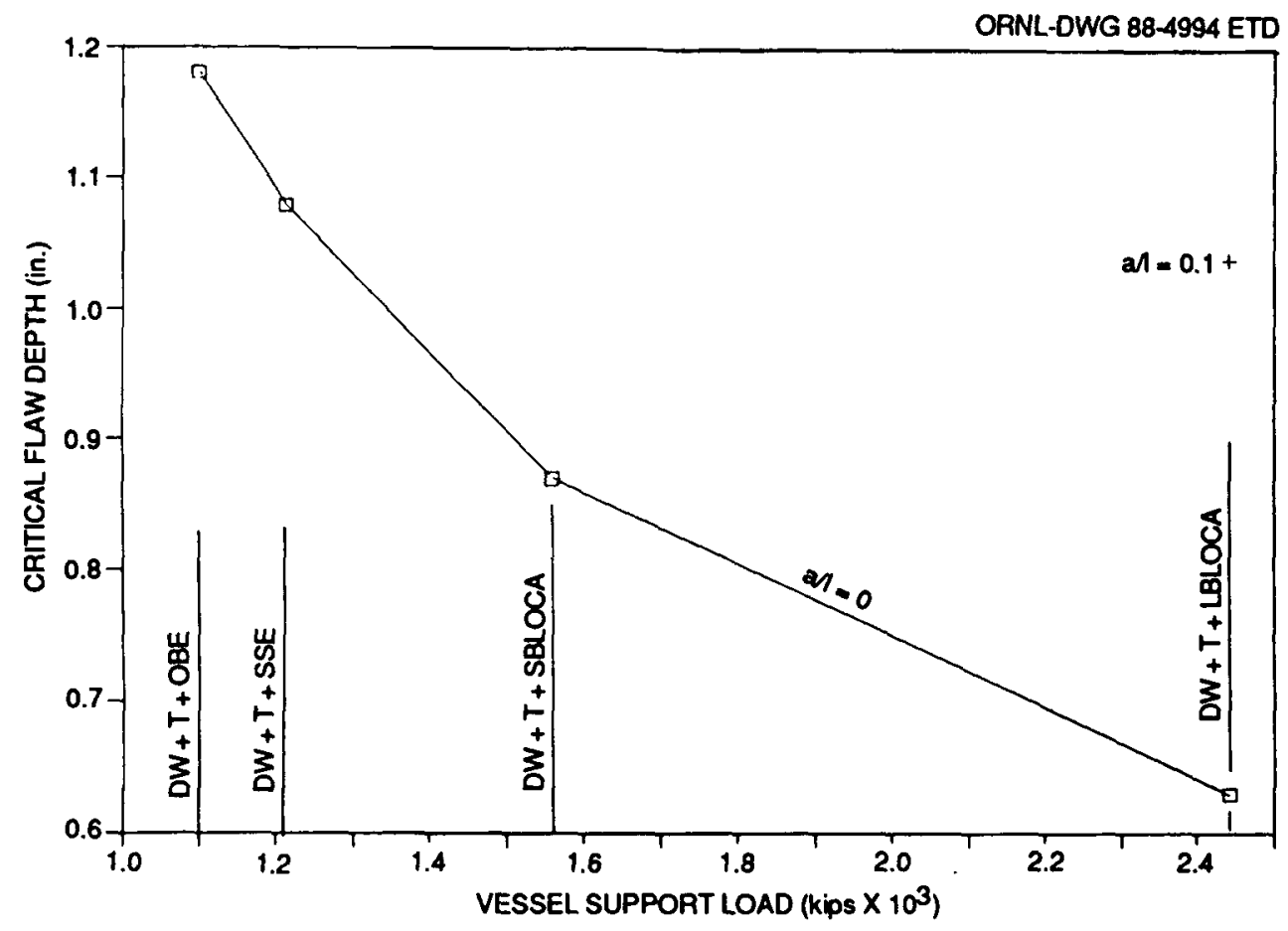

Fig. 6.36. Critical flaw depths at maximum bending-moment location after 7.4 EFPY of operation (current condition): no inner concrete support.

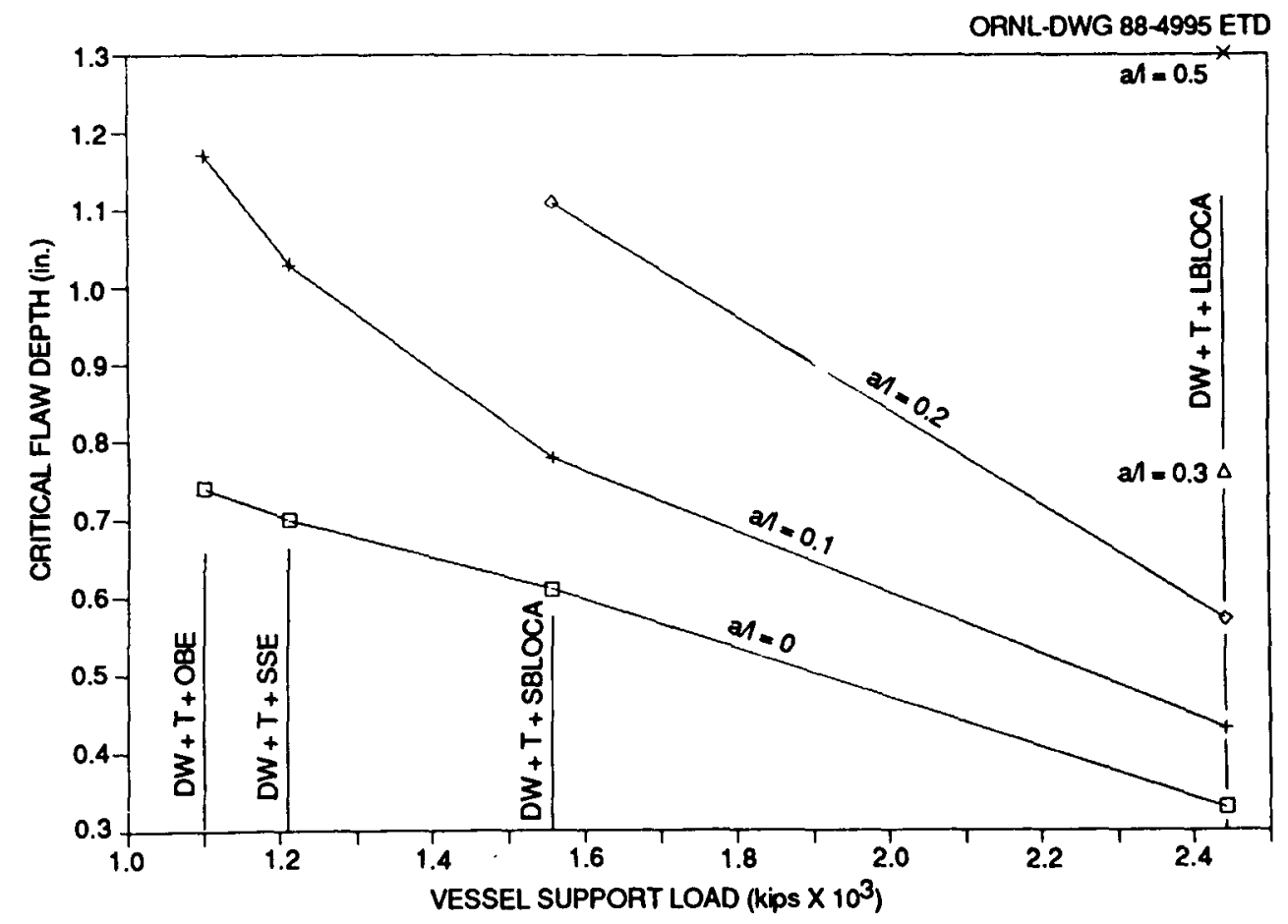

Fig. 6.37. Critical flaw depths at maximum bending-moment location after 32 EFPY of operation: no inner concrete support. 


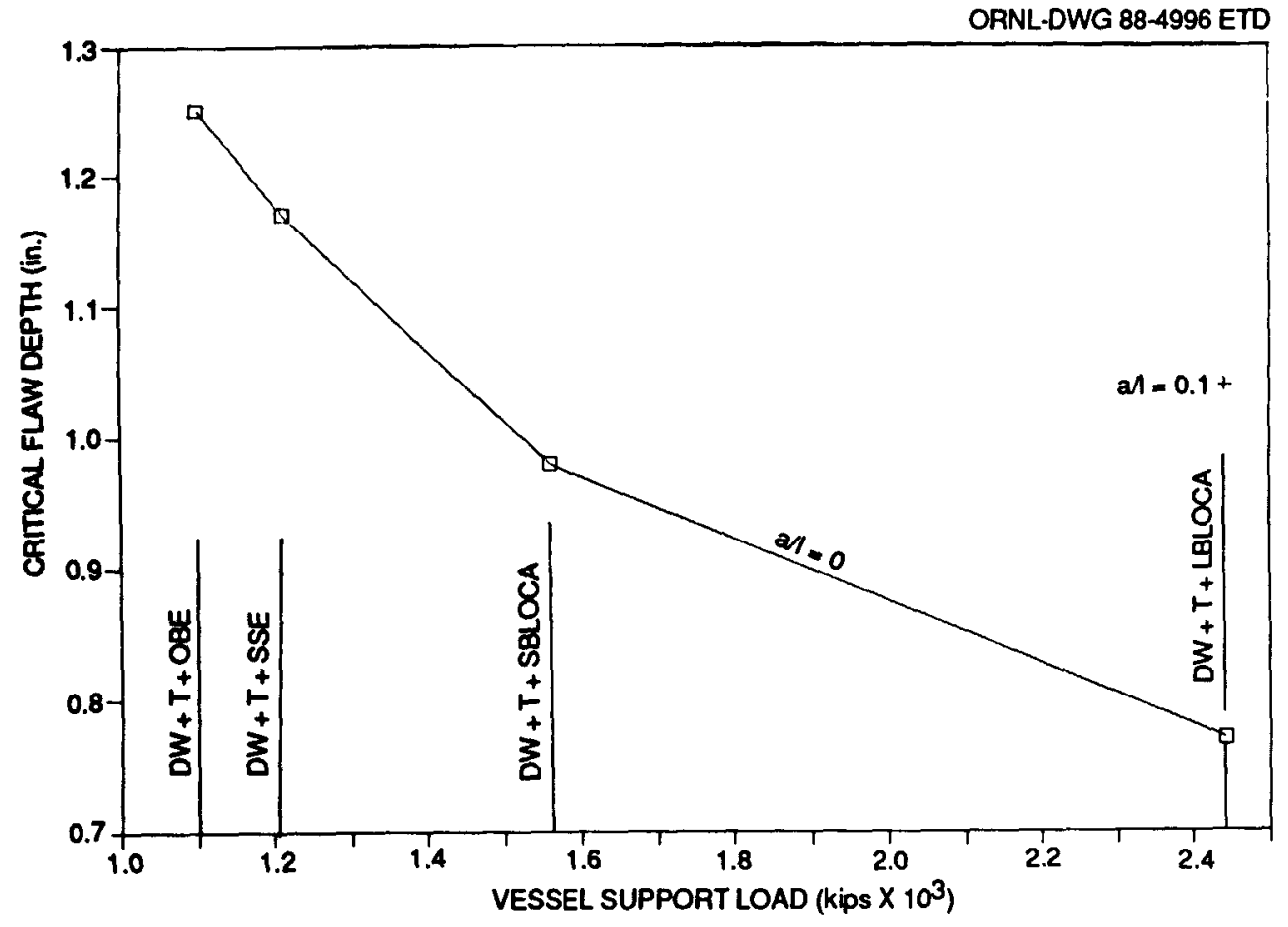

Fig. 6.38. Critical flaw depths at maximum bending-moment location after 7.48 EFPY of operation: with inner concrete support.

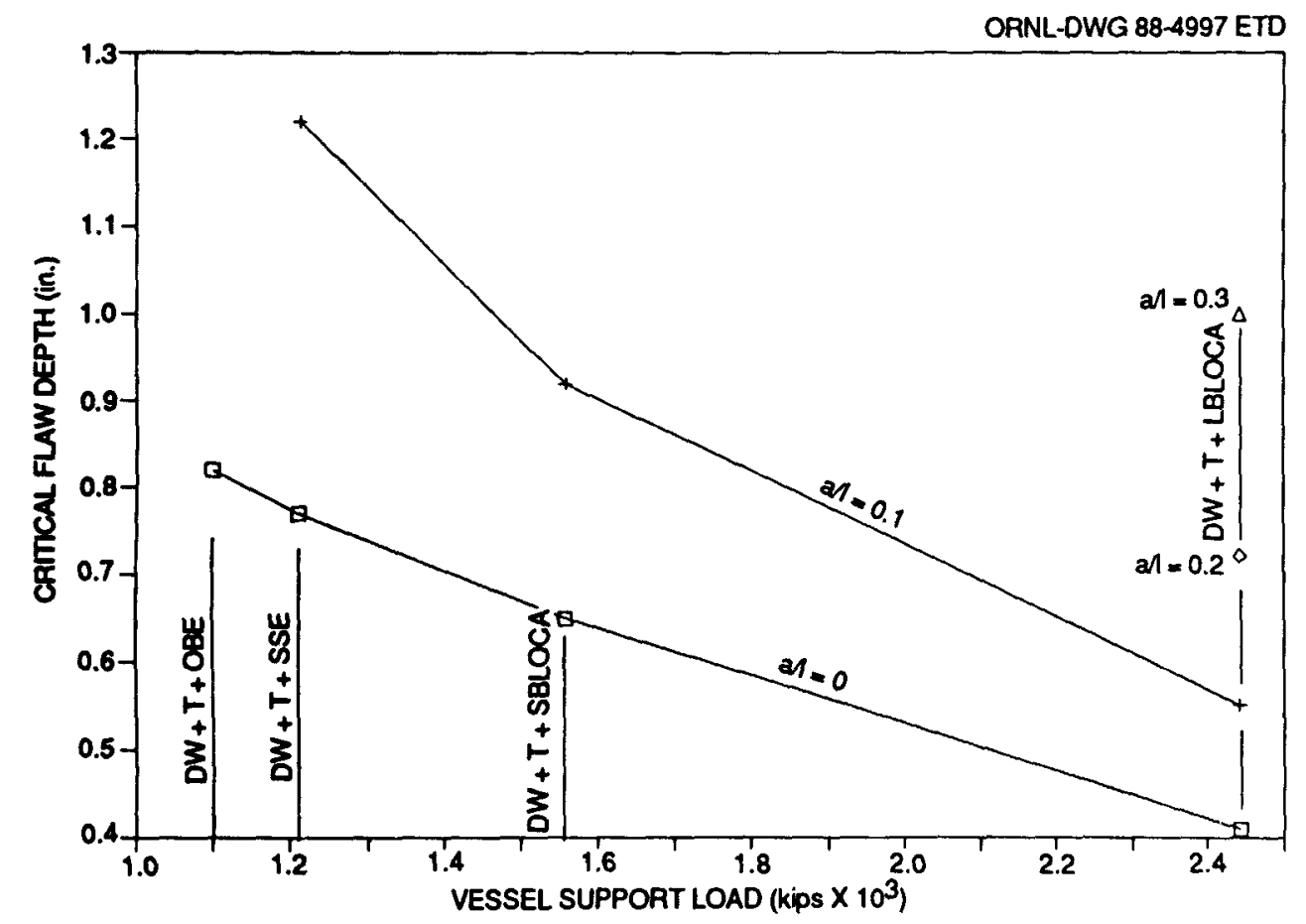

Fig. 6.39. Critical flaw depths at maximum bending-moment location after 32 EFPY of operation: with inner concrete support. 
requirement for plane-strain constraint at the crack tip. Feature (2) requires that the nonlinear stress distribution in the flange adjacent to the grout hole be factored into the stress-intensity-factor calculations.

6.7.3.1 Flaw-tip stress-intensity-factor equations. Solutions exist in the 1 iterature for the calculations of stress-intensity factors at the tip of cracks emanating from round holes in both finite- and infinite-width plates. The solution used in this analysis was taken from Ref. 20 and has the following form:

$$
K_{I}=\sigma \sqrt{\pi a} \times F \text {, }
$$

where

$$
\begin{aligned}
\sigma= & \text { the uniform far-field tensile stress on the plate (ksi); } \\
a= & \text { the half width of a symmetrical radial crack, including the } \\
& \text { hole radius; } \\
F= & a \text { factor reflecting both the concentration of stress adjacent } \\
& \text { to the hole and the finite width of the plate. }
\end{aligned}
$$

The factor $F$ is obtained from the curves of Ref. 20, which are reproduced in Fig. 6.40. Note that factor $F$ is a function of three variables, one of which $(h / b)$ is defined as follows:

$\frac{h}{b}=\frac{\text { distance from crack plane to the uniformly loaded plate edge }}{\text { plate half-width }}$

The geometry of the beam flange and the postulated flaws fits the conditions of the $K_{I}$ solution exactly, but the loading condition does not. Tensile end loads in the beam flange are generated by shear flows at the flange to shear web interface. This leads to (1) a nonuniform axial distribution of end load along the length of the flange and (2) shear stresses in the plane of the flange because of the web location. A comparison of the two plate loading conditions is given in Fig. 6.41 .

The effect of the departure from prototypic loading on the calculated $K_{I}$ values is not known at this time, but a potential exists for the calculated $K_{I}$ values, and the associated critical crack depths, to be nonconservative.* This fact should be recognized when evaluating the analysis results, particularly for cases involving $F$ values taken from the knee of the curve of Fig. 6.40 .

\footnotetext{
*Late in the preparation of this report, both cases described in Fig. 6.41 were calculated using two-dimensional finite-element analysis. These analyses checked the "exact" solution for problem (b) within $0.6 \%$ and indicate a $5 \%$ higher $\mathrm{K}_{\mathrm{I}}$ value for problem (a) than for problem (b). The $5 \%$ increase in $K_{I}$ reduces the critical flaw size for the SBLOCA loading condition by 0.1 in. This work is discussed in detail in Appendix 6 .
} 


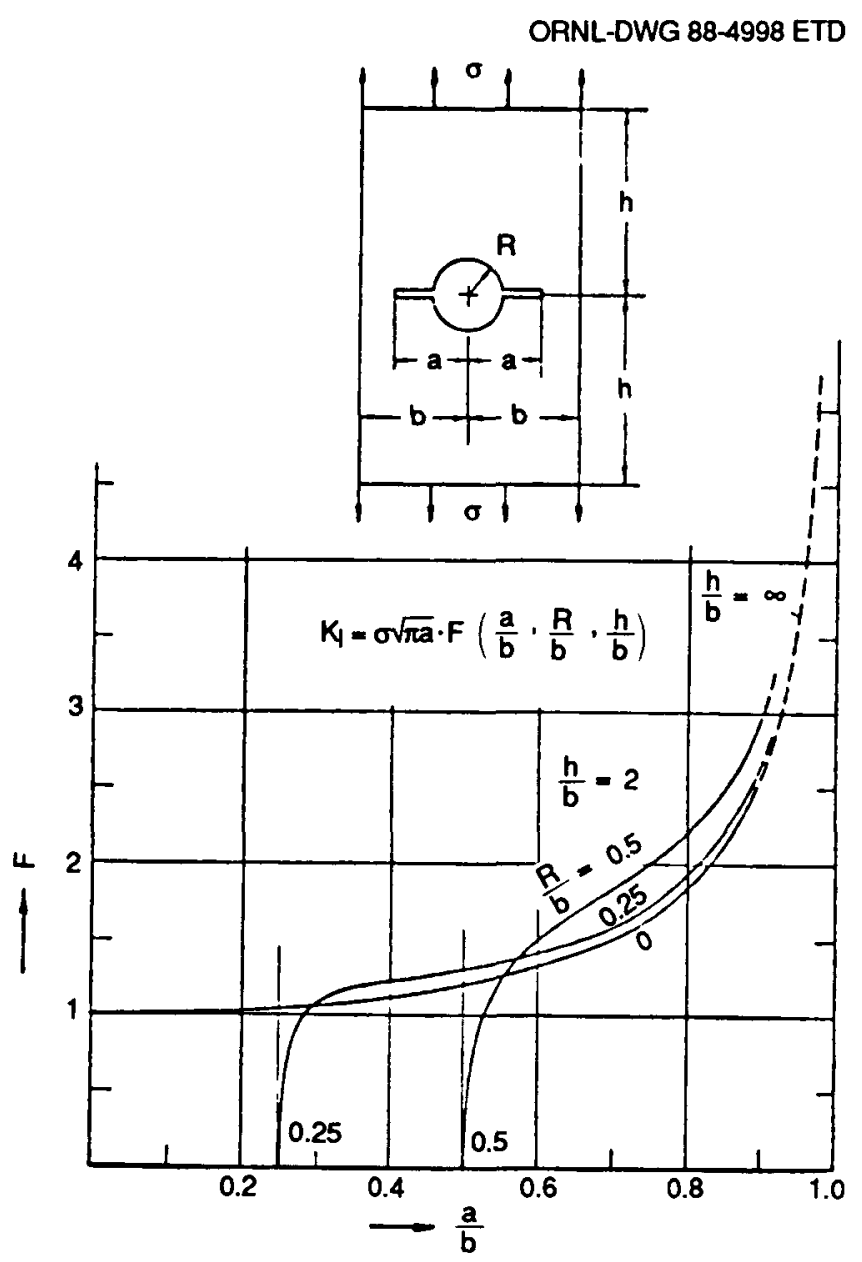

Fig. 6.40. Stress-intensity-factor equation used at beam-flange hole location. Source: Ref. 20.

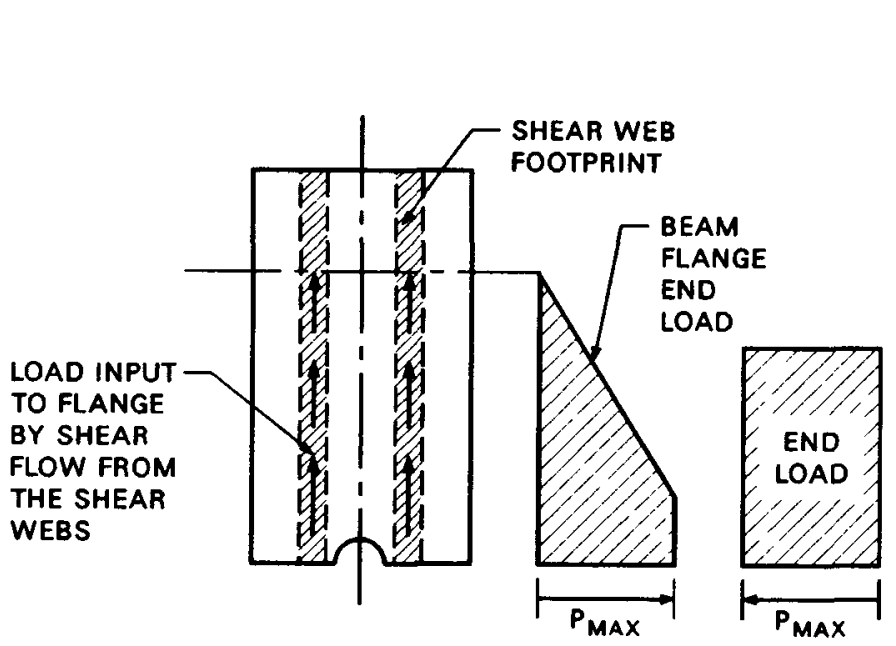

(a)

ORNL-OWG 88C-4898A ETD

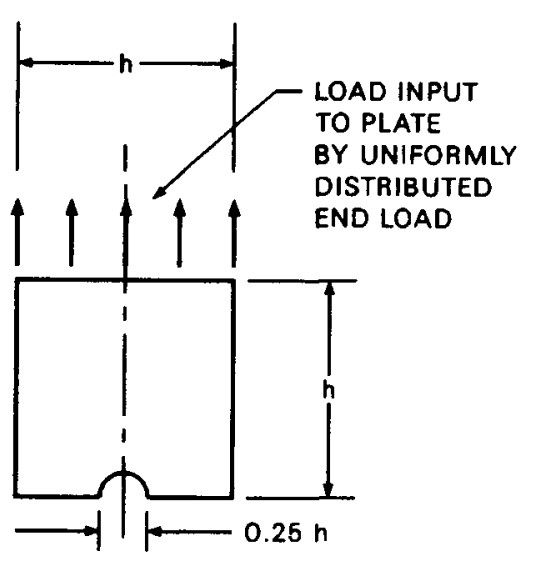

(b)

Fig. 6.41. Comparison of beam-flange boundary conditions with boundary conditions used in the Newman analysis. (a) Beam-flange loading and (b) Newman analysis loading. 
6.7.3.2 Flaw-tip stress-intensity factors. A sample spreadsheet used in the analysis of the beam flange hole radial flaws is given in Table 6.14. The mean stress entry in this table is based on the full section properties at the hole centerline (i.e., the reduction in section modulus because of the loss of flange area was not included). This approach generated a pseudo far-field stress corresponding to that defined in Fig. 6.40. Note that the beam flange end load at the plane of the hole centerline corresponds exactly with that given by the correct section properties (i.e., the bending moment calculation includes the effect of the hole).

A complete set of spreadsheets for the flaw tolerance analysis of the beam flange holes is provided in Appendix 4. A summary of flaw-tip, stress-intensity factors for the beam flange hole is given in Table 6.15 .

Plots of the flaw-tip, stress-intensity factors for each of the load combinations considered are given in Figs. 6.42-6.45. Superposition of the design fracture-toughness values from Table 6.8 onto these curves defined limiting flaw depths for each load case considered. These limiting values are summarized, along with critical crack lengths for the other locations analyzed, in Table 6.16.

6.7.3.3 Lifetime critical-flaw-depth analyses. The beam flange hole location was selected for a study of the lifetime variation in critical flaw depths on the basis of its having the smallest critical flaw size at the end of life. NDTT shifts corresponding to four intermediate times in the remaining plant life were calculated using the method of sect. 6.6 and translated into design dynamic fracturetoughness values using the design curve of Fig. 6.18. A plot of the resulting lifetime variation in the design fracture toughness is given in Fig. 6.21.

Fracture-toughness design values corresponding to intermediate plant operating periods were then superposed on the curves of Figs. 6.42-6.45 to generate critical flaw depths. Plots of the resulting critical flaw depth as a function of reactor operating period are given in Fig. 6.46 for the SBLOCA loading condition. Note that the reduction in critical flaw depth between the current time and 20 EFPY into the design life occurs as an approximately linear function of the plant equivalent full-power operating period.

Plots of critical flaw depth as a function of the maximum dynamic load on the vessel support are given in Figs. 6.47 and 6.48. The data used to construct these plots are summarized in Table 6.17 .

The flaw considered in the beam flange hole analysis is a constantdepth, through-flange flaw and thus corresponds to the $a / 1=0$ case analyzed for the other two critical locations on the support beam. Note that the average slope of the curve for 32 EFPY between the $D W+T+O B E$ and $\mathrm{DW}+\mathrm{T}+$ SBLOCA loading cases is $-2.6 \times 10^{-3} \mathrm{in} . / \mathrm{kip}$ (see Fig. 6.47). The corresponding slope for the cavity liner interface location is obtained from Fig. 6.27 as $-3.3 \times 10^{-4}$ in./kip. The slopes are seen to differ by a factor of 7.88 . Benefits to be derived from a reduction in the beam flange stress are thus greater at the beam flange hole location than at the other locations.

Factors contributing to the $7.88 \Delta \mathrm{a} / \mathrm{kip}$ slope differential are identified and discussed in Sect. 6.8 . 
Table 6.14

TROJAN : SUPPOAT DEAM CRITICAL PLAW SIZE AMALYSIS

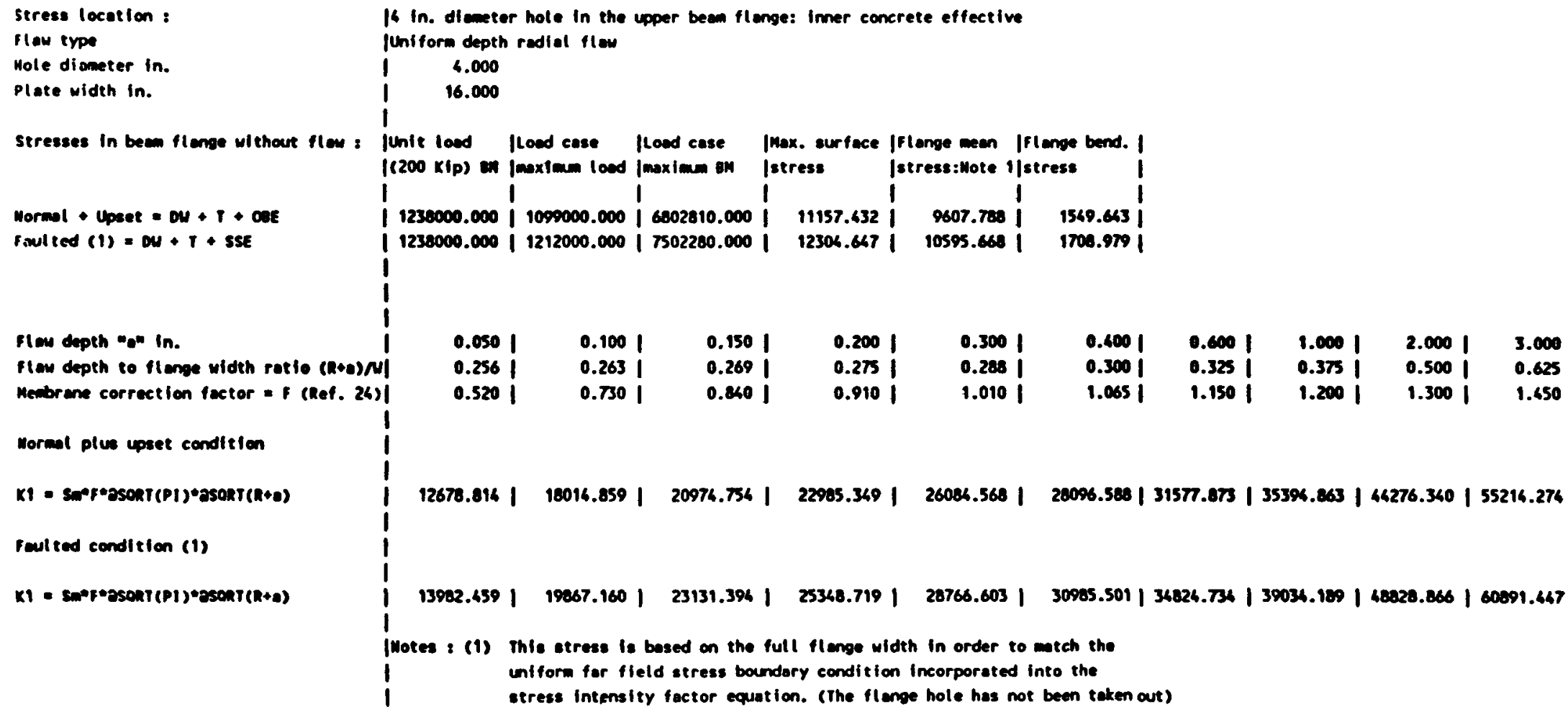




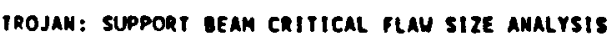

STRESS INTENSITY SUMHARY

6 IM. DIAMETER HOLE IN THE UPPER DeAM RLANGE

\begin{tabular}{|c|c|c|c|c|c|c|c|c|c|c|c|c|c|}
\hline \multirow[t]{2}{*}{ lcod case } & \multirow{2}{*}{$\begin{array}{c}\text { Imer } \\
\text { Concrete } \\
\text { Elfective? }\end{array}$} & \multirow{2}{*}{$\begin{array}{l}\text { Play } \\
\text { Aspect } \\
\text { Ratio }\end{array}$} & \multirow[b]{2}{*}{0.000} & \multirow[b]{2}{*}{0.050} & \multirow[b]{2}{*}{0.100} & \multirow[b]{2}{*}{0.150} & \multirow[b]{2}{*}{0.200} & \multirow[b]{2}{*}{0.300} & \multirow[b]{2}{*}{0.400} & \multirow[b]{2}{*}{0.600} & \multirow[b]{2}{*}{1.000} & \multirow[b]{2}{*}{2.000} & \multirow[b]{2}{*}{3.000} \\
\hline & & & & & & & & & & & & & \\
\hline DU.P.OBE & No & 0.000 & 0.000 & 15290.363 & 21725.513 & 25295.079 & 27719.811 & 31457.390 & 33883.850 & 38082.201 & 42605.406 & 53396.264 & 66587.166 \\
\hline OW-1.OBE & Yes & 0.000 & 0.000 & 12678.816 & 18016.059 & 20974.756 & 22985.349 & 26086.568 & 28096.586 & $315 \pi .873$ & 35394.863 & 44276.340 & 55214.276 \\
\hline Du. $1 \cdot$ fst & No & 0.000 & 0.000 & 16062.530 & 23959.346 & 27095.038 & 30569.902 & 36691.873 & 37367.813 & 41997.041 & 47074.349 & 58886.508 & 73433.708 \\
\hline DU. T.5SE & Yes & 0.000 & 0.000 & 13982.459 & 19867.160 & 23131.396 & 25368.719 & 28766.603 & 30985.501 & 34826.736 & 39036.189 & 48828.866 & 60091.447 \\
\hline OU. T.58:LOCA & No & 0.000 & 0.000 & 21676.420 & 30799.225 & 35859,630 & 39297.056 & 44595.658 & 48035.522 & 53907.326 & 60513.066 & 75697.343 & 94397.456 \\
\hline CU.T.58:LOCA & res & 0.000 & 0.000 & 17974.151 & 25538.808 & 29736.911 & 32585.235 & 36978.851 & 39831.196 & 46766.448 & 50177.613 & 62768.660 & 78274.669 \\
\hline$O U \cdot 1 \cdot L O: L O C A$ & No & 0.000 & 0.000 & 33989.406 & 48294.292 & 56229.188 & 61619.197 & 69927.595 & 75321.425 & 84654.064 & 94886.663 & 118696.156 & 168018.604 \\
\hline OU.1+L:L:LCA & res & 0.000 & 0.000 & 20184.116 & 40045.770 & 46625.409 & 51094.819 & 57984.160 & 62456.748 & 70195.600 & 72680.300 & 90423.201 & 122737.462 \\
\hline
\end{tabular}




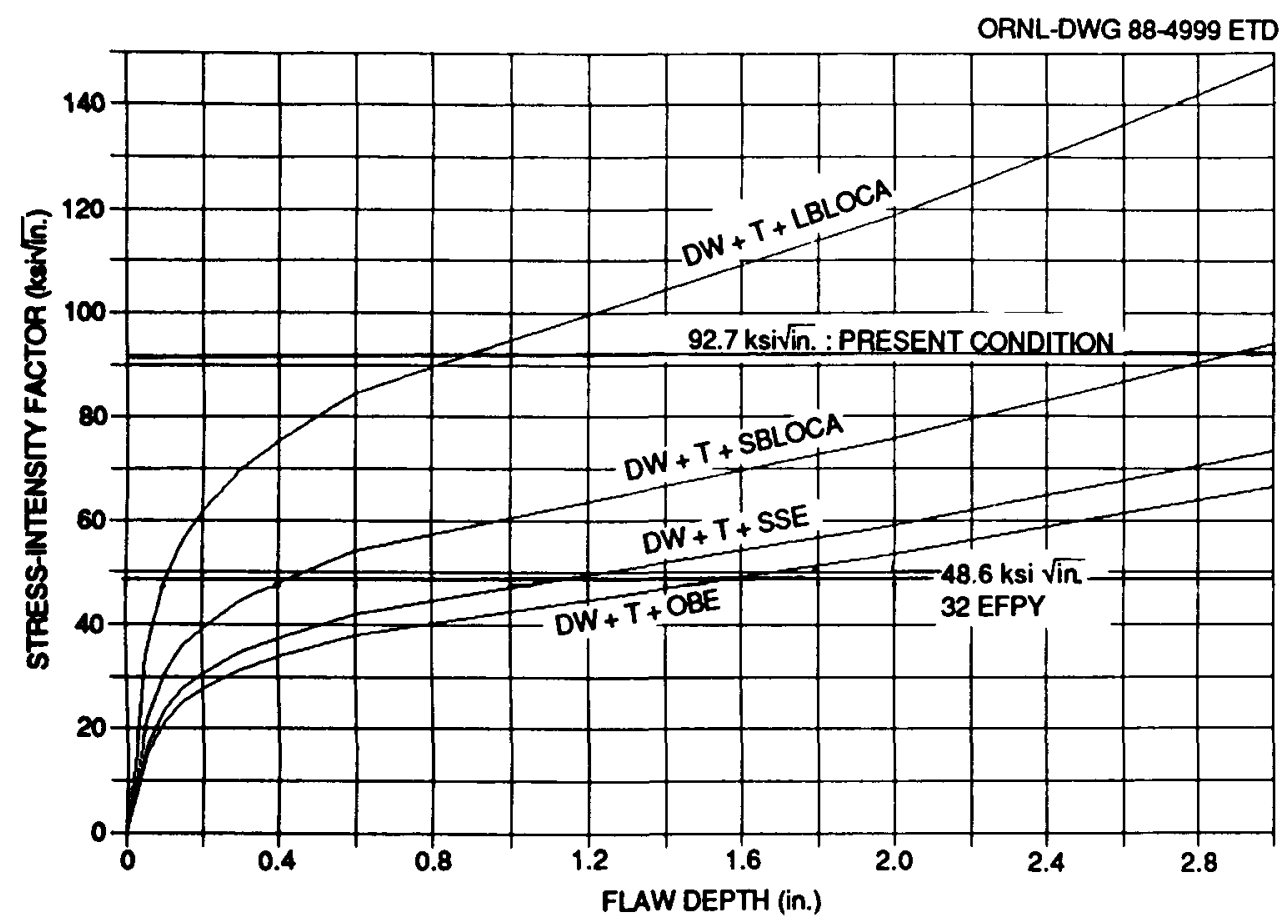

Fig. 6.42. Stress-intensity factors at beam-flange grout-hole location as function of flaw depth and vessel support loading: no inner concrete support.

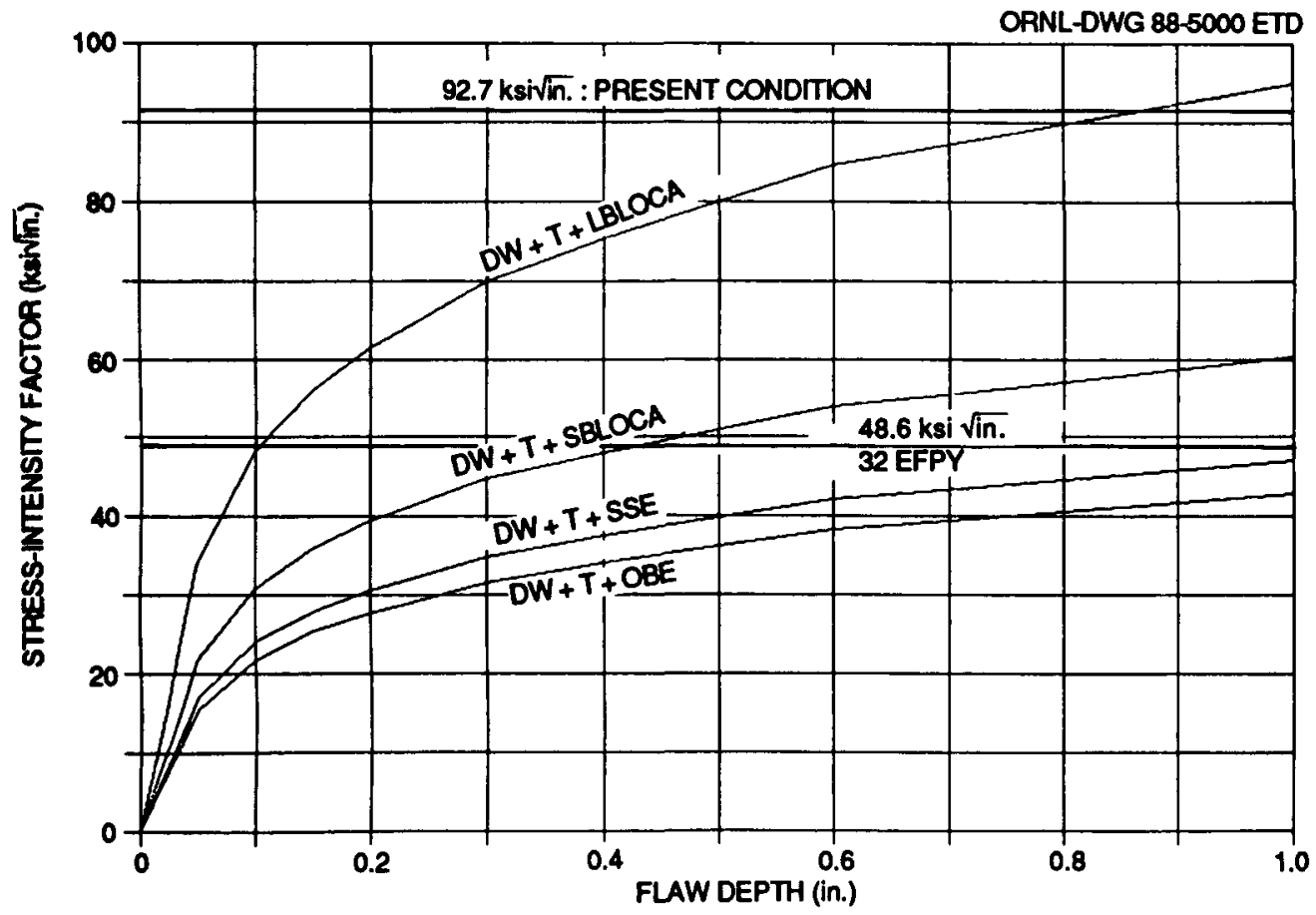

Fig. 6.43. Stress-intensity factors at beam-flange grout-hole location as function of flaw depth and vessel support loading: no inner concrete support. 


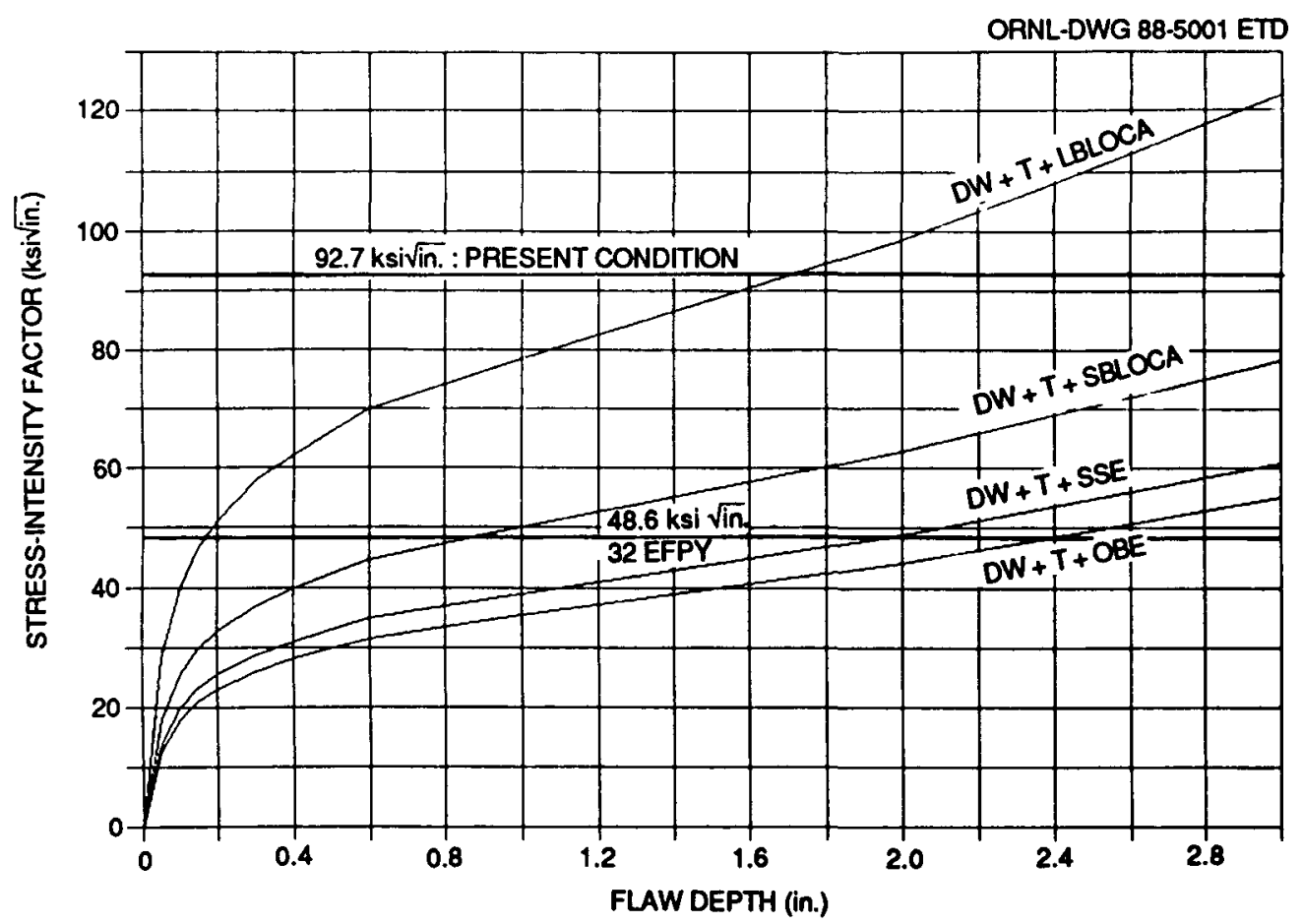

Fig. 6.44. Stress-intensity factors at beam-flange grout-hole location as function of flaw depth and vessel support loading: with inner concrete support.

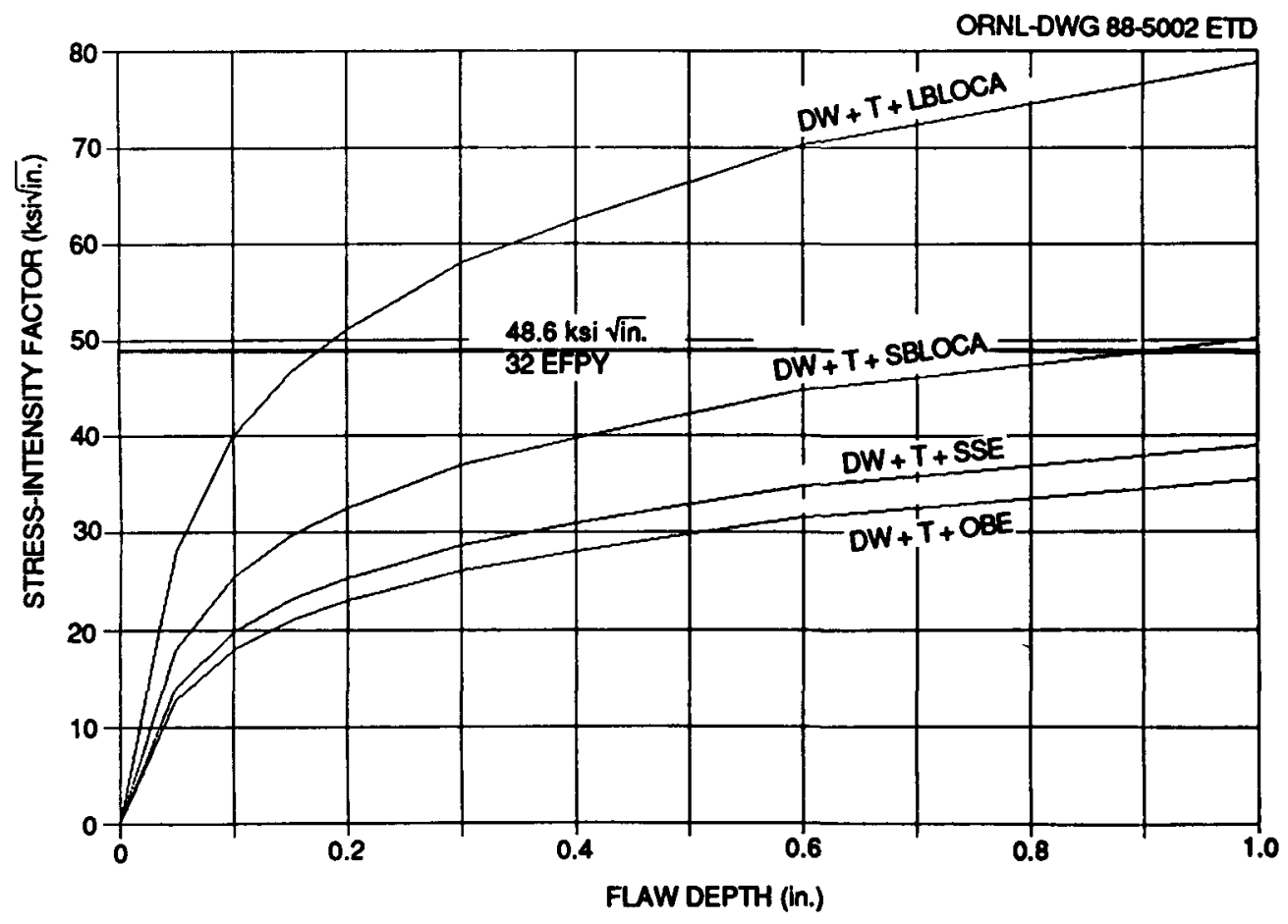

Fig. 6.45. Stress-intensity factors at beam-flange grout-hole location as function of flaw depth and vessel support loading: with inner concrete support. 
Table 6.16

SUMMARY OF CRITICAL CRACK LENGTHS

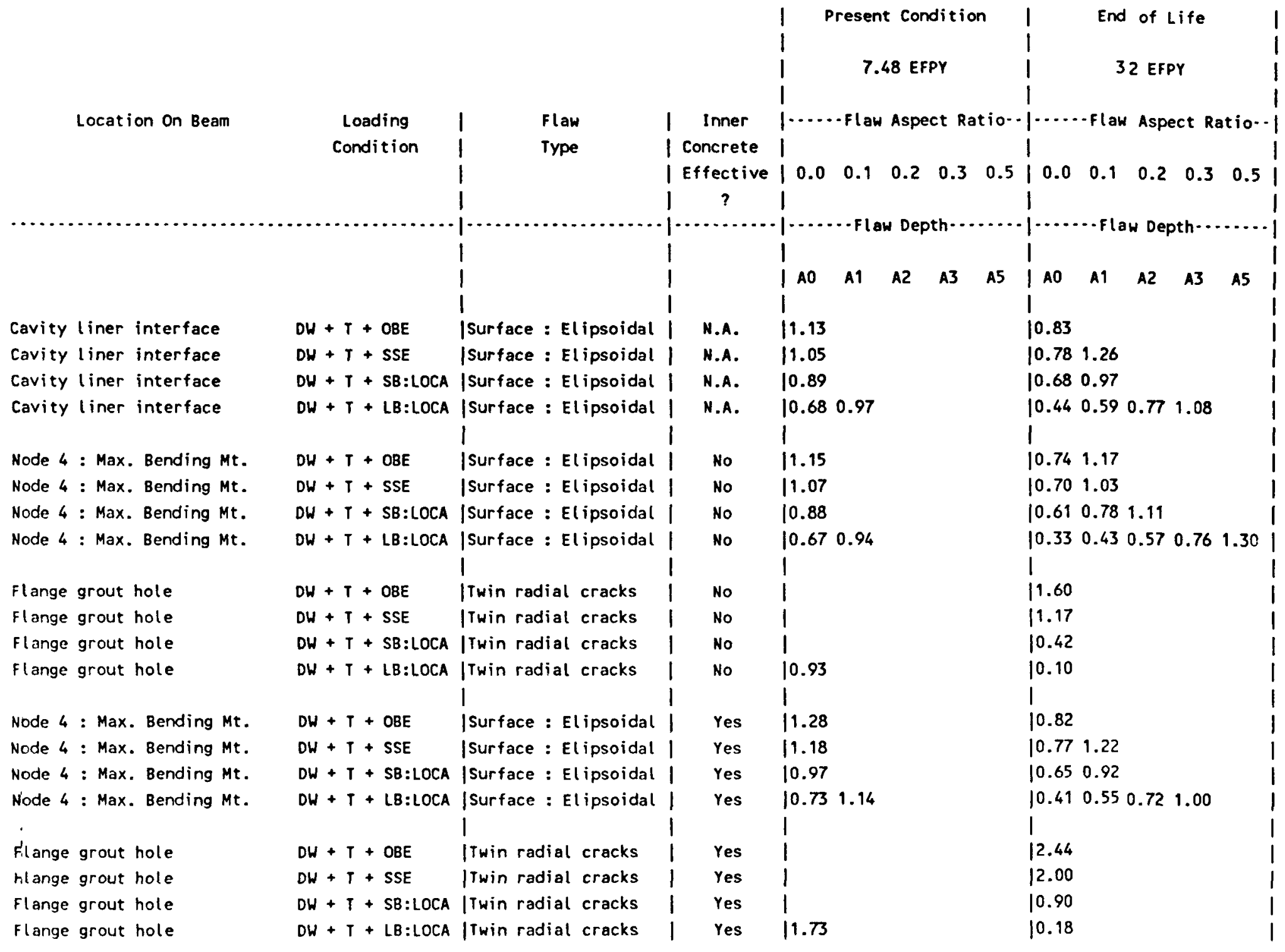




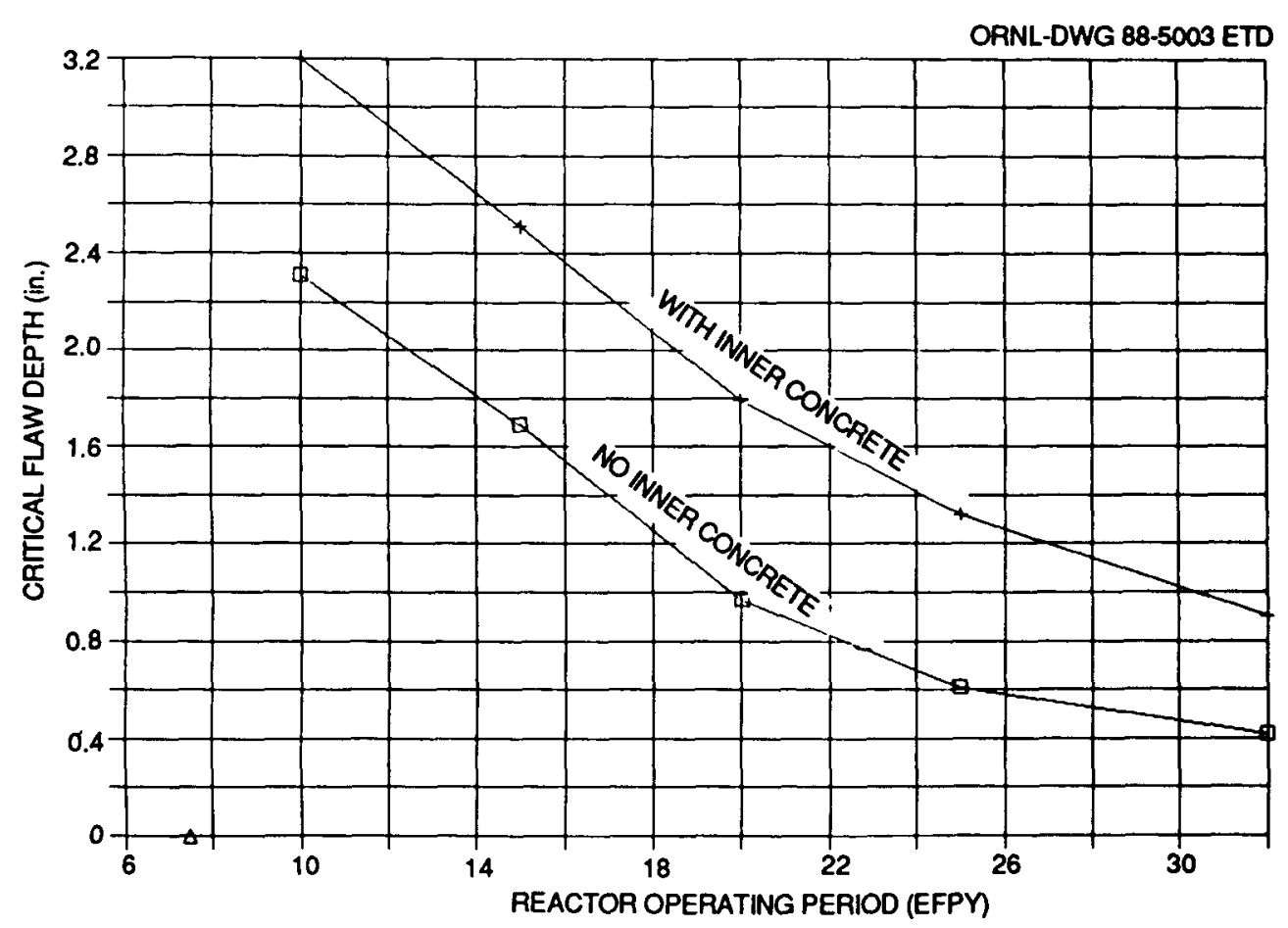

Fig. 6.46. Lifetime variation of critical flaw depths at beamflange grout-hole location for DW + T + SBLOCA loading.

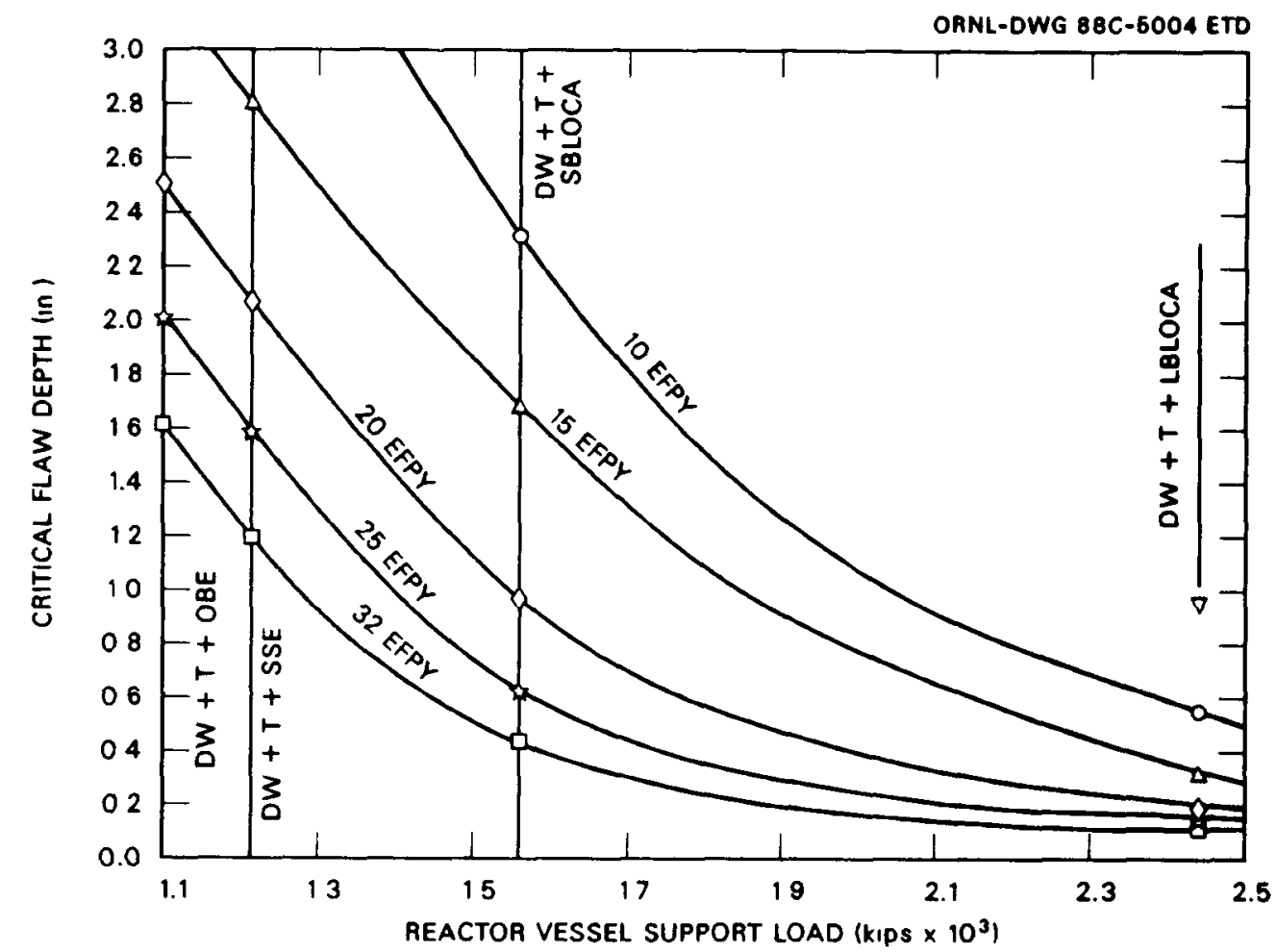

Fig. 6.47. Lifetime variation of critical flaw depths at beamflange grouthole location for range of vessel support beam loading conditions: no inner concrete support. 


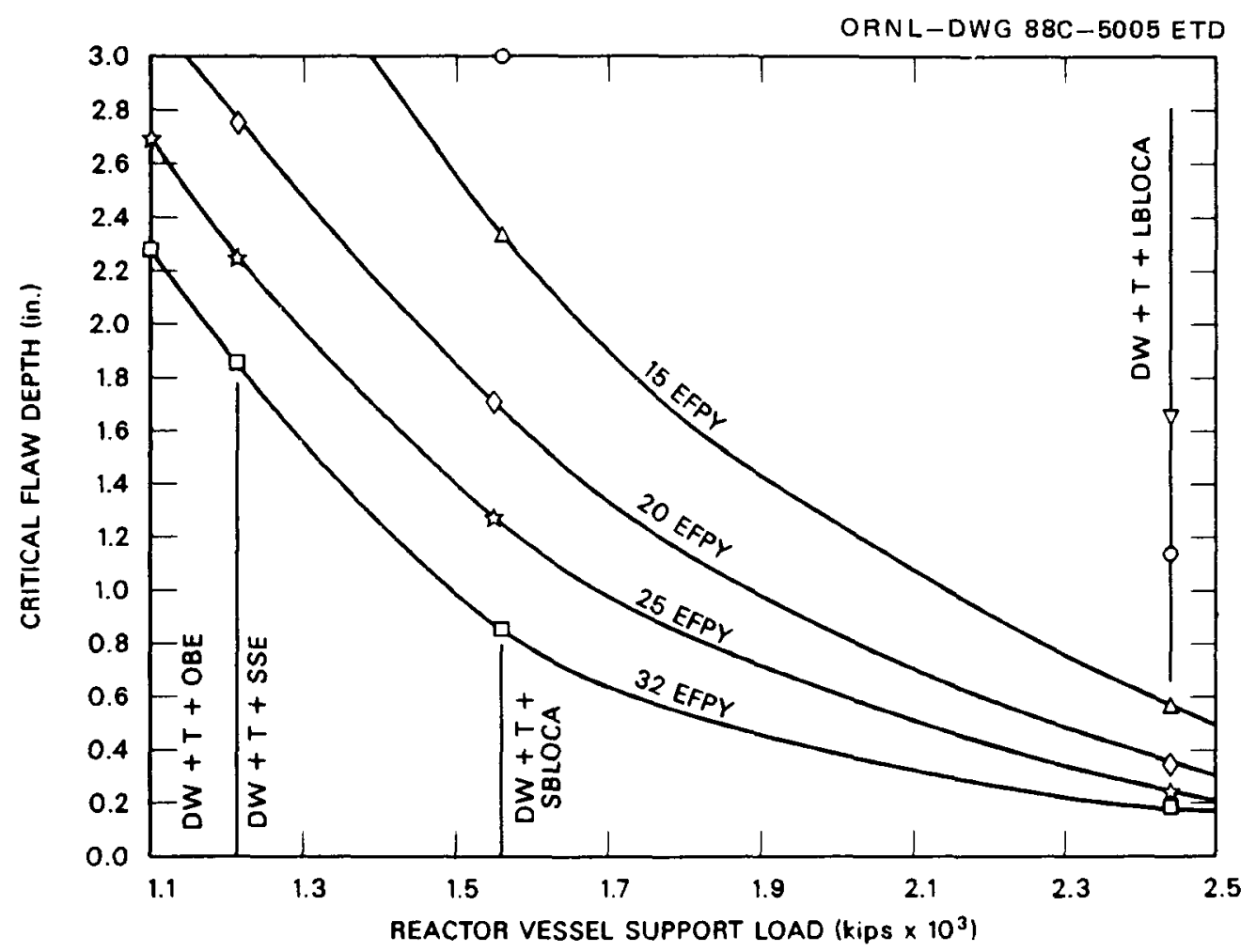

Fig. 6.48. Lifetime variation of critical flaw depths at beamflange grout-hole location for range of vessel support beam loading conditions: with inner concrete support.

6.7.3.4 The impact of NDTT variations. Variations in reported values of NDTT for A36 were reviewed in Sect. 6.5.5, and it was shown that a further temperature shift of $11^{\circ} \mathrm{F}$ must be applied to the results calculated in this report to encompass the $90 \%$ confidence 1 imit on the NDTT population. The carpet plot of Fig. 6.49 has been constructed to permit a rapid evaluation of the impact of this temperature shift on critical flaw depths at the beam flange grout hole location for the governing case where the inner concrete provides no support to the beams. Note that the plot of Fig. 6.49 can also be used to assess the impact of the departure of the beam operating temperature from the $90^{\circ} \mathrm{F}$ value used in the analysis. Analyses used to construct the plot of Fig. 6.49 are summarized in Table 6.18 .

As an example of the use of Fig. 6.49, consider the case of the 32-EFPY critical flaw depth for the SBLOCA loading condition. This value ( $0.42 \mathrm{in.})$ is shown entered on the SBLOCA load curve in Fig. 6.49 at a $\mathrm{T}$ - NDTT value of $-13^{\circ} \mathrm{F}$ as point A. (See Table 6.8 for the origin of the $\left.-13^{\circ} \mathrm{F}.\right)$ Application of the $11^{\circ} \mathrm{F}$ temperature shift required to encompass the $90 \%$ confidence 1 imit on NDTT moves the calculated $T$ - NDTT value to $-24^{\circ} \mathrm{F}$, corresponding to point $\mathrm{B}$ on Fig. 6.49. The critical flaw depth corresponding to point $B$ is seen to be 0.31 in. Application of the $90 \%$ NDT confidence 1 imit temperature shift $\left(11^{\circ} \mathrm{F}\right)$ thus reduced the critical flaw depth by 0.11 in. 
Table 6.17. Lifetime variation of critical flaw sizes at the beam flange hole location

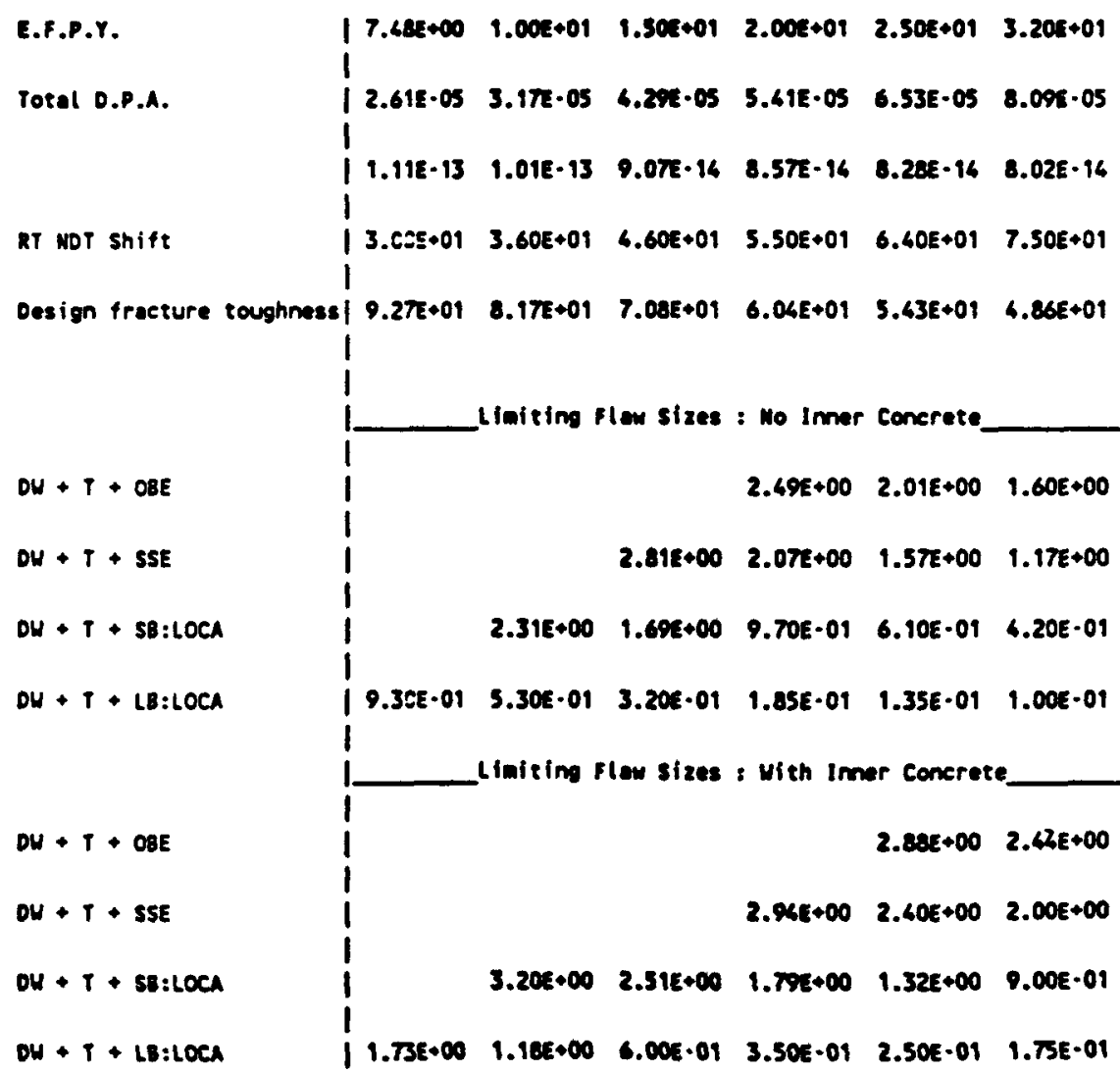

Liniting flew sizes : No Imer Concrete.

OPNL-DWG 88-4868A ETD

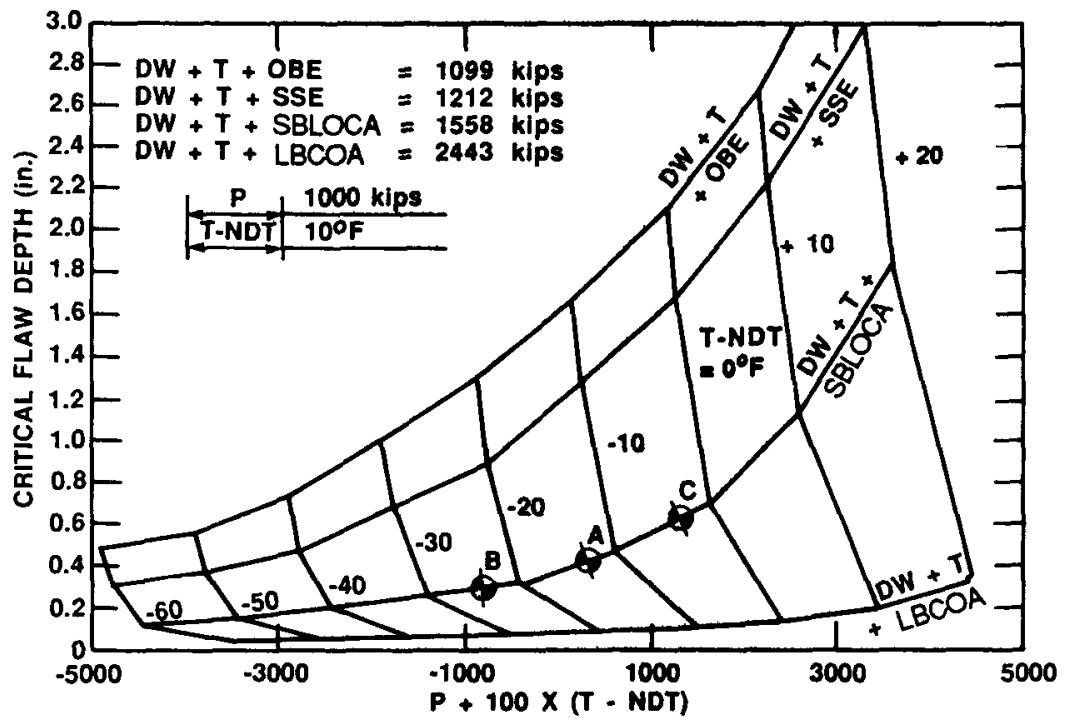

Fig. 6.49. Carpet plot used to assess the impact on critical flaw depth of variations in NDTT, support operating temperature, and support load. Point $B$ represents a $-11^{\circ} \mathrm{F}$ shift in NDTT, while point $C$ represents a $10^{\circ} \mathrm{F}$ increase in support operating temperature. 
Table 6.18

CRITICAL FLAW DEPTHS AS A FUNCTION OF SUPPORT LOAD \& (T - NDT)

BEAM FLANGE GROUT HOLE : NO INNER CONCRETE

\begin{tabular}{|c|c|c|c|c|c|}
\hline & & OBE & SSE & SB:LOCA & LB: LOCA \\
\hline & & $\begin{array}{l}1099.000 \\
\text { (Kips.) }\end{array}$ & $\begin{array}{l}1212.000 \\
\text { (Kips.) }\end{array}$ & $\begin{array}{l}1558.000 \\
\text { (Kips.) }\end{array}$ & $\begin{array}{l}2443.000 \\
\text { (Kips.) }\end{array}$ \\
\hline $\begin{array}{l}T-\text { NDT } \\
(D e g . F .)\end{array}$ & $\begin{array}{c}\text { Design } \\
K 1 d \\
(K S I \sqrt{I N})\end{array}$ & (n) & RITICAL FLA & DEPTH cin. & ) $-\ldots \ldots \ldots$ \\
\hline 40.000 & 113.986 & & & & 1.720 \\
\hline 30.000 & 88.926 & & & 2.690 & 0.750 \\
\hline 20.000 & 73.199 & & 2.990 & 1.830 & 0.360 \\
\hline 10.000 & 62.842 & 2.700 & 2.240 & 1.150 & 0.210 \\
\hline 0.000 & 55.610 & 2.130 & 1.680 & 0.650 & 0.140 \\
\hline-10.000 & 50.010 & 1.690 & 1.260 & 0.470 & 0.115 \\
\hline-20.000 & 45.700 & 1.300 & 0.890 & 0.320 & 0.085 \\
\hline-30.000 & 42.270 & 1.100 & 0.720 & 0.275 & 0.078 \\
\hline-40.000 & 39.376 & 0.720 & 0.480 & 0.205 & 0.065 \\
\hline-50.000 & 37.636 & 0.550 & 0.380 & 0.160 & 0.060 \\
\hline-60.000 & 36.400 & 0.480 & 0.330 & 0.135 & 0.055 \\
\hline
\end{tabular}

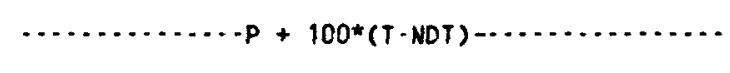

$\begin{array}{rrrrr}40.000 & & & 6443.000 \\ 30.000 & & & 4558.000 & 5443.000 \\ 20.000 & 2099.000 & 2212.000 & 2558.000 & 3443.000 \\ 10.000 & 1099.000 & 1212.000 & 1558.000 & 2443.000 \\ 0.000 & 99.000 & 212.000 & 558.000 & 1443.000 \\ -10.000 & -901.000 & -788.000 & -442.000 & 443.000 \\ -20.000 & -1901.000 & -1788.000 & -1442.000 & -557.000 \\ -30.000 & -2901.000 & -2788.000 & -2442.000 & -1557.000 \\ -40.000 & -3901.000 & -3788.000 & -3442.000 & -2557.000 \\ -50.000 & -4901.000 & -4788.000 & -4442.000 & -3557.000 \\ -60.000 & & & & \end{array}$

In a further example, if the beam operating temperature is increased by $10^{\circ} \mathrm{F}$ to $100^{\circ} \mathrm{F}$ and the temperature shift associated with the 90\% NDTT confidence $1 \mathrm{imit}$ is neglected, then $\mathrm{T}$ - NDTT changes from $-13^{\circ} \mathrm{F}$ to $-3^{\circ} \mathrm{F}$. Point $\mathrm{C}$ on Fig. 6.49 corresponds to the $-3^{\circ} \mathrm{F} \mathrm{T}-$ NDTT value. The corresponding critical flaw depth is obtained as 0.6 in., an increase of $0.18 \mathrm{in.}$ 


\subsection{Evaluation of Results}

Flaws can be present in the support beams because of cracking induced by the fabrication processes and/or cracking induced by fatigue loading. In both cases the flaws will grow as a result of the effect of cyclic loading on the supports. The magnitude of the flaw growth is of concern in the evaluation because it contributes an increment to the flaw dimensions that would not have been present during final inspection of the support beams.

\subsubsection{Flaw growth as a result of cyclic loading}

Cyclic crack-growth data were taken from Ref. 7 and are reproduced in Fig. 6.50 The data for weldments were selected for use in this evaluation because ( 1 ) the fillet weld at the cavity liner interface and the flame-cut surface of the grout hole will both be in a metallurgical condition that is representative of weld metal/heat-affected zone (HAZ) and (2) crack-growth rates for the welded specimens were higher than those for parent material. A lower bound curve was added to the data of Fig. 6.50 and used to generate the following equation:

$$
\mathrm{da} / \mathrm{dN}=1.158 \times 10^{-13} \times \Delta \mathrm{K}^{5.837} .
$$

*Other formulations of the equation for crack growth in A36 have been evaluated (Ref. 21). While these alternative formulations do give slightly different crack-growth predictions, the differences are too small to influence the conclusions drawn here.

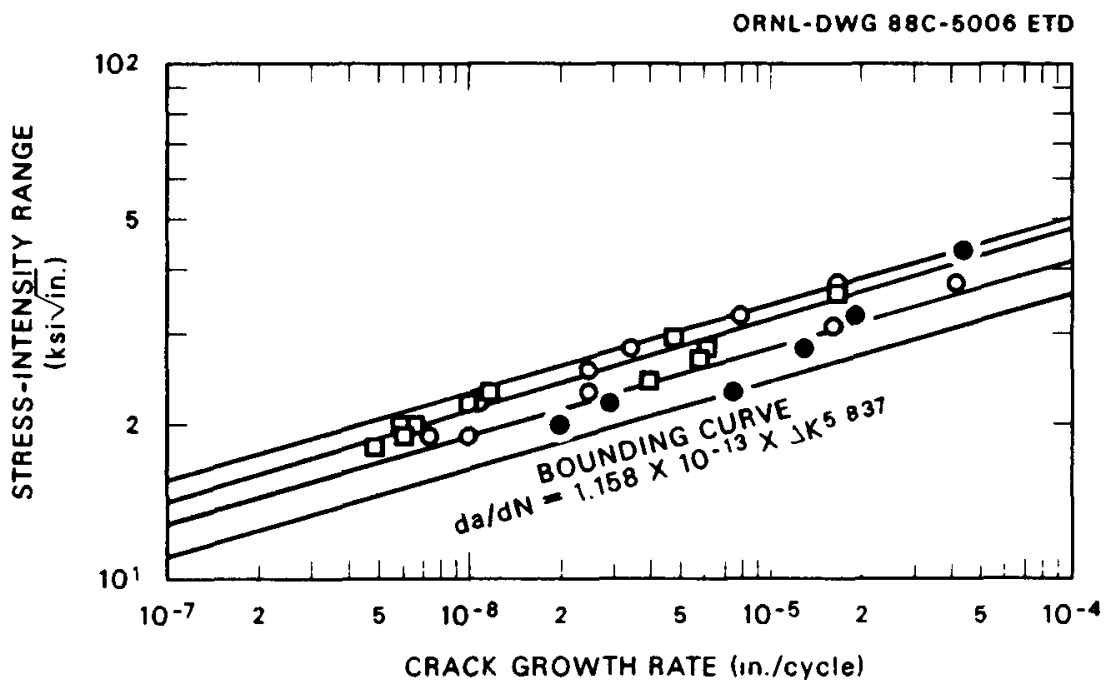

Fig. 6.50. Fatigue crack-growth rates for $\mathrm{A} 36$. 
A definition of the cyclic loading to be included in the crackgrowth analysis is given in Sect. 6.3.3.

Critical flaw dimensions are given in Table 6.16 for the SBLOCA loading. These flaws all represent conditions for which the flaw-tip, stress-intensity factor equals the local value of $\mathrm{K}_{\mathrm{Id}}$. To rapidly obtain an upper bound, order-of-magnitude assessment of $f 1$ aw growth as a result of cyclic loading, the flaw-tip stress-intensity factors for all cycles in a given loading condition were calculated using the critical flaw geometry. Results were then summed to give a cumulative flaw growth for the total of all of the support beam duty cycle events.

Results from the upper bound flaw-growth analysis are summarized in Table 6.19 Flaw growth is insignificant relative to the dimensions of the critical flaws. This result leads to the conclusion that presumably the critical flaws identified in Table 6.16 will exist in the support beams only if they escaped detection during final inspection.

\subsubsection{Interface with the reactor cavity 1 iner}

Critical flaw depths given for this location in Table 6.16 increase rapidly as the flaw aspect ratio (a/1) increases, reaching values in excess of $t / 2$ for a flaw aspect ratio of 0.2 (SBLOCA loading). The significance of this finding is that a substantial length of flaw would have been visible on the surface of the component at final inspection. The specific lengths of relevance are $16.0 \mathrm{in}$. for the a/1 = 0 case and 9.7 in. for the $a / 1=0.1$ case. Detection of surface indications of this magnitude presumably is well within the capability of a trained inspector using visual inspection techniques. Dye penetrant or magnetic particle inspection presumably would have detected such large surface indications. It is considered unlikely therefore that flaws with these critical depths and aspect ratios could exist in the support beams at the 1 iner interface location. It is recommended that the Trojan inspection procedures (and inspection records if they are available) be reviewed to confirm this tentative conclusion.

\subsubsection{Maximum bending moment location (Node 4)}

Conclusions reached for this location are identical with those previously given for the cavity liner interface. Surface lengths of flaws having the potential to produce brittle fracture under SBLOCA loading were all in excess of $5.0 \mathrm{in.}$. In this instance no weld is present, and therefore a transverse (normal to the rolling direction) surface crack of this magnitude presumably would have been readily apparent to the inspector.

\subsubsection{Beam top-flange grout-hole location}

The stress concentration produced by this large hole (4-in. diam) in a highly stressed portion of the beam upper flange results in a critical flaw depth for the SBLOCA event of only 0.42 in. (if the inboard concrete is not effective). It is considered unlikely that any 
Table 6.19

ORDER OF MAGNITUDE FATIGUE CRACK GROWTH ANALYSIS

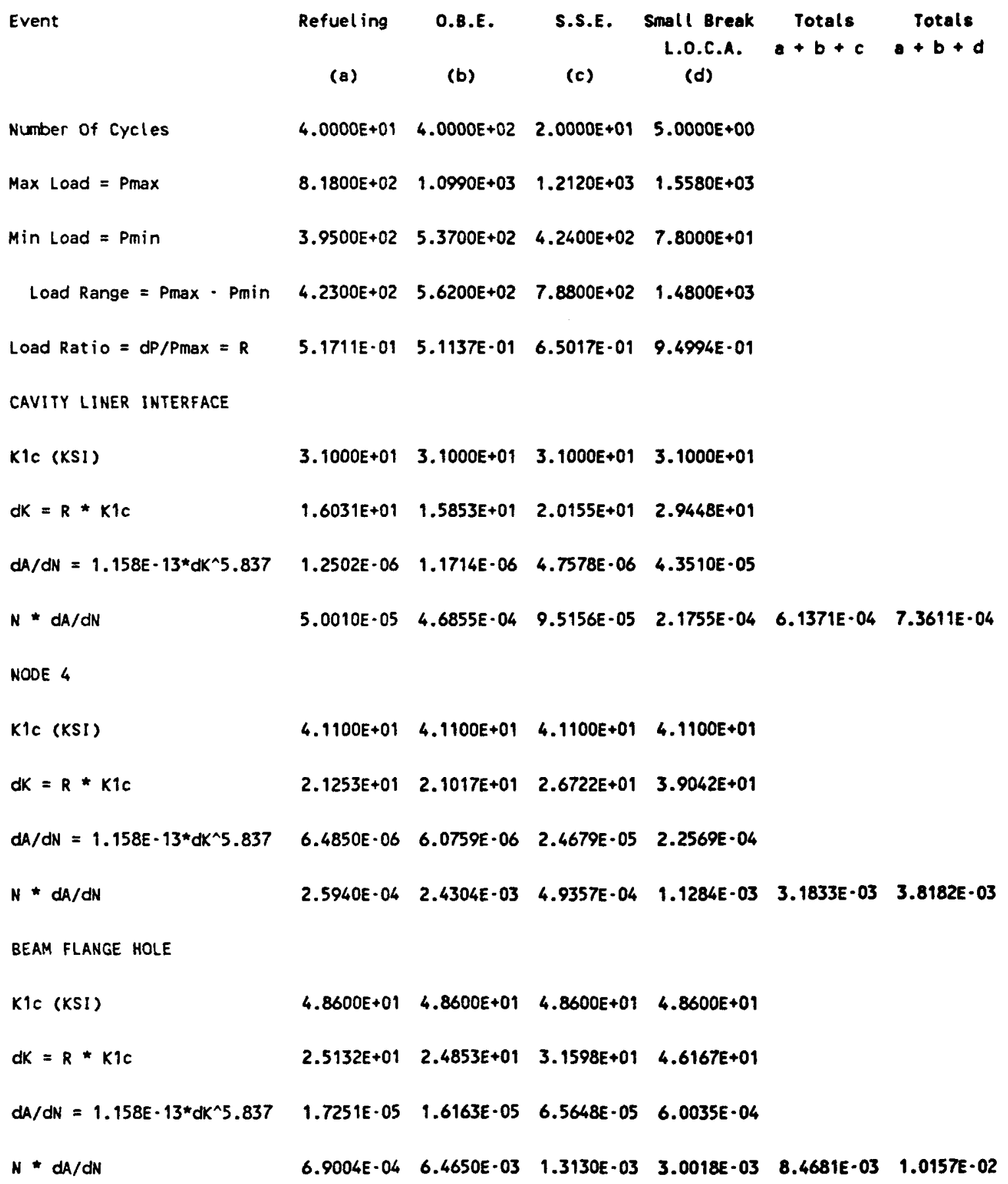

(b)

(c)

L.O.C.A. $a+b+c a+b+d$

Number of Cycles

Max Load $=$ Pmax

Min Load $=$ Pmin

$4.0000 E+01 \quad 4.0000 E+02 \quad 2.0000 E+01 \quad 5.0000 E+00$

$8.1800 E+02 \quad 1.0990 E+03 \quad 1.2120 E+03 \quad 1.5580 E+03$

$3.9500 E+02 \quad 5.3700 E+02 \quad 4.2400 E+02 \quad 7.8000 E+01$

$4.2300 E+02 \quad 5.6200 E+02 \quad 7.8800 E+02 \quad 1.4800 E+03$

5.1711E-01 5.1137E-01 6.5017E-01 9.4994E-01

$1.6031 E+01 \quad 1.5853 E+01 \quad 2.0155 E+01 \quad 2.9448 E+01$

$1.2502 E-06 \quad 1.1714 E-06 \quad 4.7578 E \cdot 06 \quad 4.3510 E-05$

$\begin{array}{llllll}5.0010 E-05 & 4.6855 E-04 & 9.5156 E-05 & 2.1755 E-04 & 6.1371 E-04 & 7.3611 E-04\end{array}$

\section{$4.1100 E+01 \quad 4.1100 E+01 \quad 4.1100 E+01 \quad 4.1100 E+01$}

$2.1253 E+01 \quad 2.1017 E+01 \quad 2.6722 E+01 \quad 3.9042 E+01$

$6.4850 E \cdot 06 \quad 6.0759 E-06 \quad 2.4679 E-05 \quad 2.2569 E-04$

$2.5940 E-04 \quad 2.4304 E-03 \quad 4.9357 E-04 \quad 1.1284 E-03 \quad 3.1833 E-03 \quad 3.8182 E-03$

\author{
$4.8600 E+01 \quad 4.8600 E+01 \quad 4.8600 E+01 \quad 4.8600 E+01$ \\ $2.5132 E+01 \quad 2.4853 E+01 \quad 3.1598 E+01 \quad 4.6167 E+01$ \\ $1.7251 E-05 \quad 1.6163 E-05 \quad 6.5648 E-05 \quad 6.0035 E \cdot 04$

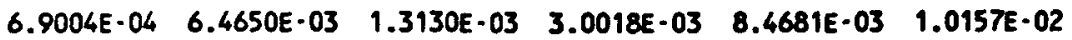


practical inspection technique applied at the time of fabrication could have reliably detected so small a flaw in and adjacent to the flame-cut surface.

The small size of the critical flaw at the flange grout hole makes it imperative that a reliable characterization be obtained of the flaws present in this region. The fact that this region of the support beam is embedded within the cavity wall makes direct inspection impossible. It is suggested therefore that a generic definition of the population of flaws adjacent to the surface of flame-cut holes in plates of similar thickness be compiled using data from (1) the manufacturers of flamecutting equipment, (2) destructive examination of any available flamecut, off-cut material, and (3) duplication of the flange hole flamecutting operation and destructive examination of the finished product.

\subsubsection{Compatibility check on the stress-intensity-factor equations}

Two separate sources were used for the stress-intensity-factor equations used in this analysis. Postulated flaws in sections of the beam flange remote from discontinuities were analyzed using equations and factors taken from Sect. XI, Appendix $A$ of the ASME Boiler and Pressure Vessel Code, 19 whereas flaws at the beam flange hole location were analyzed using equations from the Stress Analysis of Cracks Handbook. 20 The purpose of the check summarized in this section is to verify that these equations, as interpreted and utilized in this report, give compatible results.

The stress-intensity-factor equations taken from Ref. 19 were for a single-sided surface flaw, whereas those taken from Ref. 20 were for symmetric radial flaws emanating from a circular hole in a finite plate. To provide a basis for the compatibility check, the beam flange hole case was divided on its axis of symmetry and idealized as a plate with a single-sided flaw. Plate "thicknesses" were defined as the surface-tosurface distance in the direction of crack propagation. This definition gave a value of $t=2.5 \mathrm{in}$. for the locations remote from the hole and $t=8.0 \mathrm{in}$. for the hole location. The value $8.0 \mathrm{in.}$ (one-half the flange width) is used rather than the ligament width $(6.0 \mathrm{in.})$ because the stress-intensity-factor equations of Ref. 20 define the crack length to include the hole radius.

With these analytical models defined, the criteria for compatibility were defined as follows. When applied in a compatible manner on a finite-width plate, the two equations must predict compatible stressintensity/flaw-depth relationships. This requirement specifically excludes cracking regimes in which nonlinear behavior would be anticipated such as (1) the area of concentrated stress immediately adjacent to the hole and (2) secondary bending effects resulting from large-scale penetration of single-sided cracks. This latter constraint on the compatibility comparison was necessary because one of the models (the beam flange hole model) is constrained from generating secondary bending moments while the other model is not.

The compatibility check was made using the $a / 1=0$ SBLOCA results for the cavity liner interface and the beam flange hole. These results are reproduced in Table 6.20, column 7 . 
Table 6.20

STRESS INTENSITY FACTOR EQUATION COMPATIBILITY CHECK

\begin{tabular}{|c|c|c|c|c|c|c|c|c|c|c|}
\hline 1 & 2 & 3 & 4 & 5 & 6 & 6 & 7 & 8 & 9 & 10 \\
\hline Beam & Actual & Effective & Effective & "a"/"t" & |Stress & s Intensity & Factor I & $F$ l ange & Normal ized| & Design \\
\hline \multirow[t]{5}{*}{ Location } & Flaw & $\mathrm{Flaw}$ & Bean & & $\mid \cdots \cdots$ & $\ldots \ldots \ldots \ldots$ & $\cdots \ldots \ldots \mid$ & Mean & SIF & | stress \\
\hline & Depth & Depth & Thickness & & DW+T & $T+O B E \quad D W+T+$ & $+S B: L O C A \mid$ & Stress & & |Itensity | \\
\hline & & & & & i & & 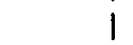 & & & | factor | \\
\hline & a & "a" & "t" & & i & KSI*(in.)^ & $1 / 2$ & KSI & $\mathrm{KI} / \mathrm{KSI}$ & 1 \\
\hline & & & & & 1 & & 1 & & & 1 \\
\hline Flange Hole & 0.00 & 2.00 & 8.00 & 0.25 & 1 & 0.00 & 0.001 & 16.43 & 0.00 & 31.001 \\
\hline Flange Hole & 0.05 & 2.05 & 8.00 & 0.26 & i & 15.29 & 21.68 & 16.43 & 1.32 & 31.001 \\
\hline Flange Hole & 0.10 & 2.10 & 8.00 & 0.26 & i & 21.72 & 30.80 & 16.43 & 1.87 & 31.001 \\
\hline Flange Hole & 0.15 & 2.15 & 8.00 & 0.27 & i & 25.29 & 35.86 & 16.43 & 2.18 & 31.001 \\
\hline $\mathrm{Flange}$ Hole & 0.20 & 2.20 & 8.00 & 0.28 & i & 27.62 & 39.301 & 16.43 & 2.39 & 31.001 \\
\hline Flange Hole & 0.30 & 2.30 & 8.00 & 0.29 & i & 31.45 & 44.601 & 16.43 & 2.71 & 31.001 \\
\hline Flange Hole & 0.40 & 2.40 & 8.00 & 0.30 & i & 33.88 & 48.041 & 16.43 & 2.92 & 31.001 \\
\hline Flange Hole & 0.60 & 2.60 & 8.00 & 0.33 & i & 38.08 & 54.001 & 16.43 & 3.29 & 31.001 \\
\hline Flange Hole & 1.00 & 3.00 & 8.00 & 0.38 & i & 42.68 & $60.51 i$ & 16.43 & 3.68 & 31.001 \\
\hline flange Hole & 2.00 & 4.00 & 8.00 & 0.50 & i & 53.39 & 75.701 & 16.43 & 4.61 & 31.001 \\
\hline Flange Hole & 3.00 & 5.00 & 8.00 & 0.63 & i & 66.59 & 94.401 & 16.43 & 5.75 & 31.001 \\
\hline Cavity Liner & 0.00 & 0.00 & 2.50 & 0.00 & i & 0.00 & 0.001 & 10.66 & 0.00 & 48.601 \\
\hline Cavity Liner & 0.05 & 0.05 & 2.50 & 0.02 & i & 3.89 & 5.54 & 10.66 & 0.52 & 48.601 \\
\hline Cavity Liner & 0.10 & 0.10 & 2.50 & 0.04 & I & 5.48 & 7.81 & 10.66 & 0.73 & 48.601 \\
\hline Cavity Liner & 0.20 & 0.20 & 2.50 & 0.08 & i & 7.96 & 11.34 & 10.66 & 1.06 & 48.601 \\
\hline Cavity Liner & 0.30 & 0.30 & 2.50 & 0.12 & 1 & 10.18 & 14.511 & 10.66 & 1.36 & 48.601 \\
\hline Cavity Liner & 0.60 & 0.60 & 2.50 & 0.24 & $i$ & 17.25 & 24.58 & 10.66 & 2.31 & 48.601 \\
\hline Cavity Liner & 1.25 & 1.25 & 2.50 & 0.50 & $i$ & 55.96 & 79.73 & 10.66 & 7.48 & 48.601 \\
\hline
\end{tabular}

The stress-intensity factors of Table 6.20 were produced by differing flange stresses, because the flange bending moment varies along the length of the beam. To provide a basis for comparison therefore the stress-intensity factors were normalized by dividing by the local flange far-field membrane stress (column 8 ). The resulting parameter has the units of ksi $\sqrt{\text { in. }} /$ ksi or $\sqrt{i n .}(\operatorname{column} 9)$.

A similar normalizing procedure was applied to the flaw depth to beam thickness ratio. In the case of the beam flange hole location, both the plate thickness " $t$ " and the flaw depth " $a$ " are pseudo values, having the geometric configuration previously defined. The resulting dimensionless a/t values are given in column 5 of Table 6.20.

The data of columns 5 and 9 of Table 6.20 were then plotted to produce the curves of Fig. 6.51. The linear portions of those curves are clearly predicting similar relationships, and the equations, as utilized in this report, are therefore considered compatible. Note that the portion of the cavity liner interface curve extending from $a / t=0.24$ to $a / t=0.5$ was defined by a single point and would not be expected to be linear over its entire length. 
ORNL-DWG 88-5007 ETD

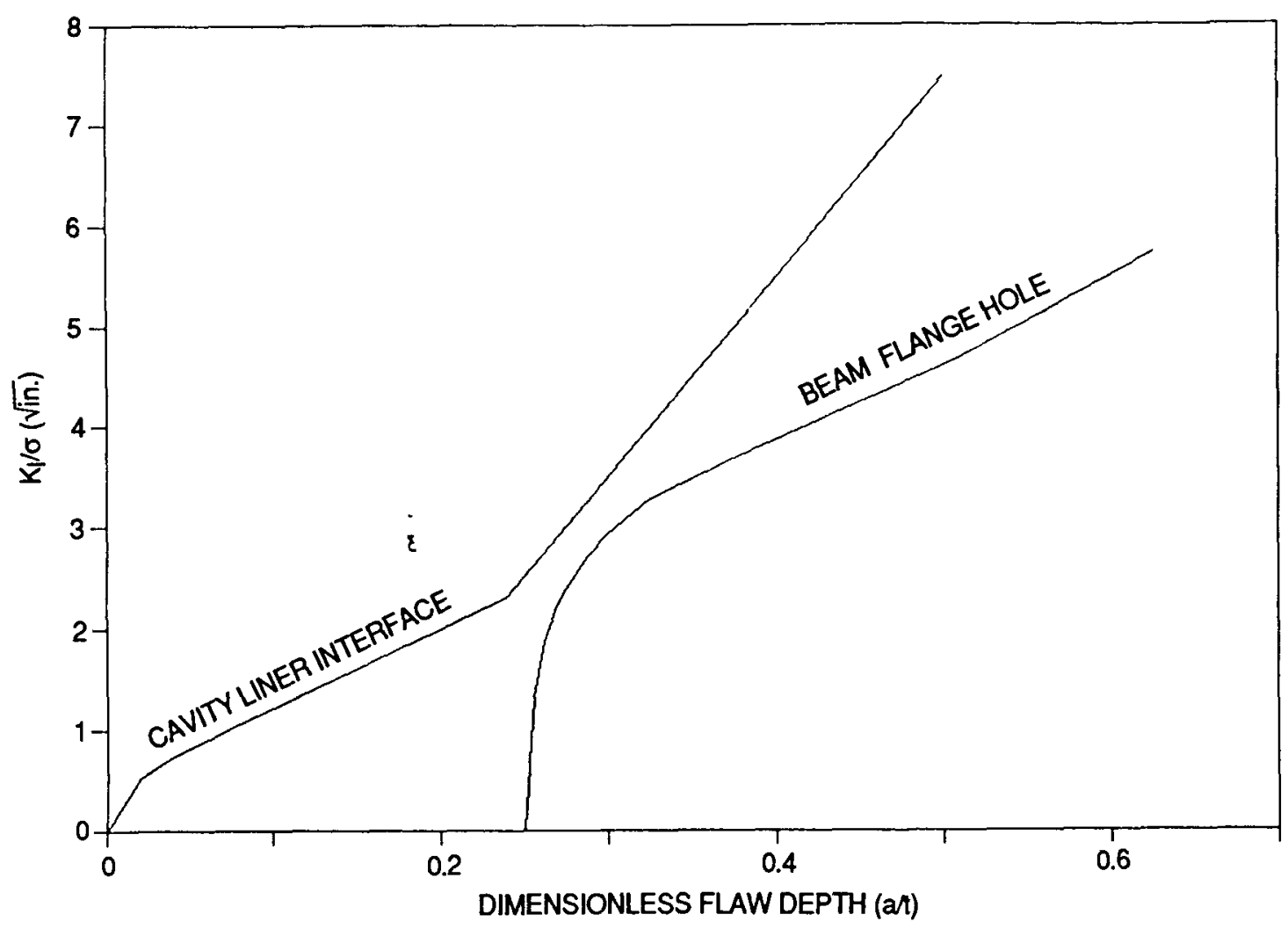

Fig. 6.51. Compatibility check on the stress-intensity-factor equations used in flaw tolerance analysis. Compatibility is demonstrated by slope continuity in linear portions of curves.

\subsubsection{Load sensitivity comparison}

As noted in Sect. 6.7 .3 .3 , the rate of decrease of allowable flaw size corresponding to a given increase in support load differed by a factor of almost 8 between the beam flange hole and the cavity liner interface locations. Higher rates of change were obtained at the beam flange hole location. The representation of the flaw depth vs the stress-intensity-factor relationship given in Fig. 6.51 provides a basis for identifying the parameters responsible for the bulk of the factor of 8 rate change.

Stress-intensity factors for the beam flange hole and cavity 1 iner interface locations are plotted as a function of the dimensionless flaw depth parameter a/t in Fig. 6.52. Curves are plotted for both the DW + $\mathrm{T}+\mathrm{OBE}$ and $\mathrm{DW}+\mathrm{T}+\mathrm{SBLOCA}$ cases. The linear portions of the curves have differing slopes, reflecting (1) the differing beam flange membrane stress levels at the two locations for a given support load because of the variation of bending moments along the beam and (2) increases in support load between the $D W+T+O B E$ and the $D W+T+$ SBLOCA cases. 
ORNL-DWG 88-5008 ETD

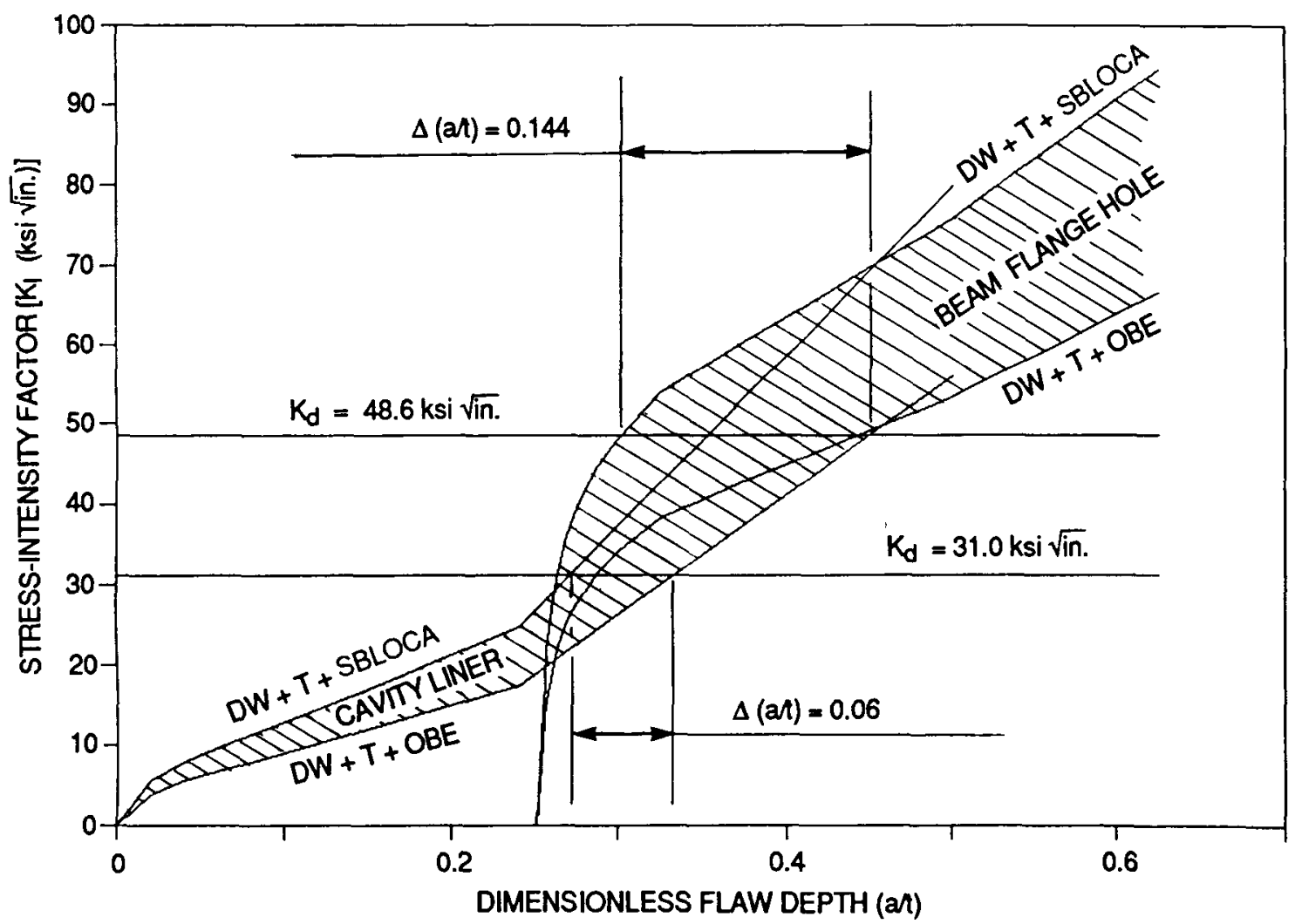

Fig. 6.52. Comparison of the critical-flaw-depth sensitivity to support load variations at cavity liner interface and beam-flange grouthole locations. The beam-flange grout-hole location shows greater sensitivity.

End-of-life design, stress-intensity-factor lines were superposed on the two sets of curves and the dimensionless flaw depth increments $\Delta(a / t)$ between the $D W+T+S B L O C A$, and the $D W+T+O B E$ curves were determined from the intercepts as follows:

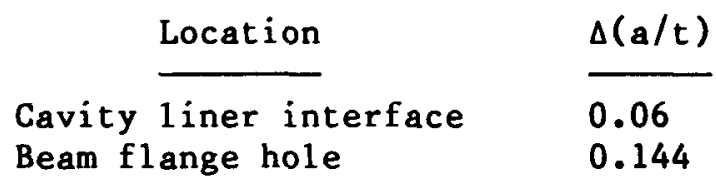

In the case of the cavity liner interface, both the a and $t$ values correspond directly to the actual flaw depth and the actual beam flange thickness. The flaw depth increment corresponding to the $\Delta(a / t)$ value of 0.06 on the 2.5-in.-thick flange can thus be obtained as follows:

$$
\Delta \mathrm{a}_{\mathrm{CLI}}=2.5 \times 0.06=0.15 \mathrm{in} .
$$


At the beam flange hole location, the pseudo crack length a corresponds to $R+a$, where $R$ is the hole radius and $a$ is the depth of $a$ uniform flaw measured from the surface of the hole. The thickness of the pseudo beam measured in the direction of propagation of the crack is in this case the half-width of the plate $(8.0$ in.). The flaw depth increment at the hole location corresponding to the $\Delta(a / t)$ value of 0.144 is thus obtained as follows:

$$
\Delta(R+a)=0.144 \times 8.0=1.152 .
$$

Because the hole radius $R$ is constant, the value $\Delta a_{B F H}$ is equal to 1.152. The ratio of the critical flaw depth change at the cavity liner interface (CLI) and the beam flange hole (BFH) locations for the same increment in applied loading is thus obtained as follows:

$$
\frac{{ }^{\Delta a_{B F H}}}{{ }^{\Delta a_{C L I}}}=\frac{1.152}{0.15}=7.68 \text {. }
$$

This value is very close to the value noted in Sect.6.7.3.3. The rate difference is therefore seen to be caused by differences in the

\begin{tabular}{|c|c|c|}
\hline Parameter & Cavity liner & $\begin{array}{l}\text { Beam flange } \\
\text { hole }\end{array}$ \\
\hline Bending moment/beam & $4.845 \mathrm{lb}$ in. $/ 1 \mathrm{~b}$ & $7.4651 \mathrm{~b}$ in. $/ 1 \mathrm{~b}$ \\
\hline $\begin{array}{l}\text { Thickness in direction } \\
\text { of crack propagation }\end{array}$ & $2.5 \mathrm{in.}$ & $8.0 \mathrm{in}$ \\
\hline $\begin{array}{l}\text { End-of-life design } \\
\text { fracture toughness }\end{array}$ & $31.0 \mathrm{ksi} / \mathrm{in}$. & $48.6 \mathrm{ksi} / \mathrm{in}$. \\
\hline
\end{tabular}
following governing parameters between the two locations:

\subsubsection{Residual stress effects}

6.8.7.1 Analysis approach. Residual stresses will be generated within the support beam elements by both the welding and flame-cutting operations. Postweld stress relief will reduce but not eliminate the residual stresses. The residual stresses are important because they add to the stresses produced by external loading of the support beams and thereby increase the stress-intensity factors at the tip of any flaws embedded within the structure.

Residual stress data for the reactor vessel support beams have not been located. Estimates of the potential effect of residual stresses were therefore made using the following ground rules to define the 
residual stress magnitude:

1. The residual stress shall not exceed the yield stress of $A 36$ at the assumed $1100^{\circ} \mathrm{F}$ postweld stress relief temperature. (The yield stress at $1100^{\circ} \mathrm{F}$ was obtained from Ref. 7 as $16.3 \mathrm{ksi}$.) Creep-induced relaxation of the residual stresses will not be considered because no data are available on the temperature-time history used in any postweld stress relief operations. (Data reported in Ref. 22 indicate that residual stress levels approaching $10 \mathrm{ksi}$ can be achieved using conventional postweld stress relief cycles.)

2. The maximum stress existing at any point within the beam, because of the sum of (a) residual stresses and (b) stresses produced by external loading, shall not exceed the material yield stress. This ground rule reflects the fact that the residual stresses are strain controlled and therefore self-limiting. A reduction of the maximum residual stress will occur if local stresses exceed the yield stress.

3. The material yield stress as defined in (2) above shall be based on the initial "as-built" yield stress of $40 \mathrm{ksi}$ and include yield stress increments as a result of a (a) prototypic straining rates and (b) irradiation hardening.

Estimates of the distribution of residual stress are discussed in Sect. $6.8 \cdot 7.4$.

6.8.7.2 Material yield stress. The material yield stress is influenced by both straining rate and irradiation hardening. Prototypic straining rates produce a 9-ksi increase in yield stress of A36 at $90^{\circ} \mathrm{F}$ (see Table 6.4). Irradiation-induced increases in yield stress for the HFIR material (A212B) are defined in Ref. 22 as follows:

$$
\Delta \sigma_{y}=\Delta \mathrm{T} / \mathrm{C},
$$

where

$$
\begin{aligned}
\Delta \sigma_{\mathrm{y}} & =\text { incremental increase in yield stress (MPa), } \\
\Delta \mathrm{T} & =\text { NDTT temperature shift }\left({ }^{\circ} \mathrm{C}\right), \\
\mathrm{C} & =\text { constant }=0.6 .
\end{aligned}
$$

The evaluation of potential residual stress effect was 1 imited to the beam flange hole location, where residual stresses can be introduced by the flame-cutting operation. Irradiation-induced NDTT shifts for the location are given in Table 6.7 as $16.7^{\circ} \mathrm{C}\left(30^{\circ} \mathrm{F}\right)$ and $41.7^{\circ} \mathrm{C}\left(75^{\circ} \mathrm{F}\right)$ for the current condition and the 32-EFPY condition, respectively. Substituting these temperature shifts and constant $C$ into Eq. (13), and converting the yield stress increments to kips per square inch, gives the following results:

$$
\text { Current condition: } \begin{aligned}
\Delta \sigma_{y} & =4.0 \mathrm{ksi} \\
32 \text { EFPY: } \Delta \sigma_{y} & =10.1 \mathrm{ksi}
\end{aligned}
$$


In summary, the yield stress values to be considered in the analysis are as follows:

\begin{tabular}{lccc}
\hline $\begin{array}{c}\text { P1ant operating period } \\
\text { (EFPY) }\end{array}$ & $\begin{array}{l}\text { Irradiation } \\
\sigma_{y} \text { increment } \\
\text { (ksi) }\end{array}$ & $\begin{array}{l}\text { Static } \\
\text { yield } \\
\text { stress } \\
\text { (ksi) }\end{array}$ & $\begin{array}{c}\text { Dynamic } \\
\text { yield } \\
\text { stress } \\
\text { (ksi) }\end{array}$ \\
\hline Zero & 0 & 40.0 & 49.0 \\
7.48 (current condition) & 4.0 & 44.0 & 53.0 \\
32.0 & 10.1 & 50.1 & 59.1 \\
\hline
\end{tabular}

To ensure a conservative result, in this table the assumption was made that strain-rate and irradiation effects on yield stress are directly additive.

6.8.7.3 Upper bound residual stress estimate. A finite-element analysis using the Microsafe 2D computer program 6 was performed to define the distribution of stresses in the beam flange ligament adjacent to the grout hole. Results from this analysis are summarized in Table 6.21 and plotted in Fig. 6.53. Peak stresses from these plots were used

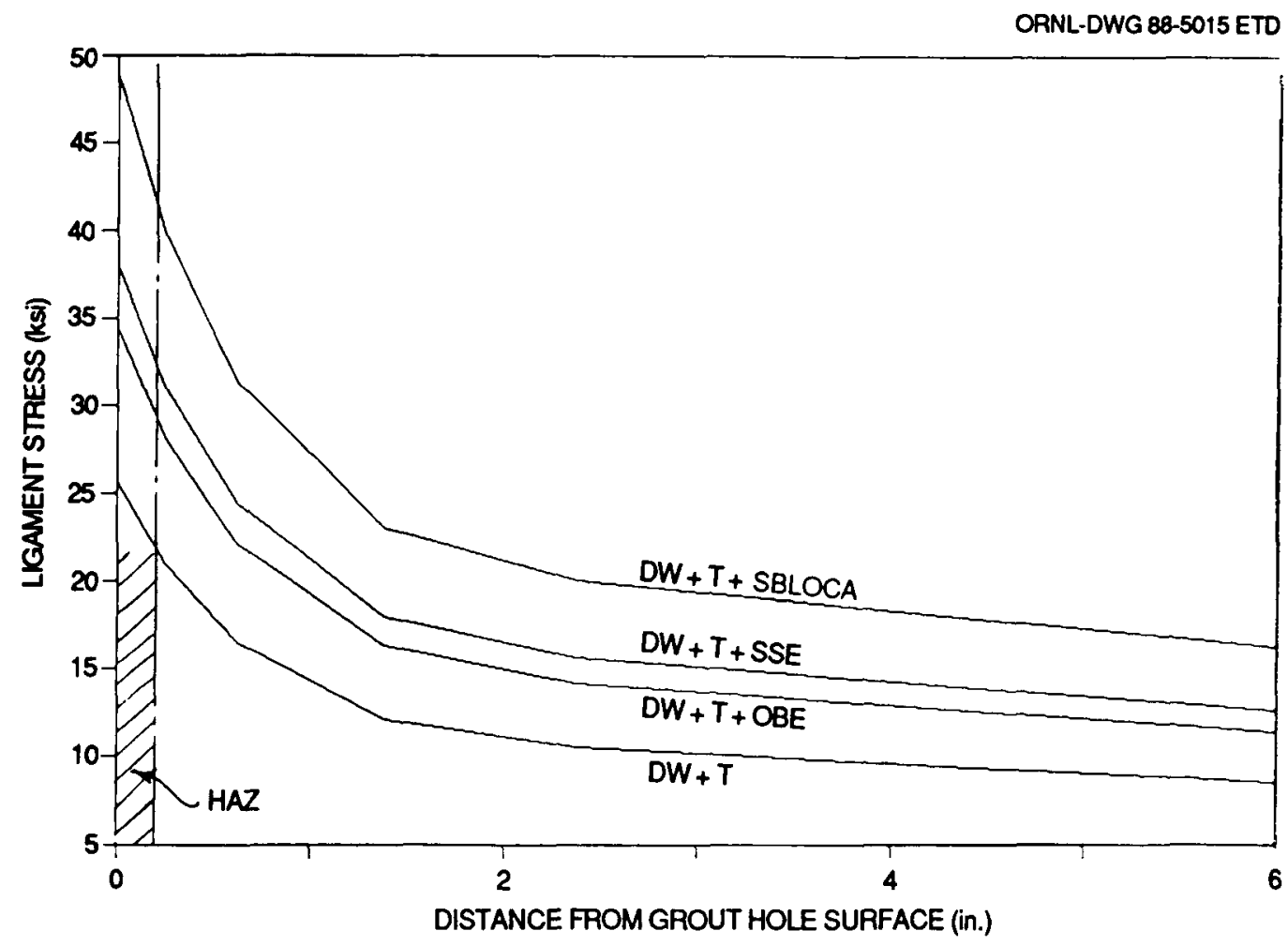

Fig. 6.53. Stress distributions in the beam-flange ligament showing stress concentrations adjacent to the grout hole. Tensile residual stresses can be superposed on stresses shown in HAZ section of ligament. 
Table 6.21

BEAM FLANGE GROUt hOLE LIGAMENT SIRESSES

Distance from hole surface

Load Combination

$D W+T H+S B L O C A$

DW+TH+SSE

$D W+T H+O B E$

DW+TH
0.00

0.25

0.63

1.38

2.38

6.00

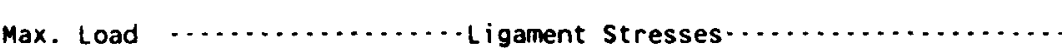

(Kips.)

$\begin{array}{rrrrrrr}1558.00 & 48903.00 & 39906.00 & 31350.00 & 23063.00 & 20049.00 & 16199.00 \\ 1212.00 & 38042.64 & 31043.69 & 24387.80 & 17941.18 & 15596.53 & 12601.53 \\ 1099.00 & 34495.76 & 28149.35 & 22114.02 & 16268.44 & 14142.39 & 11426.64 \\ 818.00 & 25675.64 & 20951.93 & 16459.76 & 12108.82 & 10526.37 & 8504.99\end{array}$


in conjunction with the yield stress result from Sect. 6.8.7.2 to define the limiting value of residual stress in the $\mathrm{HAZ}$ adjacent to the hole surface.

The first step in defining the limiting residual stress was to define the maximum residual stress that could exist at the start of life, when the material yield stress has its lowest value. This start of life limiting residual stress is the lower of (1) the material yield stress at the stress relief temperature $(16.3 \mathrm{ksi})$ or (2) the static yield stress minus the stress produced by the vessel DW and $T$ loading. This latter value is $14.3 \mathrm{ksi}(40.0-25.7)$ and is therefore the governing value. In effect, the maximum residual stress throughout 1 ife cannot exceed this start-of-life value, which is governed by local yielding as the $\mathrm{DW}$ - and $T$-induced stresses (not self-limiting) are superposed on the residual stresses from the flame-cutting operation (strain controlled and self-limiting).

At the start of 1 ife, application of any static support load in excess of the $D W+T$ load $(818 \mathrm{kips})$ would cause further yielding and a further reduction in the residual stress. The yield stress is, however, increased by both high strain rates and irradiation hardening. The net result of these hardening mechanisms is to enable the material adjacent to the hole surface to sustain higher stresses without yielding. The residual stress element of the total stress, however, cannot exceed the 14.3-ksi value derived earlier. The residual stress may be reduced below the 14.3-ksi value if the combination of non-self-limiting and self-limiting stresses exceeds the dynamic yield stress of the irradiation-hardened material.

Analysis of the maximum possible residual stress associated with the three principal dynamic loading cases considered is summarized in Table 6.22. Note that the start-of-life limiting value (14.3 ksi) governs through to the end of 1 ife for the $D W+T+O B E$ and $D W+T+S S E$ loading cases. In the case of the $D W+T+S B L O C A$ loading, however, the maximum residual stress is reduced by local yielding to $4.1 \mathrm{ksi}$ at 7.48 EFPY and $10.2 \mathrm{ksi}$ at 32.0 EFPY. The trend of increasing upper bound residual stress with increasing reactor operating period is the effect of irradiation hardening of the material.

Analysis results from Table 6.22 are plotted in Fig. 6.54. Two 1 imiting residual stress envelopes are shown in the figure. The envelope defined by points $A, B, C$, and $D$ applies at 7.48 EFPY (the current condition), while envelope A-B-E-F-C-D applies at 32 EFPY. Crack-tip, stress-intensity factors will be calculated for points $E$ and $F$ on the 32-EFPY envelope to define the limiting residual stress impact.

6.8.7.4 Residual stress distribution. Rapid cooling of the flamecut surface is to be anticipated because of the highly localized heat input that is characteristic of the flame-cutting process and the "chill-block" quenching effect of the bulk of the flange plate material. This combination of thermal conditions will produce high localized tensile residual strains in the region immediately adjacent to the flamecut surface and much lower compressive strains in the balance of the beam flange ligament. The objective in this section of the evaluation is to determine a distribution of residual stresses, compatible with the residual strain distribution, that can be used in the residual-stress/ flaw-tolerance impact assessment. 
Table 6.22

BEAM FLANGE GROUT HOLE LIGAMENT LIMITING RESIDUAL STRESSES

\begin{tabular}{|c|c|c|c|c|}
\hline Load Combination & $\mathrm{OW}+\mathrm{TH}$ & DH+TH+OBE & $D W+T H+S S E$ & $D W+T H+S B: L$ \\
\hline Max. Surface Stress $=S s\left(\left(b / i n^{\wedge} 2\right)\right.$ & 25675.64 & 34495.76 & 38042.64 & 48903.00 \\
\hline Static Yield Stress $=$ Sys $\left(1 b / i n^{\wedge} 2\right)$ & 40000.00 & M.A. & N.A. & N.A. \\
\hline Static Load Limited Sr $=\mathrm{Sr} 1=$ Sys - Ss & 14324.36 & N.A. & N.A. & N.A. \\
\hline Stress Relief Limited Sr $=S y s(1100$ Deg.F) & 16300.00 & H.A. & N.A. & N.A. \\
\hline Limiting residual Stress At $t=2 e r o:$ Srs & 14324.36 & 14324.36 & 14324.36 & 14324.36 \\
\hline Dynamic Yield At 7.48 EFY $=$ Syd1 & 53000.00 & 53000.00 & 53000.00 & 53000.00 \\
\hline Dynamic Load Limited $S r=S r 2=S d y 1-S s$ & 27324.36 & 18504.24 & 14957.36 & 4097.00 \\
\hline Dynamic Yield At 32EFPY $=$ Syd2 & 59100.00 & 59100.00 & 59100.00 & 59100.00 \\
\hline Dynamic Load Limited $\mathrm{Sr}=\mathrm{Sr} 3=\mathrm{Sdy2} \cdot \mathrm{Ss}$ & 33424.36 & 24604.24 & 21057.36 & 10197.00 \\
\hline LIMITING RESIDUAL STRESS AT 7.48 EFPY & 14324.36 & 14324.36 & 14324.36 & 4097.00 \\
\hline LIMITING RESIDUAL STRESS AT 32 EFPY & 14324.36 & 14324.36 & 14324.36 & 10197.00 \\
\hline
\end{tabular}


ORNL-DWG 88C-4870A ETD

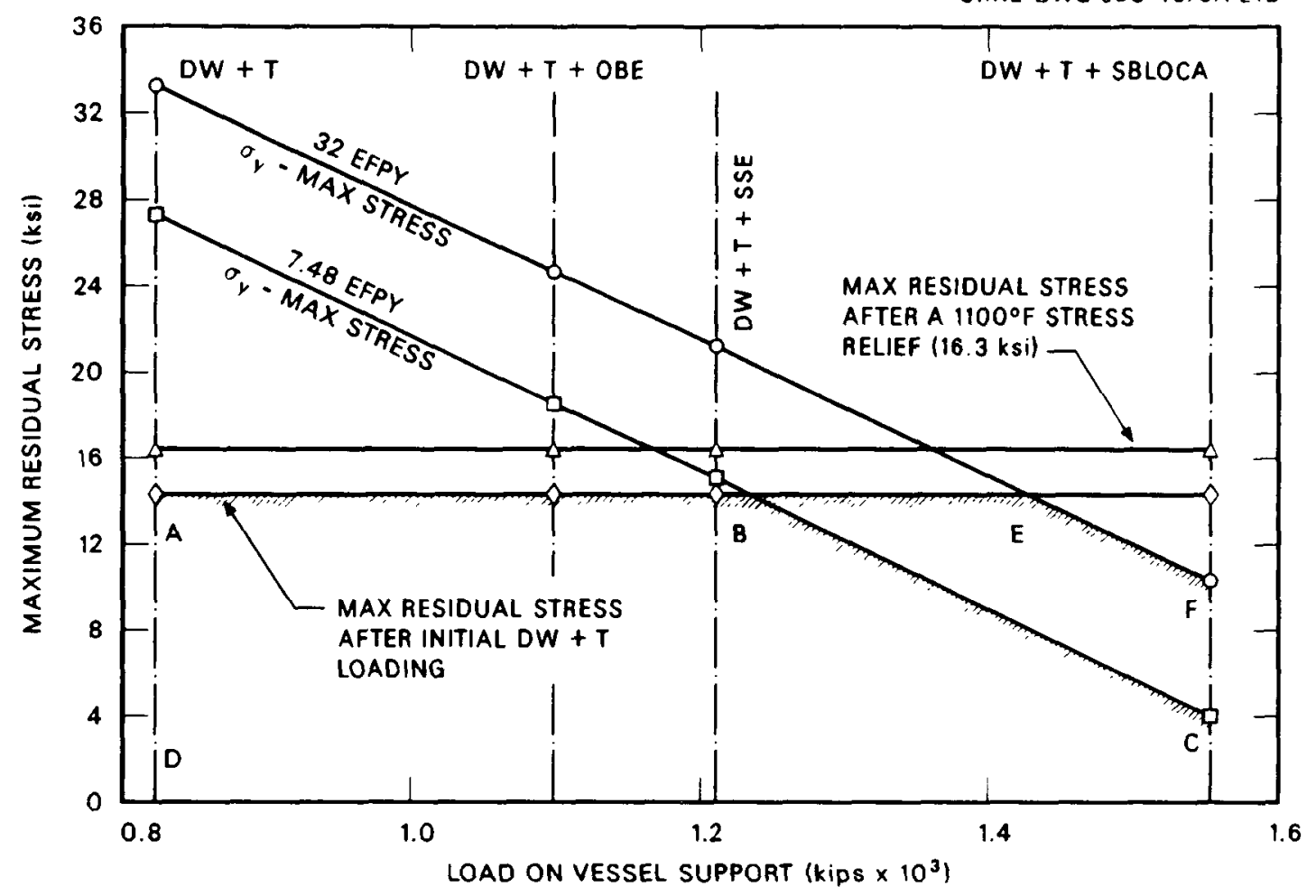

Fig. 6.54. Envelope of residual stresses used in residual stress impact assessment. This envelope was derived using short-term yield stress of $\mathrm{A} 36$ as limiting condition.

No actual data on residual stresses generated by the flame-cutting process have been located. The HAZ produced by flame-cutting heavy steel plates has, however, been investigated. Results reported in Ref. 23 indicate a HAZ extending $3 / 16$ in. into the material from the flame-cut surface. In this analysis the tensile residual stresses defined in Sect. 6.8.7.3 will be assumed to be constant over the HAZ depth. For convenience, the HAZ depth is rounded off to 0.2 in. The resulting distribution of residual stresses is given in Fig. 6.55 .

Note that data reported in Ref. 23 also show a significant reduction in the NDTT in the region immediately adjacent to the flame-cut hole. This is attributed to the fine-grain structure produced by the "chil1-block" quenching of the ASTM A533-Bl material used in the evaluation of Ref. 23. No comparable data have been located for A36, and it is therefore not possible to include an evaluation of quenchinginduced microstructure refinements in the current analysis.

6.8.7.5 Residual stress-stress-intensity factors equations. Equations for the calculation of stress-intensity factors in clad pressure vessel walls, as a result of weld shrinkage in the cladding, are given in Ref. 24. These equations were adapted to the analysis of residual stresses adjacent to the flame-cut hole by setting the HAZ 


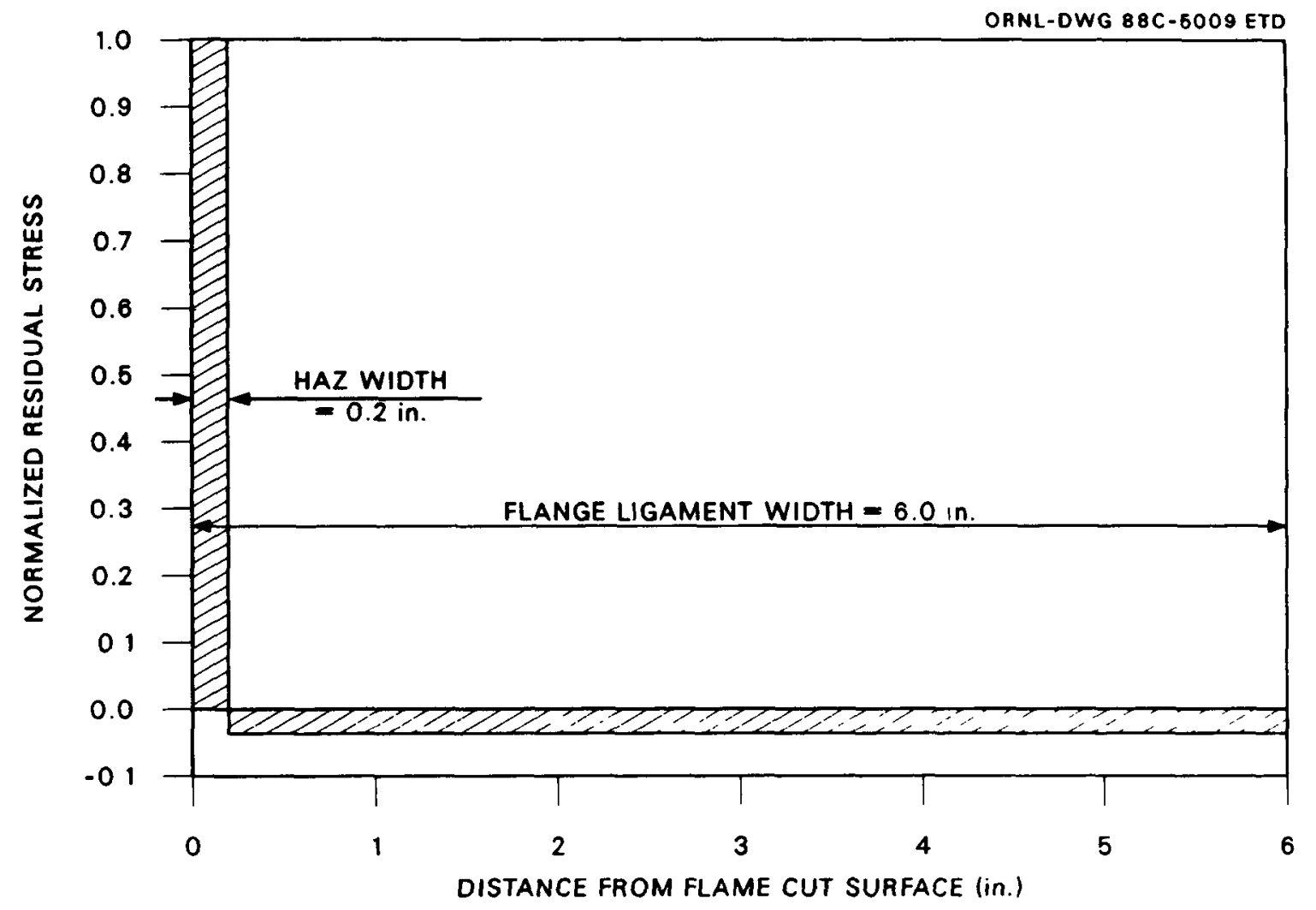

Fig. 6.55. Normalized distribution of strain-controlled residual stresses in beam-flange grout-hole ligament based on analysis of photomicrograph data taken from sections of flame-cut, 12-in.-thick ASTM A533-B1 plate.

thickness equal to the thickness of a pseudo cladding layer. The equations taken from Ref. 24 are reproduced below.'

$$
K_{I}=\sigma * \sqrt{\pi L \alpha}\left(i_{0}-q \alpha i_{1}\right)
$$

where $i_{0}$ and $i_{1}$ are the following influence functions:

$$
\begin{aligned}
& i_{0}=1.122+0.9513 \alpha-0.6240 \alpha^{2}+8.3306 \alpha^{3}, \\
& i_{1}=0.6825+0.3704 \alpha-0.0832 \alpha^{2}+2.8251 \alpha^{3} .
\end{aligned}
$$

For deeper cracks with the crack tip beyond the HAZ, the solution is 
given by

$$
\begin{aligned}
K_{I}=\sigma^{*} \sqrt{\pi L \alpha} & \left(\frac{2}{\pi-2}\right)\left\{( i _ { o } - \frac { 2 } { \pi } ) \left[(1+R) \sin ^{-1}\left(\frac{\psi}{\alpha}\right)\right.\right. \\
& \left.+a\left[(q+R p) \sqrt{1-\left(\frac{\psi}{\alpha}\right)^{2}}-q\right]-\frac{\pi}{2} R\right] \\
& +\left(i_{0}-1\right)\left[\left[(1+R)-\frac{\psi}{2}(q+R p)\right] \sqrt{1-\left(\frac{\psi}{2}\right)^{2}}\right. \\
& \left.\left.+\frac{\alpha}{2}(q+R p) \sin ^{-1}\left(\frac{\psi}{\alpha}\right)-1-\frac{\pi}{4} R p \alpha\right]\right\}
\end{aligned}
$$

In these equations, parameters $p$ and $q$ define the slopes of linear fits to the residual stress distributions. In the assumed residual stress distribution of Fig. 6.55, these slopes are zero, resulting in a considerable simplification of Eqs. (14) and (17). The remaining terms in these equations, as adapted for the HAZ residual stress analysis, are defined as follows:

$$
\begin{aligned}
& x \text { = distance from the flame-cut surface (in.) } \\
& \mathrm{L}=\mathrm{fl} \text { ange } 1 \text { igament width }=6.0 \mathrm{in} \text {. } \\
& a=f l a w \operatorname{depth}(\text { in.) } \\
& \alpha=\mathrm{flaw} \text { depth/1igament width ratio }=\mathrm{a} / \mathrm{L} \\
& \psi=\mathrm{HAZ} \text { thickness/1igament width }=0.2 / 6=0.0333 \\
& \sigma^{*}=\mathrm{HAZ} \text { residual tensile stress }\left(1 \mathrm{~b} / \mathrm{in}^{2}{ }^{2}\right) \\
& p, q=\text { stress distribution slope constants }=0
\end{aligned}
$$$$
R=\frac{\mathrm{HAZ} \text { thickness }}{(\text { Ligament width }-\mathrm{HAZ} \text { thickness })}=\frac{0.2}{(6.0-0.2)}=0.0345
$$

The above definition of $R$ applies only to the simplified residual stress distribution shown in Fig. 6.55 .

6.8.7.6 Ligament combined stress-intensity factors. Linear superposition was used to combine the residual-stress, stress-intensity factors defined in Sect. 6.8 .7 .5 with those generated by loads applied to the supports. Stress-intensity factors generated by external loading were taken from the analysis of Sect.6.7.3. Support loads and residual stresses used in the analysis (corresponding to points $E$ and $F$ on $F i g$. 
6.54) were defined as follows:

\begin{tabular}{clcc}
\hline $\begin{array}{c}\text { Point } \\
\text { on } \\
\text { Fig. } 6.54\end{array}$ & Physical significance & $\begin{array}{c}\text { Support } \\
\text { load } \\
\text { (kips) }\end{array}$ & $\begin{array}{c}\text { Residual } \\
\text { stress } \\
\text { (1b/in. }{ }^{3} \text { ) }\end{array}$ \\
\hline E & $\begin{array}{c}\text { Highest support load for which } \\
\text { the maximum residual stress } \\
\text { can be sustained } \\
\text { Maximum support load currently } \\
\text { specified for the plant }\end{array}$ & 1427 & 14,300 \\
\hline
\end{tabular}

Ligament stresses corresponding to points $E$ and $F$ in Fig. 6.54 are summarized in Table 6.23 and shown plotted in Fig. 6.56 and 6.57 .

Stress-intensity factors corresponding to the applied loading stress, the residual stress, and the combined stress are calculated in the spreadsheets of Tables 6.24 and 6.25 for cases " $E$ " and "F" respectively. The analysis was performed parametrically with the flaw depth " $a$ " as an independent variable. Plots of the stress-intensity factors obtained for the two cases are given in Figs. 6.58 and 6.59 .

Superposed on the plots of Fig. 6.58 and 6.59 is the 32-EFPY $K_{I d}$ value for the beam flange hole location $(48.6 \mathrm{ksi} \cdot \sqrt{\mathrm{in} .})$. The intercept of the $K_{I d}$ line with the $K_{I}$ curves for (1) support loading acting alone and (2) support loading combined with residual stresses provides an indication of the potential effect of the residual stresses. In case "E" (Fig. 6.58), residual stresses reduce the critical flaw depth to a combined loading value of just under 0.2 in. Case "F" results show a smaller critical flaw size reduction $(0.21 \mathrm{in.})$ to a combined loading value of just over 0.2 in. The impact of incorporating the effect of the upper bound residual stresses is therefore to reduce the critical flaw depth at the beam flange hole location to 0.2 in.

6.8.7.7 Assessment of results. Inclusion of residual stress effects in the flaw tolerance analysis of the beam flange hole reduces the 32-EFPY critical flaw size to $\sim 50 \%$ of the value calculated when residual stress effects were ignored. Several critical assumptions had to be made in the analysis that produced this result, and these could have a significant impact on the calculated flaw size reduction. There appears to be a potential for significant reductions in critical flaw sizes because of residual stress effects, however, and recognition of this potential should be factored into any evaluation of the overall analysis results.

Refinement of the microstructure adjacent to flame-cut holes in heavy-section material has been shown to have the potential for producing beneficial shifts in the NDTT of ASTM A533-B1 material. It is possible that similar beneficial microstructure changes may occur adjacent to $\mathrm{flame-cut} \mathrm{holes} \mathrm{in} \mathrm{A} 36$ material. No data on flame-cuttinginduced microstructure refinement in $A 36$ material have been located, however, and therefore it was not possible to include consideration of this effect in the flaw tolerance analysis. 
Table 6.23

COMBINED BEAM FLANGE LIGAMENT STRESSES

Distance from hole surface DW+TH+SBLOCA ( 9558 Kips) 10200 PSI Residual Stress TOTAL CASE "F"

1427 Kips Applied Support Load 14300 PSI Residual Stress TOTAL CASE "E"

$$
\begin{array}{llllllll}
10.00 & 0.20 & 0.20 & 0.25 & 0.63 & 1.38 & 2.38 & 6.00
\end{array}
$$

$\begin{array}{llllllll}48903.00 & 41705.40 & 41705.40 & 39906.00 & 31350.00 & 23063.00 & 20049.00 & 16199.00\end{array}$ $\begin{array}{llllllll}10200.00 & 10200.00 & .351 .72 & -351.72 & -351.72 & -351.72 & -351.72 & -351.72\end{array}$ $\begin{array}{llllllll}59103.00 & 51905.40 & 41353.68 & 39554.28 & 30998.28 & 22711.28 & 19697.28 & 15847.28\end{array}$

$\begin{array}{llllllll}44791.13 & 38198.72 & 38198.72 & 36550.62 & 28714.02 & 21123.81 & 18363.24 & 14836.95\end{array}$ $\begin{array}{llllllll}14300.00 & 14300.00 & -493.10 & -493.10 & -493.10 & -493.10 & -493.10 & -493.10\end{array}$ $\begin{array}{llllllll}59091.13 & 52498.72 & 37705.62 & 36057.52 & 28220.93 & 20630.72 & 17870.14 & 14343.86\end{array}$ 
ORNL-DWG 88-5010 ETD

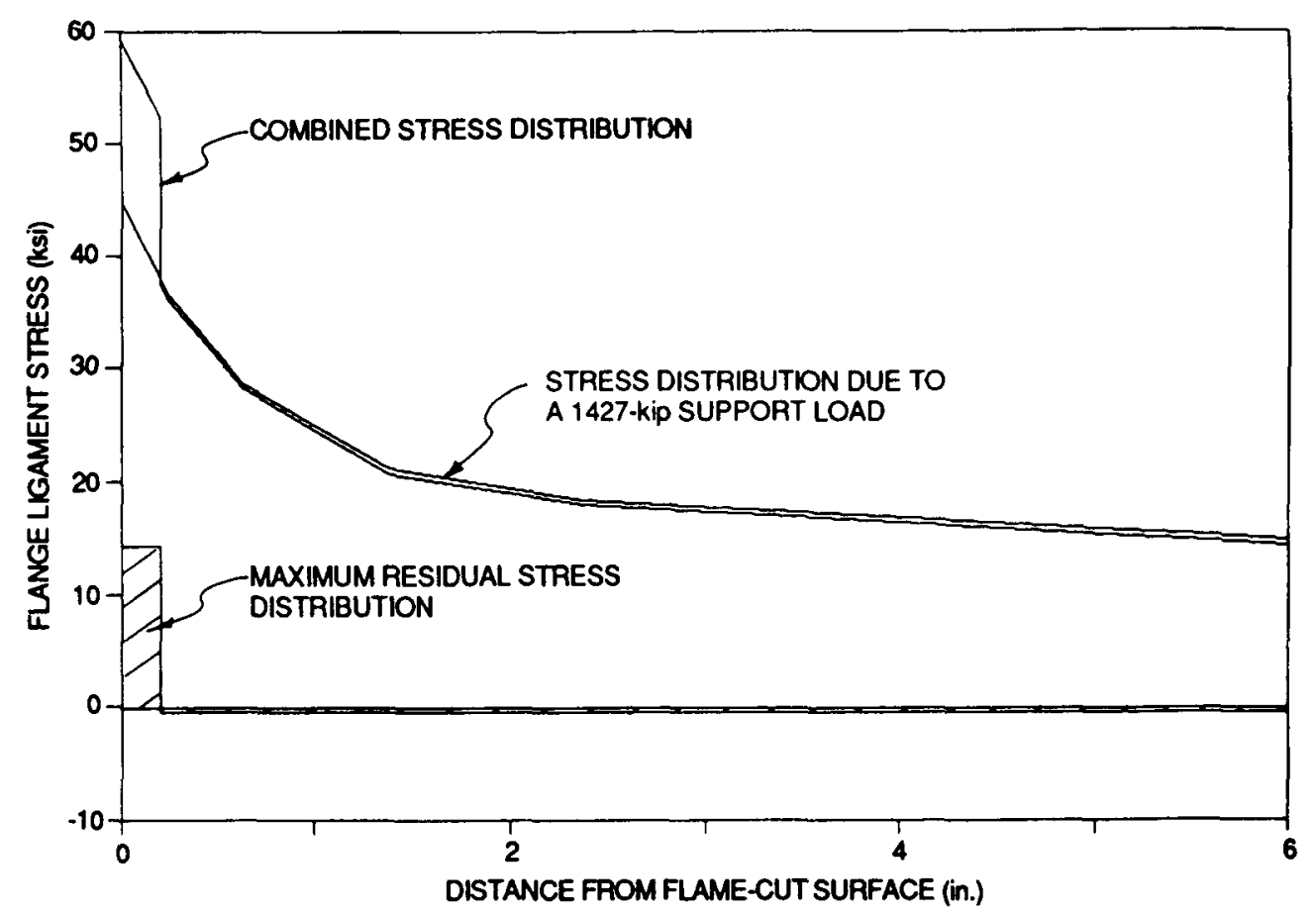

Fig. 6.56. Combination of primary stresses and residual stresses used for flaw tolerance analysis of point $E$ on residual stress envelope.

ORNL-OWG 88-5016 ETD

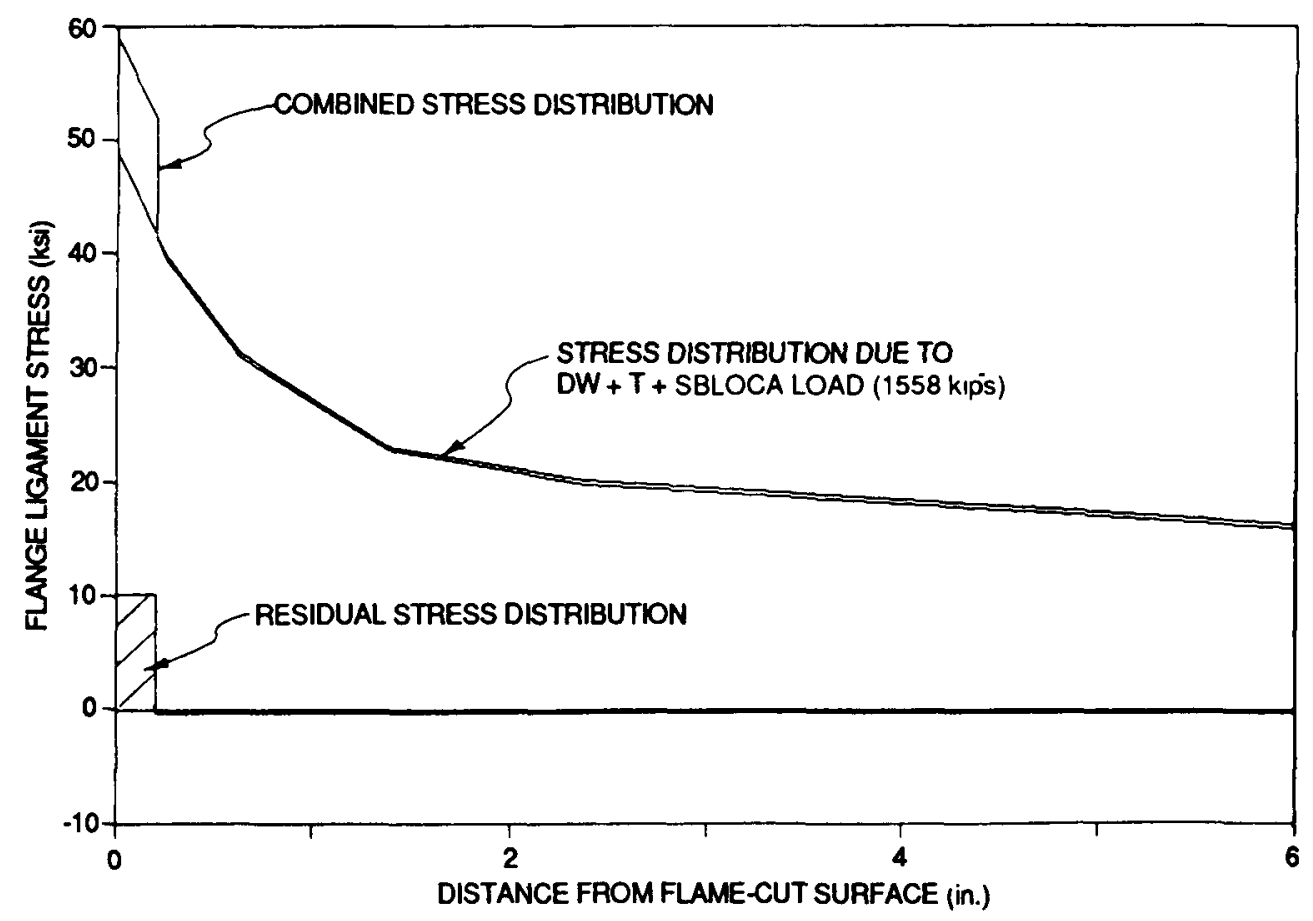

Fig. 6.57. Superposition of residual stresses and stresses produced by $\mathrm{DW}+\mathrm{T}+$ SBLOCA loading condition. This stress distribution was used in evaluation of point $F$ on residual stress envelope. 
Table 6.24

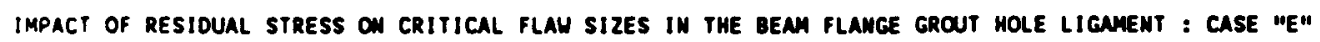

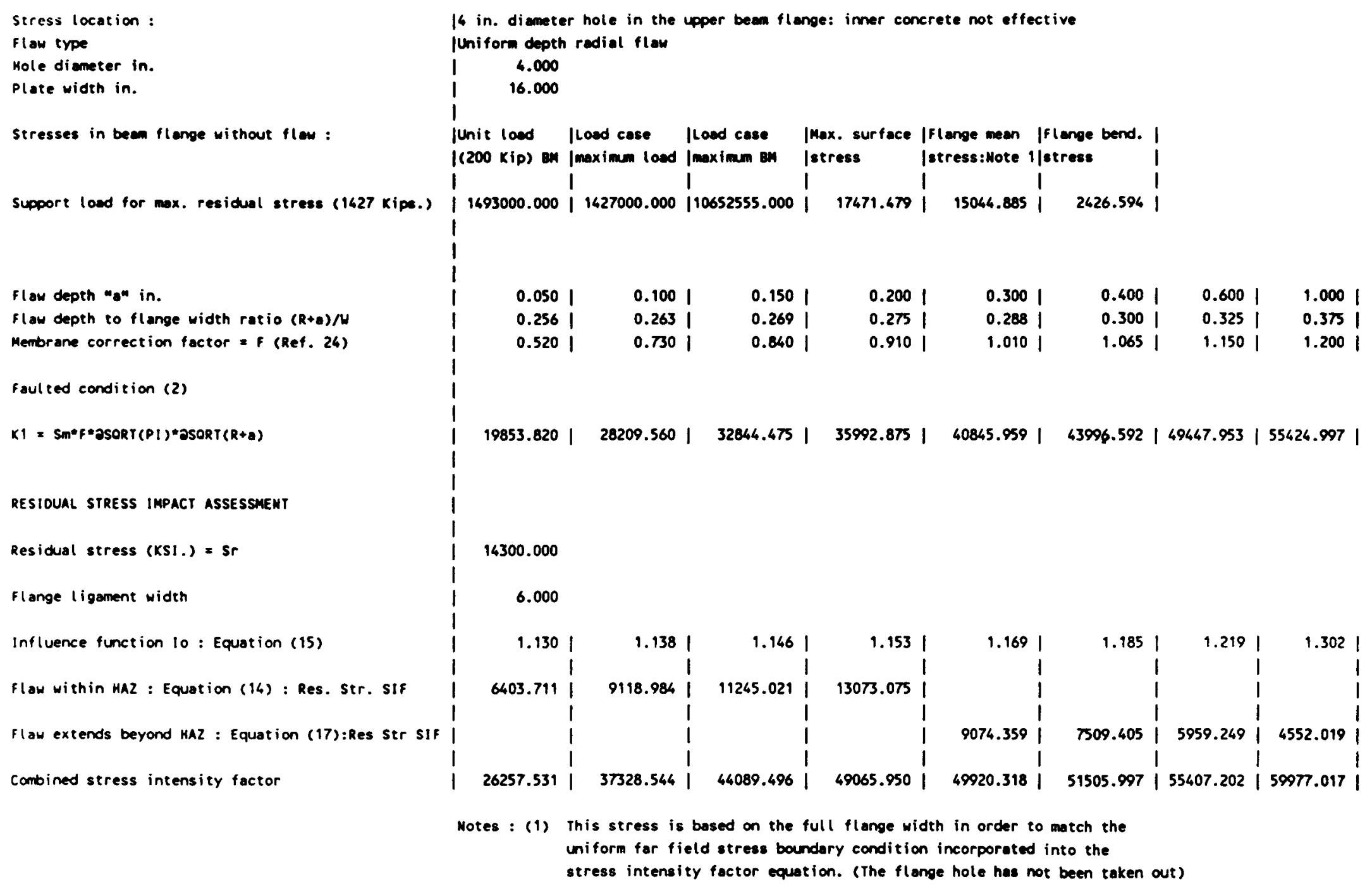


Table 6.25

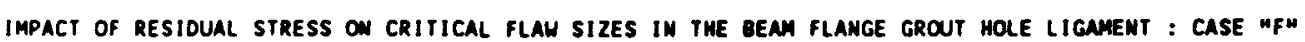

\section{Stress location : \\ Flan type \\ Hole dismeter in. \\ Plote width in.}

stresses in bean flange without flaw :

OW + T SB: LOCA support load

Flay depth "a" in.

flat depth to $f($ ange width ratio $(R+A) / 4$

membrane correction fuctor $=F$ (Ref. 26)

faulted condition (2)

$K 1=\operatorname{Sin}^{*} F * \partial S Q R T(P I) * \partial S O R T(R+a)$

RESIOUAL STRESS IMPACT ASSESSMENT

Residual stress (KSI.) $=\mathrm{Sr}$

flange ligament width

Influence function 10: Equation (15)

Flaw within HAZ : Equation (14): Res. Str. SIF

Flaw extends beyond HAZ : Equation (17):Res Str SIF I

Combined stress intensity factor

I6 in. dimeter hole in the upper bean flange: imer concrete not effective Juniform depth rodial flaw

$1 \quad 4.000$

16.000

Unit laod flood case |load case |Hax. surface friange man |flange bend. Imaximm lood Imaximen en |stress

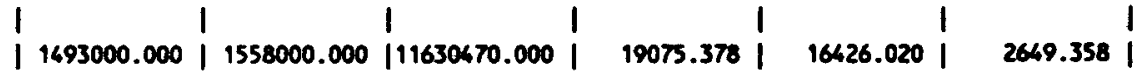

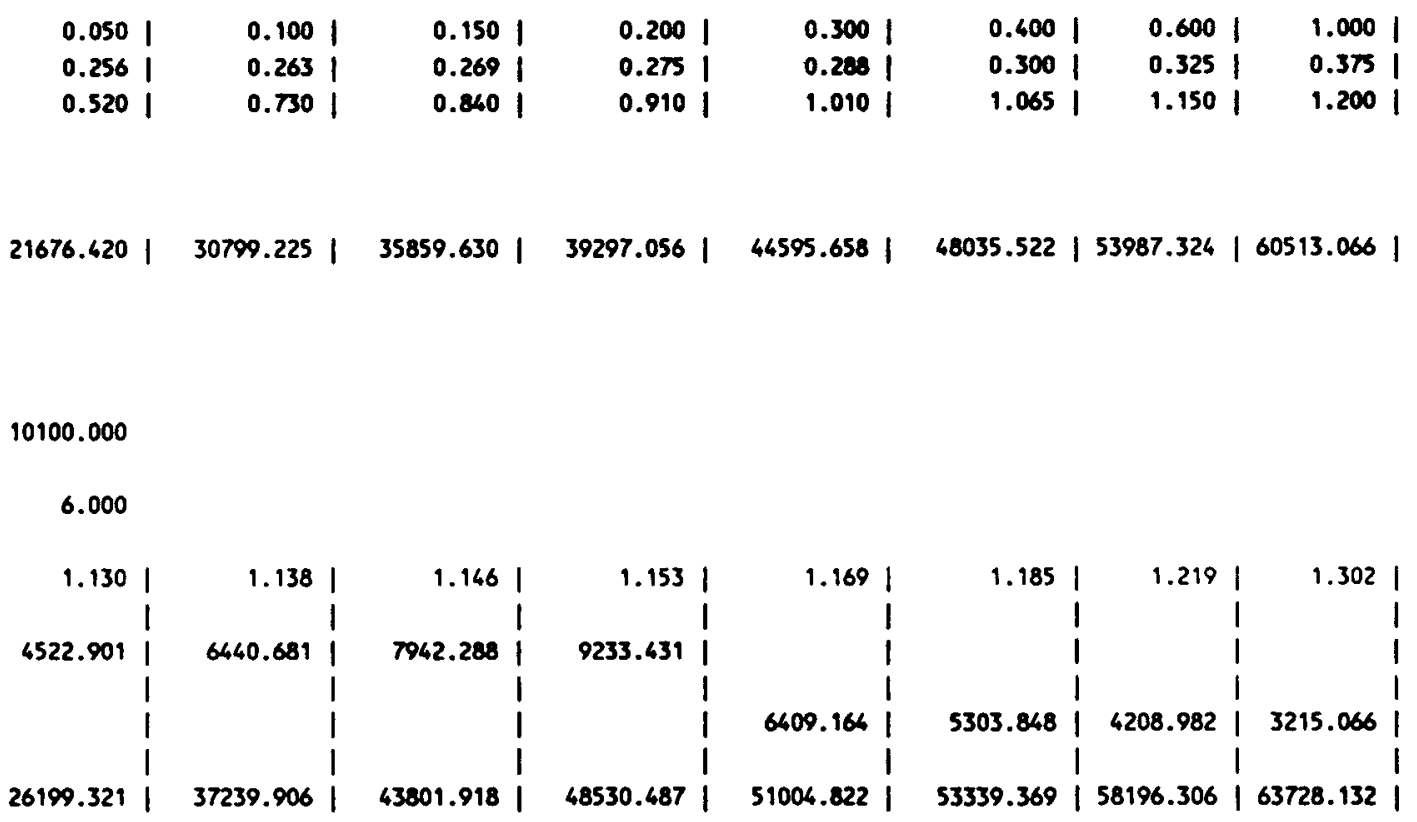




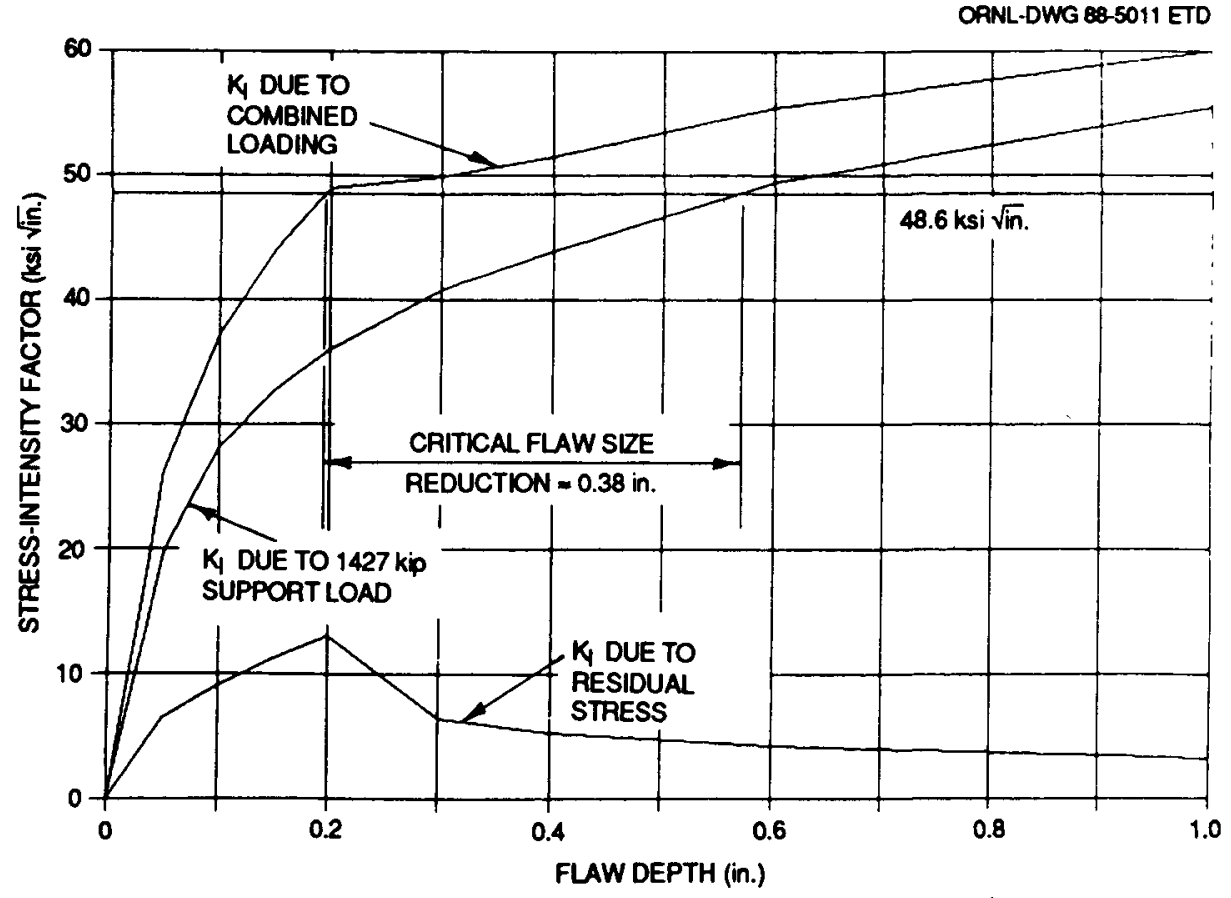

Fig. 6.58. Stress-intensity factors produced by combination of primary stresses and residual stresses at point $E$ on beam-flange grouthole residual stress envelope. Addition of residual stresses reduces critical flaw size by 0.38 to 0.2 in.

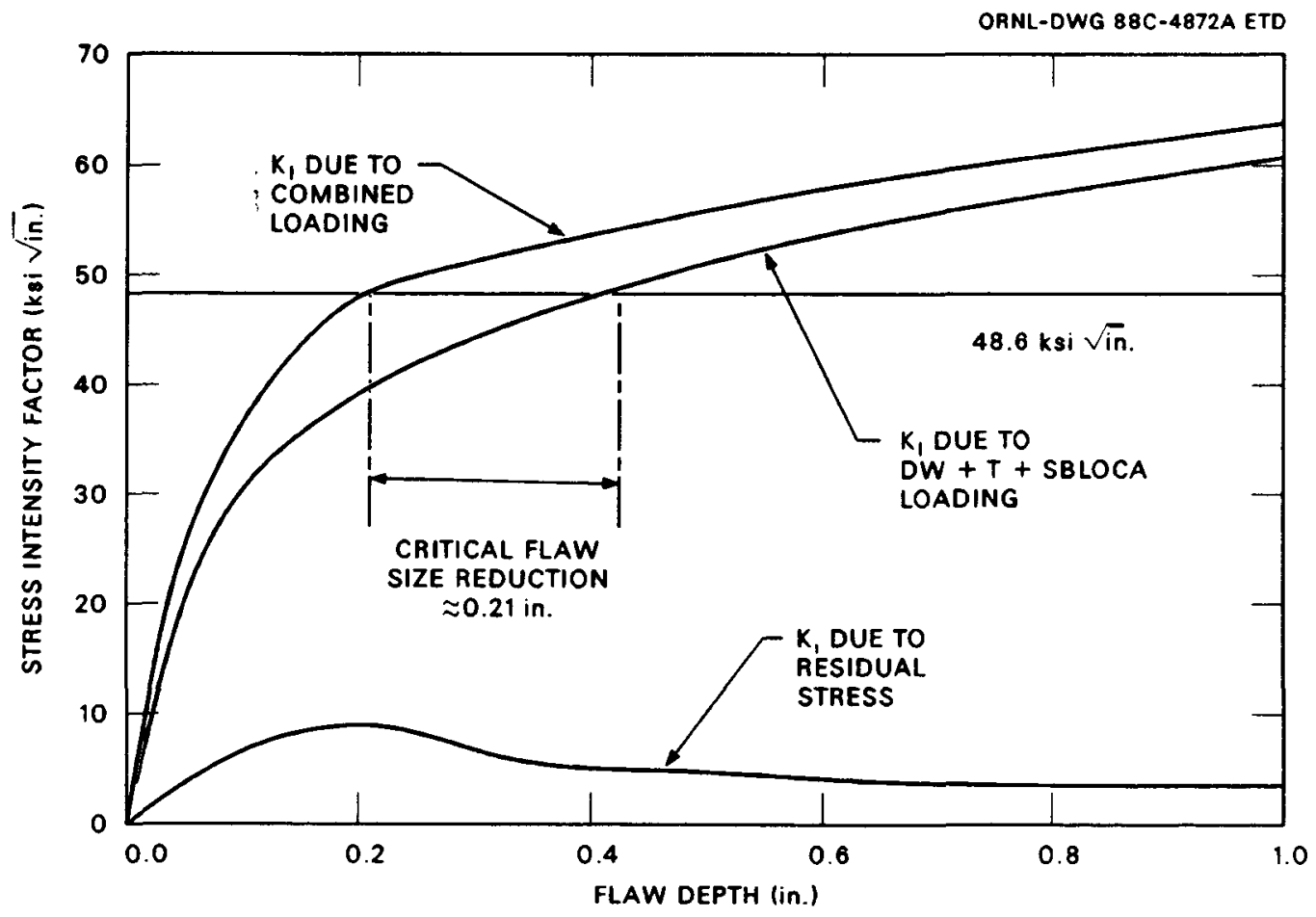

Fig. 6.59. Stress-intensity factors produced by combination of primary stresses and residual stresses at point $F$ on beam-flange grouthole residual stress envelope. Addition of residual stresses reduces critical flaw size by 0.21 in. 
The generation of data on the possible beneficial effects of chillquenching-induced microstructure refinement is recommended as an integral part of any further evaluation of the flame-cut grout hole. Potential sources for these data are identical with those identified in Sect. 6.8 .4 .

\subsection{Conclusions and Recommendations}

Accelerated irradiation-induced embrittlement of the Trojan reactor vessel support beams is predicted to occur to the point where brittle fracture becomes a credible end-of-life (32-EFPY) failure mode.

Critical flaws calculated for regions of the A36 support beams, remote from structural discontinuities, have a configuration and dimensions that would make them relatively easy to detect using surface inspection techniques (visual, dye penetrant, and magnetic particle). The contribution of fatigue flaw growth to the dimension of the critical flaw is negligible. For the critical flaws to be present in the installed support beams, they would have had to be present at the time of final inspection of the support beam assembly. It is considered unlikely therefore that a brittle fracture potential exists in those portions of the support beams remote from structural discontinuities, because flaws of the required size would have been readily detected and eliminated during the fabrication process. Bases for this conclusion should be verified by a review of the inspection procedures and any available inspection records.

Flame-cut, 4-in.-diam holes exist in the beam flanges, immediately above the inner support pedestals. Stress concentrations produced by these features reduce the end-of-life critical depth of radial flaws eminating from the hole to 0.42 in. for the SBLOCA loading condition. Residual stresses induced by the flame-cutting process could further reduce this critical flaw depth. It is considered unlikely that flaws of this magnitude could have been reliably detected in any inspection of the flame-cut surface of the hole. Recommendations are given for actions that could provide a generic definition of (1) the distribution of flaws to be anticipated adjacent to the flame-cut hole and (2) any beneficial effects produced as a result of chill-quenching-induced refinement of the material microstructure adjacent to the flame-cut surface. Further evaluation of this feature of the support will be required when these data become available.

Extrapolation of the available fracture-toughness data base for A36 was required to cover operating conditions for critical portions of the beam embedded within the concrete. Generation of fracture-toughness data for these conditions is recommended. 


\section{References}

1. Bechtel Drawing No. C-368 Rev. 9 for Job No. 6478.

2. Minutes of Trojan Reactor Vessel Support Meeting, Westinghouse, Pittsburgh, $\mathrm{Pa} .$, June 29-30, 1988.

3. Letter from D. W. Lockfield, Portland General Electric, to R. D. Cheverton, Oak Ridge National Laboratory, Subject: Reactor Vessel Support Information Request, dated August 2, 1988.

4. A. M. Neville, Properties of Concrete, John Wiley \& Sons. Inc., New York, 1963.

5. Manual of Steel Construction, American Institute of Steel Construction, 7th ed., 1970.

6. "Micro-Computer Based Structural Analysis Using Finite Elements," User's Manual for Microsafe 2-D, Microstress Corp., Seattle, Wash., 1987.

7. Structural Alloys Handbook, 1987 ed., Vol. 3, Battelle's Columbus Division, Columbus, Ohio.

8. J. M. Barsom and S. T. Rolfe, "Fracture Mechanics in Failure Analysis," Fracture Mechanics Eighteenth Symposium, ASTM STP 945, Philadelphia, 1988, p. 454.*

9. Personal communication from H. Ott, Westinghouse Electric Co., to W. E. Penne11, Oak Ridge National Laboratory, June 30, 1988.

10. ASME Boilër and Pressure Vessel Code, Sect. III, Appendix I, American Society Mechanical Engineers, New York. $†$

11. J. G. Merkle, "Fracture Safety Analysis Concepts for Nuclear Pressure Vessels, Considering the Effects of Irradiation," J. Basic Eng., June 1971. $\ddagger$

12. R. B. Madison and G. R. Irwin, "Dynamic Kc Testing of Structural Steel" Journal of the Structural Division, ASCE, 100, (ST 7), July $1974 . \ddagger$

13. S. T. Rolfe and J. M. Barsom, Fracture and Fatigue Control in Structures: Applications of Fracture Mechanics, Prentice Hall, Inc., Englewood Cliffs, New Jersey, p. 456.

14. ASME Boiler and Pressure Vessel Code, Sect. III, Subsect. NF, American Society Mechanical Engineers, New York. $t$

15. G. A. Knorovski et al., Sandia National Laboratories, Fracture Toughness of PWR Component Supports, NUREG/CR-3009, February 1983.* 
16. W. A. Sonem, R. H. Dodds, Jr., and S. J. Rolte, "An Analytical Comparison of Short Crack and Deep Crack CTOD Fracture Specimens of an A36 Steel," University of Kansas, presented at the 21st Nationa1 Symposium on Fracture Mechanics, June 1988.

17. Telephone Conference Report: W. Pennell, Oak Ridge National Laboratory, with S. Anderson, Westinghouse Electric Corp., July 12 , 1988.

18. Telephone Conference Report: W. Pennell, Oak Ridge National Laboratory, with W. Kershal1, Portland General Electric, July 12, 1988.

19. ASME Boiler and Pressure Vessel Code, Sect. XI, Appendix A, American Society Mechanical Engineers, New York.*

20. H. Tada, P. Paris, and G. Irwin, Stress Analysis of Cracks Handbook, Del Research Corporation, June 1973, p. 19.4.

21. S. T. Rolfe, "Designing to Prevent Brittle Fractures in Bridges," in Proceedings of Specialty Conference on Safety and Reliability of Metal Structures, Pittsburgh, Pennsylvania, November 2-3, 1972 , American Society of Civil Engineers, New York.

22. R. D. Cheverton et al., Martin Marietta Energy Systems, Inc., Oak Ridge Natl. Lab., Evaluation of HFIR Pressure-Vessel Integrity Considering Radiation Embrittlement," ORNL/TM-10444, Apri1 1988.

23. D. A. Canonico, Union Carbide Corp. Nuclear Div., Oak Ridge Natl. Lab., "Heat-Affected Zone Due to Flame Cutting," Heavy-Section Steel Technology Program Semiannual Prog. Rep. February 29, 1968, ORNL-4315, 1968.

24. A. Simonen et al., Pacific Northwest Laboratory, Battelle Memorial Institute, VISA-II - A Computer Code for Predicting the Probability of Reactor Pressure Vessel Failure, NUREG/CR-4486, March 1986.*

*Available for purchase from the National Technical Information Service, Springfield, Virginia 22161.

tAvailable from American National Standards Institute, 1430 Broadway, New York, New York 10018, copyrighted.

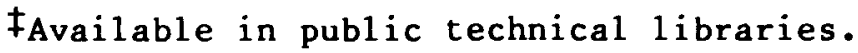




\section{BRITTLE FRACTURE EVALUATION OF TURKEY POINT UNIT 3 REACTOR PRESSURE VESSEL SUPPORTS}

\subsection{Introduction and Summary}

As indicated in Figs. 7.1-7.6, the reactor vessel for the Turkey Point Unit 3 plant is supported on steel cantilever-beam arrays that are positioned under each of the coolant nozzles and that extend from this position into the concrete biological shield. The support load at each nozzle is transmitted from the nozzle to the cantilever-beam array through a set of rollers, lateral restraints, and a steel girder that is bolted to and joins together the cantilever beams in an array. Three components of this assembly were selected for evaluation with regard to propagation of flaws: the cantilever beam, the bolts that join the

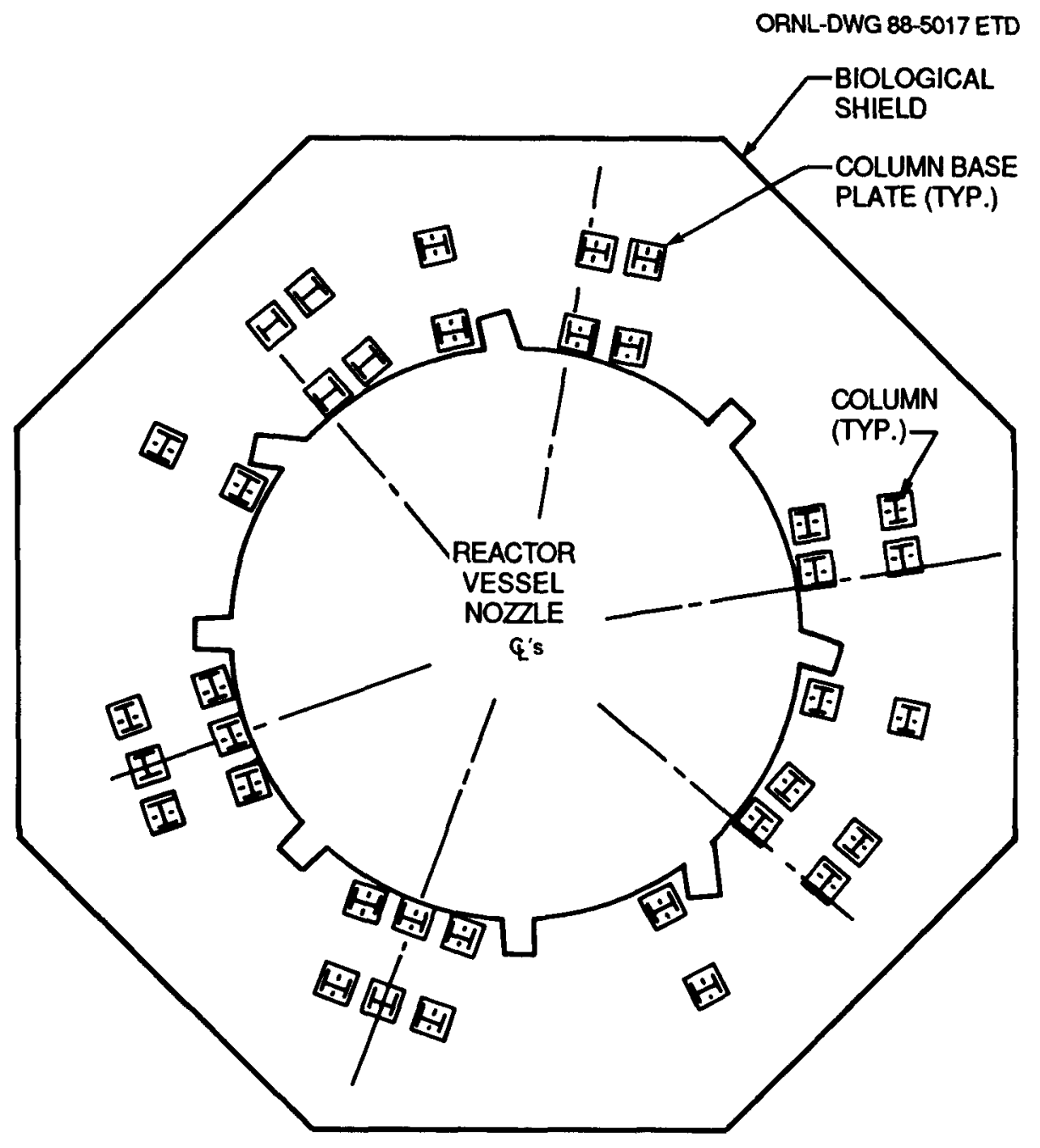

Fig. 7.1. Reactor vessel supports plan view. 
ORNL-DWG 88-5062 ETD

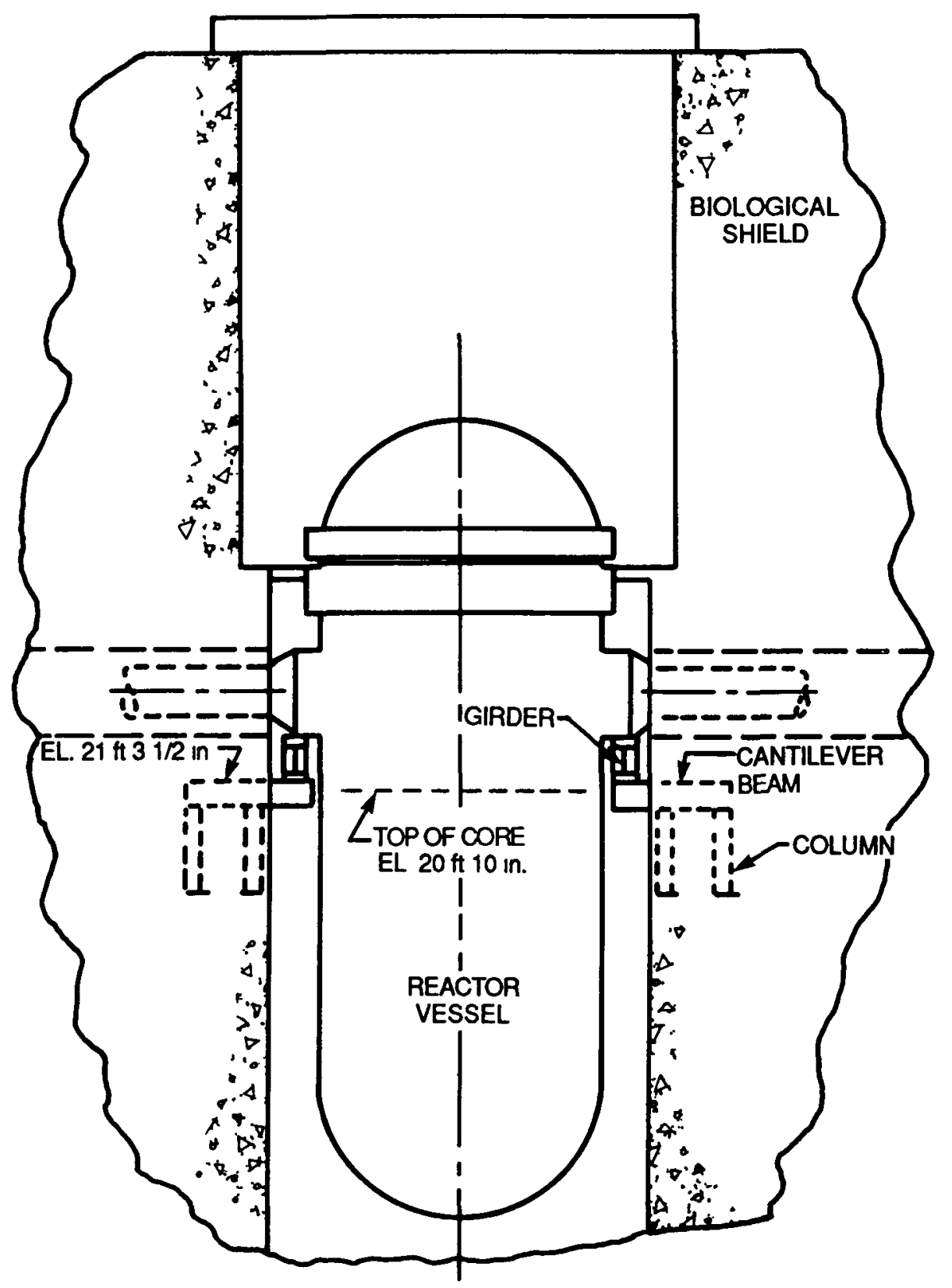

Fig. 7.2. Elevation view of reactor vessel support system. 


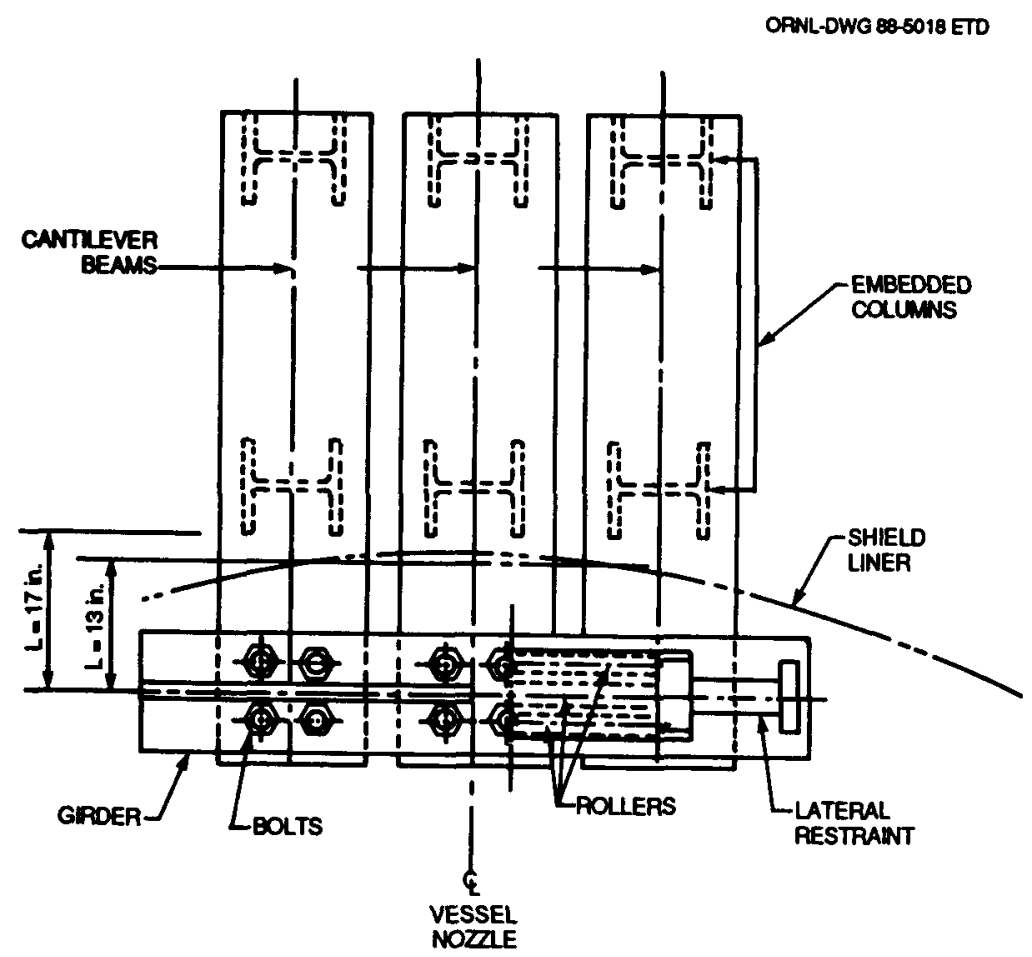

Fig. 7.3. Symmetric support-array plan view.

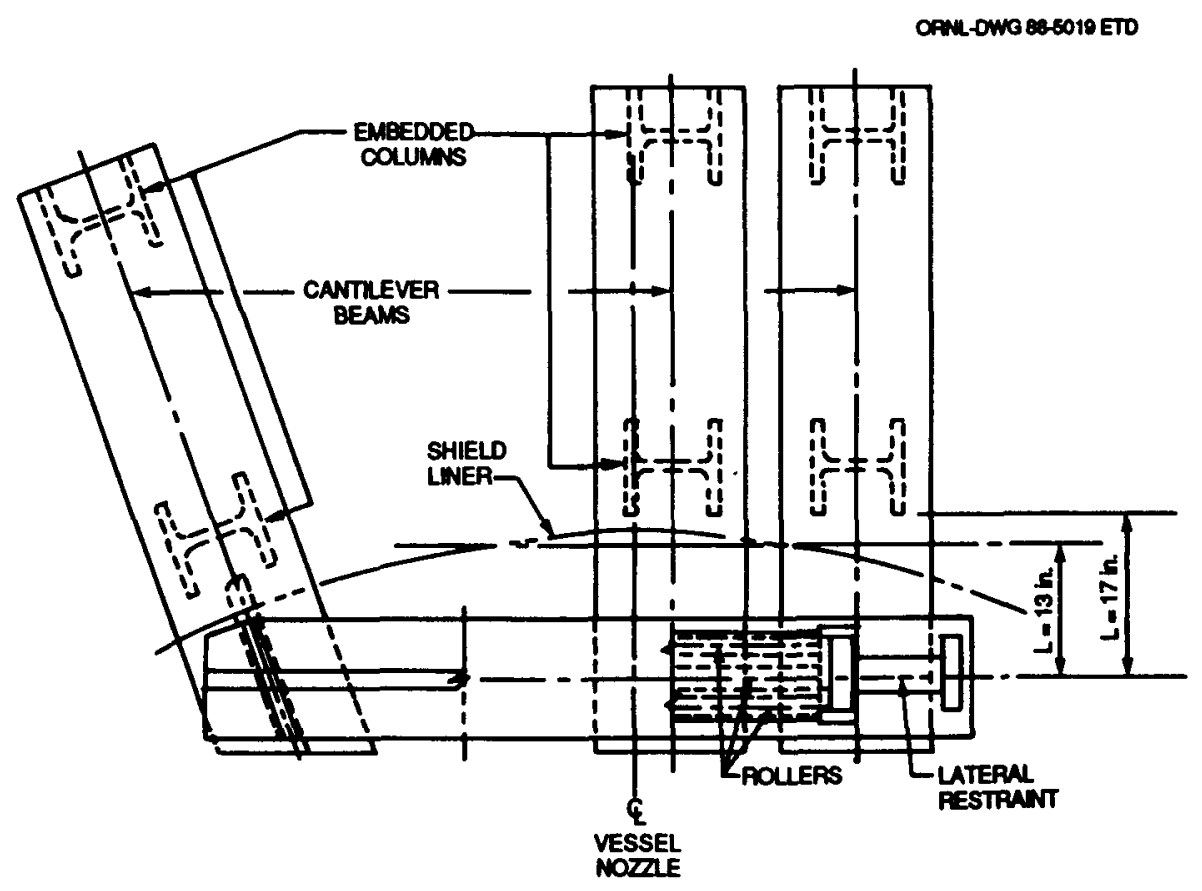

Fig. 7.4. Asymmetric support-array plan view. 


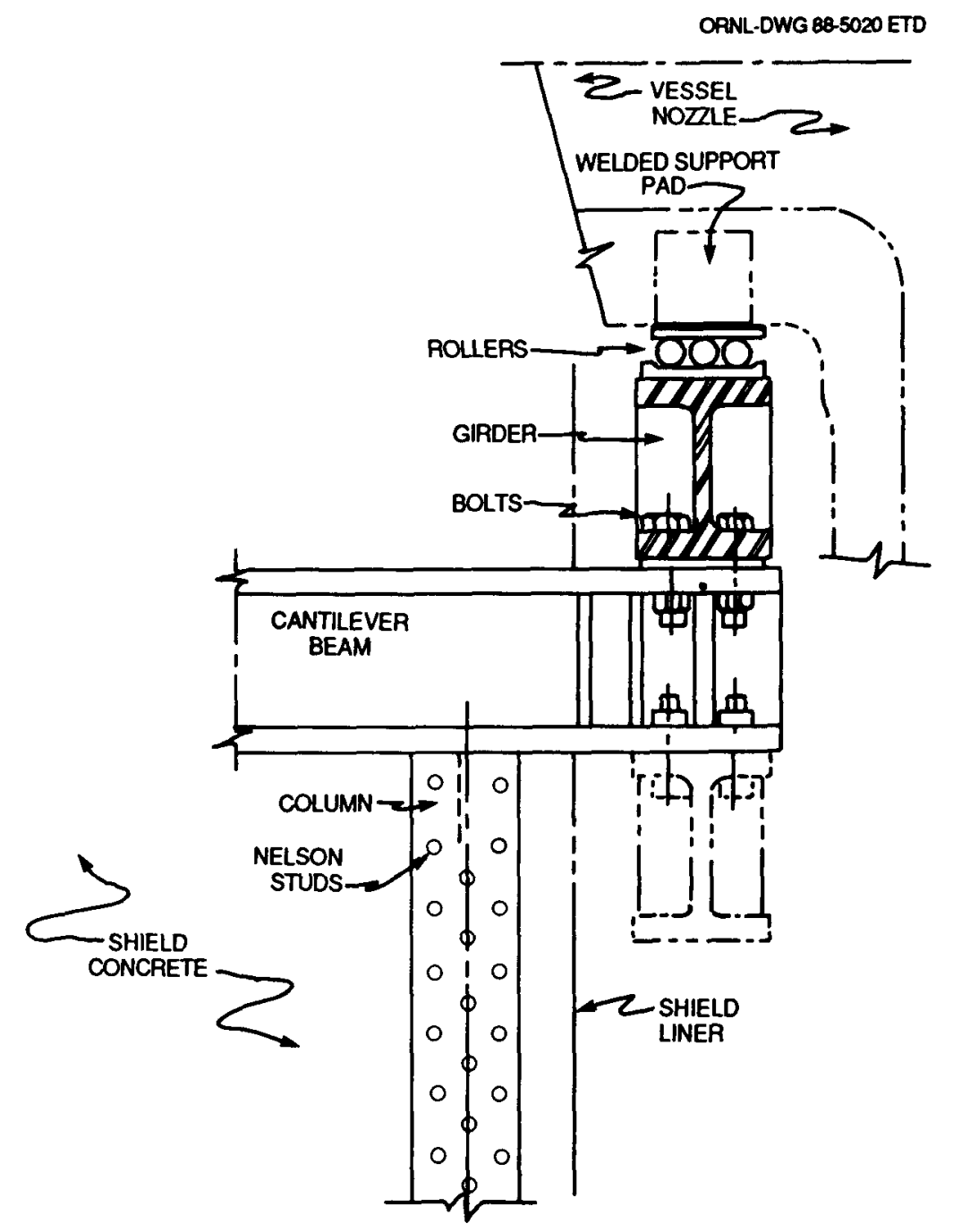

Fig. 7.5. Section elevation of symmetric array.

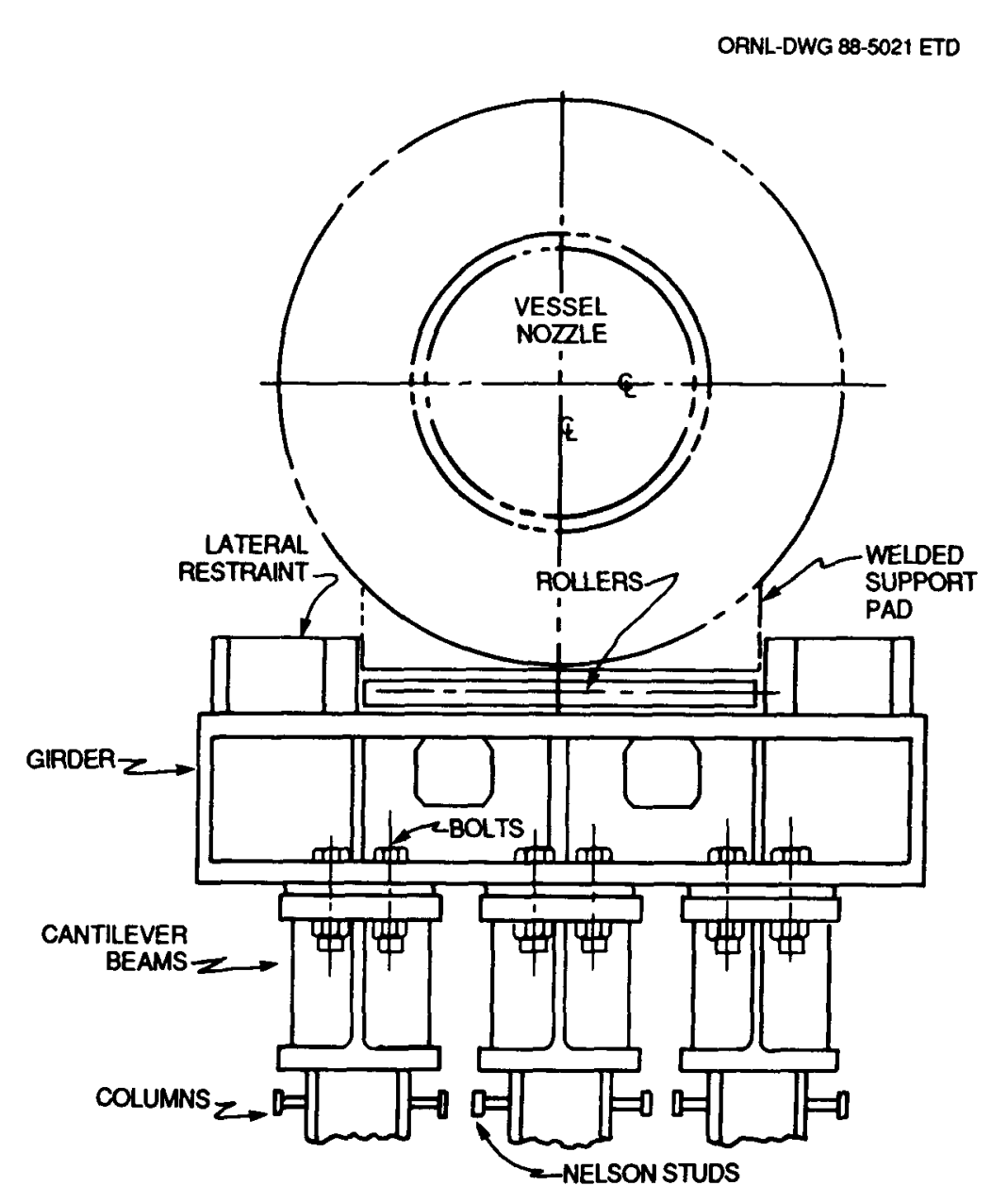

Fig. 7.6. Elevation of symmetric array. 
girder and beams, and the lateral restraints. The cantilever beam is considered to be the more critical of the three, and thus the emphasis in this report is on the beam.

The beam is fabricated from A588, a low-alloy structural steel with a minimum yield strength of 50,000 psi. The radiation sensitivity of A588 was assumed to be essentially the same as for the HFIR pressure vessel materials, and the radiation-damage trend curves deduced from the HFIR vessel surveillance data and discussed in Chap. 3 were used for this evaluation. Best-estimate present-day and 32-EFPY values of $\triangle$ NDTT corresponding to the location of the minimum critical flaw size are 30 and $55^{\circ} \mathrm{F}$, respectively.

Essentially no fracture-toughness data, other than Charpy V-notch (CVN) data, are available for A588, and thus the ASME Sects. III and XI $K_{I c}$ and $K_{I R}$ curves were used. Dynamic response data were not available for the Turkey Point vessel support system, and thus $K_{I R}$ was used as the best estimate of the appropriate $\mathrm{K}_{I d}$.

Loads applied to the supports were supplied by the utility and included those for the large-break loss-of-coolant accident (abbreviated as LOCA in this chapter of the report), operating basis earthquake $(\mathrm{OBE})$, safe shutdown earthquake (SSE), and deadweight or dead load (DL). It is ORNL's understanding that Turkey Point still must consider the LOCA credible, and thus it was treated as such in this study. $*$ (The utility did not provide loads for a small-break loss-of-coolant accident, and as mentioned previously, no dynamic loading data were furnished.)

Significant uncertainties exist in many of the parameters included in the calculation of the critical flaw size. Thus, the study was conducted in a parametric manner so that ranges of critical flaw sizes were obtained. Results for the beam (Figs. 7.7-7.12) indicate that for the most severe credible loading ( $D L+$ LOCA) and 32 EFPY, the bestestimate minimum critical flaw size (depth) is 0.3 in. The flaw size is insensitive to reactor operating time after 10 EFPY, and at plant startup ( 0 EFPY) the size is 0.6 in. The flaw is a corner crack in the upper flange anywhere between the inner surface of the biological shield and a point $\sim 4$ in. into the shield. Considering the uncertainties in the fracture toughness, initial NDTT, and the operating temperature of the beam, the \pm 10 (one standard deviation) values of the critical flaw size at 32 EFPY are $\sim 0.2$ and 0.6 in.

For the DL + SSE condition, the critical flaw size is substantially larger ( 1.1 in. compared with $0.3 \mathrm{in.}$ for best-estimate values and 32 EFPY).

\subsection{Description of Supports}

The Turkey Point reactor vessel is supported on cantilever-beam arrays positioned under each of the coolant nozzles (Figs. 7.1-7.6). A

*Many PWR plants have been exempt from consideration of large-break loss-of-coolant accident loads, but at the time of this study, Turkey Point was not. 


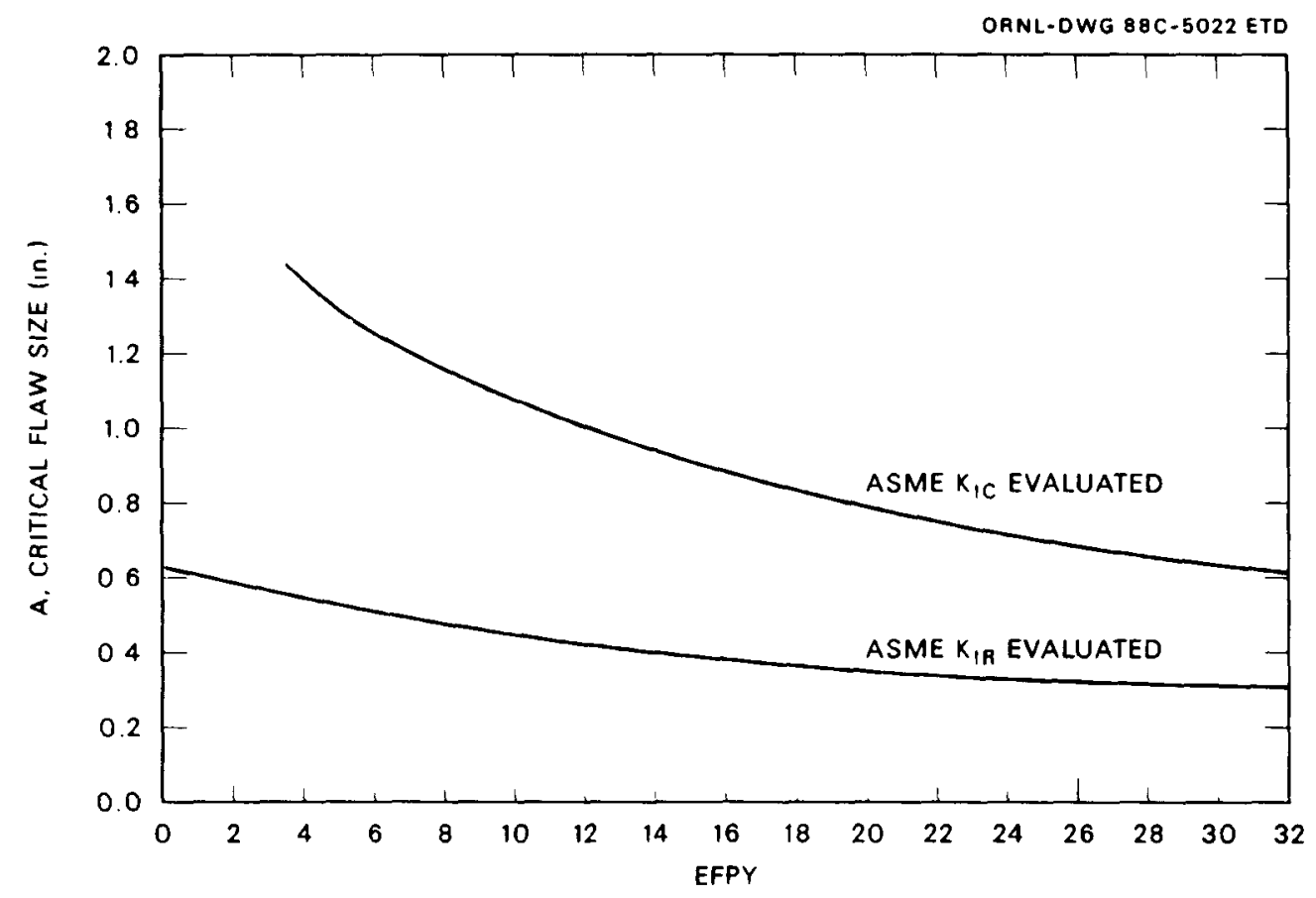

Fig. 7.7. Critical size of corner flaw in cantilever beam vs service life and fracture-toughness curve (mean value of $T-N D T, L=$ 17-in. position, DL + LOCA loading, Method B $\triangle N D T T$ ).

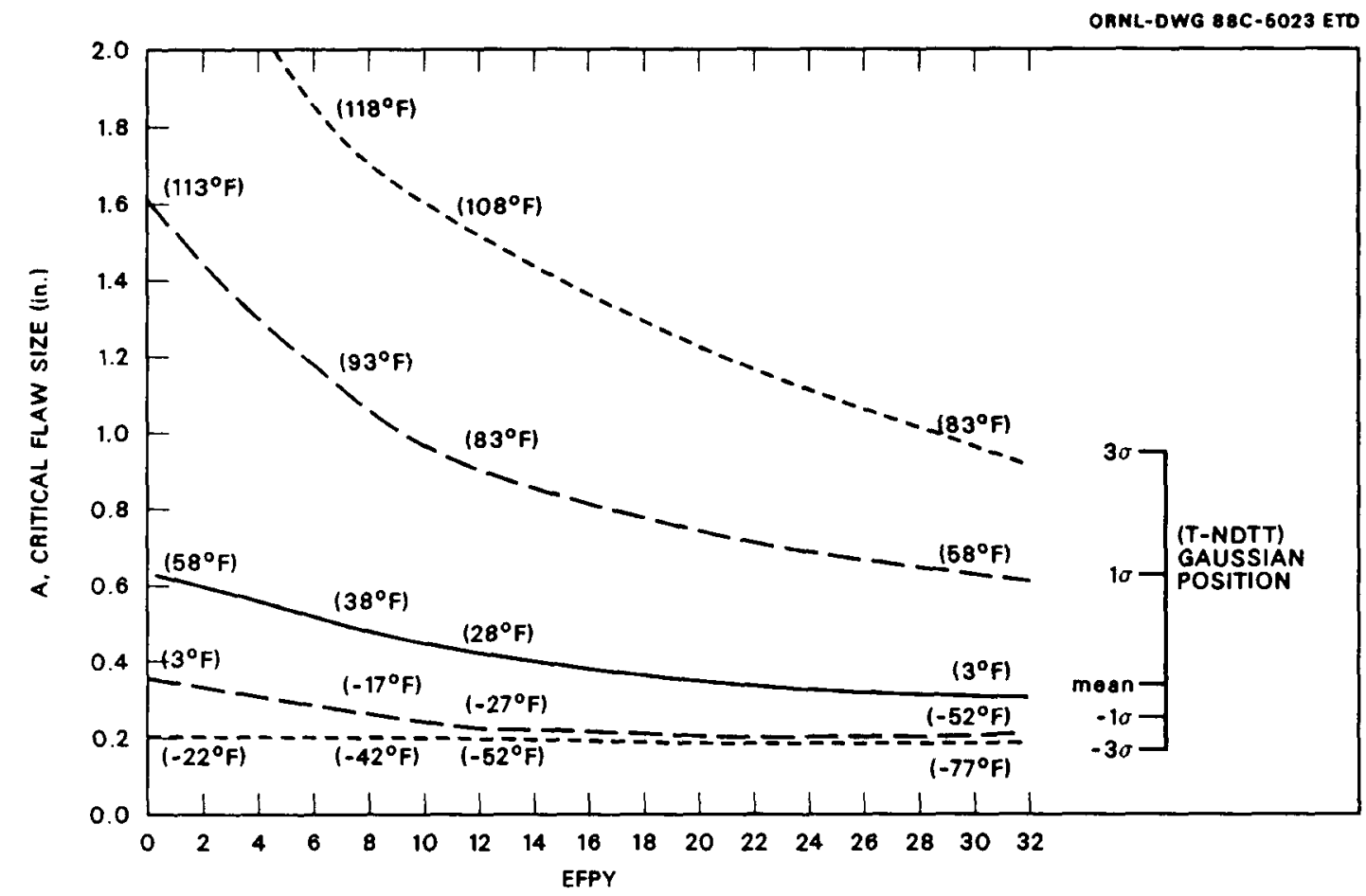

Fig. 7.8. Critical size of corner flaw in cantilever beam vs service 1 ife and $T$ - NDTT Gaussian position ( $L=17-i n$, position, $D L+$ LOCA loading, Method B $\triangle$ NDTT, ASME $K_{I R}$ ). 


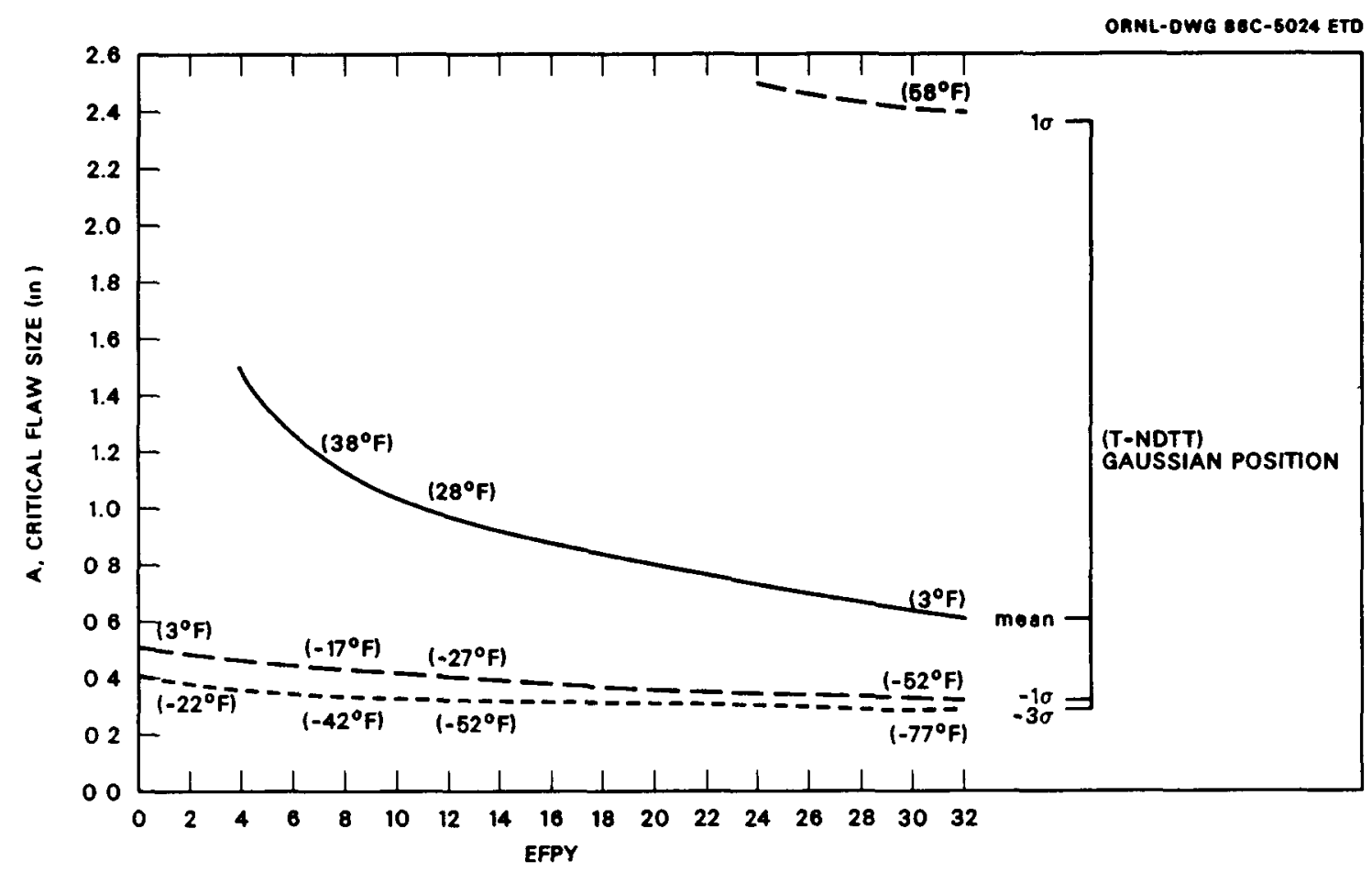

Fig. 7.9. Critical size of corner flaw in cantilever beam vs service life and $T$ - NDTT Gaussian position ( $L=17-i n$. position, $D L+$ LOCA loading, Method B $\triangle$ NDTT, ASME $\mathrm{K}_{\mathrm{IC}}$ ).

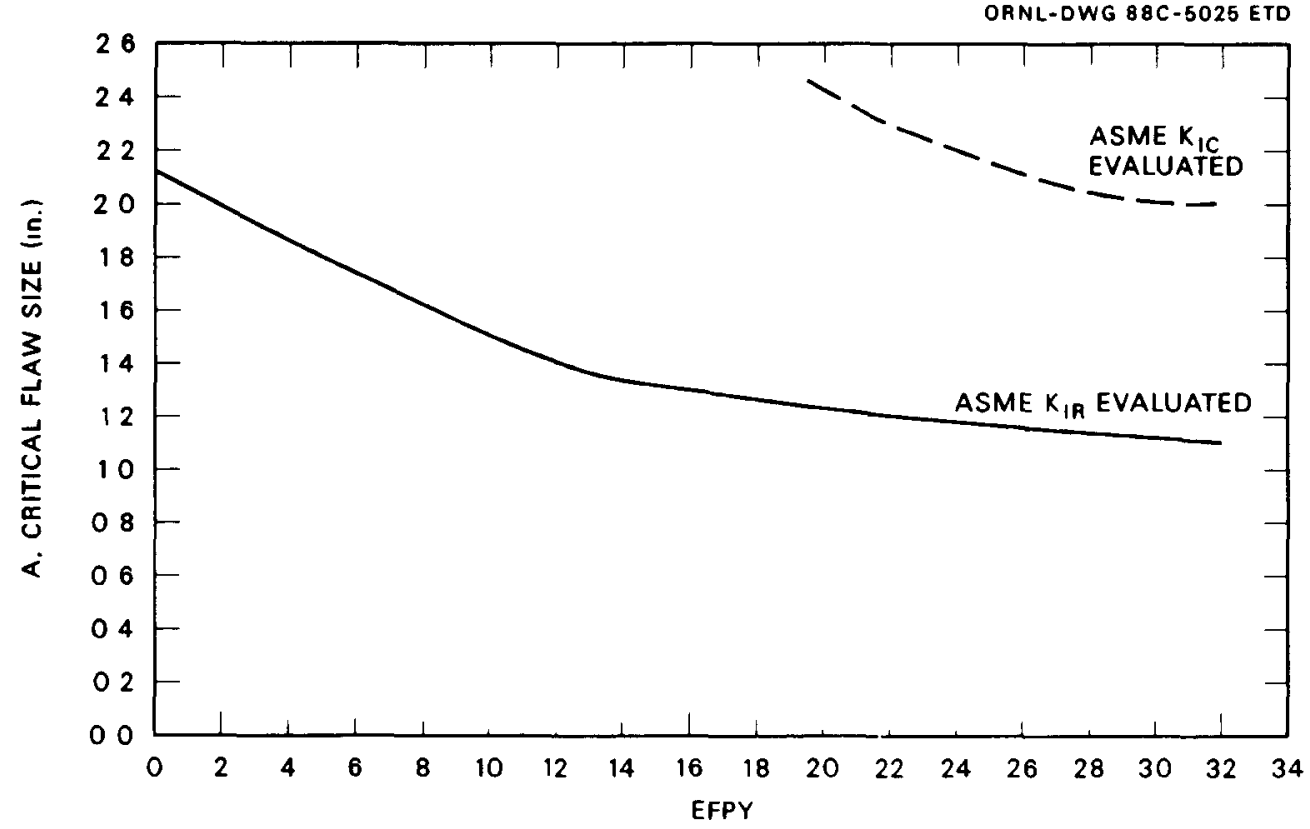

Fig. 7.10. Critical size of corner flaw in cantilever beam vs service 1 ife and fracture-toughness curve $(L=17-i n$, position, $D L+S S E$ loading, Method B $\triangle$ NDTT). 


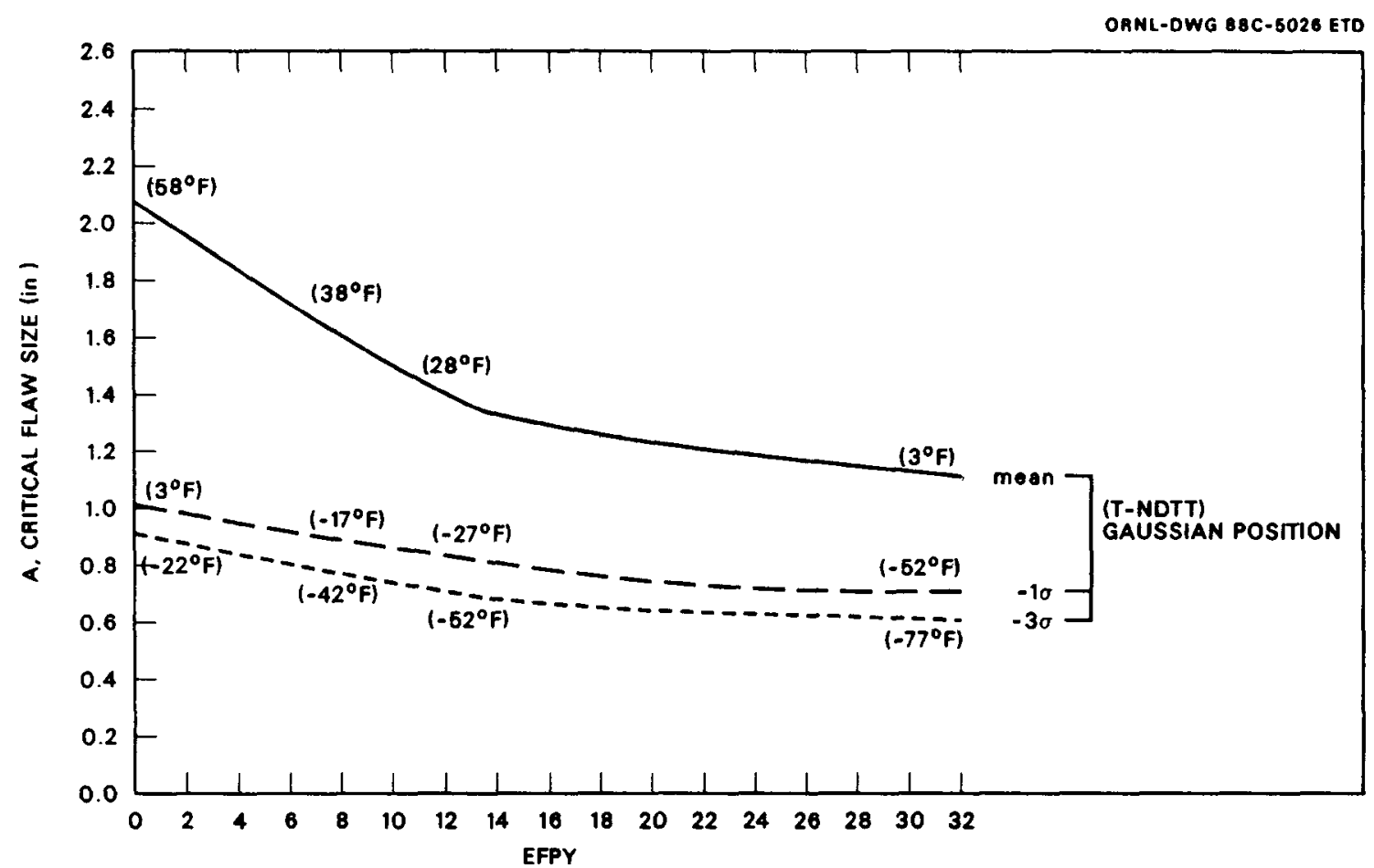

Fig. 7.11. Critical size of corner flaw in cantilever beam vs service life and $T$ - NDTT Gaussian position ( $L=17-i n$. position, $D L+$ SSE loading, Method B $\triangle \mathrm{NDTT}$, ASME $\mathrm{K}_{\mathrm{IR}}$ ).

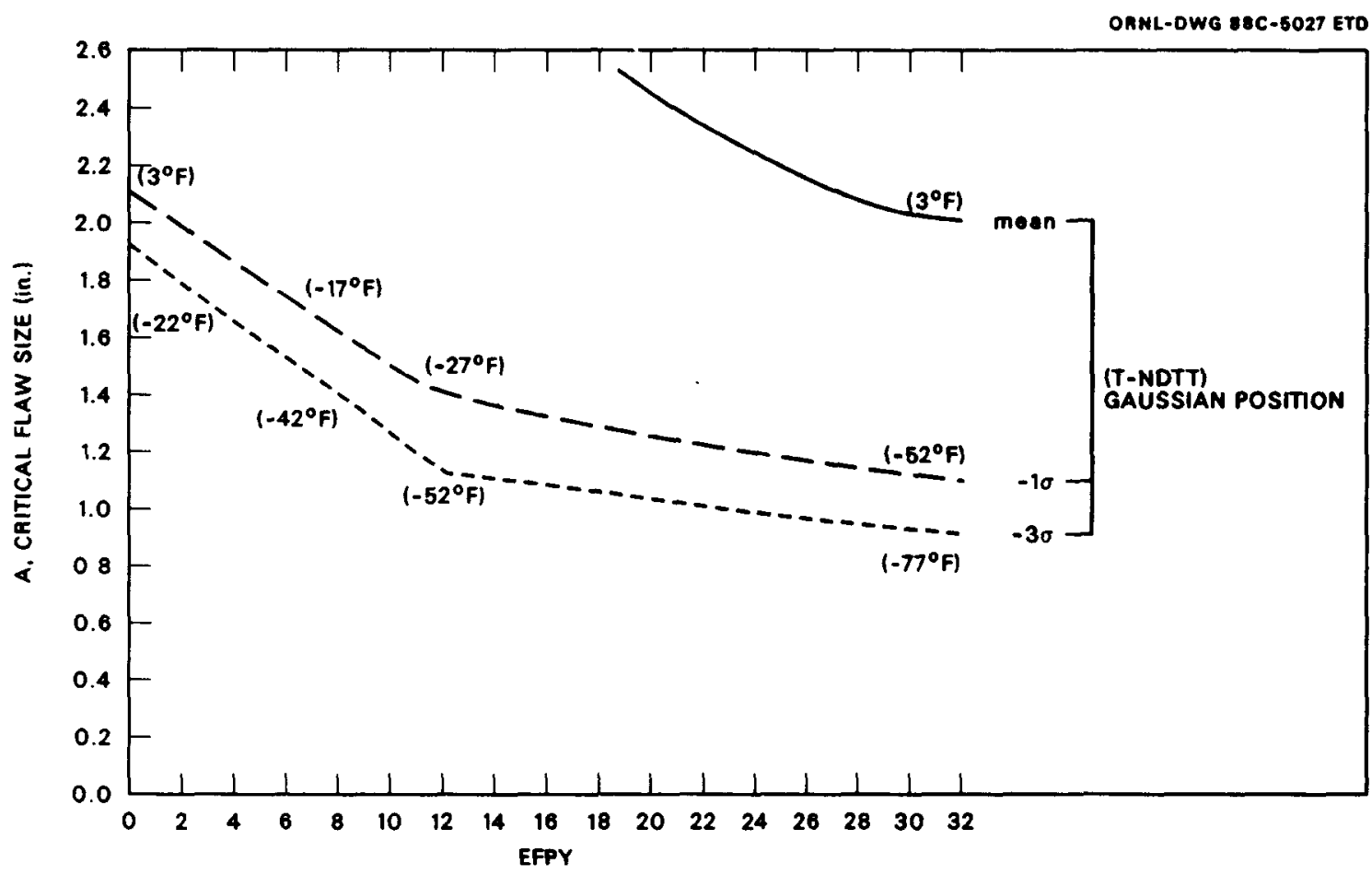

Fig. 7.12. Critical size of corner flaw in cantilever beam vs service life and $T$ - NDTT Gaussian position ( $L=17-i n$. position, $D L+$ SSE loading, Method B $\triangle$ NDTT, ASME K Ic curve). 
nested group of three rollers transmits vertical load from the pad under each nozzle to a wide-flange girder and also accommodates radial thermal expansion of the vessel. Each girder rests on three wide-flange beams that project inward from the biological shield. Welded to each girder are lateral restraints that project upward on either side of the nozzle pads to transfer horizontal loads to the cantilever beams. Each cantilever beam is welded to two supporting columns that are embedded within the biological shield. The column base plates were anchored to the biological shield at an intermediate stage of concrete pouring. Each column has an array of "Nelson" studs to provide for load transference from the structural steel members to the reinforced concrete biological shield. Two beam arrays are symmetrically oriented with respect to the vessel nozzle centerlines; four beam arrays are asymmetrically located. The two types of support arrays were designed to have equivalent compliances to vessel loading.

The dimensions $\mathrm{L}=13 \mathrm{in}$. and $\mathrm{L}=17 \mathrm{in}$. (Figs. 7.3 and 7.4 ) define the locations of flaw assessment for the cantilever beams. They are the distances from the point of load application to the interfacing of the beam with, respectively, the biological shield and the nearest support column. The location defined by $L=13$ in. is the point of maximum radiation damage and significant stress in the portion of the beam within the cavity; the location defined by $L=17$ in. is the point of maximum stress in the portion of the beam within the biological shield.

\subsection{Materials}

The principal vessel support components of interest and the corresponding materials for Turkey Point are as follows:

$\begin{array}{ll}\frac{\text { Component }}{\text { Cantilever beams }} & \begin{array}{l}\text { Material } \\ \text { Bethlehem Steel Co: propri- } \\ \text { etary steel Mayari R-50 } \\ \text { conforming to American } \\ \text { Society for Testing and } \\ \text { Materials (ASTM) A588 }\end{array} \\ \begin{array}{l}\text { Girder-to-cantilever } \\ \text { beam bolts }\end{array} & \text { ASTM A354-BC } \\ \text { Lateral restraints } & \text { ASTM A302-B }\end{array}$

\subsection{Material Fracture-Toughness Properties}

No mechanical or fracture-toughness properties are available for the heats used in fabrication of the supports, and no data are available in the open literature for ASTM A354-BC. However, a few dynamic data (unknown loading rate) are available for $A 588^{1}$ and are compared with the ASME $K_{I c}$ and $K_{I R}$ curves $^{2}$ in Fig. 7.13 (the data as published are not 


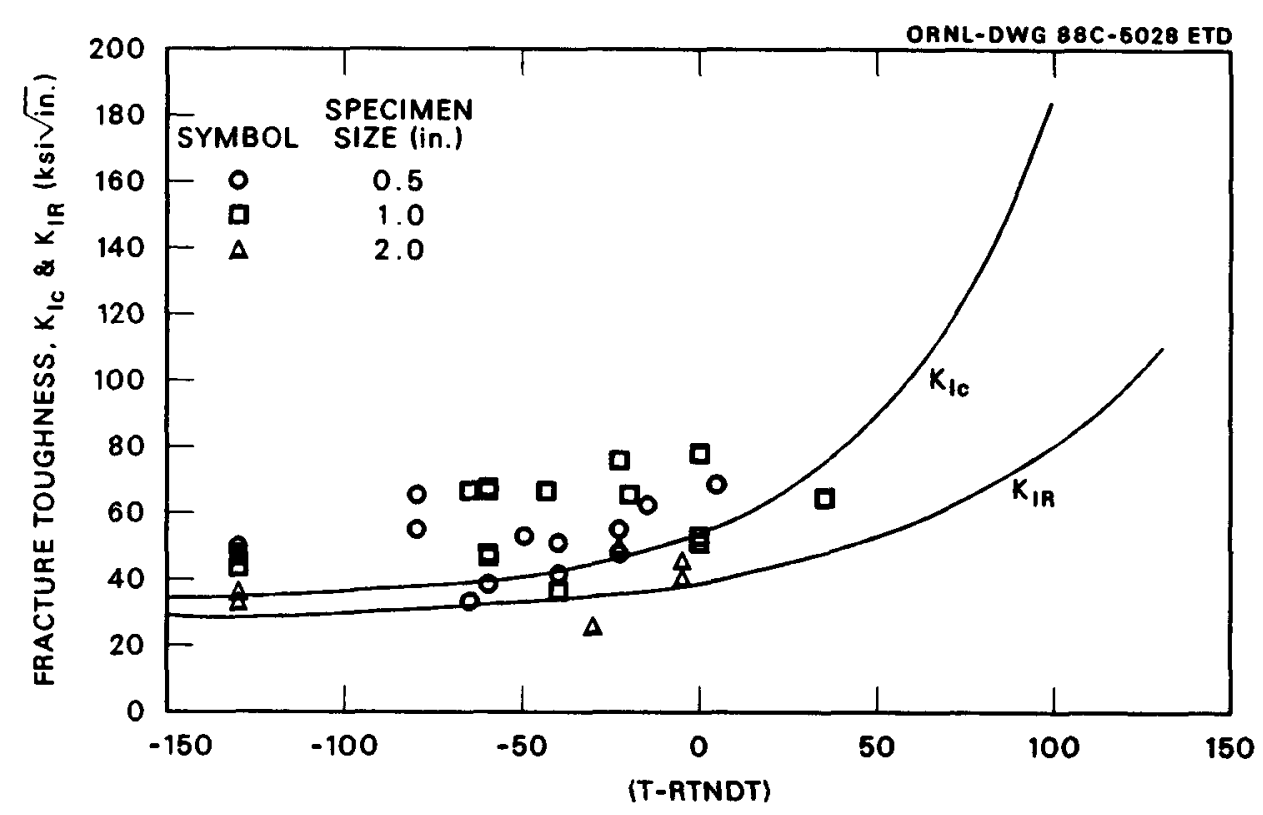

Fig. 7.13. Estimated $K_{I d}$ values for $A 588$ steel from $B_{K_{c}}$-corrected $K_{c}$ data compared with ASME $K_{I c}$ and $K_{I R}$ curves.

valid in accordance with ASTM E399,3 but those shown in Fig. 7.13 have been converted to "valid" values using a method proposed by Merkle ${ }^{4}$ ). Except for one data point, the $K_{I R}$ curve, appears to represent the dynamic data adequately. In the absence of more definitive data, ORNL chose to evaluate the cantilever beams premised on the ASME $K_{I R}$ curve. Because ASTM A302-B fracture-toughness data are an integral basis for the $\mathrm{K}_{\mathrm{IR}}$ curve, evaluation of the lateral restraints logically should use this data base also. The evaluation of girder-to-cantilever beam bolts has also employed the $K_{I R}$ curve.

Although the $K_{I R}$ curve was selected for evaluation of the Turkey Point vessel supports, it was also of interest to perform some calculations using the ASME $K_{I c}$ curve, which represents the lower bound of static crack initiation data for a select group of pressure vessel low alloy carbon steels.

As previously noted, no specific data on the initial nil-ductility transition temperature ( $\mathrm{NDTT}_{0}$ ) are available for the components assessed. However, Ref. 1 includes CVN data for A588 and indicates that for this material $\mathrm{NDTT}_{0}=\mathrm{T}_{30}$, the temperature at which $\mathrm{CVN}=30 \mathrm{ft} \cdot 1 \mathrm{~b}$. Based on this approach and the included CVN data (Fig. G-5 of Ref. 1), $\mathrm{NDTT}_{0} \cong 35^{\circ} \mathrm{F}$.

An inquiry was made to Bethlehem steel on fracture toughness and NDTT of Mayari R50 steel. In response, 5 it was recommended that data on ASTM A572, provided in an accompanying paper, 6 would represent a "worstcase" condition for large rolled-section steels. Assuming $\operatorname{NDTT}_{0}=\mathrm{T}_{30}$ to be appropriate, Fig. 7 of Ref. 6 indicates a range in NDTT of 10 to $95^{\circ} \mathrm{F}$. In earlier studies ${ }^{7}, 8$ conducted at Lehigh University, in a few instances, the use of $\mathrm{T}_{30}$ would infer $\mathrm{NDTT}_{0}$ s exceeding $150^{\circ} \mathrm{F}$. 
Reference 9 includes a statistical analysis of several heats of A572 steel that indicates mean values for NDTTo of $25^{\circ} \mathrm{F}$ for the as-hotrolled condition and $-50^{\circ} \mathrm{F}$ for the normalized condition. A review of Table B.8 of Ref. 9 indicates that data for a thickness range of 0.625 to 2.5 in. were used for the as-hot-rolled condition and that data for a range of 0.5 to 1.5 in. were used for the normalized condition. Furthermore, when restricted to a range of 1 to 1.5 in., the NDTTo for the as-hot-rolled condition exhibited a range from 20 to $50^{\circ} \mathrm{F}$. The pooled NDTT $_{0}$ data on A572 from Ref. 9 (Fig. B13) exhibited a range from -60 to $100^{\circ} \mathrm{F}$. The low-temperature values in this range appear to represent data taken from thin, normalized material, while the higher values correspond to the as-hot-rolled thicker sections.

The data of Refs. 10 and 11 indicate that the NDTT of A588 material and associated heat-affected zone (HAZ) and weld may be raised by as much as $40^{\circ} \mathrm{F}$ as a result of a postweld heat treatment.

It is not known whether the cantilever beam was normalized and/or subjected to a postweld heat treatment. In the absence of this information but considering the data that are available (Refs. 5-11) and the thickness of the beam flanges ( 2.5 in.), ORNL selected $\operatorname{NDTT}_{0}=65 \pm$ $65^{\circ} \mathrm{F}$. No definitive data for the $A 354-B C$ bolting material could be found, and thus $\operatorname{NDTT}_{0}=65 \pm 65^{\circ} \mathrm{F}$ was selected for the bolts also.

Munse ${ }^{12}$ estimates that a typical range for $\mathrm{NDTT}_{0}$ for 2-1/2 to 4-1/2-in.-thick steel material conforming to ASTM A302-B would be 10 to $100^{\circ} \mathrm{F}$. Thus, $\mathrm{NDTT}_{0}=55 \pm 45^{\circ} \mathrm{F}$ was selected for the evaluation of the lateral restraints.

As discussed in Chap. 3, the radiation-damage trend curve (ANDTT vs dpa, dpa/s) was assumed to be the same for the support materials as for the HFIR vessel materials, and it was necessary to extrapolate the HFIR data relative to $\mathrm{dpa}$ and $\mathrm{dpa}$ rate to apply it to the supports. Two methods of extrapolation (Method A and B, as discussed in Chap. 3) have been used in this evaluation. Figure 7.14 applies to Method A, and Fig. 7.15 applies to Method B. As discussed in Chap. 3, Method B is perhaps the preferable procedure for obtaining $\triangle$ NDTT. Nevertheless, because of the considerable uncertainty as to the best method for extrapolation of HFIR data, it was considered prudent to incorporate both methods in the evaluation of the Turkey Point reactor vessel supports.

As indicated in Fig. 7.13, the ASME $K_{I c}$ and $K_{I R}$ values are plotted as a function of $\mathrm{T}-\mathrm{RT}_{\mathrm{NDT}}$, where $\mathrm{RT}_{\mathrm{NDT}}$ is the reference nil-ductility temperature. It was assumed for this study that $\mathrm{RT}_{\mathrm{NDT}}=\mathrm{NDTT}=\mathrm{NDTT}_{\mathrm{O}}$ $+\triangle N D T T$. Each of the terms in the expression ( T - NDTTo - $\triangle N D T T$ ) has considerable uncertainty. To account for these uncertainties in a simplistic manner for this initial study, it was assumed that the expression has a Gaussian distribution and that the algebraic sums of the uncertainty limits for $T$ and NDTT $_{0}$ correspond to the $\pm 3 \sigma$ position of the Gaussian distribution for T - NDTT (no uncertainty is assigned to $\triangle$ NDTT). The fracture toughness ( $K_{I c}$ and $K_{I R}$ ) was evaluated at the following values of the presumed $T$ - NDTT Gaussian distribution: $-3 \sigma,-1 \sigma$, mean, $+1 \sigma$, and $+3 \sigma$. The $1 \sigma$ values have been determined as follows:

$$
(T-N D T T)_{1 \sigma}= \pm \frac{0.6827}{0.9973}\left[(T-N D T T)_{\max }-(T-N D T T)_{\min }\right] / 2,
$$


ORNL-DWG 88C-8020 ETD

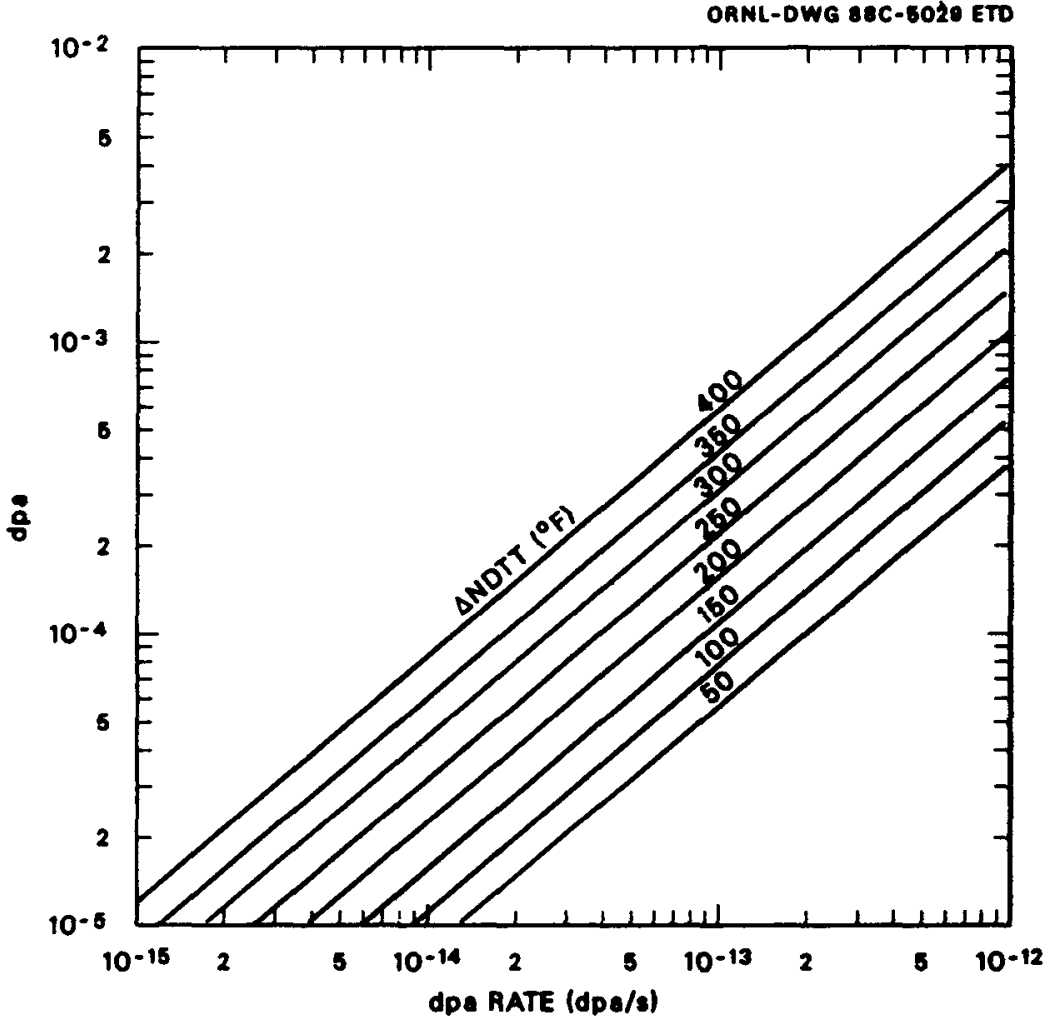

Fig. 7.14. Method A extrapolation of HFIR $\triangle N D T T$ vs dpa, dpa/s data.

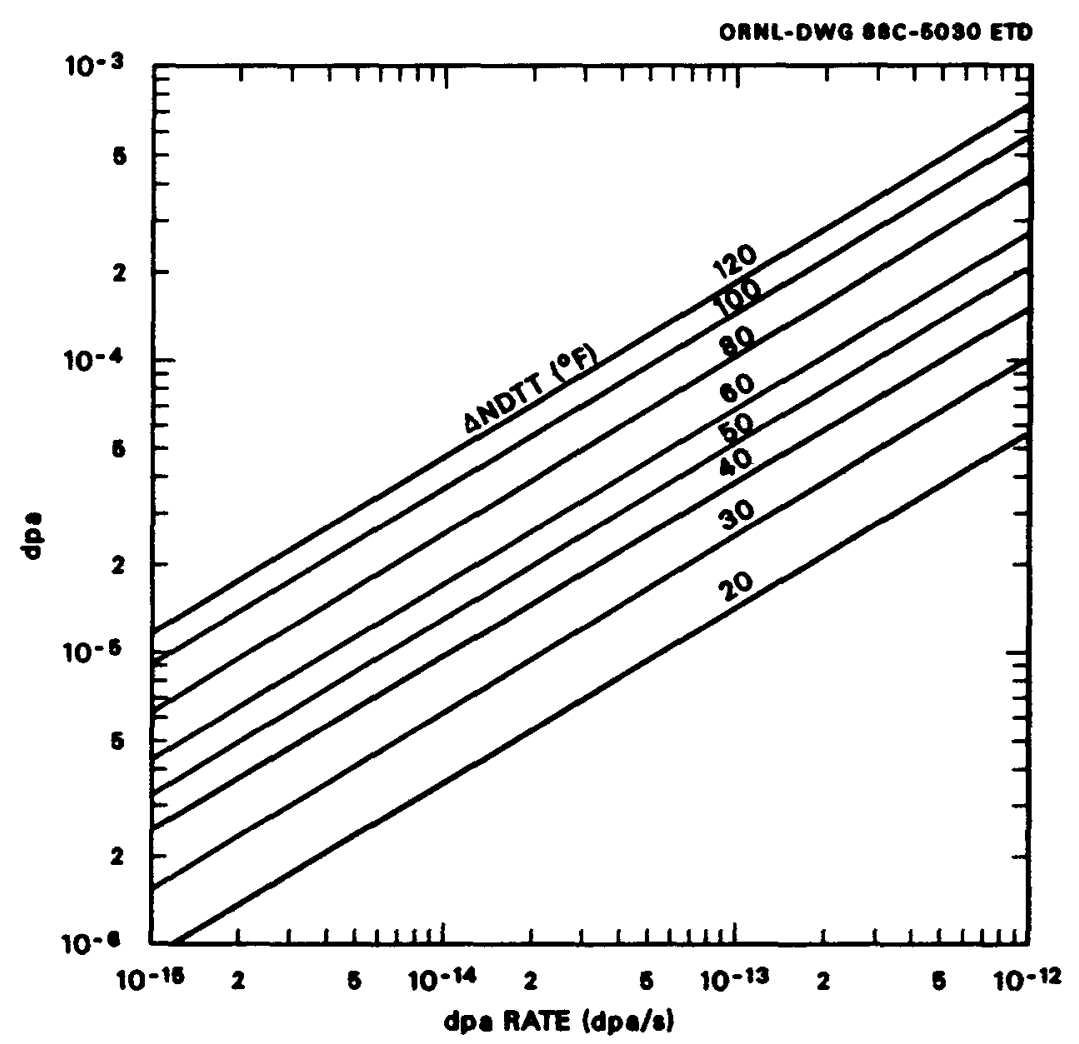

F

Fig. 7.15. Method B extrapolation of HFIR $\triangle N D T T$ vs dpa, dpa/s data. 
where "max" and "min" refer to the uncertainty limits. Thus, the T - NDTT values evaluated as functions of the Gaussian distribution are as follows:

\begin{tabular}{|c|c|}
\hline $\begin{array}{l}\text { Gaussian } \\
\text { point }\end{array}$ & Evaluation expression \\
\hline-30 & $(T-N D T T)_{\min }$ \\
\hline-10 & $(\mathrm{~T}-\mathrm{NDTT})_{\text {mean }}-0.6845[\mathrm{~T}-\mathrm{NDTT}]($ min - mean $)$ \\
\hline Mean & $0.5\left[(T-N D T T)_{\max }+(T-N D T T)_{\min }\right]$ \\
\hline$+1 \sigma$ & $(\mathrm{T}-\mathrm{NDTT})_{\text {mean }}+0.6845(\mathrm{~T}-\mathrm{NDTT})_{(\max }-$ mean $)$ \\
\hline $3 \sigma$ & $(T-N D T T)_{\max }$ \\
\hline
\end{tabular}

\subsection{Thermal and Radiation Environment}

The range of operating temperatures $T$ for the Turkey Point reactor vessel support components is not known at this time. The maximum operating temperature for the containment is understood to be $120^{\circ} \mathrm{F}$. Figure $V$ of Ref. 13 provides the maximum anticipated temperatures that will exist across the biological shield. At the $L=13-i n$. position (interface with the biological shield), the inferred maximum temperature for the cantilever beam is $130^{\circ} \mathrm{F}$. At the $L=17-i n$. position, the point of highest vertical and horizontal bending stress, the inferred maximum temperature is $138^{\circ} \mathrm{F}$. Information received from Westinghouse Electric Corporation on the temperature of the shoe of the Trojan Plant reactor vessel support (see Chap. 6) infers that the lateral restraints of the Turkey Point reactor vessel supports will operate at a temperature of $\sim 340^{\circ} \mathrm{F}$ at the point of maximum bending stress.

ORNL has assumed a $30^{\circ} \mathrm{F}$ operating temperature range for all components of the reactor vessel support other than the lateral restraint. A $10^{\circ} \mathrm{F}$ operating range has been assumed for this latter component. Consequently, the operating temperature ranges are as follow:

\section{Component}

Cantilever beam

$\mathrm{L}=13-\mathrm{in}$. position

$\mathrm{L}=17-\mathrm{in}$. position

Girder-to-cantilever beam bolt

Lateral restraint
Temperature range
$\left({ }^{\circ} \mathrm{F}\right)$

$\begin{array}{rrr}100 & \text { to } & 130 \\ 108 & \text { to } & 138 \\ 90 & \text { to } & 120 \\ 330 & \text { to } & 340\end{array}$

Extensive sophisticated calculations of neutron flux and dpa rate were performed by Florida Power and Light Co.14,15 for the Turkey Point vessel supports. Figure 7.16 shows the location of ten points on the 


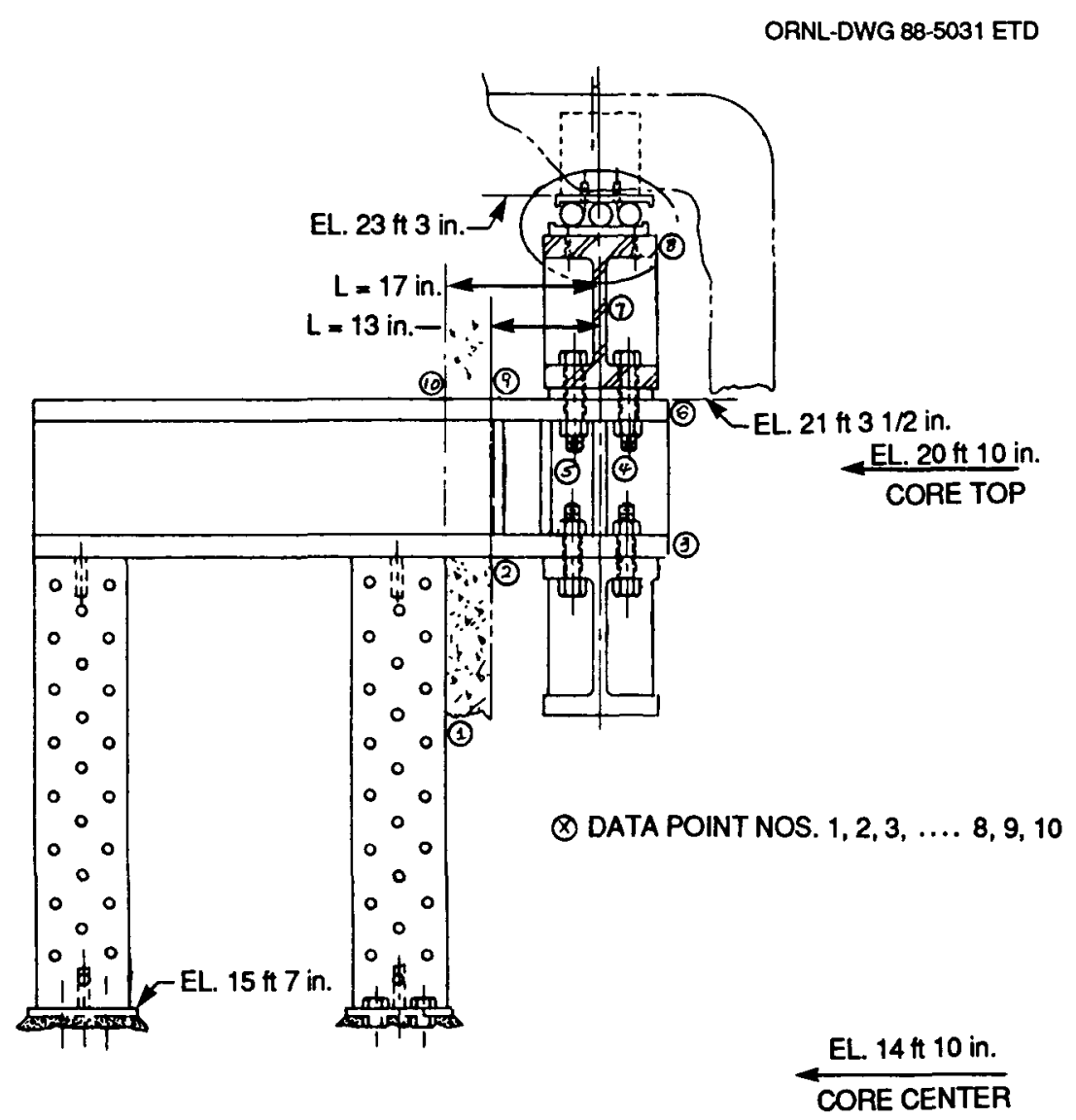

Fig. 7.16. Location for which neutron fluxes calculated.

supports for which neutron flux and dpa rate were calculated. Points 4, 8,9 , and 10 correspond to, respectively, (1) the girder-to-cantilever bolts, (2) lateral restraints, (3) cantilever beams at loading arm length $\mathrm{L}=13$ in. (interface with biological shield surface), and (4) cantilever beams at loading arm length $\mathrm{L}=17 \mathrm{in}$. (intersection with support column and location of maximum bending stress).

Table 7.1 summarizes the dpa-rate data for the ten points as a function of time, that is, fuel cycles (the dpa rate for point 10 was estimated by multiplying the dpa rates at point 9 by the ratio of fluxes at points 10 and 9 given in Fig. 7.17). The data in Table 7.1 were adjusted by time weighting to provide an estimate of the mean dpa rate and dpa from initial plant startup until the end of the eighth fuel cycle (7.04 EFPY, Oct. 1, 1983), ninth fuel cycle (11.79 EFPY, Aug. 3, 1988), and 32 EFPY for points $4,8,9$, and 10. These data are provided in Table 7.2. 
Table 7.1. Calculated dpa rates around the Turkey Point reactor vessel supports

\begin{tabular}{|c|c|c|c|c|}
\hline \multirow{2}{*}{$\begin{array}{c}\text { Data } \\
\text { point } \\
\text { No. }\end{array}$} & \multicolumn{2}{|c|}{$\begin{array}{l}\text { dpa/s (before } \\
\text { October } 1,1983)^{a}\end{array}$} & \multicolumn{2}{|c|}{$\begin{array}{l}\text { dpa/s (beginning with } \\
\text { January } 7,1984 \text { ) }\end{array}$} \\
\hline & $E \geq 1.0 \mathrm{MeV}$ & $E \geq 0.11 \mathrm{MeV}$ & $E \geq 1.0 \mathrm{MeV}$ & $E \geq 0.11 \mathrm{MeV}$ \\
\hline 1 & $3.844-13^{b}$ & $5.909-13$ & $2.103-13$ & $3.213-13$ \\
\hline 2 & $4.930-13$ & $9.123-13$ & $2.750-13$ & $5.010-13$ \\
\hline 3 & $6.523-13$ & $1.163-12$ & $3.802-13$ & $6.683-13$ \\
\hline 4 & $3.492-13$ & $6.996-13$ & $2.073-13$ & $4.066-13$ \\
\hline 5 & $2.088-13$ & $4.713-13$ & $1.204-13$ & $2.787-13$ \\
\hline 6 & $2.297-13$ & $4.666-13$ & $1.440-13$ & $2.830-13$ \\
\hline 7 & $8.888-14$ & $2.009-13$ & $5.816-14$ & $1.249-13$ \\
\hline 8 & $4 \cdot 319-14$ & $1.272-13$ & $2.705-14$ & $7.640-14$ \\
\hline 9 & $3.829-14$ & $1.141-13$ & $2.296-14$ & $6.621-14$ \\
\hline 10 & & $3.582-14$ & & $2.052-14$ \\
\hline
\end{tabular}

${ }^{a}$ Steel displacement cross sections and calculation procedures for dpa/s are based on ASTM E 693-79.

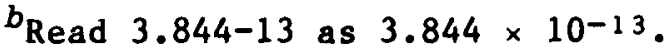

Table 7.2. Time-weighted dpa rates ( $E>0.1 \mathrm{MeV}$ ) and dpa as a function of fuel cycle

\begin{tabular}{|c|c|c|c|c|c|c|}
\hline \multirow[t]{2}{*}{$\begin{array}{l}\text { Data } \\
\text { point } \\
\text { No. }\end{array}$} & \multicolumn{2}{|c|}{$\begin{array}{c}\text { Data through } \\
\text { Oct. 1, 1983, } \\
8 \text { fuel cycles } \\
7.04 \text { EFPY } \\
\text { Total time lapse: } \\
2.020+8 \mathrm{~s}^{a}\end{array}$} & \multicolumn{2}{|c|}{$\begin{array}{c}\text { Data through } \\
\text { Aug. 3, 1988, } \\
7 \text { fuel cycles } \\
11.79 \text { EFPY } \\
\text { Total time lapse: } \\
3.719+8 \mathrm{~s}\end{array}$} & \multicolumn{2}{|c|}{$\begin{array}{l}\text { Data through to } \\
32 \text { EFPY } \\
\text { Total time lapses } \\
10.091+8 \mathrm{~s}\end{array}$} \\
\hline & $\begin{array}{l}\text { Mean } \\
\mathrm{dpa} / \mathrm{s}\end{array}$ & dpa & $\begin{array}{l}\text { Mean } \\
\text { dpa/s }\end{array}$ & $d p a$ & $\mathrm{dpa} / \mathrm{s}$ & dpa \\
\hline 4 & $6.996-13$ & $1.553-4$ & $5.815-13$ & $2.163-4$ & $4.719-13$ & $2.302-4$ \\
\hline 8 & $1.272-13$ & $2.824-5$ & $1.067-13$ & $3.969-5$ & $8.773-14$ & $8.853-5$ \\
\hline 9 & $1.141-13$ & $2.533-5$ & $9.02-14$ & $3.525-5$ & $7.67-14$ & $7.744-5$ \\
\hline 10 & $3.582-14$ & $7.95-6$ & $2.965-14$ & $1.103-5$ & $2.393-14$ & $2.415-5$ \\
\hline
\end{tabular}


ORNL-DWG 88C-6032 ETO

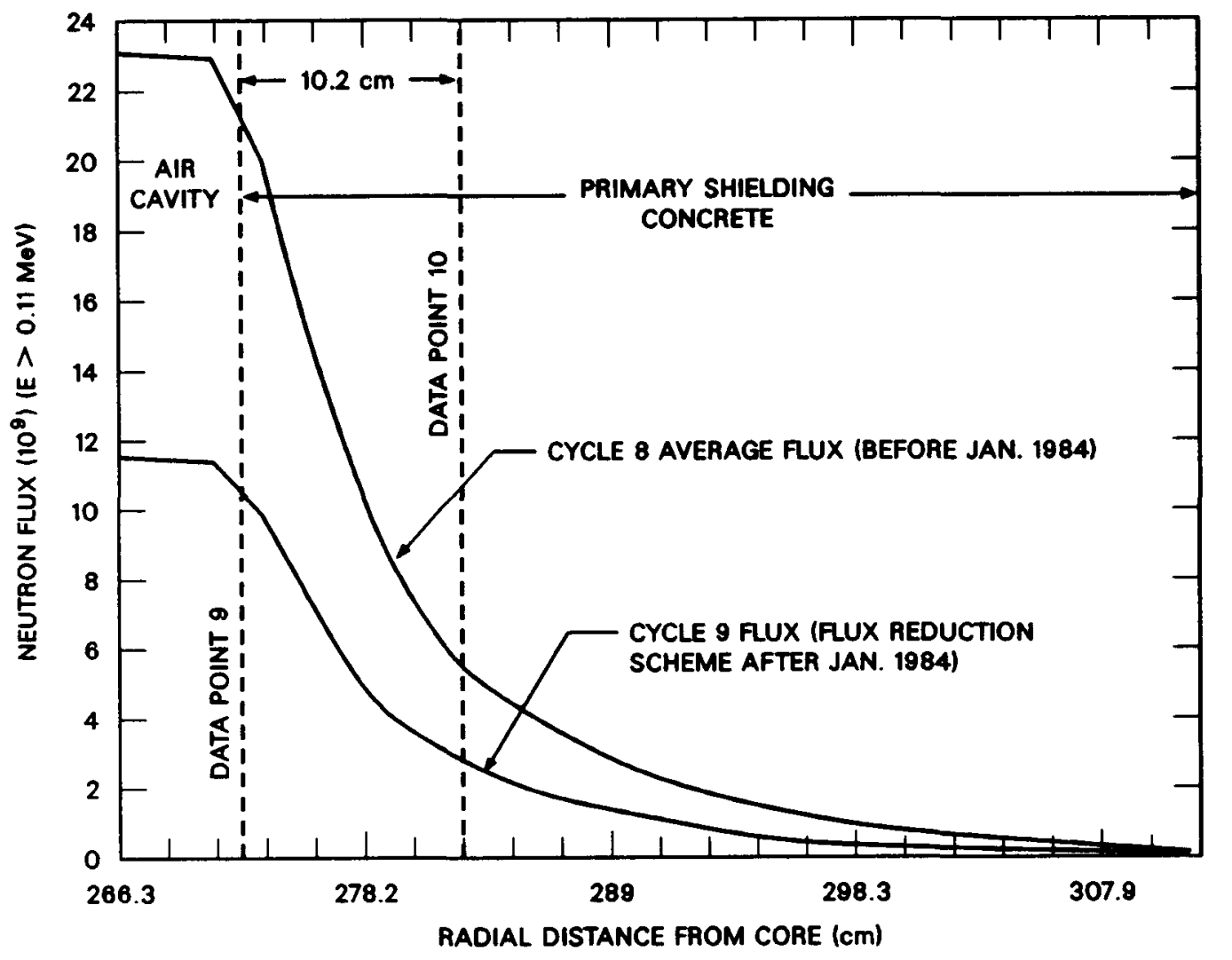

Fig. 7.17. Fast-flux distribution in biological shield.

\subsection{Estimates of $\triangle$ NDTT}

The radiation-damage trend curves ( $\triangle$ NDTT vs dpa and dpa rate) used in this study for the support materials are discussed in Sects. 7.3 and 7.4 , and the dpa rate and dpa data for the support are given in Tables 7.1 and 7.2. Values of $\triangle N D T T$ derived from this information are provided in Table 7.3 as a function of time and trend curve for each support component considered.

\subsection{Support Loadings and Stress Analysis}

Critical-flaw-size assessment of components of the Turkey Point reactor vessel supports has been premised on utilization of the design analysis performed by Bechtel Corporation, the architect-engineer (AE) for this plant. Only minor corrections or extensions in analysis to the Bechtel stress analyses have been required for the assessments as hereafter explained. 
Table 7.3. Summary of estimated radiation-damage shift $\triangle$ NDTT as a function of extrapolation method and service life for each component

\begin{tabular}{|c|c|c|c|c|c|c|}
\hline \multirow{3}{*}{ Component } & \multicolumn{6}{|c|}{$\triangle \operatorname{NDTT}\left({ }^{\circ} \mathrm{F}\right)$} \\
\hline & \multicolumn{2}{|c|}{7.04 EFPY } & \multicolumn{2}{|c|}{11.79 EFPY } & \multicolumn{2}{|c|}{32 EFPY } \\
\hline & $A^{a}$ & $\mathrm{~B}^{a}$ & A & B & A & B \\
\hline $\begin{array}{l}\text { Cantilever beam } \\
\text { Point } 9, \mathrm{~L}=13 \text { in. }\end{array}$ & $b$ & 30 & $b$ & 40 & 130 & 75 \\
\hline $\begin{array}{l}\text { Cantilever beam } \\
\text { Point } 10, L=17 \text { in. }\end{array}$ & $b$ & 20 & $b$ & 30 & $30^{b}$ & 55 \\
\hline $\begin{array}{l}\text { Girder-to-cantilever beam } \\
\text { bolt - Point } 4\end{array}$ & $b$ & 45 & $40^{b}$ & 65 & 70 & 75 \\
\hline $\begin{array}{l}\text { Lateral restraint } \\
\text { Point } 8\end{array}$ & $b$ & 30 & $30^{b}$ & 40 & 130 & 80 \\
\hline
\end{tabular}

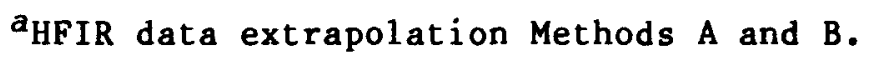

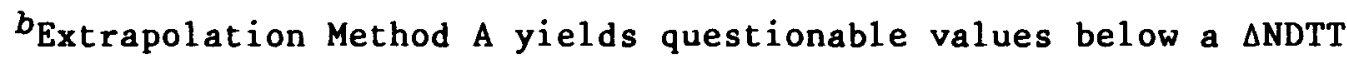
shift of $50^{\circ} \mathrm{F}$.

As noted in Chap. 4, the AE analysis of PWR supports in general does not incorporate an assessment of the effect of differential friction in support provisions for radial expansion. Such an effect was not examined by the Turkey Point $\mathrm{AE}$, and ORNL has not made an assessment of the potential consequences. Furthermore, residual and thermal stresses are important with regard to evaluating critical flaw sizes, but insufficient information was available for their inclusion. As a result of these omissions, it may be that actual critical flaw sizes are less than those calculated in this study.

The Bechtel design document for the Turkey Point containment structures ${ }^{3}$ and five sets of Bechtel calculationsi6-20 in support of the design thereof were supplied by Florida Power and Light Co. Design calculations included in Refs. 16 and 17 appear to involve a conceptual stage of design, whereas Refs. 18-20 appear to represent the final design. In the conceptual stage of design, the AE designer assumed that the cantilever beams were "built-in" at the point of interface with the biological shield (identified as the $\mathrm{L}=13$-in. position on Figs. 7.3 and 7.4). In the final stage of design, the $A E$ designer assumed that the cantilever beams were "built-in" at the inner face of the inboard column (identified in Figs. 7.3 and 7.4 with the dimension $L=17$ in.). The $\mathrm{AE}$ designer assumed that the concrete between the biological shield inner surface and the inboard column provided no effective support to the cantilever beams. These assumptions reflect standard design practice and are consistent with the analysis performed in Chap. 6 . 
The evaluations of the cantilever beams and lateral restraints were performed using the loadings and stresses from Refs. 18-20. The loads and stresses for the girder-to-cantilever-beam bolts are covered only in Refs. 16 and 17 but were corrected to reflect the subsequent design changes in Refs. 18-20 that are a consequence of a required increase in girder size. In addition to this correction, the stresses that result from the load combination of DL and no-loss-of-function earthquake ( $E^{-}$) (SSE in the vernacular of later plant designs) were also evaluated. This latter loading condition was not germane to the Bechtel design analysis because it did not control the size of the components. Therefore, it was not included in Refs. 16-20.

Note that in contrast to the Trojan Plant discussed in Chap. 6, pipe loadings resulting from thermal constraint were considered to be insignificant for Turkey Point. In addition, dynamic methods of analysis were evidently unavailable at the time of the Turkey Point design so that static analysis of enveloped loads were employed to ensure that the reactor vessel support design could adequately accommodate loadings involving LOCAs. In further contrast to Trojan, the LOCA was included by the utility as a credible loading condition for Turkey Point. Many PWR plants have been exempt from consideration of LOCA loads, but at the time of this study Turkey Point was not.

The LOCA "break" was assumed to be a multioriented, axially split pipe failure rather than a guillotine type. A significant attendant consequence of this assumption is the important role of horizontal loadings in the design analysis and the calculation of critical flaw size for the cantilever beams.

Table 7.4 provides the load combinations used by the Bechtel Corp. designer for the final design of the Turkey Point vessel supports, and Table 7.5 provides the corresponding stresses for the cantilever beams, girder-to-cantilever beam bolts, and lateral restraints. As previously noted, to permit evaluation of critical flaw size as a function of loading condition 3 (Table 7.5), ORNL calculated the stresses shown in parentheses in Table 7.5, using the stress analysis method of the $\mathrm{AE}$ given in Refs. 16-20.

\subsection{Stress-Intensity-Factor $\left(K_{I}\right)$ Evaluation}

Because of the large influence that the horizontal load had on the design of the vessel-support cantilever beams, a variety of flaw shapes was assumed - some more responsive to vertical loading, some to horizontal, and one to both directions of loading. Semielliptical surface flaws with varying ratios of major to minor diameter ffrom 1.0 (semicircular) to $\infty$ [single-edge-notch (SEN) flaw] were assumed to exist on the top surface of the cantilever-beam flange; these flaws were particularly responsive to vertical loading. SEN flaws were assumed to exist on the edges of the top flange (these flaws were particularly responsive to horizontal loading), and quarter-circular corner flaws were assumed to exist in the upper corner of the top flange (these flaws were responsive to both vertical and horizontal loading). 
Table 7.4. Sumnary of Turkey Point vessel and vessel support loads

\begin{tabular}{|c|c|c|c|}
\hline Loading condition & $\begin{array}{c}\text { Vessel loads } \\
\text { force (k1ps) } \\
\text { moment } \\
(k 1 p s \cdot f t)\end{array}$ & $\begin{array}{l}\text { Number of } \\
\text { support arrays } \\
\text { assumed } \\
\text { reacting }\end{array}$ & $\begin{array}{l}\text { Load per } \\
\text { support } \\
\text { array } \\
\text { (kıs) }\end{array}$ \\
\hline 1. $\mathrm{DL}$ & $v=1684$ & 3 & $V=562$ \\
\hline 2. DL and $E$ & $\begin{array}{l}V=1802 \\
H=200\end{array}$ & $\begin{array}{l}6 \\
3\end{array}$ & $\begin{array}{l}V=300 \\
H=66\end{array}$ \\
\hline 3. $D L$ and $E^{\prime}$ & $\begin{array}{l}V=2105 \\
H=623\end{array}$ & $\begin{array}{l}6 \\
3\end{array}$ & $\begin{array}{l}V=350 \\
H=203\end{array}$ \\
\hline 4. $D L+\operatorname{LOCA}(V)$ & $\begin{array}{l}V=3074 \\
M=21,000\end{array}$ & 6 & $V=1418(\max )$ \\
\hline 5. $\mathrm{DL}+\mathrm{LOCA}(\mathrm{H})$ & $\begin{array}{l}V=1684 \\
H=900\end{array}$ & $\begin{array}{l}6 \\
1\end{array}$ & $\begin{array}{l}V=280 \\
H=900(\max )\end{array}$ \\
\hline 6. $D L+\operatorname{LOCA}\left(45^{\circ}\right)$ & $\begin{array}{l}V=2666 \\
H=635 \\
M=14,900\end{array}$ & $\begin{array}{l}5 \\
6\end{array}$ & $\begin{array}{l}V=1084 \\
H=635\end{array}$ \\
\hline
\end{tabular}

a Notation used in Refs. 16-20

DL: operational dead load,

E: operat 2 ng basis earthquake $(O B E)=0.3 \mathrm{E}^{\prime}$,

$E^{\prime}:$ no-loss-of-functions earthquake Isafe shutdown earthquake (SSE) I,

LOCA(V): vertically acting large-break loss-of-coolant-accident load,

LOCA(H): horizontally acting (normal to nozzle axis) LOCA load,

LOCA $\left(45^{\circ}\right)$ : LOCA load (normal to nozzle axis) at $45^{\circ}$ to vertical.

$b_{\mathrm{V}}=$ vertical component,

$\mathrm{H}=$ horizontal component,

$M=$ moment.

$c_{A}$ support array includes three cantilever beams (see Figs. 7.3 and

7.4).

Table 7.5. Summary of stress values for components of Turkey Pount reactor vessel supports as a function of loading condition

\begin{tabular}{|c|c|c|c|c|c|c|c|c|}
\hline \multirow{3}{*}{$\begin{array}{l}\text { Case } \\
\text { No. }\end{array}$} & \multirow{3}{*}{$\begin{array}{l}\text { Loading } \\
\text { condition }\end{array}$} & \multirow{3}{*}{$\frac{L^{b}}{(1 \mathrm{n} .)}$} & \multicolumn{6}{|c|}{ Stress $(0), c^{C}$ ks 1} \\
\hline & & & \multicolumn{2}{|c|}{$\begin{array}{c}\text { Symmetric } \\
\text { cantilever } \\
\text { beam }\end{array}$} & \multirow{2}{*}{$\begin{array}{l}\text { Girder-to- } \\
\text { cantilever- } \\
\text { beam bolt } \\
0\end{array}$} & \multirow{2}{*}{$\frac{\begin{array}{c}\text { Lateral } \\
\text { restraint }\end{array}}{\sigma}$} & \multicolumn{2}{|c|}{$\begin{array}{c}\text { Nonsymmetric } \\
\text { cant } 1 \text { lever } \\
\text { beam }\end{array}$} \\
\hline & & & ${ }^{o} y$ & $\alpha_{x}$ & & & $\sigma_{Y}$ & $\sigma_{\mathbf{x}}$ \\
\hline 1 & DL & 17 & 5.7 & & & & 5.3 & \\
\hline 2 & $D L+E$ & 17 & $4.6^{d}$ & $5.1^{d}$ & & & & \\
\hline $\begin{array}{l}3 \mathrm{~A} \\
3 \mathrm{~B}\end{array}$ & $\mathrm{DL}+\mathbf{E}^{-}$ & $\begin{array}{l}17 \\
13\end{array}$ & $\begin{array}{l}8.2^{d} \\
(6.27)^{d}\end{array}$ & $\begin{array}{l}5.6^{d} \\
(11.9)^{d}\end{array}$ & $9.30^{d}$ & 6.2 & & \\
\hline 4 & $\mathrm{DL}+\mathrm{LOCA}(\mathrm{V})$ & 17 & 14.3 & & & & & \\
\hline $\begin{array}{l}5 A \\
5 B\end{array}$ & $\mathrm{DL}+\operatorname{LOCA}(\mathrm{H})$ & $\begin{array}{l}17 \\
13\end{array}$ & $\begin{array}{c}23.2 \\
(17.7)^{d}\end{array}$ & $\begin{array}{l}23.0 \\
(17.6)^{d}\end{array}$ & $41.22^{d}$ & 27.4 & 12.0 & 16.3 \\
\hline $\begin{array}{l}6 A \\
6 B\end{array}$ & $\mathrm{DL}+\operatorname{LOCA}\left(45^{\circ}\right)$ & $\begin{array}{l}17 \\
13\end{array}$ & $\begin{array}{l}25.5 \\
(19.5)^{d}\end{array}$ & $\begin{array}{l}16.3 \\
(12.5)^{d}\end{array}$ & & & 10.3 & 16.6 \\
\hline
\end{tabular}

asee footnote a in Table 7.4 .

bApplies to cantilever beam only,

$L=13 \mathrm{in}$. is at inner surface of shield,

$\mathrm{L}=17 \mathrm{in}$. is at location of maximum bending moment.

$c_{\sigma}=$ stress, $y$ subseript bending about $x-x$ neutral axis, $x$ subscript bending about $y-y$ axis.

dEvaluation by ORNL based on Bechtel Corp. design analysis. 
The girder-to-cantilever beam bolts were assumed to have complete circumferential flaws oriented perpendicular to the bolt centerline and therefore were responsive to bolt tensile loading. The lateral restraints were assumed to have semielliptical surface flaws oriented perpendicular to and intersecting the vertical surfaces and therefore were responsive to horizontal loading. Aspect ratios of $1: 1$ to $6: 1$ were considered for these latter flaws.

The stress-intensity factors for semielliptical flaws in the cantilever beam and lateral restraint were evaluated by means of the method suggested by Merkle.21,22 (Previous comparisons ${ }^{23}$ of this solution with finite-element analyses indicate that the stress-intensity factors for some elliptical shapes other than semicircular are overestimated. Nevertheless, its use was considered to be expedient for this study because the analytical format facilitates the parametric investigation.)

The Merkle solution was developed for a combined tension and bending-stress field and permits evaluation of $K_{I}$ as a function of position on the crack profile. In this study the maximum value of $k_{I}$ on the crack front was assumed to be the critical value. Figures 7.18-7.21 show the stress-intensity factor as a function of flaw depth, aspect ratio, and loading condition.

The stress-intensity factors for the SEN flaws located on the top surface and the edge of the top flange of the cantilever beam were evaluated by the expression given for SEN specimens under pure bending given in Ref. 24 ( $p .2 .13)$. The expression is

$$
K_{I}=\sigma \sqrt{\pi a} F\left(\frac{a}{b}\right),
$$

where $K_{I}$ is the stress-intensity factor, $\sigma$ is the maximum bending stress, $a$ is the flaw depth, and $b$ is the specimen depth. Figures 7.227.25 show the stress-intensity factor as a function of flaw depth for the SEN flaws located on the top surface of the top flange. Figures 7.26-7.29 show the stress-intensity factor as a function of flaw depth for SEN flaws located on the edge of the top flange of the cantilever beam.

Two methods of solution ( $\mathrm{Liu}^{25}$ and Newman and Raju26) were used to evaluate the stress-intensity factor for the quarter-circular corner crack subtending the edge and top surface of the top flange of the cantilever beam. Both solutions are premised on a uniform stress field, and the stress used in the analyses was the sum of the maximum bending stresses resulting from the vertical and horizontal loads. In both cases, the maximum value of $k_{I}$ on the crack front was used for calculating the critical flaw size.

Figures 7.30-7.35 show the maximum stress-intensity factor for the corner crack of the cantilever beam evaluated by the Liu method; Figs. 7.36-7.41 show the maximum stress-intensity factor for the corner crack of the cantilever beam evaluated by the Newman-Raju method.

Two methods were used for estimating the stress-intensity factor for the assumed circumferential flaw of the girder-to-cantilever beam bolts. One method is given in Ref. 24, and the other is by Brown and Srawley. 27 The calculated $K_{I}$ values are given in Figs. 7.42 and 7.43 ; 


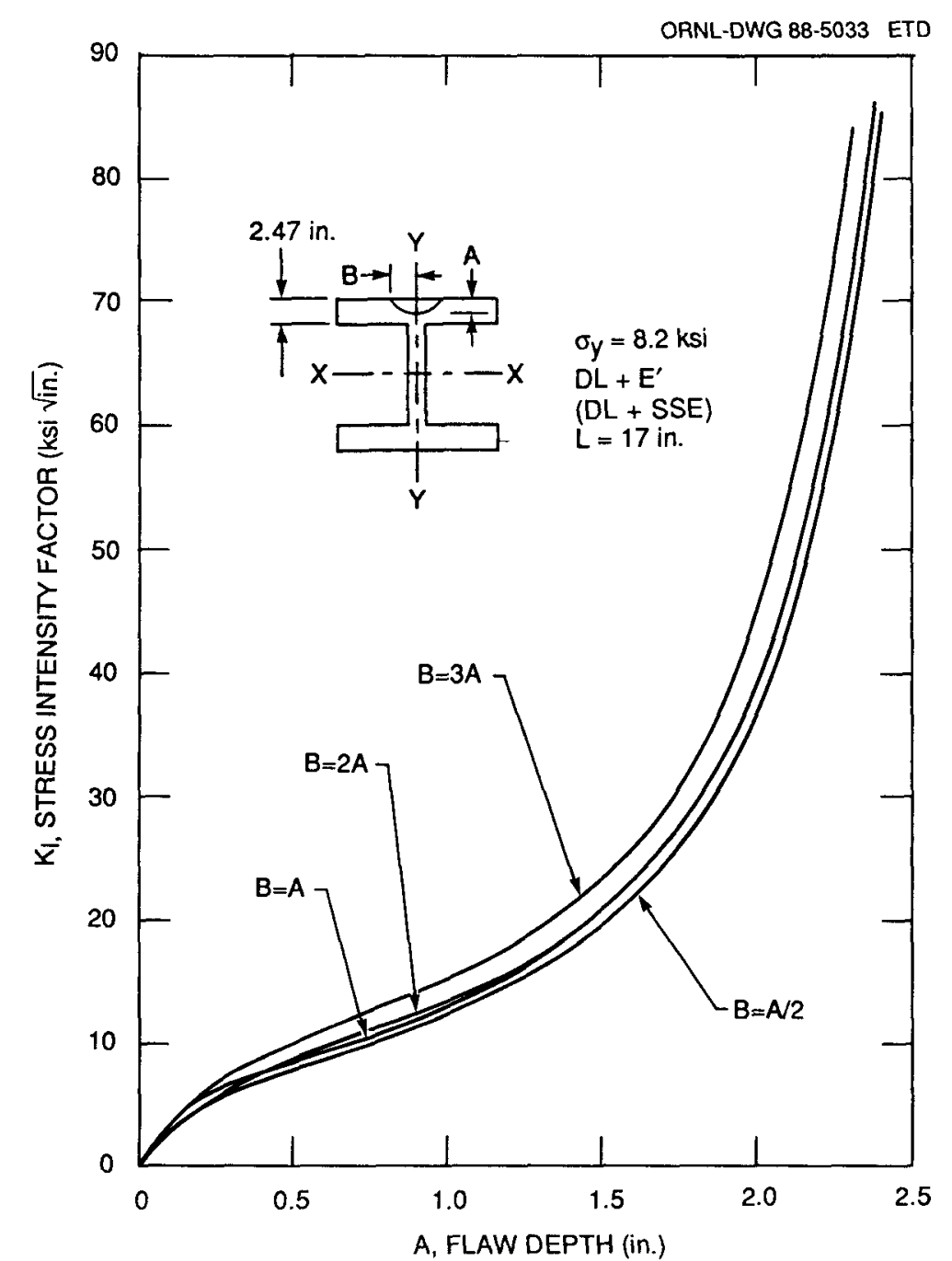

Fig. 7.18. Stress-intensity factor vs crack depth for cantilever beam with semielliptical surface flaw (case $3 A$ ).

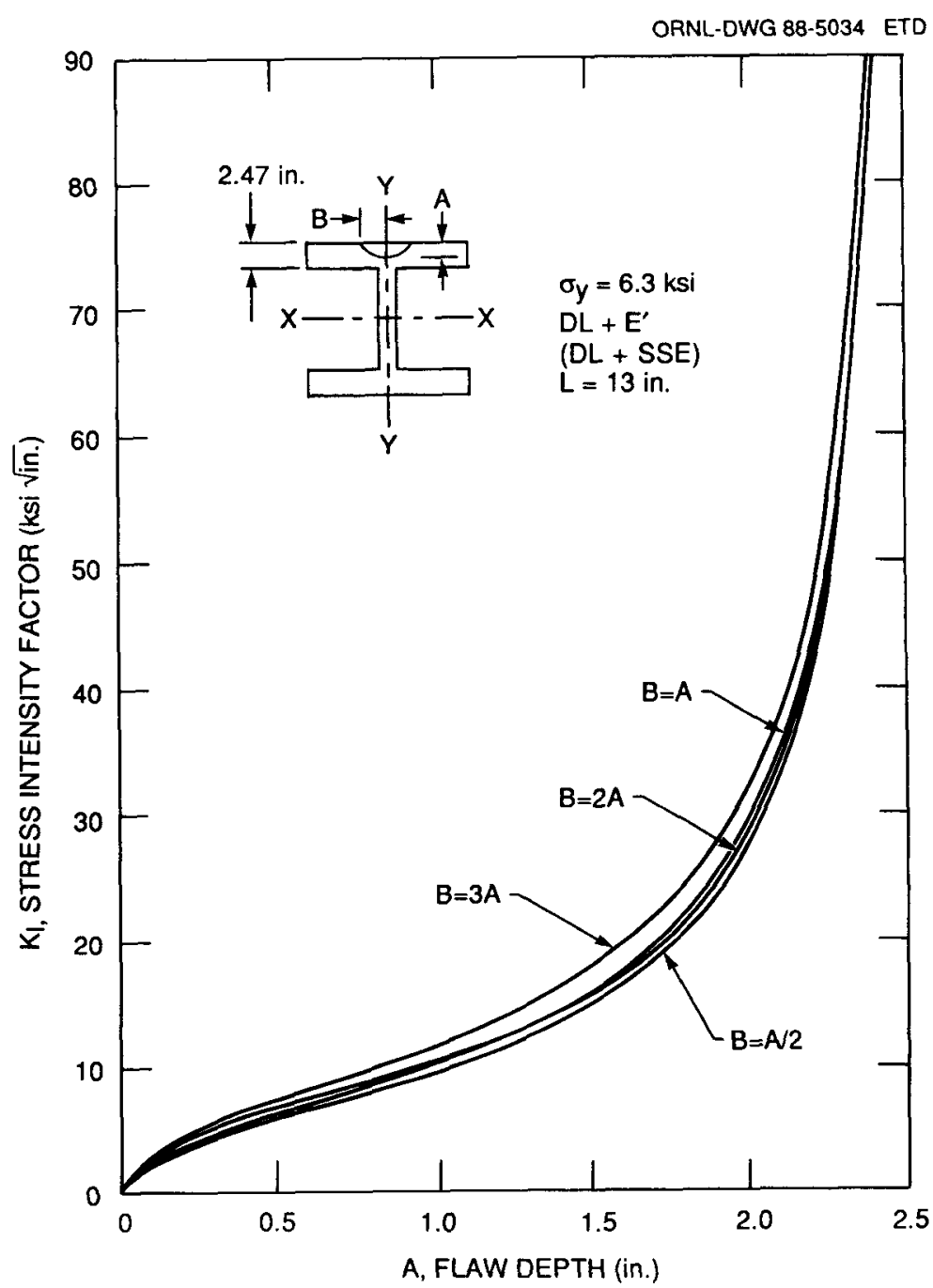

Fig. 7.19. Stress-intensity factor vs flaw depths for cantilever beam with semielliptical surface flaw (case 3B). 


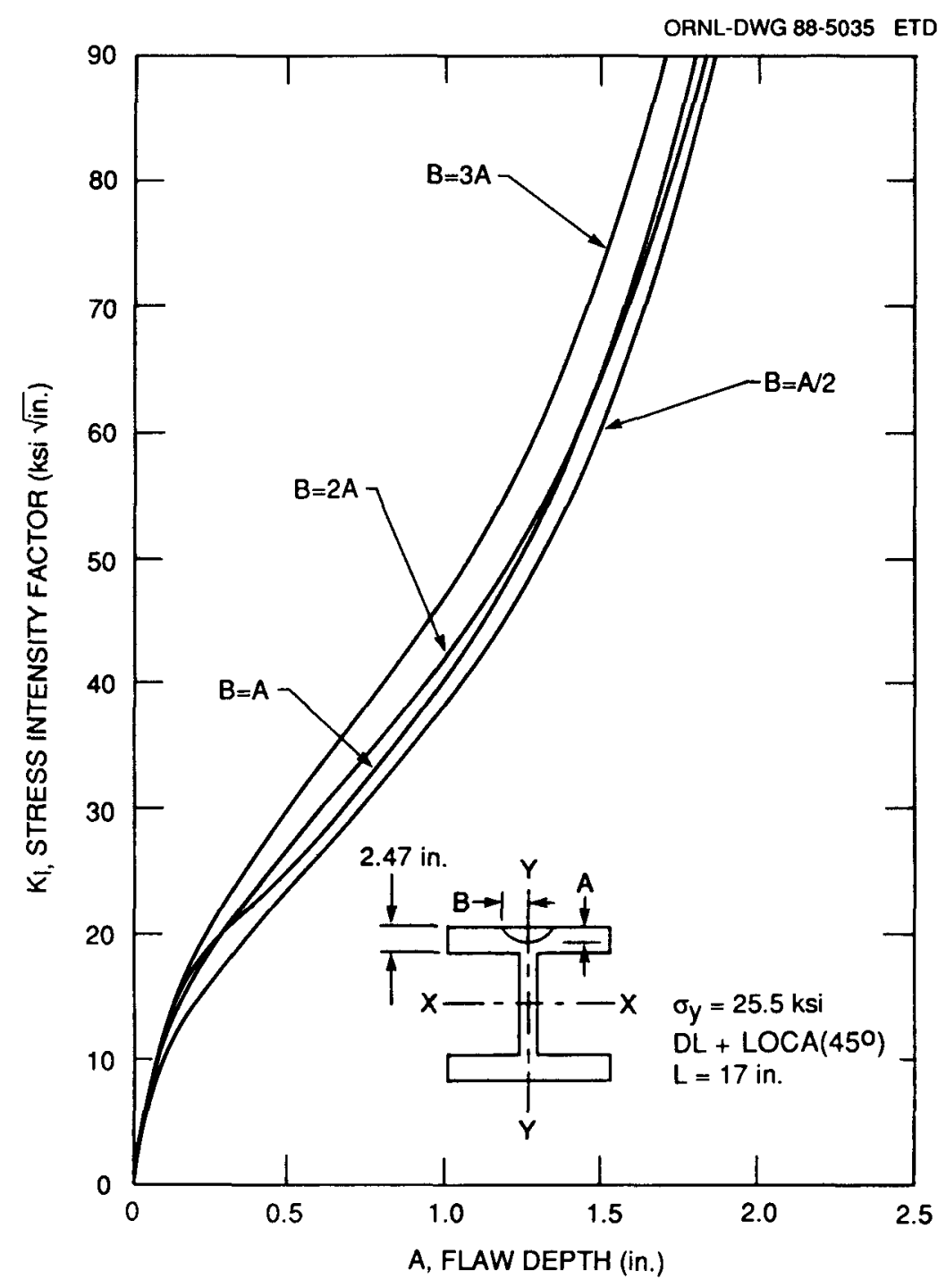

Fig. 7.20. Stress-intensity factor vs crack depth for cantilever beam with semielliptical surface flaw (case $6 \mathrm{~A}$ ).

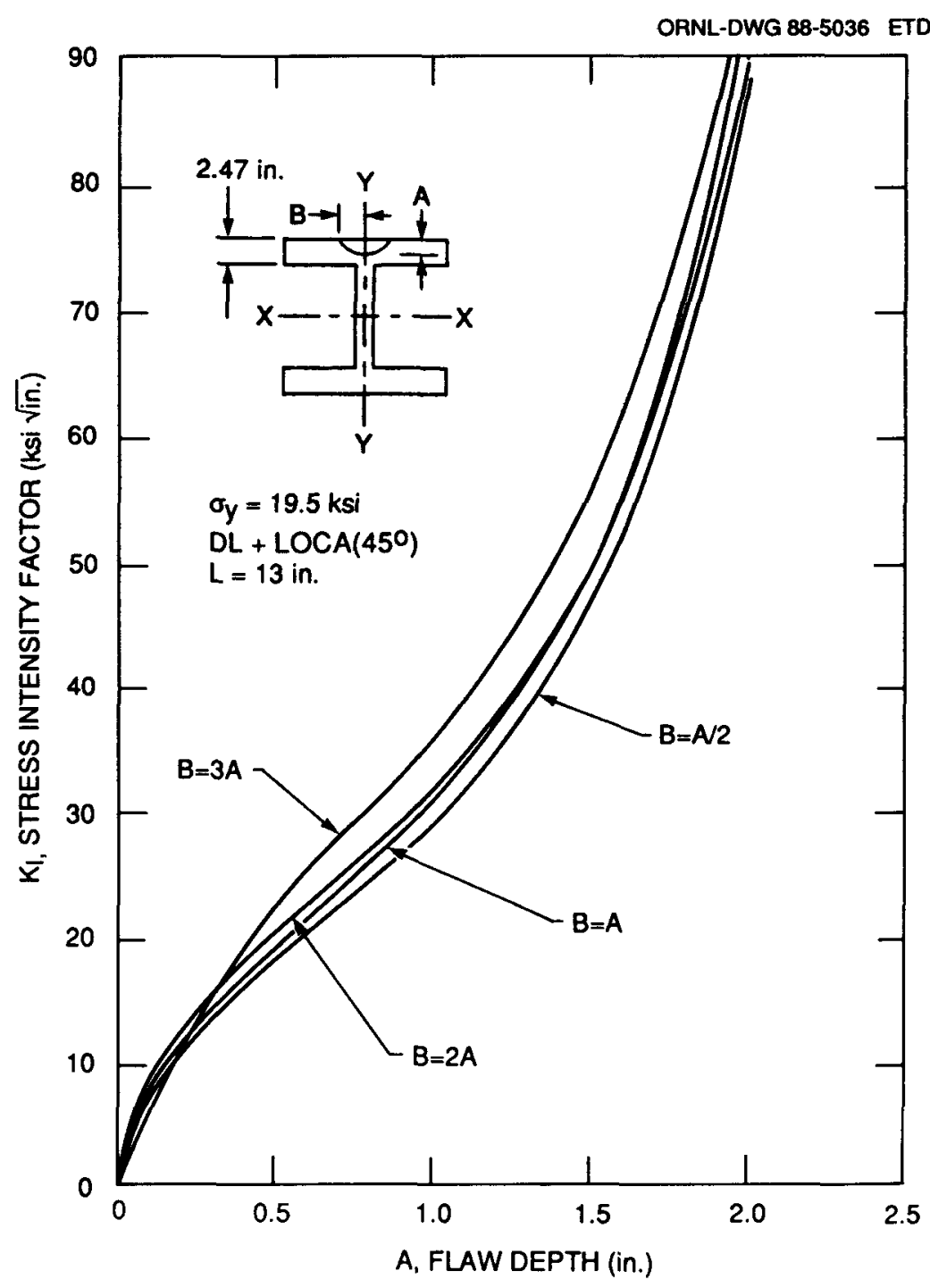

Fig. 7.21. Stress-intensity factor vs crack depth for cantilever beam with semielliptical surface flaw (case 6B). 


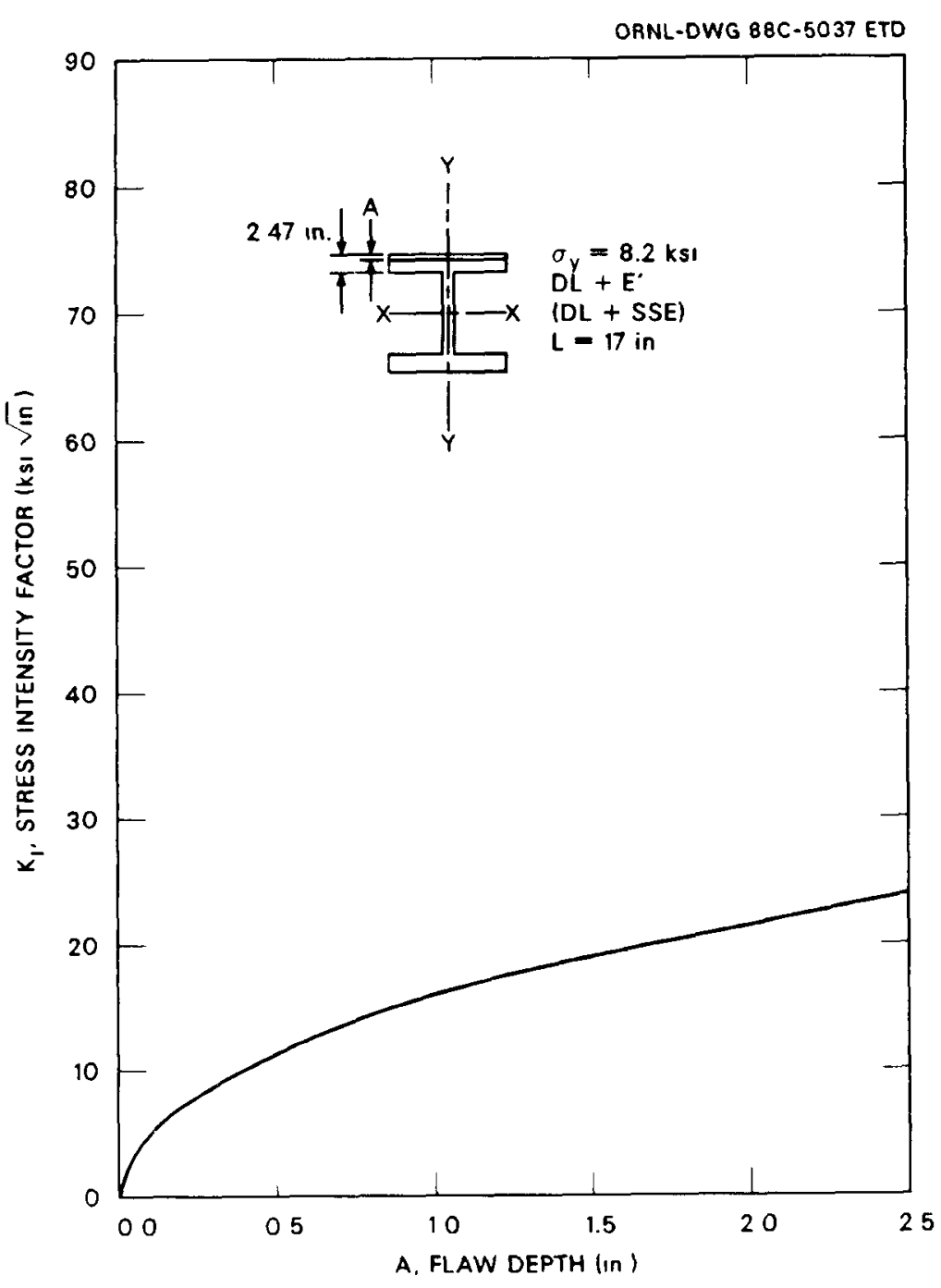

Fig. 7.22. Stress-intensity factor vs crack depth for cantilever beam with SEN flaw on top surface (case $3 A$ ).

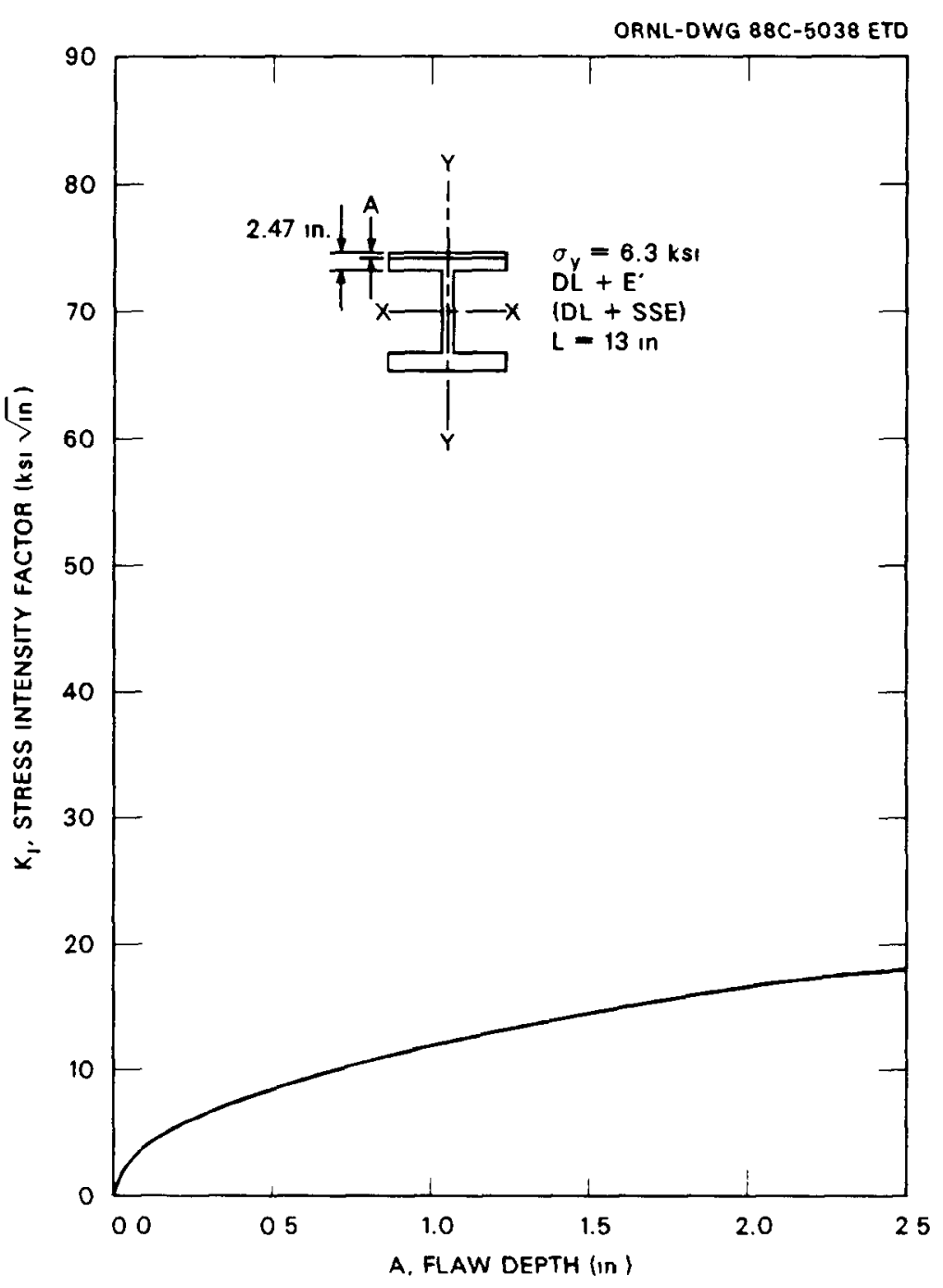

Fig. 7.23. Stress-intensity factor vs crack depth for cantilever beam with SEN flaw on top surface (case 3B). 
OANL-DWE 8EC-5039 ETD

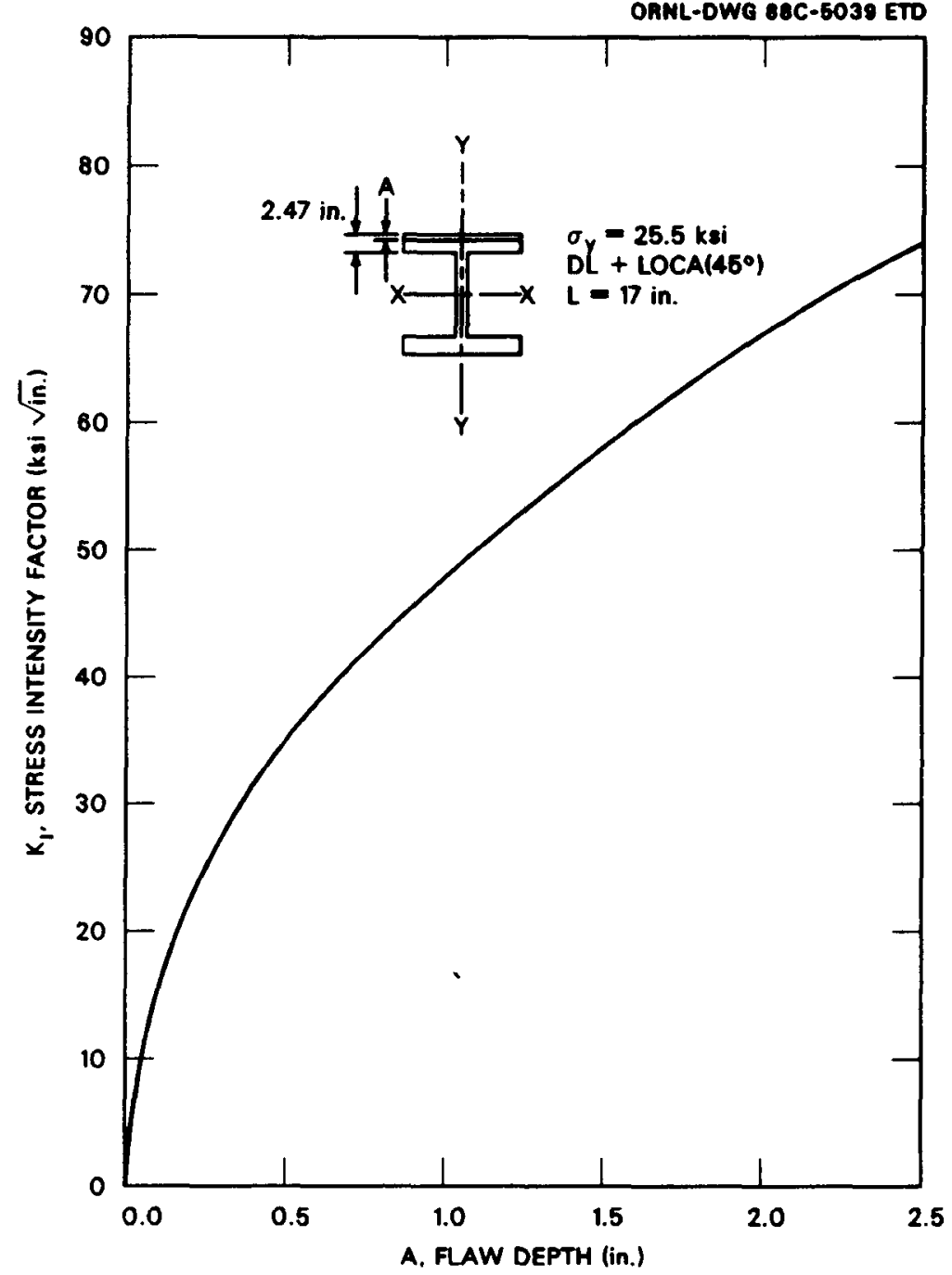

Fig. 7.24. Stress-intensity factor vs crack depth for cantilever beam with SEN flaw on top surface (case 6A).

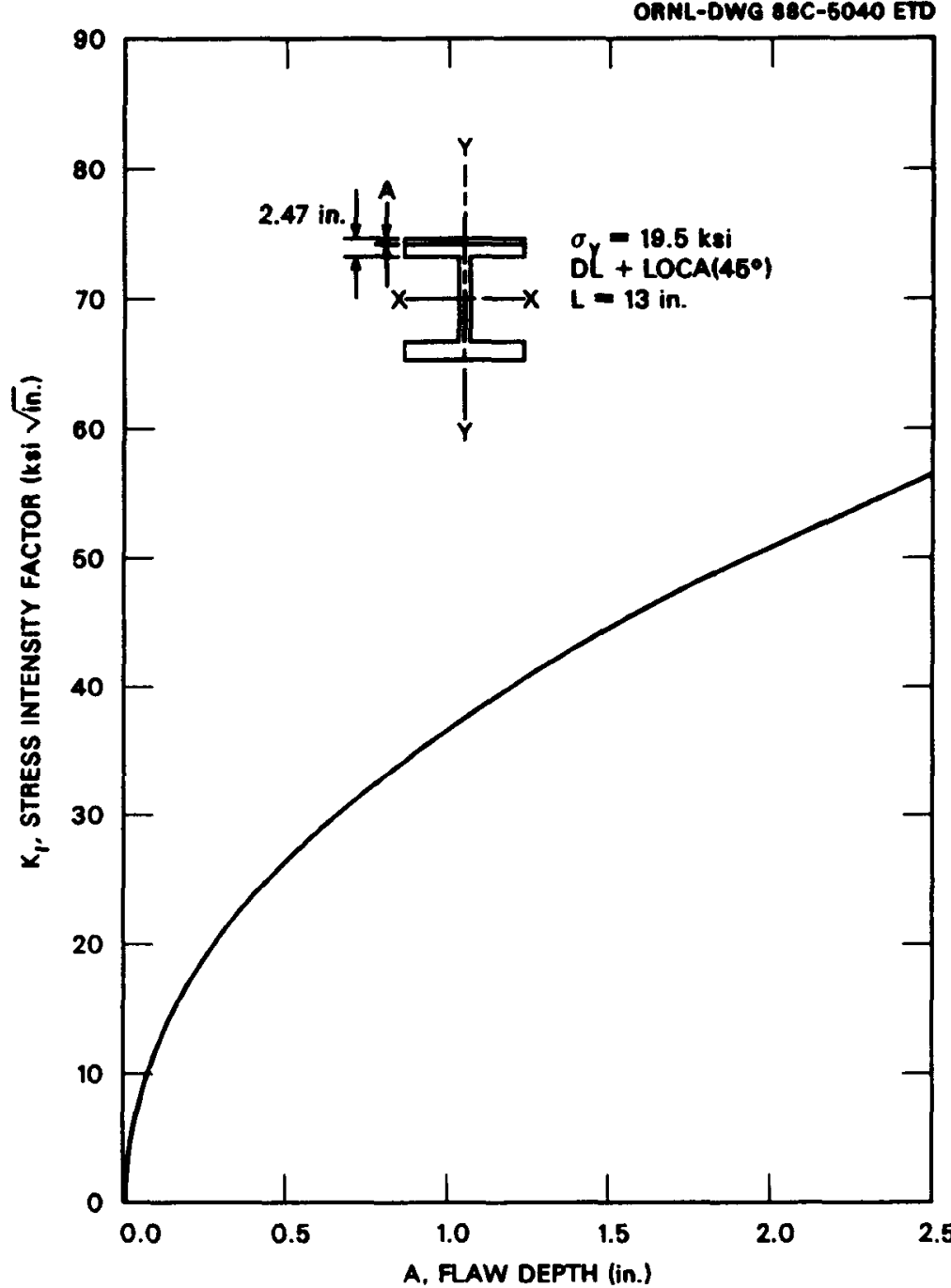

노

Fig. 7.25. Stress-intensity factor vs crack depth for cantilever beam with SEN flaw on top surface (case 6B). 


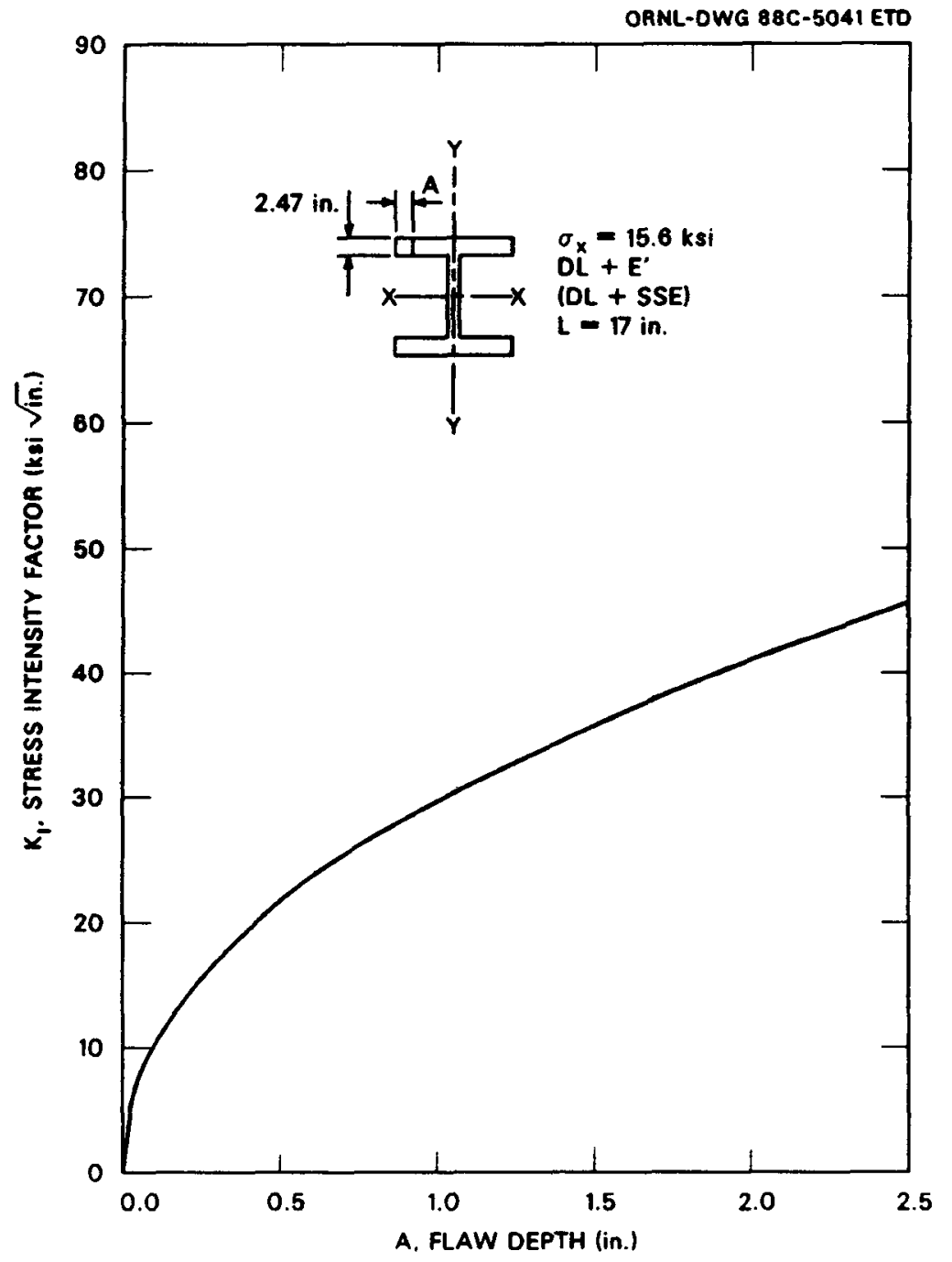

Fig. 7.26. Stress-intensity factor vs crack depth for cantilever beam with SEN flaw on edge (case 3A).

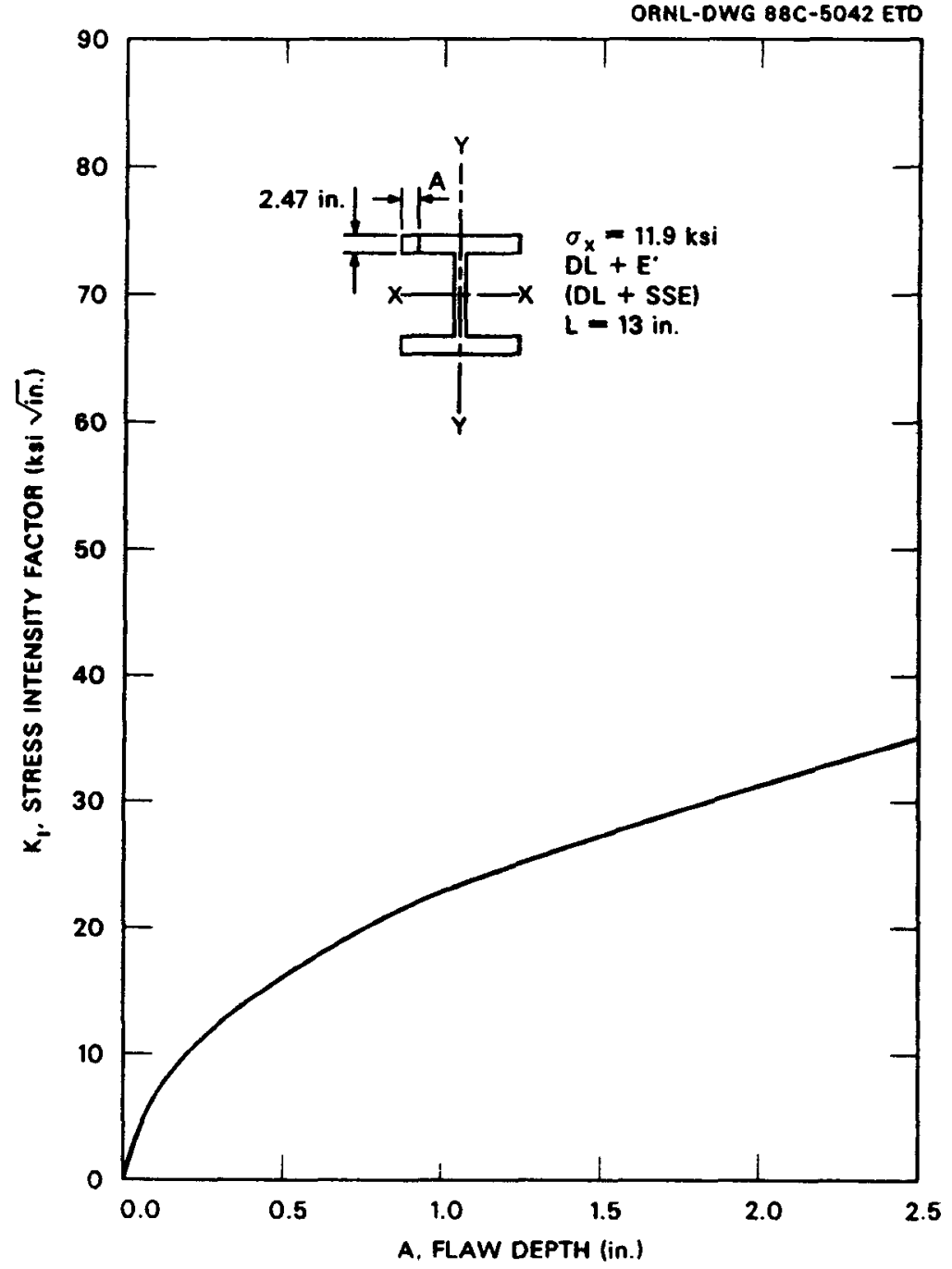

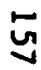

Fig. 7.27. Stress-intensity factor vs crack depth for cantilever beam with SEN flaw on edge (case 3B). 


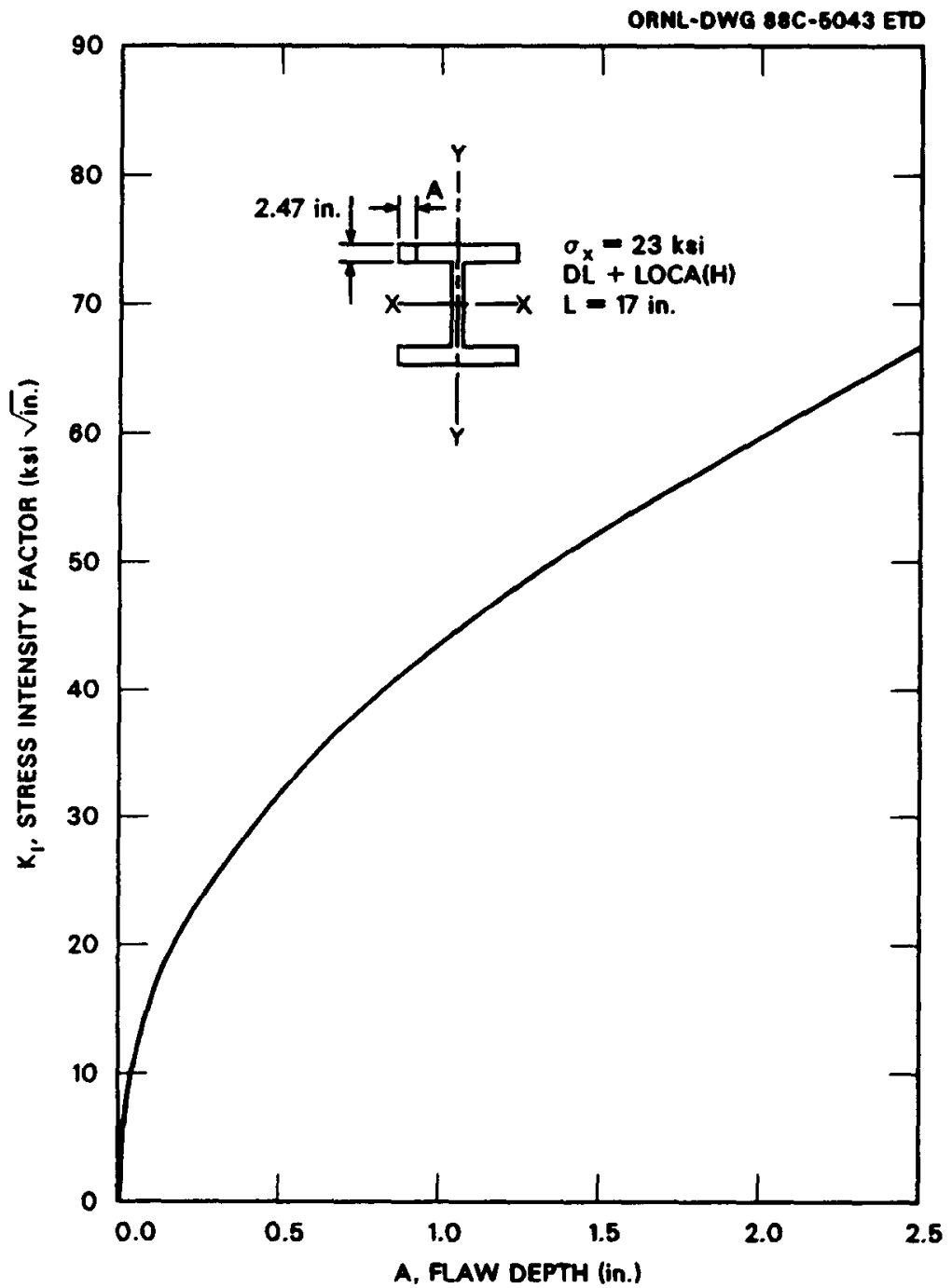

Fig. 7.28. Stress-intensity factor vs crack depth for cantilever beam with SEN flaw on edge (case 5A).

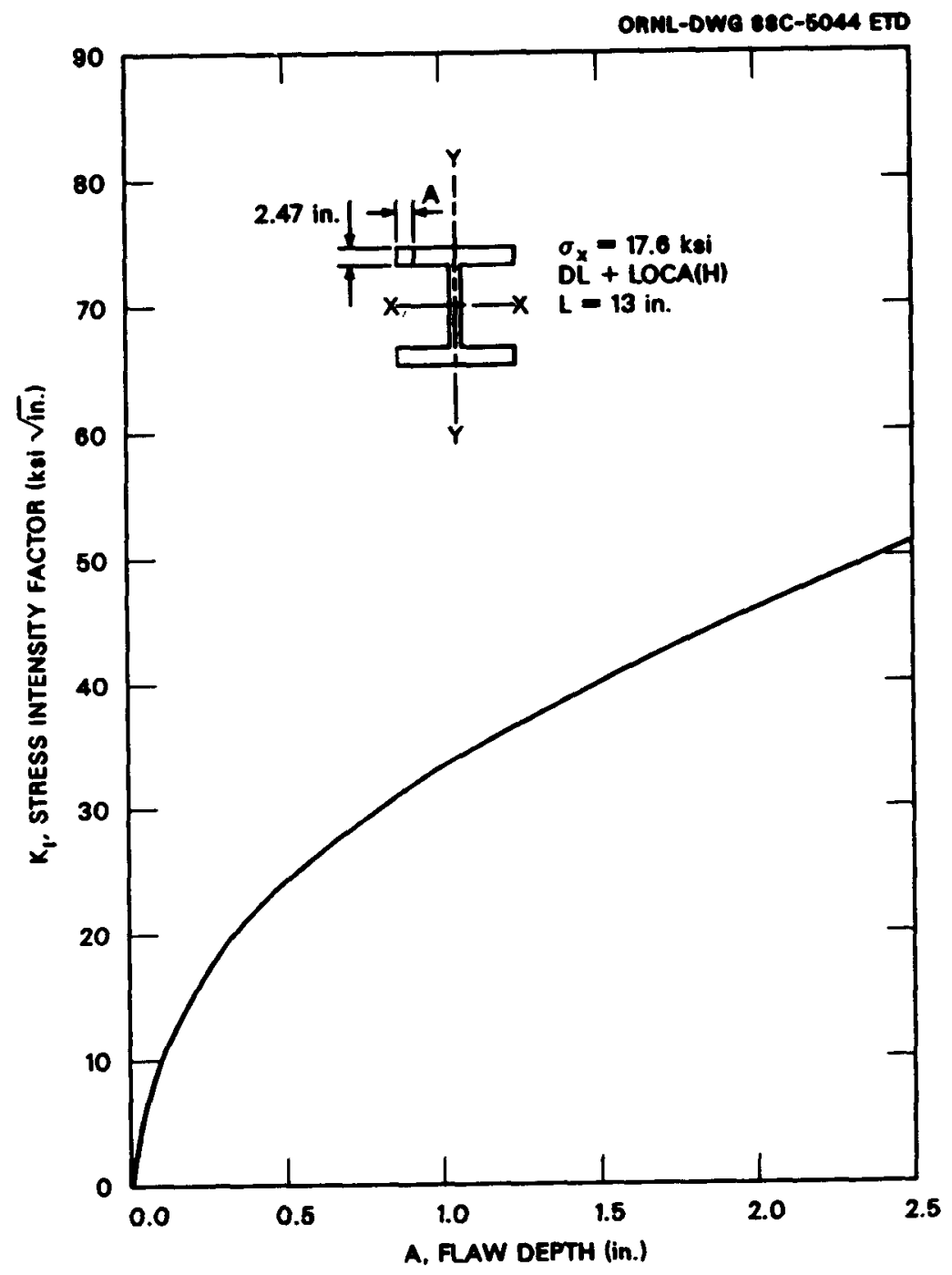

Fig. 7.29. Stress-intensity factor vs crack depth for cantilever beam with SEN flaw on edge (case 5B). 
ONNL-DWG 88C-6046 ETO

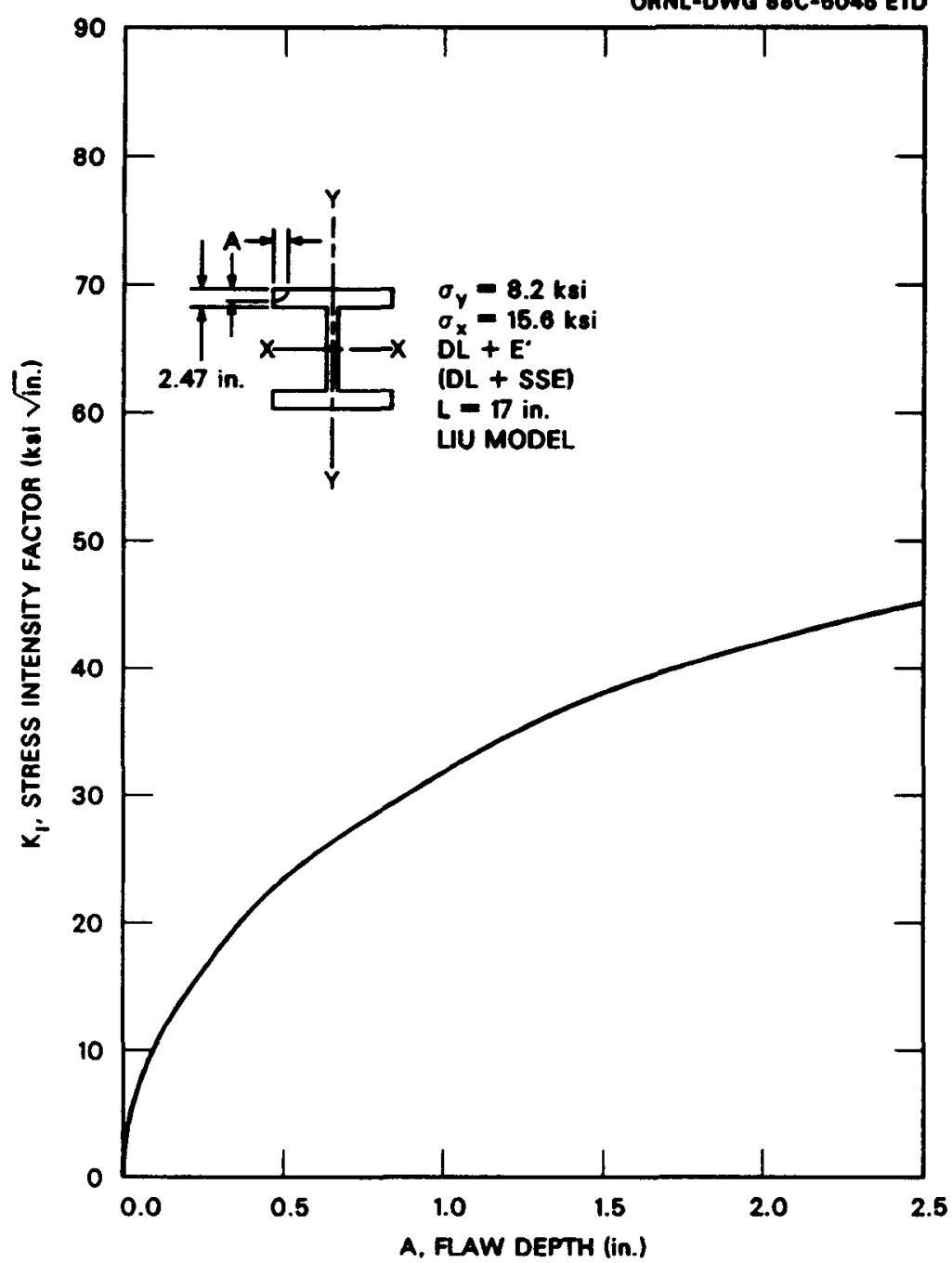

Fig. 7.30. Stress-intensity factor vs crack depth for cantilever beam with corner crack (case 3A, Liu model).

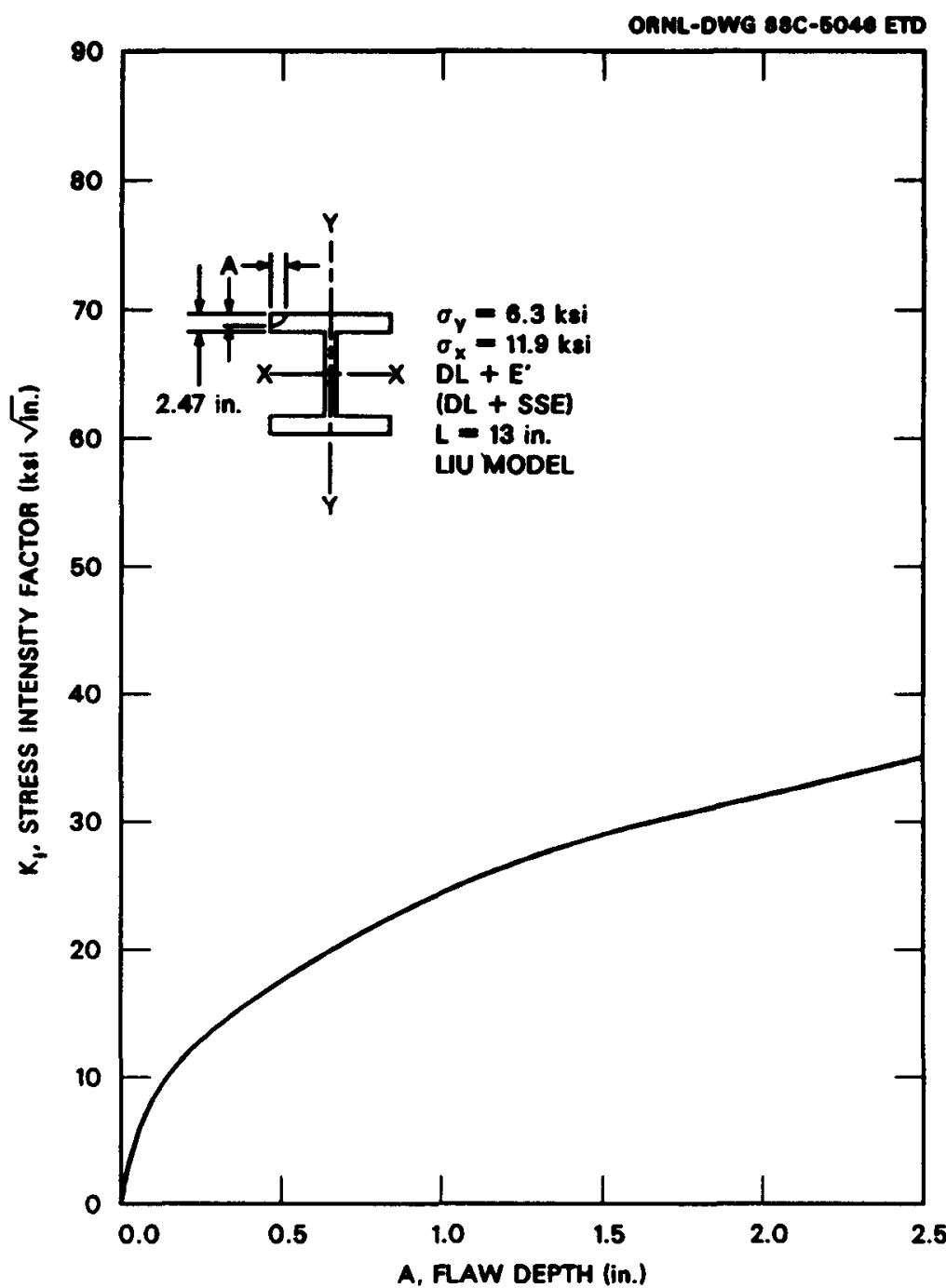

Fig. 7.31. Stress-intensity factor vs crack depth for cantilever beam with corner crack (case 3B, Liu model). 


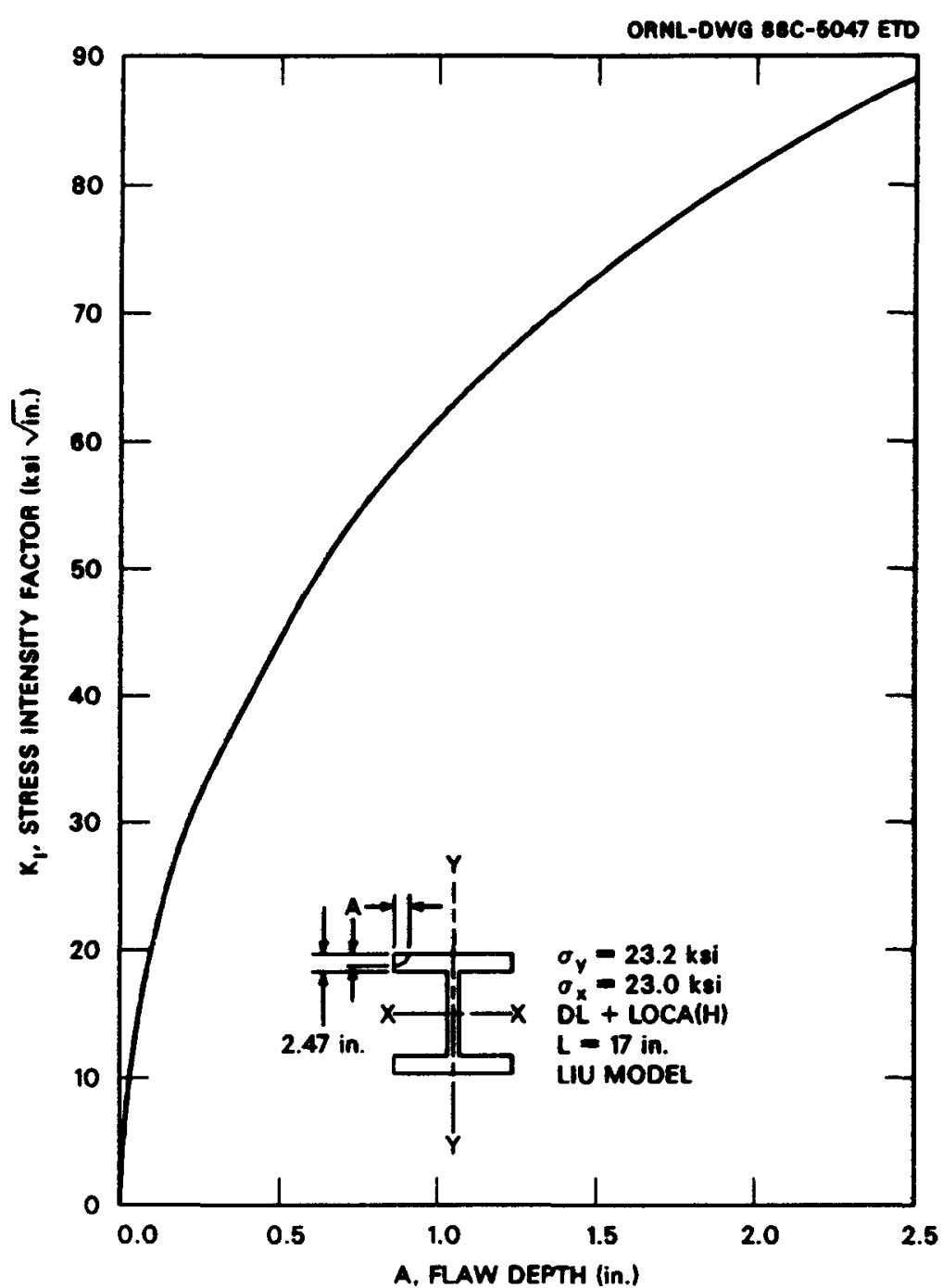

Fig. 7.32. Stress-intensity factor vs crack depth for cantilever beam with corner crack (case 5A, Liu model).

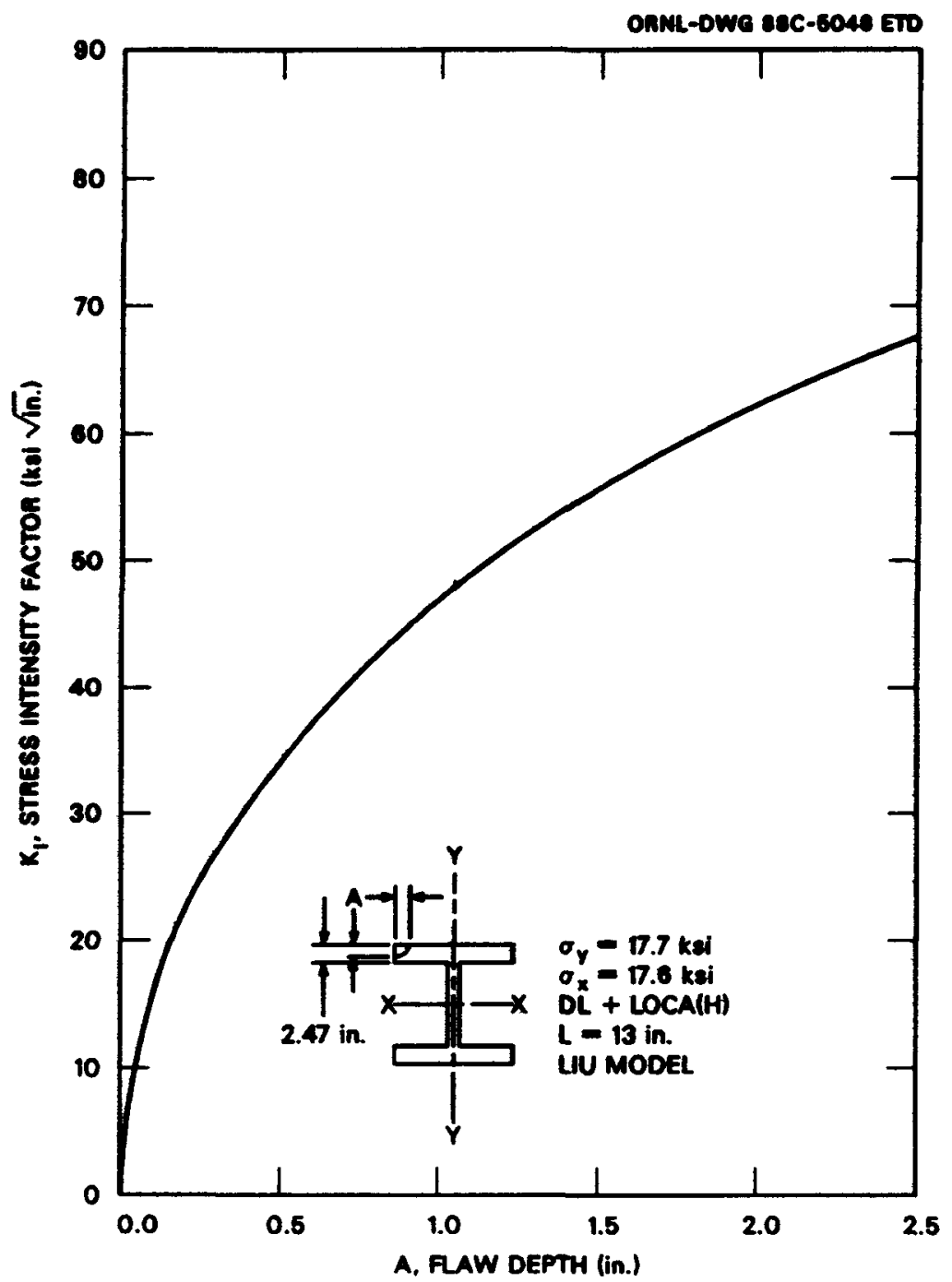

$\check{g}$

Fig. 7.33. Stress-intensity factor vs crack depth for cantilever beam with corner crack (case 5B, Liu model). 


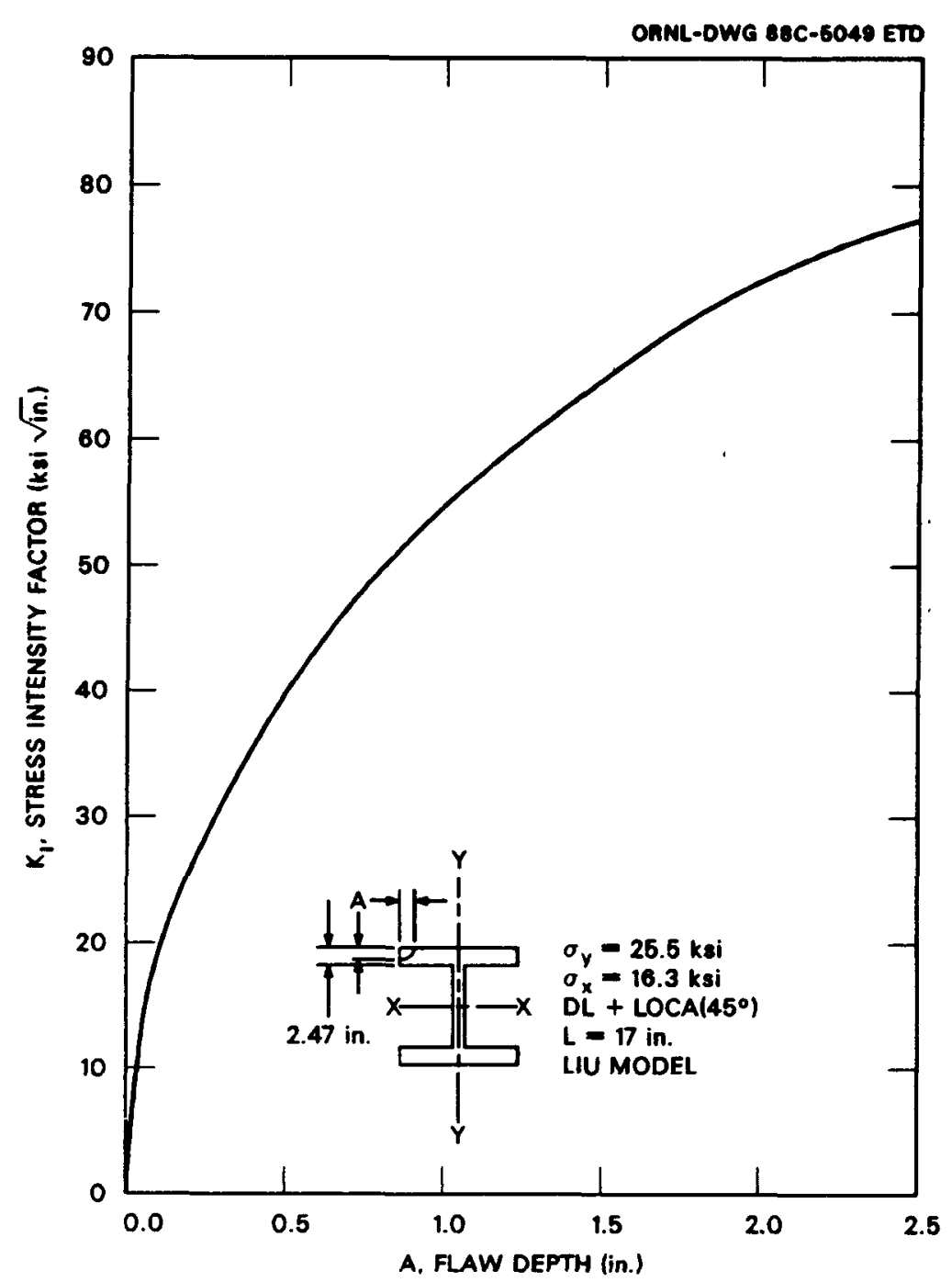

Fig. 7.34. Stress-intensity factor vs crack depth for cantilever beam with corner crack (case $6 \mathrm{~A}$, Liu model).

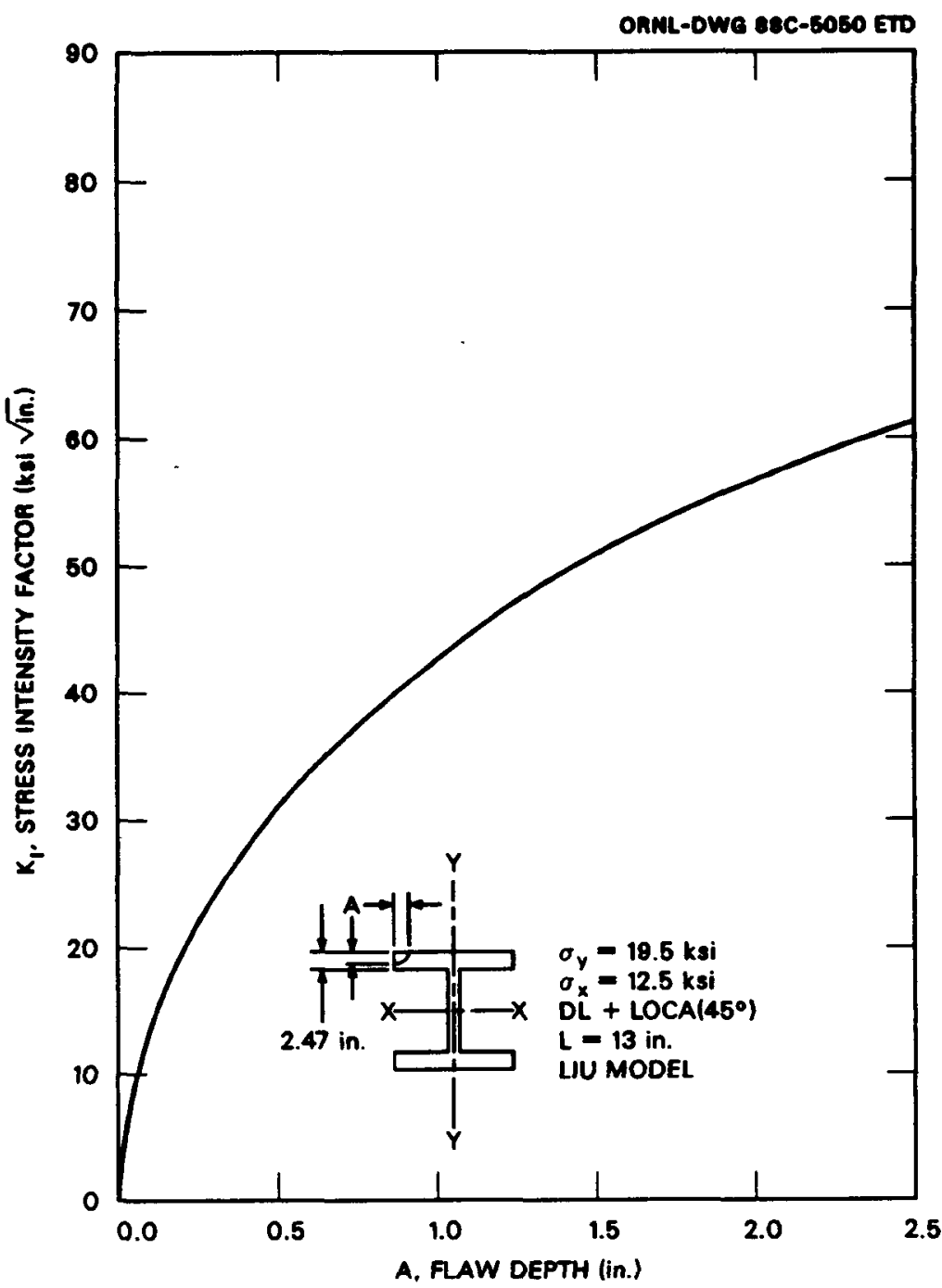

5

Fig. 7.35. Stress-intensity factor vs crack depth for cantilever beam with corner crack (case 6B, Liu model). 


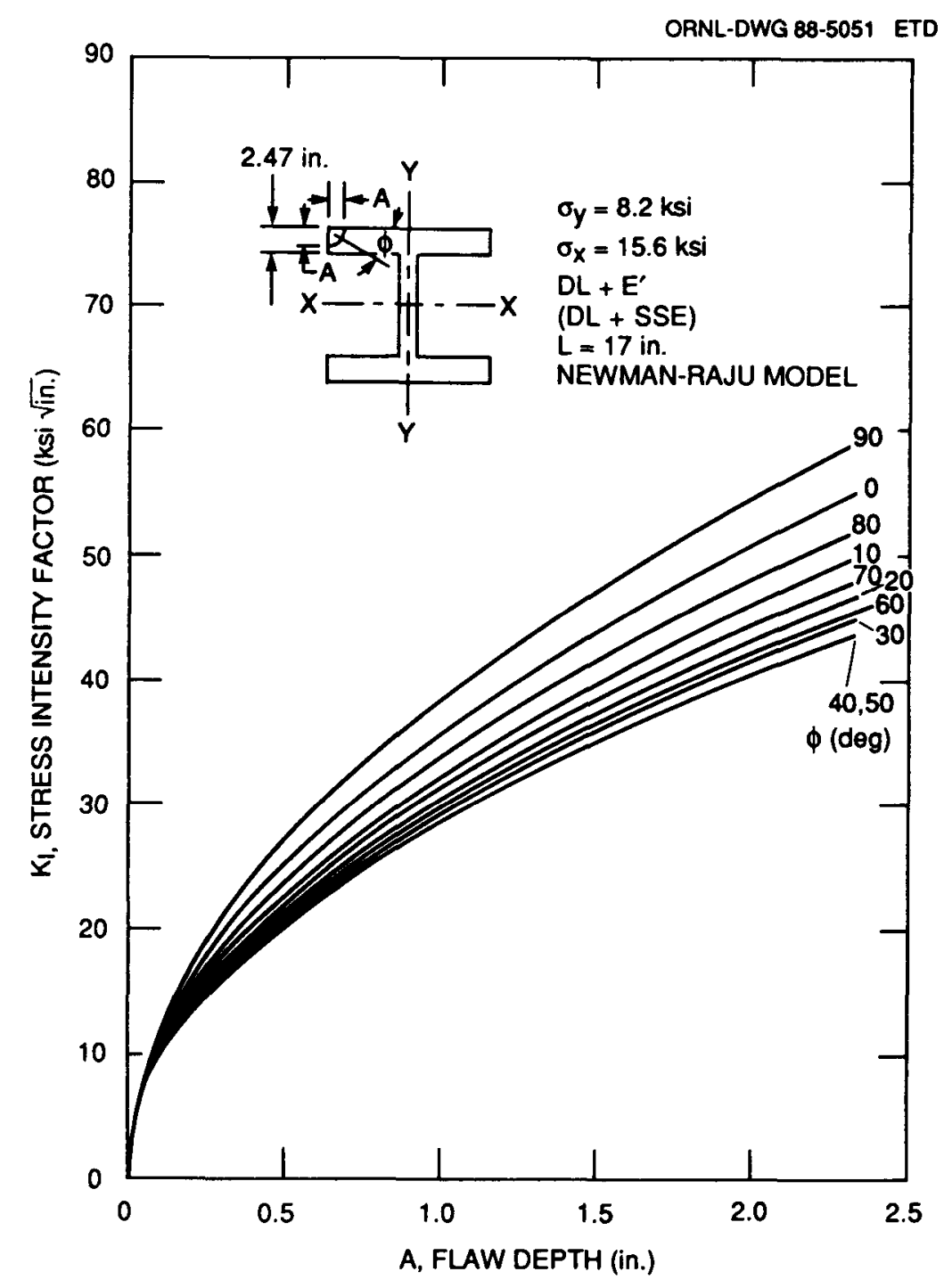

Fig. 7.36. Stress-intensity factor vs crack depth for cantilever beam with corner crack (case $3 A$, Newman-Raju model).

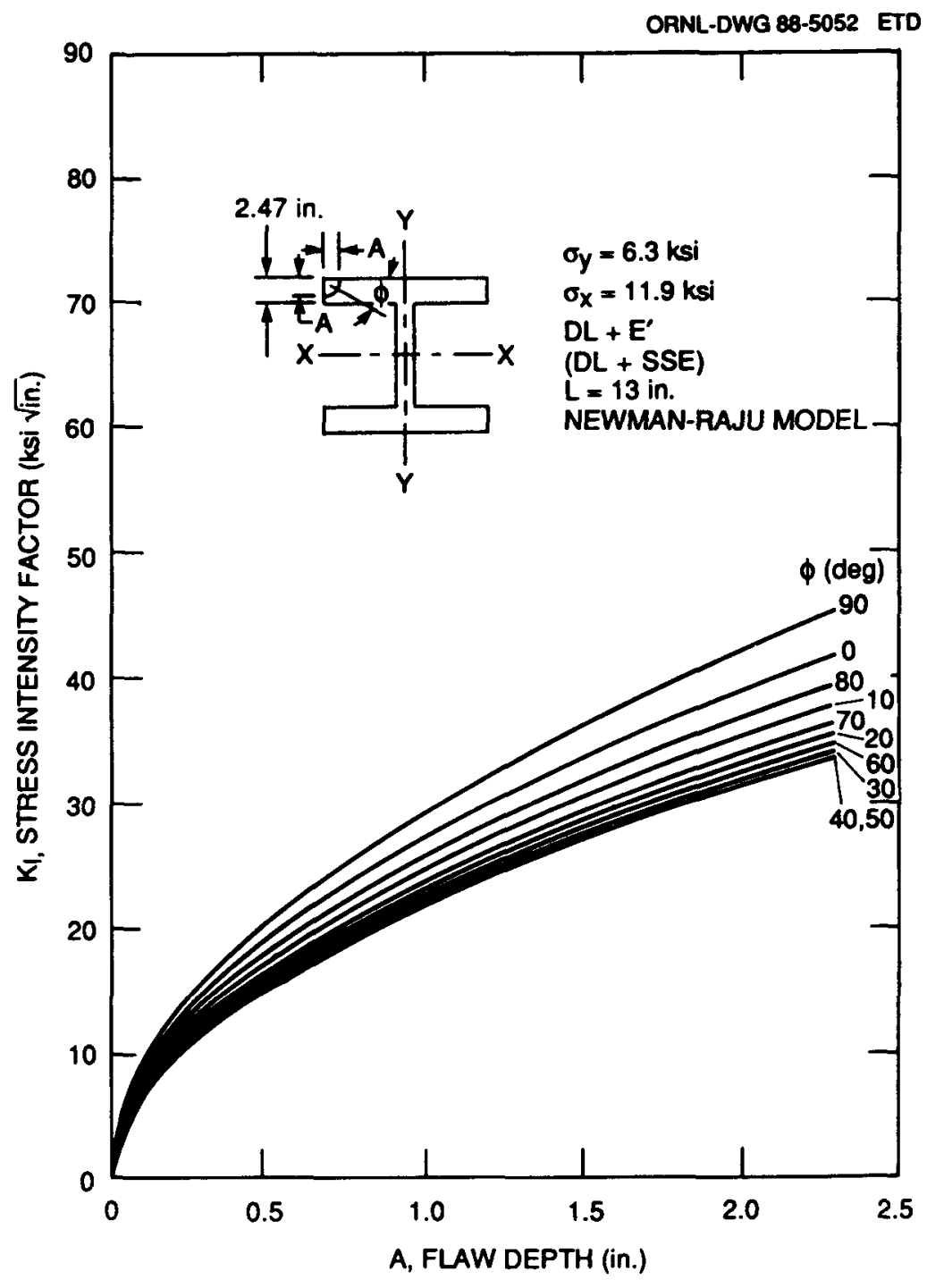

Fig. 7.37. Stress-intensity factor vs crack depth for cantilever beam with corner crack (case 3B, Newman-Ra ju model). 


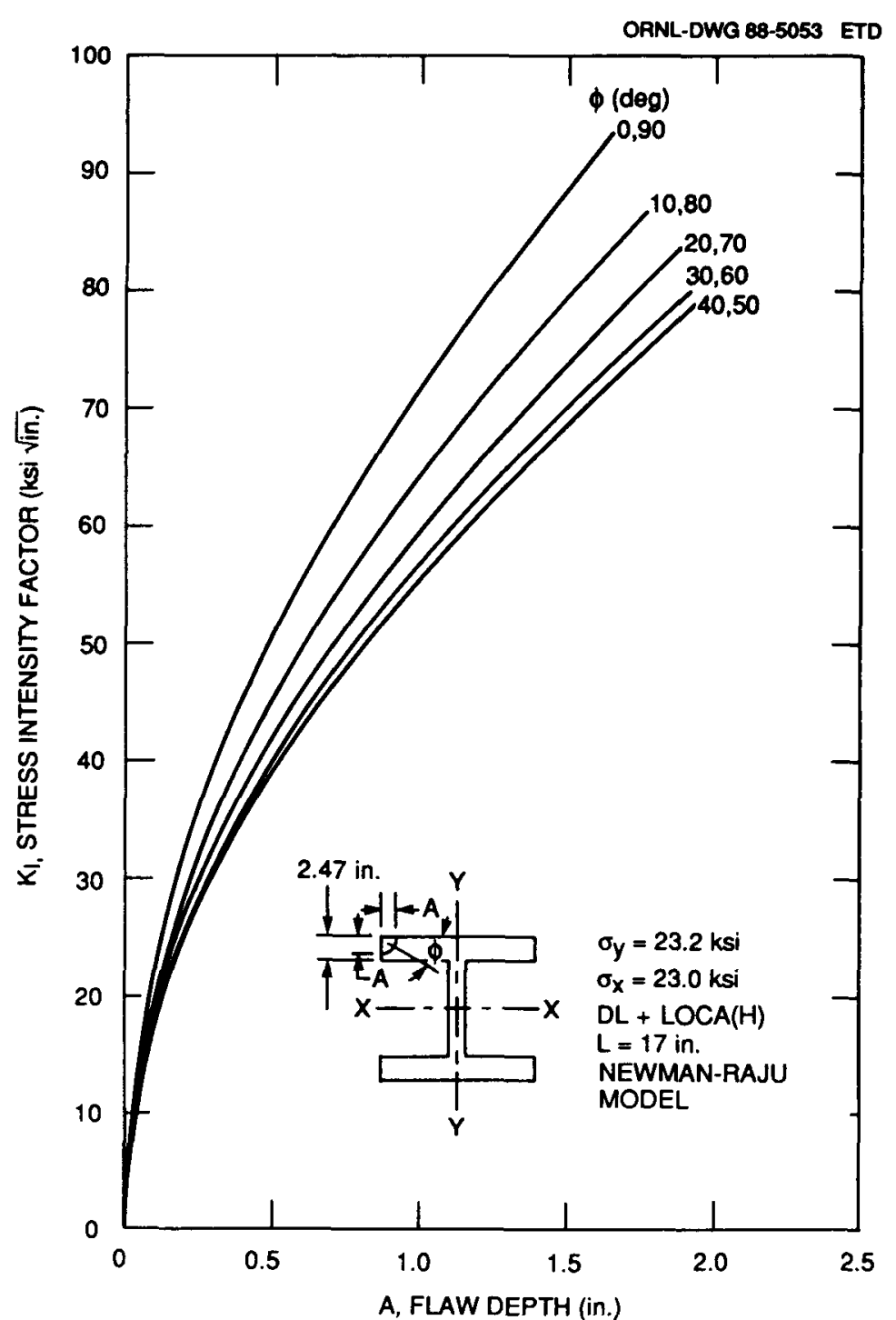

Fig. 7.38. Stress-intensity factor vs crack depth for cantilever beam with corner crack (case $5 A$, Newman-Ra ju model ).

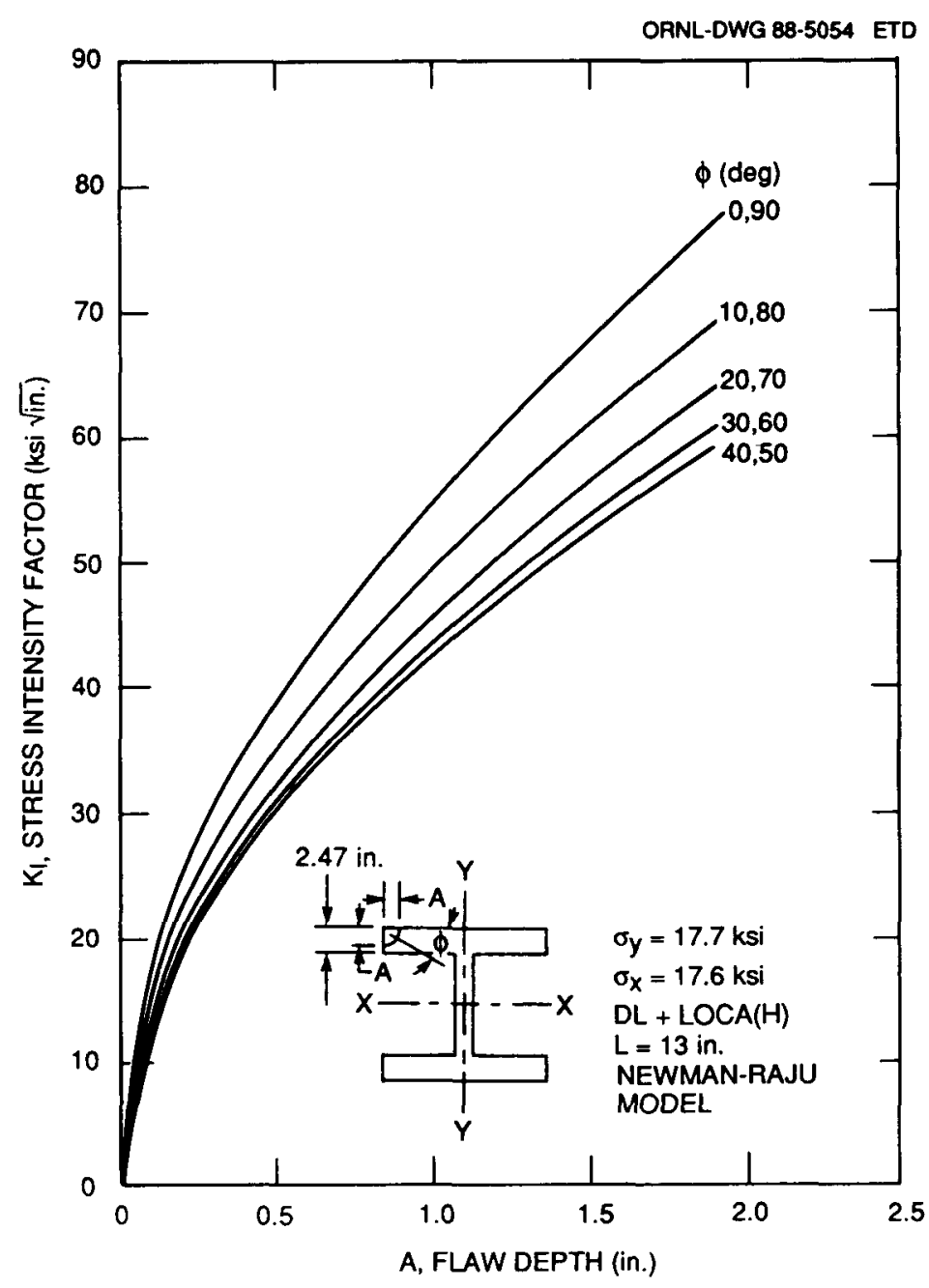

灾
Fig. 7.39. Stress-intensity factor vs crack depth for cantilever beam with corner crack (case 5B, Newman-Ra ju model). 


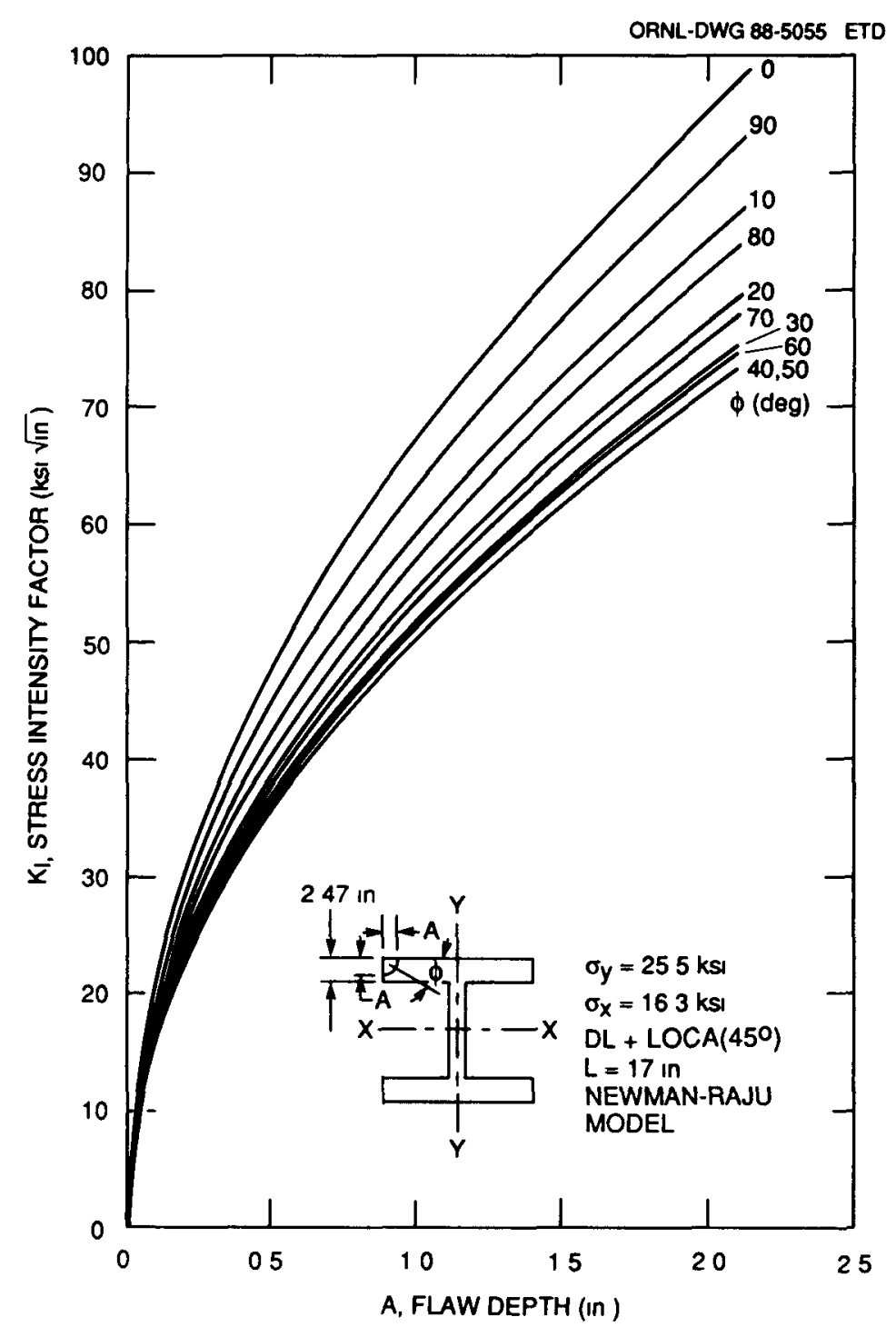

Fig. 7.40. Stress-intensity factor vs crack depth for cantilever beam with corner crack (case $6 \mathrm{~A}$, Newman-Ra ju model).

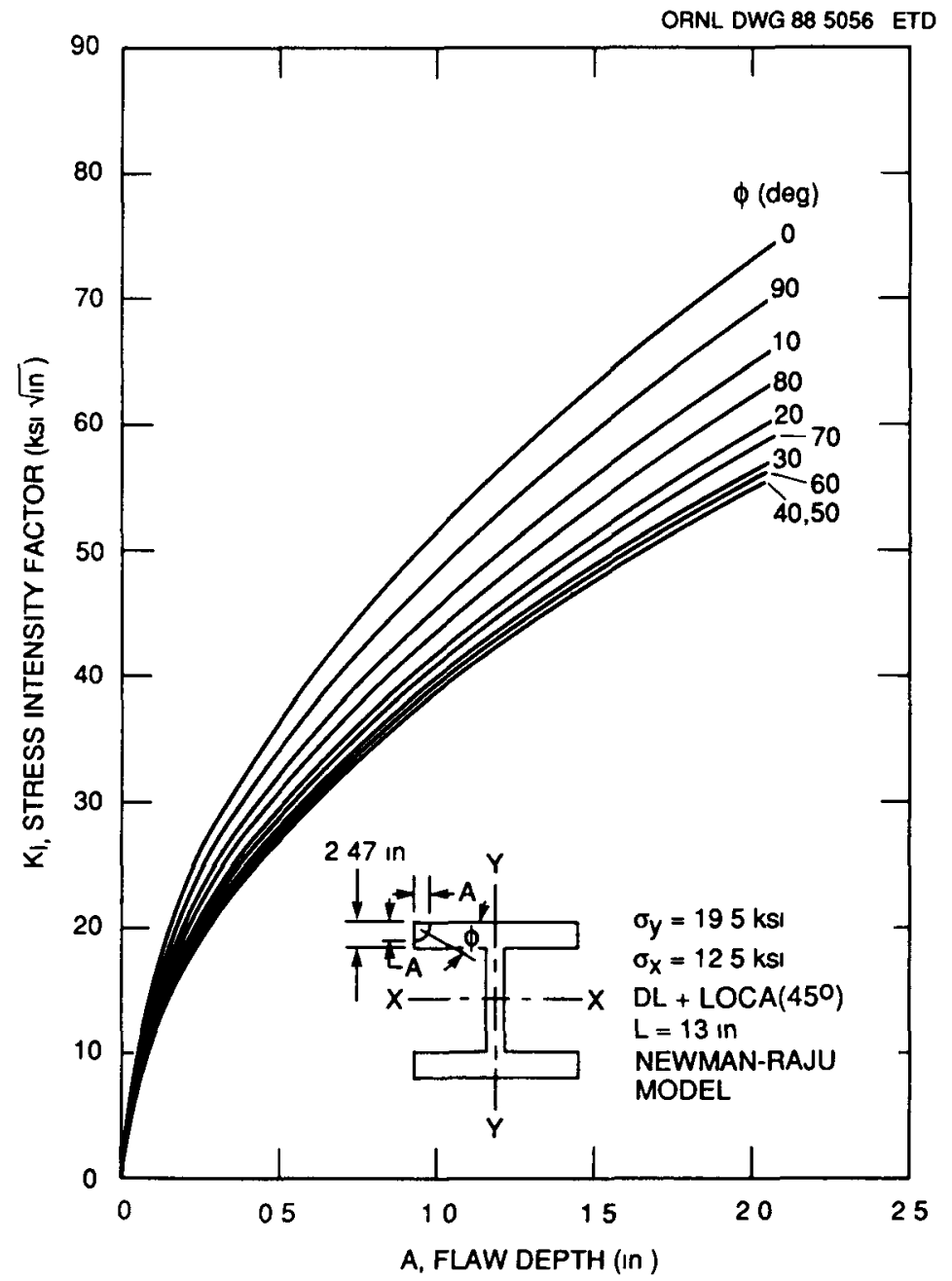

F

Fig. 7.41. Stress-intensity factor vs crack depth for cantilever beam with corner crack (case 6B, Newman-Raju model). 


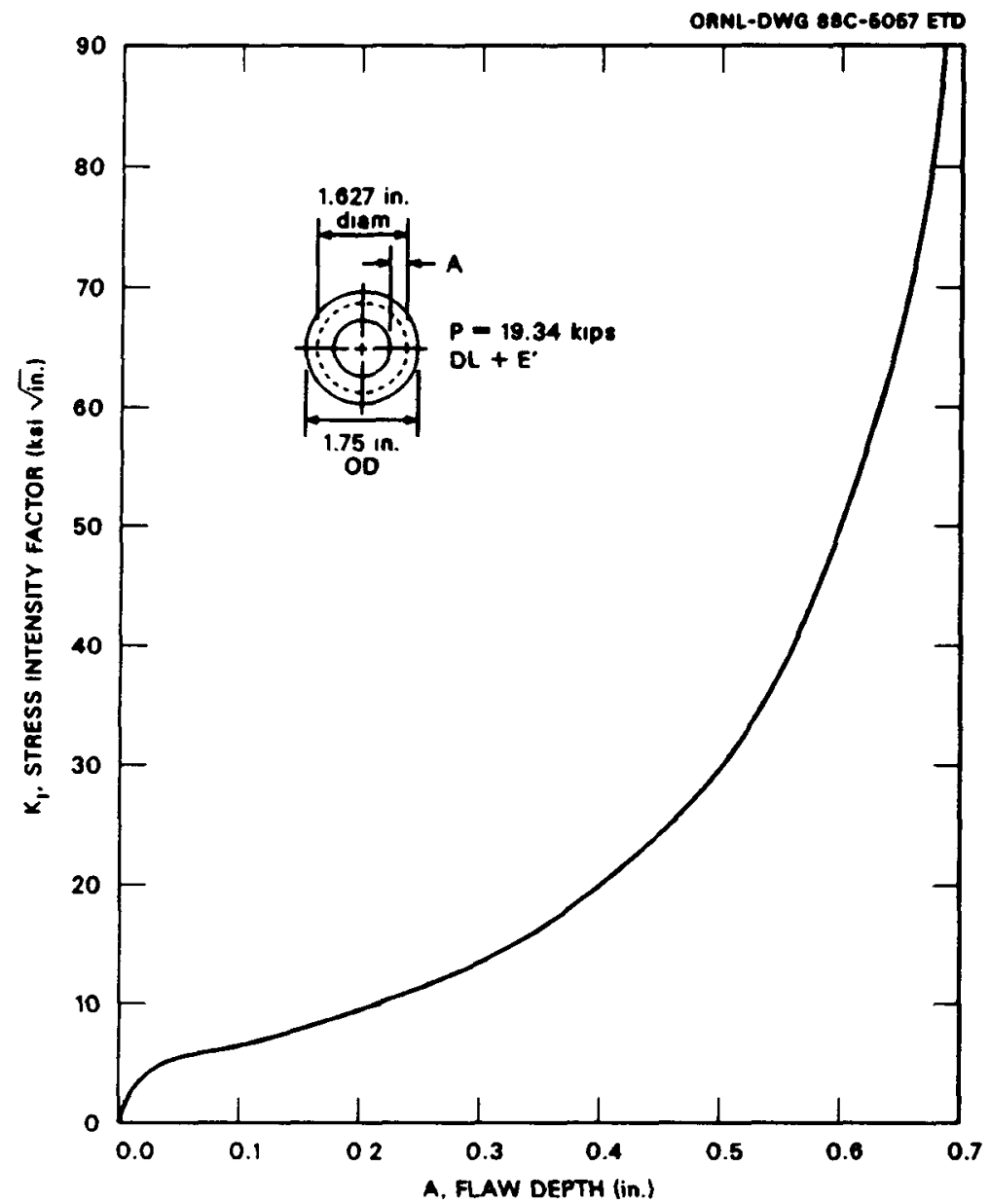

Fig. 7.42. Stress-intensity factor vs crack depth for girder-to-cantilever-beam bolt circumferential flaw (case $3 \mathrm{~A}$ ).

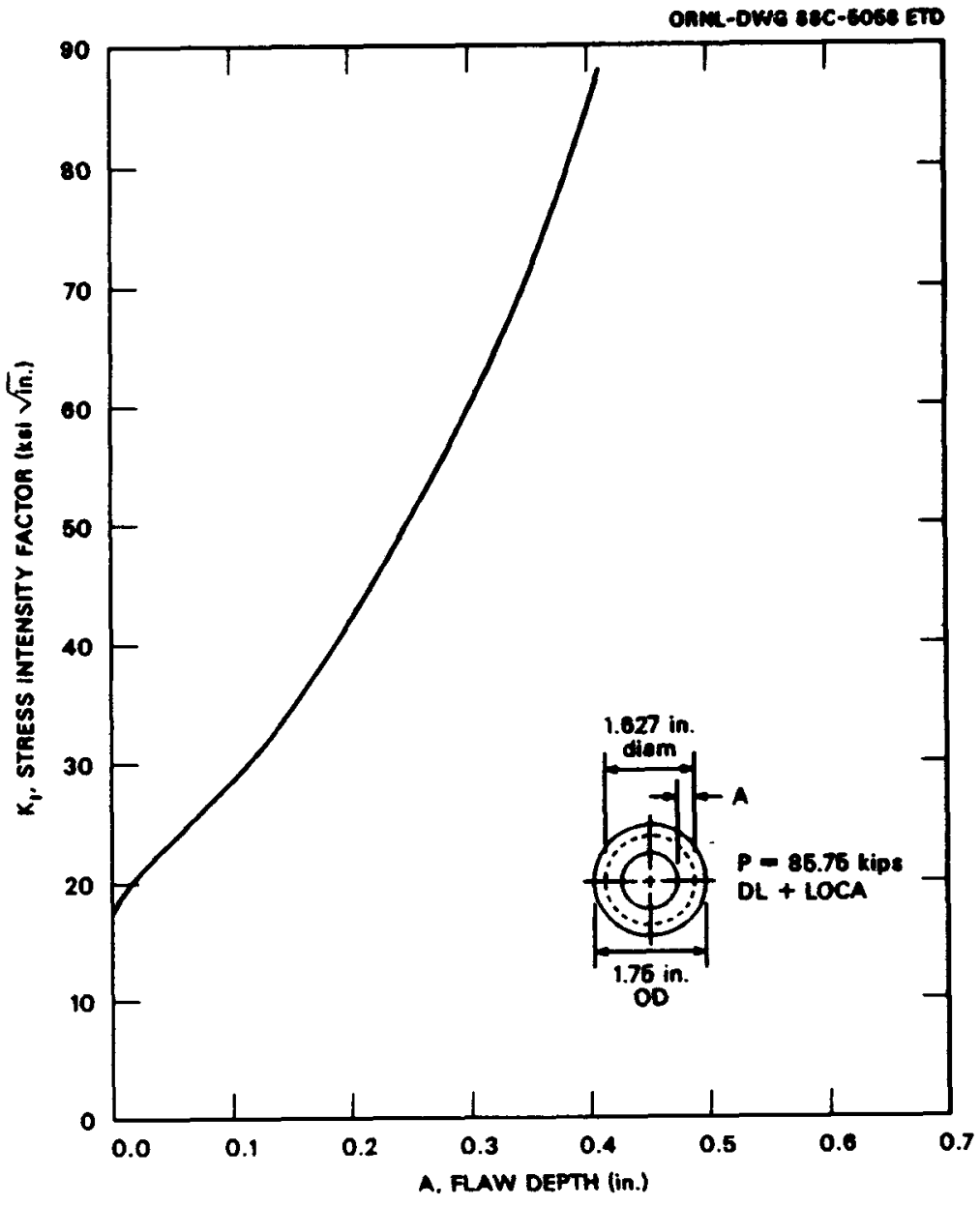

Fig. 7.43. Stress-intensity factor vs crack depth for girder-to-cantilever-beam bolt circumferential flaw (case $5 \mathrm{~A}$ ). 
as indicated, the agreement between the two methods is good. A similar calculation of stress-intensity factor for an assumed pretightening load of the bolts is shown in Fig. 7.44 .

As previously noted, the method developed by Merkle was used to evaluate the stress-intensity factor for assumed semielliptical flaws in the lateral restraint; results are shown in Figs. 7.45 and 7.46 .

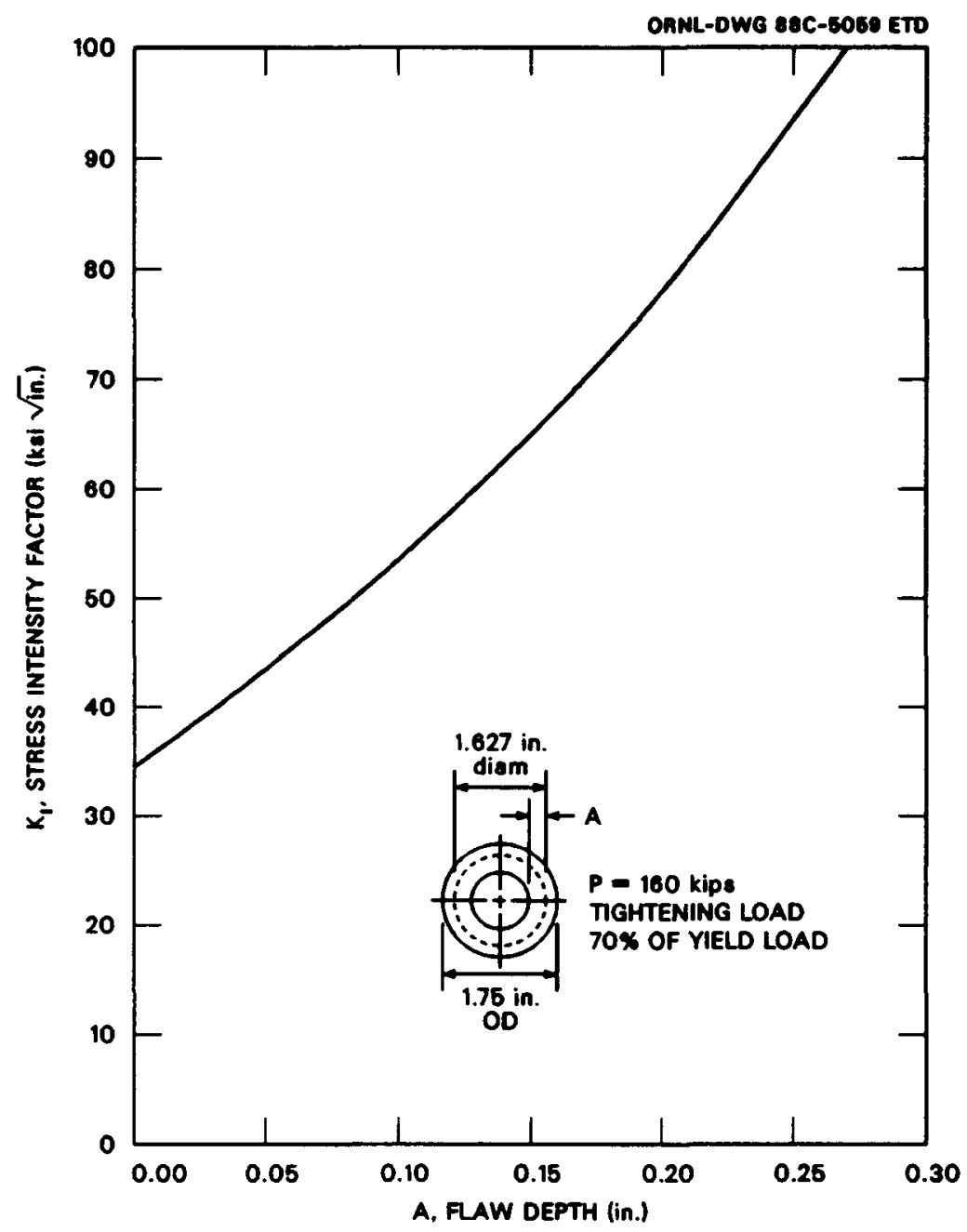

Fig. 7.44. Stress-intensity factor vs crack depth for girder-tocantilever-beam bolt with circumferential flaw for assumed tightening load.

\subsection{Discussion of Results and Conclusions}

Using the definition of the fracture-toughness temperature parameter ( $T$ - NDTT) developed in Sect. 7.4 as a Gaussian distribution with the values for $\triangle$ NDTT taken from Table 7.3 , Table 7.6 provides a summary of $T$ - NDTT as a function of method of extrapolation of $\triangle$ NDTT, Gaussian 


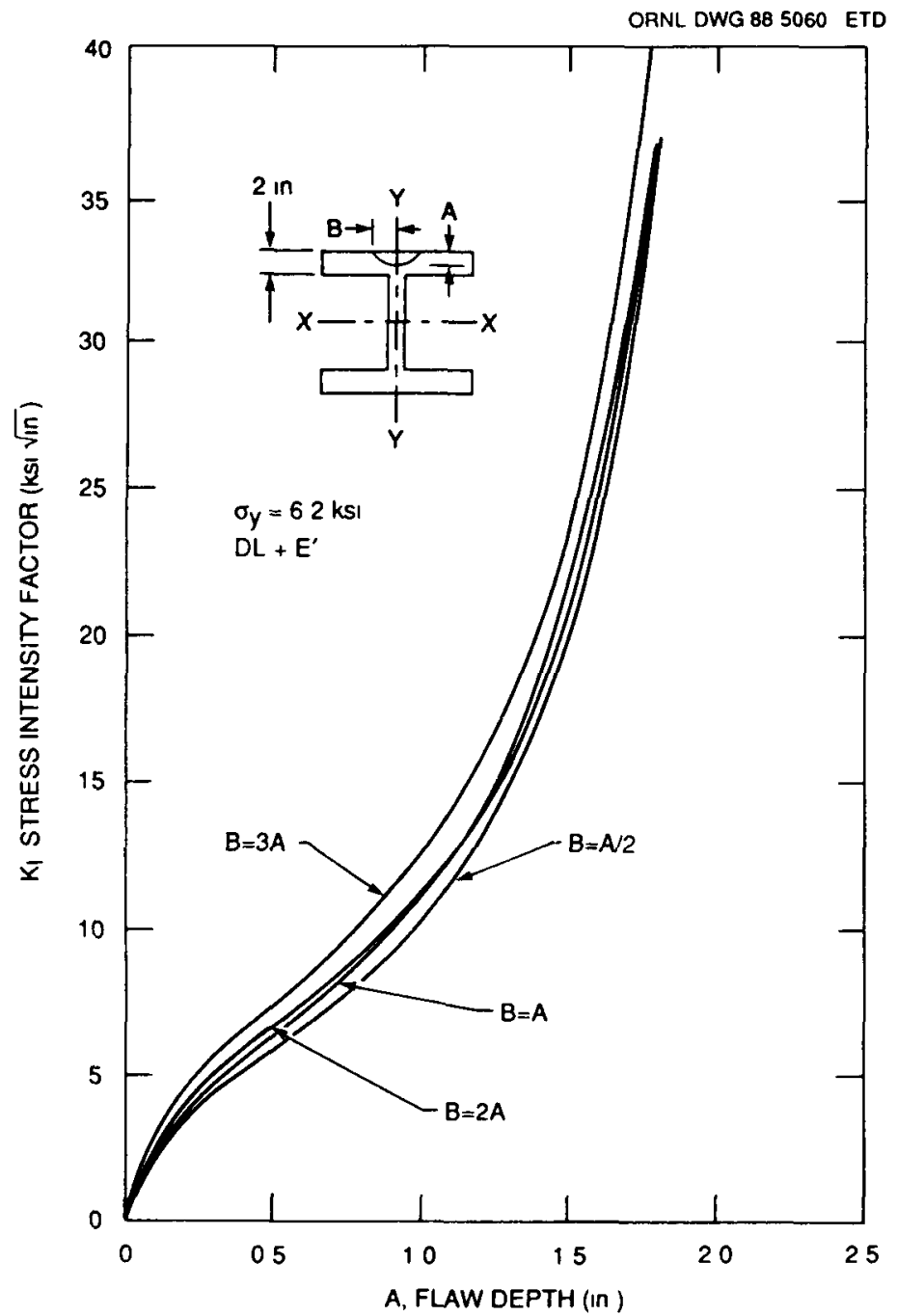

Fig. 7.45. Stress-intensity factor vs crack depth for lateral restraint with semielliptical surface flaw (case $3 A$ ).

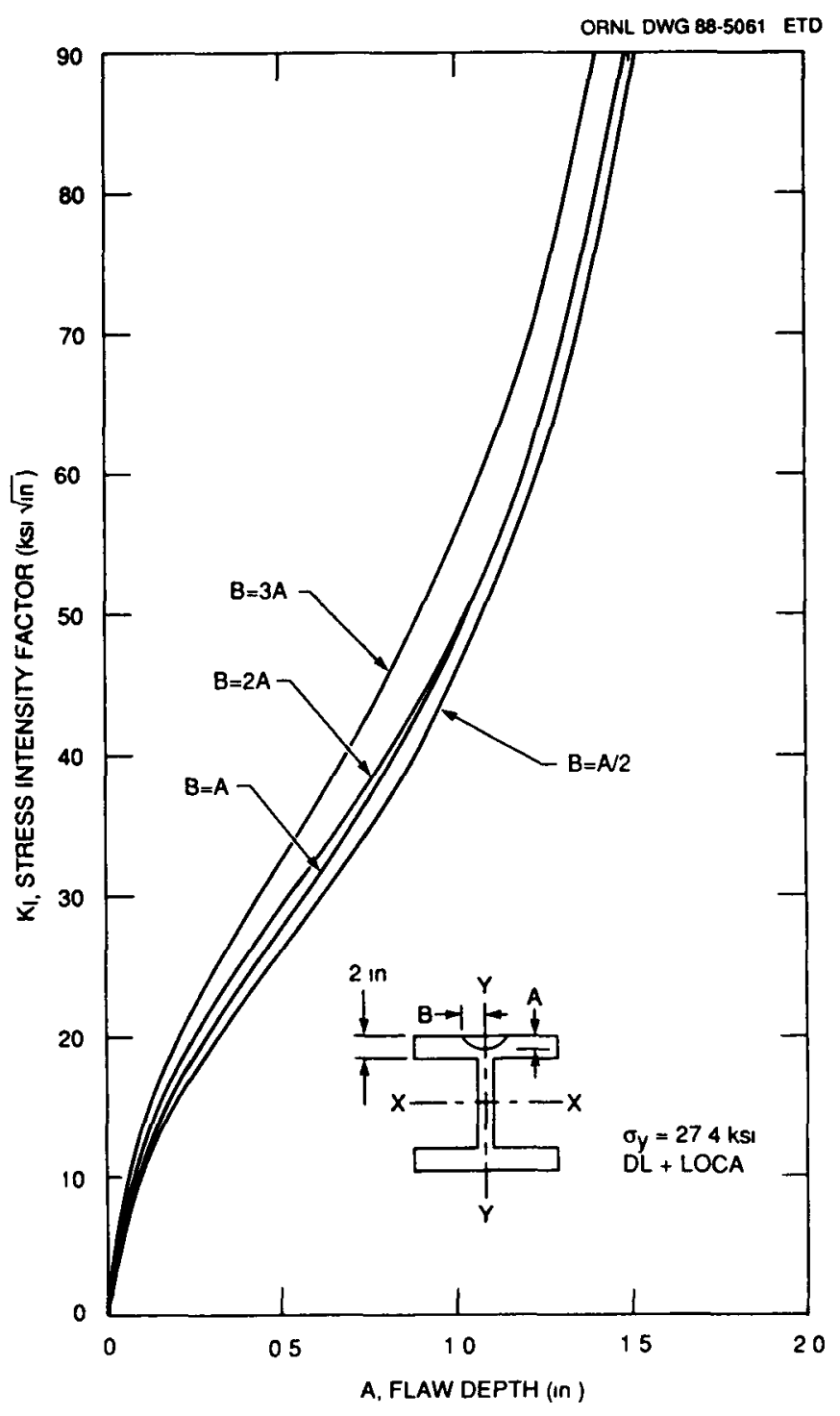

Fig. 7.46. Stress-intensity factor vs crack depth for lateral restraint with semielliptical surface flaw (case $5 \mathrm{~A}$ ). 
Table 7.6. Summary of ( $T$ - NDTT) as a function of Gaussian point and service life for each component

\begin{tabular}{|c|c|c|c|c|c|c|c|c|c|c|}
\hline \multirow{3}{*}{ Component } & \multicolumn{10}{|c|}{$\mathrm{T}-\operatorname{NDTT}\left({ }^{\circ} F\right)$} \\
\hline & \multicolumn{5}{|c|}{$\begin{array}{l}\text { Method A } \triangle \text { NDTT } \\
\text { (Gaussian point) }\end{array}$} & \multicolumn{5}{|c|}{$\begin{array}{l}\text { Method B } \triangle N D T T \\
\text { (Gaussian point) }\end{array}$} \\
\hline & $-3 \sigma$ & $-1 \sigma$ & Mean & 10 & $3 \sigma$ & -30 & $-1 \sigma$ & 'Yean & 10 & $3 \sigma$ \\
\hline \multicolumn{11}{|c|}{$0.0 E F P Y$} \\
\hline $\begin{array}{l}\text { Cantilever beam } \\
\text { Point } 9, L=13 \mathrm{in.}\end{array}$ & -30 & -4.8 & 50 & 104.8 & 130 & -30 & $-4 \cdot 8$ & 50 & 104.8 & 130 \\
\hline $\begin{array}{l}\text { Cantllever beam } \\
\text { Point } 10, \mathrm{~L}=17 \text { in. }\end{array}$ & -22 & 3.2 & 58 & 112.8 & 138 & -22 & $3 . ?$ & 58 & 112.8 & 138 \\
\hline $\begin{array}{l}\text { Girder-to-cantilever- } \\
\text { beam bolt Point } 4\end{array}$ & -40 & -14.8 & 40 & 94.8 & 120 & -40 & -14.8 & 40 & 94.8 & 120 \\
\hline $\begin{array}{l}\text { Lateral restraint } \\
\text { Point } 8\end{array}$ & 230 & 245.8 & 280 & 314.2 & 330 & 230 & 245.8 & 280 & 314.2 & 330 \\
\hline \multicolumn{11}{|c|}{7.04 EFPY } \\
\hline $\begin{array}{l}\text { Cantilever beam } \\
\text { Point } 9, L=13 \mathrm{in} \text {. }\end{array}$ & -30 & -4.8 & 50 & 104.8 & 130 & -60 & -34.8 & 20 & 74.8 & 100 \\
\hline $\begin{array}{l}\text { Cantilever beam } \\
\text { Point } 10, L=17 \text { in. }\end{array}$ & -22 & 3.2 & 58 & 112.8 & 138 & -42 & 16.8 & 38 & 92.8 & 118 \\
\hline $\begin{array}{l}\text { Girder-to-cantilever- } \\
\text { beam bolt Point } 4\end{array}$ & -40 & -14.8 & 40 & 94.8 & 120 & -85 & -59.8 & -5 & 49.8 & 75 \\
\hline $\begin{array}{l}\text { Lateral restraint } \\
\text { Point } 8\end{array}$ & 230 & 245.8 & 280 & 314.2 & 330 & 230 & 241 & 265 & 289 & 300 \\
\hline \multicolumn{11}{|c|}{$11.79 E P P Y$} \\
\hline $\begin{array}{l}\text { Cantilever beam } \\
\text { Point } 9, L=13 \text { in. }\end{array}$ & -30 & -4.8 & 50 & 104.8 & 130 & -70 & -44.8 & 10 & 64.8 & 90 \\
\hline $\begin{array}{l}\text { Cantilever beam } \\
\text { Point } 10, L=17 \text { in. }\end{array}$ & -22 & 3.2 & 58 & 112.8 & 138 & -52 & 26.8 & 28 & 82.8 & 108 \\
\hline $\begin{array}{l}\text { Girder-to-cantilever- } \\
\text { beam bolt Point } 4\end{array}$ & -80 & $-54 \cdot 8$ & 0 & 54.8 & 80 & -105 & -79.8 & -25 & 29.8 & 55 \\
\hline $\begin{array}{l}\text { Lateral restraint } \\
\text { Point } 8\end{array}$ & 200 & 215.8 & 250 & 284.2 & 300 & 190 & 205.8 & 240 & 274.2 & 290 \\
\hline \multicolumn{11}{|c|}{32 EPPY } \\
\hline $\begin{array}{l}\text { Cantilever beam } \\
\text { Point } 9, L=13 \mathrm{in} \text {. }\end{array}$ & -160 & -134.8 & -80 & -25.2 & 0 & -105 & -79.8 & -25 & 29.8 & 55 \\
\hline $\begin{array}{l}\text { Cantilever beam } \\
\text { Point } 10, L=17 \mathrm{in} .\end{array}$ & -52 & -26.8 & 28 & 82.8 & 108 & -77 & -51.8 & 3 & 57.8 & 83 \\
\hline $\begin{array}{l}\text { Girder-to-cantilever- } \\
\text { beam bolt Point } 4\end{array}$ & -110 & -84.8 & -30 & 24.8 & 50 & -115 & -89.8 & -35 & 19.8 & 45 \\
\hline $\begin{array}{l}\text { Lateral restraint } \\
\text { Point } 8\end{array}$ & 100 & 115.8 & 150 & 184.2 & 200 & 150 & 165.8 & 200 & 234.2 & 250 \\
\hline
\end{tabular}


point, and service 1 ife at $0,7.04,11.79$, and 32 EFPY for each of the locations being evaluated for each of the structural components. Table 7.7 was developed from Table 7.6 by reading the value of toughness, $K_{I c}$ or $K_{I R}$, from Fig. 7.13 for each value of $T$ - NDTT.

Equating $\mathrm{K}_{I c}$ or $\mathrm{K}_{\mathrm{IR}}$, given in Table 7.7, to $\mathrm{K}_{\mathrm{I}}$ in Figs. $7.18-7.46$ permits an estimate of the critical flaw size for the various parameters considered in Table 7.7. Following this procedure, Table 7.8 provides a summary of the estimated critical flaw sizes for the cantilever beam for semicircular, 6:1-semielliptical surface, SEN top-surface, SEN edge, and corner quarter-circular flaws, both methods of extrapolation of $\triangle N D T T$, evaluation per ASME $K_{I c}$ and $K_{I R}$ and for each loading condition of interest, as a function of the Gaussian point stress-intensity factor temperature parameter and as a function of service 1 ife.

The significant points to be noted about Table 7.8 are the following:

1. The calculated mean value of flaw size represents the best estimate.

2. In every loading case involving both horizontal and vertical loading, the critical corner crack is the smallest of the various types and consequently the type of greatest concern.

3. The use of Method A vs Method B for extrapolation of $\triangle$ NDTT data does not lead to significantly different results for this evaluation.

4. Very little difference in critical flaw size exists between evaluations at the $L=17-i n$. vs $L=13-i n$. locations.

Table 7.9, a summary of the estimated critical flaw sizes for girder-to-cantilever-beam bolts, was developed in the same manner as Table 7.8. Variables considered in Table 7.8 include both methods of extrapolation of $\triangle$ NDTT, evaluation by ASME $K_{I c}$ and $K_{I R}$ curves, two loading cases, the assumed temperature-parameter Gaussian distribution, and service life. In general, the points made about Table 7.8 apply also to Table 7.9. The small best-estimate critical flaw sizes for loading Case 5 and $K_{I R}$ evaluation are small enough to be of concern. However, tightening of the bolting at the time of erection tends to alleviate the problem. Table 7.10 provides a summary of the best-estimate critical flaw size as a function of NDTT, operating temperature $T$, and evalua$t$ ion by both ASME $K_{I c}$ and $K_{I R}$ curves for pretightening to $70 \%$ of the minimum yield load, that is, $160 \mathrm{kips}$. It is evident that the small critical flaw sizes of Table 7.9 would be eliminated by the application of a pretightening load as noted. The Turkey Point supports were specified to be installed according to Ref. 28 in accordance with the standards of the American Institute for Steel Construction (AISC). AISC practice requires that bolting conforming to ASTM A325 or A490 be preloaded to $70 \%$ of the minimum tensile strength. 28

An examination of Table 7.7 shows that the estimated fracture toughness for the lateral restraints for both methods of $\triangle$ NDTT shift, for both $K_{I c}$ and $K_{I R}$ evaluations, and as a function of service 1 ife is consistently high. The best-estimate value at 32 EFPY is $>200 \mathrm{ksi} / \mathrm{in}$., and the smallest value $(-3 \sigma$, Method $A \Delta N D T T)$ is $80 \mathrm{ksi} \sqrt{\mathrm{in} \text {., }}$, which corresponds to a critical flaw size of $\sim 1.2$ in. (Fig. 7.46). Thus, the lateral restraints do not appear to be the critical component in the support assembly. 
Table 7.7. Summary of estimated fracture toughness frow ASME $K_{I C}$ and $K_{I R}$ curves as a function
of Gaussian point and service 11 fe for each component

\begin{tabular}{|c|c|c|c|c|c|c|c|c|c|c|}
\hline \multirow{3}{*}{ Component } & \multicolumn{10}{|c|}{$\begin{array}{c}\text { Fracture toughness; } \\
(\mathrm{ksi} \sqrt{1 \mathrm{n}})\end{array} \mathrm{k}_{\mathrm{Ic}}\left(\mathrm{K}_{\mathrm{IR}}\right)$} \\
\hline & \multicolumn{5}{|c|}{$\begin{array}{c}\text { Method A ANDIT } \\
\text { (Gaussian point) }\end{array}$} & \multicolumn{5}{|c|}{$\begin{array}{c}\text { Method B } \Delta \text { NDTT } \\
\text { (Gauss1an point) }\end{array}$} \\
\hline & $-3 \sigma$ & $-1 \sigma$ & Mean & 10 & 30 & $-3 \sigma$ & -10 & Mean & 10 & 30 \\
\hline \multicolumn{11}{|c|}{0.0 EEPY } \\
\hline $\begin{array}{l}\text { Cantilever beam } \\
\text { Point } 9, \mathrm{~L}=13 \mathrm{in} .\end{array}$ & $44.5(35)$ & $52.5(39)$ & $89.5(52.5)$ & $>200(84.5)$ & $>200(110)$ & $44.5(35)$ & $52.5(39)$ & $89.5(52.5)$ & $>200(84.5)$ & $>200(110)$ \\
\hline $\begin{array}{l}\text { Cantilever beam } \\
\text { Point } 10, \mathrm{~L}=17 \text { in. }\end{array}$ & $47(36)$ & $53(39)$ & $99.5(56)$ & $>200(91.5)$ & $>200(120)$ & $47(36)$ & $53(39)$ & $99.5(56)$ & $>200(91.5)$ & $>200(120)$ \\
\hline $\begin{array}{l}\text { Girder-to-cantllever- } \\
\text { beam bolt Point } 4\end{array}$ & $42.5(34)$ & $49(37)$ & $126(64)$ & 171 (77) & $>200(98.5)$ & $42.5(34)$ & $49(37)$ & $126(64)$ & 171 (77) & $>200(98.5)$ \\
\hline $\begin{array}{l}\text { Lateral restralnt } \\
\text { Point } 8\end{array}$ & $>200(>200)$ & $>200(>200)$ & $>200(>200)$ & $>200(>200)$ & $>200(>200)$ & $>200(>200)$ & $>200(>200)$ & $>200(>200)$ & $>200(>200)$ & $>200(>200)$ \\
\hline \multicolumn{11}{|c|}{$7.04 \mathrm{EFPY}$} \\
\hline $\begin{array}{l}\text { Cantilever beam } \\
\text { Point } 9, \mathrm{~L}=13 \text { in. }\end{array}$ & & & & & & $39(32)$ & $43.5(34)$ & $64(44)$ & $126(64)$ & $186(80)$ \\
\hline $\begin{array}{l}\text { Cantilever beam } \\
\text { Point } 10, \mathrm{~L}=17 \text { in. }\end{array}$ & & & & & & $42(34)$ & $48(36.5)$ & $78(49)$ & $166(75)$ & $>200 \quad(97)$ \\
\hline $\begin{array}{l}\text { Girder-to-cantilever- } \\
\text { beam bolt Point } 4\end{array}$ & & & & & & $37(30.5)$ & $39(32)$ & $52(38.5)$ & $89.5(53)$ & $126(64)$ \\
\hline $\begin{array}{l}\text { Lateral restraint } \\
\text { Point } 8\end{array}$ & & & & & & $>200(>200)$ & $>200(>200)$ & $>200(>200)$ & $>200(>200)$ & $>200(>200)$ \\
\hline \multicolumn{11}{|c|}{$11.79 \mathrm{EPPY}$} \\
\hline $\begin{array}{l}\text { Cant1lever beam } \\
\text { Point } 9, \mathrm{~L}=13 \text { in. }\end{array}$ & & & & & & $38(31.5)$ & $41.5(33)$ & $58.5(41.5)$ & $109.5(59)$ & $157.5(78)$ \\
\hline $\begin{array}{l}\text { Cantilever beam } \\
\text { Point } 10, \mathrm{~L}=17 \text { in. }\end{array}$ & & & & & & $40(33)$ & $45(35)$ & $70(46)$ & $143(69)$ & $>200 \quad(87)$ \\
\hline $\begin{array}{l}\text { Girder-to-cantilever- } \\
\text { beam bolt Point } 4\end{array}$ & & & & & & $36(30)$ & $37(31)$ & $46(36)$ & $71(46)$ & $96(54)$ \\
\hline $\begin{array}{l}\text { Lateral restraint } \\
\text { Point } 8\end{array}$ & & & & & & $>200(>200)$ & $>200(>200)$ & $>200(>200)$ & $>200(>200)$ & $>200(>200)$ \\
\hline \multicolumn{11}{|c|}{$32 E R P Y$} \\
\hline $\begin{array}{l}\text { Cant1lever beam } \\
\text { Point } 9, \mathrm{~L}=13 \mathrm{in} .\end{array}$ & $36(30)$ & $36(30)$ & $37(31$ & $46(36)$ & $54(39)$ & $36(30)$ & $37(31)$ & $46(36)$ & $71(46)$ & $95.5(54)$ \\
\hline $\begin{array}{l}\text { Cantilever beam } \\
\text { Point } 10, \mathrm{~L}=17 \text { in. }\end{array}$ & $40(33)$ & $45(35)$ & $70(46)$ & $142(69)$ & $>200(87)$ & $37(31)$ & $40(33)$ & $55(40)$ & $100(56)$ & $143(69)$ \\
\hline $\begin{array}{l}\text { Girder-to-cantilever- } \\
\text { beam bolt Point } 4\end{array}$ & $36(30)$ & $37(30.5)$ & $45(35)$ & $67(45)$ & $89.5(53)$ & $36(30)$ & $37(30)$ & $44(34)$ & $64(44)$ & $84(51)$ \\
\hline $\begin{array}{l}\text { Lateral restraint } \\
\text { Point } 8\end{array}$ & $186(80)$ & $>200(94)$ & $>200(137)$ & $>200(>200)$ & $>200(>200)$ & $>200(137)$ & $>200(164)$ & $>200(>200)$ & $>200(>200)$ & $>200(>200)$ \\
\hline
\end{tabular}



Table 7.8. Summary of eatimated critical flaw sizes for cantilever beam as a function of type of flaw, DNDTT method, Gaussian point,
ASME $\mathrm{K}_{\text {Ic }}$ or $\mathrm{K}_{\text {IR }}$ evaluation, location, loading case, and service life

\begin{tabular}{|c|c|c|c|c|c|c|c|c|c|c|c|c|c|c|c|c|c|c|c|c|c|c|}
\hline \multirow{4}{*}{$\begin{array}{l}\text { Case } \\
\text { No. }\end{array}$} & \multirow{4}{*}{$\begin{array}{l}\text { Loading } \\
\text { condition }\end{array}$} & \multirow{4}{*}{$\begin{array}{l}\text { Gauss Ian } \\
\text { point }\end{array}$} & \multicolumn{20}{|c|}{$\begin{array}{c}\text { Critical flaw depth } \\
\text { (in.) }\end{array}$} \\
\hline & & & \multicolumn{10}{|c|}{ Method A $\triangle$ NDTT } & \multicolumn{10}{|c|}{ Method B $\triangle \mathrm{NDTT}$} \\
\hline & & & \multicolumn{2}{|c|}{ Semictrcular } & \multicolumn{2}{|c|}{$\begin{array}{l}\text { 6:1 Sem1- } \\
\text { el11ptical }\end{array}$} & \multicolumn{2}{|c|}{$\begin{array}{c}\text { SEN } \\
\text { top } \\
\text { surf ace }\end{array}$} & \multicolumn{2}{|c|}{$\begin{array}{l}\text { SEN } \\
\text { edge }\end{array}$} & \multicolumn{2}{|c|}{ Corner } & \multicolumn{2}{|c|}{ Semicircular } & \multicolumn{2}{|c|}{$\begin{array}{l}\text { 6:1 Semi- } \\
\text { elliptical }\end{array}$} & \multicolumn{2}{|c|}{$\begin{array}{c}\text { SEN } \\
\text { top } \\
\text { surface }\end{array}$} & \multicolumn{2}{|c|}{$\begin{array}{l}\text { SEN } \\
\text { edge }\end{array}$} & \multicolumn{2}{|c|}{ Corner } \\
\hline & & & $\mathrm{K}_{\mathrm{Ic}}$ & $\mathrm{K}_{\mathrm{IR}}$ & $\mathrm{K}_{I_{c}}$ & $\mathrm{R}_{\mathrm{IR}}$ & $\mathrm{K}_{\mathrm{Ic}}$ & $\mathrm{K}_{\mathrm{IR}}$ & $\mathrm{K}_{\mathrm{Ic}}$ & $\mathrm{K}_{\mathrm{IR}}$ & $\mathrm{K}_{\mathrm{Ic}}$ & $\mathbf{R}_{\text {IR }}$ & $\mathrm{K}_{\mathrm{Ic}}$ & $\mathbf{R}_{\mathbf{I R}}$ & $\mathrm{R}_{\mathrm{Ic}}$ & $\mathrm{K}_{\mathrm{IR}}$ & $\mathrm{K}_{\mathrm{I}_{\mathrm{c}}}$ & $\mathrm{K}_{\mathrm{IR}}$ & $\mathrm{K}_{\mathrm{Ic}}$ & $\mathrm{K}_{\mathrm{IR}}$ & $\mathrm{K}_{\mathrm{Ic}}$ & $K_{I R}$ \\
\hline \multicolumn{23}{|c|}{$0.0 \mathrm{BPPY}$} \\
\hline $3 \mathrm{~A}$ & $\begin{array}{l}\mathrm{DL}+\mathrm{E}^{-} \\
(D L+S S E) \\
\mathrm{L}=17 \mathrm{ln} .\end{array}$ & $\begin{array}{c}-3 \sigma \\
-10 \\
\text { Mean } \\
10 \\
30\end{array}$ & $\begin{array}{r}2.1 \\
2.2 \\
>2.4 \\
>2.4 \\
>2.4\end{array}$ & $\begin{array}{r}2.0 \\
2.0 \\
2.2 \\
>2.4 \\
>2.4\end{array}$ & $\begin{array}{r}2.0 \\
2.1 \\
>2.4 \\
>2.4 \\
>2.4\end{array}$ & $\begin{array}{r}1.9 \\
1.9 \\
2.1 \\
>2.4 \\
>2.4\end{array}$ & $\begin{array}{l}>2.4 \\
>2.4 \\
>2.4 \\
>2.4 \\
>2.4\end{array}$ & $\begin{array}{l}>2.4 \\
>2.4 \\
>2.4 \\
>2.4 \\
>2.4\end{array}$ & $\begin{array}{l}>2.4 \\
>2.4 \\
>2.4 \\
>2.4 \\
>2.4\end{array}$ & $\begin{array}{r}1.5 \\
1.8 \\
>2.4 \\
>2.4 \\
>2.4\end{array}$ & $\begin{array}{r}1.5 \\
1.9 \\
>2.4 \\
>2.4 \\
>2.4\end{array}$ & $\begin{array}{r}0.9 \\
1.0 \\
2.1 \\
>2.4 \\
>2.4\end{array}$ & $\begin{array}{r}2.1 \\
2.2 \\
>2.4 \\
>2.4 \\
>2.4\end{array}$ & $\begin{array}{r}2.0 \\
2.0 \\
2.2 \\
>2.4 \\
>2.4\end{array}$ & $\begin{array}{r}2.0 \\
2.1 \\
>2.4 \\
>2.4 \\
>2.4\end{array}$ & $\begin{array}{r}1.9 \\
1.9 \\
2.1 \\
>2.4 \\
>2.4\end{array}$ & $\begin{array}{l}>2.4 \\
>2.4 \\
>2.4 \\
>2.4 \\
>2.4\end{array}$ & $\begin{array}{l}>2.4 \\
>2.4 \\
>2.4 \\
>2.4 \\
>2.4\end{array}$ & $\begin{array}{l}>2.4 \\
>2.4 \\
>2.4 \\
>2.4 \\
>2.4\end{array}$ & $\begin{array}{r}1.5 \\
1.8 \\
>2.4 \\
>2.4 \\
>2.4\end{array}$ & $\begin{array}{r}1.5 \\
1.9 \\
>2.4 \\
>2.4 \\
>2.4\end{array}$ & $\begin{array}{r}0.9 \\
1.0 \\
2.1 \\
>2.4 \\
>2.4\end{array}$ \\
\hline 3B & $\begin{array}{l}\mathrm{DL}+\mathrm{E}^{\prime} \\
(\mathrm{DL}+\mathrm{SSE}) \\
\mathrm{L}=13 \mathrm{in} .\end{array}$ & $\begin{array}{c}-30 \\
-10 \\
\text { Mean } \\
10 \\
30\end{array}$ & $\begin{array}{r}2.2 \\
2.3 \\
>2.4 \\
>2.4 \\
>2.4\end{array}$ & $\begin{array}{r}2.1 \\
2.2 \\
2.3 \\
>2.4 \\
>2.4\end{array}$ & $\begin{array}{r}2.2 \\
2.2 \\
>2.4 \\
>2.4 \\
>2.4\end{array}$ & $\begin{array}{r}2.0 \\
2.1 \\
2.2 \\
>2.4 \\
>2.4\end{array}$ & $\begin{array}{l}>2.4 \\
>2.4 \\
>2.4 \\
>2.4 \\
>2.4\end{array}$ & $\begin{array}{l}>2.4 \\
>2.4 \\
>2.4 \\
>2.4 \\
>2.4\end{array}$ & $\begin{array}{l}>2.4 \\
>2.4 \\
>2.4 \\
>2.4 \\
>2.4\end{array}$ & $\begin{array}{l}>2.4 \\
>2.4 \\
>2.4 \\
>2.4 \\
>2.4\end{array}$ & $\begin{array}{r}2.2 \\
>2.4 \\
>2.4 \\
>2.4 \\
>2.4\end{array}$ & $\begin{array}{r}1.4 \\
1.7 \\
>2.4 \\
>2.4 \\
>2.4\end{array}$ & $\begin{array}{r}2.2 \\
2.3 \\
>2.4 \\
>2.4 \\
>2.4\end{array}$ & $\begin{array}{r}2.1 \\
2.2 \\
2.3 \\
>2.4 \\
>2.4\end{array}$ & $\begin{array}{r}2.2 \\
2.2 \\
>2.4 \\
>2.4 \\
>2.4\end{array}$ & $\begin{array}{r}2.0 \\
2.1 \\
2.2 \\
>2.4 \\
>2.4\end{array}$ & $\begin{array}{l}>2.4 \\
>2.4 \\
>2.4 \\
>2.4 \\
>2.4\end{array}$ & $\begin{array}{l}>2.4 \\
>2.4 \\
>2.4 \\
>2.4 \\
>2.4\end{array}$ & $\begin{array}{l}>2.4 \\
>2.4 \\
>2.4 \\
>2.4 \\
>2.4\end{array}$ & $\begin{array}{l}>2.4 \\
>2.4 \\
>2.4 \\
>2.4 \\
>2.4\end{array}$ & $\begin{array}{r}2.2 \\
>2.4 \\
>2.4 \\
>2.4 \\
>2.4\end{array}$ & $\begin{array}{r}1.4 \\
1.7 \\
>2.4 \\
>2.4 \\
>2.4\end{array}$ \\
\hline $5 \mathrm{~A}$ & $\begin{array}{l}D L+\operatorname{LACA}(H) \\
\mathrm{L}=17 \mathrm{in} .\end{array}$ & $\begin{array}{c}-3 \sigma \\
-1 \sigma \\
\text { Mean } \\
1 \sigma \\
3 \sigma\end{array}$ & & & & & & & $\begin{array}{r}1.2 \\
1.5 \\
>2.4 \\
>2.4 \\
>2.4\end{array}$ & $\begin{array}{r}0.7 \\
0.8 \\
1.7 \\
>2.4 \\
>2.4\end{array}$ & $\begin{array}{r}0.4 \\
0.5 \\
>1.6 \\
>1.6 \\
>1.6\end{array}$ & $\begin{array}{r}0.2 \\
0.3 \\
0.6 \\
1.6 \\
>1.6\end{array}$ & & & & & & & $\begin{array}{r}1.2 \\
1.5 \\
>2.4 \\
>2.4 \\
>2.4\end{array}$ & $\begin{array}{r}0.7 \\
0.8 \\
1.7 \\
>2.4 \\
>2.4\end{array}$ & $\begin{array}{r}0.4 \\
0.5 \\
>1.6 \\
>1.6 \\
>1.6\end{array}$ & $\begin{array}{r}0.2 \\
0.3 \\
0.6 \\
1.6 \\
>1.6\end{array}$ \\
\hline 5B & $\begin{array}{l}\mathrm{DL}+\operatorname{LOCA}(\mathrm{H}) \\
\mathrm{L}=13 \text { in. }\end{array}$ & $\begin{array}{c}-3 \sigma \\
-10 \\
\text { Mean } \\
10 \\
30\end{array}$ & & & & & & & $\begin{array}{r}1.9 \\
>2.4 \\
>2.4 \\
>2.4 \\
>2.4\end{array}$ & $\begin{array}{r}1.1 \\
1.4 \\
>2.4 \\
>2.4 \\
>2.4\end{array}$ & $\begin{array}{r}0.7 \\
0.9 \\
>2.4 \\
>2.4 \\
>2.4\end{array}$ & $\begin{array}{r}0.4 \\
0.5 \\
0.9 \\
1.9 \\
>2.4\end{array}$ & & & & & & & $\begin{array}{r}1.9 \\
>2.4 \\
>2.4 \\
>2.4 \\
>2.4\end{array}$ & $\begin{array}{r}1.1 \\
1.4 \\
>2.4 \\
>2.4 \\
>2.4\end{array}$ & $\begin{array}{r}0.7 \\
0.9 \\
>2.4 \\
>2.4 \\
>2.4\end{array}$ & $\begin{array}{r}0.4 \\
0.5 \\
0.9 \\
1.9 \\
>2.4\end{array}$ \\
\hline $6 \mathrm{~A}$ & $\begin{array}{l}D L+\operatorname{LOCA}\left(45^{\circ}\right) \\
L=17 \mathrm{in.}\end{array}$ & $\begin{array}{c}-30 \\
-10 \\
\text { Mean } \\
10 \\
3 \sigma\end{array}$ & $\begin{array}{r}1.2 \\
1.4 \\
>1.9 \\
>1.9 \\
>1.9\end{array}$ & $\begin{array}{l}0.9 \\
1.0 \\
1.4 \\
1.8 \\
>1.9\end{array}$ & $\begin{array}{r}1.0 \\
1.1 \\
>1.7 \\
>1.7 \\
>1.7\end{array}$ & $\begin{array}{r}0.7 \\
0.8 \\
1.2 \\
>1.7 \\
>1.7\end{array}$ & $\begin{array}{r}1.0 \\
1.2 \\
>2.4 \\
>2.4 \\
>2.4\end{array}$ & $\begin{array}{r}0.5 \\
0.6 \\
11.4 \\
>2.4 \\
>2.4\end{array}$ & & & $\begin{array}{r}0.5 \\
0.6 \\
>1.9 \\
>1.9 \\
>1.9\end{array}$ & $\begin{array}{r}0.3 \\
0.3 \\
0.7 \\
1.8 \\
>1.9\end{array}$ & $\begin{array}{r}1.2 \\
1.4 \\
>1.9 \\
>1.9 \\
>1.9\end{array}$ & $\begin{array}{r}0.9 \\
1.0 \\
1.4 \\
1.8 \\
>1.9\end{array}$ & $\begin{array}{r}1.0 \\
1.1 \\
>1.7 \\
>1.7 \\
>1.7\end{array}$ & $\begin{array}{r}0.7 \\
0.8 \\
1.2 \\
>1.7 \\
>1.7\end{array}$ & $\begin{array}{r}1.0 \\
1.2 \\
>2.4 \\
>2.4 \\
>2.4\end{array}$ & $\begin{array}{r}0.5 \\
0.6 \\
1.4 \\
>2.4 \\
>2.4\end{array}$ & & & $\begin{array}{r}0.5 \\
0.6 \\
>1.9 \\
>1.9 \\
>1.9\end{array}$ & $\begin{array}{l}0.3 \\
0.3 \\
0.7 \\
1.8 \\
>1.9\end{array}$ \\
\hline 6B & $\begin{array}{l}D L+\operatorname{LOCA}\left(45^{\circ}\right) \\
L=17 \mathrm{in} .\end{array}$ & $\begin{array}{c}-3 \sigma \\
-1 \sigma \\
\text { Mean } \\
10 \\
3 \sigma\end{array}$ & $\begin{array}{r}1.5 \\
1.6 \\
2.0 \\
>2.0 \\
>2.0\end{array}$ & $\begin{array}{r}1.2 \\
1.3 \\
1.6 \\
22.0 \\
>2.0\end{array}$ & $\begin{array}{r}1.2 \\
1.4 \\
1.9 \\
>1.9 \\
>1.9\end{array}$ & $\begin{array}{r}1.0 \\
1.1 \\
1.4 \\
1.9 \\
>1.9\end{array}$ & $\begin{array}{r}1.5 \\
2.1 \\
>2.4 \\
>2.4 \\
>2.4\end{array}$ & $\begin{array}{r}0.9 \\
1.1 \\
2.1 \\
>2.4 \\
>2.4\end{array}$ & & & $\begin{array}{r}0.7 \\
1.0 \\
>2.5 \\
>2.5 \\
>2.5\end{array}$ & $\begin{array}{r}0.4 \\
0.6 \\
1.0 \\
2.5 \\
>2.5\end{array}$ & $\begin{array}{r}1.5 \\
1.6 \\
2.0 \\
>2.0 \\
>2.0\end{array}$ & $\begin{array}{r}1.2 \\
1.3 \\
1.6 \\
2.0 \\
>2.0\end{array}$ & $\begin{array}{r}1.2 \\
1.4 \\
1.9 \\
>1.9 \\
>1.9\end{array}$ & $\begin{array}{r}1.0 \\
1.1 \\
1.4 \\
1.9 \\
>1.0\end{array}$ & $\begin{array}{r}1.5 \\
2.1 \\
>2.4 \\
>2.4 \\
>2.4\end{array}$ & $\begin{array}{r}0.9 \\
1.1 \\
2.1 \\
>2.4 \\
>2.4\end{array}$ & & & $\begin{array}{r}0.7 \\
1.0 \\
>2.5 \\
>2.5 \\
>2.5\end{array}$ & $\begin{array}{r}0.5 \\
0.6 \\
1.0 \\
>2.5 \\
>2.5\end{array}$ \\
\hline
\end{tabular}


Table 7.8 (continued)

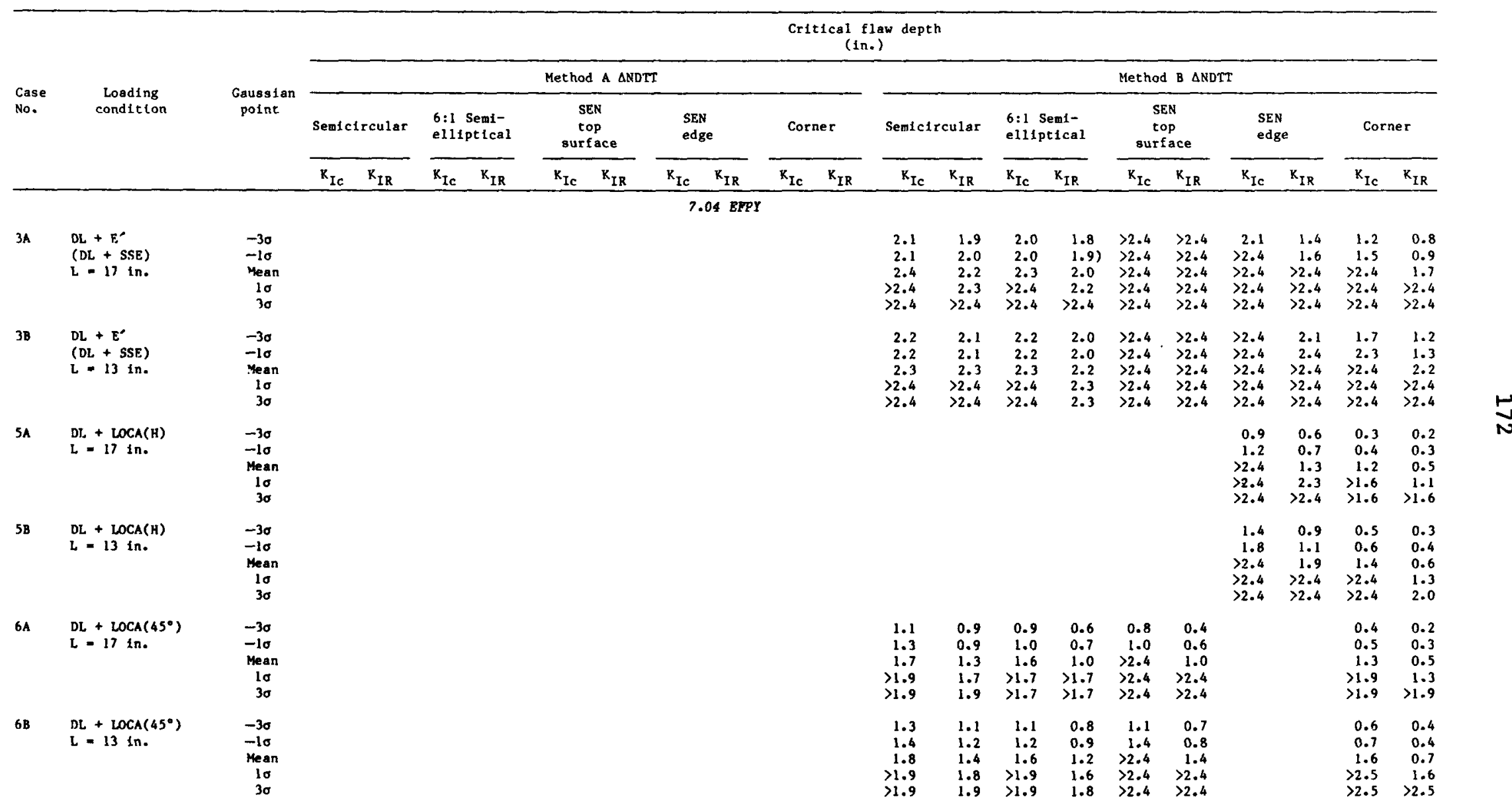


Table 7.8 (continued)

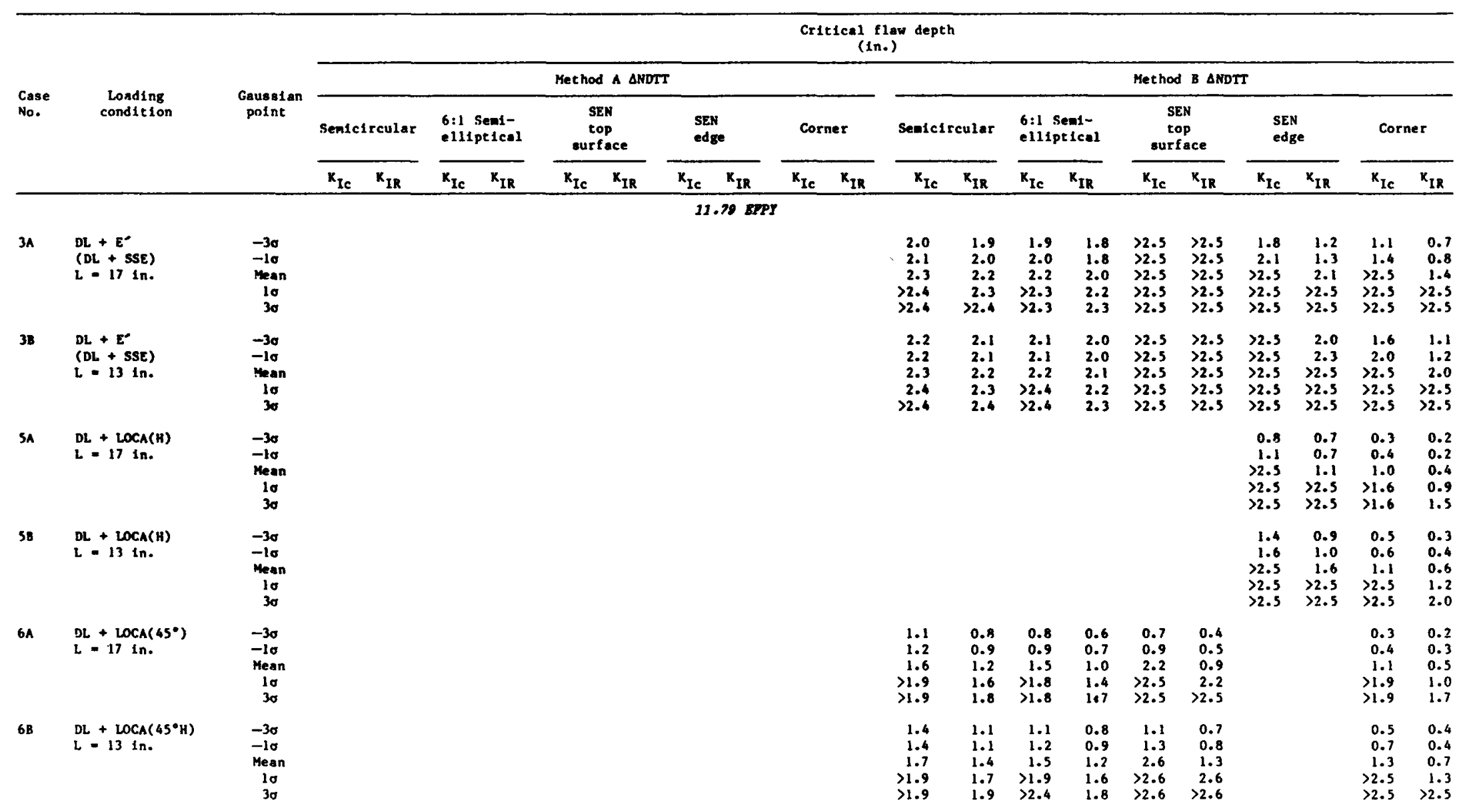


Table 7.8 (continued)

\begin{tabular}{|c|c|c|c|c|c|c|c|c|c|c|c|c|c|c|c|c|c|c|c|c|c|c|}
\hline \multirow{4}{*}{$\begin{array}{l}\text { Case } \\
\text { No. }\end{array}$} & \multirow{4}{*}{$\begin{array}{l}\text { Loading } \\
\text { condition }\end{array}$} & \multirow{4}{*}{$\begin{array}{l}\text { Gaussian } \\
\text { point }\end{array}$} & \multicolumn{20}{|c|}{$\begin{array}{c}\text { Critical flaw depth } \\
\text { (in.) }\end{array}$} \\
\hline & & & \multicolumn{10}{|c|}{ Method A $\triangle N D T T$} & \multicolumn{10}{|c|}{ Method B $\triangle$ NDTT } \\
\hline & & & \multicolumn{2}{|c|}{ Semicircular } & \multicolumn{2}{|c|}{$\begin{array}{l}\text { 6:1 Seni- } \\
\text { elliptical }\end{array}$} & \multicolumn{2}{|c|}{$\begin{array}{c}\text { SEN } \\
\text { top } \\
\text { surface }\end{array}$} & \multicolumn{2}{|c|}{$\begin{array}{l}\text { SEN } \\
\text { edge }\end{array}$} & \multicolumn{2}{|c|}{ Corner } & \multicolumn{2}{|c|}{ Semici rcular } & \multicolumn{2}{|c|}{$\begin{array}{l}\text { 6:1 Semi- } \\
\text { e1liptical }\end{array}$} & \multicolumn{2}{|c|}{$\begin{array}{c}\text { SEN } \\
\text { top } \\
\text { surface }\end{array}$} & \multicolumn{2}{|c|}{$\begin{array}{l}\text { SEN } \\
\text { edge }\end{array}$} & \multicolumn{2}{|c|}{ Corner } \\
\hline & & & $\mathrm{K}_{\mathrm{Ic}}$ & $\mathrm{k}_{\mathrm{IR}}$ & $\mathrm{K}_{\mathbf{I c}}$ & $\mathrm{K}_{\mathrm{IR}}$ & $\mathrm{K}_{\mathrm{I} c}$ & $\mathrm{~K}_{\mathrm{IR}}$ & $\mathrm{K}_{\mathrm{Ic}}$ & $\mathbf{x}_{\text {IR }}$ & $\mathrm{x}_{\mathrm{Ic}}$ & $x_{\text {IR }}$ & $\mathrm{K}_{\mathrm{IC}}$ & $\mathrm{K}_{\mathrm{IR}}$ & $\mathrm{K}_{\mathrm{IC}}$ & $K_{\text {IR }}$ & $\mathrm{K}_{\mathrm{Ic}}$ & $\mathbf{k}_{1 \mathrm{R}}$ & $\mathrm{K}_{\text {Ic }}$ & $\mathrm{K}_{\mathrm{IR}}$ & $\mathrm{K}_{\mathrm{Ic}}$ & $\mathrm{K}_{\mathrm{IR}}$ \\
\hline \multicolumn{23}{|c|}{38 EFPY } \\
\hline $3 A$ & $\begin{array}{l}\mathrm{DL}+\mathrm{E}^{\prime} \\
(\mathrm{DL}+\mathrm{SSE}) \\
\mathrm{L}=17 \mathrm{in} .\end{array}$ & $\begin{array}{c}-3 \sigma \\
-10 \\
\text { Mean } \\
\text { lo } \\
30\end{array}$ & $\begin{array}{r}2.0 \\
2.1 \\
2.3 \\
>2.4 \\
>2.4\end{array}$ & $\begin{array}{l}1.9 \\
2.0 \\
2.1 \\
2.3 \\
2.4\end{array}$ & $\begin{array}{r}1.9 \\
2.0 \\
2.2 \\
>2.3 \\
>2.3\end{array}$ & $\begin{array}{l}1.8 \\
1.8 \\
2.0 \\
2.2 \\
2.3\end{array}$ & $\begin{array}{l}>2.5 \\
>2.5 \\
>2.5 \\
>2.5 \\
>2.5\end{array}$ & $\begin{array}{l}>2.5 \\
>2.5 \\
>2.5 \\
>2.5 \\
>2.5\end{array}$ & $\begin{array}{r}2.0 \\
>2.5 \\
>2.5 \\
>2.5 \\
>2.5\end{array}$ & $\begin{array}{r}1.3 \\
1.5 \\
>2.5 \\
>2.5 \\
>2.5\end{array}$ & $\begin{array}{r}1.1 \\
1.4 \\
>2.5 \\
>2.5 \\
>2.5\end{array}$ & $\begin{array}{r}0.7 \\
0.8 \\
1.4 \\
>2.5 \\
>2.5\end{array}$ & $\begin{array}{r}2.0 \\
2.0 \\
2.2 \\
>2.4 \\
>2.4\end{array}$ & $\begin{array}{l}1.9 \\
1.9 \\
2.0 \\
2.2 \\
2.3\end{array}$ & $\begin{array}{r}1.9 \\
1.9 \\
2.1 \\
>2.3 \\
>2.3\end{array}$ & $\begin{array}{l}1.7 \\
1.8 \\
1.9 \\
2.1 \\
2.2\end{array}$ & $\begin{array}{l}>2.5 \\
>2.5 \\
>2.5 \\
>2.5 \\
>2.5\end{array}$ & $\begin{array}{l}>2.5 \\
>2.5 \\
>2.5 \\
>2.5 \\
>2.5\end{array}$ & $\begin{array}{r}1.7 \\
2.0 \\
>2.5 \\
>2.5 \\
>2.5\end{array}$ & $\begin{array}{r}1.1 \\
1.3 \\
1.9 \\
>2.5 \\
>2.5\end{array}$ & $\begin{array}{r}0.9 \\
1.1 \\
2.0 \\
>2.5 \\
>2.5\end{array}$ & $\begin{array}{r}0.6 \\
0.7 \\
1.1 \\
>2.5 \\
>2.5\end{array}$ \\
\hline 38 & $\begin{array}{l}\mathrm{DL}+\mathrm{E}^{\circ} \\
(\mathrm{DL}+\mathrm{SSE}) \\
\mathrm{L}=13 \mathrm{ln} .\end{array}$ & $\begin{array}{c}-3 \sigma \\
-1 \sigma \\
\text { Mean } \\
1 \sigma \\
3 \sigma\end{array}$ & $\begin{array}{l}2.1 \\
2.1 \\
2.2 \\
2.2 \\
2.3\end{array}$ & $\begin{array}{l}2.0 \\
2.0 \\
2.1 \\
2.1 \\
2.2\end{array}$ & $\begin{array}{l}2.1 \\
2.1 \\
2.1 \\
2.1 \\
2.2\end{array}$ & $\begin{array}{l}2.0 \\
2.0 \\
2.0 \\
2.1 \\
2.1\end{array}$ & $\begin{array}{l}>2.5 \\
>2.5 \\
>2.5 \\
>2.5 \\
>2.5\end{array}$ & $\begin{array}{l}>2.5 \\
>2.5 \\
>2.5 \\
>2.5 \\
>2.5\end{array}$ & $\begin{array}{l}>2.5 \\
>2.5 \\
>2.5 \\
>2.5 \\
>2.5\end{array}$ & $\begin{array}{r}1.9 \\
1.9 \\
2.0 \\
>2.5 \\
>2.5\end{array}$ & $\begin{array}{r}1.5 \\
1.5 \\
1.6 \\
2.3 \\
>2.5\end{array}$ & $\begin{array}{l}1.0 \\
1.0 \\
1.1 \\
1.5 \\
1.7\end{array}$ & $\begin{array}{l}2.1 \\
2.2 \\
2.3 \\
2.3 \\
2.4\end{array}$ & $\begin{array}{l}2.0 \\
2.1 \\
2.1 \\
2.2 \\
2.3\end{array}$ & $\begin{array}{l}2.1 \\
2.2 \\
2.2 \\
2.3 \\
2.4\end{array}$ & $\begin{array}{l}2.0 \\
2.0 \\
2.0 \\
2.2 \\
2.2\end{array}$ & $\begin{array}{l}>2.5 \\
>2.5 \\
>2.5 \\
>2.5 \\
>2.5\end{array}$ & $\begin{array}{l}>2.5 \\
>2.5 \\
>2.5 \\
>2.5 \\
>2.5\end{array}$ & $\begin{array}{l}>2.5 \\
>2.5 \\
>2.5 \\
>2.5 \\
>2.5\end{array}$ & $\begin{array}{r}1.9 \\
2.0 \\
>2.5 \\
>2.5 \\
>2.5\end{array}$ & $\begin{array}{r}1.5 \\
1.6 \\
2.4 \\
>2.5 \\
>2.5\end{array}$ & $\begin{array}{r}1.0 \\
1.1 \\
1.5 \\
2.4 \\
>2.5\end{array}$ \\
\hline $5 \mathrm{~A}$ & $\begin{array}{l}\mathrm{pL}+\mathrm{LOCA}(\mathrm{H}) \\
\mathrm{L}=17 \mathrm{in} .\end{array}$ & $\begin{array}{c}-3 \sigma \\
-1 \sigma \\
\text { Mean } \\
1 \sigma \\
3 \sigma\end{array}$ & & & & & & & $\begin{array}{r}0.8 \\
1.1 \\
>2.5 \\
>2.5 \\
>2.5\end{array}$ & $\begin{array}{r}0.6 \\
0.6 \\
1.1 \\
>2.5 \\
>2.5\end{array}$ & $\begin{array}{r}0.3 \\
0.4 \\
1.0 \\
>1.6 \\
>1.6\end{array}$ & $\begin{array}{l}0.2 \\
0.2 \\
0.4 \\
0.9 \\
1.5\end{array}$ & & & & & & & $\begin{array}{r}0.7 \\
0.8 \\
1.7 \\
>2.5 \\
>2.5\end{array}$ & $\begin{array}{r}0.5 \\
0.6 \\
0.8 \\
1.7 \\
>2.5\end{array}$ & $\begin{array}{r}0.3 \\
0.3 \\
0.5 \\
>1.5 \\
>1.5\end{array}$ & $\begin{array}{l}0.2 \\
0.2 \\
0.3 \\
0.6 \\
0.9\end{array}$ \\
\hline 58 & $\begin{array}{l}\mathrm{DL}+\operatorname{LOCA}(\mathrm{H}) \\
\mathrm{L}=13 \mathrm{in} .\end{array}$ & $\begin{array}{c}-3 \sigma \\
-1 \sigma \\
\text { Mean } \\
1 \sigma \\
3 \sigma\end{array}$ & & & & & & & $\begin{array}{r}1.2 \\
1.2 \\
1.3 \\
2.0 \\
>2.5\end{array}$ & $\begin{array}{l}0.8 \\
0.8 \\
0.8 \\
1.2 \\
1.5\end{array}$ & $\begin{array}{l}0.4 \\
0.4 \\
0.5 \\
0.7 \\
1.0\end{array}$ & $\begin{array}{l}0.3 \\
0.3 \\
0.3 \\
0.4 \\
0.5\end{array}$ & & & & & & & $\begin{array}{r}1.2 \\
1.3 \\
2.0 \\
>2.5 \\
32.5\end{array}$ & $\begin{array}{r}0.8 \\
0.9 \\
1.2 \\
2.0 \\
>2.5\end{array}$ & $\begin{array}{c}0.4 \\
0.5 \\
0.7 \\
1.6 \\
>2.5\end{array}$ & $\begin{array}{l}0.3 \\
0.3 \\
0.4 \\
0.7 \\
1.0\end{array}$ \\
\hline $6 \mathrm{~A}$ & $\begin{array}{l}\mathrm{DL}+\operatorname{LOCA}\left(45^{\circ}\right) \\
\mathrm{L}=17 \mathrm{nn} .\end{array}$ & $\begin{array}{c}-3 \sigma \\
-1 \sigma \\
\text { Mean } \\
1 \sigma \\
3 \sigma\end{array}$ & $\begin{array}{r}1.1 \\
1.2 \\
1.6 \\
>1.8 \\
>1.8\end{array}$ & $\begin{array}{l}0.8 \\
0.9 \\
1.2 \\
1.6 \\
1.8\end{array}$ & $\begin{array}{r}0.8 \\
1.0 \\
1.5 \\
>1.8 \\
>1.8\end{array}$ & $\begin{array}{l}0.6 \\
0.7 \\
1.0 \\
1.4 \\
1.7\end{array}$ & $\begin{array}{r}0.7 \\
0.9 \\
2.2 \\
>2.5 \\
>2.5\end{array}$ & $\begin{array}{r}0.4 \\
0.5 \\
0.9 \\
2.2 \\
>2.5\end{array}$ & & & $\begin{array}{r}0.4 \\
0.4 \\
1.1 \\
>1.9 \\
>1.9\end{array}$ & $\begin{array}{l}0.2 \\
0.3 \\
0.4 \\
1.1 \\
1.7\end{array}$ & $\begin{array}{r}1.0 \\
1.1 \\
1.4 \\
1.9 \\
>1.9\end{array}$ & $\begin{array}{l}0.8 \\
0.8 \\
1.1 \\
1.4 \\
1.6\end{array}$ & $\begin{array}{r}0.7 \\
0.8 \\
1.2 \\
1.8 \\
>1.8\end{array}$ & $\begin{array}{l}0.5 \\
0.6 \\
0.8 \\
1.2 \\
1.4\end{array}$ & $\begin{array}{r}0.6 \\
0.7 \\
1.3 \\
>2.5 \\
>2.5\end{array}$ & $\begin{array}{l}0.4 \\
0.4 \\
0.7 \\
1.4 \\
2.2\end{array}$ & & & $\begin{array}{r}0.3 \\
0.3 \\
0.7 \\
>1.9 \\
>1.9\end{array}$ & $\begin{array}{l}0.2 \\
0.2 \\
0.35 \\
0.7 \\
1.1\end{array}$ \\
\hline 6B & $\begin{array}{l}D L+\operatorname{LOCA}\left(45^{\circ}\right) \\
L=13 \ln .\end{array}$ & $\begin{array}{c}-3 \sigma \\
-1 \sigma \\
\text { Mean } \\
1 \sigma \\
3 \sigma\end{array}$ & $\begin{array}{l}1.2 \\
1.2 \\
1.3 \\
1.4 \\
1.6\end{array}$ & $\begin{array}{l}1.0 \\
1.0 \\
1.1 \\
1.2 \\
1.3\end{array}$ & $\begin{array}{l}1.0 \\
1.0 \\
1.0 \\
1.3 \\
1.5\end{array}$ & $\begin{array}{l}0.8 \\
0.8 \\
0.8 \\
1.0 \\
1.1\end{array}$ & $\begin{array}{l}1.0 \\
1.0 \\
1.0 \\
1.6 \\
2.3\end{array}$ & $\begin{array}{l}0.7 \\
0.7 \\
0.7 \\
1.0 \\
1.2\end{array}$ & & & $\begin{array}{l}0.5 \\
0.5 \\
0.5 \\
0.8 \\
1.1\end{array}$ & $\begin{array}{l}0.3 \\
0.3 \\
0.3 \\
0.5 \\
0.6\end{array}$ & $\begin{array}{l}1.2 \\
1.3 \\
1.4 \\
1.8 \\
2.1\end{array}$ & $\begin{array}{l}1.0 \\
1.1 \\
1.2 \\
1.5 \\
1.6\end{array}$ & $\begin{array}{l}1.0 \\
1.0 \\
1.3 \\
1.7 \\
1.9\end{array}$ & $\begin{array}{l}0.8 \\
0.8 \\
1.0 \\
1.3 \\
1.5\end{array}$ & $\begin{array}{r}1.0 \\
1.0 \\
1.6 \\
>2.5 \\
>2.5\end{array}$ & $\begin{array}{l}0.7 \\
0.7 \\
1.0 \\
1.6 \\
2.3\end{array}$ & & & $\begin{array}{r}0.5 \\
0.5 \\
0.8 \\
>2.5 \\
>2.5\end{array}$ & $\begin{array}{l}0.3 \\
0.4 \\
0.5 \\
0.8 \\
1.1\end{array}$ \\
\hline
\end{tabular}


Table 7.9. Summary of critical flaw sizes for girder-to-cantilever beam bolts as a function of $\triangle N D T T$ method, Gaussian point, loading condition, and service life

\begin{tabular}{|c|c|c|c|c|c|c|c|c|c|c|c|c|c|c|c|c|c|c|}
\hline \multirow{5}{*}{$\begin{array}{l}\text { Case } \\
\text { No. }\end{array}$} & \multirow{5}{*}{$\begin{array}{l}\text { Loading } \\
\text { condition }\end{array}$} & \multirow{5}{*}{$\begin{array}{c}\text { Temperature } \\
\text { parameter } \\
\text { Gaussian } \\
\text { point }\end{array}$} & \multicolumn{16}{|c|}{$\begin{array}{c}\text { Critical flaw depth } \\
\text { (in.) }\end{array}$} \\
\hline & & & \multicolumn{8}{|c|}{ Method A $\triangle$ NDTT } & \multicolumn{8}{|c|}{ Method B $\triangle$ NDTT } \\
\hline & & & \multicolumn{8}{|c|}{ Service life, FFPY } & \multicolumn{8}{|c|}{ Service $11 \mathrm{fe}$, EFPY } \\
\hline & & & \multicolumn{2}{|c|}{0.0} & \multicolumn{2}{|c|}{7.04} & \multicolumn{2}{|c|}{11.79} & \multicolumn{2}{|c|}{32} & \multicolumn{2}{|c|}{0.0} & \multicolumn{2}{|c|}{7.04} & \multicolumn{2}{|c|}{11.79} & \multicolumn{2}{|c|}{32} \\
\hline & & & $\mathrm{K}_{\mathrm{Ic}}$ & $\mathrm{K}_{\mathrm{IR}}$ & $\mathrm{K}_{\mathrm{Ic}}$ & $\mathrm{K}_{\mathrm{IR}}$ & $\mathrm{K}_{\mathrm{Ic}}$ & $\mathrm{K}_{\mathrm{IR}}$ & $\mathrm{K}_{\mathrm{Ic}}$ & $\mathrm{K}_{\mathrm{IR}}$ & ${ }^{\mathrm{K}} \mathrm{Ic}$ & $\mathrm{K}_{\mathrm{IR}}$ & $\mathrm{K}_{\mathrm{Ic}}$ & $\mathrm{K}_{\mathrm{IR}}$ & $\mathrm{K}_{\mathrm{Ic}}$ & $\mathrm{K}_{\mathrm{IR}}$ & $\mathrm{K}_{\mathrm{Ic}}$ & $\mathrm{K}_{\mathrm{IR}}$ \\
\hline 3 & $\begin{array}{l}D L+E^{\circ} \\
(D L+S S E)\end{array}$ & $\begin{array}{l}-3 \sigma \\
-1 \sigma \\
\text { Mean } \\
1 \sigma \\
3 \sigma\end{array}$ & $\begin{array}{l}0.58 \\
0.6 \\
>0.7 \\
>0.7 \\
>0.7\end{array}$ & $\begin{array}{l}0.53 \\
0.55 \\
0.64 \\
0.67 \\
0.7\end{array}$ & & & & & $\begin{array}{l}0.54 \\
0.55 \\
0.57 \\
0.65 \\
0.68\end{array}$ & $\begin{array}{l}0.5 \\
0.51 \\
0.54 \\
0.58 \\
0.61\end{array}$ & $\begin{array}{l}0.58 \\
0.6 \\
>0.7 \\
>0.7 \\
>0.7\end{array}$ & $\begin{array}{l}0.53 \\
0.55 \\
0.64 \\
0.67 \\
0.7\end{array}$ & $\begin{array}{l}0.55 \\
0.56 \\
0.61 \\
0.68 \\
>0.7\end{array}$ & $\begin{array}{l}0.5 \\
0.52 \\
0.55 \\
0.61 \\
0.64\end{array}$ & $\begin{array}{l}0.54 \\
0.53 \\
0.58 \\
0.65 \\
0.69\end{array}$ & $\begin{array}{l}0.5 \\
0.51 \\
0.54 \\
0.59 \\
0.62\end{array}$ & $\begin{array}{l}0.54 \\
0.55 \\
0.58 \\
0.64 \\
0.68\end{array}$ & $\begin{array}{l}0.5 \\
0.5 \\
0.53 \\
0.58 \\
0.61\end{array}$ \\
\hline 5 & $\mathrm{DL}+\operatorname{LOCA}(H)$ & $\begin{array}{l}-3 \sigma \\
-1 \sigma \\
\text { Mean } \\
1 \sigma \\
3 \sigma\end{array}$ & $\begin{array}{l}0.2 \\
0.24 \\
>0.4 \\
>0.4 \\
>0.4\end{array}$ & $\begin{array}{l}0.14 \\
0.17 \\
0.32 \\
0.37 \\
0.43\end{array}$ & & & & & $\begin{array}{l}0.16 \\
0.17 \\
0.22 \\
0.33 \\
0.41\end{array}$ & $\begin{array}{l}0.11 \\
0.12 \\
0.15 \\
0.22 \\
0.27\end{array}$ & $\begin{array}{l}0.2 \\
0.24 \\
>0.4 \\
>0.4 \\
>0.4\end{array}$ & $\begin{array}{l}0.14 \\
0.17 \\
0.32 \\
0.37 \\
0.43\end{array}$ & $\begin{array}{c}0.17 \\
0.18 \\
0.26 \\
0.41 \\
>0.4\end{array}$ & $\begin{array}{l}0.12 \\
0.15 \\
0.18 \\
0.27 \\
0.32\end{array}$ & $\begin{array}{l}0.16 \\
0.17 \\
0.23 \\
0.35 \\
0.42\end{array}$ & $\begin{array}{l}0.11 \\
0.12 \\
0.16 \\
0.23 \\
0.27\end{array}$ & $\begin{array}{l}0.16 \\
0.27 \\
0.22 \\
0.32 \\
0.39\end{array}$ & $\begin{array}{l}0.11 \\
0.11 \\
0.15 \\
0.22 \\
0.25\end{array}$ \\
\hline
\end{tabular}


Table 7.10. Summary of girder-to-cantilever-beam bolt critical flaw sizes with pretightening to $70 \%$ yield load ( $160 \mathrm{kips}$ ) as a function of NDTT, operating temperature, and assumed fracture toughness (ASME $\mathrm{K}_{\mathrm{IC}}$ or $\mathrm{K}_{\mathrm{IR}}$ )

\begin{tabular}{|c|c|c|c|c|c|c|}
\hline$\left({ }^{\top} F\right)$ & $\begin{array}{l}\text { NDTT } \\
\left({ }^{\circ} F\right)^{\circ}\end{array}$ & $\begin{array}{c}T-\mathrm{NDTT}_{0} \\
\left({ }^{\circ} \mathrm{F}\right)\end{array}$ & $\begin{array}{c}\text { ASME } \\
K_{\text {Ic }} \\
\left(k_{\text {sin. }}\right)\end{array}$ & $\begin{array}{c}\left(\begin{array}{c}A \\
\left(K_{I c}\right)\end{array}\right. \\
\left(\text { in. }_{.}\right)\end{array}$ & $\begin{array}{c}\text { ASME } \\
\text { K }_{\text {IR }} \\
\text { (ksi } \sqrt{\text { in. })}\end{array}$ & $\begin{array}{c}{ }_{\left(K_{I R}\right.}^{A} \\
\left(\text { in. }_{.}\right)\end{array}$ \\
\hline 130 & $\begin{array}{r}-40 \\
-20 \\
0 \\
10 \\
40 \\
70 \\
100\end{array}$ & $\begin{array}{r}170 \\
150 \\
130 \\
120 \\
90 \\
60 \\
30\end{array}$ & $\begin{array}{r}>200 \\
>200 \\
>200 \\
>200 \\
158 \\
102 \\
71\end{array}$ & $\begin{array}{c}>0.3 \\
>0.3 \\
>0.3 \\
>0.3 \\
>0.3 \\
0.28 \\
0.18\end{array}$ & $\begin{array}{r}175 \\
137 \\
110 \\
99 \\
73 \\
61 \\
46\end{array}$ & $\begin{array}{c}>0.3 \\
>0.3 \\
0.3 \\
0.27 \\
0.18 \\
0.13 \\
0.06\end{array}$ \\
\hline 100 & $\begin{array}{r}-40 \\
-20 \\
0 \\
10 \\
40 \\
70 \\
100\end{array}$ & $\begin{array}{r}140 \\
120 \\
100 \\
90 \\
60 \\
30 \\
0\end{array}$ & $\begin{array}{r}>200 \\
>200 \\
187 \\
158 \\
102 \\
71 \\
54\end{array}$ & $\begin{array}{c}>0.3 \\
>0.3 \\
>0.3 \\
>0.3 \\
0.28 \\
0.18 \\
0.1\end{array}$ & $\begin{array}{r}122 \\
98 \\
80 \\
73 \\
56 \\
46 \\
39\end{array}$ & $\begin{array}{c}>0.3 \\
0.27 \\
0.21 \\
0.18 \\
0.11 \\
0.06 \\
0.03\end{array}$ \\
\hline
\end{tabular}

\section{References}

1. R. Roberts et al., Practure Toughness of Bridge Steels - Phase II Report, Lehigh University, Department of Transportation, Federal Highway Administration Report, FHWA-RD-74-59 (National Tech. Information Service PB-239-188), September, 1974.*

2. ASME Boiler and Pressure Vessel Code, Section XI, "Rules for Inservice Inspection of Nuclear Power Plant Components Article, A-4000 Material Properties," 1986 ed., The American Society of Mechanical Engineers, New York.t

3. "Standard Test Method for Plane-Strain Fracture Toughness of Metallic Materials," ASTM E399, American Society for Testing and Materials, $1983 . t$

4. J. G. Merkle, Union Carbide Corp. Nuclear Div., Oak Ridge Natl. Lab., An Bxamination of the Size Effects and Data Scatter observed in Small-Specimen Clearance Fracture Toughness Testing, NUREG/CR3672 (ORNL/TM-9088), April 1984.* 
5. D. C. Krouse, Bethlehem steel Corporation, letter to G. C. Robinson, Oak Ridge National Laboratory, July 20, 1988.

6. G. J. Buragino, S. S. Hansen, and D. C. Krouse, "Metallurgical Characterization of Jumbo Sizes," AISC National Engineering Conference, June 10, 1988.

7. J. W. Fisher and A. W. Pense, "Experience with Use of Heavy W Shapes in Tension", Pp. 18-1 to 18-47 in Proceedings - National Engineering Conference and Conference of Operating Personnel, May 1987.*

8. J. W. Fisher, A. W. Pense, and E. Kaufmann, NSF Engineering Research Center, Lehigh University, "Cracking and Toughness Problems in Jumbo Rolled Sections: Occurrence and Avoidance," Advanced Technology for Large Structural Systems publication, December 1987.

9. G. A. Knorovski, R. D. Krieg, and G. C. Allen, Jr., Sandia National Laboratories, Fracture Toughness of PWR Component Support, NUREG/ CR-3009 (SAND78-2347), February 1983.*

10. C. V. Robino et al., "The Fracture Behavior of A 588 Grade A and A 572 Grade 50 Weldment'," Welding Research Council Bulletin 330, January $1988 . \ddagger$

11. P. J. Konkol, "Effect of Long-Time Postweld Heat Treatment on Properties of Constructional-steel Weldments," Welding Research Council Bulletin 330 , January $1988 . \mp$

12. W. H. Munse, Structural Engineering Handbook, PP. 4-1 to 4-19, McGraw-Hil1 Book Co., New York, 1968.

13. I. Sihweil, Bechtel Corporation, "Florida Power \& Light Company Turkey Point Units $3 \& 4$ (Nuclear) Containment Building Interior Civil Structura1 Design," 1967-1968.

14. J. B. Sun, Florida Power and Light Co., letter to R. D. Cheverton, Oak Ridge National Laboratory, dated June 16, 1988 (FRN-88-447).

15. J. B. Sun, Florida Power and Light Co., letter to R. D. Cheverton, Oak Ridge National Laboratory, dated July 13, 1988 (FRN-88-537).

16. I. Sihweil, Bechtel Corporation, "Turkey Point Nos. 3 \& 4 Calculations, Reactor Supports, Calculation Sheets 1-17," Job. No. 5610, Oct. 31, 1966.

17. I. Sihweil, Bechtel Corporatton, "Turkey Point 3-4. 4 Reactor Support Cantilever Beam and R. S. Erection, Calculation Sheets 1-11, 14-20," Job No. 5610, Feb. 8, 1968.

18. I. Sihweil, Bechtel Corporation, "Turkey Point Unit 3 \& Reactor Support (Calculation Sheets A-B) and Reactor Vessel Supports-Design 
Loads (Calculation Sheets $1,2,4,5,7,7 a, 7 b, 8-21,21 a, 22-26)$," Job No. 5610 , Feb. 8, 1968.

19. I. Sihweil, Bechtel Corporation, "Turkey Point $3 \& 4$ Reactor Supports - Revision \& R. S. Design, Calculation Sheets 1-4," Job No. 5610, February 8, 1968.

20. I. Sihweil, Bechtel Corporation, "Turkey Point $3 \& 4$ R. S. Design, Calculation Sheets 1-4, 4a-4f, (3 unnumbered), 5-18," Job No. 5610 , February 1968.

21. J. G. Merkle, Union Carbide Corp. Nuclear Div., Oak Ridge Nat1. Lab., "Stress-Intensity Factors Estimates for Part-Through Surface Cracks in Plates Under Combined Tension and Bending," pp. 3-22 in Quarterly Progress Report on Reactor Safety Programs Sponsored by the Division of Reactor Safety Research for July-September 1974, ORNL/TM-4729, Vol. II. *

22. R. D. Cheverton et al., Union Carbide Corp. Nuclear Div., Oak Ridge Nat1. Lab., Applicability of LEFM to the Analysis of PWR Vessels Under LOCA-ECC Thermal Shock Conditions, NUREG/CR-0107 (ORNL/NUREG40), October 1978.*

23. R. D. Cheverton and S. E. Bolt, Union Carbide Corp. Nuclear Div., Oak Ridge Natl. Lab., Pressure Vessel Fracture studies Pertaining to a PWR, LOCA-ECC Thermal Shock: ExperimentS TSE-3 and TSE-4 and Updata of TSE-1 and TSE-2 Analysis, ORNL/NUREG-22, December 1977.*

24. H. Tada, P. C. Paris, and G. R. Irwin, The Stress Analysis of Cracks Handbook, Del Research Corporation, Millertown, Pa., 1973.

25. A. F. Liu, "Stress Intensity Factor for a Corner Flaw," Eng. Frac. Mech. 4, 175-79 (1972). ¥

26. J. C. Newman, Jr. and J. S. Raju, National Aeronautics and Space Administration, Stress-Intensity Factor Equations for Cracks in Three-Dimensional Finite Bodies, NASA Technical Memo 83200, August 1981.

27. W. F. Brown, Jr. and J. E. Srawley, "Plain Strain Crack Toughness Testing of High Strength Metallic Materials", Fig. 9, p. 15, ASTM STP 410, American Society for Testing and Materials, Philadelphia, 1966.

28. "Specification for Structural Joints Using ASTM A325 or A490 Bolts," American Institute of Steel Construction, Section 5 Installation, pp. 5-214, April 26, 1978.

*Available for purchase from National Technical Information Service, Springfield, Virginia 22161.

tAvailable from American National Standards Institute, 1430 Broadway, New York, New York 10018, Copyrighted.

favailable in public technical libraries. 


\section{CONCLUSIONS AND RECOMMENDATIONS}

\subsection{Conclusions}

1. Best-estimate minimum critical flaw sizes corresponding to the most severe credible loading condition at 32 EFPY are small enough to be of concern for both Trojan and Turkey Point.

2. Considering the type of structural components, flaws, and flaw locations evaluated for both the Trojan and Turkey Point vessel support structures, crack arrest is not likely if flaw propagation takes place.

3. A critical location for the flaws, referred to in item 1 , is in a portion of the support structure embedded in the concrete biological shield, making inspection for flaws in one critical area very difficult, if not impossible.

4. No specific safety factors were applied in the evaluation, and thus their consideration would reduce the size of the allowable flaws.

5. The use of the ASME $K_{I R}$ fracture-toughness curve for the Turkey Point best-estimate analysis does in a sense represent the application of a safety factor. This conservative approach was used because of a lack of system dynamic response data and specific-material fracturetoughness data.

6. Modification of the $\mathrm{K}_{\mathrm{IR}}$ curve for lack of plane-strain conditions at 11.8 EFPY was not considered for Turkey Point, but presumably would result in larger critical flaw sizes if it were. (It was considered in the Trojan analysis.)

7. Significant uncertainties in the calculation of critical flaw size result in a broad range of critical sizes. More definitive data on radiation-induced embrittlement, fracture toughness, and operating temperature could result in substantially larger critical flaw sizes. of course, the opposite is true as well.

8. The minimum critical flaw size for Trojan is associated with a somewhat unique design feature (grout hole in a critical structural member). Critical flaw sizes at other locations are considerably greater but not necessarily inconsequential.

9. Consistent with information supplied by the utility, the LOCA was used as the most severe loading condition for Turkey Point. A utility/NRC reevaluation of the need to do this, based perhaps on leakbefore-break considerations, could result in the definition of a less severe loading condition for critical-flaw-size evaluation. This could increase the calculated minimum critical flaw size substantially.

10. Low-cycle fatigue is not a mechanism for creating flaws of critical size.

11. Best-estimate minimum critical flaw depths calculated for operating times consistent with the present date (1988) are double the 32-EFPY value for Trojan, and the type and location of the two flaws are different. For Turkey Point, the type, location, and size of the minimum critical flaw are the same for both times.

12. For Turkey Point, significant unequal horizontal forces associated with variations in sliding friction in the components that accommodate radial thermal expansion may exist and can decrease the critical flaw size appreciably. 


\subsection{Recommendations}

1. An effort should be made to reduce the uncertainties in the material and operating data used as input to the evaluation. Parameters of particular concern are

(a) interpretation and extrapolation of the HFIR surveillance data;

(b) fracture-toughness of specific materials, including NDTTo;

(c) credible static and dynamic loading conditions (Turkey Point); and

(d) operating temperature.

2. The likelihood of the existence of flaws of estimated critical size and larger should be evaluated. An examination of inspection procedures and results, if and when they become available, may be useful in this regard.

3. Because shield-tank and long-column supports are exposed to the maximum fluxes in the cavity, a review of utility/industry evaluations of these structures or an independent evaluation should be conducted.

4. The variation in horizontal loads resulting from unequal friction in the components that accommodate thermal radial expansion should be quantified: 
$181 / 182$

APPENDIXES 
Appendix 1

TROJAN SUPPORT BEAM ANALYSIS INPUT AND OUTPUT FILES 
trojam muclear rlamt : reactor vessg support

\begin{tabular}{|c|c|c|c|c|c|}
\hline $\begin{array}{l}\text { Deas } \\
\text { linde } \\
\text { meaber }\end{array}$ & $\begin{array}{c}\text { 'p. } \\
\text { Ordimte. } \\
\text { (in.) }\end{array}$ & $\begin{array}{l}\text { lemgth of } \\
\text { Foundation } \\
\text { (In.) }\end{array}$ & $\begin{array}{l}\text { Foundationa } \\
\text { Uidth } \\
\text { (in./in.) }\end{array}$ & $\begin{array}{c}\text { Foundotion } \\
\text { Ares } \\
\text { (ia.A) }\end{array}$ & $\begin{array}{l}\text { Foundation } \\
\text { nodulus } \bar{E} \\
\text { (ib/in.A }\end{array}$ \\
\hline 1 & 0 & & & & \\
\hline 2 & $11.35^{\circ}$ & 3.31 & $32 . \pi 5$ & 102.4025 & 6000900 \\
\hline 3 & 13.63 & 1.25 & 16 & 20 & 29000000 \\
\hline 4 & 16.5 & 4.5 & 44.23 & IM.!!:5 & 60500000 \\
\hline s & 19 & 0. & & & \\
\hline 6 & 21 & 4.3 & 44.23 & 199.125 & 6000000 \\
\hline 7 & 23 & 0 & & & \\
\hline 8 & 25.5 & 4.5 & 44.25 & 199.125 & 6000000 \\
\hline 9 & 28.37 & 1.25 & 16 & 20 & 290130060 \\
\hline 10 & 31.54 & 5.09 & 32.75 & 166.6975 & 6005000 \\
\hline 11 & 36.63 & 3.69 & 32.73 & 156.3975 & 6000000 \\
\hline 12 & 41.72 & 5.99 & 32.73 & 166.6975 & 6003000 \\
\hline 13 & 46.81 & 5.09 & 32.75 & 166.6975 & 6000000 \\
\hline 14 & 51.9 & 5.69 & 32.75 & 166.6775 & 6000000 \\
\hline 15 & 36.99 & 5.09 & 32.73 & 166.6975 & 6000000 \\
\hline 16 & 62.18 & 3.09 & 32.75 & 156.6975 & 6000090 \\
\hline 17 & 65.16 & $1.06 \varepsilon$ & 15.5 & 16.451. & - 29000000 \\
\hline 18 & 67.79 & 4.21 & 35.3? & 148.4919 & 6000000 \\
\hline 19 & 72 & 4.21 & 35.39 & 148.9919 & 6000000 \\
\hline 20 & 76.21 & 4.21 & 35.39 & 148.5919 & 6000000 \\
\hline 21 & 78.844 & 1.062 & 15.5 & 16.461 & 29000000 \\
\hline
\end{tabular}

Table B. Microsafe 2-D input file

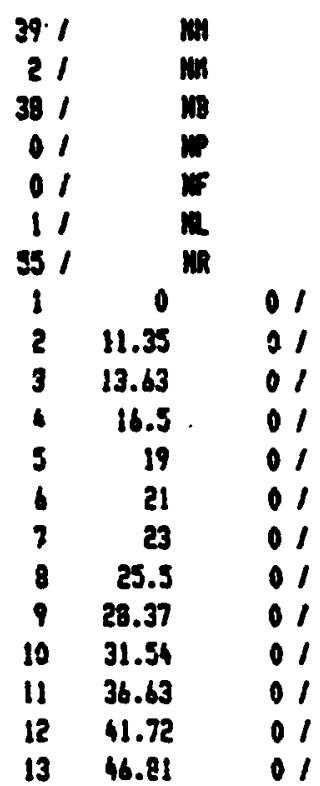

\begin{tabular}{|c|c|c|}
\hline 14 & 51.9 & 01 \\
\hline 15 & 56.99 & 01 \\
\hline 13 & 62.08 & 01 \\
\hline 17 & 65.16 & 0 \\
\hline 10 & 67.79 & 0 \\
\hline 19 & $\boldsymbol{\eta}$ & 0 \\
\hline 20 & 76.21 & 0 \\
\hline 21 & 78.84 & 0 \\
\hline 22 & 11.35 & -29 \\
\hline 23 & 13.63 & -281 \\
\hline 24 & 16.5 & -29 \\
\hline २ङ & 21 & -29 \\
\hline 23 & 25.5 & -29 \\
\hline 27 & 28.37 & -29 \\
\hline 29 & 31.54 & -29 \\
\hline 29 & 36.63 & -29 \\
\hline 30 & 41.72 & -291 \\
\hline 31 & 46.81 & -29 \\
\hline 2 & 31.9 & -29 \\
\hline & & \\
\hline
\end{tabular}


Table B (continued)

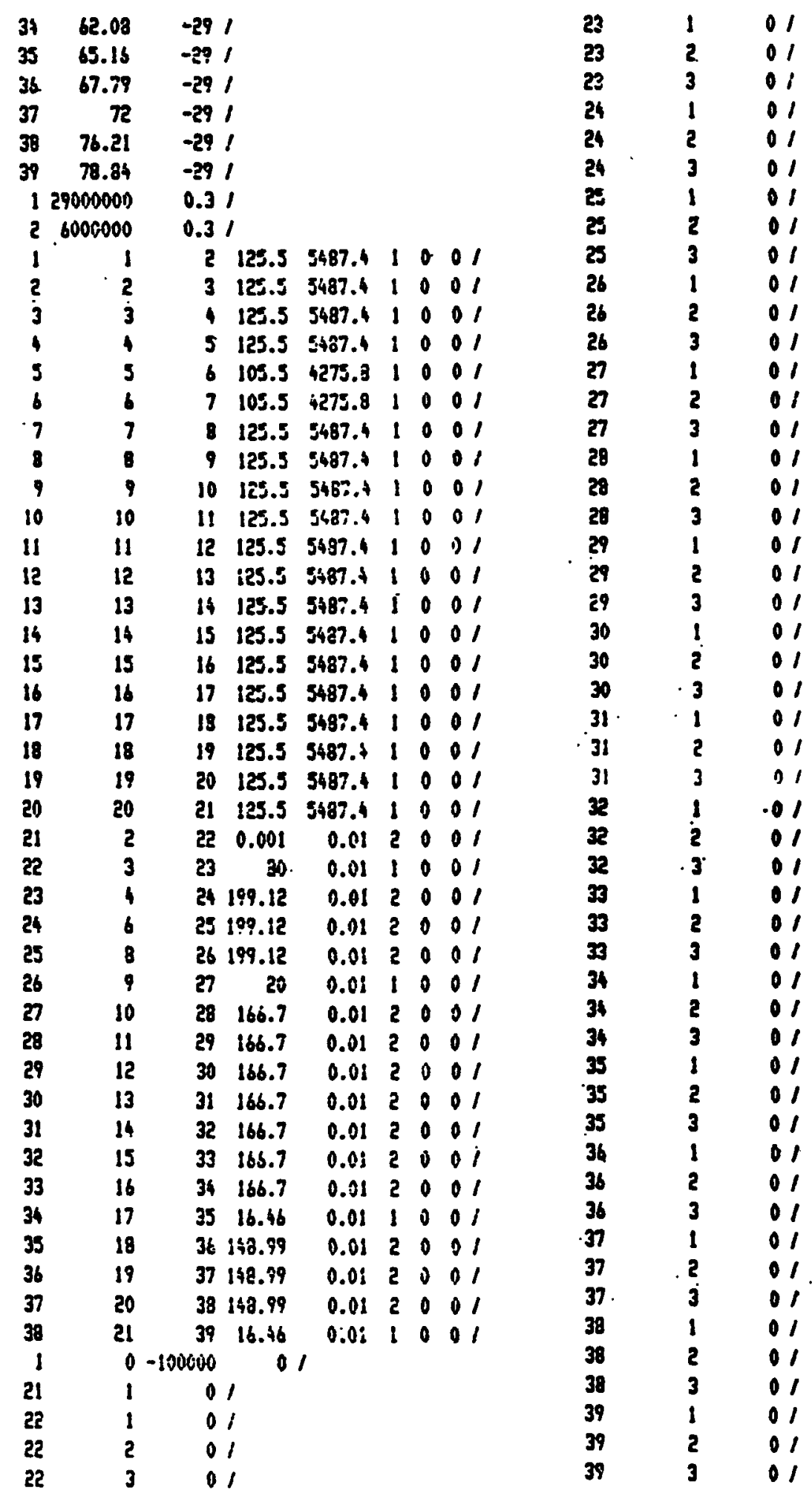


Table C. Solution (a): inboard

concrete assumed load bearing

Mode Displacenents

\begin{tabular}{|c|c|c|}
\hline Node & $\dot{y}$ & Dotga \\
\hline$i$ & $0-0.00437$ & 0.000226 \\
\hline 2 & $0-0.00196$ & 0.009185 \\
\hline 3 & $0-0.00 \mathrm{i} 56$ & 0.000168 \\
\hline 4 & $0-0.00111$ & 0.000145 \\
\hline 5 & $\begin{array}{lll}0 & -0.00077\end{array}$ & 0.000124 \\
\hline$b$ & $0-0.00054$ & 0.000104 \\
\hline 7 & $0-0.00036$ & 0.000085 \\
\hline .8 & $0 \cdot-0.00017$ & 0.000067 \\
\hline 9. & $0-0.00000$ & 0.00005 \\
\hline 10 & 00.000129 & 0.000034 \\
\hline 11 & 00.000248 & 0.000014 \\
\hline .12 & 00.000284 & 0.000001 \\
\hline 13 & 00.000269 & -0.00000 \\
\hline 14 & 00.000226 & -0.00001 \\
\hline 13 & 00.000171 & -0.00001 \\
\hline 16 & 00.009114 & -0.00001 \\
\hline 17 & 00.00008 & $-0.0000 i$ \\
\hline 18. & 00.000052 & -0.00091 \\
\hline 19 & 00.000009 & -0.00001 \\
\hline 20 & $0-0.00003$ & -0.00001 \\
\hline 21 & $0-9.00006$ & -0.00001 \\
\hline 22 & $0 \quad 0$ & 0 \\
\hline 23 & 0 & 0 \\
\hline 24 & 0 & 6 \\
\hline 25 & 0 & 0 \\
\hline 26 & 0 & 0 \\
\hline 27 & 0 & 0 \\
\hline 28 & 0 & - \\
\hline 29 & 0 & 0 \\
\hline 30 & 0 & 0 \\
\hline 31 & 0 & 0 \\
\hline 32 & 0 & 0 \\
\hline 33 & 0 & 0 \\
\hline 34 & 0 & 0 \\
\hline 35 & 0 & 0 \\
\hline 36 & 0 & 0 \\
\hline 37 & 0 & 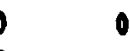 \\
\hline 38 & 0 & 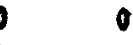 \\
\hline 39 & 0 & . \\
\hline
\end{tabular}

Dean Corn er forces

\begin{tabular}{|c|c|c|c|c|c|c|c|c|}
\hline BEAN & & $!$ & EXI & Fỳ & MZI & FX2 & FY2 & nZ2 \\
\hline 1 & 1 & 2 & 0 & -100000 & 0 & 0 & 100000 & \\
\hline 2 & 2 & 3 & 0 & -55921 & 1134999 & 0 & 35921 & \\
\hline 3 & 3 & 4 & 0 & -24680 & 1262491 & 0 & 24680 & \\
\hline 4 & 4 & 5 & 0 & 21161 & 1333322 & 0 & -21161 & \\
\hline 3 & s & 6 & ? & $2 ! 1 s \mid$ & 1230420 & 0 & -21161 & -1135000 \\
\hline$b$ & 6 & 7 & $-i$ & 43762 & 1238079 & 1 & -43762 & -1242498 \\
\hline 7 & 7 & 8 & -1 & 43762 & 1150574 & 1 & -43762 & -1333323 \\
\hline
\end{tabular}


Table C (continued)

\begin{tabular}{|c|c|c|c|c|c|c|c|c|}
\hline 8 & 8. & 9 & -1 & 50798 & 1041168 & -1 & $-50728-$ & -1280420 \\
\hline 9 & 9 & 10 & -1 & 50842 & 895404 & 1 & $-50942-$ & -1239099 \\
\hline 10 & 10 & "I & -1 & 46338 & $734234^{\circ}$ & 1 & $-46388-$ & -1150574 \\
\hline It & 11 & 12 & -1 & 37851 & 498121 & 1 & -37851 & -1041168 \\
\hline 12 & 12 & 13 & -1 & 28069 & 305460 & 1 & -28059 & -895406 \\
\hline 13 & 13 & 14 & -1 & 18893 & 162590 & 1 & -18803 & -734235 \\
\hline 14 & 14 & 15 & -1 & 11012 & 66882 & 1 & -ilote & -488121 \\
\hline 15 & 15 & 16 & -1 & 5106 & 10833 & 1 & -5106 & -305460 \\
\hline 16 & 16 & 17 & -1 & 1176 & -15158 & 1 & -1176 & -152590 \\
\hline 17 & 17 & 18. & -1 & -142 & -18781 & 1 & 142 & -66882 \\
\hline 18 & 18 & $19^{\circ}$ & -1 & -1746 & -18403 & 1 & 1746 & -10233 \\
\hline 19 & 19 & 20 & -1 & -2013 & -11057 & 1 & 2013 & 15159 \\
\hline 20 & 20 & 21 & -1 & -981 & -2591 & 1 & 9ด1 & 18781 \\
\hline 21 & 2 & 22 & $?$ & -44079 & 2 & 0 & 44079 & 18408 \\
\hline 22 & 3. & 23 & 0 & -31241 & 7 & 0 & 31241 & 11057 \\
\hline 23 & 4 & 24 & 0 & -45840 & 1 & 0 & 45840 & 2581 \\
\hline 24 & 6 & 25 & 0 & -22502 & 1 & 0 & 22602 & 0 \\
\hline 25 & 8 & 26 & 0 & $-702 b$ & 1 & 0 & 7026 & 1 \\
\hline 26 & 9 & 27 & 0 & -54 & 2 & 0 & 54 & 3. \\
\hline 27 & 10 & 28 & 0 & 4454 & 6 & 0 & $-\$ 454$ & 1 \\
\hline 23 & 11. & 29 & 0 & 8537 & 0. & 0 & -8537 & 0 \\
\hline 29 & 12 & 30 & 0 & 9782 & 0 & 0 & -9782 & 0 \\
\hline 30 & 13 & 31 & 0 & 9265 & 0 & 0 & -9265 & 1 \\
\hline 31 & 14 & 32 & 0 & 7792 & 0 & 0 & -7792 & 0 \\
\hline 32 & 13 & 33 & 0 & 5905 & 0 & 0 & -5905 & 0 \\
\hline 33 & 16 & 34 & 0 & 3930 & 0 & 0 & -3930 & 0 \\
\hline 34 & 17 & 35 & 0 & 1318 & 0 & 0 & -1318 & 0 \\
\hline 35 & 18 & 36 & 0 & 1604 & 0 & 0 & -1604 & 0 \\
\hline 36 & 19 & 37 & 0 & 267 & 0 & 0 & -267 & 0 \\
\hline 37 & 20 & 38 & 0 & -1032 & 0 & 0 & 1032 & 0 \\
\hline 38 & 2! & 39 & 0 & -981 & 0 & 0 & 981 & \\
\hline
\end{tabular}

Beax Loads and Stresses

\begin{tabular}{|c|c|c|c|c|c|c|c|c|}
\hline Dean & 1 & J & PAX & $\operatorname{sax}$ & SHI & SHR & BH & Bhe \\
\hline 1 & 1 & 2 & 0 & 0 & 100000 & 100000 & & -1135000 \\
\hline 2 & $?$ & 3 & 0 & 0 & 55721 & 55921 & -1134979 & -1252498 \\
\hline 3 & 3 & 1 & 0 & 0 & 24680 & 24680 & -1262492 & -1333323 \\
\hline 4 & 4. & 5 & 0 & 0 & -21161 & -21161 & $-133332 ?$ & -1280420 \\
\hline 5 & 5 & 6 & 0 & 0 & -21161 & $-21 ! 61$ & -1280420 & -1238099 \\
\hline 6 & $b$ & 7 & 1 & 0 & -43762 & -43762 & -1238098 & -1150574 \\
\hline 7 & 7 & 8 & $\boldsymbol{I}$ & 0 & -43762 & -43762 & -1150574 & -1041168 \\
\hline 8 & 8 & 9 & $\cdot 1$ & 0 & -50758 & -50798 & -1041188 & -895406 \\
\hline 9 & 9 & 10 & 1 & 0 & -50842 & -50842 & -895404 & -734235 \\
\hline 10 & $10^{\circ}$ & II & 1 & 0 & -46388 & -46388 & -734234 & -498121 \\
\hline 11 & 18 & 12 & 1 & 0 & -37851 & -37851 & -498121 & -305460 \\
\hline 12 & 12 & 13 & $i$ & 0 & -28069 & -23069 & -305460 & -162570 \\
\hline 13 & 13 & 14 & I & 0 & -18903 & -18303 & -162590 & -66892 \\
\hline 16 & 14 & 15 & 1 & 0 & -11012 & -11012 & -66682 & -16833 \\
\hline 15 & 15 & 16 & 1 & 0 & $-510 s$ & -5106 & -10833 & 15159 \\
\hline 16 & 16 & 17 & 1 & 0 & -1176 & -1176 & 15158 & 18791 \\
\hline 17 & 17 & 18 & $i$ & 0 & 142 & i42 & 18781 & $19+08$ \\
\hline
\end{tabular}


Table C (continued)

\begin{tabular}{|c|c|c|c|c|c|c|c|c|}
\hline 18 & 18 & 19 & 1 & 0 & 1746 & 1746 & 18408 & 11057 \\
\hline 19 & 19 & 20 & 1 & 0 & 2013 & 2013 & 11057 & 2581 \\
\hline 20 & 20 & 21 & 1 & 0 & 981 & 991 & 2581 & 0 \\
\hline 21 & 2 & 22 & $-\$ 4079$ & -407 & 0 & 0 & -2 & 1 \\
\hline 22 & 3 & 23 & -31241 & $-156 ?$ & 0 & 0 & -7 & 3 \\
\hline 23 & 4 & 24 & -45840 & -230 & 0 & 0 & 1 & 1 \\
\hline 24 & 6 & 25 & -22602 & -114 & 0 & ? & -1 & 0 \\
\hline 25 & 8. & 26 & -7026 & -35 & 0 & 0 & -1 & 0 \\
\hline 26 & 9 & 27 & -54 & -3 & O & 0 & -2 & 1 \\
\hline 27 & 10 & 28 & 4434 & 27 & 0 & 0 & 0 & 0 \\
\hline 28 & 11: & 27 & 6537 & $5 t$ & 0 & 0 & 0 & 0 \\
\hline 29 & 12. & 30 & $m 72$ & 58 & 0 & 0 & 0 & 0 \\
\hline 30 & $13^{\circ}$ & 31 & 9265 & 56 & 0 & 0 & 0 & 0 \\
\hline 31 & 14 & 32 & 7792 & 47 & 0 & 0 & 0 & 0 \\
\hline 32 & 13 & 30 & 5\%5s & 35 & 0 & 0 & 0 & 0 \\
\hline 33 & 16 & 34 & 3330 & 24 & 0 & 0 & 0 & 0 \\
\hline 34 & 17 & 35 & 1318 & 80 & 0 & 0 & 0 & 0 \\
\hline 35 & 18 & 36 & 1604 & If & 0 & 0 & 0 & 0 \\
\hline 36 & 19 & 3̦; & 267 & 2 & 0 & 0 & 0 & 0 \\
\hline 37 & 20 & 38 & -1032 & -7 & 0 & 0 & 0 & 0 \\
\hline 38 & 21 & 39 & . & -60 & 0 & 0 & 0 & 0 \\
\hline
\end{tabular}

Mode internal Forcis and pieactions

\begin{tabular}{|c|c|c|c|c|c|}
\hline Bode & 1 & $y$. & FI & $\mathbf{F Y}$ & $n z$ \\
\hline 1 & 0 & 0. & 0 & 0 & 0 \\
\hline 2 & 11.35 & 0 & 0 & 0 & 0 \\
\hline 3 & 13.63 & 0 & 0 & 0 & 0 \\
\hline 4 & 16.5 & 0 & 0 & 0 & 0 \\
\hline 5 & 19 & 0 & 0 & 0 & 0 \\
\hline 6 & $2 t$ & 0 & 0 & 0 & 0 \\
\hline 7 & 23 & 0 & 0 & 0 & 0 \\
\hline 8 & 25.5 & 0 & 0 & 0 & 0 \\
\hline 9 & 28.37 & 0 & 0 & 0 & 0 \\
\hline 10 & 3i.54 & 0 & 0 & 0 & 0 \\
\hline 11 & 36.63 & 0 & 0 & 0 & 0 \\
\hline 12 & 41.72 & 0 & 0 & 0 & 0 \\
\hline 13 & 46.8! & 0 & 0 & 0 & 0 \\
\hline 14 & 31.9 & 0 & 0 & 0 & 0 \\
\hline 15 & 56.99 & 0 & 0 & 0 & 0 \\
\hline 16 & 62.02 & 0 & 0 & 0 & 0 \\
\hline 17 & 65.16 & 0 & 9 & 0 & 0 \\
\hline 18 & 67.79 & 0 & 0 & 0 & 0 \\
\hline 19 & 72 & 0 & 0 & 0 & 0 \\
\hline 20 & 26.21 & 0 & 0 & 0 & 0 \\
\hline 21 & 78.34 & 0 & I & 0 & 0 \\
\hline 22 & 11.35 & -29 & 0 & 44079 & 1 \\
\hline 23 & 13.63 & -29 & 0 & 31241 & 3 \\
\hline 24 & 16.3 & -27 & 0 & 45840 & 1 \\
\hline 23 & 21 & -29 & 0 & 22602 & 0 \\
\hline 26 & 25.5 & -29 & 0 & 7025 & 0 \\
\hline 27 & 23.37 & -29 & 0 & 54 & 1 \\
\hline
\end{tabular}


Table C (continued)

$\begin{array}{rrrrrr}28 & 31.54 & -29 & 0 & -4654 & 0 \\ 29 & 36.63 & -29 & 0 . & -8537 & 0 \\ 30 & 41.72 & -29 & 0 & -9792 & 0 \\ 31 & 46.81 & -29 & 0 & -9265 & 0 \\ 32 & 51.9 & -29 & 0 & -7792 & 0 \\ 33 & 56.99 & -29 & 0 & -5905 & 0 \\ 34 & 62.08 & -29 & 0 & -3930 & 0 \\ 35 & 65.16 & -29 & 0 & -1313 & 0 \\ 36 & 67.79 & -29 & 0 & -1604 & 0 \\ 37 & 72 & -29 & 0 & -267 & 0 \\ 39 & 76.21 & -29 & 0 & 1032 & 0 \\ 39 & 78.24 & -29 & 0 & 981 & 0\end{array}$

Table D. Solution (b): inner concrete assumed non load bearing

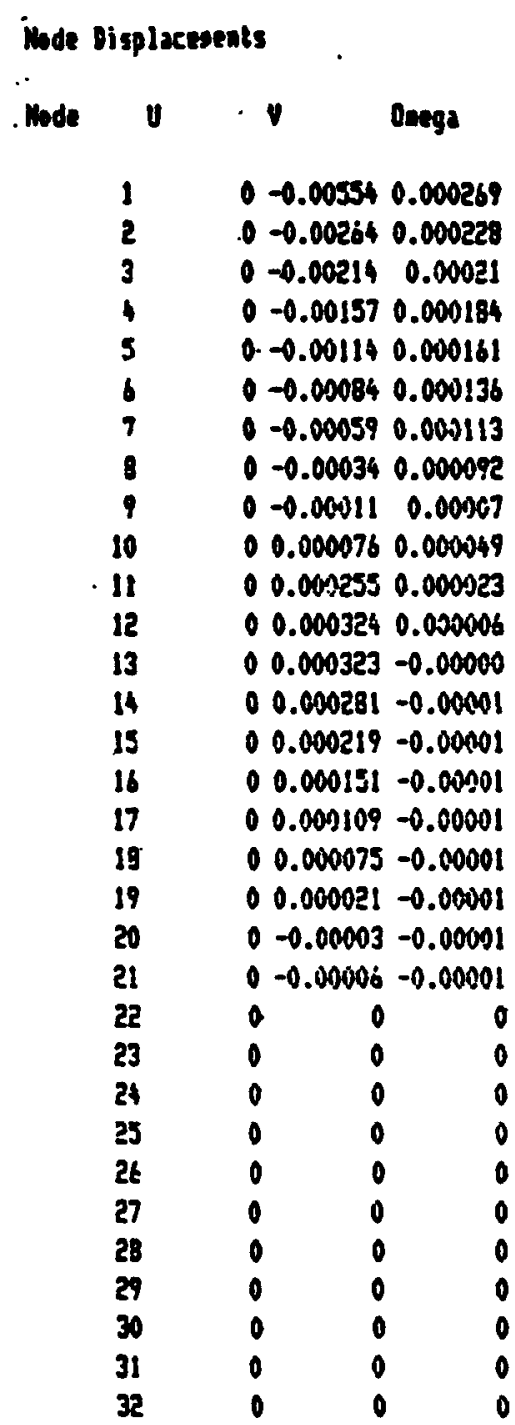


Table D (continued)

$\begin{array}{llll}33 & 0 & 0 & 0 \\ 34 & 0 & 0 & 0 \\ 35 & 0 & 0 & 0 \\ 36 & 0 & 0 & 0 \\ 37 & 0 & 0 & 0 \\ 39 & 0 & 0 & 0\end{array}$

Vean Cormer- Forces

\begin{tabular}{|c|c|c|c|c|c|c|c|c|}
\hline DEAM & $I$ & ) & FII & FYI & REI & F12 & FY2 & $\mathbf{M 2 2}$ \\
\hline 1 & 1 & $2^{\circ}$ & 0 & -100000 & 0 & 0 & 100000 & -1135000 \\
\hline 2 & 2 & 3 & 0 & -99999 & 1134993 & 0 & 99999 & -1362997 \\
\hline 3 & 3 & 1 & -1 & - -57173 & 13629:88 & I & 57173 & -1527075 \\
\hline 1 & 4 & 5 & -1 & 7675 & 1527073 & 1 & -7675 & -1507825 \\
\hline 5 & 3 & $b$ & -1 & 7675 & 1507895 & 1 & -7675 & -1492535 \\
\hline 6 & 6 & 7 & -1 & 42537 & 1492534 & 1 & -42537 & -1407460 \\
\hline 7 & 7 & 8 & -1 & 42537 & 1407460 & 1 & -42533 & -1301119 \\
\hline 1 & 1 & 9 & -1 & 56615 & 1301113 & 1 & -56615 & -1139632 \\
\hline 1 & 9 & 10 & -1 & 58934 & 1138629 & 1. & -58834 & -952125 \\
\hline 10 & 10 & 11 . & -1 & ssets & 952125 & 1 & $-5 \div 215$ & :665980 \\
\hline 11 & 11 & 12 & -1 & 47427 & 665990 & 1 & -47427 & -424588 \\
\hline 12 & 12 & 13 & -1 & 36251 & 424589 & 1 & -36251 & -240071 \\
\hline 13 & 13 & 14 & -1 & 25124 & 240071 & 1 & -25124 & -ILE198 \\
\hline 14 & 14 & 15 & -1 & 15449 & 112189 & 1 & -15449 & -32555 \\
\hline 15 & 15 & 16 & -1 & 7899 & 33555 & 1 & -7899 & 6653 \\
\hline 16 & 16 & 17 & -1 & 2701 & -6653 & 1 & -2701 & 14972 \\
\hline 17 & .17 & 18 & -1 & $\$ 00$. & -16972 & 1 & -900 & 17339 \\
\hline .18 & 18 & 19 & -1 & -1406 & -17339 & 1 & 1406 & 11421 \\
\hline 19 & .19 & 20 & -1 & -2048 & $-! 1+21$ & 1 & 2048 & 2799 \\
\hline$\theta$ & 20 & 2i & -1 & -1064 & -2799 & $i$ & 1064 & 0 \\
\hline 21 & 2 & 22 & 0 & -1 & 2 & 0 & 1 & \\
\hline 22 & 3 & 23 & 0 & -42827 & 8 & 0 & $\$ 2827$ & 4 \\
\hline 23 & 4 & 24 & 0 & -64948 & 2 & 0 & 64948 & 1 \\
\hline 24 & 6 & 25 & 0 & -34861 & 1 & 0 & 34861 & I \\
\hline 25 & 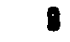 & 26 & 0 & -14079 & 1 & 0 & 14079 & 0 \\
\hline 26 & 9 & 27 & 0 & -2217 & 3 & 0 & 2217 & 1 \\
\hline 27 & 10 & 28 & 0 & 2619 & 0 & 0 & -2619 & 0 \\
\hline 2 & 11 & 29 & 0 & 8789 & 0 & 0 & -8789 & 0 \\
\hline 89 & 12 & 30 & 0 & 11176 & 0 & 0 & -11176 & 0 \\
\hline 30 & 13 & 31 & 0 & 11126 & 0 & 0 & $-111 \geq 6$ & 0 \\
\hline 31 & 14. & 32 & 0 & 9676 & 0 & 0 & -9676 & 0 \\
\hline 32 & 15 & 33 & 0 & 7549 & 0 & 0 & -7549 & 0 \\
\hline 33 & 16 & 39 & 0 & 5158 & 0 & 0 & -5199 & 0 \\
\hline 34 & 17 & 35 & 0 & 1801 & -1 & 0 & -1201 & 0 \\
\hline 35 & 18 & 36 & 0 & $2300^{\circ}$ & 0 & 0 & -2306 & 0 \\
\hline 36 & $1 ?$ & 37 & 0 & 342 & 0 & 0 & -642 & 0 \\
\hline 37 & 20 & 38 & 0 & -984 & 0 & 0 & 584 & \\
\hline 39 & 21 & 39 & 0 & -1064 & 0 & 0 & 1064 & \\
\hline
\end{tabular}


Table D (continued)

Jeas Loads and Stresses

\begin{tabular}{|c|c|c|c|c|c|c|c|c|}
\hline seso & 1 & J & PaX & $\cdot \operatorname{sen} x$ & SNI & SH2 & Bnt & BH? \\
\hline 1 & $\cdot 1$ & 2 & 0 & & 100403 & 100000 & & 1135000 \\
\hline 2 & 2 & 3 & 0. & 0 & 9999 & $99599-$ & $-1134793-$ & -1362997 \\
\hline 3 & 3 & 4 & 1 & 0 & 57173 & 57173 - & $-1362989-1$ & 1527075 \\
\hline 4 & .4 & 3 & 1 & 0 & -7675 & -7675 & $-1523073-$ & 1907ess \\
\hline 3 & $\mathbf{3}$ & 6 & 1 & 0 & -7675 & -7675 & $-1507995-1$ & i492335 \\
\hline b & $b$ & 7 & 1 & $?$ & -42537 & $-42537-$ & $-1492536-1$ & 1407460 \\
\hline 7 & 7 & - & 1 & 0 & -42537 & -42537 & $-1407460-1$ & 1301119 \\
\hline 1 & 8 & 1 & 1 & 0 & -56615 & $-56615-$ & $-1301118-1$ & 113853? \\
\hline 9 & 1 & 10 & 1 & 0 & -580034 & -58654 & -1138629 & -952123 \\
\hline 10 & 10 & 11 & 1 & 0 & -56213 & -56215 & -952125 & -665990 \\
\hline 11 & 11 & 12 & 1 & 0 & -47427 & -47427 & -665990 & -424589 \\
\hline 12 & 12 & 13 . & 1 & $?$ & -36231 & -36251 & -424580 & -240071 \\
\hline 13 & 13 & 14 & 1 & 0 & -23124 & -25124 & -240071 & -112188 \\
\hline 14. & 14 & 15 & 1 & 0 & -15449 & -15449 & -112188 & -33555 \\
\hline 15 & 15 & 16 & 1 & 0 & -7899 & -7899 & -33555 & 6653 \\
\hline 16 & 16 & 17 & 1 & 0 & -2701 & -2701 & 6533 & 16772 \\
\hline 17 & 17 & 18 & 1 & 0 & -900 & -900 & 14972 & 17339 \\
\hline 18 & 18 & 19 & 1 & 0 & 1606 & 1406 & 17339 & 11421 \\
\hline 19 & 19 & 20 & 1 & 0 & 2040 & 2048 & 11421 & 279 \\
\hline 20 & 20 & 21 & .1 & 0 & 1064 & 1064 & 2799 & 0 \\
\hline 21 & 2 & 22 & -1 & -547 & - & 0 & -2 & 1 \\
\hline 22 & 3 & 23 & -42827 & $-214 i$ & - & $0^{\circ}$ & -8 & 1 \\
\hline 23 & 4 & 24 & -64008 & -326 & D & 0 & -2 & 1. \\
\hline 24 & 6 & 23 & -34661 & -173 & 0 & 0 & -1 & $l$ \\
\hline 25 & $!$ & 26 & $-160 \pi 9$ & -71 & ? & $0^{\circ}$ & -1 & 0 \\
\hline 26 & 1 & 27 & -2219 & $-I I I$ & 0 & .0 & -3 & I \\
\hline 27 & .10 & a & 2619 & - 16 & 0 & 0 & 0 & $\bullet$ \\
\hline 8 & $\mathbf{1 1}$ & 29 & $m$ & 53 & 0 & 0. & 0 & 0 \\
\hline 8 & 12 & $\mathbf{3 0}$ & 11176 & 67 & 0. & 0 & 0 & 0 \\
\hline 30 & 13 & 31 & 11126 & 67 & $\bullet$ & 0 & 0 & 0 \\
\hline 31 & 14 & 32 & 9676 & 50 & 0 & 0 & 0 & 0 \\
\hline 32 & 13 & 35 & $730^{\circ}$ & 45 & 0 & 0 & 0 & 0. \\
\hline 33 & 16 & 3 & $51 \%$ & 31 & 0 & 0 & 0 & 0 \\
\hline 34 & 17 & 3 & 1001 & 109 & - & 0. & 1 & 0 \\
\hline 35 & 18 & 36. & $2306^{\circ}$ & 15 & 0 & 0 & 0 & 0 \\
\hline 36 & 19. & 37 & 64 & 1 & $\cdot 0$ & 0 & 0 & 0 \\
\hline 37 & 20 & 39 & -984 & -7 & 0 & 0 & 0 & 0 \\
\hline 38 & 21 & 39 & -1064 & -65 & 0 & 0 & 0 & $Q$ \\
\hline
\end{tabular}

Wode Internsl foress and Reactions

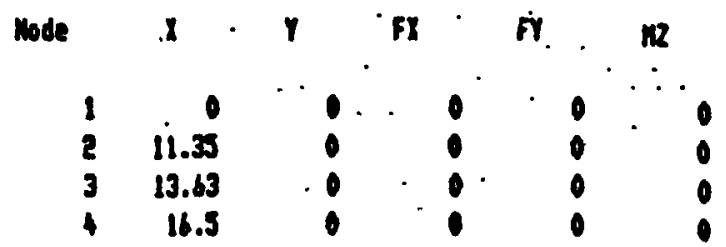


Table D (continued)

\begin{tabular}{|c|c|c|c|c|c|}
\hline 5 & 19 & 0 & 0 & 0. & -0 \\
\hline 6 & 21 & 0 & $.0^{\circ}$ & 0 & 0 \\
\hline 7 & 23 & 0 & 0 & $0^{\circ}$ & 0 \\
\hline 8 & 25.5 & 0 & 0 : & 0 & 0 \\
\hline 9 & 28.37 & 0 & 0 & 0 & 0 \\
\hline 10 & 31.54 & 0 & 0 & 0 & 0 \\
\hline 11 & 36.63 & 0 & 0 & $\theta$ & 0 \\
\hline i2 & 41.72 & 9 & 0 & 0 & 0 \\
\hline 13 & 46.81 & 0 & 0 & 0 & 0 \\
\hline 14 & $5: .9$ & 0 & 0 & 0 & 0 \\
\hline 15 & 36.99 & D. & 0 & 0 & 0 \\
\hline 16 & 62.08 & 0 & 0 & 0 & 0 \\
\hline 17 & 65.16 & 0 & 0 & 0 & 0 \\
\hline 18 & 67.79 & 0 & 0 & 0 & 0 \\
\hline 19 & $\eta 2$ & 0 & e. & 0 & 0 \\
\hline 20 & 76.21 . & .0 & 6 & 0 & 0 \\
\hline 21 & '7R.84 & - & 1 & 0 & 0 \\
\hline 22 & 11.35 & -29 & 0. & 1 & 1 \\
\hline 23 & 13.63 & -29 & 0 & 42827 & 4 \\
\hline 24 & 16.5 & -27 & 0 & 64848 & 1 \\
\hline 23 & 21 & -29 & 0 & 34Es1: & 1 \\
\hline 26 & 25.5 & -28 & 0 & 14079 & 0 \\
\hline 27 & 28. 37 & -29 & 0 & 2219 & 1 \\
\hline 29 & 31.54 & -29 & 0 & -2619 & 0 \\
\hline 29 & $3 j .63$ & -29 & 0 & -8798 & 0 \\
\hline 30 & 41.72 & -29 & 0 & -11176 & 0 \\
\hline $3 !$ & 43.81 & -29 & 0 & -11125 & 0 \\
\hline 32 & 51.9 & -29 & 0 & -9676 & 0 \\
\hline 33 & 5.99 & -29 & 0 & -7549 & 0 \\
\hline 34 & t2.08 & -29 & 0. & -.5198 & 0 \\
\hline 35 & 65.16 & -29 & 0 & -1801 & 0 \\
\hline 36 & 67.79 & -29 & 0 & -2306 & $\theta$ \\
\hline 37 & 72 & -29 & 0 & -642 & 0 \\
\hline 38 & 76.21 & -29 & 0. & 984 & 0 \\
\hline 39 & 73.84 & -29 & 0 & 1066 & 0 \\
\hline
\end{tabular}

Table E. Foundation reaction: inner concrete load bearing

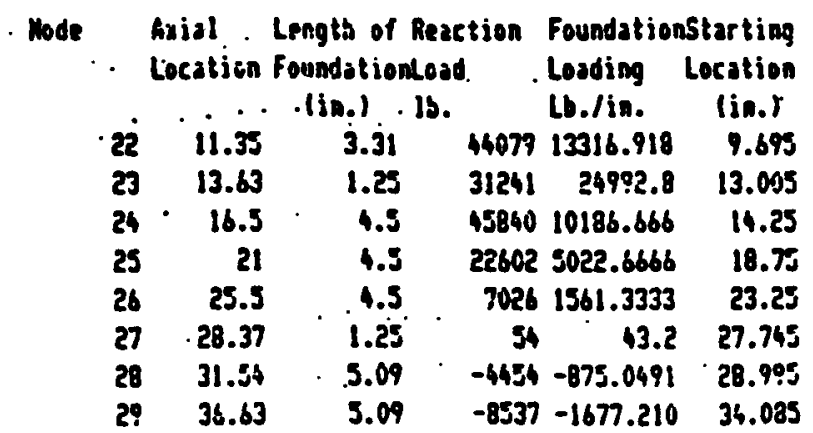


$193 / 194$

Table E (continued)

$\begin{array}{rrrrrr}30 & 41.72 & 5.09 & -9782 & -1921.297 & 39.175 \\ 31 & 46.81 & 5.09 & -9265 & -1825.235 & 44.265 \\ 32 & 31.9 & 5.09 & -7792 & -1530.844 & 49.355 \\ 33 & 56.99 & 5.09 & -5905 & -1160.117 & 54.645 \\ 34 & 50.052 & 5.09 & -3930 & -772.1021 & 55.507 \\ 35 & 65.16 & 1.062 & -1318 & -1241.054 & 64.629 \\ 30 & 67.79 & 4.21 & -1604 & -380.7976 & 65.685 \\ 37 & 72 & 4.21 & -267 & -63.42042 & 69.995 \\ 38 & 73.062 & 4.21 & 1032 & 245.13064 & 70.957 \\ 39 & 78.844 & 1.062 & 981 & 923.72881 & 78.313 \\ & & . & 923.72891 & 79.375\end{array}$

Foundation Peaction : Innar Concrete Hot Losd Bearing

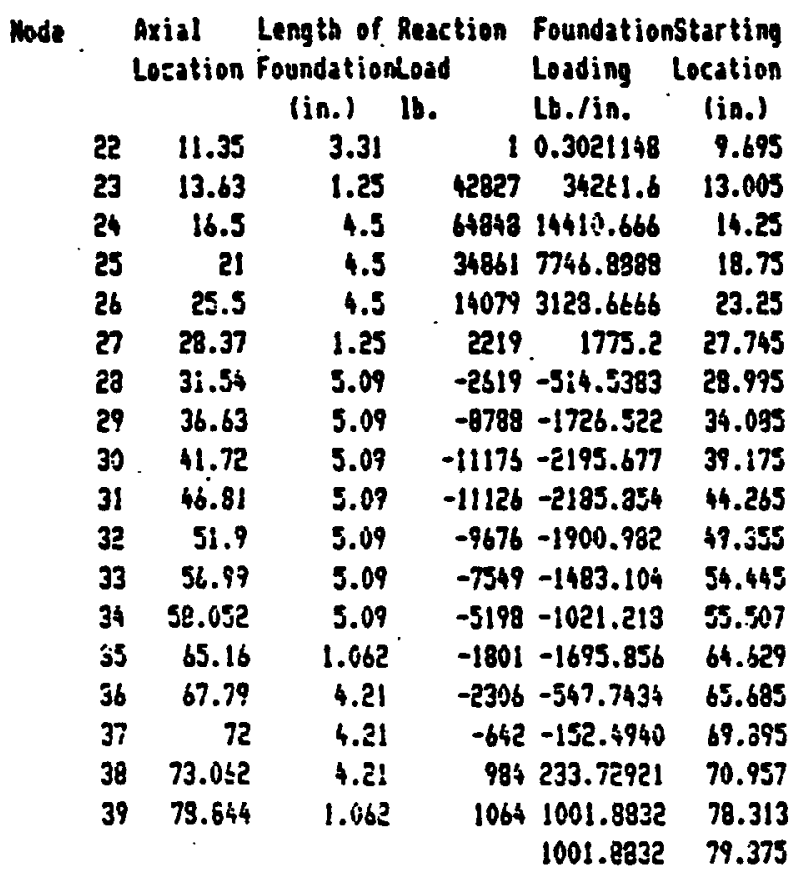





\section{Appendix 2}

TROJAN CRITICAL-FLAW-SIZE ANALYSIS FOR THE BEAM-TOP FLANGE AT THE INTERSECTION WITH THE REACTOR CAVITY LINER 
IROJAN : SUPPORT BEAH CRITICAL. FLAN SIZE AMALYSIS

Stress location:

Flaw type

Flaw aspect ratio a/l

Plate thickness in.

Stresses in bean flange without flaw :

Faulted (2) $=\mathrm{DH}+\mathrm{T}+$ SB:LOCA

Faulted $(3)=D U+T+$ LB:LOCA

\section{Flaw shape paraneter $=9$}

Flaw depth 'a" in.

Flaw depth to flange thickness ratio Mecbrane correction factor be

Bending correction factor th

Faulted condition (2)

$$
\begin{aligned}
& \text { (a) }=\text { So+HanaSQRT(PI)+2SQRT }(a / 0) \\
& \text { (b) }=\text { sb+hth+JSQRT }(P I)+2 S E R T(a / \theta) \text { : } \\
& K 1=(a)+(b)
\end{aligned}
$$

Faulted condition (3)

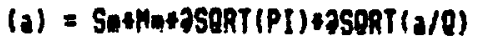

$$
\begin{aligned}
& \text { (b) }=\text { Sb+HbraSQRT(PI) +2SQRT(A/Q) : } \\
& K 1=(a)+(b)
\end{aligned}
$$

\section{Interface with the cavity liner}

inifora depth sirface flaw

0.000

2.500

IUnit load itead case iload case (200 Kip)

; $969000.000: 559000.000: 7548510.000$

969000.000 i $3 \$ 43000.000: 111836335.000:$

istress

$$
\begin{aligned}
& \text { Sy }=\quad \text { 10n00.000:Faulted(2) } \quad(5 n+5 b) / 5 y=0.310 ; \quad 0=0.990 \\
& \text { iFaulted (3) } \quad \text { (Sa }+ \text { Sb) } / S y=0.485: \quad \theta=0.970
\end{aligned}
$$

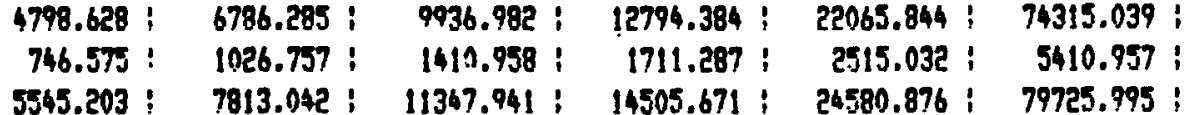

7601.597 ～10750.292： $15741.360 ： 20267.825 ； 36954.918 ： 117723.849 ：$ 1182.664 ； 1626.506 : 2235.126 ; 2710.881； 3934.109 ; 8571.598 ; 8784.261： i2376.787： 17976.486 ；22979.706：38939.027； 126295.467： 
IROJAM : SUPPORT BEAM CRITICA FLAN SIZE AMALYSIS

Stress location :
Flaw type
Flaw aspect ratio a/l
Plate thickness in.
Stresses in bean flange without flaw :

Faoltad (a) $=\mathrm{OW}+T+$ SB:LOCA

Faulted (3) $=$ ON $+T+$ LB:LOCA

Flaw shape paraneter $=0$

Flaw depth 'a" in.

Flaw depth to flange thickness ratio

Reabrane correction factor $\mathrm{he}$

Bending correction factor mo

Faulted condition (2)

(a) = SathatasorT(PI) a SORT(a/g)

(b) = SbrHo+OSERT(PI) ESSQRT $(a / Q)$ :

$K_{1}=(a)+(b)$

Faulted condition (3)

$(a)=$ Sa+Ha+2SQRT(P) $+2 S Q R T(a / Q)$ (b) $=5 b+$ tho +25 SRT (PI) FoSORT $(a / \theta)$; $K_{1}=(a)+(b)$
Interface with the cavity liner

Eliptical surface flax

$$
0.100
$$

2.300
Ithit load lload case iload case ; (200 Kjp) bn . inaxious load inaxioun Bh $969000.000: 1558000.000: 7548510.000$ $969000.000 \div 2443000.000: 11836335.000$ :

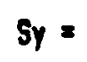

0.050

$0.020:$

$1.100 ;$

$1.040:$
40000.000 ifoultedi?)
iFaulted(3)

$$
\begin{aligned}
& 0.100: \\
& 0.040: \\
& 1.100: \\
& 1.020:
\end{aligned}
$$

\section{$0.200:$}

0.680

$1.120:$

$0.980:$

$(5 n+5 b) / 5 y=$
$(5 n+5 b) / 5 y=$

$0.300:$

0.120

$1.140:$

$0.940:$

$4451.800:$ $678.867:$ 5130.667 :
6295.797
941.600 :
7237.397

9065.485 $1279.403:$ 10344.888 :
11301.172 ; 1502.986 : 12804.158

17524.420：36626.177： 1967.257： 2904.767 : 19491.677 : 39530.944

7078.676 ～ 10010.759 ： 1079.446 : 1497.210 : 0158.122：11507.970 :
14414.758 : 2034.341: $16449.099 ;$
$17969.658 ;$ 2389.853 : 20359.511
27865.059 ： 58238.196 : 3129.078： 4618.784 ; 30993.137 : $62856.981:$ 
TROJAM : SUPPORT BEA CRITICA fLAN SIZE AMMUSIS

\section{Stress location :}

Flan trpe

Flaw aspect ratio a/l

Plate thickness in.

Stresese in beas flange without flaw:

Fanjted $(2)=0 H+T+$ SB:LOCA

Fanlted $(3)=\mathrm{DH}+T+$ LBiLOCA

\section{Flaw shape paranter $=0$}

Flan depth "a" in.

Flaw depth to flange thickness ratio Mechrane correction factor the

Bending correction factor in

Faulted condition (2)

(a) = SAHHa+OSORT (PI) rasoRT(a/9) (b) = Sb erto EDSERT (PI) EOSORT (a/D)

$$
K I=(a)+(b)
$$

Faulted condition (3)

(a) = SenharaserT(PI) EaserT(a/O) : (b) = So +mo 2 SQRT (PI) IJSERT(a/Q) :

$\mathrm{KI}=(\mathrm{a})+(\mathrm{b})$ interface with the eavity liner iEliptical sarface flaw

i $\quad 0.200$

thit load iload ease iload case

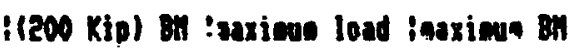

:

; $969000.000: 1558000.000: 7548510.000$

$969000.000 ; 2443000.000$ i11836335.000 :

inax. surfor

istress

:

(2300,470

$12390.470:$

17960.960 : 171910 :

Sy $=$

40000.000 ifaultedte)

$(5 *+50) / 5 y=$

$(5 x+5 b) / 5 y=$

ifaulted(3)

$0.310:$

$0.485:$

$P=1.290$

$Q=1.250$

$0.050: \quad 0.100: 0.200: 0.300: 0.600 ; \quad 1.250:$

$0.020: 0.040: 0.080: 0.120: 0.240: 0.500 ;$

$1.100: \quad 1.100: \quad 1.100 ; \quad 1.100 ; \quad 1.150 ; \quad 1.400 ;$

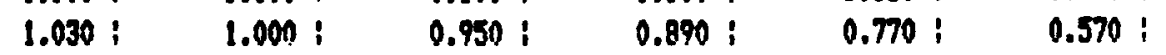

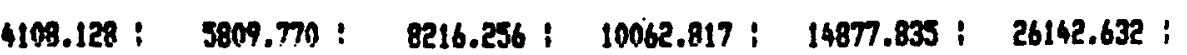

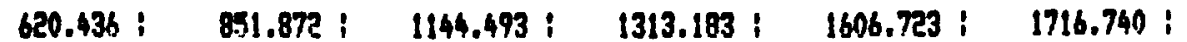
4728.564: 6661.643: 9360.749 : $11376.000: 16484.558$ : 27859.372 ;

6492.615: 9181.945: 12985.231：15903.595: 23513.402：41316.644： 990.556： 1346.326： 1808.793 ; 2075.396 ; 2539.315 ; 2713.190 ; 7473.172: 10528.271: 14794.024: 17978.991: 25052.717: 44029.834: 
IROJAN : SLPPORT BEAM CRITICAL FLAN SIZE AMALYSIS

Stress location :

Flan type

Flaw aspect ratio a/l

Plate thickness in.

Stresses in bean flange without flaw :

Faulted (2) $=04+T+5 B: L B C A$

Faulted (3) $=$ DU $+T+$ LB:LOCA

Flaw shape paraceter $=0$

Flaw depth "a" in.

Flaw depth to flange thichness ratio

Meabrane correction factor ho $^{\circ}$

Bending correction factor wo

Faultad condition (2)

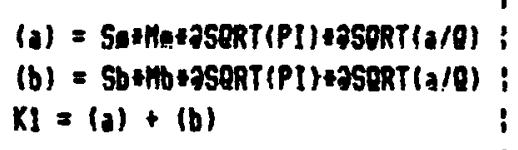

Faulted condition (3)

(a) = SarhatOSPRT(PI) egSORT(a/D)

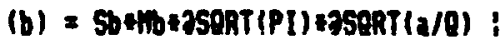
$x_{1}=(a)+(b)$
IInterface with the cavity liner iEliptical surface tlaw

0.300
$: \quad 2.500$
IUnit load iLoad ease iload case i(200 Xip) BM .ieaximes load inaxicun on 969000.000 : 1558000.000 ; 75485510.000 $969000.000 ; 2443000.000 ; 11836335.000$
Sy $=$

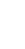

$0.050 ;$

0.020 :

$1.100:$

$1.01 \hat{v}:$

$3640.451:$

539.129 !

$4179.579:$

5743.704

850.607

6594.311 :
40000.000 ifaulted(2)
ifaulted(3)

$0.100:$

0.040

$1.100:$

$0.790:$

$$
\begin{aligned}
& 0.200: \\
& 0.080: \\
& 1.100: \\
& 0.920:
\end{aligned}
$$

$(5 a+5 b) / 5 y=$

(5a $+5 b) / 5 y=$

inax. stren

stress

i

12380.470

19413.022:

iflonge

stress

?

10660.960

16716.769 ;

iflange bend. :

istress

istr

1719.510:

1719.510 :

96.253

$5148.375:$ 737.798

7260.901: $98 ? .174$ 5898.170 :

\section{$0.300:$} 0.120 !

$1.100:$

$0.860:$

$0.310:$

$0.600: 1.250:$

$0.240: \quad 0.500$ :

$1.120: \quad 1.230:$

$0.720: 0.420:$

8263.076 :

$8917.246:$

1124.462 :

10041.709:

12840.180

1331.355

14171.535:

20353.428 :

1120.960 i

21474.388 : $\theta=1.630$

$\theta=1.610$ 
TROJAM : SUPPORT BEAN CRITICAL FLAN SIZE AMALYSIS

Stress location :

Flaw type

Flaw aspect ratio a/l

Plate thickness in.

Stresses in beas flange nithout flaw :

Faulted $(2)=$ OH $+1+5 B$ B LOCA

Faulted $(3)=D U+T+$ LB:LOCA

Flaw shape paraneter =

Flan depth "a" in.

Flaw depth to flange thickness ratio Menbrane correction factor tha

Bending corraction factor

Faulted condition (2)

$$
\begin{aligned}
& \text { (a) = Sa+ha+2SORT(PI)+2SQRT(a/g) } \\
& \text { (b) }=\$ b+H b+2 \operatorname{SORT}(P[)+9 S Q R T(a / \theta) \\
& K_{1}=(a)+(b)
\end{aligned}
$$

Faulted condition (3)

$$
\begin{aligned}
& \text { (a) = Sa+ha+2SOAT (PI) +2SORT(a/q) } \\
& \text { (b) }=5 b+1 \text { b +2SPRT(PI) +25QRT(a/Q) } \\
& k_{1}=(a)+(b)
\end{aligned}
$$

Interface with the cavity liner

ieliptieal surfate flaw

i $\quad 0.500$

$\quad 2.500$

IUnit load iload case iload case

i(200 Kip) Bn : aximus load isaximun Bn

;

969000.000:1558000.000:7548510.000:

istress

i

$969000.000 ; 2643000.000$ :11836335.000 :

iflange mean istress :

iflange bend. :

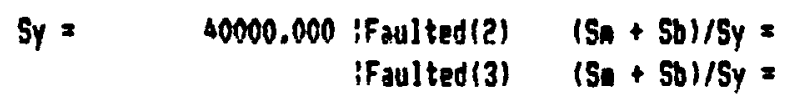$$
40000.000 \text { if aulted(2) }
$$$$
\text { [Faulted (3) }
$$

$(S n+5 b) / S y=$

19413.022: istress

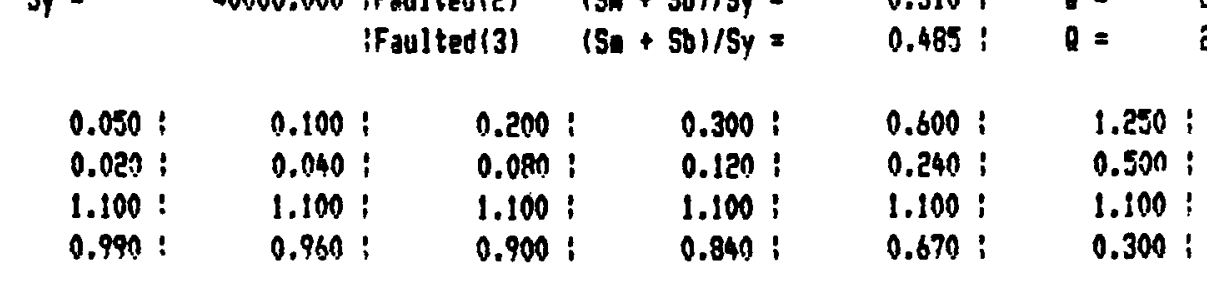

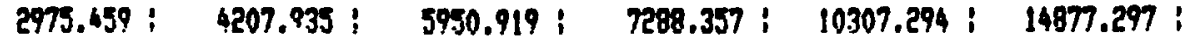

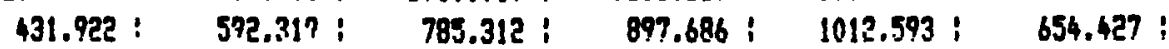
3407.381： 4800.254：6736.231： 8196.044：11319.297：15531.724：

4684.867：6625.403：9369.734：11475.534：16228.256：23424.335：

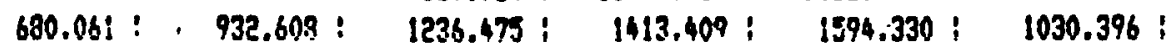
5364.929 : 7558.011: 10606.209： 12889.943：17823.186：24454.731： 
TROJAN : SUPPORT BEAM CRITICAL FLAN SIZE AMALYSIS

Stress location :

Flaw type

Flan aspect ratio a/l

Plate thickness in.

Mormal + Upset $=0 H+T+$ OBE

Faulted $(t)=0 H+T+55 E$

Flaw shape parameter $=0$

Flan depth " $z$ " in.

Flaw depth to flange thickness ratio

heabrane correction factor ha

Bending correction factor th

Nornal plus upset conditions

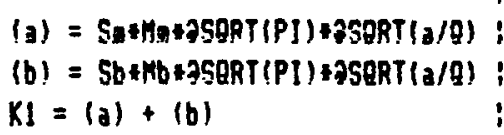

Faulted condition 11

(a) = Sa+MataSERT(PI) +2SGRT(a/Q) ;

(b) $=5 b+h b+25 S R T(P I)+3 S Q R T(a / Q)$ i

$K I=(a)+(b)$
IInterface vi:- the cavity liner

iUnifore dept* aurface flas

i 0.000

2.500

\section{Unit load}

'oed case lload case

ihax. surface iflange mean (20.9 Kip) BM. : saximun load ieaxioun BH istiess

I

$969000.00 n+1099000.090 ! 3324655.000$

$969000.000: ! 212000.000: 5872140.000$;

8733.679

istres5

iFlange bend. i

sy $=$

$9631.020 ;$

$7520.15 !$

9293.378

1212.928

$1337.642:$

\subsection{0 ithreal+lupset \\ iFaulted(I) \\ $(5 a+5 b) / 5 y=$}

0.218

0.241 i

$\theta=1.000$

$0.050:$

0.02 : :

$0.100:$

$0.200:$

0.300 :

0.600 :

0.240 :

$\theta$

1.000

1.130:

$0.080:$

0.120 :

1.500 :

1.250:

i. 094 :

$1.130:$

1.170 :

$1.230 ;$

1.060 :

0.500

3.500 ;

1.580 !

\section{$3367,945:$}

523.95? :

$4762.993:$

720.636 :

6974.328

990.239 :

7954.617 :

8979.91? : $1201.076:$

10180.898 :

15487.038： 52159.434 ; 176.5.189：3797.711 ; 3991.9??' $5483.628:$

$3714.23^{\circ}-5252.727$;

7691.433 :

9903.123: 1092.111: 1324.57?: 4292.106: 6047.459 ; 
TROJAK : SUPPORT BEAM CRITICAL FLAU SIZE AUALYSIS

Stress location :

Flaw aspect ratio a/l

Plate thickness in.

Stresses in beas flange without flaw :

Nornal + Upset $=D H+T+$ OBE

Foulted $(1)=D W+T+$ SSE

Flaw shape paraneter $=0$

Flow depth "a" in.

Flaw depth to flange thickness ratio

Meabrane correction factor Ma

Bending correction factor tho

Morad plus upset conditions

$$
\begin{aligned}
& \text { (a) = SaHHn+OSQRT(PI) HaSgRT(a/g) }
\end{aligned}
$$

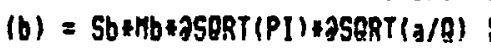

$$
\begin{aligned}
& K 1=(a)+(b)
\end{aligned}
$$

Faulted condition (1)

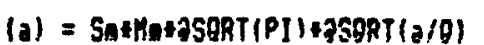

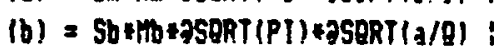

$$
\begin{aligned}
& X I=(a)+(b)
\end{aligned}
$$

Interface with the cavity liner iEliotieal sure::a flan

$$
\begin{array}{ll}
: & 0.100 \\
: & 2.500
\end{array}
$$
; $969000.000 \div 1099000.000 \div 5324655.000$ $969000.000: 212000.000 ; 5872140.000$ : istress

Max. surface iflange rean iflange bend. :

Sy \$0000,000 :Normal+1jpset
iFaulted(1)

$(5 n+5 b) / 5 y=$ $15 x+5 b) / 5 y=$ istress istres5 8733.079 7520.151 $i$ 1212.728 $9631.020 \div \quad 8293.379: \quad 1337.642$ :

\section{$0.050:$}

$0.020:$

$0.100:$

$0.200:$

0.300

$0.120:$

$1.100:$

$0.140:$

0.080

1.109

$1.120:$

$1.900:$

$0.940:$
$0.218: \theta=1.100$
$0.241 ; \quad a=1.100$

$1.040:$

$1.020:$

$0.980:$

$0.600:$

$0.240:$

$1.250:$

0.500 !

$1.250: \quad 1.810:$

$0.870 ; 0.890$;

\subsection{6 :} $476.685:$ 3602.641 :

$\begin{array}{rrrrrr}3447.369: & 4875.316: & 7020.097: & 8751.369: & 13579.499: & 28362.465: \\ 525.698: & 729.153: & 990.739: & 1163.876: & 1523.399: & 2249.383: \\ 3979.067: & 5604.669: & 8010.836: & 9915.237: & 15093.893: & 30611.828:\end{array}$


TrOJAM : SUPPORT BEAN CRIIICAL FLAH SIZE AMALYSIS

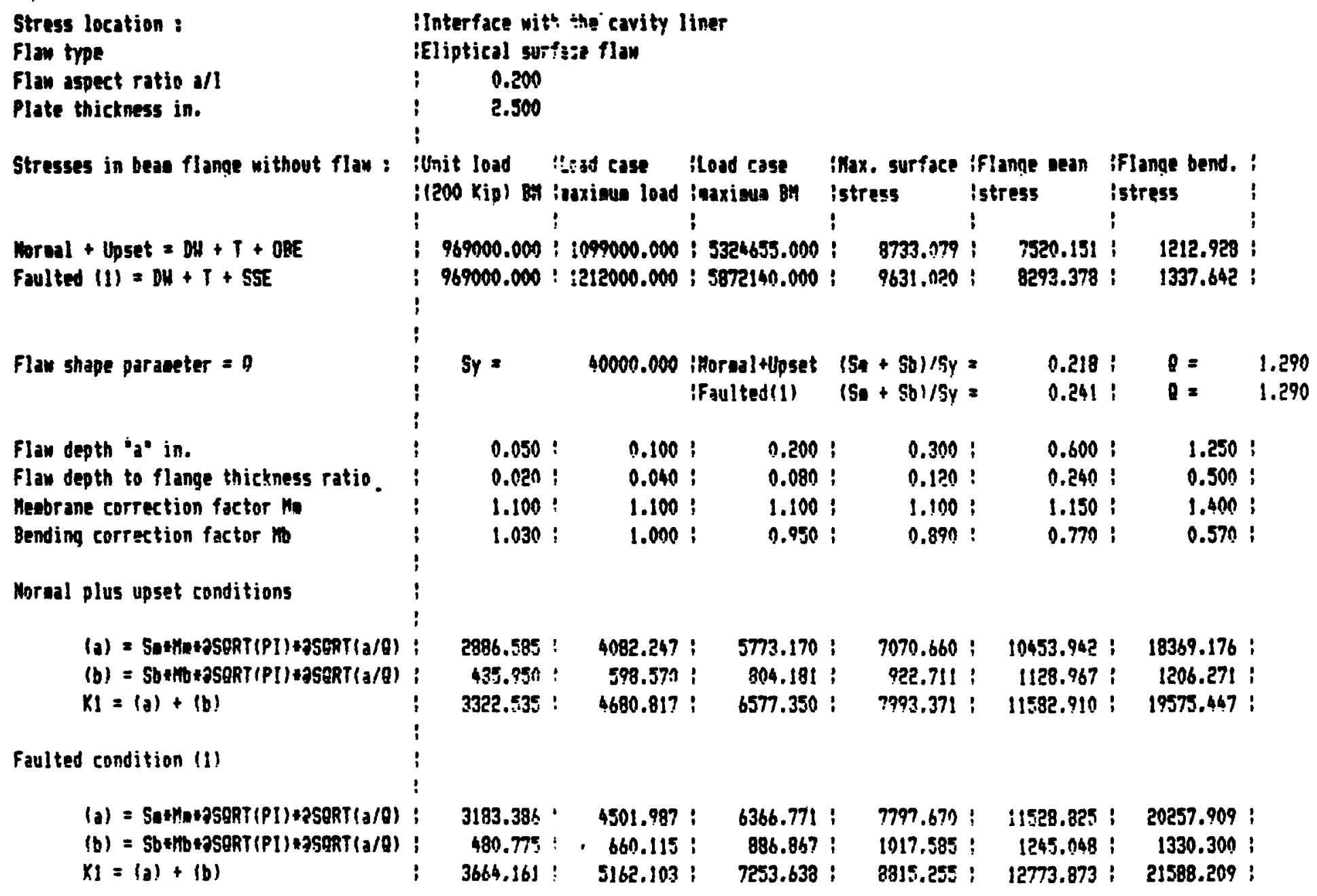


TROJAM : SUPPORT REAM CRITICAL FLAN SIZE aMALYSIS

\section{Stress location :}

Flaw type

Flaw aspect ratio a/l

Plate thickness in.

Stresses in beas flange without flaw:

Mornal + Upset $=$ ON $+T+0 B E$

Faulted $(1)=\mathrm{DH}+T+$ SSE

Flaw shape paraneter $=0$

Flaw depth "as" in.

Flaw depth to flange thickness ratio

Heabrane correction factor he

Bending correction factor ito

Morsal plus upset conditions

(a) = Sa+ha+aSaRT (PI) + aseRT(a/Q)

(b) $=5 b+n b+259 R T(P I)+259 R T(a / Q)$

$$
k 1=(a)+(b)
$$

Faulted condition (1)

(a) = SathabaSgRT (PI) + 2SGRT $(a / Q)$

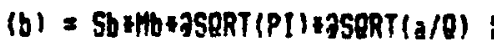

$$
K I=(a)+(b)
$$

Interface with the-cavity liner

iEliptical surface flan

i $\quad 0.200$

2.590

i

i(200 $x$ io) an ioarieus load ieaxioum bn

$969000.000: 1099000.000 ; 5324655.000$

inar, surface :Flance wean iflange bend.

stress

(2703.079

$969000.000 \div 1212000.000 \div 5872140.000$;

$9631.020:$

istress

istress

i

$7520.151:$

$8293.378: \quad 1337.642:$

Sy $=$

40000.000 iHornal+1jp5at

ifaulted(s)

$(5 e+5 b) / 5 y=$

0.218

$0.24 !:$

$\theta=1.640$

$0.050:$

0.100

$0.200:$

$(S a+s b) / S y=$

$0.600:$

1.650

$0.020:$

$0.040:$

$0.300:$

$0.240:$

$1.250 !$

1.100:

$1.100:$

0.090

$0.120:$

1.100 :

1.120:

0.500 :

0.980 :

$0.920:$

0.860 :

0.720 :

0.420 :

$2560.102:$ $379.135 ;$

3620.531

5120.204

6270.943

9029.699:

936.259:

14313.297 :

2939.23? :

4140.793

$5810.906:$

7965.957 :

$2814.765:$

3980.479 :

5629.530 :

6894.738

9927.916 :

15737.095

2.004

(3).

869.424：

9.392

866.716:

3231.316 ： 4552.62?: 6389.939 ：
$7764.162:$ i6603.812: 
TROJAN : SUPPORT BEAM CRITICAL FLAH SIZE ANALYSIS

Stress location :

Flaw type

Flaw aspect ratio a/l

Plate thickness in.

Stresses in bean flanee without flaw:

Mores] + Upset $=D U+T+$ OBE

Faulted $(1)=D U+T+$ SSE

Flan shape paraceter $=0$

Flaw degth " 3 " in.

Flaw depth to flange thickness ratio

Meabrane correction factor ha

Bending correction factor th

Noral plus upset conditions

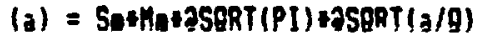

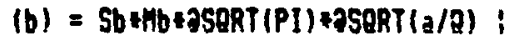

$X I=(a)+(b)$

Faulted condition ( 1 )

(a) = Sa+Ha+OSSQRT(PI) +OSPRT(a/Q) ; (b) = Sb+(b) * SQRT (PI) + ASQRT (a/Q) :

$X 1=(a)+(b)$
Interface nith the cavity liner iEliptical surfase flow

2.500

Unit load iload case iload case

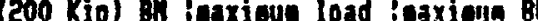

$969000.000 ; 1099000.000 \div 5324655.000$

$969000.000 ; 1212000.000 ; 5872140.000:$

istress

surfare iflange aean

iflange bend. :

8793.079

9631.020

7520.151

istress

Sy $=$

40000.000 :thorad+ Hopset $\left(S_{n}+54\right) / 5 y=$ iFauitad(1)

$(5 a+5 b) / 5 y=$

0.218

$0.241:$

$0.300:$

$0.100:$

$0.200:$

0.120 :

$0.600:$

$0.240:$

$0.020:$

.060

0.190

$1.100:$

$0.960:$

0,900

0.840

1.100

0.670 :

$1212.928:$

0.990

5130,643 ;

7255,824

712.816 ;

$7968.640:$

0472.880

304.051 :

416.933

552.821

631.927

5762.569 :

$460.684:$

2399.627 :

$3379.141:$

4741.973 :

5704.942

8068.006：11645.164;

2329,033： 3293,750

6659.065 :

702.661:

792.605

512.251

2667.118 : 3757.386

5272.766 : $6407.603:$

8960.611:

12157.414 : 
Table A 2.11

TROJAN: SUPPORT BEAN CRITICAL FLAN SIZE ANALYE'S

STRESS INTENSITY SUMHARY : INTERFACE UITH THE :ZVITY LIMER

\begin{tabular}{|c|c|c|c|c|c|c|c|c|c|}
\hline \multirow[t]{2}{*}{ Load case } & \multirow{2}{*}{$\begin{array}{c}\text { Inner } \\
\text { Concrete } \\
\text { Effective? }\end{array}$} & \multirow{2}{*}{$\begin{array}{l}\text { Flan } \\
\text { Aspect } \\
\text { Ratio }\end{array}$} & \\
\hline & & & 0.60 & 0.05 & 0.10 & 0.20 & 0.30 & 0.60 & 1.25 \\
\hline$B N+T+0 B E$ & No & 0.00 & 0.09 & 3991.00 & 5483.00 & 7964.00 & 10130,00 & 17252.00 & 55956.00 \\
\hline$B u+T+0 B E$ & No & 0.10 & 0.00 & 3602.00 & 5081.00 & 7263.00 & 8990.00 & 13686.00 & 27757.00 \\
\hline$B N+T+0 B E$ & Ho & 0.20 & 0.60 & $3322.0 n$ & 4680.00 & 6577.00 & 7993.00 & 11582.00 & 19575.00 \\
\hline $0 y+T+0 D E$ & No & 0.30 & 0.00 & 2939.00 & 4140.00 & $\$ 810.00$ & 7061.00 & 9965.00 & 15101.00 \\
\hline$B W+T+O B E$ & Mo & 0.50 & 0.53 & 2393.00 & 3379.00 & 4741.00 & $576 ? .09$ & 7968.00 & 10933.00 \\
\hline$E n+T+0 D E$ & Yes & 0.00 & 0.10 & N,A, & M.A. & R.A. & N.A. & N.A. & H.A. \\
\hline$D H+T+D B E$ & Yes & 0.10 & 0.01 & H.A. & M.A. & H.A. & H.A. & H.A. & H.A. \\
\hline$D U+T+O B E$ & Yes & 0.20 & 0.10 & N.A. & N.A. & M.A. & M.A. & M.A. & N.A. \\
\hline$B N+T+O B E$ & Yes & 0.30 & 0.01 & N.A. & H.A. & M.A. & M.A. & M.A. & H.A. \\
\hline $04+T+00 E$ & Yes & 0.50 & 0.00 & N.A. & H.A. & M.A. & M.A. & M.A. & M.A. \\
\hline $0 N+T+5 S E$ & no & 0.00 & 0.09 & 4292.00 & 6047.00 & 8793.00 & 11227.00 & 19026.00 & 61709.00 \\
\hline $04+T+55 E$ & no & 0.10 & 0.00 & 3973,00 & 5604.00 & 8010.00 & 9915.00 & 15093.00 & 30611.00 \\
\hline$B U+T+55 E$ & Mo & 0.20 & $0 . \mathrm{Mn}$ & 3664,00 & 5162.00 & 7253.00 & 8815.00 & 12773.00 & 21598.00 \\
\hline$B W+T+5 S E$ & No & 0.30 & 0.00 & 3231.00 & 4552.00 & 6399.00 & 7764.00 & 10957.00 & 16603.00 \\
\hline DW+T+SSE & $N_{0}$ & 0.50 & 0.00 & 2667.00 & 3757.00 & 5272.00 & 6407.00 & 8860.00 & 12517.00 \\
\hline$D^{w}+7+55 E$ & Yes & 0.00 & 0.60 & H.A. & ค.A. & N.A. & R.A. & M.A. & N.A. \\
\hline OW+T+SSE & Yes & 0.10 & 0.50 & H.A. & M.A. & M.A. & H.A. & M.A. & M.A. \\
\hline$D A+7+5 S E$ & Yes & 0.20 & 0.09 & N.A. & N.A. & N.A. & M.A. & M.A. & H.A. \\
\hline DUt+T+SSE & Yes & 0.30 & 0.09 & H.A. & H.A. & M.A. & H.A. & M.A. & M.A. \\
\hline $0 N+T+5 S E$ & Yes & 0.50 & 0.00 & N.A. & N.A. & M.A. & H.A. & H.A. & M.A. \\
\hline DH+T+SB:LOCA & No & 0.00 & 0.00 & $5345.2 n$ & 7813.04 & 11347.94 & 14505.67 & 24580.88 & 79726.00 \\
\hline OU'T+5B:LOCA & no & 0.10 & 0.80 & $\$ 1130.67$ & 7237.40 & 10344.89 & 12804.16 & 19491.68 & 39530.94 \\
\hline $04+7+5 B: L O C A$ & No & 0.20 & 0.19 & 4728.56 & 6661.64 & $936 n .75$ & 11376.00 & 16484.56 & 27859.37 \\
\hline$D U+T+58: L O C A$ & No & 0.30 & 0.10 & 4179,58 & 5898.17 & 8263.08 & 10041.71 & 14171.53 & 21474.39 \\
\hline$B H+T+58: L O C A$ & no & 0.50 & 0.00 & 3407.38 & 4800.25 & 6736.23 & 3186.04 & 11319.89 & 15531.72 \\
\hline OU+T+58:LOCA & Yes & 0.00 & 0.00 & N.A. & M.A. & M.A. & H.A. & N.A. & N.A. \\
\hline DU+T+5D:LOCA & Yes & 0.10 & 0.00 & H.A. & A.A. & H.A. & H.A. & H.A. & M.A. \\
\hline$B W+T+5 B: L O C A$ & Yes & 0.20 & 0.60 & A.A. & N.A. & M.A. & H.A. & M.A. & H.A. \\
\hline DH+T+58:LOCA & Yes & 0.30 & 0.00 & N.A. & H.A. & M.A. & N.A. & M.A. & N.A. \\
\hline$D W+T+S B: L O C A$ & Yes & 0.50 & 0.09 & N.A. & $N_{0} A$. & M.A. & B.A. & B.A. & M.A. \\
\hline Bu+THLB:LOCA & no & 0.00 & 0,00 & 8794.00 & 12378.00 & $1797 h .00$ & 22978.00 & 38939.00 & 126295.00 \\
\hline DU+T+LB:LOCA & Wo & 0.10 & 0.60 & 8158.00 & 11507.00 & 16449.00 & $203 \pm 9.00$ & 30993.00 & 629.66 .00 \\
\hline DUNTT+LB:LOCA & Ho & 0.20 & 0.00 & 7473.00 & 10528.00 & 14794.00 & 17978.00 & 26052.00 & 44029.00 \\
\hline OU+T+LB:LOCA & $N_{0}$ & 0.30 & $0 . \hat{Q}$ & 6594.00 & 9990.10 & 13037.00 & 15843.60 & 22359.00 & 33881.00 \\
\hline$D N+J+L B: L B C A$ & No & 0.50 & $0 . \hat{v 0}$ & 5364.00 & 7558.00 & 10606.00 & 12888.09 & 17823.00 & 24454.00 \\
\hline$B N+T+L B: L O C A$ & Yes & 0.00 & 0.60 & N.A. & N.A. & N.A. & M.h. & H.A. & M.A. \\
\hline$O H+T+L B: L O C A$ & $Y_{95}$ & 0.10 & 0.00 & H.A. & n.a. & M.A. & M.A. & N.A. & H.A. \\
\hline$D W+T+1 B: L O C A$ & Yes & 0.20 & 0.90 & N.A. & M.A. & R.A. & M.A. & H.A. & N.A. \\
\hline$D W+T+L B: L O C A$ & Yes & 0.39 & 9.920 & n,A. & A.A. & R.A. & M.A. & N.A. & N.A. \\
\hline$B u+T+L B: L O C A$ & Yes & 0.90 & 0.90 & M.A. & H.A. & M.A. & A.A. & N.A. & M.A. \\
\hline
\end{tabular}

$D U+T+0 B E=1099$ K1pS. $\quad 0 u+T+9 B: 19 C 4=1558$ Kips.

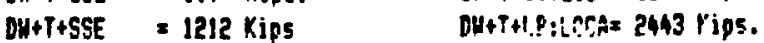




$$
207 / 20^{8}
$$

\section{Appendix 3}

TROJAN CRITICAL-FLAW-SIZE-ANALYSIS FOR THE BEAM-TOP FLANGE AT THE PEAK BENDING

$$
\text { MOMENT LOCATION (NODE 4) }
$$



TROJAN : SUPPORT BEAM CRITICAL FLAU SIZE AMALYSIS

Stress location :

Flaw type

Flaw aspect ratio a/l

Plate thickness in.

Stresses in beas flange without flaw :

Faulted (2) $=$ DU + T + SB:LOCA

Faulted $(3)=D H+T+$ LB:LOCA

Flaw shape paraneter $=0$

Flaw depth "a" in.

Flan depth to flange thickness ratio

Meabrane correction factor Mo

Bending correction factor the

Faulted condition (2)

$$
\begin{aligned}
& \text { (a) = SarharOSQRT(PI) BJSQRT(a/Q) } \\
& \text { (b) }=\text { Sb }+H b+O S E R T(P])+a S E R T(a / Q) \text {; } \\
& x_{1}=(a)+(b)
\end{aligned}
$$

Faulted condition (3)

(a) = Sa*thetasQRT(PI)*asert(a/Q) :

(b) = Sb+hb+aSERT(P1) saSQRT(a/Q) ;

$K_{1}=(a)+(b)$ i Mode 4: Max. gy: Inner concrete not effective

iUnifors depth surface flaw

i $\quad 0.000$

$\quad 2.500$

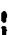

IUnit load :load case iLoad case i(200 Kip) 8n isoximu load inaxisun Bn

; $1527000.000: 1559000.000$ il1895230.000 i

$1527000.000: 2443000.000: 18652305.000:$

Max. surface iflanne oean

istress

i

$19509.781: 16800.089$ :

30592.037：26343.143: 4248.896 :

$$
\begin{aligned}
& \text { Sy }=\quad 40000.000 ; \text { Faulted(2) } \quad(50+56) / 5 y=0.489 ; \quad Q=0.720 \\
& \text { ifaulted(3) } \quad(5 n+5 b) / 5 y=0.765: \quad Q=0.870
\end{aligned}
$$

$\begin{array}{llllll}0.050: & 0.100: & 0.200: & 0.300: & 0.600: & 1.250: \\ 0.020: & 0.040 ! & 0.080: & 0.120: & 0.240: & 0.500: \\ 1.130: & 1.130: & 1.170: & 1.230: & 1.500: & 3.500: \\ 1.090: & 1.060: & 1.030: & 1.020: & 1.060: & 1.580:\end{array}$

7844.333：11093.563：16244.018：20915.023：36071.108：121483.040：

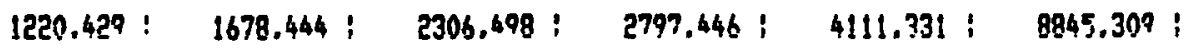

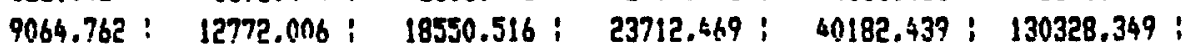

12648.713： 17887.992： 26192.911； $33724.742 ； 58163.400 ： 195997.152 ；$ 1967.899: , 2706.43? : 3719.149: 4510.794: 6629.377: 14262.751: 14616.612 : 20596.414: 29912.058: 38235.526 : 64792.777 ; 210149.904; 
TROJAN : SUPPERT BEAM CRITICAL FLALU SIZE ANALYSIS

Stress location :

Flaw type

Flaw aspect ratio a/l

Plate thickness in.

Stresses in beas flange without flaw :

Faulted $(2)=D U+T+$ SB:LOCA

Faulted $(3)=D U+T+$ LB:LOCA

Flaw shape paraseter $=$ ?

Flaw depth 'a" in.

Flaw depth to flange thickness ratio

Meabrane correction factor in

Bending correction factor th

Faulted condition (2)

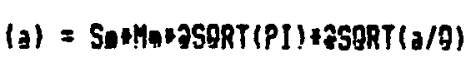

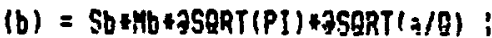

$$
\begin{aligned}
& K !=(a)+(b)
\end{aligned}
$$

Faulted condition (3)

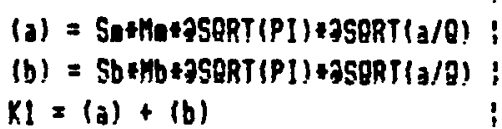

:

i

; i Wode 4: Hax. Bh: Inner concrete not effective

iEliptical zurface flas

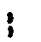

thit load iload case iload case i(200 Kip) gn igaxiaua load iaxisua

;

: 1527000.000: $1558000.009: 11189.5330 .000$

; 1527000.060：2443000.000!18652305.000 ;

0.150

$2.50 \mathrm{n}$

sy $=$

40000.000 :Faulted(2)

iFaulted(3)

$15 e+5 b 1 / 5 y=$

inax. surfa

fFlange aean ifla stress

istress

iflanee bend.

; i

$2709.69 ?$

$30592.037 ; \quad 26343.143$; $\quad 4248.894$

0.

$\begin{array}{llllll}0.050: & 0.100: & 0.200: & 0.300: & 0.600: & 1.250: \\ 0.020: & 0.040: & 0.030: & 0.120: & 0.240: & 0.500: \\ 1.100: & 1.100: & 1.120: & 1.340: & 1.250: & 1.810: \\ 1.150: & 1.020: & 0.980: & 0.940: & 0.870: & 0.890:\end{array}$

$1.150: \quad 1.020: 0.980: 0.960 ; 0.870 ; 0.890 ;$

7287.999 ： $10306.679 ： 14840.852 ： 18500.834 ＼mathrm{~ 28688.739 ： 59959.694 ： ~}$ 1111.25: : 1541.467： 2094.475! 2460.49h：3220.542：4755.313：

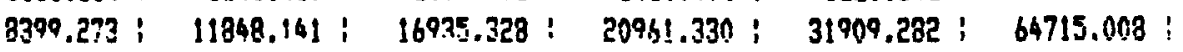

11660.961: '16491.089：23745.957：29602.074：45903.130：95937.968： 1778.211：2466.409：3351.244：3936.89?：5152.997：7608.69?： 13439.1?2: 18957.499: 27097.201:335.39.966: 51056.126 : 103546.599: 
TROJAN : SUPPORT BEAN CRITICAL FLAN SIZE ANALYSIS

Stress location :

Flaw type

Flaw aspect ratio a/l

Plate thickness in.

Stresses in bean flange without flan:

Faulted (2) $=D H+T+5 B: L O C A$

Faulted $(3)=D H+T+$ LB:LOCA

Flaw shape oaraneter $=0$

Flaw depth 'a" in.

Flaw deoth to flange thickness ratio

Mesbrane correction factor in

Bending correction factor

Faulted condition (2)

$$
\begin{aligned}
& \text { (a) = Su+MazaSgRT(PI) +aSgRT(a/Q) } \\
& \text { (b) }=\text { Sb+Rb+ZSQRT(PI) +ZSERT }(a / g) \\
& k_{1}=(a)+(b)
\end{aligned}
$$

Faulted condition (3)

(a) = So+hn+7SQRT (PI)+aSPRT (a/Q) :

$(b)=5 b+H b+2 S Q R T(P I)+2 S Q R T(a / 9)$ :

$X_{1}=(a)+(b)$
iNode 41: Yax. Bh: Inner concrete not effective

iEliptical surface flaw

$\quad 0.200$

2.500

i

innit load Lload case :Load case

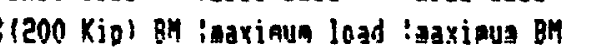
; 1527000.000 : 1558000.000 í11895330.000 : ; 1527000.000: 2443000.0000 :18652305.000 ; Max. 5 stress iflanqe bend. :

\section{$0.050:$}

$0 .+20:$

$$
0.100:
$$

$0.040:$

$0.200:$

$0.080:$

$$
0.300:
$$

0.600 :

$1.250 \div$

$1.100:$

$1.100:$

$1.100:$

$1.00 n$ :

$0.950:$

$0.120 ;$

0.240

$0.500:$

$1.031:$

1.100

$1.150:$

$1.500:$

$0.570:$

\section{$6604,070:$}

$9339.565:$

997.399 :

1369.439 :

13208.139 1979.843 ;

16176.601 2111.023 :

23917.040 : 2782.906 :

42025. 898 ： 7601.458 ;

$10709.003:$

15047.783 :

19287.624

26499.746

2759.765 : 44785.663 !

10484.R62：14825.703：20969.125：25680.603：37968.669：66716.760： 1583.379: $2174.003: 2920.780: 3351.281: 4100.403: 4381.170 ;$ 12067.432: 17000.79h: 23983.904: 2903i.884: 42069.072: 71097.930: 
TROJAM : SUPPORT BEAM CRITICAL FLAN SIZE ANALYSIS

\section{Stress location :}

Flaw type

Flaw aspect ratio a/l

Plate thickness in.

Stresses in beas flange nithout flan 1

Faulted (2) $=D H+T+$ SB:LOCA

Faulted $(3)=D W+T+$ LB:LDCA

Flaw shape paraneter $=0$

Flaw depth 'a' in.

Flaw depth to flanqe thicknose ratio

Mentrane correction factor $M_{a}$

Bending correction factor th

Faulted condition (2)

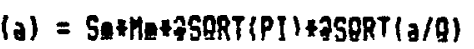

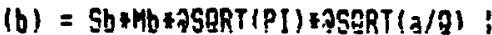
$Y 1=|z|+|b|$

Faulted condition (3)

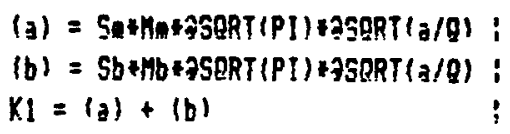

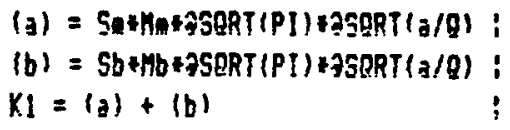

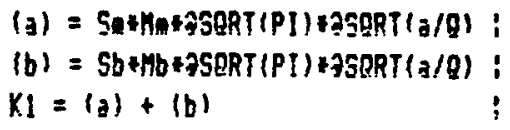

Fode 4: Max. gu; Imner concrete not offective

iEliptical surf ite flaw

$\quad 0.309$

Linad case

iload case

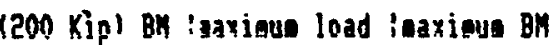

$: 1527000.000: 1558000.000: 11895330.000$
$: 1527000.000: 2643000.000: 186652305.000:$ istress

Max. surface iflange aean iflange bend. :

19509.781

30592 , ก37 :

istress

!

15800.089

26343.143

istress

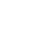

$2709.692:$

4.268, $894:$

\begin{tabular}{|c|c|c|c|c|c|}
\hline$s_{y}=$ & 40000.000 & $\begin{array}{l}\text { iFaul ted(2) } \\
\text { ifaulted (3) }\end{array}$ & $\begin{array}{l}(5 z+5 b) / 5 y= \\
(5 z+5 b) / 5 y=\end{array}$ & $\begin{array}{l}n .698: \\
n .765:\end{array}$ & $\begin{array}{l}\theta= \\
\theta=\end{array}$ \\
\hline
\end{tabular}

$5864.107: 9293.190 ; 11729.214: 14364.070: 20693.206: 32785.690:$ $968.439 ; 1191.677 \div \quad 1582.105: 1811.305 \div \quad 2144.572 ; 1805.664 ;$

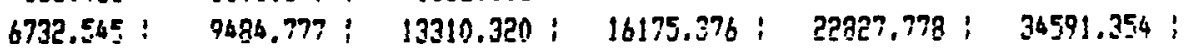

\begin{tabular}{|c|c|c|c|c|c|}
\hline $\begin{array}{l}9315.336 \text { ' } \\
1379.546 \quad: \\
10694.877 \text { ' }\end{array}$ & $\begin{array}{r}13973.879: \\
1897.02 n: \\
15066.891:\end{array}$ & $\begin{array}{r}18630.668: \\
2513.228: \\
21143.295:\end{array}$ & $\begin{array}{r}22217.215 ： \\
2977.320 ： \\
25695.134 ：\end{array}$ & $\begin{array}{r}32855.977 ! \\
3696.726 ： \\
36362.702 ：\end{array}$ & $\begin{array}{r}52081.186 \\
2868.358 \\
54949.542\end{array}$ \\
\hline
\end{tabular}


IROJAN : SUPPORT BEAM CRITICAL FLAW SIZE aMALYSIS

\section{Stress location :}

Flaw type

Flaw aspect ratio a/l

Plate thickness in.

Stresses in bean flange uithnut flaw:

Faulted (2) $=D H+T+$ SB:LOCA

Faulted $(3)=D H+T+L B: L O C A$

Flan shape paraneter $=9$

Flaw depth "a" in.

Flaw depth to flange thickness ratio henorane correction factor Mo

Bending correction factor

Faulted condition (2)

$$
\begin{aligned}
& \text { (a) = SathataSQRT(PI)+2SQRT }(a / Q) \\
& \text { (b) = SbrHb+ASERT(PI)+BSERT(a/Q) } \\
& k 1=(a)+(b)
\end{aligned}
$$

Faulted condition (3)

$$
\begin{aligned}
& \text { (a) = Sarhat2SQRT(PI) *aSQRTIa/Q) ; } \\
& \text { (b) }=\text { Sb*Hb*?SERT(PI)*2SERT(a/Q) } \\
& K_{1}=(a)+(b)
\end{aligned}
$$

;
iHode 4: Max. EM: Inner concrete not effective

iEliptiesl surf::a flax

$$
\quad 0.500
$$$$
2.500
$$

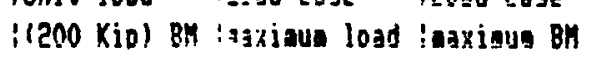

;

: 1527000.000 '1558000.000 :11895330.000 :

; 1527000.000: $: 3443000.000$ :18652305.000 :

iMax. surfare iflange aean stress

1950

19509.781 istress

:Fl ange bend.:

$$
\text { Sy }=
$$

$$
40000.000 \text { if aulted(5) }
$$

\begin{tabular}{|c|c|c|c|c|c|}
\hline $0.050 !$ & $0.100:$ & 0.200 & $0.300 ：$ & $0.600 ;$ & $1.250:$ \\
\hline $0.020 !$ & $0.040:$ & 0.080 & $0.120:$ & $0.240:$ & $0.50 n$ \\
\hline $1.100:$ & 1.j00! & $1.100 !$ & $1.100:$ & $1.100:$ & $1.10 n$ \\
\hline 0.999 : & $0.940 !$ & $0.900:$ & $0.840:$ & $0.670 ;$ & 0.300 \\
\hline
\end{tabular}

\begin{tabular}{|c|c|c|c|c|c|}
\hline 4738.023： & $6771.289:$ & $9576.047:$ & 11728.214 & $16586.200 ;$ & $23940.117:$ \\
\hline & $953.143:$ & $1263.70 ! i$ & 1444.531 & $1629.636:$ & 3.686 \\
\hline 5483,059 & $7724.431:$ & $10839.748:$ & $13172.745:$ & $12215.636:$ & 26993.20? \\
\hline
\end{tabular}

(Su $+5 b) / S y=$ [Faulted(3)

15e $+5 b 1 / 5 y=$

16800.089

$30592.037 \div \quad 26343.143$

istress

2709.692

$6248.994:$

$7556.398: 10686.34 \mathrm{~h} ; 15112.775 ; 18509.294 ; 26 \div 76.094 ; 37781.738:$ 1096.895: 1506.233: 1994.354: $2279.737 ; \quad 2571.552: 1661.962 ;$ $8653.283 \cdot 12190.582: 17107.130 ; 20789.031 ; 28747.646$; 39443.9nn! 
TROJAM : SUPPORT BEAN CRITICAL FLAY SIZE AMALYSIS

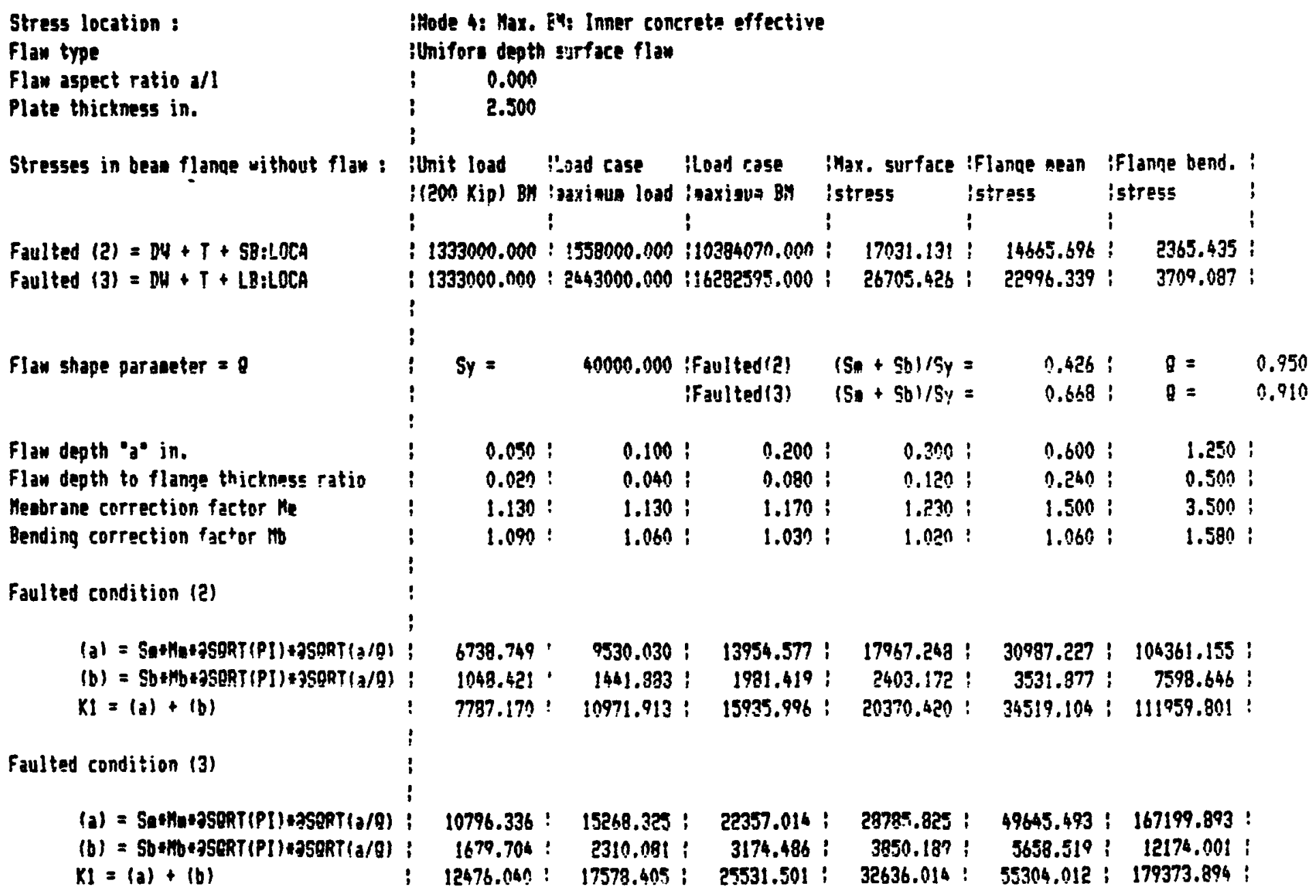


TROJAN : SUPPQRT BEAY CRITICAL. FLAU SIZE AMALYSIS

Stress location :

Flaw type

Flaw aspect ratio a/l

Plate thickness in.

Stresses in bese flange vithout flan

Faulted $(2)=D H+T+S B: L O C A$

Faulted $(3)=D H+T+$ LB:LOCA

Flaw shape paraneter $=\theta$

Flaw depth 'a" in.

Flaw depth to flanae thickness ratio

Meabrane corrertion factor Me

Bendina correction factor the

Faulted condition (2)

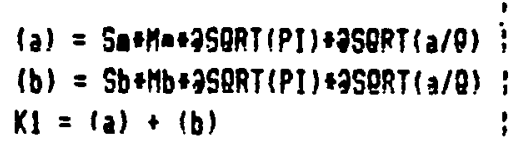

Faulted condition (3)

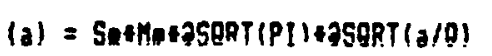 $(b)=S b+M b+7$ SQRT $(P I)+7$ SQRT $(a / Q)$; $X I=(a)+(b)$

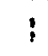

IXode 4; Max. By: Inner concrete effectiye iEliptieal surface flaw

0.100

2.500

;

ithit load iload case iload case i(200 Kip) BM isaxinus load inaximun Bn

: $1333000.000 \div: 1558000.000$ :10384070.000 :

$1333000.000: 2443000.000: 116282595.000$

Hax. surface iflange aean iflange bend. : istress istress istress

:

$17031.131: 14565.696:$ $26705.426: 22996.339$ :

$2365.435:$

3709.087 ;

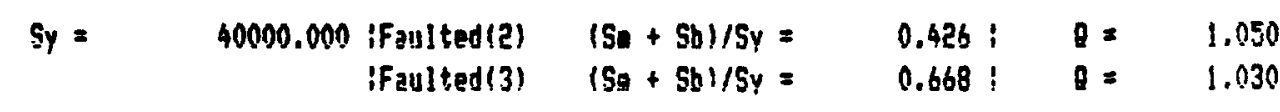

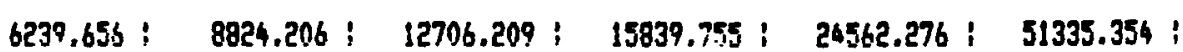
951.502：1319.749; 1793.215: 2106.599; 2757.314； 4071.330 : $7191.158 ： 10143.956$ : 14499.424：17946.344：27319.590：55406.684:
9879.539： 13970.364：20116.297：25077.234： $39986.662 ： 81273.434 ：$

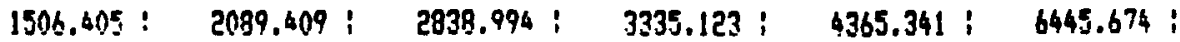
11384.946 ; 16059.779; 22955.291; 28412.407; 43252.004; 87719.109: 
TrOJAM : SUPPBRT BEAM CAITICAL FLAY SIZE AMALYSIS

Stress location :

\section{Flaw type}

Flaw aspect ratio a/l

Plate thickness in.

Stresses in beas flange without flaw :

Faulted (2) $=$ DH $+T+$ SB:LOCA

Faulted $(3)=$ DU $+T+$ LB:LOCA

\section{Flaw shape paraeeter $=9$}

Flaw depth "a" in.

Flaw depth to flange thickness ratio Mesbrane correction factor to

Bending correction factor

Faulted condition (2)

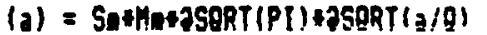

$$
\begin{aligned}
& \text { (b) }=\text { Sb+mb+aSQRT (PI! + ASERT (a/Q) } \\
& K 1=(a)+(b)
\end{aligned}
$$

Faulted condition (3)

$$
\begin{aligned}
& \text { (a) = SutharDSQRT(PI) +2SQRT(a/Q) }
\end{aligned}
$$

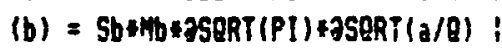

$$
\begin{aligned}
& K_{1}=(a)+(b)
\end{aligned}
$$

inode 41: ha:, an: Inner concrete affective EEliptical stoface flam

$0.56 n$

$2.50 \AA$

IUnit load

! la lo

13330000, 0MA - 1558000.000 i10384070.000

1333000.010: :2443000.000:16282595.000 ;

stress

istring

17031.131

26705.426

IFlange

iflanae bend.

$$
5 y=
$$

$$
\text { 40090.000 ifaulted(2) }
$$

$(s a+s b) / s y=$
$(s m+s b) / 5 y=$

iFaulted(3)

0.426 :

0.668 :

\section{$0.300:$}

0.600 :

$0.260:$

$0.02 n:$

$0.100:$

0.080

$0.120:$

1.150

$0.770:$

istress

$$
\text { 1.10: }
$$

1.1000

0.950

$0.890:$

2365.435 :

3709.087 :$$
\vdots
$$ 
TROJAM : SUPPORT BEAN CRITICAL FLAU SIZT ANAY YSIS

Stress location :

\section{Flaw type}

Flaw aspect ratio a/l

Plate thickness in.

Stresses in beas flange without flaw :

Faulted (2) $=\mathrm{DH}+\mathrm{T}+$ SB:LOCA

Faulted $(3)=0 H+T+$ LB:LOCA

\section{Flaw shade paraneter $=0$}

Flan depth " $a$ " in.

Flaw depth to flange thickness ratio

Mestrane correstion factor the

Bending correction factor $\mathrm{Hb}$

Faulted condition (2)

$$
\begin{aligned}
& \text { (a) = Sa+Ma*3SQRT(PI)+2SERT } 13 / Q) \\
& (b)=S b+H+2 S Q R T(P I)+2 S O R T(a / Q) ; \\
& k 1=(a)+(b)
\end{aligned}
$$

Faulted condition (3)

$$
\begin{aligned}
& \text { (a) }=\text { Sa+Ha+2GQRT(PI)+2SQRT/a/QI } \\
& \text { (b) }=5 b+\text { Hb+2SQRT (PI) +2SQRT/a/QI : } \\
& K I=(a)+(b)
\end{aligned}
$$

INoda 4: Max. SY: Inner concrete effective iEliptical suriace flaw

; $\quad 0.309$

$\quad 2.500$

Unit logd (200 Kip) ingaxious load inaxiaue BH

?

$1333000.000 \cdot 1558000.000+110394070.000$

; $1333000.000 \cdot 2443000.000$ :16282595.0n0 :

stress

surface :Flange opan

iFlange bend. :

$$
\begin{aligned}
& \text { Sy } 40000.000 \\
&: \text { Faulted(2) } \\
& \text { iFaultad(3) }
\end{aligned}
$$

$(5 n+5 b) / 5 y=$

istress

istress

$17031.131 !$

$26705.426 ; \quad 22996.339 ; \quad 3709.087$

$\begin{array}{llllll}0.050: & 0.100: & 0.200: & 0.300: & 0.600: & 1.250: \\ 0.020: & 0.040: & 0.080: & 0.120: & 0.260: & 0.500: \\ 1.100: & 1.100: & 1.100: & 1.100: & 1.120: & 1.230: \\ 1.010: & 0.990: & 0.920: & 0.860: & 0.720: & 0.420:\end{array}$

$5070.570 ： 7170.368 ； 10141.139 ; 12420.308 ； 17894.332 ： 28349.094 ；$

750.929：1030.419：1368.013：1566.197；1854.366：1561.317：

$5821.491 \div 8201.286: 11509.152 \div \quad 13986.506 \div 19738.698: 29910.413$

7975.757：11279.706：15951.913：19537.024：28131.879：44592.249：

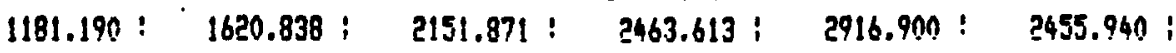
9157.147：12900.544：18103.784：22000.637：31048.779：47048.789： 
TROJAN I SUPPORT BEAM CRITICAL FLOU SIZE AMALYSIS

Stress location :

Flaw type

Flaw aspect ratio a/l

Plate thickness in.

Stresses in bean flanoe without flaw :

Faulted (2) $=$ DN $+T+$ SB:LOCA

Faulted $(3)=D H+T+L B$ iLCA

\section{Flaw shape paraneter $=0$}

Flaw depth 'a" in.

Flaw depth to flange thickness ratio Menbrane correction factor ha

Bending correction factor th

Faulted condition (2)

$$
\begin{aligned}
& \text { (a) = SA+He+2SQRT(PI) }+ \text { SSQRT }(a / \theta)
\end{aligned}
$$

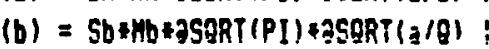

$$
\begin{aligned}
& K I=(a)+(b)
\end{aligned}
$$

Faulted condition (3)

$$
\begin{aligned}
& \text { (a) = SabHa+2SERT(PI) *2SGRT(a/Q) } \\
& (b)=\text { Sb*Hb*3SERT(PI) \& PSQRT (a/q) } \\
& K 1=(a)+(b)
\end{aligned}
$$

IHode 4: Max. S4: Inner concrete effective

iEliptical surface flaw

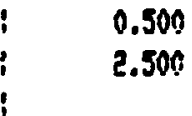

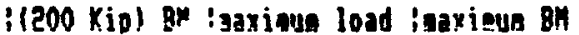
$i$ : 1333000.000:1558000.000:10384070.000 $1333000.000 \div 2443000.000 ; 16282595.000$ :

imax. surface iflanne nean istress istress

:Flange bend. : 17031 131 : istress

$$
\text { Sy }=
$$

0.050

$0.020:$

$1.100:$

$0.990:$

4153.186: $602.882:$

$4756.065:$

5873.489 $826.767:$

$6700.255:$ 1096.148

$9402.516:$

$(5 a+5 b) / 5 y=$
$(5 a+5 b) / 5 y=$ iFaulted(3)

$\begin{array}{lll}0.100: & 0.200 \\ 0.040: & 0.080 \\ 1.100: & 1.100 \\ 0.960: & 0.900\end{array}$

$0.300:$

0.120 :

$1.100:$

$0.840 i$

$0.426: \quad \theta=2.370$

$0.668: \quad 0=2.370$

$0.600: 1.250:$

$0.240 ; \quad 0.500:$

$1.100: 1.100:$

$0.670 ; \quad 0.300:$

6512.341：9209.841：13024.683：15951.913：22559.412：32561.707： 945.360: 1296.400: 1718.800: 1964.752: 2216.247: 1432.333： 7457.681：10506.261：14763.482：17916.665：26775.659：33994.040： 
TROJAM : SUPPQRT BEAM CRITICAL FLAU SIZE AMALYSIS

Stress location :

Flaw type

Flaw aspect ratio a/l

Plate thickness in.

Stresses in beas flange without flaw :

Mraal + Upset $=D H+T+$ OBE

Faulted $(1)=D H+T+$ SSE

Flaw shape paraneter $=\theta$

Flan depth " 3 " in.

Flaw depth to flange thickness ratio Heabrane correction factor mo

Bending correction factor th

Moreal plus upset conditions

(a) = Sn+MataSQRT(PI)+âSGRT(a/Q)

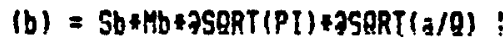
$K_{1}=(a)+(b)$

Faulted condition (1)

$$
\begin{aligned}
& \text { (a) = Sm + Ma*JSQRT(PI)+2SQRT (a/Q) ; } \\
& (b)=5 b+h b+2 S Q R T(P[1+2 S Q R T(a / \theta) \\
& K_{1}=(a)+(b)
\end{aligned}
$$

i $!$

iNode 4: Max. en: Inner concrete not effective IUnifore depth surface flaw

: $\quad 0.000$

$\quad 2.500$

Unit lood lload case il.oad case !'?00 Xip) Bn : aximu load iazigue an $1527000.000: 1099000.000: 8390865.000 ;$ $1527000.000 \div: 1212000.000 \div 9253620.000$

Sy $=$

\subsection{0}

$0.020:$

$1.130:$

$1.090:$

$5307.380:$

825.727 :

6133.107 !

5912.513

919.874 6832.387 : istress

40000.000 iKormal+10set $\left(S_{w}+56\right) / 5 y=$ (Faultedil)

$(5 a+5 b) / 5 y=$

$$
0.100:
$$

$0.040:$

$1.130:$

$0.200 ;$

$$
0.080:
$$

$1.170 !$

$1.060:$

$1.030:$

$0.300:$

0.120 :

1.230 :

$1.020:$

iflange mean istress

iflanqe bend. :

13762.034: 13762.034

11850.640 13069.132 stress ;

$1911.394:$ 2107.925:

$\begin{array}{ll}0.344: & \theta=1.000 \\ 0.379: & =0.980\end{array}$


TROJAM : SUPPORT BEAM CRITICAL FLAM SIZE AMALYSIS

Stress Jocation :

Flaw type

Flaw aspect ratio a/1

Plate thickness in.

Stresses in beas flange without flan:

Morasl + Upset $=04+T+$ OAE

Faulted $(1)=D U+T+$ SSE

Flaw shape parameter $=9$

Flaw depth "a" in.

Flaw depth to flange thickness ratio Meabrane corraction factor $\mathrm{M}^{\circ}$

Bending correction factor

Moreal plus upset conditions

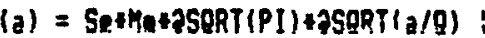
(b) $=$ Sb+Hb+2SQRT (PI) +7SGRRT $(a / Q)$ $K 1=|a|+|b|$

Faulted condition (I)

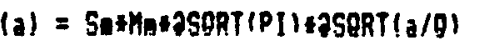

$$
\begin{aligned}
& \text { (b) }=5 b+4 b+7 S Q R T(P I)+75 Q R T(a / Q) \\
& K_{1}=(a)+(b)
\end{aligned}
$$

iNode 4: Max. Bn: Inner conerete not effective iEliptical surface flaw

0.100
2.500

! $1527000,000 \div: 0990000000 \div 9390965,000$ $1527000.000:: 212000.000 ; 9253620.000$ istress

(15)

13762.036 :

15177.057 :

iflanoe sean istress

iflance bend. :

Sy

40000.000 i Mnradillnset $150+56) / 5 y=$ :Faulted(1)

$(5 a+5 b) / 5 y=$

0.379

$9=$
$q=$

1.100

0.050

$0.109:$

0.200 :

$0.300:$

0.600 :

$1.250 \div$

$0.020:$

$0.040:$

0.090 :

$0.120:$

0.240

1.250

$0.500 ;$

$1.100:$

$1.020:$

$0.980:$

0.960

0.870

$1.810:$

$0.890:$

4926.062：6966.475；10031.213： $12505.063 １$ 17391.261：40527.890：

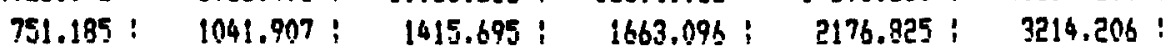

5677.227： 8009.382：11446.908：14169.159：21568.086：43742.096：

$5508.172 ： 7799.731 ； 11216.641 ； 13992.836 ： 21682.803 ４ 45317.232 ：$

839.956: $1165.039 ; \quad 1582.994 ; 1859.630 ; \quad 2434.070 ; \quad 3594.042 ;$

6348.128：8954.764：12799.634：15942.466：24116.873：48911.274： 
TROJAM : SUPPDRT BEAN CRITICAL FLAN SIZE AHAL YSIS

Stress location :

\section{Flan type}

Flan aspect ratio a/1

Plate thickness in.

Stresses in bean flanqe without flay :

Normal + Upset $=$ DU $+T+$ OBE Faulted $(1)=$ DH $+T+$ SSE

Flaw shape paraweter $=$ ?

Flaw depth "a" in.

Flaw depth to flanne thickness ratio Meabrane correction factor ho

Bending correction factor to

Noreal plus unset conditions

$$
\begin{aligned}
& (a)=\text { SmEMat2GQRT(P) }+2 S Q R T(a / Q) \\
& (b)=5 b+M b+2 S Q R T(P 1)+3 S Q R T(a / Q) \\
& k 1=(a)+(b)
\end{aligned}
$$

Faulted condition (l)

$$
\begin{aligned}
& \text { (a) = So-Hat2SQRT(PI) *2SQRT(a/Q) } \\
& \text { (b) = Sb*/Hb*3SQRT (PI) ESSQRT(a/Q) }
\end{aligned}
$$$$
K_{1}=|a|+|b|
$$

Hode 41: Max. E*: Inner conerate not effective iEliptical surfa:a $f$ law

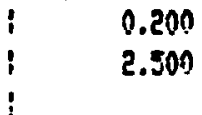

iUnit load is: $x$ j רu load Imaximan ; 1527000.000 : :299000.000 : 9390965.000 : ; 1527000.000 : :212000.000 : 9253620.000 : inar. surf Max. surface iflange mean istress IF lanne bend. :

1376.

0,890 :

0.770

\begin{tabular}{|c|c|c|c|c|c|}
\hline 899 & 7150.106 ; & 10111.777 ; & 12384.348 : & 18310.209 ; & 897 \\
\hline 5919,461 & neng sen & $1152 n 31$ & & วกว27 608 & \\
\hline
\end{tabular}

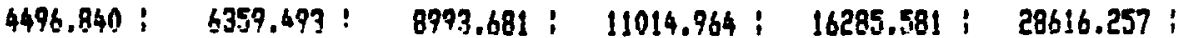

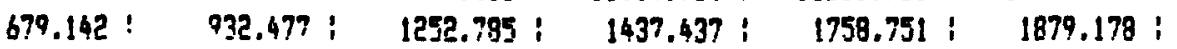
$5175.982: \quad 7291.970 ; \quad$ In246.466: $12452.401: 18044.332 ; \quad 30495.435:$ 
TMOJAM : SUPPDRT BEAN CRITICAL FLAN SIZE GNaLYSIS

Stress location :

Flaw type

Flam aspect ratio a/l

Plate thickness in. ithode 4: Wax. By: Inner concrete not effertiya iEliptical surface flaw

$\quad 0.300$
$; \quad 2.500$

Stresses in bea flange without flaw:

Mormol + Upset $=D 4+T+$ DBE

Fanlted $(1)=04+T+$ SSE

Flaw shape paraneter $=0$

Flaw depth $\cdot a^{\circ}$ in.

Flan depth to flange thickness ratio Meabrane correction factor

Bending corraction factor th

Moreal plus upset conditions

$$
\begin{aligned}
& \text { (a) = Smbhas?SQRT(PI) \&agAPT(a/g) }
\end{aligned}
$$

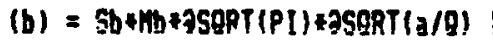

$$
\begin{aligned}
& K I=(a)+(b)
\end{aligned}
$$

Faulted condition (I)

$$
\begin{aligned}
& \text { (a) = SuSKM AZSERT(PI) *ASERT (a/8) }
\end{aligned}
$$

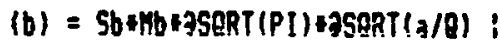

$$
\begin{aligned}
& K I=(a)+(b)
\end{aligned}
$$

;

$$
\begin{aligned}
& 0.300 \\
& 2.500
\end{aligned}
$$

Itnit load fload case thoad case imax. surface iflange mean iflange bend, : (1200 Kio) in :axieun load inaximo Bn istress

i

: 1527000.000 : 1099000.000; 8390965.000: $1527000.000 ; 1212000.000 \div 9253620.000$;

istress : 13762.034 15177.057 :

11950.649 13069,132 :

1911.394 $2107.925:$

$$
\text { sy }=
$$

$$
\text { 40000.000 INornal+1pget }
$$$$
\text { ifaulted(I) }
$$

$\left(S_{e}+5 b\right) / s_{y}=$

$0.344: \quad 0=1.650$

$0.050:$

$$
0.100:
$$

$0.200:$

$0.020:$

$1.100:$

0.040 :

$0.080:$

$$
1.100:
$$

1.100 :

0.990 :

$0.920:$

$0.3 n 0:$

$0.120:$

l.jon:

$0.860:$

$0.600:$

$0.240:$

1.120:

$0.720:$

$1.250 !$

0.500 :

$1.230:$

$0.420:$

4022.096:

5688.103

8044.193 :

14126.27\% i 224.87.175 :

595.648

124?.345:

1470.927： 1238.475

4617.746 ;

$6505.458:$

9129.333 :

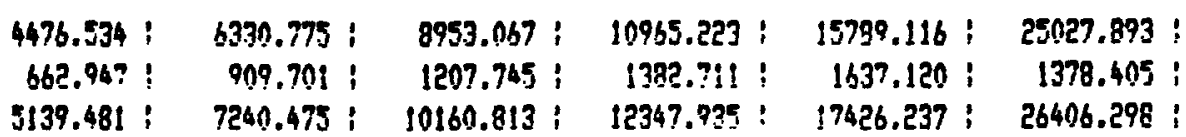


TROJAM : SUPPDRT GEAM CRITICAL FLAU SIZE AMALYSIS

Stress location :

Flaw type

Flow aspect ratio a/l

Plate thickness in.

ane nithout flan

Moreal + loset $=0 Y+T+$ OBE

Faulted $(1)=0 U+T+$ SSE

\section{Flaw shape paraacter $=0$}

Flaw depth "ap in.

Flaw depth to flange thickness ratio

Heabrane correction factor wo

Bending correction factor

Moreal plus upset conditions

$$
\begin{aligned}
& \text { (a) = SarHanosQRT (PI)*2SGRT(a/g) } \\
& (b)=\text { Sb+m * SSRRT (PI) *ISQRT! a/Q) } \\
& K I=(a)+(b)
\end{aligned}
$$

Faulted condition (1)

$$
\begin{aligned}
& \text { (a) = SashanasgRT(PI)egSaRT(a/l) } \\
& \text { (b) }=\text { Sb AHbrgSORT TPI) IGSQRT(a/B) } \\
& K I=(a)+(b)
\end{aligned}
$$

iNode 4: sar. Buy: lnner concrate not effective iEliptical surface flaw

$$
\begin{array}{ll}
i & 0.500 \\
i & 2.500
\end{array}
$$

iUnit load lload case fload case il200 Xipl gN isaxious load isaxima on$$
\text { ! }
$$$$
\text { - 1527000.0m : } 10990000000 \text { : } 8300965.000
$$$$
\text { 1527000.000 : 1212000.000:9253620.000 : }
$$$$
\text { gaxieun load igax }
$$

$$
\text { sy }=
$$

40000.000 ithoral+10pet (Sa + 5b)/Sy = (Faulted(1)

$$
(5 x+5 b) / 5 y=
$$

0.364

$0.379:$

\subsection{0 i}

0.020 :

\subsection{0 :}

$0.200:$

$0.040:$

0.080

$0.300:$

0.120 :

$0.600:$

$0.24 !$

1.100:

$1.100:$

0.999

$0.960:$

$0.900:$

1.100:

0.840 :

1.100!

0.670 :

iflange bend. : stress

13762.034 istress istress

1850.640

:

1911.394

2107.925 :

\subsection{6 :}

484.105:

4716.326

663.882 :

6669.892

\begin{tabular}{|c|c|c|c|c|}
\hline $\begin{array}{l}5693.269 ! \\
536.120 ! ! \\
229.389 !:\end{array}$ & $\begin{array}{r}5223.070 ： \\
735.212 ： \\
5958.283 ：\end{array}$ & $\begin{array}{r}7386.537: \\
974.763: \\
8361.300:\end{array}$ & $\begin{array}{r}9046.623 ! \\
1114.247 ! \\
10160.870 !\end{array}$ & $\begin{array}{r}12793.858: \\
1256.875: \\
14050.732:\end{array}$ \\
\hline
\end{tabular}

8168.916

1006.14?

9179.059

11552.592
1134.932

6674.731 ! $5380.208:-7550.083$ :

7550.083 :

12687.524:

733.493 :

17408.223: 
TROJAM : SUPPORT BEAM CAITICAL FLAU SIZE AMALYSIS

Stress location :

Flaw type

Flaw aspact ratio a/l

Plate thickness in.

Stresses in beas flange without flaw :

Moraal + Upeet $=\mathrm{DH}+\mathrm{T}+$ OBE

Faulted $(I)=D U+T+$ SSE

\section{Flaw shape paraeter $=9$}

Flaw depth 'a, in,

Flaw depth to flange thickness ratio

heabrane correction factor the

Bending correction factor to

Horgal plus upset conditions

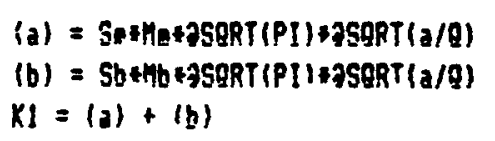

Faulted condition (I)

(a) $=$ Sa+Ma+3SGPT(PII+ESQRT(a/Q)

(b) $=5 b+h b+359 R T(P I 1+358 R T(a / \theta)$;

$K_{1}=(a)+(b)$
iNode 4: Mas. EY: Inner concrete affective IUnifors depth surface fląu

: $\quad 0.000$

2.500

Unit load iload case iload case

i(200 Kip) Bn !ayximun load isaximuan

i

; 1333000.000 : 1049000.0000; 7324835.000 :

; $1333000.000 ; 1212000.000: 8077980.600$ :

istrass

i

(a)

sy $=$

40000.000 iNorael +Upeet

$(50+5 b) / 5 y=$

3248.865

:Flanqe nean iflange bend. :

istress

istress

034 ;

thess

$0.020: 0.040 ; 0.090 ; 0.120 \div \quad 0.240 \div \quad 0.500:$

$1.130 \div \quad 1.130 ; \quad 1.170 \div \quad 1.230 ; \quad 1.500 ; \quad 3.500 ;$

$1.090: 1.060: 1.030 ; 1.020 \div \quad 1.060 \div \quad 1.580:$

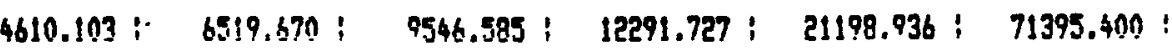

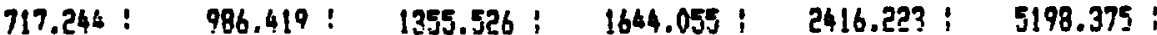

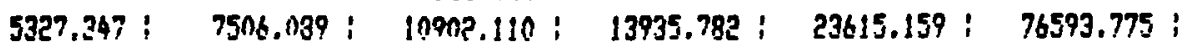

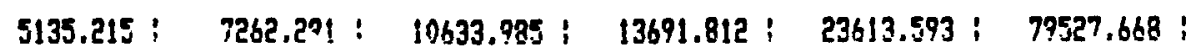
799.942： 1098.777： 1509.926：1831.320： 2691.442：5790.494；

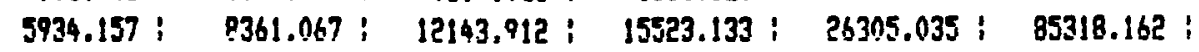


TROJAN : SUPPDRT BEAM CRITICAL FLAN SIZE ANALYSIS

Stress lecation:

Flaw type

Flaw aspect ratio a/l

Plate thickness in.

Stresses in bean flame nithout flay :

Faulted $(1)=$ DU $+T+$ SSE

Flaw shape parameter $=9$

Flan depth 'a" in.

Flaw depth to flange thickness ratio

Meabrane correction factor $H_{1}$

Bending correction factor the

Morad plus upset conditions

(a) = Sa+MarasgRT (PI) +\{SGQRTIa/QI

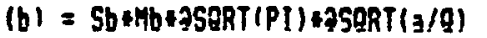
$K_{1}=(a)+(b)$

Faulted condition (1)

$$
\begin{aligned}
& \text { (a) = Sa+ha BaSERT (PI) A JSERT }(a / q) \text {; }
\end{aligned}
$$

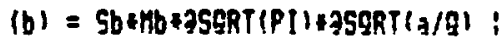

$$
\begin{aligned}
& K_{1}=(a)+(b)
\end{aligned}
$$
$:$

iNode 4: Max. By: Inner concrate offertive

iEliptical surfase flau

$$
\text { i } \quad 0.100
$$

\section{i(200 Kip) bh ? gaxinus load iqaximus Bh} : | 1333400.000 : 1099000.000 : 7324835.000 : $1333000.000: 1212000.000 ; 8077980.000$ : istress

:Flange kean

iflanqe bend. : istress istress 12013.616 19.45.059: $1668.559 ;$ $3248.865 ; \quad 11409.745$

$1840.120:$

$$
\text { sy }=
$$

$=$

$$
\text { 40060.000 iNoraal+Unset }
$$$$
\text { iFaulted(1) }
$$

$(s+s b) / 5 y=$ $(5 a+5 b) / 5 y=$

$0.050:$

$0.020:$

$1.100:$

$1.040:$

$$
\begin{aligned}
& 0.100: \\
& 0.040: \\
& 1.100: \\
& 1.020:
\end{aligned}
$$

$0.200:$
$0.080:$
$1.120:$
$0.990:$

$4280.791:$ $652.789:$ 4933.58!:

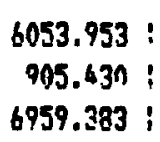

4764,060! 726.486 :

6737.399 1007.646 : 7745.045 :
97ก1. $359:$ 1369.143 : 11070.502 :
12093.862 : $1603.408:$ 13702.271 :
16851.246 ! 35219.238 : 1891.698 : 2793.185 : $18742.934 ; \quad 38 n 12.423$; 2105.245 ; 3108.514: 20859.868 : 42303.736 :
18753.623：39195.222： 
TROJAM : SUPPORT BEAN CRITICAL. FLAH SIZE ANALYSIS

Stress location :

Flaw trpe

Flaw aspect ratio a/1

Plate thirkness in.

Stresses in beas flange without flaw :

Moraal + Upset $=D H+P+D B E$

Faulted (1) $=$ OW $+T+$ SSE

\section{Flaw shape paraneter $=0$}

Flaw depth "a" in.

Flaw depth to flange thickness ratio

Meabrane correction factor he

Bending correction factor ho

Moral olus upset conditions

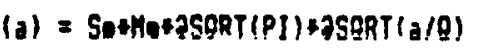

$$
\begin{aligned}
& \text { (b) }=5 b+H b+3 S Q R T(P I)+2 S Q R T(\div / Q) \\
& X I=(a)+(b)
\end{aligned}
$$

Faulted condition (1)

$$
\begin{aligned}
& (a)=\text { SerHa+2SQRT(PI) +2SQRT }(a / Q): \\
& (b)=S b+h b+2 S Q R T(P I)+3 S Q R T(a / Q): \\
& K I=(a)+(b)
\end{aligned}
$$

iNode 41: Max. 3h: Inner concrete effective Eliptical surfase flay

! $\quad 0.200$

i

IUnit load iload case iLoad case iHax. surface iflange aean iflange bend. ! (20n Kin! an iaxigus load igaxisus Bn 1333000.000 : 1099000.000 : 7324835.000 : $1333000.000: 1212000.000 ; 8077980.000$ istress ; 12013.616 istress istress

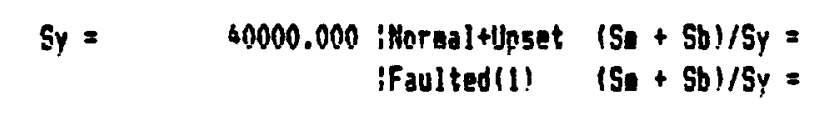

$(S s+5 b) / S y=$ (Se $+5 b) / 5 y=$

$$
\text { sy }=
$$

$3248.865:$

10345.058

\begin{tabular}{|c|c|c|c|c|c|}
\hline $\begin{array}{r}4362.333: \\
658.927 ?: \\
5021.160:\end{array}$ & $\begin{array}{r}6169.270 ： \\
904.585: \\
7073.255:\end{array}$ & $\begin{array}{l}9724.666: \\
1215.313: \\
9939.978:\end{array}$ & $\begin{array}{r}10695.490: \\
1394.461: \\
12079.930:\end{array}$ & $\begin{array}{r}15798.454: \\
1706.144: \\
17506.598:\end{array}$ & $\begin{array}{r}27760.300 \\
1822.969\end{array}$ \\
\hline
\end{tabular}

11408.745 :

1668.558 ; 1840.120 ;

$\begin{array}{llllll}0.050: & 0.100: & 0.200: & 0.300: & 0.600: & 1.250: \\ 0.020: & 0.040: & 0.090: & 0.120: & 0.240: & 0.500: \\ 1.100: & 1.100 ! & 1.100: & 1.100: & 1.150: & 1.400: \\ 1.030: & 1.000 ! & 0.950: & 0.890: & 0.7700 & 0.570:\end{array}$

$\begin{array}{rrrrrr}3910.747: & 5530.632: & 7921.494: & 9579.335: & 14163.009: & 24386.573: \\ 599.626: & 810.743: & 1089.504: & 1250.099: & 1529.525: & 1634.256: \\ 45011.372: & 6341.575: & 8910.999: & 10829.424: & 15692.534: & 26520.829:\end{array}$


TROJAN : SUPPORT BEAN CRITICAL FLAN SIZE ANALYSIS

Stress location ;

Flan type

Flaw aspect ratio a/l

Plate thickness in.

Norgal + Upset $=D H+T+$ DBE

Faulted $(1)=D 4+T+$ SSE

Flan shape paraeeter $=0$

Flaw depth "a" in.

Flaw depth to flange thickness ratio Menbrane correction factor $\mathrm{Mo}$

Bending correction factor th

Moral plus upset conditions

$$
\begin{aligned}
& \text { (a) = Sathn*2SQRT(PI) *aSgRT (a/Q) } \\
& \text { (b) }=5 b+m b+35 Q R T(P I)+25 Q R T(a / Q) \\
& k 1=(a)+(b)
\end{aligned}
$$

Faulted condition (1)

$$
\begin{aligned}
& \text { (a) = So+He+3SQRT(PI)+250RT(a/G) } \\
& (b)=\text { Sb+FbagSgRT(PI) +ASQRT(a/R) } \\
& x 1=(a)+(b)
\end{aligned}
$$

;

inode 4: Max. Bh: Inner concrete effective

iEliptical surface flaw

$\quad 0.300$

$$
2.500
$$
; $1333000.000 \div 1099000.000 \div 7324835.000$ : 1333000.000 ; $1212000.000 ; 8077980.000$ :

iflange aean

iFlange bend. :

Sy $=$

$0.020:$

$1.109:$

$1.010:$

$3490.015:$

$516.850:$

4006.265 :

$576.746:$

4472.746： istress ; i

12013.616 :

13268.865 istress

(15trest

40000.000 i Horeal+15pet $(58+5 b) / 5 y=$ iFaulted(1)

$(5 m+5 b) / 5 y=$

$0.100:$

0.040 :

\section{$0.200:$}

0.090 :

$1.100:$

$1.100:$

$0.980:$

$0.9 ? 0:$

$0.300:$
$0.120:$
$1.100:$
$0.860:$

0.300

$0.331:$

$0.600 \div$

$0.240:$

1.120:

$0.72 n:$

stress

:

1668.558

$1840.120:$

4935.627:

$6980.030 \div$

$8542.75 \mathrm{~K}:$ 709.225 ： 941.589 ; 1077.795 :

9626.752 !

$2309.581: 19512.358$;

5644.852 :

7931.618 !

$1276.339: \quad 1074.638$ :

13585.920: 20586.996 :

\section{5} 791.687 6301.180 :

\subsection{0 :} 1051.056: 8842.667 I
9542.72?： $13740.820 ： 21781.065$ 1203.335：1424.739; 1199.587: 10746.057 ： 15165.559 ; 22980.651 ; 
TROJAN : SUPPORT BEAM CRITICAL FLAW SIZE AMALYSIS

Stress location :
Flaw type
Flaw aspect ratio a/l
Plate thickness in.
Stresses in bean flange without flaw :

Nornal + Upset $=$ DU $+T+$ DBE

Faulted $(1)=D U+T+$ SSE

Flaw shape paraeter $=0$

Flaw depth "a" in.

Flaw depth to flange thickness ratio

Meabrane correction factor the

Bending corraction factor ito

Noral plus upset conditions

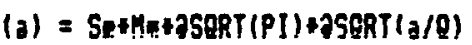
$(b)=5 b+H b+2 S Q R T(P I)+2 S Q R T(a / \theta)$

$$
K I=(a)+(b)
$$

Faulted condition (1)

$(z)=$ Satha+2SQRT (PI)+2SERT $(z / \theta)$

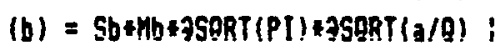
$K J=(a)+(b)$
Inode 4: M2x. Bn: Inner concrete effertive iEliptical surface flaw

: $\quad 0.800$

2.500
iUnit load iload case llood case

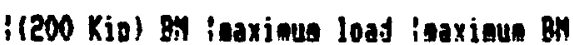

;

; 13330

: 1099000.000 : 7324835.000

1333000.000 : $1212000.000 ; 8077980.000$ :

$5 y=$

$$
\begin{gathered}
\text { 40000.000 iMorual+llpset } \\
\text { iF } 201 \text { ted(1) }
\end{gathered}
$$

$0.050:$

$0.020:$

$1.100:$

0.990 :

$$
\begin{aligned}
& 0.100: \\
& 0.040: \\
& 1.100: \\
& 0.960:
\end{aligned}
$$

$0.200:$

$0.080:$

$1.1 \mathrm{nn}:$

$0.900:$

2992.226 :

419.984

$3313.211:$

4091.640
575.949

575.949
4667.539

$5786.453:$
$763.609:$

$\$ 550.061$ :

3210.590

466.053

$3676.643:$
Hay. surface iflance mean istress

istress

12013.616 :

13248.865 :

istress

iflanne bend.

istress

10345.058

11408.745 :

1668.559 :

1840.120 :

$15 n+5 b) / 5 y=$
$19 n+5 b) / 5 y=$

$0.300:$

$0.331:$

$\theta=$

2.430

$\theta=2.400$
$0.300:$
$0.120:$
1.100 ;

0.600

$1.250:$

0.840 :

$0.240:$

$1.100:$

0.500

1.100:

$0.670:$

$0.300:$

$7086.728:$ 872.877 : 7959.905 :

10022.430 $994.608:$ 11007.039 :

14466.132 636.340 15102.47?

$\begin{array}{rr}4540.460: & 8421.180: \\ 639.126: & 847.370 ! \\ 5179.586: & 7268.550:\end{array}$

96 968.624 8832.932 ;
$11121.810 ： 16052.950$ : 1092.61?：706.14? : $12214.422 ： 16759.092$ : 


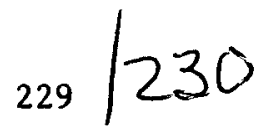

Table A 3.21

TROJAN: SUPPORT REAN CRITICAL FLAU SI ZE AHAIYYIS

STRESS INTENSITY SUMYARYRY : MODE 4 : LOCATIOY SF MAYIMUN BENDIQG MOMENT

\begin{tabular}{|c|c|c|c|c|c|c|c|c|c|}
\hline \multirow[t]{2}{*}{ Load case } & \multirow{2}{*}{$\begin{array}{c}\text { Inner } \\
\text { Concrete } \\
\text { Effective? }\end{array}$} & \multirow{2}{*}{$\begin{array}{l}\text { Flan } \\
\text { Aspect } \\
\text { Ratio }\end{array}$} & & & 1 & 3W Depth & $.1=$ & & \\
\hline & & & 0.00 & 0.05 & 0.10 & 0.20 & 0.30 & 0.60 & 1.25 \\
\hline$D H+T+O B E$ & No & 0.00 & 0.00 & 6133.00 & 3641.00 & 12551.00 & 16043.00 & 27196.00 & 88178.00 \\
\hline$D W+T+0 B E$ & Mo & 0.10 & $n, \hat{C O}$ & 5677.00 & 8008.00 & 11446.00 & 14168,00 & 21568.00 & 43742.00 \\
\hline$O H+T+0 B E$ & No & 0.20 & $n . \hat{0} ?$ & 5175.00 & $7 ? 91.00$ & 10246.00 & 12452.00 & 18044.00 & 30495.00 \\
\hline$D W+T+0 \mathrm{BE}$ & No & 0.30 & 0.00 & 9617.00 & 6505.00 & 9129.00 & 11094,00 & 15657.00 & 23725.00 \\
\hline$D U+T+D B E$ & No & 0.50 & 0.00 & 3819.09 & 5390.00 & 7550.00 & 9175.00 & 12687.00 & 17408.00 \\
\hline$D N+T+D B E$ & Yes & 0.00 & 0.00 & 5327.00 & 7506.00 & 10902.00 & 13935.00 & 23615.00 & 76593.00 \\
\hline$O N+T+O B E$ & Yes & 0.10 & 0.0 & 4933.00 & 6959.00 & 9947.00 & 12312.00 & 18742.00 & 38012.00 \\
\hline$D U+T+0 \mathrm{BE}$ & Yes & 0.20 & $0 . \hat{n}$ & 4501.00 & 6341.00 & 8910.00 & 10829.00 & 15692.00 & 26520.00 \\
\hline$D W+T+0 B E$ & Yes & 0.30 & 0.00 & 4006.00 & 5644.00 & 7921.04 & 9826.00 & 13535.00 & 20535.00 \\
\hline$D U+T+O B E$ & Yes & 0.50 & 0.93 & 3313,10 & 4667,00 & 6550.00 & 7959.00 & 11007.00 & 15102.00 \\
\hline OH+T+SSE & $\mathrm{Na}$ & 0.00 & 0.60 & 6832.00 & 9626.00 & 13989.00 & $1787 ? .00$ & 30286.00 & 98232.00 \\
\hline DN+T+SSE & Mo & 0.10 & 0.00 & 6348.90 & 8956,00 & 12799.00 & 15842.00 & 24116.00 & 48911.00 \\
\hline DU+T+SSE & No & 0.20 & $0, n ?$ & 5817.00 & 8198.00 & 11520.00 & 14000.00 & 20287.00 & 34296,00 \\
\hline DH+T+SSE & No & 0.30 & $0.6 n$ & 5139.00 & 7240.00 & 10160.00 & 12347.00 & 17426.00 & 28406.00 \\
\hline$D H+T+5 S E$ & No & 0.50 & $0.0^{n}$ & 4229.00 & 5959.00 & 8361.00 & 10150.00 & 14050.00 & 19278.00 \\
\hline DU+T+5SE & Yes & 0.00 & 0.00 & 5934.00 & 8361.00 & 12143,00 & $1,5523.00$ & 26305.00 & 85318.00 \\
\hline$D H+T+5 S E$ & Yes & 0.10 & 0.19 & 5490.00 & 7745.00 & 11070.00 & 13702.00 & 20859.00 & 42303.00 \\
\hline DU $+T+$ SSE & Yes & 0.20 & $0, \mathrm{fm}^{n}$ & 5021.00 & 7073.00 & 9939.00 & 12079.00 & 17504.00 & 29593.00 \\
\hline$D U+T+5 S E$ & Yes & 0.30 & 0.9 & 4472.00 & 6301.00 & $884 ? .00$ & 10746.00 & 15165.00 & 22980.00 \\
\hline OU+T+SSE & Yes & 0.50 & $0 . \hat{n}^{n}$ & 3676.00 & 5179.00 & 7268.06 & 8832.00 & 12214.00 & 16759.00 \\
\hline$D U+T+58: \angle D C A$ & Ho & 0.00 & 0.00 & 9064.76 & $1277 ? .01$ & 18550.52 & 23712,47 & 40182.44 & 130328.35 \\
\hline$O H+T+S B: L O C A$ & Ho & 0.10 & 0.00 & 8399.27 & 11 Bด. 14 & 16935.33 & 20961.33 & 31909.28 & 64715.01 \\
\hline$O U+T+5 B: L O C A$ & Ho & 0.20 & $0 . n$ & 7601.46 & 10709.00 & 15047,98 & 18237.62 & 26499.95 & 44735.66 \\
\hline$D N+T+5 B: L O C A$ & No & 0.30 & 0.80 & 6732.55 & 9484,79 & 13310.32 & 16175.38 & 22.827 .78 & 34591,35 \\
\hline$D H+T+5 B: \angle O C A$ & No & 0.50 & 0.00 & 5483.06 & 7726.43 & 10837.75 & 13172.75 & 18215.64 & 24993.20 \\
\hline$D U+T+5 B: L O C A$ & Yes & 0.00 & n.en & 7787.17 & 10971.91 & 15936.00 & 20370.42 & 34519.10 & 111759,80 \\
\hline$O U+T+S B: L O C A$ & Yes & 0.10 & 0.01 & 7191.16 & 10143.96 & $14699.4 ?$ & 17946.34 & 27319.59 & 55406.68 \\
\hline$D H+T+58: L O C A$ & Yes & 0.20 & 0.00 & 6530.38 & 9200.06 & 12927.67 & 15710.83 & 22766.00 & 38475.19 \\
\hline$D U+T+S B: L D C A$ & Yes & 0.30 & $0.8 ?$ & 5821.69 & $820: .29$ & 11509.15 & 13996.51 & 19738.70 & 29910.41 \\
\hline$D U+T+5 B: L O C A$ & Yes & 0.50 & $0, \mathrm{c}$ & 4756.07 & 6700.26 & 9402.52 & 11426.18 & 15800.44 & 21679.38 \\
\hline$B H+T+L B: \angle D C A$ & No & 0.00 & 0.00 & 14616.00 & 20594.00 & 27913.00 & 38235.00 & 64772.00 & 210149.00 \\
\hline$D U+T+L B: L C C A$ & $\mathrm{No}$ & 0.10 & $0, m$ & 13439.00 & 18957.00 & 27097.00 & 33538.00 & 51056.00 & 103546,00 \\
\hline$D H+T+\angle B: L O C A$ & No & 0.29 & $0 . \hat{0}^{n}$ & 12067.00 & 170000.00 & 23988.00 & 29031.00 & 42069.00 & 71097.00 \\
\hline$D U+T+L B: L O C A$ & Ho & 0.30 & 0.00 & 10694.00 & 15066.00 & 21143.00 & 25695.00 & 36262.00 & 54949,00 \\
\hline$D W+T+L B: L O C A$ & Ho & 0.50 & $0.5 ?$ & 8653.00 & 12190.00 & 17107.00 & 20789.00 & 28747.00 & 39443.00 \\
\hline$D H+T+18: \angle D C A$ & Yes & 0.00 & 0.50 & 12476.00 & $57578.0 n$ & 25531.00 & 32636.00 & 55304,00 & 179373.00 \\
\hline$D H+T+L B ; L D C A$ & Yes & 0.10 & 0.10 & 11334.00 & 16059.00 & 2?955.00 & 28412.00 & 43252.100 & 87719.00 \\
\hline$O N+T+L B: L O C A$ & Yes & 0.20 & $0.0^{\circ}$ & 10383.00 & 14599,00 & 20514.00 & 24931,00 & 36127.00 & 61055.00 \\
\hline$D W+T+L B: \angle O C A$ & Yes & 0.30 & $9 . n$ & 9157.00 & 12900.00 & 18103.00 & 22000.00 & 31048.00 & 47048.00 \\
\hline$D H+T+L B: L D C A$ & Yes & 0.50 & $n . . n$ & 7457.00 & 10.505 .00 & 14743.00 & 17916.00 & 24775.00 & 33994.00 \\
\hline
\end{tabular}

$D H+T+08 E=1099 \mathrm{Kips} . \quad \quad D H+T+54: L C C A=1558 \mathrm{Kips}$. NH+T+SSE = $1212 \mathrm{KiFs} \quad$ DH+T+19!1CCA= 2643 Hins. 
.

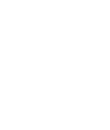

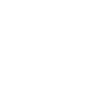
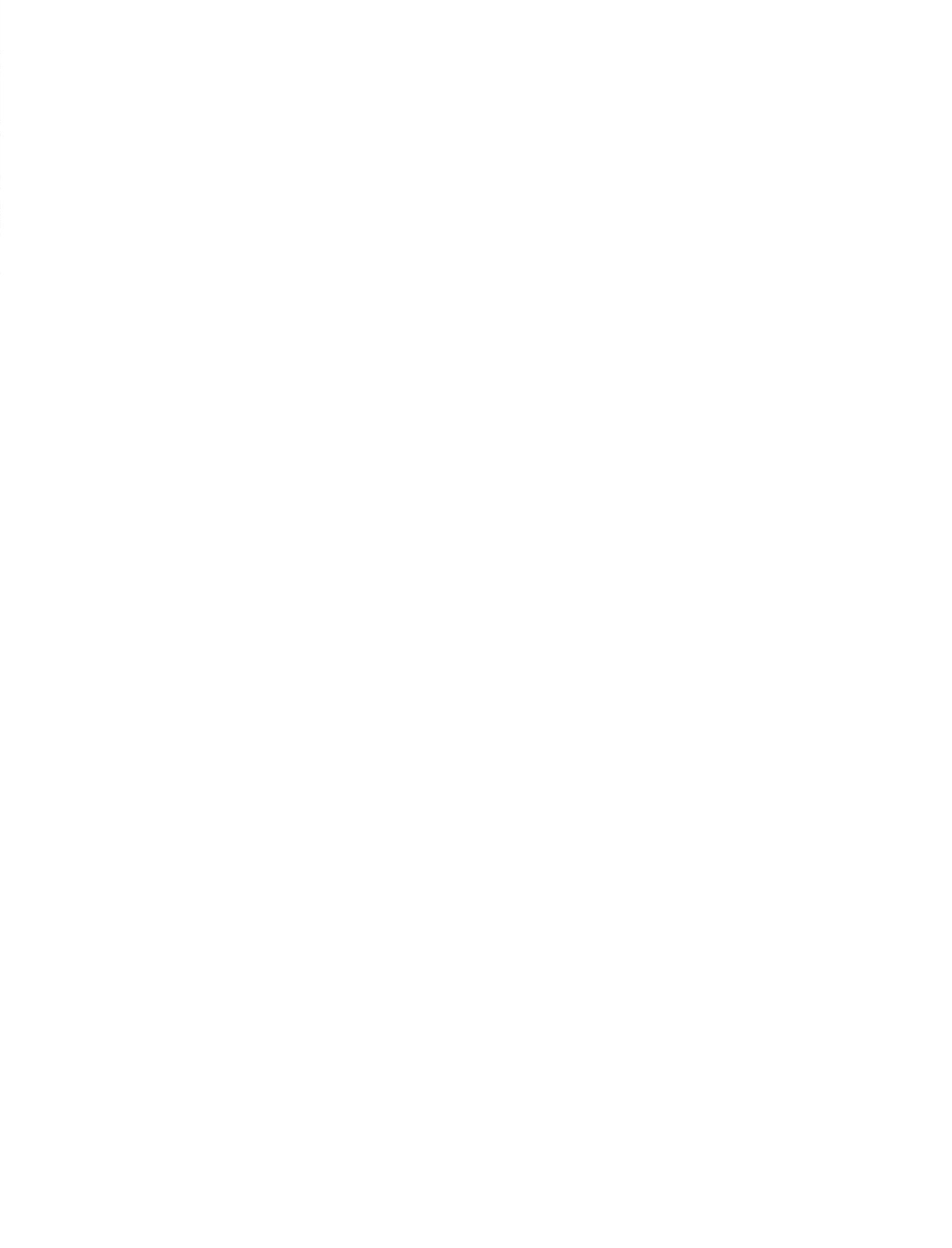
Appendix 4

TROJAN CRITICAL-FLAW-SIZE ANALYSIS FOR THE

BEAM-TOP FLANGE AT THE LOCATION OF THE 4-in.-diam GROUT HOLES 
TROJAN : SUPPORT BEAM CRITICAL FLAM SIZE AMALYSIS

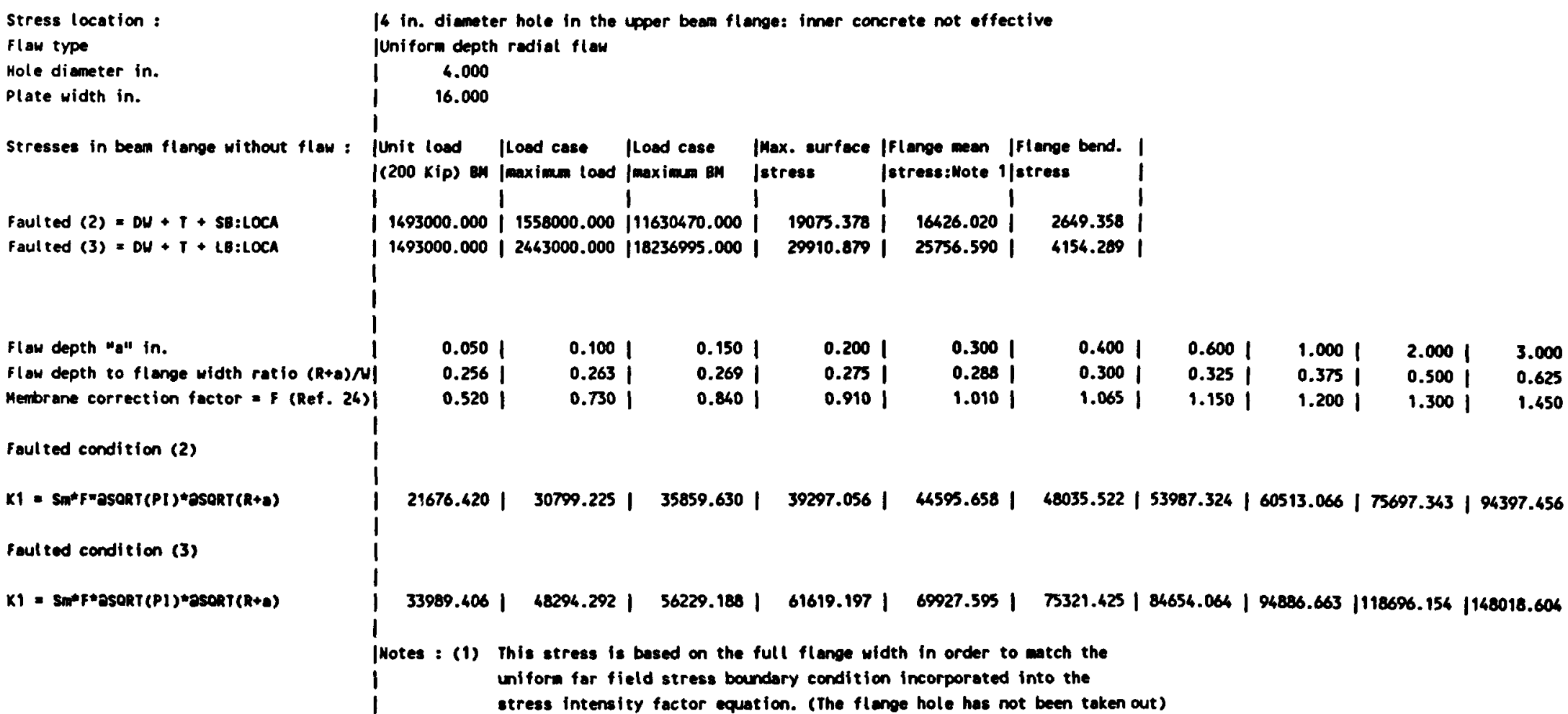


TROJAN : SUPPORT BEAM CRITICAL FLAH SIZE AMALYSIS

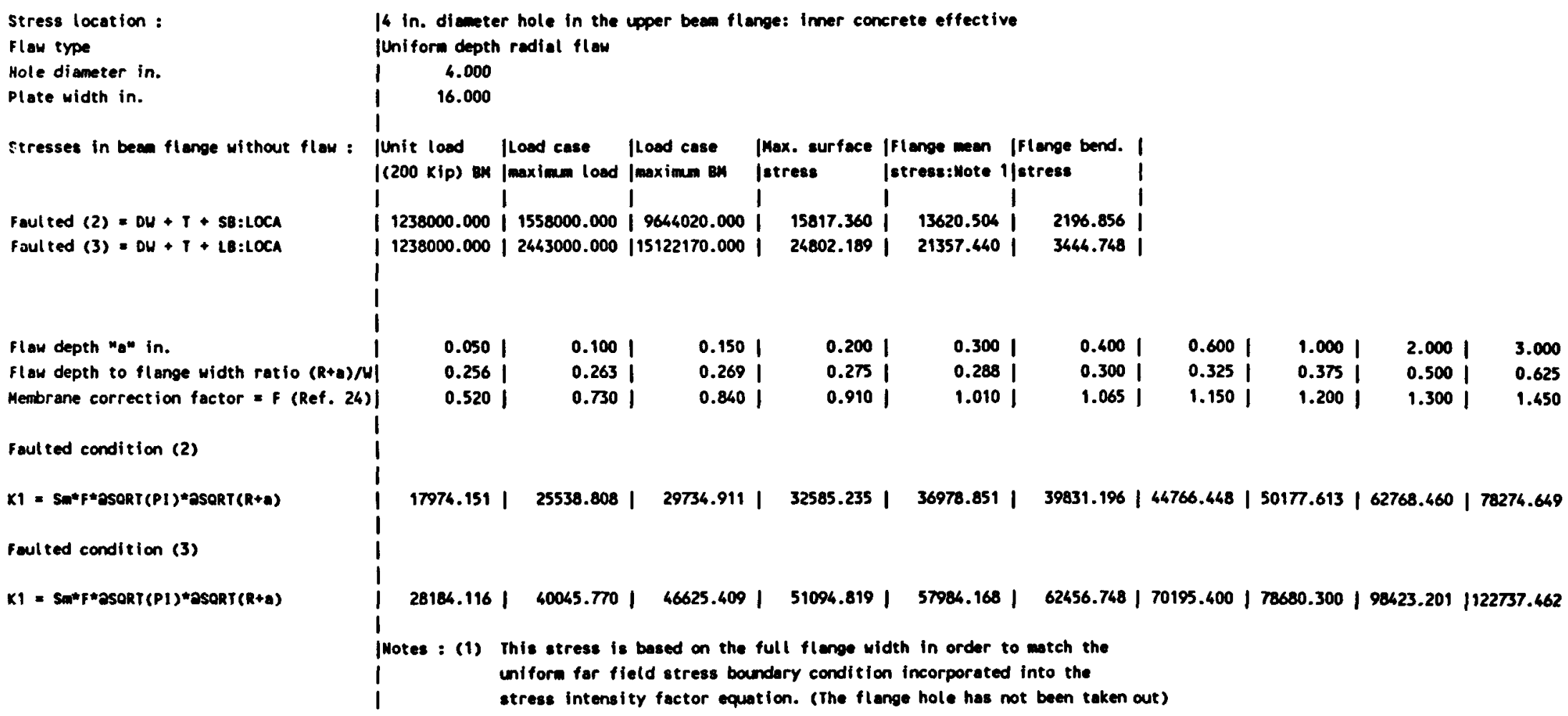


TROJAN : SUPPORT BEAM CRITICAL FLAW SIZE ANALYSIS

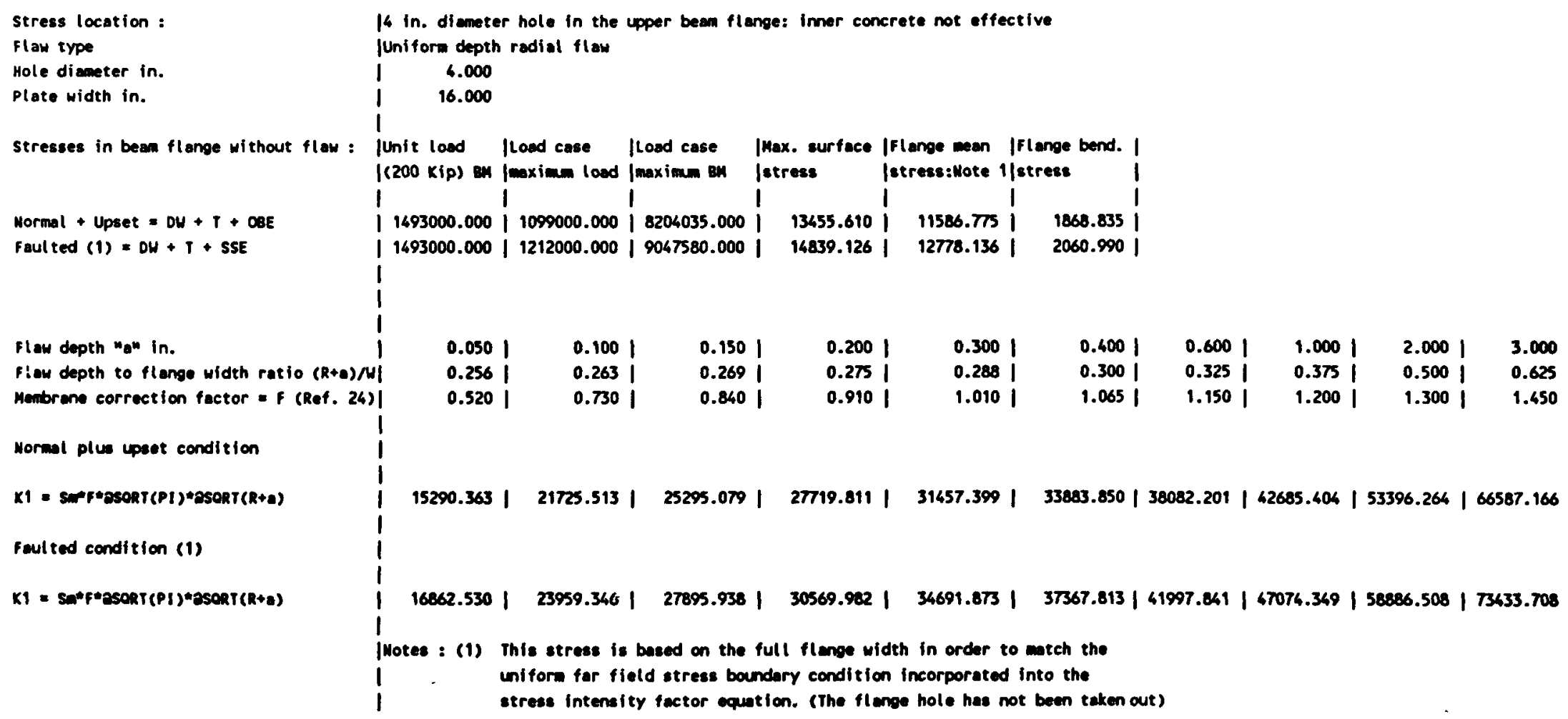


Table 14.4

TROJAN : SUPPORT BEAM CRITICAL FLAH SIZE AMALYSIS

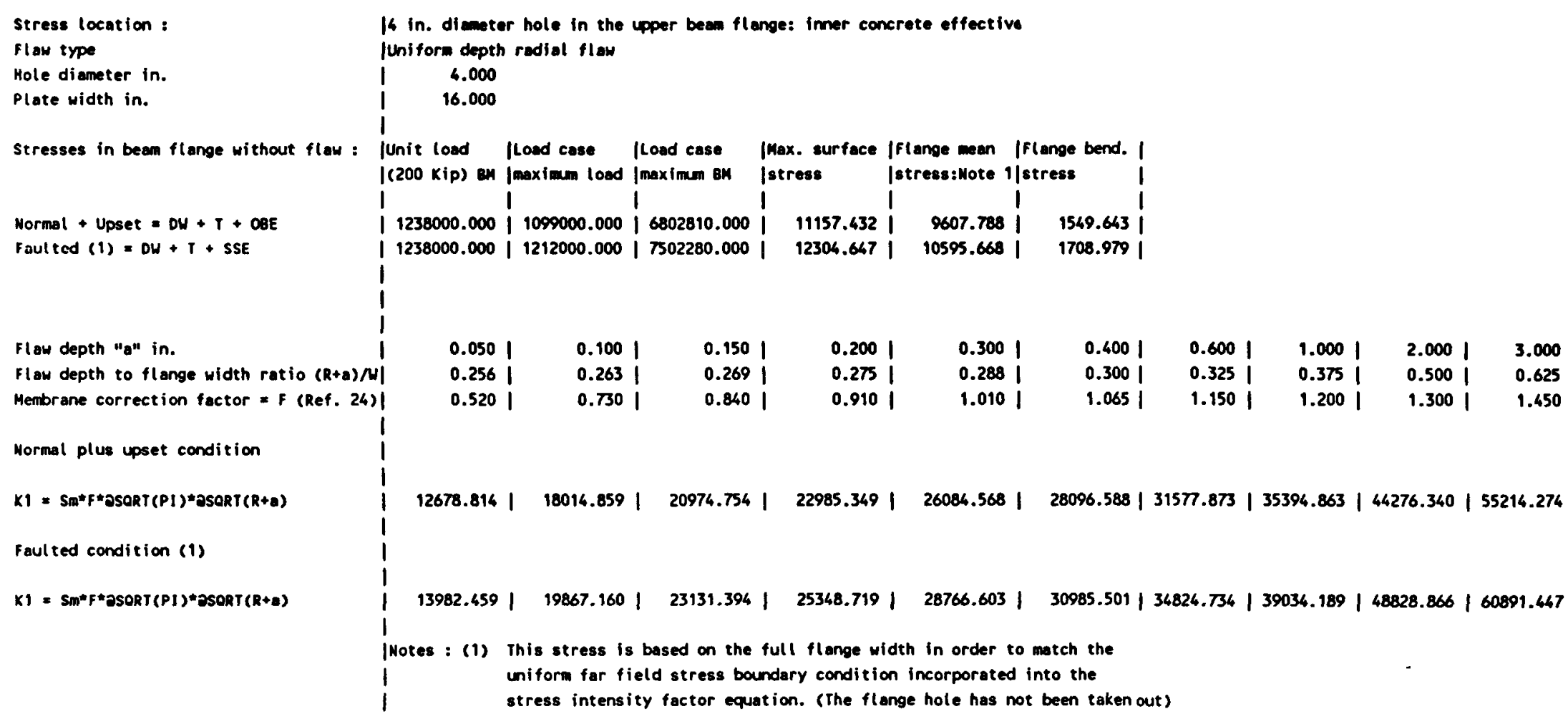


TROJAN: SUPPORT BEN CRITICAL FLAH SIZE AHALYSIS

SIRESS IMTENSITY SUMURY

6 IN. OIMMETER MOLE IN TME UPPER BEAM FLANGE

\begin{tabular}{|c|c|c|c|c|c|c|c|c|c|c|c|c|c|}
\hline \multirow[t]{2}{*}{ lood case } & \multirow{2}{*}{$\begin{array}{c}\text { Imner } \\
\text { concrete } \\
\text { effective? }\end{array}$} & \multirow{2}{*}{$\begin{array}{l}\text { Plow } \\
\text { Aspect } \\
\text { Rotlo }\end{array}$} & & & \multirow{2}{*}{\multicolumn{2}{|c|}{0.150}} & \multirow[b]{2}{*}{0.200} & \multirow[b]{2}{*}{0.300} & \multirow[b]{2}{*}{0.400} & \multirow[b]{2}{*}{0.600} & \multirow[b]{2}{*}{1.000} & \multirow[b]{2}{*}{2.000} & \multirow[b]{2}{*}{3.000} \\
\hline & & & 0.000 & 0.050 & & & & & & & & & \\
\hline DW+T+OQE & No & 0.000 & 0.000 & 15290.363 & 21725.513 & 25295.079 & 27719.811 & 31457.399 & 33883.850 & 38082.201 & 42685.404 & 53396.264 & 66587.166 \\
\hline OU. $1 \cdot 0 B E$ & res & 0.000 & 0.000 & 12678.816 & 18016.859 & 20974.754 & 22905.369 & 26004.560 & 20096.588 & 31577.873 & 35396.863 & 46276.340 & 55216.276 \\
\hline OU•T+5SE & Mo & 0.000 & 0.000 & 16862.530 & 23959.346 & 27895.938 & 30569.982 & 34691.873 & 37367.813 & 41997.841 & 67074.349 & 58086.508 & 73433.708 \\
\hline OU+T+5SE & Yes & 0.000 & 0.000 & 13982.659 & 19867.160 & 23131.396 & 25348.719 & 28766.603 & 30985.501 & 34824.734 & 39034.189 & 48282.866 & 60091.647 \\
\hline OU. T+5E: :LCA & wo & 0.000 & 0.000 & 21676.620 & 30799.225 & 35859.630 & 39297.056 & 64595.658 & 48035.522 & 53987.326 & 60513.066 & 75697.343 & 94397.456 \\
\hline OH+T•SE :LOCA & res & 0.000 & 0.000 & 17974.151 & 25538.808 & 29736.911 & 32585.235 & 36978.851 & 39631.196 & 46766.448 & 50177.613 & 62768.460 & 78274.649 \\
\hline OU+T+LA:LOCA & Mo & 0.000 & 0.000 & 33999.406 & 48296.292 & 56229.188 & 61619.197 & 69927.595 & 73321.425 & 84654.064 & 94886.663 & 11869.154 & 148018.604 \\
\hline Du+polle:Loca & res & 0.000 & 0.000 & 28184.116 & 60045.770 & 46625.409 & 51096.819 & 57984.168 & 62456.748 & 70195.400 & 70620.300 & 3423.201 & 22737.462 \\
\hline
\end{tabular}




\section{Appendix 5}

\section{AN EVALUATION OF THE IMPACT OF ASSUMPTIONS MADE IN MODELING THE VESSEL-SUPPORT BEAM ELASTIC FOUNDATION}

\section{A5.1 Background}

Several assumptions were made in modeling the concrete foundation elements in the original analysis. The sensitivity of the beam bending moment diagram to these assumptions will now be assessed. The assumptions of concern are as follows:

1. The concrete compressive modulus was set at $6 \times 10^{6} 1 \mathrm{~b} / \mathrm{in}$. in an attempt to reflect the maximum foundation stiffness. Concrete stiffnesses down to $E=5 \times 10^{6} 1 \mathrm{~b} /$ in. ${ }^{2}$ will be evaluated.

2. Two rings of vertical rebar exist near the inner pedestal and were not included in the foundation stiffness.

3. Two wide-flange struts that join the upper and lower supports for alignment and assembly purposes were not included in the analyses. These will now be added.

In total, this foundation modeling sensitivity assessment is comprised of six cases. A summary of the parameter combination included in each of the cases is given in Fig. A5.1.

ORNL-DWG 88-5079 ETD

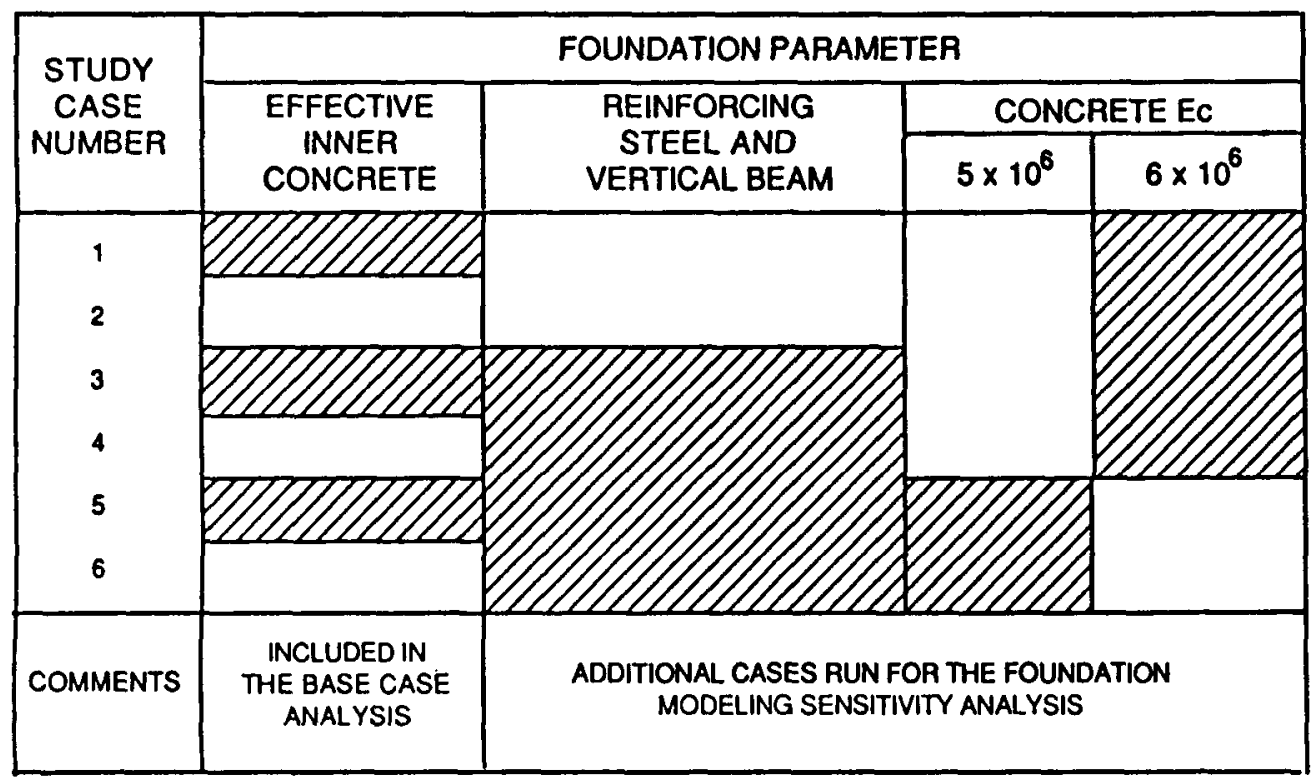

Fig. A5.1. Study scope. 


\section{A5.2 Geometry of reinforcing steel}

A section through the cavity wall showing both the distribution of the reinforcing bars and the beam elastic foundation footprint is given in Fig. A5.2. Derivation of the foundation footprint average width (32.75 in.) is given in Sect. 6.4.2.3 of the report. Reinforcing bars falling within the foundation footprint were included in the foundation stiffness on a case-by-case basis, as indicated in Fig. A5.1.

The radius to the beam 1 ug centerline is $9 \mathrm{ft} 2-1 / 2$ in. Offsets to the rebar centerlines are

$$
\begin{aligned}
& \text { (1) inner circle: } x=124-110.5=13.5 \mathrm{in} . \\
& \text { (2) outer circle: } x=140-110.5=29.5 \mathrm{in} .
\end{aligned}
$$

In addition to the reinforcing bars, two vertical wide-flange members are incorporated into the vessel-support assembly design. The primary purpose of these vertical members is to join the upper and lower vessel-support assemblies and thereby maintain alignment between the two assemblies during erection. They do, however, provide some additional

ORNL-DWG 88-5000 ETO

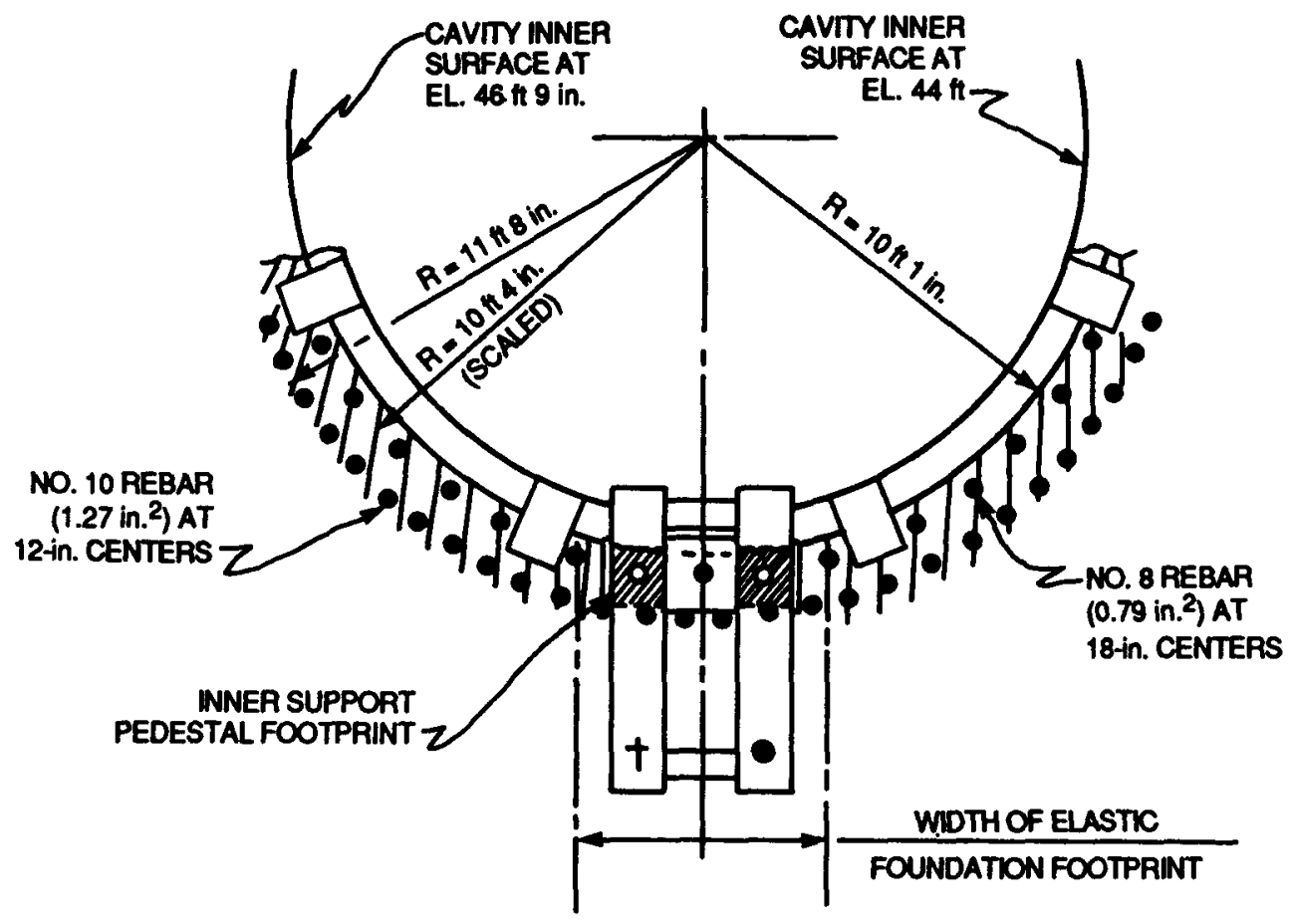

Fig. A5.2. Reinforcing bar distribution. 
vertical restraint to the beam and were therefore included in the modified foundation model along with the reinforcing steel. The vertical wide-flange members are located 45 in. from the beam loading point and have an area of $8.25 \mathrm{in.}{ }^{2}$ each $\left(I_{x x}=98.0\right.$ in. 4$)$.

\section{A5.3 Analytical model adjustment}

The inner rebar circle offset (13.5 in.) aligns closely with the inner flange of the front pedestal. The rebar was therefore added directly to the front-pedestal, front-flange area (see beam No. 22 extending between nodes 3 and 23). The No. 8 rebar is spaced on 18.0-in. centers, giving a maximum of two bars to be added to the flange area; that is,

$$
\mathrm{A}=20+2 \times 0.79=21.58 \mathrm{in.} .
$$

The outer rebar circle offset $(29.5)$ is located midway between nodes 9 and 10. The rebar area was added in its entirety to foundation beam No. 25, which represents the inner pedestal outer flange. The average width of a concrete support element is obtained from Sect. 6.4.2.3 as 32.75 in. The additional steel area for this location is thus $(32.75 / 12) \times 1.27=3.47$ in. ${ }^{2}$.

Details of the model modifications made to incorporate the reinforcing steel into the foundation elements are given in Fig. A5.3. The addition of the vertical wide-flange beam to the model is shown in Fig. A5.4(b).

\section{ORNL-OWG 88C-6081 ETD}

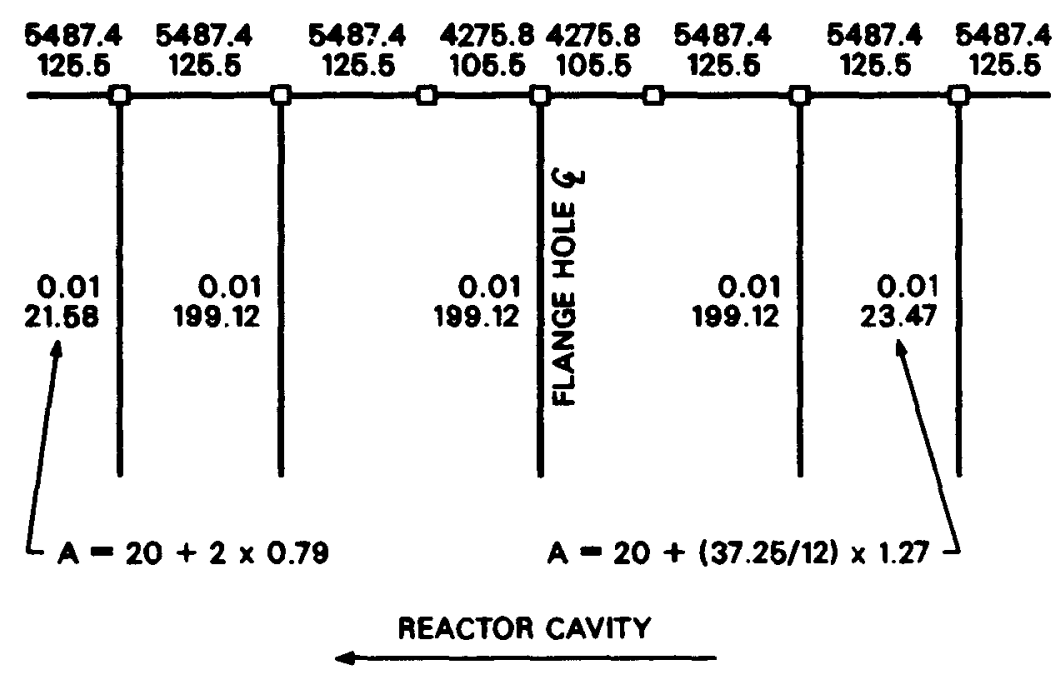

Fig. A5.3. Reinforcing bar representation. 


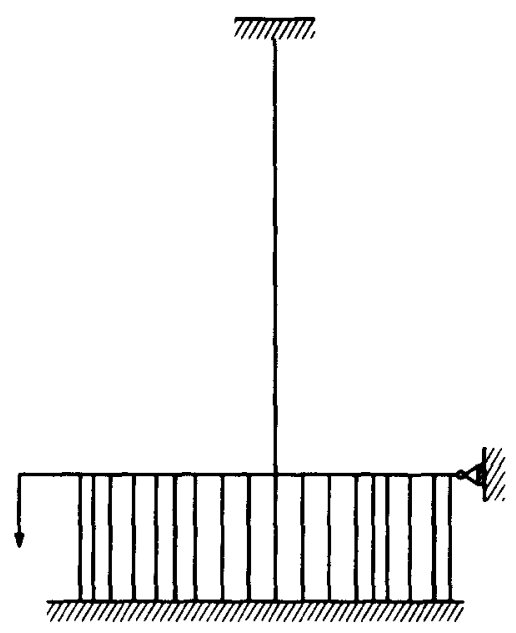

(o)

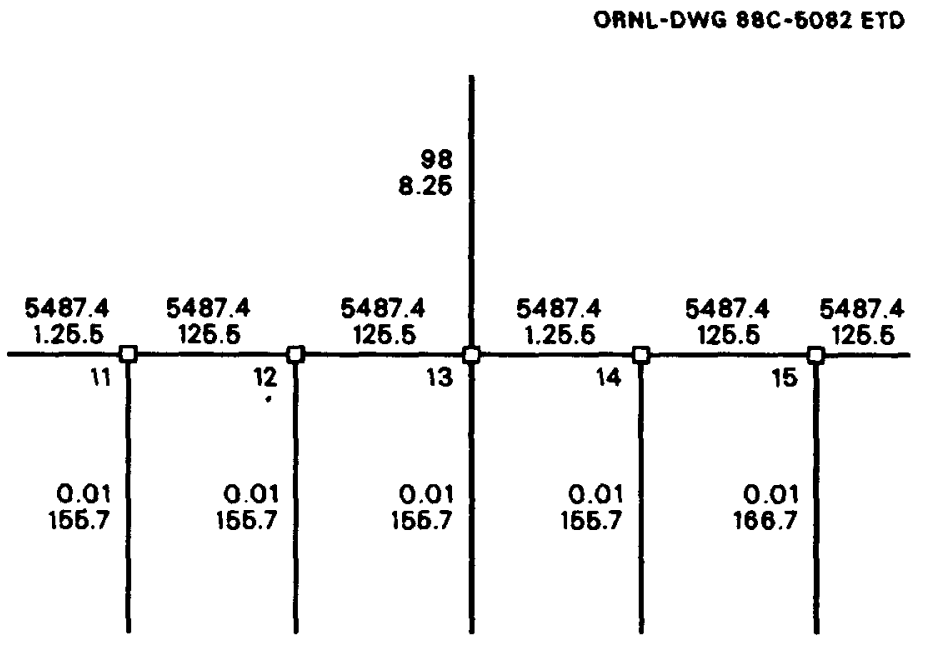

(b)

Fig. A5.4. Analytical model: (a) complete model and (b) detail of vertical beam modeling.

Evaluation of the impact of a reduced elastic modulus for the concrete required that the model foundation member areas be modified in some locations, because areas of mixed steel and concrete foundation were modeled as equivalent concrete members. The adjusted areas, reflecting the effect of the reduced concrete elastic modulus, are shown in Fig. A5.5.

ORNL-DWG 88C-6083 ETO

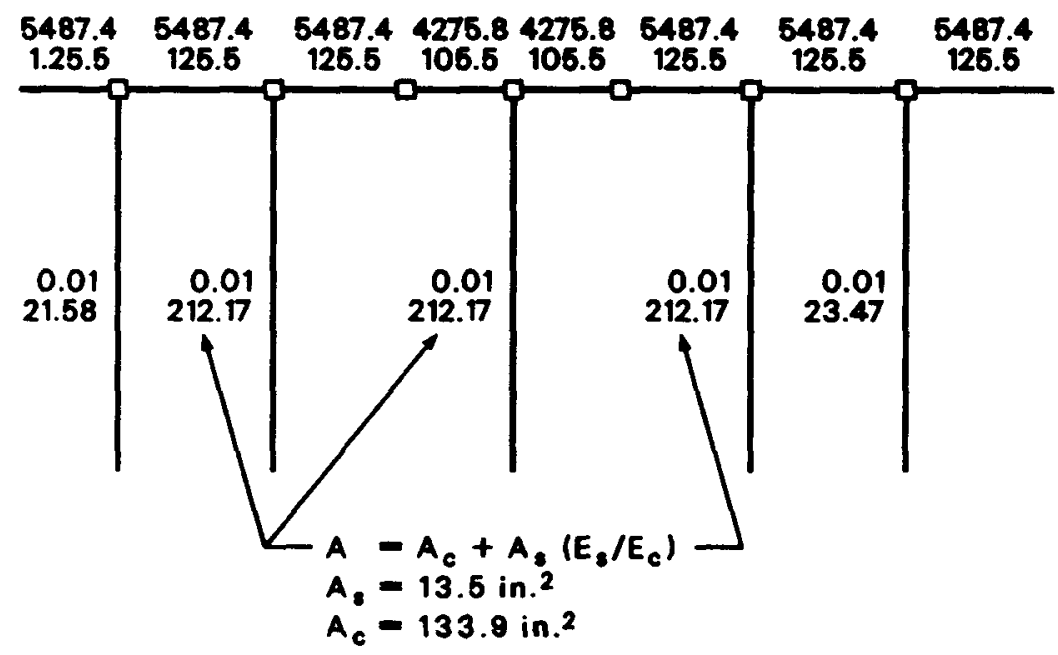

Fig. A5.5. Concrete elastic modulus adjustment. 


\section{A5.4 Foundation sensitivity analysis}

Separate runs of the finite-element model were made for each of the cases identified in Fig. A5.1. Beam bending moments and foundation reactions obtained from those runs are summarized in Tables $A 5.1$ and A5.2, respectively.

Table A5.1

BEAM FMUNDATICN PARAMETER SENGITIUTTY ANAI YGTS

EFFECT ON BEAM RENDING MDMENTS

PARAMETERG : (1) Inner conrrete $\left(T_{0}\right): T=$ Inrlured. NI = Hot include (2) Re-bar and vertiral heam (Re) : $T=$ Inrluded

NI = ilo: 3n:Iuder

(3) Crincrete olastir mortulue (F) : Lew mritiluls = 5*1006

High mridusus $=6 * 10^{n}$

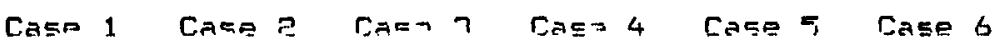

\begin{tabular}{|c|c|c|c|c|c|c|c|}
\hline Inner & concreter & I & NI & 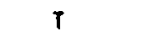 & $N I$ & I & $N I$ \\
\hline Ratar & \& beam & NT. & NI & $\mathbf{T}$ & I & $\mathbf{I}$ & I \\
\hline
\end{tabular}

Distance from loadinn pount

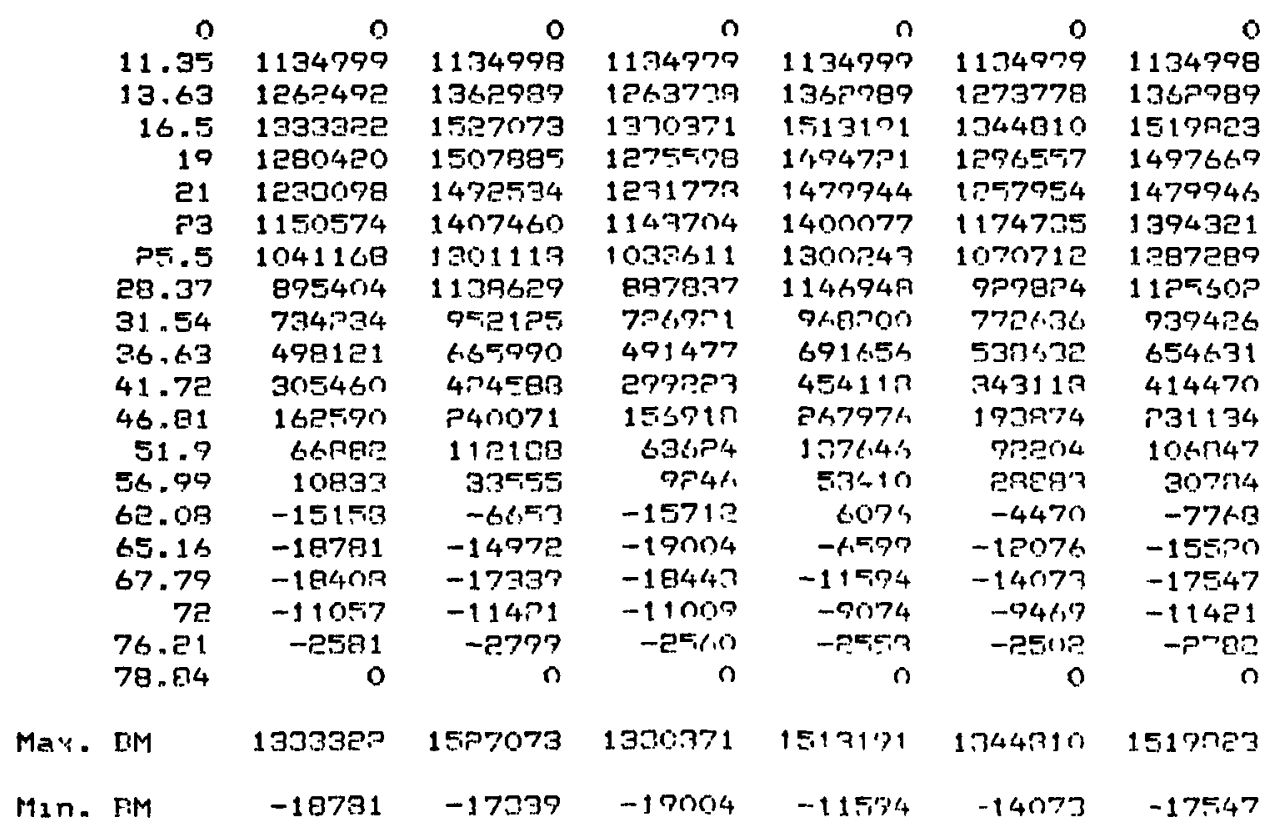


Table A5.2

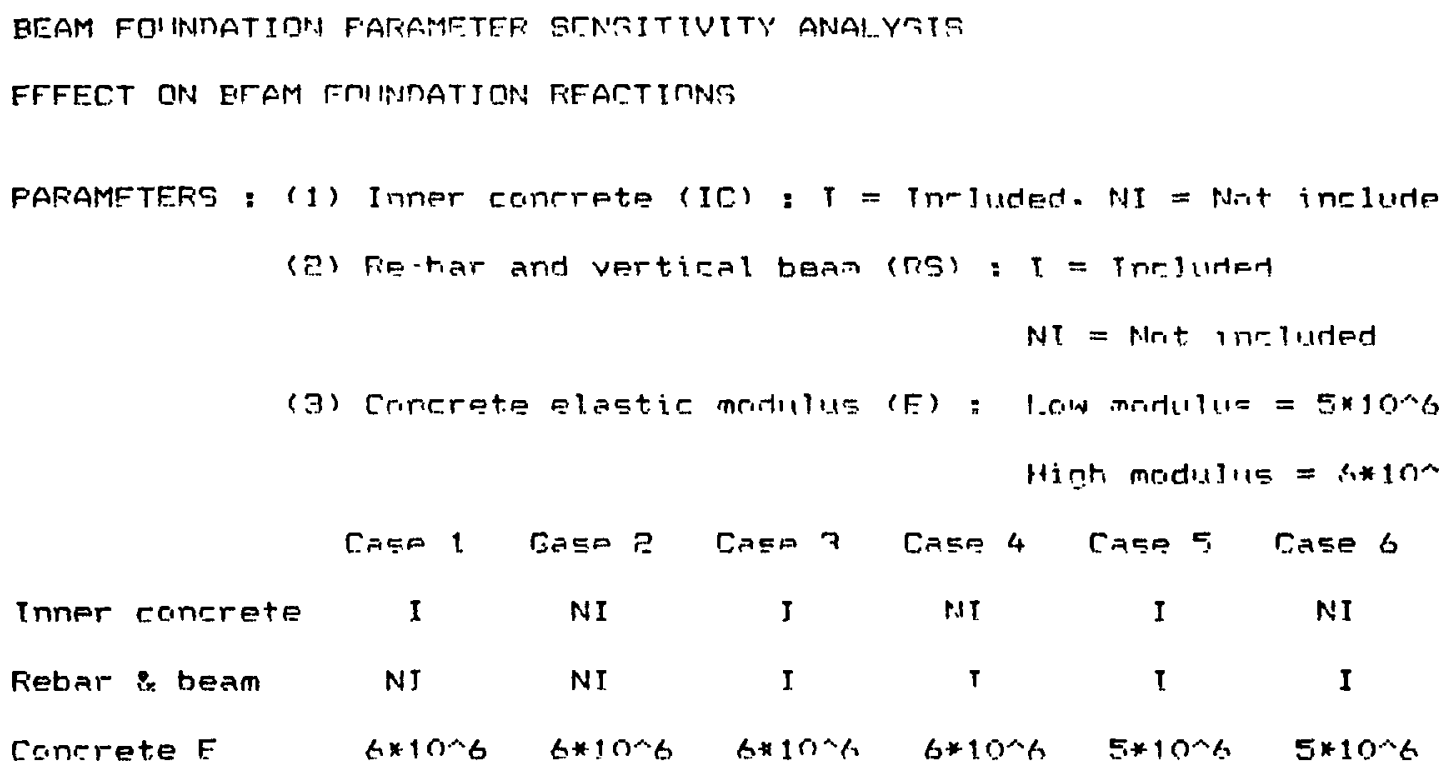

Distance from loading point

\begin{tabular}{|c|c|c|c|c|c|c|}
\hline 0 & 0 & 0 & 0 & 0 & 0 & 0 \\
\hline 11.35 & 44079 & 0 & 43532 & 0 & 371 무 & 0 \\
\hline 13.63 & 31241 & 4องค7 & 3नק:0 & 45753 & $361 P 1$ & 47.364 \\
\hline 16.5 & 45940 & 64849 & 45127 & 6.5.50 & 4405.2 & 59724 \\
\hline ?1 & PEGOP & 34861 & $\operatorname{er} 1$ PA & 33951 & 2P3on & 32545 \\
\hline 25.5 & 70R6 & 14079 & 6754 & 13504 & 7480 & 13479 \\
\hline 28.37 & 5,4 & epto & $-3 n$ & P395 & 477 & 2967 \\
\hline
\end{tabular}

\section{A5.5 Results}

Bending moments generated by unit loading on each of the six models are plotted in Fig. A5.6. The curves fall into two families, corresponding to the two inner concrete support conditions evaluated. Peak bending moments for the family with inner-concrete foundation support included in the model are $\sim 13 \%$ lower than those from the family with no inner-concrete support. Within the families, however, changes in the modeling of the reinforcing steel and the stiffness of the concrete influence the peak beam bending moments by $<1 \%$.

The effect of the foundation modeling assumptions on the distribution of reaction forces between the foundation members is shown in Fig. A5.7. The effect of the modeling changes is to move load onto the steel elements and away from the concrete elements. Maximum load shifts are <13\%. Note that the flaw tolerance of the pedestal members was not evaluated because the members are in compression at all times. 


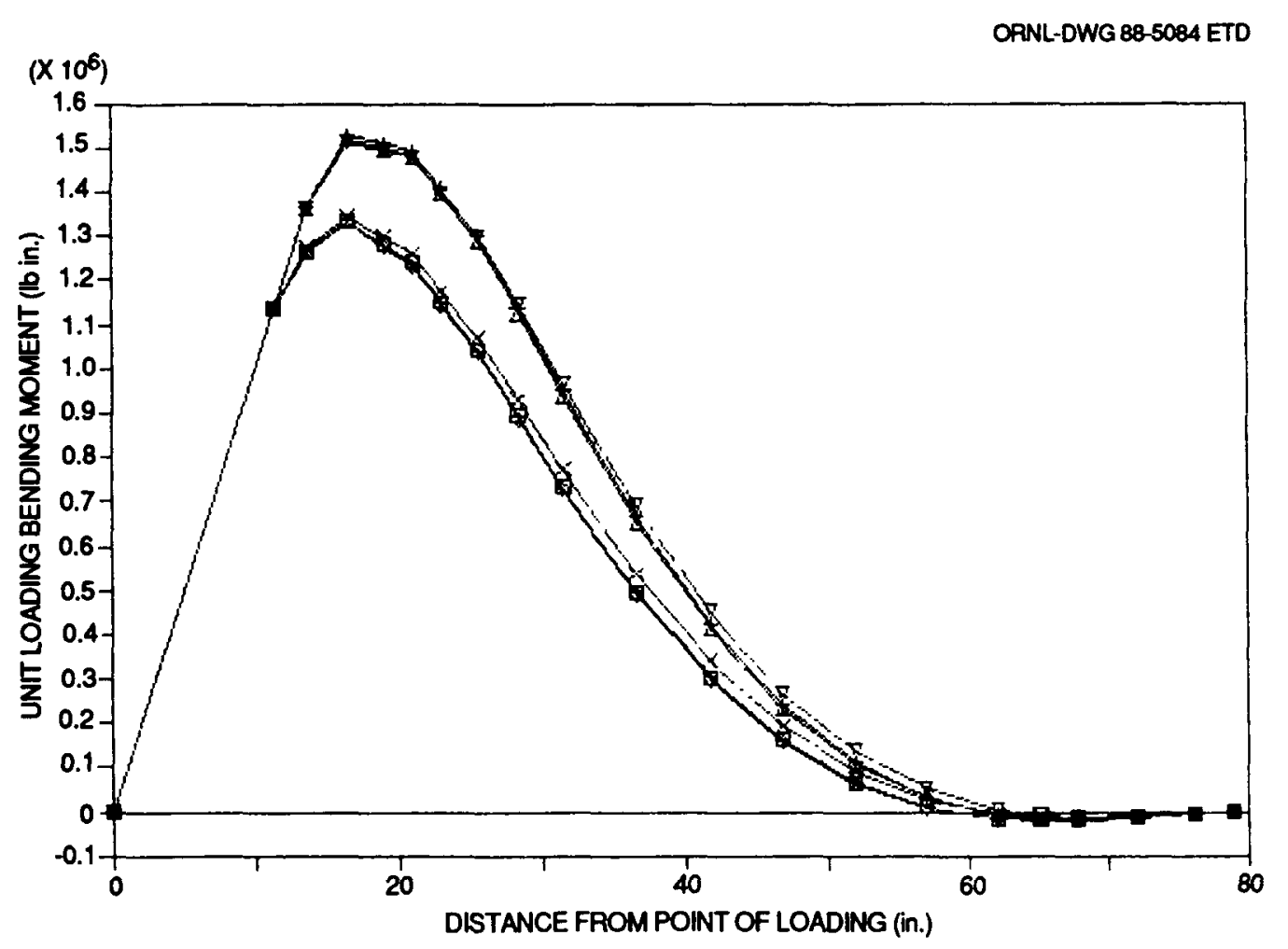

Fig. A5.6. Bending moment sensitivity.

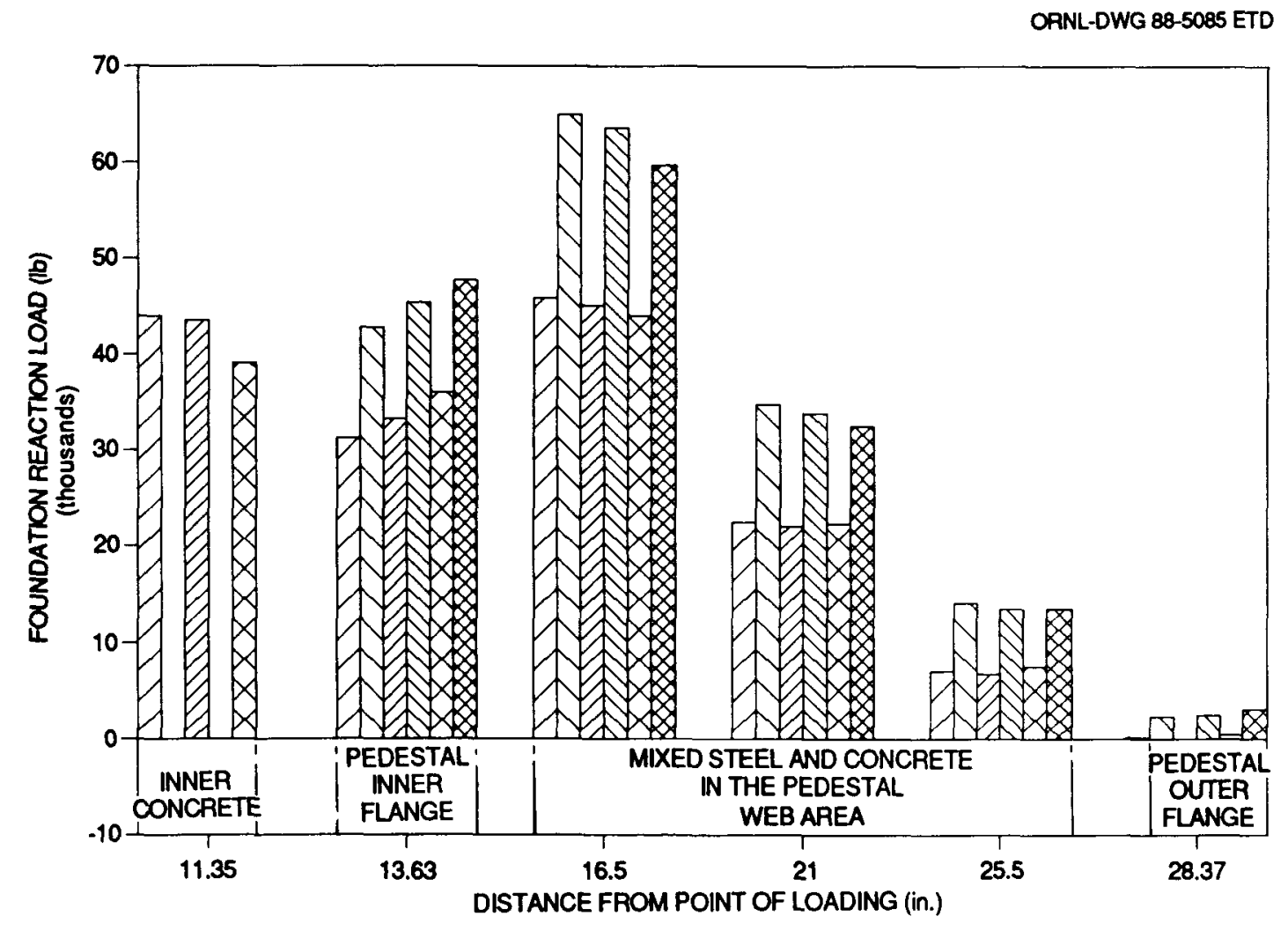

Fig. A5.7. Foundation reaction sensitivity. 


\section{A5.6 Conclusions}

In the range of foundation modeling parameters evaluated, only the effectiveness of the inner concrete in providing support for the beam has any significant effect on the beam flange stresses. This variable was included in the support beam parametric analysis. 


\section{Appendix 6 \\ CALCULATION OF $\mathrm{K}_{\mathrm{I}}$ VALUES FOR CRACKS EMANATING FROM \\ A HOLE IN A PLATE (TROJAN)}

Finite-element calculations of $K_{I}$ values for cracks emanating from a hole in a plate were performed in support of the $K_{I}$ evaluations discussed in Sect. 6.7.3.1. In this latter section, $K_{I}$ values were calculated using the model shown in Fig. 6.41 and Fig. A6.1. As mentioned in sect. 6.7.3.1, the loads are more nearly applied to the flange portion of the beam as shown in Fig. 6.41. The finite-element models corresponding to Figs. 6.41 are shown in Figs. $A 6.2$ and $A 6.3$.

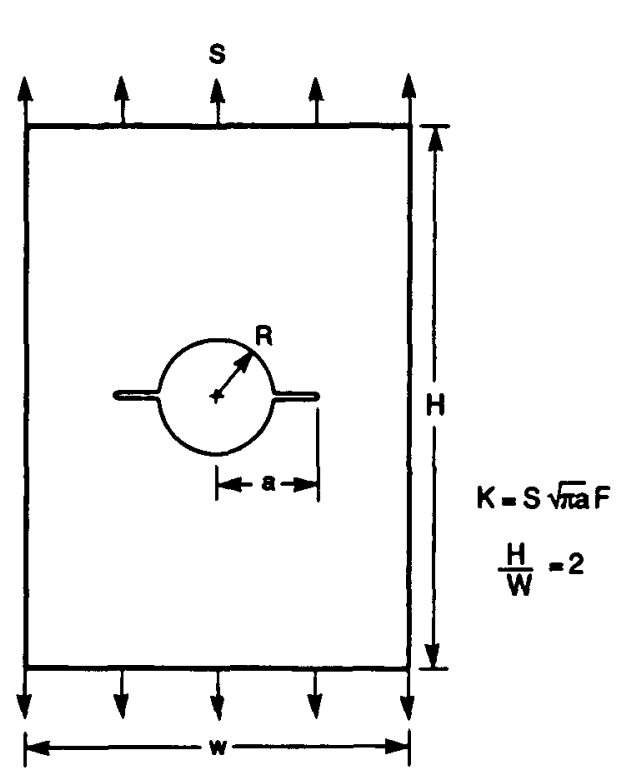

\begin{tabular}{|l|l|}
\hline $2 a / W$ & $F\left(\frac{2 R}{W}=0\right)$ \\
\hline 0 & 1.0000 \\
0.1 & 1.0061 \\
0.2 & 1.0249 \\
0.3 & 1.0583 \\
0.4 & 1.1102 \\
0.5 & 1.1876 \\
0.6 & 1.3043 \\
0.7 & 1.4891 \\
0.8 & 1.8161 \\
0.9 & 2.5482 \\
\hline
\end{tabular}

\begin{tabular}{|l|l|}
\hline $2 a / w$ & $F\left(\frac{2 R}{W}=0.25\right)$ \\
\hline 0.25 & 0 \\
0.26 & 0.6593 \\
0.27 & 0.8510 \\
0.28 & 0.9605 \\
0.29 & 1.0304 \\
0.30 & 1.0776 \\
0.35 & 1.1783 \\
0.40 & 1.2156 \\
0.50 & 1.2853 \\
0.60 & 1.3965 \\
0.70 & 1.5797 \\
0.80 & 1.9044 \\
0.85 & 2.1806 \\
0.90 & 2.6248 \\
\hline
\end{tabular}

\begin{tabular}{|l|l|}
\hline $2 a / w$ & $F\left(\frac{2 R}{W}=0.5\right)$ \\
\hline 0.50 & 0 \\
0.51 & 0.6527 \\
0.52 & 0.8817 \\
0.525 & 0.9630 \\
0.53 & 1.0315 \\
0.54 & 1.1426 \\
0.55 & 1.2301 \\
0.60 & 1.5026 \\
0.70 & 1.8247 \\
0.78 & 2.1070 \\
0.85 & 2.4775 \\
0.90 & 2.9077 \\
\hline
\end{tabular}

Fig. A6.1. Newman solution for cracks emanating from circular hole in finite rectangular plate subjected to uniaxial stress. 


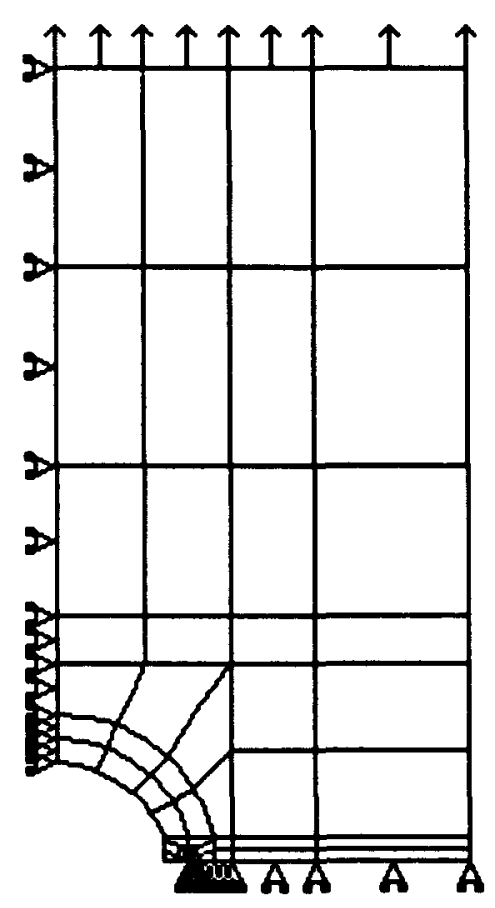

ORNL-DWG 88-5087 ETD

\begin{tabular}{|c|c|c|}
\hline \multicolumn{3}{|c|}{$\begin{array}{c}\text { BOUNDARY CONDITIONS } \\
0=\text { FREE } \\
1=\text { FIXITY }\end{array}$} \\
\hline & X-DISP & Y-DISP \\
\hline 2 & 1 & 0 \\
\hline A & 0 & 1 \\
\hline$\Delta$ & 1 & 1 \\
\hline \multicolumn{3}{|c|}{ LOADS } \\
\hline \multicolumn{3}{|c|}{ CONCENTRATED FORCE } \\
\hline \multicolumn{3}{|c|}{ DISTRIBUTED FORCE } \\
\hline \multicolumn{3}{|c|}{$\triangle T$ THERMAL LOAD } \\
\hline
\end{tabular}

(a) FULL MODEL

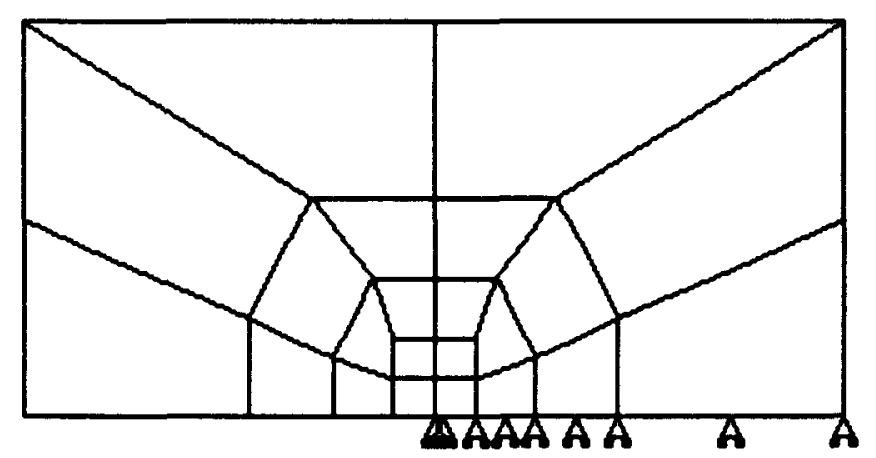

\begin{tabular}{|c|c|c|}
\hline \multicolumn{3}{|c|}{$\begin{array}{c}\text { BOUNDARY CONDITIONS } \\
0=\text { FREE } \\
1=\text { FIXITY }\end{array}$} \\
\hline & X-DISP & Y-DISP \\
\hline$D$ & 1 & 0 \\
\hline$A$ & 0 & 1 \\
\hline$\Delta$ & 1 & 1 \\
\hline \multicolumn{3}{|c|}{ LOADS } \\
\hline & \multicolumn{2}{|c|}{$\begin{array}{l}\text { CONCENTRATED FORCE } \\
\text { DISTRIBUTED FORCE } \\
\text { THERMAL LOAD }\end{array}$} \\
\hline
\end{tabular}

(b) CRACK-TIP REGION

Fig. A6.2. Finite-element model for beam flange with uniform end load. (a) Full model and (b) crack-tip region. 


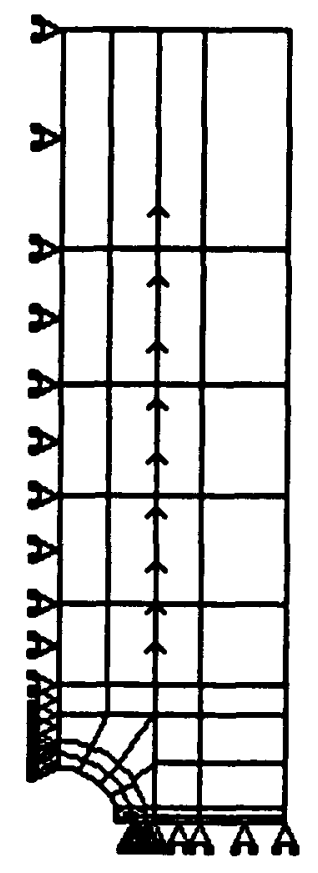

(a) FULL MODEL

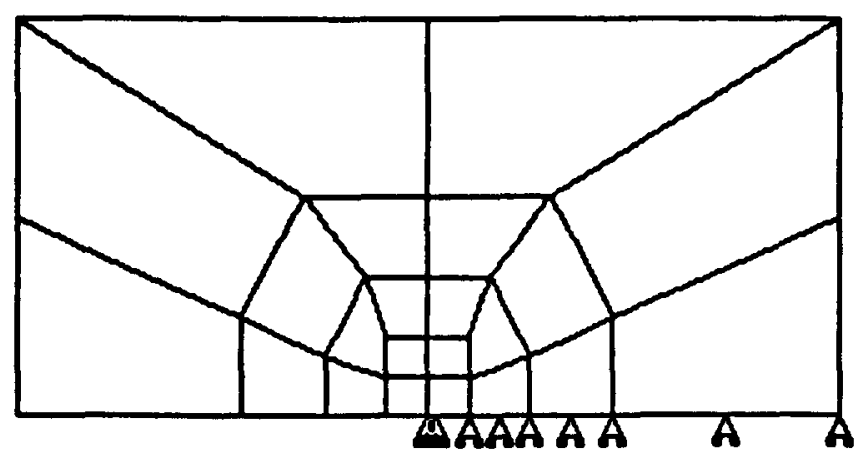

(b) CRACK-TIP REGION
ORNL-DWG $88-5088$ ETD

\begin{tabular}{|c|c|c|}
\hline \multicolumn{3}{|c|}{$\begin{array}{c}\text { BOUNDARY CONDITIONS } \\
0=\text { FREE } \\
1=\text { FIXITY }\end{array}$} \\
\hline & X-DISP & Y-DISP \\
\hline 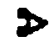 & 1 & 0 \\
\hline$A$ & 0 & 1 \\
\hline$\Delta$ & 1 & 1 \\
\hline \multicolumn{3}{|c|}{ LOADS } \\
\hline \multicolumn{3}{|c|}{ CONCENTRATED FORCE } \\
\hline & \multicolumn{2}{|c|}{ DISTRIBUTED FORCE } \\
\hline$\Delta T$ & \multicolumn{2}{|c|}{ THERMAL LOAD } \\
\hline
\end{tabular}

Fig. A6.3. Finite-element model for beam flange with line load. 
The finite-element and "handbook" values of $K_{I}$ for the problem depicted in Figs. A6.1 and A6.2 are shown in Table A6.1. As indicated, the agreement is within $0.7 \%$.

A comparison of $K_{I}$ values for the models depicted in Figs. A6.2 and A6.3 shows that the line-load model results in a $5 \%$ higher value of $K_{I}$ for the range of crack depths considered (Table A6.2). Assuming a critical flaw depth of 0.4 in., based on the model in Fig. A6.1, the required reduction in critical flaw depth to maintain the same critical value of $K_{I}=K_{I}$ is 0.1 in., which is obtained by interpolation of the data in either Table $A 6.1$ or $A 6.2$. A flaw size reduction of 0.2 in. is obtained when the starting critical flaw size is 0.9 in.

Table A6.1. Comparison of "handbook" and finite-element-analysis $K_{I}$ values for the problem in Fig. A6.1 with $\mathrm{s}=16.43 \times 10^{3} \mathrm{psi}$

\begin{tabular}{lllccc}
\hline $\mathrm{a}$ & $2 \mathrm{a} / \mathrm{w}$ & $\mathrm{F}$ & $\mathrm{K}_{\mathrm{I}}$ (Newman) & $\mathrm{K}_{\mathrm{I}}($ ORVIRT.PC) & X Diff. \\
\hline 2.25 & 0.28125 & 0.9692 & 42.33 & 42.35 & 0.04 \\
2.50 & 0.3125 & 1.1028 & 50.77 & 51.12 & 0.68 \\
3.00 & 0.3750 & 1.1970 & 60.37 & 59.99 & 0.63 \\
4.00 & 0.5000 & 1.2853 & 74.84 & 74.95 & 0.15 \\
\hline
\end{tabular}

asee Ref. 1 .

Table A6.2. Comparison of finite-elementanalysis $K_{I}$ values for the problems in

Figs. A6. 2 and $A 6.3$ with equivalent end stresses of $16.43 \times 10^{3} \mathrm{psi}$

\begin{tabular}{cccc}
\hline \multirow{2}{*}{ Crack depth } & \multicolumn{2}{c}{$K_{I}$ (ORVIRT.PC) $^{a}$} & \multirow{2}{*}{ * Diff. } \\
\cline { 2 - 4 } & Line load & End load & \\
\hline 0.25 & 44.61 & 42.35 & 5 \\
0.50 & 53.75 & 51.15 & 5 \\
1.00 & 62.72 & 59.99 & 5 \\
2.00 & 77.66 & 74.95 & 4 \\
\hline
\end{tabular}

asee Ref. 1 .

\section{Reference}

1. J. W. Bryson, Martin Marietta Energy Systems, Inc., Oak Ridge Nat1. Lab., ORVIRT.PC: A 2-D Finite Element Fracture Analysis Program for a Microcomputer, NUREG/CR-4367 (ORNL-6208), October 1985.*

*Available for purchase from National Technical Information Service, Springfield, Virginia 22161. 
249

NUREG/CR-5320

ORNL/TM-10966

Dist. Category RF

Internal Distribution

$\begin{aligned} \text { 1. } & \text { D. J. Alexander } \\ 2 . & \text { B. R. Bass } \\ 3 . & \text { R. H. Bryan } \\ 4 . & \text { J. W. Bryson } \\ 5-11 . & \text { R. D. Cheverton } \\ 12 . & \text { J. M. Corum } \\ 13-18 . & \text { W. R. Corwin } \\ 19 . & \text { J. A. Getsi } \\ 20 . & \text { R. C. Gwaltney } \\ 21 . & \text { F. M. Haggag } \\ 22 . & \text { S. K. Iskander } \\ 23 . & \text { F. B. Kam } \\ 24 . & \text { A. P. Malinduskas } \\ 25 . & \text { J. G. Merkle }\end{aligned}$
26-28. R. K. Nanstad
29. D. J. Naus
30-34. W. E. Pennell
35. N. Perrone
36. C. B. 01 and
37. C. E. Pugh
38-42. G. C. Robinson
43. G. M. Slaughter
44. H. E. Trammel1
45. ORNL Patent office
46. Central Research Library
47. Document Reference Section
48-49. Laboratory Records Department
50. Laboratory Records (RC)

\section{External Distribution}

51-100. C. Z. Serpan, Division of Engineering, Nuclear Regulatory Commission, Washington, DC 20555

101-150. M. E. Mayfield, Division of Engineering, Nuclear Regulatory Commission, Washington, DC 20555

151. M. Vagins, Division of Engineering, Nuclear Regulatory Commission, Washington, DC 20555

152-153. T. E. Bushnel1, Portland General Electric, 121 S.W. Salmon Street, Portland, OR 97204

154-155. T. G. Grozan, P.0. Box 14000, Juno Beach, FL 33408-0420

156. Office of Assistant Manager for Energy Research and Development, Department of Energy, Oak Ridge Operations office, Oak Ridge, TN 37831

157-158. Office of Scientific and Technical Information, P.0. Box 62, Oak Ridge, TN 37831

159-408. Given distribution as shown in category RF (NTIS-10) 